
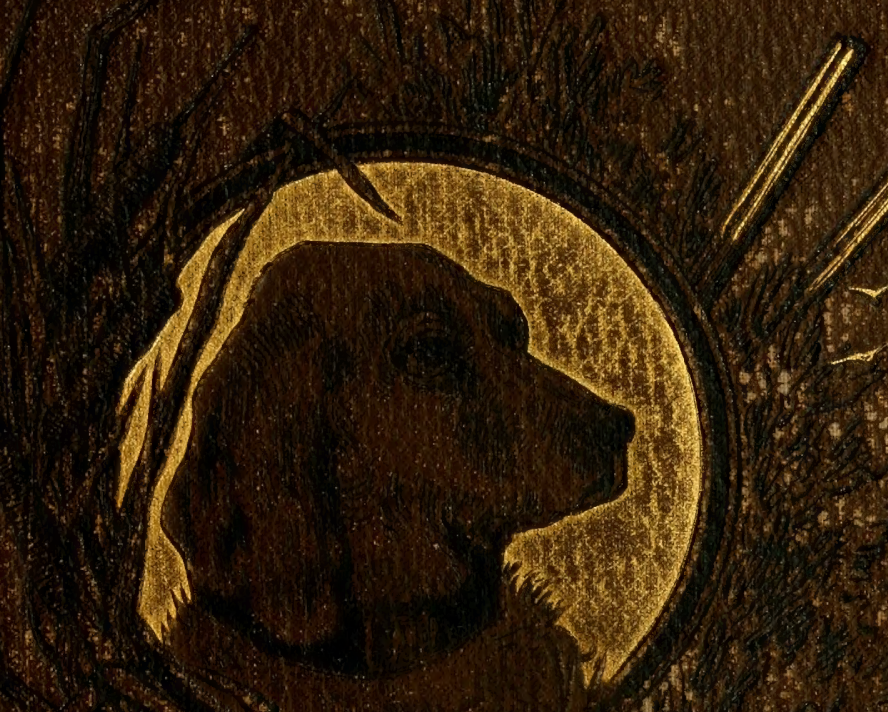

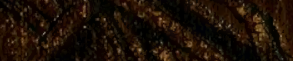

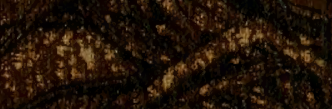

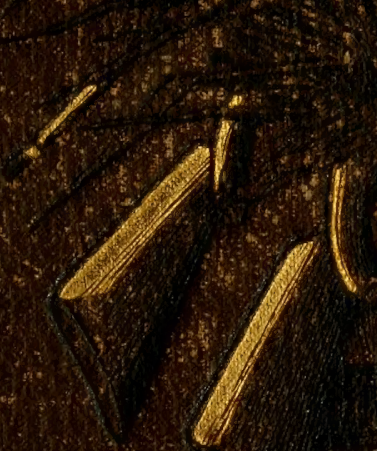

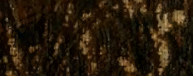

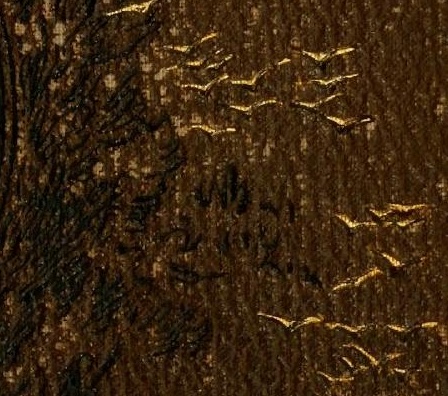

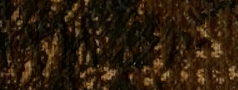

18.

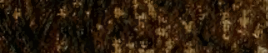

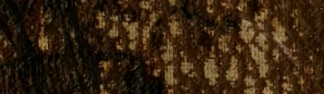

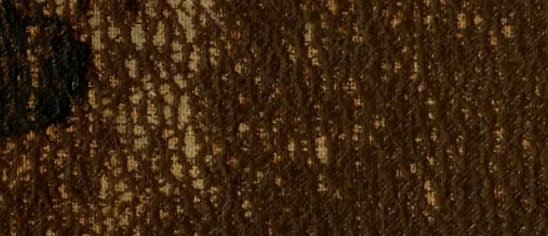

$x^{2} x^{2}=57^{2}$

4. 5,460 ,

$7 x^{2}+x^{2}$

17.

r.

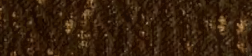

1. 8

$+2$

1 
LIBRARY OF CONGRESS,

Cfytant

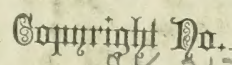

Shelf

UNITED STATES OF AMERICA. 


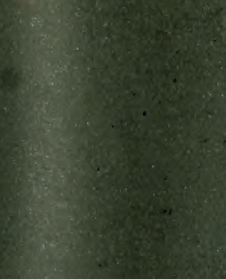

4.

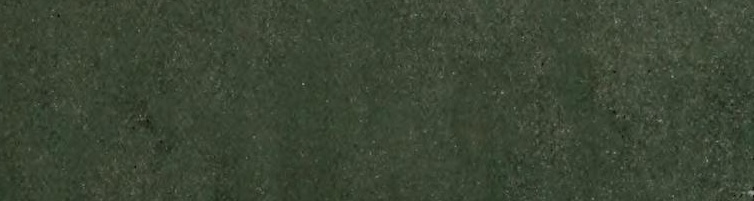
(5020) (2)

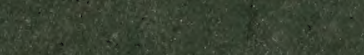

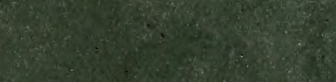
sis 






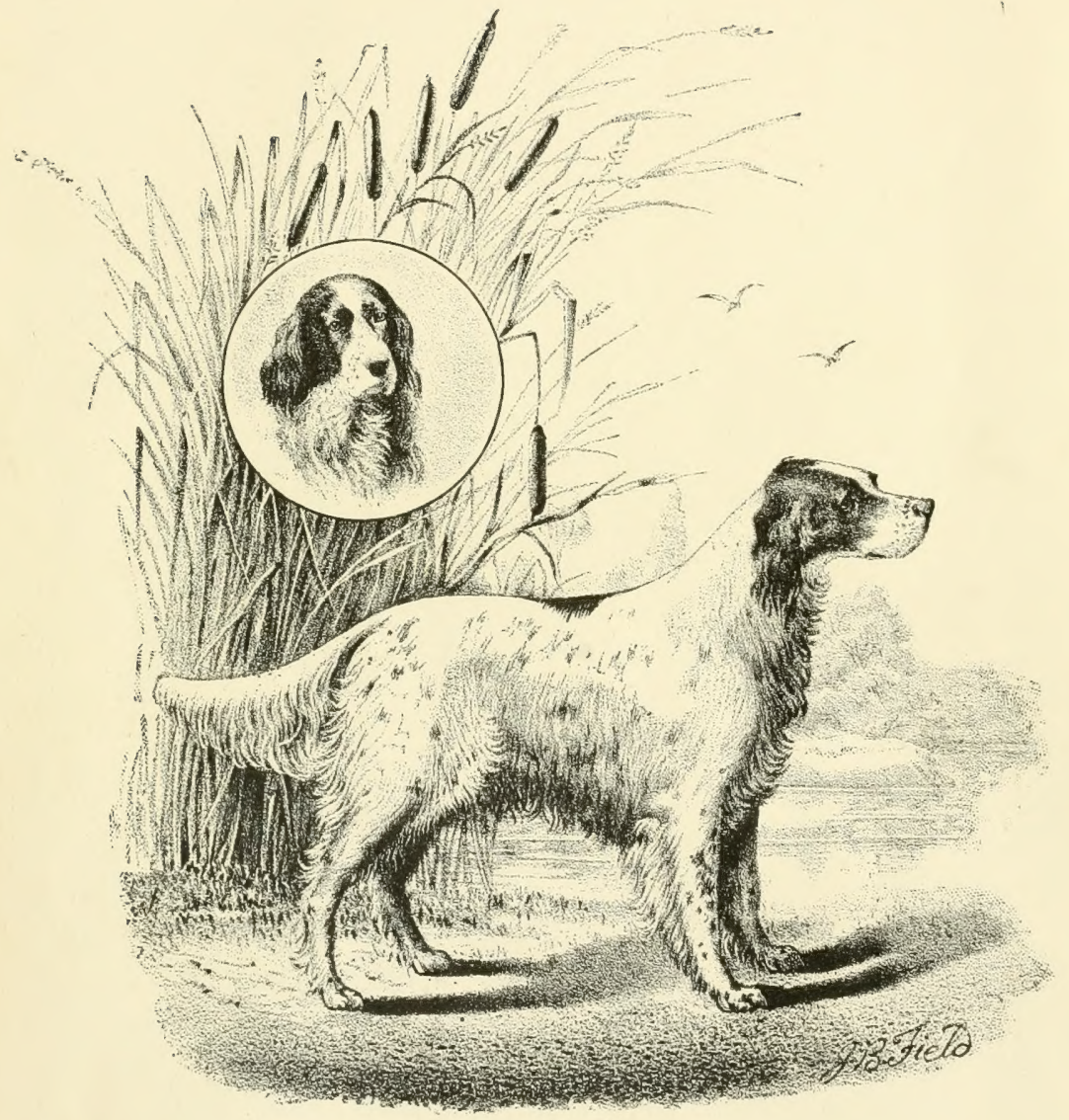

"DRUID"-(4267.)

"Prince," "Dora."

Imported and owned by Arnold Burges. 




\title{
AMERICAN SPORTSMAN:
}

CONTAINING

\section{HINTS TO SPORTSIEN, NOTES ON SHOOTING,}

\author{
AND THE HABITS OF THE
}

Game Birds and Widd fowl of America.

\author{
BY \\ ELISHA J. LEWIS, M.D.,
}

MEMbER OF THE AMERICAN PHILOSOPHICAL SOCIETY; MEMBER OF THE ACADEMY OF NATURAL SCLENCES of Philadelpiia; american editúr of "youatt on the dug," etc., etc.

\section{A NEW EDITION, THOROUGHLY REVISED,}

CONTAINING NEW CHAPTERS ON THE ORIGIN, BREEDING, AND SCIENCE OF BREAKING DOGS, AND FULL INFORMATION ON BREECH-LOADING AND HAMMERLESS GUNS, ETC., ETC.

By ARNOLD BURGES.

PROFUSELY ILLUSTRATED.

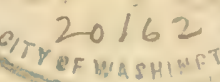

P H I L A D E L P H I A :

J. B. L I P P I N C T T \& CO.

1885 . 
Copyright, 1884, by J. B. Lippincott \& Co. 
My dear Doctor :-

A FEW months only have elapsed since the appearance of the second edition of my book on Sporting; and the publishers, much to my gratification, notify me that they are once more in need of another supply. To this flattering appeal I most cheerfully assent, and trust that you will again find the volume, on this its third advent, much improved, as a number of illustrations have been added and the text somewhat enlarged.

With sentiments of the warmest esteem, I am, in all sincerity,

$$
\text { My dear Doctor, }
$$

Most truly and faithfully yours, ELISHA J. LEWIS.

To Professor J. K. Mitchell. 



\title{
PUBLISHERS' AN NOUNCEIIEN'T.
}

\author{
EDITION OF 1885.
}

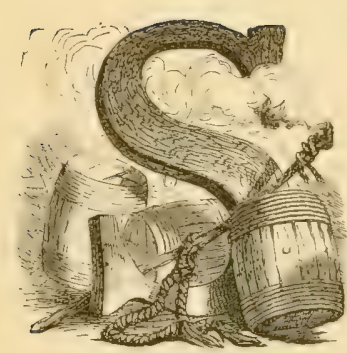

INCE the publication of the earlier editions of "Lervis's American Sportsman" many important improvements in the art of which it treats have come into general use; and with the view of embodying such of these as may be essential to the sportsman of the present day, this revised and enlarged edition of the work has been prepared and is now offered to the public.

As notable among the improvements in this edition, attention is invited to the three new chapters on dogs, one of which is devoted to the "Origin of the Dog," another to the "Science of Breeling," and a third to "Breaking," thus bestowing upon this important subject a proportionate amount of attention. Other topies of interest and importance are either now for the first time introducedas, for instance, the full description of breech-loaders-or else the previous treatment of them is so thoroughly revised as to render the present volume an exceptionally entertaining and reliable manual, both for the practical sportsman and others who maty be interested in the literature of field sports.

The Publishers. 



\section{P REFACE}

\section{TO THE THIRD EDITION.}

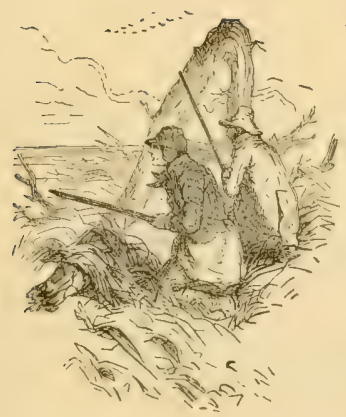

It is not, as many narrow-minded astutes ignorantly suppose, the mere slaugner of the timorous partridge which so early calls him forth to the stubble-field; neither is it the coveted possession of the savory woodcock that lures him to the entangled brake; $r_{1}$ or is it the soaring wisps of fickle snipes which alone entice him to the oozy meadows; nor yet the booming grouse that makes him climb the mountainside or seek the far-off rolliug prairie.

There are other incentive. O ye incredulous, pent-up inhabitants of a crowded city, which impel the sportsman, as with a siren's wand, to hie joyfully away with $\mathrm{dog}$ and gun to the fields, to the hills, to the rich autumn-tinted forests.

Our sportsman has become an admirer of nature; he has 
learned to appreciate the quiet beauties of a wide-extended landscape as it spreads out majestically before him; he views with enthusiastic delight the startling grandeur of a mountaingorge as it suddenly bursts upou his sight; he wanders in silent satisfaction through the murmuring forests of stately oaks, and lingers for a while in pleasant meditation ere he leaps the noisy gurgling streamlet that coquettishly crosses his path.

Then, resting for a time from his pursuits, our happy sportsman plucks a half-hidden flower from its heathery bed, listens to the far-resounding echoes of the unerring gun, joins the merry laugh of his boon-companions, or returns the wild halloo of approaching friends.

Now again he slakes his burning thirst with the sparkling waters of a mountain-spring, or laves his manly brow with the crystal drops from the purling rill that so musically babbles at his very feet; and, giving full freedom to those warmer sentiments of the heart which too often become choked and stifled by the close contact of selfish city life, he breathes a prayer of gratitude to a beneficent Providence for all these enjoyments, for all these pleasurable sensations.

To the fields, then,- - to the bright and beautiful fields,the forests, all clothed in the gorgeous livery of the winter's frosts,- to the mountains, rich in eternal verulure,- to the limpid streams and gushing rills,-do we once more invite you, to spend those flitting hours of leisure vonchsated to us all anid the busy scenes of active life.

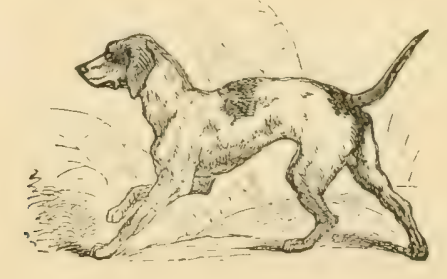




\section{MY DEAR DOCTOR:-}

I AM fully conscious of the fact that it does not seem well in the present age for an author to appear egotistical, and it therefore becomes him even far less to allude to his own productions in terms of praise or commendation; but still I may, I trust, in this instance at least, be pardoned for expressing a conviction that you will be much gratified with the new dress that my volume on Sporting has assumed on this its second advent.

I beg particularly to call your attention to my Introduction to this second edition, which, in connection with some other matters, explains the motives that impelled me to change the title of my book, and of which I dare hope you will equally approve.

In its present improved form and attractive gear, I flatter myself that the "American Sportsman" will give increased satisfaction to my sporting friends, and withal again afford you an hour or so of pleasant relaxation from the more severe studies and weighty responsibilities which your eminent position in the profession necessarily imposes upon you.

With many more kind wishes, and with sentiments of high esteem and great personal regard, I have much pleasure as well as pride in subscribing myself, as ever,

My dear doctor,

Most truly and faithfully yours, ELISHA J. LEWIS.

To Professor J. K. Mitchell. 



\section{PREFACE}

\section{TO THE SECOND EDITION.}

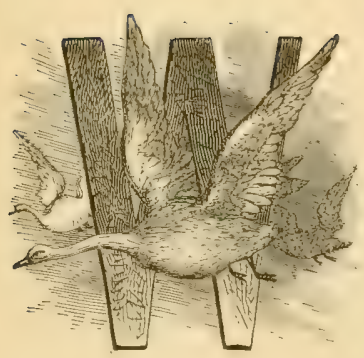

E must confess that it was with sorne degree of surprise, as well as pleasure, that we learned from our publishers that they were so soon ready to enter into an arrangement with us for a second edition of our "Hints to Sportsmen," as it was a gratifying assurance, on their part, that the unpretending volume which we had sent forth from the press with many misgivings as to its merits had met with a kind and liberal reception from those for whom we had in our hours of leisure compiled it.

It would be affectation in us not to acknowledge that it was with considerable satisfaction we observed from time to time the many flattering reviews and complimentary notices which appeared in the various journals in reference to our work.

We sincerely trust that on this, its second advent, in an entirely new as well as doubly attractive garb, we will meet with the like good treatment from our friends of the press. We can assure all our readers that nothing has been wanting on our part to render the volume still more instructive and interesting, both as regards the style of getting-up and the additional matter inserted. 
'I'here additions, however, though numerous, have been in most instances ingrafted so insidiously on the old text that they can scarcely be discerned, save by those who may have felt their deficiency in the first edition, and will now, we trust, in the present volume, find a portion at least of these defects supplied.

In accordance with the repeated suggestions of some of our sporting friends, we have deemed it advisable to change the title of our book from "Hints To Sportsuen" to that of the "American Sportsman."

The former appellation, considering the great variety of subjects introduced, and the copiousness with which many of them are treated, seemed rather too restricted in its signification, and far less comprehensive in its general bearing than a work of this character merited. Besides all this, the large additions as well as alterations that we have made in the present volume seemed still further to urge upon us the propriety of this change, and more especially as the work in its entirely new and beautiful dress can scarcely be regarded as the same book, or even recognised as the offspring of the first edition. We cannot refrain from calling the attention of our sporting friends to the wood-cuts of the various game-birds, most of which, in point of execution, have not been equalled, let alone excelled, by any thing of the kind before done in this country.

To the Messrs. Louderback and Hoffmann we are indebted for the skill and faithfulness with which they have accomplished their portion of the work, and we cheerfully acknowledge that their great attention to our suggestions, corpled with a becoming ambition on their part to do what would be creditable to themselves, relieved us of much trouble as well as anxiety. Of the truthfulness of these engravings to nature we need say but little, as they speak for themselves, the most of them being really very lifelike both in position and ex. pression. We may remark, however, en passant, that every 
bird and every fowl was sketched from choice specimens obtained from the Acadeniy of Natural Sciences, or from other equally good sources; and in almost every instance, the drawings were subjected to the approval of our muchesteemed friend, John Cassin, Esq., before the blocks were placed in the hands of the engravers.

This latter circumstance alone should of itself be a sufficient guarantee of their correctness, as every one at all conversant with science well knows of Mr. Cassin's rare acquirements in this particular department of Natural History.

And we now gladly avail of this opportune occasion to make our public acknowledgments to this gentleman for his many valuable suggestions in reference to the execution of these drawings, the securing of which, by-the-by, has been by far the most difficult - in fact, we may freely say, the only unpleasant as well as vexations-portion of our task. We also return thanks to Mr. John Krider for his generous aid in supplying us with the skins of several specimens of birds, which assisted materially in insuring correct drawings.

This is not the only good service which Mr. Krider has done us as well as the rest of the craft during the last year; for, independently of the many fine guns that he has turned out from his workshop, he has, with the valuable assistauce of his friend, Mr. H. M. Klapp, furnished us with his "Sporting Anecdotes," a book replete not only with amusing but very instructive information regarding the habits of our gamc-birds, sporting-dogs, \&c. \&c.

Mr. George G. White, the principal draughtsman, and, I may say, pupil, of Mr. Cassin's in this particular kind of drawing; has displayed much taste as well as artistic skill in his delineations of the birds; and we doubt if he has any superior, if equal, on our side of the vasty deep in this special branch of designing. His chapter-headings and many 
of the vignettes are also spirited and characteristic; the title. page of the four seasons, and frontispiece, are very pleasing compositions, and give still further evidences of his talent and genius as an artist.

With these few comments, we again send our volume forth from the press, trusting, as before, far more to the well-know generosity of the craft for its lind reception, than to any great merit of its own, but at the same time bearing in mind the good old Latin proverb, that-"Frustra laborat qui omnibus placero studet."

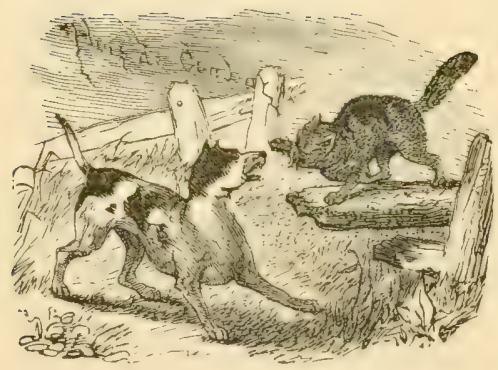




\section{MY DEAR DOCTOR:-}

Although wa have nerer flushed the corey, started the woodcock, or winged the wild duck, in company, yet I know full well your partiality for the country, as also your early fondness for field and rural sports; and, if you had not been so early engrossed by professional duties, I doubt not that you would have been the foremost among those who derive so much enjoyment and healthful recreation from the dog and gun.

Be not surprised, therefore, my dear sir, that, without any previous intimation, I should dedicate this volume to you; and at the time rest assured that, in so doing, I am not alone influenced by those early feelings of friendship naturally engendered by your many kindnesses to me while a student in your office, but I beg rather to present it as a slight token of the high appreciation I entertain of your varied talents and distinguished worth in the profession of which you are so successful a teacher and practitioner.

Accept, then, dear sir, this little tribute of esteem from one who has ever regarded the period of his association with you when a pupil as a bright spot in the vista of life, to which he ever refers with peculiar feclings of pleasure; and, in conclusion,

Believe me, my dear doctor,

\section{Very faithfully yours,}

ELISHA J. LEWIS.

To Professor J. K. Mitchell. 



\section{PREFACE}

\section{TO THE FIRST EDITION.}

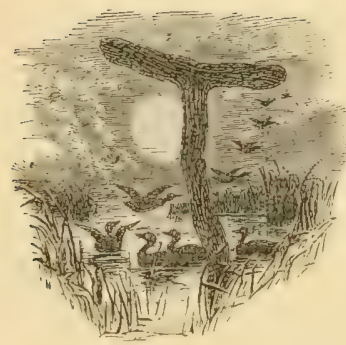

HE lovers of the dog and gun are under many and great obligations to Henry William Herbert, Esq., for his most excellent works on Sporting, which speak for themselves and need no commendation from our pen. They abound in information and research which few have had so great opportunities of collecting or so much talent to put together. We also owe much to William T. Porter, Esq., for his raluable and beautiful edition of "Hawker;" and we should not forget to thank J. S. Skinner, Esq., * for his many contributions to the same branch of literature. The general favor which the productions of these gentlemen have met with from the public has the more emboldened us to venture forth with this unpretending volume, trusting, howerer, far more to the well-known generosity of "the craft" for its kind reception than to any great merit of its own.

We shall not, in a short preface like this, attempt to offer, for the consideration of our readers, any thing like an eulo-

* Since writing the above, Mr. Skinner has been gathered to his fathers, ripe in years and full of honors. His contributions to the cause of agriculture, rural sports, and other kindred subjects, were numerous, and insured for him a wicleextended and well-deserved reputation throughout our country 
gium upon field-sports; nol shall we endeavor to exhibit to the rorld the many benefits and advantages to be derived from the general encouragement of these healthful pursuits.

We beg merely to remind the student of science, the cunning expounder of Blackstone, the deeply-read follower of Galen, the shrewd devotee of commerce, as well as the most skilful and industrious of artisans, that their intellectual powcrs demand some remission of their lathors, and that their physical energies also need a certain degree of recreation or resuscitation to enable then to pursue those studies and attain those ends which stern necessity or exalted ambition prompts. them to undertake.

How, then, or where, then, may we ask, can this relaxation of the mind as well as of the body be more agreeably obtained than in the open fields and beantiful forests of our favored country? There, and there alone, far away from the busy througs of selfish men, wandering with some favored friend, in sweet communion with the green fields, the stately forests. and limpid streams, the mind of the most grave and studious becomes truly unbent and freed from its labors. There the heart beats with renewed vigor, the blood courses through its usually sluggish channels with a quickened pace, and the whole animal as well as intellectual economy becomes sharpened and revivified under exciting and healthful influences.

Add, then, to this scene the eager sportsman, surrounded by his faithful and sagacious dogs; call up the sharp echo of the unerring gun; recollect the plaintive call of the timid partridge, the startling whirr of the affrighted pheasant, the rapid flight of the lonely woodeock, the devious course of the fickle snipe, or, perchance, the sudden rush of the skulking hare, and the picture is complete. Then tell us whether such scenes as these are not calculated to cnliven the mind, expand the energies, and not only bring the glow of health to the cheek of youth, but infuse renewed vigor into the very soul of the infirm and sedentary. 
Is there not a time when the wan-ficed student of science may neglect for a while the sickly flickerings of the midnight lamp? Is there not a time when the learned counsellor may escape the wranglings, the jeerings, the bitter feuds of the halls of justice? And is there not a moment of leisure, an hour of repose, when the skilful physician may turn a deaf ear to the harassing solicitations of suffering humanity, and draw for a brief period the curtain of oblivion aronnd the couch of disease and death?

Yes! there is a time for all these; and there is a time when even the anxions, upright, and enterprising merchant may, for a brief period, while quaffing, as it were, the fabled waters of Lethe, forget the perplexities of commerce, the fluctuations of trade, the uncertainty of riches, and remain even unmindful of his gallant ships, that come bounding across the briny deep, heavily freighted with the fine wares of the North, the South, the East, and the West.

Yes! there is a time, thanks to the noble founders of our liberal institutions, when even the industrious artisun, freed from all care and anxiety, may forget the labors and duties of the shop, and wander forth to enjoy the works of nature and learn more highly to appreciate the boon of freedom, his country's dearest gift.

To the fields, then,- - to the bright and beautiful fields, - with "dog and gun," do we invite you, one and all, to spend those hours of leisure and participate in those innocent enjoyments so captivating to a true sportsman.

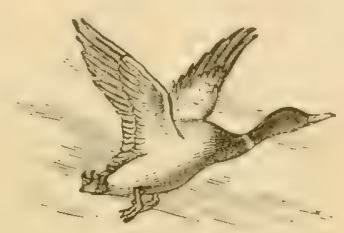





\title{
CONTENTS.
}

\author{
C H A P'T ER I.
}

Exposition of the Techical Terms used by Ornithologists $\quad 25$

C II A P'TER II.

Sensation in Feathers. . . . . . . . . . 29

CH A P'TER III.

Sporting Terms

C II A P'TER IV.

TuE Dog (Canis familiaris)

CII A P'TE R V.

The Science of Breeding

C II A P T E V V.

BREAKING

C II A P'T R VII.

Art of Shooting on the Wing

C II A P'I E R VIII.

The Partridge (Perdix Virginianus) . . . . . . . 11 .

C H A P'I E R IX.

T'ни Wild TuRkey (Meleagris gallipuvo) - 172

CH A P T E R X.

The Ruffed Grouse, or Pheasant (Tetrao umbellus) . . . 159

C II A P'TER XI.

Pinnated Grouse, or Prairie-Hen (Tetrao Cupido) . . . . 202

CHA PTE R XII.

The Woodcock (Scolopax minor) . . . . . . . . 212

C II A P'T E R X I I I.

Wilson's; or English SNipe (Scolopax Wilsonii-Scolopax gallinago). 240

CHA P'IER XIV.

ReEd-Bird, or Rice Bunting (Emberiza oryzivora) . . . . 2̀jt; 
C II A P T E R X V.

The RaIl, or Sora (Rallus Carolinus).

C II A P'I'E R X V I.

Great Red-ibeasted Rail (Rallus elegans).

CH A P'IER X V II.

Clapper-Rail, or Mud-Hen (Rallus crepitans)

C II A P'I'E R X T I I I.

Esquimaux Curlew, or Short-Billed Curlew (Scolopax borealis) • 287

C II A P'IER XIX.

Long-Bilded Curlew, or Stckle-Bill (Numenius longirostris) .

CHA P TER X X.

Black-Bellied Plover (Charadrius apricarius).

C II A P'T' E R X X I.

Semipalmated Snipe, Willet, or Stone-Curlew' (Sculopax semipalmata)

CHA P'TER X III.

Wild-Fowl Shooting

C II A P TEI XXIII.

Canvas-BaCK (Anas valisineria) 313

C II I P'T E R X X I V.

Different Varieties of Ducks .

C H A P T E R X X V.

American Hare, or Gray Rabitit (Lemes sylvaticus) 385

CHA P'TER X X VI.

THE SquirReL .

C II A P'T E R X X V II.

Miscellaneous Hints

C II A P'T E R X X III.

Discovery and Introduction of Gunpowder .

C II A P TER XXIX.

The Art of Cooking Game .

CHA P'IE R X X X.

Some Hints on Taxidermy. The Art of Oitaining and PreSERving the Skins of Birds

CH A P'TE XXXJ.

General Hyaienic Remarks 


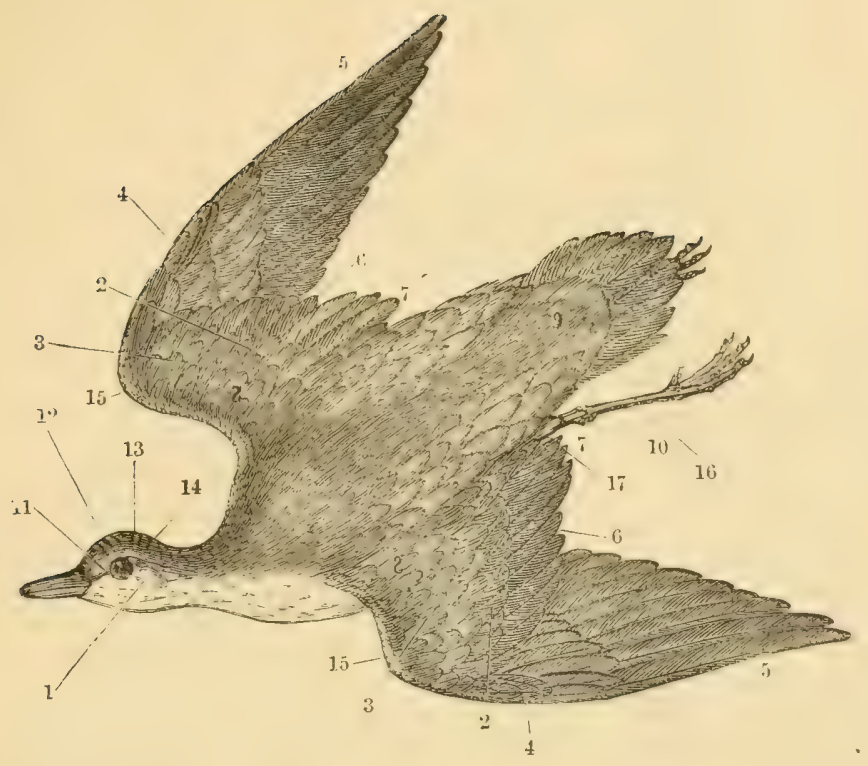

CHAPTER I.

EXPOSITION GF THE TECHNICAL TERMS USED BY ORNITHOLOGISTS.

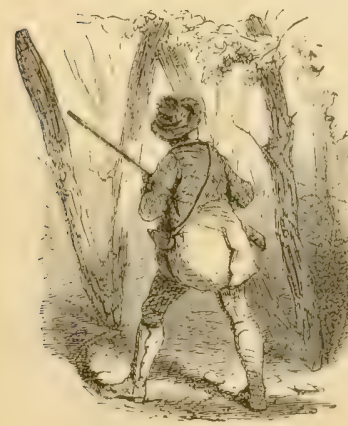

ITHOUT a cursory knowledge, at least, of the technical terms employed by Ornithologists in their. delineations of the feathered race, we cannot expect all our readers to understand or appreciate the scientific descriptions which we have inserted of the game-birds of our country; it therefore appears to us that we cannot do better than devote the first few pages of this volume to the full elucidation of these appellatives, which, in fact, are the A B C of Ornithology, the Alpha and Jrega of the branch. 
This information, so important to the intelligent sportsman, can be easily and quickly acquired by reference to the accompanying drawing, in connection with the explanations following immediately after.

1. Auriculars, the ear coverts. - The soft feathers that corer the organs of hearing

2, 2. The basturd wing, consisting of three or five feathers, resembling the quills of the true wing; they are placed on a small bone rising from the wrist-joint of the wing. The bastaril wing assists in flight by keeping the wing from turning upwards, and contracts the points of the wing in a downward and backward position to that of the course of the bird through the air.

3, 3. The lesser coverts of the wings. - These are the feathers which are found in successive rows upon the wings; those on the inside are termed under coverts, and are much less regarded by ornithologists as a means of distinetion than the others.

4, 4. The greater coverts. - The wing feathers lying under the lesser coverts; they are much larger and stronger than the latter.

5, 5. The mimaries.-Large quill feathers taking their growth from below the wrist-joint. The length and proportion of the feathers control, in a wide degree, the movements of the bird in the air. The nearer the longer frimary quill approaches the body, the more dexterous and beautiful will be the motion of the bird when on the wing. The Huwks, Suallow's, and various other birds of rapid flight, that seize their prey in mid air, have the longest primary feather very near the body, and con sequently are enabled to turn and twist themselves with great facility.

6, 6. The secondaries, or second quill feathers, spring from the second bone of the wing. When the wing is extended, they frequently appear like a continuation of the primaries.

7, 7. The tertiary, or third quill feather's, also arise from the second bone, but much nearer the elbow-joint.

8, 8. The scapulars, or shoulder feathers, are formed by the soft and downy feathers that corer the shoulder-bones, and are 
serviceable only as a protection to the parts which they surround; they unite without any regularity with the plumage of the back and wings.

9. The rump feathers and upper-tail coverts.-These feathers are the continuation of the covering of the back, and are strong in proportion to the peculiar habits of the bird. In the Woodpecker tribe, for instance, these feathers are very strong and unusually long, as they make constant use of the tail as a support and aid when climbing the trunks of trees; and so it is with some water-fowl not webfooted, but obliged frequently to take flight from the water. The tail feathers in these lastmentioned birds afford the greatest assistance in springing into the air.

10. The vent feathers and under-tail coverts, that extend from the anus, or vent, to the tail underneath. These feathers are much longer in some tribes of birds than others. Those that have a constant habit of flirting up their tails-like, for example, the Rallus Carolinus, and several species of small shore-birdshave the vent feathers unusually well developed.

The tail feathers are various in size and numbers, and are generally the most ornamental part of a bird. The tail performs the most necessary office in the navigation of the bird through the air; in fact, it is the rudder by which its course is determined, and acts in concert with the will of the bird as freely as a ship obeys her helm.

11. Loral space.-The space between the bill and eye.

12. Frons.-The forehead.

13. Corona.-Crown of the head.

14. Occiput.-The hind part of the head.

15. Flexure-Bend of the wing.

16. Tarsi.-Shanks of the legs.

17. Tibia.-Thigh.

The upper and lower bills are called the superior and inferior. maxilla, or upper and lower mandibles.

Iris-irides.-The colored circle surrounding the pupil of the eye. 
Mentum.-The chin.

Guttur.-The throat.

Collum.-The neck.

Pectus.-The breast.

In measurement, the total length means from point of bill to the end of middle tail feathers. Length of the wings means from the bend of the wing to the end of the longest quill feather.

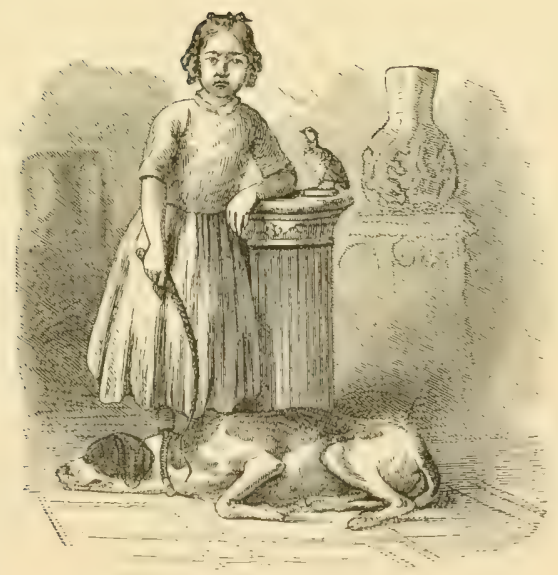




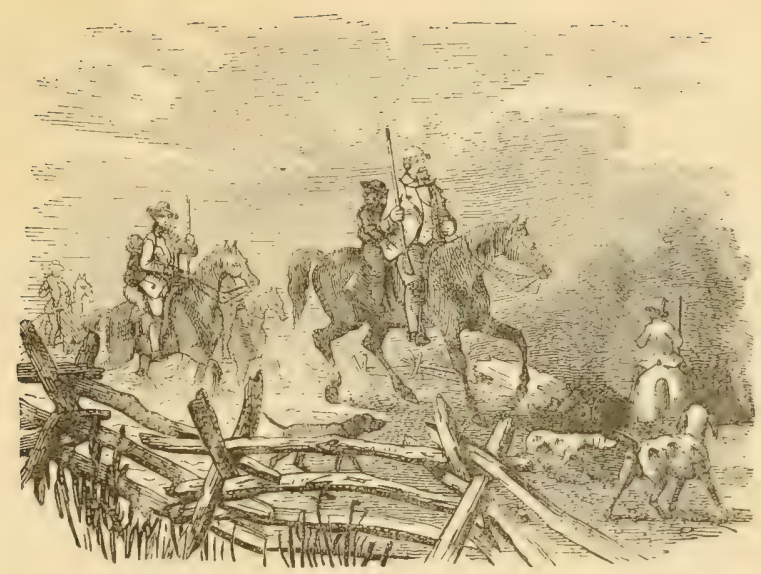

CHAPTER II.

SENSATION IN FEATHERS.

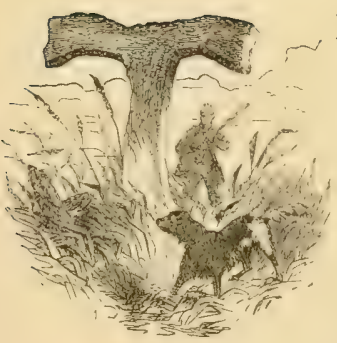

IIE keenest sense of feeling through the medium of the plumage is indispensably necessary to the well-being of all the feathered race.

The feathers, it is true, in themselves, like several other portions of the body: such, for example, as the nails, claws, beak, and hoofs, have no real consciousness or actual perception of the sense of touch; still, they are enabled by the nicest possible organization to convey the most delicate impressions to those functions of the animal economy that do feel

If such a wise provision of Nature did not exist, what, we might ask, would become of all the numerous noctumal birds which seek their food only during the dark hours of night? The whole tribe most indubitably would soon be killed off by striking themselves against the various obstacles that they necessarily encounter in their midnight rambles. This acute sensitiveness on the part of feathers to outward impressions is not, perhaps, as 
essentual for those birds which fly only in the broad daylight as it is to the numerous variety of owls, bats, \&c. that seek their prey solely during the lonely hours of darkness.

Nerertheless, a certain degree of this delicacy of perception is ahsolutely requisite even for them, to secure their safety while performing rapid flights through the thickets and forests which they most generally inhabit or take shelter in. This, then, being the case, is it not reasonable to infer that the feathers should at all times be in the highest state of perfection? This physical condition, however, could not be preserved if they were not shed or renewed from time to time, as they necessarily would become soiled, dried, broken, and ultimately totally unfit for this nice serrice by the constant exposure they are subjected to, as well as the many accidents they must, from their mode of life, encounter.

To remedy these evils, or rather to make provision for such casualties, Nature, ever provilcnt in all her works, very wisely ordains that the feathered race shall moutt, or, in other words, doff their plumage entire, once or twice a year. The simple shedding of the feathers is not the only precaution which a beneficent Providence has established for the preservation of these, the most extensive and beautiful portion of his creations. For we may here also notice the remarkable changes that take place in the tints of the plumage, more especially in those birds which remain in the northern latitudes during the long and bleak winters. Many of them, from the most sombre hues of spring and summer, become pied, or eren pure white: thus cunningly arlapting themselves to the pervading color of the oljects lyy which they are surrounded, they are the better able to conceal themselves from the attacks of their many prowling enemies that are now driven to great extremes for food. 'The protection afforded birds, as well as many of the smaller quadrupeds, in this alteration of the color of their plumage and pelage, from the aggressions of their more powerful foes, is not the only benefit which results from this wise providence; as the chilling effects of constant exposure to the excessive cold of those hibernal 
regions are somewhat abated by the transition to white, from the well-established fact that a surface purely white reflects heat far more copiously than a dark one; and consequently it is not difficult for us to infer that, in like manner, it prevents any undue waste of the animal heat by radiation.

The moulting of birds is very gradual, and few of them are ever so bare of feathers as to prevent them from taking wing, and even flying long distances.

The time of shedding the feathers varies in the different species and in different climes; some moult late in the summer, some in the early autumn, and some in the early spring.

The summer or autumnal moult is always the mast complete; the perennial is generally only a change of color of some portions of the plumage, and not a thorough shedding of the feathers.

Those birds, as well as water-fowl, which extend their migrations far to the North, for the purposes of procreation, receive their fresh plumage after the period of incubation has entirely passed by, so that they come out fresh and entirely freed from all the filth and vermin which their previous sedentary occupations may have entailed on them.

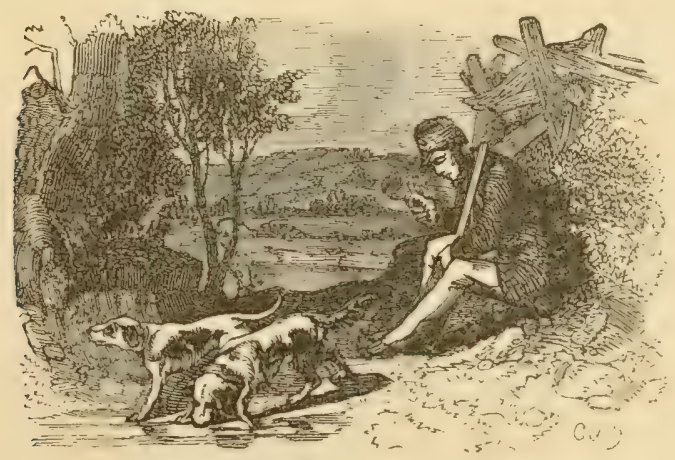




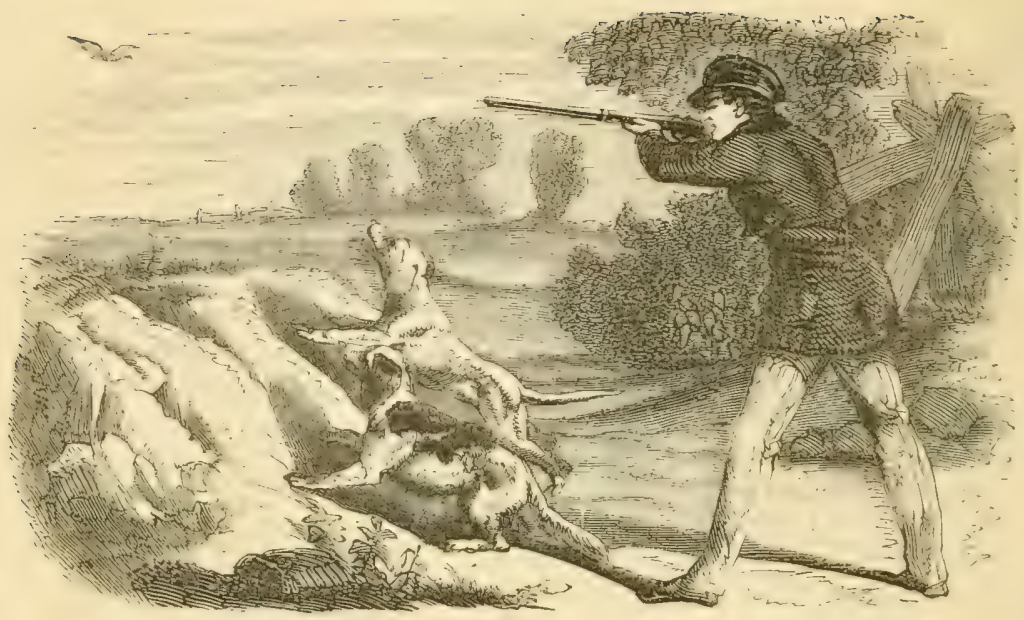

CHAPTER III.

SPORTING TERMS.

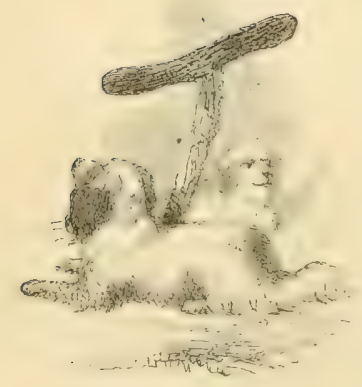

HE technical terms adopted by writers on field-amusements should be perfectly familiar to every sportsman, and ought to be made use of on all occasions when rural diversions are the subject of conversation. Many of our sporting acquaintances are most wofully deficient in a knowledge of these designations, and consequently make the most egregious blunders in their vain efforts to appear au fait in all that pertains to the lng and gun. A few minutes of study and reflection, my patient friends, will make you all proficients in this branch of Orismology: therefore remain no longer in ignorance, even if it be bliss.

TERYS APPLICABLE TO DOGS.
A brace of pointers or setters.
A couple of spaniels.
A leash of
s6
A couple and a half of spaniels. 
1. Toho!

2. Down charge!

3. Back or heel!

4. Steady! steady there!

5. Go on! on!

6. Hold up! up!
7. Seek dead! find dead bird!

8. Fetch!

9. Drop, sir!

10. To mouth a bird.

11. To run wild.

EXPI,ANATION OF TIE ABOVE TERMS.

1. To make pointers or setters come to a stand.

2. " " " " $"$ lie down while loading.

3. " " " " go behind.

4. " " " " " carcful when game is about.

5. " " " " " " $"$ "ise- a term of encouragement.

6. " " " " " " " " " " "

7. " " " " look for a dead bird.

8. " " " " " " " " " " "

9.4 " " $"$ deliver up the dead bird.

10. To bite or chew a bird severely.

11. To run heedlessly, without caution.

By a pair is understood two of the same kind or species united or paired by nature, male and female. Therefore, how evidently wrong it is to say a pair of pointers, or a pair of setters!

By a couple, or brace, is understood the involuntary union of two individual companions of the same species, either by a chain, noose, or tio.

\section{PARTRIDGES.}

A covey of partridges or birds.

A brace of " "

To spring or flush " "6

GROUSE.
A brood of grouse.
A pack of "6
A brace of "

\begin{abstract}
A leash of grouse.
\end{abstract}
To raise a "

WOODCOCKS.
A couple of woodcocks.
A flight or fall of woodcocks.

A couple and a half of woodcocks.

To flush or start a woodcock.
A wisp or walk of snipes.

A wing or congregation of plovers.

A couple of snipes or plovers.
SNIPE OR PLOVER.

A couple and a half of snipes or plovers.

To spring a snipe or plover. 
SYALI, WIJD-FOWI, OR SHORE-BIRDS, OF EVERY DESCRIPTIUN.

\section{A flock of.}

$\Lambda$ couple of.
A llock of reed-birds.

$\Lambda$ dozen of reed-birds.
A couple and a half of.

Five, ten, fifteen, or twenty rails.

\section{HARES.}

A brace of hares.

To start or move a hare

A leash of hares.

To get up a rail.

'To mark a rail.

\section{JARGE WIJD-FOWI.}

A flock, team, or barlelynge of wild ducks.

A company or trip of wild ducks.

A gaggle or flock of geese.
A flock of teal.

A gang of brent.

A whiteness of swans.

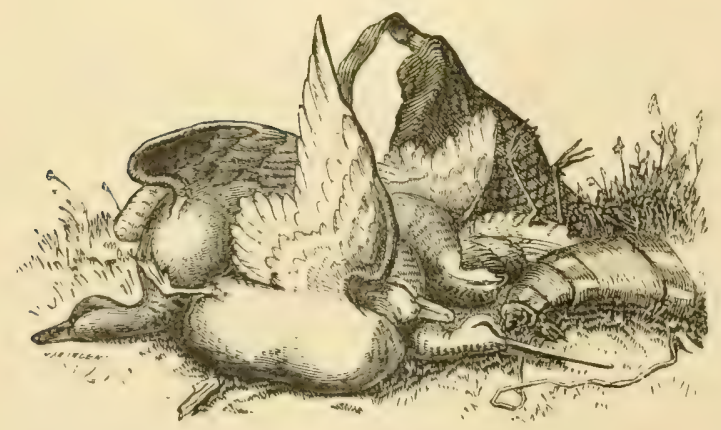




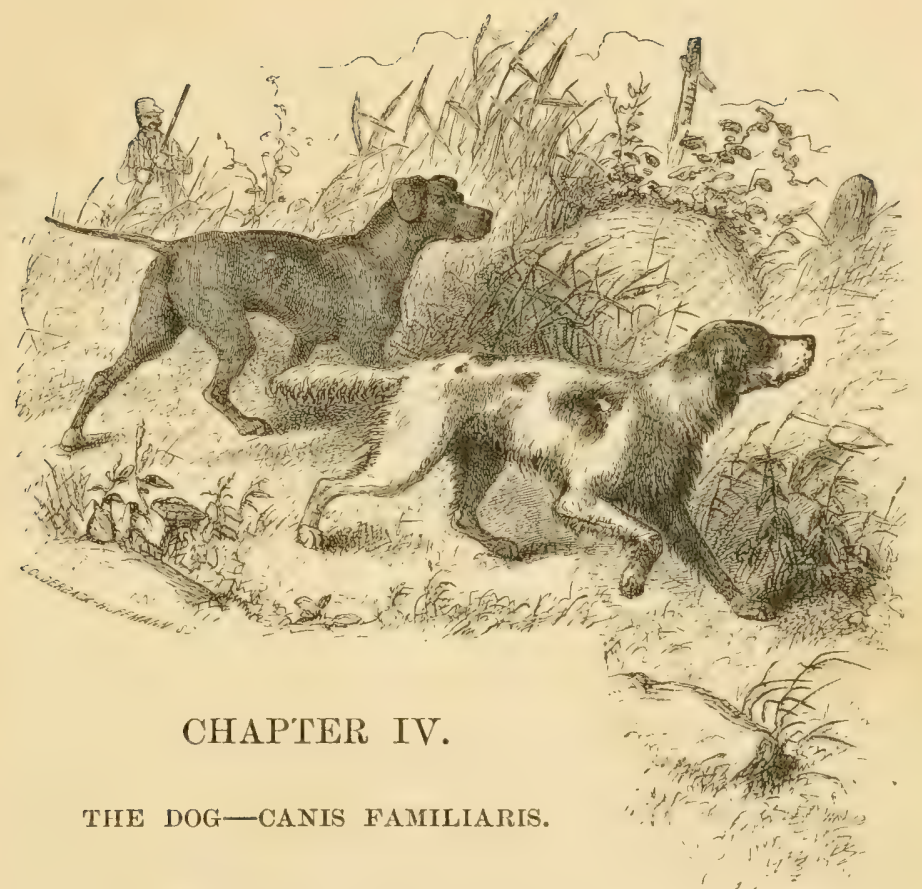

THEORIES OF ORIGIN.

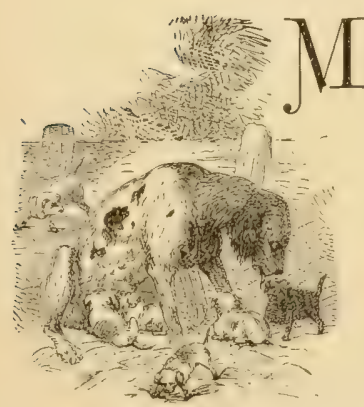

ANY theories upon the origin of the $\operatorname{dog}$ have been advanced by ancient and modern writers, some claiming for him the honor of a distinct race, and supporting this view by the assertion of individual peculiarities, and still more strongly by the assertion that the descendants from crosses between the $\operatorname{dog}$ and any of the animals he most nearly resembles, and from which alone he can have sprung, are true hybrids incapable of reproduction inter se. If the latter could be sustained, it would prove the distinct character of the dog beyond question, since science accepts the production of hybrid offspring as indubitable evidence of difference 
in the species of the parents, but unfortunately for this claim, investigation has brought to light the fertility of such cross-bred produce. Pennant claimed the $\log$ is only a domesticated jackal crossed with the wolf or fox. Bell, in his work on British quadrupeds, published in 1837, declared the anatony and osteology of the dog and wolf are identical, and that they will breed together, and the produce be fertile, and these views are fully sustained by experience with the Indian rogs of the West, as it has been demonstrated beyond doubt, that they breed freely with the coyotes and wolves, and the produce of these unions are as fertile as their parents. Before such showing all theories of distinct race must go down, and modern scientists regard the dog as a mongrel brought up to his present standard by the improving influences of domestication.

\section{THE DOG IN HIS RELATION TO MAN.}

No other member of the animal kingdon can compare with the $\operatorname{dog}$ in his intimate relations to man. As the protector of his house and flocks; his companion and assistant in the sports of the ficld; his rescuer from death mid Alpine snows or angry waves, and as the watcher and guardium of his dead body, writers, sacred and profane, poets, painters, and sculptors, ancient and modern, all unite in bearing testimony to the faithfulness and devotion of the $\operatorname{dog}$ to his master. As he is the inhabitant of nearly every portion of the globe, lie enjoys special opportunities for this association, and attaches himself to man in all the different comlitions of life, from the most degraded of the tribes, to the elegance of wealth, and the nobility of the scholar.

\section{DIVISIONS INTO BREEDS.}

Two influences have undoubtedly produced the division of the original stock into the various breeds of the present time. The first and natural influence is that of climate; the second, the different uses to which man has put the dog. Although the former cannot be ignored, it is to the latter we must ascribe the greatest changes. Certain men by circumstances or taste for certain pur- 
suits, are specially dependent upon their dogs, and it is easy to see that by long-continued use for peeuliar work, characteristics adapted to such work could be produced even in dogs which did not possess them naturally, and when produced, they could be confirmed and strengthened by eareful selection in breeding, till classes were formed to which these characteristies become instinctive.

By ancient writers dogs were divided into three classes, viz.: Pugnaces, Śrgaces, and Celeres, but this arrangement has given way to modern ones, more distinctive, though not perhaps more satisfactory. Cuvier made three divisions, based upon the shape of the head and the length of the jaws; these being supposed by him to vary in accordance with the intelligence and scenting power. These classes are,-1, Matins ; 2, Spaniels ; and, 3, House-dogs.

Matins are characterized by " head more or less elongated; parietal bones insensibly approaching each other; condyles of the lower jaw placed in a horizontal line with the upper molar teeth." This class is exemplified by, -

"1. Half-reclaimed dogs, hunting in packs; such as the Dingo, the Dhole, the Pariah, etc.

“2. Domesticated dogs, hunting in packs or singly, but using the eye in preference to the nose, such as the Albanian dog, Deerhound, ete.

"3. Domesticated dogs, which hunt singly and almost entirely by the eye. Example, the Greyhound."

Spaniels are characterized by "head moderately elongated; parietal bones do not approach each other above the temples, but diverge and swell out, so as to enlarge the forehead and cavity of the brain." In this class are found,-

"4. Pastoral dogs, or such as are employed for domestic purposes. Example, the Shepherd's dog.

"5. Water-dlogs, which delight in swimming. Examples, the Nervfoundland dog, Water-Spaniel, etc.

"6. Fowlers, or such as have an inclination to chase or point birds by scenting only, and not killing. Examples, the Setter, the Pointer, the Field-Spaniel, etc. 
"\%. Hounds, which hunt in packs by scent, and kill their game. Examples, the Foxhound, the Harrier, ete.

"8. Crossed breeds for sporting purposes. Example, the Re. triever."

House-rlogs are characterized by "muzzle more or less shortened; skull high ; frontal sinuses considerable; condyle of the lower jaw extending above the line of the upper cheek teeth. Cranium smaller in this group than in the first or second, in consequence of its peculiar formation." This class is made up of,-

"9. Hatch-dogs, which have no propensity to hunt; but are solely employed in the defence of man or his property. Examples, the Mastiff, the Bulldog, the Pug-dog, etc."

This classification, though based upon natural laws, presents some anomalies, notably in the case of the greyhound, which will hunt in packs as well as singly, and would use his nose if he was not taught to depend upon sight alone. Also in the dogs showing "inclination to chase and point birds," but which will also chase and point rabbits or hares, unless restrained by education.

It is not the province of this work to discuss dogs generally, but to take up only those which are used in sporting. Nor all of these indeed, as many branches of field sports are followed abroad, which are not pursued here. We shall therefore devote our attention to setters, pointers, spaniels, retrievers, and those breeds of hounds in common use, taking for our standard the Euglish types, as they are universally conceded to be better than those native to this country, owing to the greater attention which has been given to their breeding and development.

\section{THE POINTING INSTINCT.}

What is called the "pointing instinct," common to the setter and pointer, is probably an acquired faculty, resulting from the use and consequent elucation which we have spoken of as instrumental in the formation of breeds. Certain writers have accounted for it upon the theory that wild animals steal up to their prey and crouch to gather energy for a spring, and man, finding this crouch 
promised to be useful in certain kinds of work, developed it by education in certain breeds till it became characteristic of them, while others lost it by disuse. This view we think wrong. The crouch alluded to is characteristic of the feline tribe, but not of the canine. The domestic cat exhibits it as strongly as the tiger. All wild members of the cat tribe habitually seize their prey in this manner; but wild dogs, though they approach their quarry with caution, generally seize it by rushing upon it, and springing, if at all, from the running position. That the point is not a developed natural crouch, but the result of special education, is also indicated by the original differences in the pointing position of the setter and pointer, the former dropping to his game, and the latter standing erect. As no natural reason appears for the crouch being changed to the stand in the pointer, it seems reasonable that the pause in both positions was taught and not instinctive, and that the difference was due to the different uses the dogs were originally put to. As we shall show presently, the setter is the descendant of the spaniel, a dog originally used by sportsmen to assist in netting birds before the art of shooting was introduced. 'The dog was used to discover the whereabouts of birds by his scenting powers, but if he pushed on he would flush them, and so destroy the sportsman's chances for capture, and to prevent this he was taught to crouch, and remain in that position while the net was drawn over him. If he stood erect, such drawing would be difficult, if not impossible, hence the advantage of the drop or crouch. So far as we have any means of knowing, the pointer was never used for this kind of work. It appears probable he was not used as a bird-dog till a much later period, when the introduction of guns made the sportsman independent of the net, by enabling him to kill his game from a distance, and consequently all that was necessary was that the dog should pause long enough to enable the gun to come up, before the game was starter. The position in which the pause was made was, however, no longer material, and, being unrestrained, the $\log$ naturally remained erect, and pointed rather than set his birds. The results of this difference in edu- 
cation are still observable, since, though setters generally have adopted the erect "point" in place of the "set," many individuals still drop to their game, while pointers very seldom do so, and then only under peculiar circumstances, such as when going at great speed they catch the scent, and drop because they cannot in any other way arrest their advance. Drake, one of the most noted pointers of modern times, habitually dropped, but Drake was one of the fastest dogs that ever ran in English field trials, and it was conceded it was impossible for him to come to a point in a standing position. It is claimed that some of his offspring exhibit his peculiarity, even though not as fast as he was, but this can be more naturally accounter for as the transmission of an individual peculiarity than as a reversion to original instincts, because Drake's ancestors did not drop, nor, as we have said, do pointers generally. The theory of reversion would not therefore be tenable, because it would claim a throw back to something which has never been characteristic of the breed. It is casy to account for the change in position in setters upon the ground that they have been encouraged to assume the more elegant erect "point," but the frequency of exhibition of the original "set" shows that the habit resulting from original education is still latent, though weakened by later influences.

A further argument supporting the view that the set was taught and not instinctive, is found in the fact that, eren in the days when spaniels were used in the manner we have described, only a portion of them exhibited this faculty. There was a class known as "Setting Spaniels," yet the carliest pictures of spaniels show no marked differences or apparent variations in characteristics in the individuals represented, so that we are forced to suppose all pictures are those of the same class, or, what is more probable, that there were no decided class distinctions in the land-spaniels, and all belonged to the same division, and possessed the same natural attributes. That some should be taught to set and others not, is easily accounted for by the limited demand for setting dogs, and when the demand increased, it would certainly be more natural to supply it by breed- 
ing from those already educated, than by educating others ab initio. Thus, in time, a breed could be formed in which the acquired "set" would be firmly fixed, and exhibited as naturally as any other characteristic, and from this our present-day setters could be evolved, with no greater change than marks the improvement of other breeds from the original types. That portion of the original class which was not educated, would transmit only the characteristics originally possessed by all. All spaniels have delighted in the pursuit of game from time immenorial. This is purely instinctive, and thus we have to-day in our setters and spaniels the same common love for hunting, with just such difference in action upon game as marks descent from the educated or unerlucated portion of the original stock.

\section{THE SETTER.}

By all recognized authorities the setter is regarded as the descendant of the land-spaniel. In the ancestral line he has existed in England for over four centuries, and is pronounced by Stonehenge to be the most national of all dogs found there. At what period he first became a setter is not known, but in Daniel's "Rural Sports" there appears a copy of a bond given by John Harris, October 7, 1485, in which he covenants "to keep and break a certain spaniel to set partridges and other game, for ten shillings of lawful English money." Stonehenge says, "A Duke of Northumberland trained one to set birds in 1555, and shortly after the setter was produced." Writing of the "Setting Spaniel," Richard Surflet, who wrote in the year 1600, said, "There is another sort of land-spannyels which are called setters, and they differ nothing from the former but in instruction and obedience, for these must neither hunte, range, nor retaine, more or less, than as the master appointeth, taking the whole limit of whatsoever they do from the eie or hand of their instructor. They must never quest at any time, what occasion soever shall happen, but as being dogs without voices, so they must hunt close and mute. And when they come upon the haunt of that they hunt, they shall 
sodainly stop and fall down upon their bellies, and so leasurely creep by degrees to the game till they come within two or three yardes thereof, or so neare that they cannot press nearer without danger of retrieving. Then shall your setter stick, and by no persuasion go further till yourself come in and use your pleasure."

From this setting spaniel the setter of to-day has been evolved. Whether crosses were resorted to to perfect the dog, or whether he was simply brought up by careful selection in breeding, is an open question, some writers holding one and others the other theory. 'The probability is, though experimental crosses were tried in some instances, the main line of the setter family is as nearly pure, in the sense of uncrossed, as any family of dogs we have. Certainly, even the present setter retains the marks of his origin in what would seem an unusual degree in a dog subjected to violent crosses, and the changes which have been made, could result as well from selection and effort to breed out undesirable qualities and perpetuate those which are desirable, as from crossing.

\section{THE POINTER.}

The pointer was not introduced into Eingland till many years after the setter had come into general use. He was imported from Spain in his pointer form, but is considered by authorities as the descendant of some of the hounds, though how bred no one can say. The Spanish pointer had his merits, and also his radical defects, and to correct the latter foxhound and greyhound crosses were introduced, so that the modern pointer is not only essentially a cross-bred $\log$, but also materially changed in form and attributes from even his near ancestors.

THE SPANIEL.

As the progenitor of the setter this dog would seem entitled to earlier mention, but we have given the various breeds in the order of their comparative relation to present field sports, and the spaniel cannot therefore take precedence of the setter and pointer. Of his origin even the earliest writers give no reliable information, 
and we must simply accept him as the oldest representative of the dogs used in the pursuit of birds, without indulging in profitles: speculations of his ancestry.

Many varieties of the spaniel are now in existence. Originally all were field-dogs, but fashion has of late years drawn a dividingline, and the smaller breeds are assigned to the non-sporting class. Practically this is no loss, as sufficient are left to meet all demands for work, and the surplus may be utilized as pets, and bred down to a size and delicacy suitable for this purpose, withont injury to the interests of sportsmanship.

\section{THE HOUND.}

What in common parlance are known as hounds, are also found in great varieties; but sporting law has invaded the ancient division and struck out of it some of its members. It may seem strange to the uninitiated that the greyhound is no longer regarded as a hound proper, and that the deerhound is classed among the retrievers, but the modern limitation of hounds includes only those which hunt and kill their game by scent alone, and as the greyhound hunts by sight, and the deerhound is used only to follow the wounded quarry and bring it to bay, these dogs by the peculiarity of their employments are excluded from the hound class. The hounds which conform to the present limitation are the bloodhound, the foxhound, the harrier, the beagle, and the otter-hound, and of those in this class which are used in this country we shall speak at the proper time.

\section{THE RETRIEVER.}

This term applies only to dogs bred and kept exclusively for retrieving game, and does not properly include dogs which are taught to perform this duty in connection with their other field work. In England field-dogs are not as a rule allowed to retrieve, but in this country it is the custom of sportsmen to break their setters, pointers, and spaniels to retrieve, and so save the loss of much game or the employment of special retrievers. In England the 
water-spaniel is not included in the retriever class, but here he is a very useful $\log$ for men who delight in duck-shooting, and do not wish to wear out their field-rlogs by exposing them in water work. In a later portion of this chapter we shall speak of the water-spaniel, and indeed might dispense with all mention of the retriever proper but for the fact that efforts have been made to popularize the dog here, and occasional specimens are met with, also that we have on the Chesapeake, a true retriever of high character which we shall refer to, and it certainly seems inappropriate therefore to pass the class over in silence. Without going into particulars, it is sufficient to say English retrievers and the Chesapeake dog are cross-bred, being made up in the former instance of combinations of blood, which experience has shown are specially adapted to the production of the desired qualities, and in the latter by a cross of the English water-dog and the Newfoundland.

\section{SETTER DIVISIONS.}

The setter family is divided into three great national classes according to origin, viz. : the English, Irish, and Gordon, or blackand-tan, the latter being of Scotch descent. All are largely represented in this country, and each breed has its special admirers. The first is, however, the most generally popular, and is in fact entitled to pride of place as first in the list of American field-clogs.

\section{THE ENGLISH SETTER.}

In describing this and other dogs we shall give the points of form as laid down by Stonehenge, they being accepted as the standard in judging at shows.

"The slull (value 10) has a character peculiar to itself, somewhat between that of the pointer and cocker-spaniel, not so heary as the former's and larger than the latter's. It is without the prominence of the occipital bone so remarkable in the pointer, is also narrower between the ears, and there is a decided brow over the eyes.

"The nose (value 5) should be long and wide without any fulness under the eyes. There should be in the average dog setter at 
least four inches from the inner corner of the eye to the end of the nose. Between the point and the root of the nose there should be a slight depression; at all events there should be no fulness, and the eyebrows should rise sharply from it. The nostrils must be wide apart and large in the openings, and the end should be moist and cool, though many a dog with exceptionally good scenting power's, has had a remarkably dry nose, amounting in some cases to roughness like that of shagreen. In all setters the end of the nose should be black or dark liver-colored, but in the very best whites, or lemon and whites, pinkris often met with, and may in them be pardoned. The jaws should be exactly even in length, a 'snipe nose' or 'pig jaw,' as the receding lower one is called, being greatly against its possessor.

"Ear's, lips, and eyes (value 4). With regard to ears, they should be shorter than those of the pointer and rounderl, but not so much as those of the spaniel. 'The 'leather' should be thin and soft, carried closely to the cheeks, so as not to show the inside, without the slightest tendency to prick the ear, which should be clothed with silky hair little more than two inches in length. The lips also are not so full and pendulous as those of the pointer, but at their angles there should be a slight fulness, not reaching quite to the extent of hanging. The eyes must be full of animation and of medium size, the best color being a rich brown, and they should be set with their angles straight across.

"The neck (value 6) has not the full rounded muscularity of the pointer, being considerably thinner, but still slightly arched, and set into the head withont that prominence of the occipital bone which is so remarkable in that dog. It must not be 'throaty,' though the skin is loose.

"The shoulders and chest (value 15) should display great liberty in all directions, with sloping deep shoulder-blades and elbows well let down. The chest should be deep rather than wide, the ribs should be well sprung behind the shoulder, and great depth of the back ribs should be especially demanded.

"Back quarters and stifles (value 15). An arched loin is de- 
sirable, but not to the extent of being 'roached' or 'wheel-backed,' a defect which generally tends to a slow up-and-down gallop. Stifles well bent and set wide apart, to allow the hind legs to be brought forward with liberty in the gallop.

"Legs, elbows, and hocks (value 12). The elbows and toes which generally go together should be set straight, and if not, the 'pigeon toe' or inturned leg is less objectionable than the out turn, in which the elbow is confined by its close attachment to the ribs. 'The arm should be muscular and its bone fully developed, with strong and broad knees, short pasterns, of which the size in point of bone should be as great as possible (a very important point), and their slope not exceeding a very slight deviation from the straight line. Many good judges insist upon a perfectly upright pastern, like that of the foxhound; but it must not be forgotten that the setter has to stop himself suddenly when at full stretch he catehes scent, and to do this with an upright and rigid pastern causes a considerable strain on the ligaments, soon ending in 'knuckling over;' hence a very slight bend is to be preferred. The hind legs should be muscular, with plenty of bone, clean strong hocks, and hairy feet.

"The feet (value 8 ) should be carefully examined, as upon their capability of standing wear and tear depends the utility of the dog. A great difference of opinion exists as to the comparative merits of the cat- and hare-foot for standing work. Foxhound masters invariably select that of the cat, and as they have better opportmities than any other class of instituting the necessary comparison, their selection may be accepted as final. But as setters are specially required to stand wet weather, it is imperatively necessary that there should be a good growth of hair between the toes, and on this account a hare-foot, well clothed with hair, as it generally is, must be preferred to a cat-foot naked, as is often the case, except on the upper surface.

"The flug (value 5) is in appearance very characteristic of the breed, although it sometimes happens that one or two puppies in a well-bred litter exhibit a curl or other malformation, usually considered to be indicative of a stain. It is often compared to a scimitar, 
but it resembles it only in respect of its narrowness, the amount of curl in the blade of this Turkish weapon being far too great to make it the morlel of the setter's flag. Again, it has been compared to a comb, but as combs are usually straight, here again the simile fails, as the setter's flag should have a gentle sweep; and the nearest resemblance to any familiar form is to the scythe with the curve reversed. The feather must be composed of straight silky hairs, and beyond the root the less short hair on the flag the better, especially towards the point, of which the bone shonld be fine and the feather tapering with it.

"Symmetry and quality (value 5). In character the setter should display a great amount of 'quality,' a term which is difficult of explanation, though fully appreciated by all experienced sportsmen. It means a combination of symmetry, as understood by the artist, with the peculiar attributes of the breed under examination, as interpreted by the sportsman. Thus a setter possessed of such a frame aud outline as to charm the artist, would be considered by the sportsman defective in 'quality' if he possessed a curly or harsh coat, or if he had a heavy head with pendent bloodhoundlike jowl and throaty neck. The general outline is very elegant, and more taking to the eye of the artist than that of the pointer.

"The texture and feather of coat (value 5) are much regarded among setter breeders, a soft silky hair without curl being considered a sine qua non. The feather should be considerable, and should fringe the hind as well as fore legs.

"The color of coat (value 5) is not much insisted on among. English setters, a great variety being admitted. These are now generally classed as follows in the order given: 1, Black and white ticked, with large splashes, or more or less marked with black, known as blue Belton; 2, orange and white freckled, known as orange Belton; 3, plain orange or lemon and white; 4 , liver and white; 5 , black and white with slight tan markings; 6 , black and white; 7 , liver and white; 8 , pure white; 9 , black; 10 , liver; 11 , red or yellow."

We would call attention to a repetition in numbers 4 and 7 , 
which is evidently a mistake in the first instance, as liver and white ranks below black, white, and tan, and black and white, with setter breeders.

\section{THE IRISH SETTER.}

This dog differs from the English setter as follows; the value of points being the same in both cases:

"The skull is somewhat longer and narrower, the eyebrows being well raised, and the occipital prominence as marked as in the pointer.

"The nose is a trifle longer, with good width, and square at the end; nostrils wide and open, with the nose itself of a deep mahogany or very dark fleshy color, not pink or black.

"Eyes, ears, and lips. The eyes should be a rich brown or mahogany color, well set, and full of intelligence; a pale or gooseberry eye is to be avoided. Ears long enough to reach within half an inch or an inch of the end of the nose, and though more tapering than in the English dog, never coming to a point; they should be set low and close, but well back, and not approaching to the hound's in setting and leather. Whiskers red; lips deep, but not pendulous.

"In frame, the Irish dog is higher on the leg than either the English or black-and-tan, but his elbows are well let down nevertheless; his shoulders are long and sloping; brisket deep, but never wide; and his back ribs are somewhat shorter than those of his English brethren; loin good, slightly arched, and well coupled to his hips, but not very wide; quarters slightly sloping, and flag set on rather low, but straight, fine in bone, and beautifully carried. Breeders are, however, going for straight backs like that of Palmerston, with flags set on as high as in the English setter.

"Legs very straight, with good hocks, well-bent stifles, and muscular but not heavy haunches.

"The feet are hare-like, and moderately hairy between the toes.

"The flag is clothed with a long, straight comb of hair, never bushy or curly, and this is beautifully displayed on the point. 
"The coat should be somewhat coarser than that of the English setter, being midway between that and the black-and-tan, wavy but not curly, and by no means long. Both hind and fore legs are well feathered, but not profusely, and the ears are furnished with feather to the same extent, with a slight wave, but no curl.

"The color should be a rich blood-red, without any traces of black on the ears or along the back; in many of the best strains, however, a pale color or an occasional tinge of black is shown. A little white on the neck, breast, or toes is by no means oljectionable, and there is no doubt that the preponderance of white, so as to constitute what is called 'white and red,' is met with in some good strains."

THE GORDON, OR BLACK-AND-TAN SETTER.

The points of difference between this dog and the Euglish setter are,-

"The skull is usually a little heavier than that of the English setter, but in other respects it resembles it.

"The nose also is like the English setter's, but it is usually a trifle wider.

"The flag is usually a trifle shorter than that of the English setter, which it otherwise resembles in shape.

"The coat is generally harder and coarser than that of the English or Irish setter, occasionally with a strong disposition to curl, as in the celebrated champions Reuben and Regent.

"The color is much insister on. The black should be rich, without mixture with the tan, and the latter should be a deep mahogany-red withont any tendency to fawn. It is admitted that the original Gordons were often black-tan and white; but as in all our shows the classes are limited to black-tan, the long arguments which have been adduced on that score are now obsolete. A little white on the chest, and a white toe or two, are not objected to; but a decided frill is considered by most judges to be a blemish. The red-tan should be shown on cheeks, lips, throat, spot over the eyes, fore legs nearly to the elbors, hind legs up to. 
the stifles, and on the under side of the flag, but not rumning into its long hair."

\section{THE POINTER.}

The pointer family has no divisions like those in setters, but is divided according to weight into large and small classes, those over fifty pounds composing the former, and those under the latter.

The points of form are, -

"The skull (value 10) should be of good size, but not as heavy as in the old Spanish pointer, and in a lesser degree his half-bred descendants. It should be wider across the ears than that of the setter, with a forehead rising well at the brows. A full development of the occipital protuberance is indispensable, and the upper surface should be in two slightly rounded flats, with a furrow between.

"The nose (value 10) should be long (four inches to four and three-quarters inches) and broal, with widely-open nostrils. The end must be moist, and in health cold to the touch. It should be black or very dark brown, in all but the lemon and whites, but in them it may be a deep flesh-color. It should be cut off square and not pointerl, known as the 'snipe nose' or 'pig jaw.' Teetl meeting evenly.

"The neck (value 6) should be arched towards the head, long and round, without any approach to dewlap or throatiness. It should come out with a graceful sweep from between the shonderblades.

"The shoulders and chest (value 15) are dependent upon each other for their formation. Thus a wide and hooped chest cannot have the blades lying flat against its sides; and, consequently, instead of this and their sloping backwarks, as they ought to do in order to give free action, they are upright, short, and fixed. Of course a certain width is required to give room for the lungs; but the volume required should be obtained by depth rather than width. Behind the blades the ribs should, however, be well arched, but still deep; this depth of back rib is specially important.

"The back, quarters, and stifles (value 15) constitute the main pro- 
pellers of the machine, and on their proper development the speed and power of the dog depend. The loin should be very slightly arched and full of muscle, which should run well over the back ribs; the hips should be wide, with a tendency even to ruggedness, and the quarters should droop very slightly from them. These last must be full of firm muscle, and the stifles should be well bent and carried widely apart, so as to allow the hind legs to be bronght well forward in the gallop, instituting a form of action which does not tire.

"Legs, elbows, and hocks (value 12). These chiefly bony parts, though merely the levers by which the muscles act, must be strong enough to bear the strain given them; and this must act in the straight line of progression. Substance of bone is therefore demanded, not only in the shanks but in the joints, the knees and hocks being especially required to be bony. The elbows should be well let down, giving a long upper arm, and should not be turned in or out; the latter being, however, the lesser fault of the two, as the confined elbow limits the action consilemably. The reverse is the case with the hocks, which may be turned in rather than out; the former being generally accompanied with that wideness of stifles which I have already insister on. Both hind and fore pasterns should be short, nearly upright, and full of bone.

"The feet (value 8) are all-important; for however fast and strong the action may be, if the feet are not well shaped and their horny covering hard, the dog will soon become footsore when at work, and will then refuse to leave his master's heels, however high his courage may be. Breeders have long disputed the comparatively good qualities of the round cat-like foot and the long one resembling that of the hare. In the pointer my own opinion is in faror of the cat-foot, with the toes well arched and close together. This is the desideratum of the M. F. H., and I think stands work better than the hare-foot, in which the toes are not arched but still lie close together. In the setter the greater amount of hair to a certain extent condones the inherent wealness of the hare-foot; but in the pointer no such superiority can be claimed. The main point, how- 
ever, is the closeness of the pads, combined with thickncss of the horny covering.

"The stern (ralue 5) must be strong in bone at the root, but should at once be reduced in size as it leaves the body, and then gradually taper to a point like a bee's sting. It should be very slightly curved, carried a little above the line of the back, and without the slightest approach to curl at the tip.

"Of symmetry and quality (value 7) the pointer should display a goodly proportion, no dog showing more difference between the gentleman and his opposite. It is impossible to analyze these cssentials, but every good judge carries the knowledge with him.

"The teature (value 3 ) of coat in the pointer should be soft and mellow, but not absolutely silky.

"In color (value 5) there is now little choice, in point of fashion, between the liver and lemon and whites. After them come the black and whites (with or without tan), then the pure black, and lastly the pure liver. Dark liver ticked is perhaps the most beautiful color of all to the eye."

\section{THE SPANIEL.}

Under the head of the modern cocker all field-spaniels are now grouped, with the exception of the Sussex, the Clumber, the Norfolk, and the Welsh, or Devon cocker. A few specimens of the Clumber have been imported into this country, but they are not in sufficient numbers to warrant present description, except by saying they are the largest of all the field-spaniels seen here. They are distinguished by a heavy head, long body, and very short legs, which formation, with their weight, makes them slow workers with little endurance. They take their name from a seat of the Duke of Newcastle, by whom they were bred, are lemon and white in color, difficult to raise, and have few attributes of value to American sportsmen. The Norfolk, Sussex, and Welsh spaniels have, we think, no representatives in this comntry, thus leaving us only the cocker. Much attention has been given to this dog of late, and 
clubs have been formed for the purpose of breeding and introducing him more generally. His points of form are,-

"The head (value 15) should be long, with a marked brow, but still only gradually rising from the nuse, and the occipital protuberance well defined. Nose long and broad, without any tendeney to the suipe form. Eye expressive, soft, and gentle, but not too full or watery.

"The ear (value 5) should be set on low down, lobular in shape, not over-long in the leather or too heavily clothed with feather, which should always be wavy and free from ringlets.

"The neck (value 5) should be long enough to allow the nose to reach the ground easily, strong and arched, coming easily out of well-shaped shoulders.

"Chest, back, and loins (value 20). The chest should be deep and with a good girth; back and loin full of muscle, and running well into one another, with wide couplings and well-turned hindquarters.

"The length (value 5) of the spaniel should be rather more than twice his height at the shoulder.

"The legs (value 10) must be full of bone and straight; elbows neither in nor out; quarters full of muscle, and stifles strong but not very much bent.

"The feet (value 10) are round and cat-like, well clothed with hair between the toes, and the pards furnished with very thick horn.

"The color (value 5) preferred is a brilliant black, but in the best strains of the dog an occasional liver or red puppy will appear.

"The coat (value 10) is flat, slightly wavy, soft and silky; the legs are well fringed or feathered like the setter, as are also the ears; there must be no topknot or curl between the eyes, indicating a cross of the water-spaniel.

"The tuil (value 10), which is always cropper short, must have a downward carriage, and should not be set on too high.

"The symmetry (value 5) of the spaniel is considerable, and any, departure from it should be penalized accordingly." 


\section{THE HOUND。}

What may be called the foxhound is the hound most commonly used in this country. We say may be called, because he resembles the foxhound more closely than any other variety ; yet from the fact that he is seldom purely bred, and also that he is as often used for hare- as for fox-hunting, and even for deer-driving, he cannot with propriety be said to belong absolutely to any one class. Beagles have been imported and appear in force at shows, but are comparatively little employed in the field. So too other varieties have a few representatives, but as the present work is confined to dogs commonly used in our field-sports, we are justified by circumstances in considering the foxhound the most general representative of the dogs used for "pursuing" by American sportsmen.

The points of the foxhound are,-

"The head (value 15) should be of full size, but by no means heavy. Brow pronounced, but not high or sharp. There must be a good length and breadth, sufficient to give in the doghound a girth in front of the ears of fully sixteen inches. The nose should be long (four and one-half inches) and wide, with open nostrils. Ears set on low and lying close to the cheeks.

"The neck (value 5) must be long and clean, without the slightest throatines:. It should taper nicely from the shoulders to the heal, and the upper outline should be slightly convex.

"The shoulders (value 10) should be long and well clothed with muscle, without being heavy, especially at the points. They must be well sloped, and the true arm between the front and the elbow must be long and muscular, but free from fat or lumber.

"Chest and back ribs (value 10). The chest should girth over thirty inches in a twenty-four-inch hound, and the back ribs must be very deep.

"The back and loin (value 10) must both be very muscular, running into each other without any contraction or 'nipping' between them. The couples must be wide even to raggedness, and there 
should lie the very slightest arch in the loin, so as to be searcely perceptible.

"The hind-quarters (value 10) or propellers are required to be very strong, and as endurance is of even more consequence than speed, straight stifles are preferred to those much bent, as in the greyhound.

"Elbows (value 5) set quite straight, and neither turned in nor" out, are a sine qua non. They must be well let down by means of the long true arm above mentioned.

"Legs and feet (value 20). Every master of foxhounds insists on legs as straight as a post, and as strong; size of bone at the ankle being specially regarded as all-important. The desire for straightness is, I think, carried to excess, as the very straight leg soon knuckles over, and this defect may almost always be seen more or less in old stallion hounds. The bone cannot, in my opinion, be too large, but I prefer a slight angle at the knee to a perfectly straight line. ... The feet in all eases should be round and cat-like, with well-developed knuckles and strong horn, which last is of utmost insportance.

"The color and coat (value 5) are not regarded as very important so long as the former is a 'hound-color' and the latter is short, dense, hard, and glossy. Hound-colors are black, tan, and white, black and white, and the various 'pies' compounded of white and the color of the hare and badger, or yellow or tan. In some old strains the blue mottle of the Southern hound is still preserved, but it is generally rated 'slow.'

"The stern (value 5) is gently arched, carried gaily over the back, and slightly frimged with hair below. The end should taper to a point.

"The symmetry (value 5) of the foxhound is considerable, and what is called 'quality' is highly regarded by all good judges."

\section{THE RETRIEVER.}

In this class we shall include the Chesapeake Bay dog and the Irish water-spaniel. The latter is not classed as a retriever in Eng- 
land, but as he is largely used in this country for this purpose, and daily growing in favor, it seems appropriate to so place him in a work devoted to American dogs. The Chesapeake Bay dog was before the war quite numerous on that cclebrated shooting-ground. The war, however, put an end, temporarily, to the wild fowling, and the dogs were scattered, so that when the demand for their services was revived but few pure specimens existed. These were, however, carefully preserved, and, being in the hands of men who appreciated their value, efforts have been made to bring the breed up to its former strength. Prominent sportsmen of the West have also taken them up, and there is every probability that they will not again be allowed to run out, an end which would be just cause for regret, as they are the only strictly American sporting-dogs we have.

The Chesapeake Bay dog is also known as the "Brown Winchester" or "Red Chester," and is claimed to be rlescended from a cross of "the English water-poodle and the Newfonndland." This is the pedigree given by one of the best-known duck-shooters of the bay, a man who has owned the breed for many years, and has been largely instrumental in preserving it. The following is his deseription: "They are a low, heavy-set, densely-coated dog, of a dark redklish-brown color on the back, shading lighter on the sides, and rumning into a very light yellow or white on the belly and inside of the legs; the throat and breast are also frequently marked with white. They are of other colors, but any change from the brown shows a want of careful breeding." This dog possesses an extremely hardy constitution and great strength in swimming, being frequently known to "chase a crippled duck one and two miles." For tidewater or any open shooting, where sight and not seent is required for retrieving, he has no superior; and as he has been accustomed to follow by sight only, it is possible his scenting powers can bo developed by putting him to different work, or by some judicious cross, which will supply this deficiency without impairing his excellence in other respects. If keenness of nose can be given him in any way, he will be as valuable to duck-shooters generaily as the setter or pointer is to those who hunt the uplands. 
The Irish water-spaniels found in this country are almost exclusively of the McCarthy breed, from the south of Ireland, which Stonehenge says, "may be considered the type of Irish waterspaniel, and his description ... is the standard by which the breed is judged." The description is as follows:

"The head (value 10) is by no means long, with very little brow, but moderately wide. It is covered with curls, rather longer and more open than those of the body, nearly to the eyes, but not so as to be wigged like the poodle.

"The fuce and eycs (value 10) are very peculiar. Face very long and quite bare of curl, the hair being short and smooth, though not glossy; nose loroad, and nostrils well developed; tecth strong and level; eyes small and set almost flush, without eyebrows.

"The topknot (value 10) is characteristic of the true breed, and is estimated accordingly. It should fall between and over the eyes in a peaked form.

"The ears (value 10) are long, the leather extending, when drawn forward, a little beyond the nose, and the curls with which they are clothed two or three inches beyond. The whole of the ears is thickly covered with curls, which gradually lengthen towards the tips.

"Chest and shoulders (value $7 \frac{1}{2}$ ). There is nothing remarkable about these points, which must nevertheless be of sufficient dimensions and muscularity. The chest is small compared with most breeds of similar substance.

"The back and quarters (value $7 \frac{1}{2}$ ) also have no peculiarity, but the stifles are almost always straight, giving the appearance of legginess.

"Legs and feet (value 10). The legs should be straight, and the feet large, but strong; the toes are somewhat open, and covered with short crisp curls. In all dogs of this breed the legrs are thickly clothed with short curls, slightly pendent behind and at the sides, and some have them all round, hanging in ringlets for some time before the annual shedding. No feather like that of 
the setter should be shown. The front of the hind legs below the hocks is always bare.

"The tail (value 10) is very thick at the root, where it is clothed with very short hair. Beyond the root, however, the hair is perfectly short, so as to look as if the tail had been clipped, which it sometimes fraudulently is at our shows, but the natural bareness of the tail is a true characteristic of the breed.

"The coat (value 10) is composed of short curls of hair, not woolly, which betrays the poodle cross. A soft, flossy coat is objected to as indicative of admixture with some one of the landspaniels.

"The color (value 10) must be a deep pure liver without white; but as in other breeds, a white toe will occasionally appear even on the best-bred litter.

"The symmetry (value 5) of this dog is not very great."

\section{RELATIVE MERITS.}

The relative merits of setters, pointers, and spaniels is a question upon which many battles royal have been fought. Sportsmen have their preferences, and will continue to hold to them, in spite of argument, until satisfied by experience that they are wrong. For spaniels there is of course but limited use. Their place is in thickets and close woodlands, and their game the ruffed grouse and woodcock. Comparison with setters and pointers must therefore be restricted to this kind of work, as for open shooting the greater speed and range of the latter logs give them an unquestionable superiority. It is elaimed that the short range required in woodland shooting is injurious to the speed of setters and pointers. This is an English idea, which has been adopted here; but, speaking for ourselves, we have seen too many cases in which this theory has been utterly refuted, to admit that it is based upon either reason or fact. The question in our mind is not one of speed, but simply of natural adaptation for work, and upon this we have a decided opinion, though we do not propose to express it, but to 
give to others the same liberty in thought and action we claim for ourselves.

Pointers and setters are used upon the same game, and, other things being equal, they would afford chance for fair comparison. We think, however, no equality exists between them, owing to natural physical characteristies, which plainly indieate the very different circumstances of ground and climate to which they are suited. We have had many year's' experience with both dogs, and our preference is based upon what experience has taught us is the better of the two for the sport we indulge in. We are satisfied each is superior to the other under certain circumstances, but that one has a more extended sphere of usefulness thim the other we also as firmly believe. In times past we have expressed our views and backed them by arguments, but in the present instance we deem it better to avoid the vexed question, since there can be no debate when only the writer has an opportunity to express an opinion. In fact, we should not have touched the matter at all but for the impropriety of utterly ignoring what has been, and probably will always be, a bone of contention to sportsmen anil breeders. 


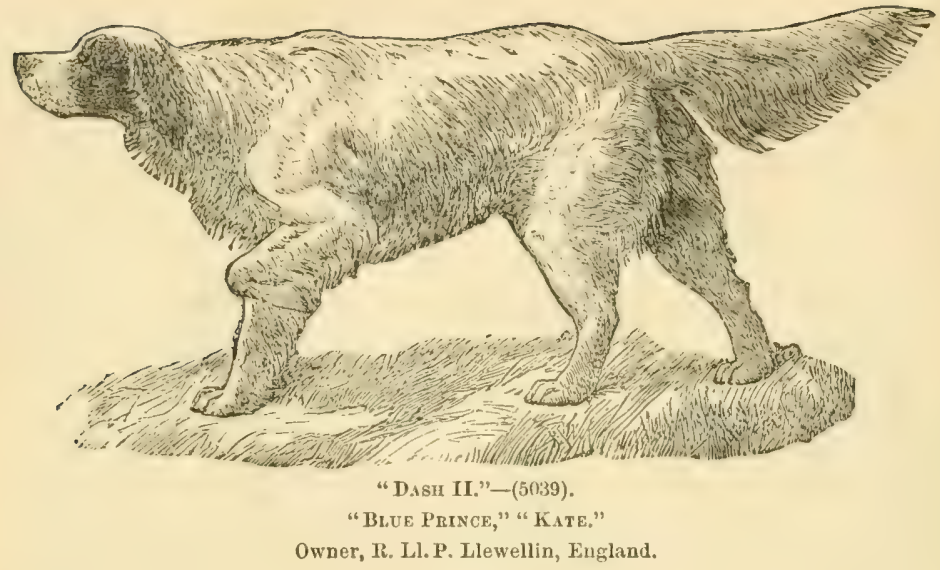

CHAP'TER V.

THE SCIENCE OF BREEDING.

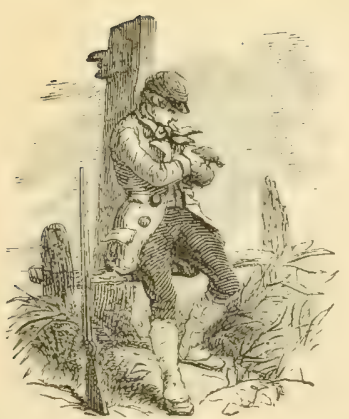

$\mathrm{N}$ no one respect is the change in popular feeling upon what relates to field sports more marked than in the opinion now entertained of those who breed dogs. A few years since field sports themselves were hardly tolerated, but a man who bred dogs was regarded as a low character, not to be recognized by gentlemen except as the supplier of their wants. The high rank which sportsmanship has since taken has, as a natural sequence, raised breeding proportionally. Gentlemen wish to deal with gentlemen. Canine breeding hats been recoguized as a science, and an American gentleman takes as much pleasure in breeding a crack field-trial winner as an English lord takes in breeding a winner of the Derby. Even sportsmen who do not breed extensively like to breed occasional litters, and it is therefore fitting that something should be said of the science, since only by knowledge and observance of its laws can success be reasonably expected. 
Experience is of as much value in this matter as in any other, yet there are certain general principles which inexperienced persons can understand, and by following them closely cannot go far wrong even in first essays.

\section{THE THEORY THAT "LIKE PRODUCES LIKE."}

It is claimed that "like produces like." This is true, but equally so of the bad as of the good, and a thorongh appreciation of what constitutes similarity, and to what extent this is desirable, is absolutely necessary for the successful application of this theory to the production of dogs with desirable characteristics. As formerly understood, like to like meant nothing more than the mating of one good field performer with another, but, as we shall presently show, this is only the alphabet of the theory, and such unions were more liable to produce worthless than good progeny.

In the first place blood was not regarded, and in this more intelligent age it is hardly necessary to say blood is of the highest importance. Dogs of entirely different strains were bred together, and when it is remembered that each breed has its individual characteristics, such fixed and definite character being in fact the very foundation of the claim to be considered a breed, it must be apparent that the mating of individuals of different breeds produces, as a primary result, a mingling of the different attributes of the parents in their progeny. The tendency of all domesticated animals, and especially of those which have been developed in what may be called an unnatural degree, is to degenerate, and this inclination can be overcome only by persistent strengthening of the cultivated attributes, by continued breerling in the line which produced them. To mingle different characteristics is, therefore, to introduce conflicting forces, each striving to assert its supremacy, and in a litter thus bred there will naturally be great variation in the character of individuals. Some will resemble one parent, some the other, and others will differ from both. This resemblance and variation will not be confined to physical form, but will extend to the higher faculties also, and while some individuals may be as grood as their 
parents, others will certainly fall short of their standard, owing to the disturbing influences of the different strains. If the blood of the parents is impure the variations will be all the greater, but even with the purest blood they will be present, and utterly destroy that uniformity of characteristics which is sought for in breeling. We see, then, we may mate individuals of equally fine qualities, and even of equal purity in blood, yet they will not produce progeny equal to themselves. Like does not produce like, therefore, in such cases.

Even if we advance a step further and demand that in addition to similarity in field qualities there shall be similarity in blood, we shall find, if we stop here, we have not got all that is essential to the highest success. There may be as wide divergence in physical characteristics or in character in individuals of the same blood as in those of different strains, and the union of these will destroy the equilibrium which naturally exists in cases of true like to like. 'To fully meet the requirements of the theory, there must be similarity and equally high development in blood, physical characteristics, character, disposition, and field qualities. When all these are present we have indeed a union of like with like, in which there can be no disturbing elements, and the effect of which must be the perpetuation and intensifying of the qualities of the indivirluals mated.

This is the perfection in theory of breeding, but it is seldom reduced to practice, owing to the fact that comparatively very few breeders are so circumstanced that they can examine with sufficient closeness into the fitness of one individual for another. If it was possible to obtain a general and strict adherence to the rule, there is no doubt the result would be a race of dogs superior to those we have, for we see the superiority of those produced by breeders most careful in their selection of their breeding stock, and the principle which produces such results on a small scale has no limits, and will be equally effectual if applied to general breeding. The difficulties in the way, and the effect of past carelessness in mating, fully account for the differences observable in individual:s nearly related, and as we must take dogs as we find them, we can only 
study their good and bad qualities, and then apply the theory in mating, so as to increase the good and diminish the bacl. In other words, we must constantly strive to breed up to the good and away from the bad attributes.

\section{A COMMON MISTAKE.}

Before attempting to give in detail the plan to be followed in breeding, we must say a word of warning against the most common and fatal mistake which occasional breeders make, viz.: that of thinking because a dog has a first-class show and field record this is sufficient to make him a good one to breed to. Certainly these qualities are of great importance, and in the absence of special unfitness such a dog should be used in preference to one of whom nothing is known, or of less reputation; but, on the other hand, it must be remembered that no male that ever lived has produced equally fine progeny from all the females sent to him, even when they have been equally fine between themselves. This variation in progeny is due to the variation in individual characteristics to which we have referred, and the consequent greater fitness in some unions than in others. Men who own breeding-kennels will bear us out in the assertion, that it is very rare for an applicant for a dog's services to ask any questions as to his physical peculiarities, character, or disposition, yet as regards the contemplated union these are as important items as any others. It seems to be taken for granted that a noted dog is all right in these particulars, and so he may be in the abstract, yet all wrong in view of the special requirements in a given union. No absolutely perfect animal exists, and though a good $\log$ must certainly possess a great preponderance of good over bad qualities, the best have their faults, and if care is not taken to discover these, it ma easily happen that two individuals with the same faults are brought together, in which case natural law will compel the reproduction of the faults in still greater degree in the progeny. As we have said, the influence of like on like is equally potent in bad as in grood qualities, an intelligent breeder will therefore make such selection as will 
insure the desired influence, and avoid that which is undesirable. Occasional breeders are more liable to select unsuitable mates than regular breeders, because the former generally send to other men's dogs, while the latter own individuals of both sexes, and have abundant opportunity to study their peculiarities and mate them accordingly.

WHA'T TO BREED FOR.

As the object in breeding is the production of dogs of high quality, the first step is to obtain a thorough knowledge of what such quality consists in. In general, it may be said a first-class dog will possess a form approaching as nearly as possible to perfection, field qualities of a high order, a strong character, and a fine disposition.

Perfection of form consists in truth to breed characteristics, and the combination of bone and muscle in proportions which give the greatest ability to stand work. By truth to breed characteristics we mean that the dog must display the form peculiar to his breed, whatever it may be, and must not show any approach to that of others. For example, the Irish setter must not have a head like the English setter, or the shorter legs of the latter. The pointer must not return to the hound type, and the water-spaniel must not have the woolly coat of the poodle.

Field qualities consist in speed, endurance, style, stanchness, keenness of scenting power, and love of hunting. Speed is necessary to enable the dog to beat a wide expanse of comntry while the sportsman walls over only a small portion of it, thus saving him labor, and at the same time insuring the finding of all the game on the range. The possession of speed does not necessarily incapacitate the $\operatorname{dog}$ for the close range necessary in cover-shooting, as the pace can be regulated in breaking, as we shall show under that head. The endurance must be great or the dog will soon give way under the strain of fast work, and by tiring become practically useless, very possibly just when speed is most needed. This quality, therefore, cannot be too highly developed, and its presence gives the dog 
value in proportion to its degree. Style means the beauty of the dog's action when at work. Practically, it does not add to or detract from his efficiency, but it certainly adils to the sportsman's pleasure, as the appearance of a stylish dog beating his ground, drawing to birds, or pointing, is much more attractive than that of a slovenly though equally efficient performer. Stanchness is a sine qua non. Without tenacity of point other work, however brilliaut, is rendered useless, as the dog, pointing the birds far in advance

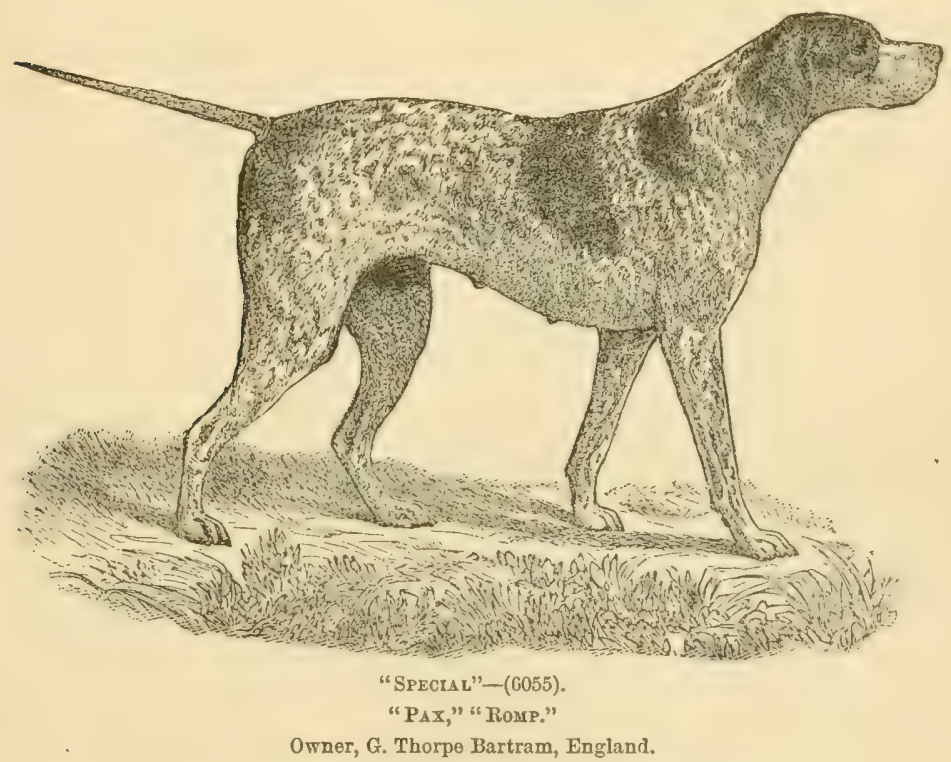

of the gun, will by breaking point flush them before the sportsman can come up. Keenness of scenting powers, commonly called "nose," is also a quality which cun never be excessive. It is one of the most important attributes of a field-(log, and may indeed be placed in the front rank, as upon it depents the success of the dog's work. Without it there can be no point, as the dog will receive no warning of the birds' presence, and consequently will gillop into them insteal of stopping. Fir-t-class noses are as rare an brilliancy in other of the higher faculties, but being so desirable they must be bred for, and thus made as common as possible. Love of hunting 
is sometimes wrongly ealled ambition. Ambition is often mere love of action, the delight of an athlete in the use of his powers, but love of hunting is an instinctive pleasure in the pursuit of game. It is nearly allied to intelligence, since there must be recognition of game itself, and also recognition of ability to find it by certain action. It is not ambition, but it gives rise to ambition, since the dog that loves to hunt will be prompted to work hard, and to bear the fatigue consequent upon such work uncomplainingly. Herein lies the benefit of this love to a breeder. Withont it a dog will work till he begins to tire, and then, having no special incentive, will give up, but with it he is constantly promptel by his pleasure to renewed exertion. It is also a great help to the breaker, being in fact the only thing which induces the dog to hunt with a purpose. A breaker can drill any dog mechanically, but if he does not love to hunt no amount of breaking will make him do it. There is no doubt but this love increases with experience of the pleasure it gives. Thus some dogs who do not show it at first will develop it later ; such individuals are, however, at best doubtful, and without a pronounced instinctive love of hunting displayed by the don on his first entry to game, there is little satisfaction or hope to repay the breaker's trouble.

By character we mean intelligence and courage. These are frequently classed with the field qualities, but as they are also ats commonly called into play by every-day life out of the field, we think they deserve a place by themselves. Upon intelligence depends the dog's capacity for receiving instruction, not only in what pertains to field work, but also upon those points which render him generally useful to his master. In the field it directs and regulates the application of his powers and experience to the discovery and outwitting of his game, thus enabling the sportsman to obtain shots he would not get with a less intelligent assistant. Intelligence varies in dogs as widely as in human beings, but in the former it is under control, so far at least that it may be specially bred for by selection and mating of individuals, which will be likely to give this quality to their progeny through their mutual possession of it. 
Courage is very essential to a field-dog both in and ont of the field. Its presence insures the breaker against intinidating the dog in breaking, and also against that timidity under the gun which is so difficult to overcome. In every-day life it certainly renders the dog a far more pleasant and useful companion than any timid one can be, and, in short, is necessary to that general perfection in quality which every fir-t-class dog should approach to as closely. as possible.

By fine disposition we refer to the affection, readiness to forget

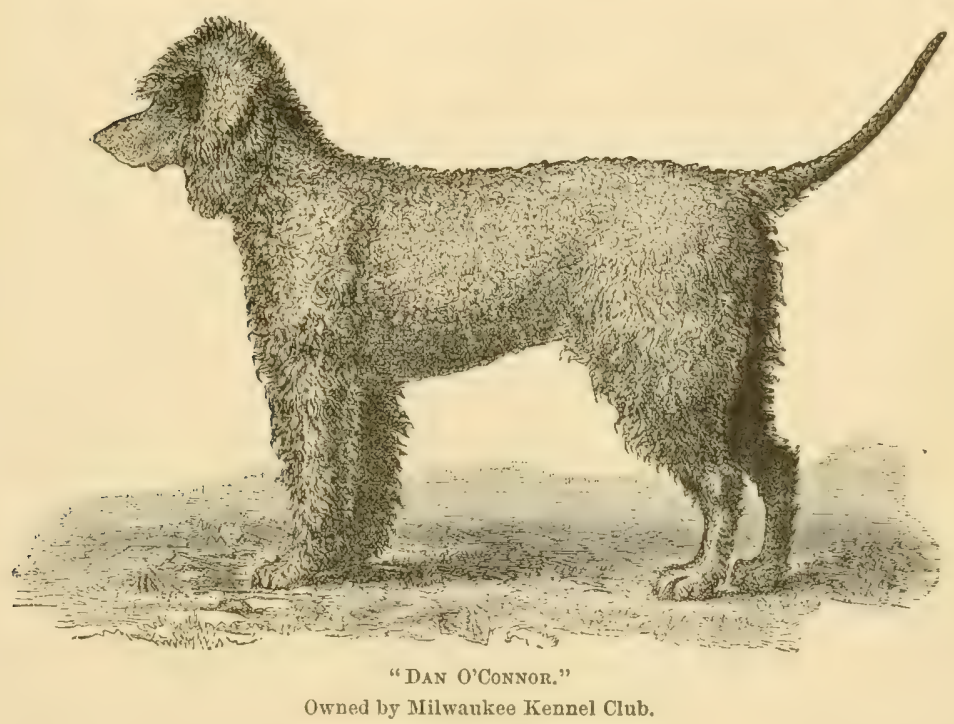

injury, and natural inclination to do the master's will and pleasure, which form the attration of the noble canine character. This is largely due to the way in which the dog is brought up, as it may be developed or suppressed by good or bad treatment, but dependis also somewhat upon instinctive inclination. It is obviously too important to need much mention, but cannot be omitted in enumerating the qualities a breeder must strive to gain. 


\section{HOW TO BREED.}

As we have already shown that confusion follows the mixing of different strains, it is evident the only certainty of obtaining specific results lies in strict adherence to one strain, which has possessed and transmitted the desired qualities for a number of generations, thus proving its fixed character. This of course involves interbreeding, which is really the law of nature, as shown by the actions of those wild animals which dwell enntinuously in herds. We cannot, however, follow this law as far as animals in a state of nature, owing to the fact that in them purely physical perfection is all that is required, and this is secured by a direct provision for the survival of the fittest through the law of force ; in other words, by the strong destroying the weak. The domesticated dog is an artificial creature, prosessed of higher faculties than his ancestor: and the development of these, with also the enervating effect of an unnitural life, has caused certain weaknesses which, common to all, are naturally specially shared in the same degree by those most closely related. By interbreeding we of course obtain in some degree an intensifying of these weaknesses, but this evil is more than compensated for by at corresponding intensifying of the gool qualities peculiar to the strain, which cannot be got in any other way. There is of course a difference in individuals of the same strain, and by selecting those which display the good qualities in the highest and the weaknesses in the lowest degree, we get the best substitute for natural selection and survival of the fittest, and thus secure the perpetuation of the strain characteristics, with the greatest freedom from its defects. By inbreeding, or breeding decendants of the same parents, we intensify the good and bad qualities in equal proportions, and at the same time we intensify the natural tendency to degeneration, which is only corrected in other cases by comnteracting influence. A rery good illustration of the effect of external influences is furnished by the different results of the union of brothers with sisters, and that of parents with offspring. In the former all the influences from both individuals are precisely the same, but in the latter there is in 
the offspring a counteracting influence in the one-half blool cierived from an outside source. The precisely similar blood in the first instance will give one result, and the influence of the outside strain in the other will produce a very different one. It must not be supposed that we advocate the breeding in either of these close relations. We quote them simply as examples, as they are so nearly alike that only a shade of difference exists, yet from that shate we get results which indicate how we ought to select to get the best.

Various strains of each breed exist, some much better than others, and these better ones must be selected, the best of their representatives discovered, and resorted to in breeding, thus securing continuance in the same blood, and at the same time progression in the same line that has produced past excellence.

\section{DEFECTS AND THEIR CORRECTION. •}

If all dogs of the same strain were equally good there would be no need for selection. They are not, however, and the intelligent breeder will carefully study each individual to discover his or her defects, and then select mates which, from the possession of opposite characteristics in excess, will produce a correction of these defects in the progeny.

The common defects are those of form, character, and some particular field quality. Form is defective in two ways without departure from breed characteristics, viz.: there may be too much weight of bone, ealled lumber, or there may be too little, resulting in weakness. A frame that is excessively heavy imposes a very severe strain upon the powers when at work. Such dogs are slow in motion and have but little endurance. They may perform brilliantly for a short time, but they cannot "stay," and by their" break-down put a premature end to the sportsman's pleasure. Those which are too smatl or too light are equally inefficient. They usually have a flaslyy turn of speed, and may even perform for some length of time under specially favorable circumstances, but (ither by continuance of work or by the trying character of the ground hunted they are forced to "quit." Doggs of both types often posisess some 
specially desirable qualities, and consequently should not be utterly discarded on account of their defects, but should be mated with their opposites in physical structure, thus producing progeny with the good and without the bad qualities of the parent.

In this connection it is proper to call attention to the fact that an individual may be a marked exception to his or her line, and in this case cannot be depended on to proluce his or her own characteristics in any large degree, as the influence of the line will assert itself in a majority of that portion of the progeny influenced by the particular parent. The degree of influence which one parent will exert cannot be predetermined, and cases have been known where an individual has displayed a marked faculty for impressing his or her own likeness, or line attributes, upon a very large percentage of offspring, even when extensively bred from and mated with individuals of different types. A breeder should therefore not only inquire into the characteristics of the individual, but also into those of the ancestors, that the combined influence may be predetermined as far as possible.

Minor physical defects should be corrected in the same way as the important ones we have referred to, and so should those of character or field quality, but it must be borne in mind that these defects will naturally be reproiluced in a portion of the descendants, though corrected in others, also that until mature form and full developinent are reached the degree in which the defects have been reproduced will not be fully apparent, so that the results of a union which in early life promises to be highly satisfactory, may later prove disappointing. The only safety, therefore, lies in the mating of individuals as nearly perfect as possible, and inheriting this perfection from a line of similarly perfect ancestors. When this perfection exists on both sides there cannot be unfitness on the part of one for the other, and the variation in progeny will be avoided. 


\section{UNIFORMITY, NOT " SORTINESS."}

In breeding for the uniformity which we have said is so desirable, we must not be led by fashion to seek "sortiness," or that close resemblance of one to the other which is desirable in dogs which are habitually used in packs, like foxhounds. Certain colors are often made fashionable by bench shows, and breeders are sometimes led to give undue importance to special marking by the favor shown to it. Uniformity should extend to similarity in form and field characteristics, but color or marking, so long as it is true to the breed, should not be regarded. Each breed has its natural colors, and if some are made more popular than others, the effort to get the fashionable ones results in discarding dogs of otherwise high merit, possibly the best in the lot. Such culling must in the end lead to depreciation, as it makes a matter of mere funcy paramount to others of real importance. A careful breeder who seeks to obtain dogs valuable for field work, will therefore never reject a dog simply for color, but will take the best he can find, when considered with regard for the most valuable qualities. 


\title{
CHAPTER VI.
}

\author{
BREA KING.
}

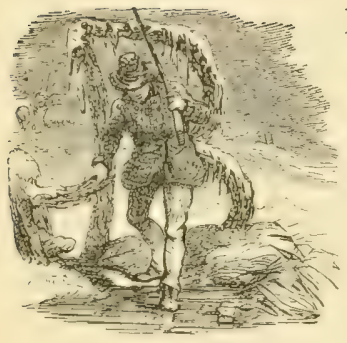

REAKING a dog is not, as many persons suppose, necessarily the work of a professional. There are many amateur breakers in the country whose dogs will compare favorably with those of any professional, and the number of such increases with every year, as experience demonstrates the ease with which the work can be accomplished. Any man capable of handling a broken dog well in the field is competent to break one. To hunt a dog well means something more than mere following one about, depending upon the influence of past instruction to keep him under control and up to his work. Dogs are as cumning and wilful as other animals, and need as constant restraint. The best broken ones will try to get their own way, and if they find their masters do not appreciate and correct their wrong actions, they quickly come to despise the authority which is not enforced, and apparently forget all that their breakers have taught them. 'To hunt a dog properly implies, then, linowing what he should do and making him do it, and when the ability for this is present, the man is capable of breaking for himself.

In their first field essays men will of course know no more of working than of breaking dogs, but if such will go out a few times with experienced friends, watch how they work their dogs, and then getting a well-bred, promising puppy, apply their observations to his instruction, they will be surprised at their own improvement in knowledge and their success in teaching their pupils. We do not 72 


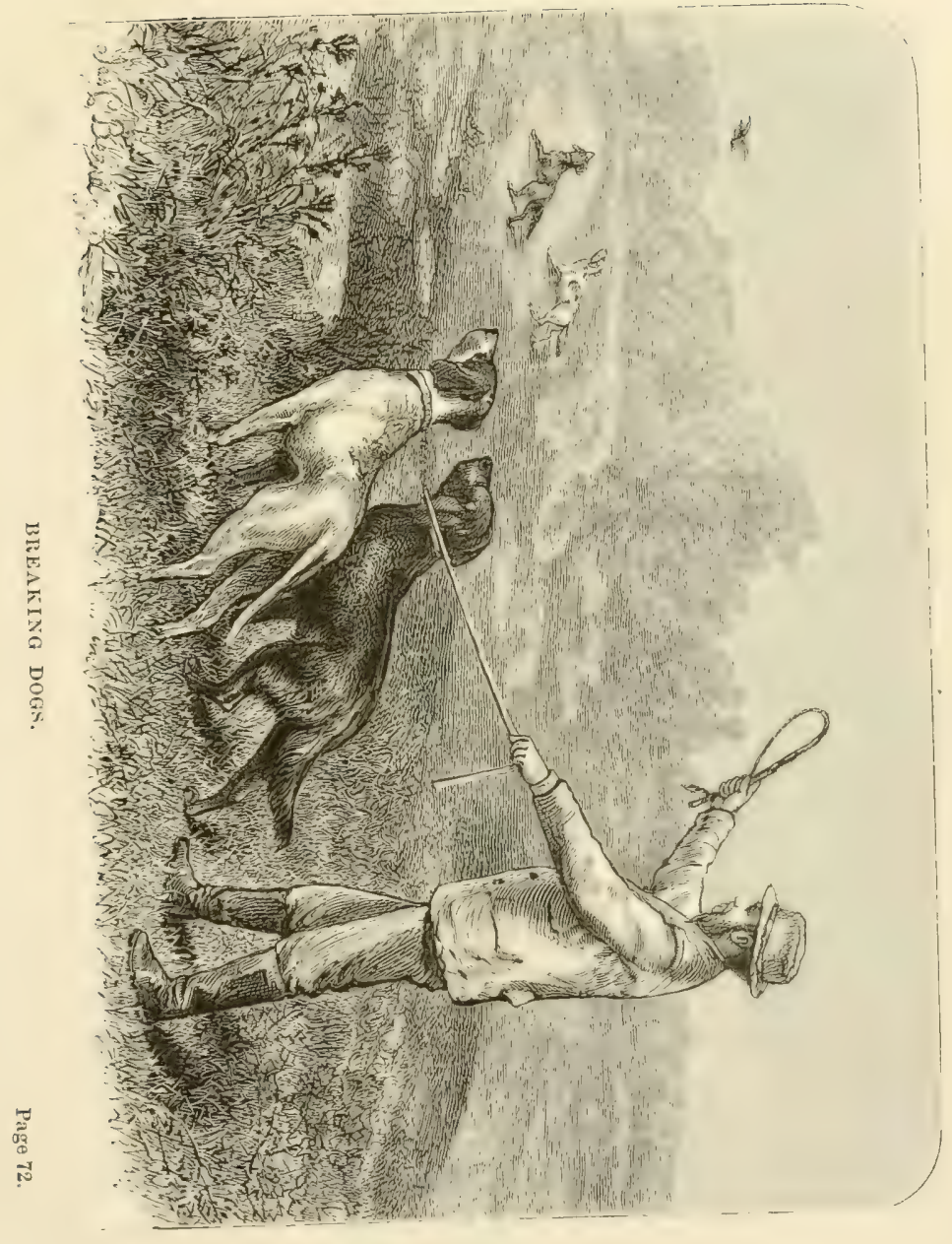



hesitate to say sportsmen will fund much greater pleasure in owning dogs broken by themselves than in those professionally broken. A man would find but little pleasure in hiring a professional to shoot for him, and the same principle will apply to professional breaking. The possession of personal skill is all that gives attraction to field sports, and the greater and more general this is, the greater proportionally will be the enjoyment derived from it. The man who breaks his own dogs finds in their performance a reward for his labor, and in their perfection a pronf of his own ability, which is flattering, yet a legitimate cause for satisfaction. Every man delights in the skilful work of his own hands, and feels for such an affection he will never feel for that which he pays for. For a noble dog every true man has this affection, but when that nobility is developed by the man himself, the sympathy between man and brute, which has existed from time immemorial, is tenfold strengthened and intensified.

The only other obstacle which lies in the way of the amateur breaker is supposed want of time. No greater mistake is ever made, for all the time necessary is those old, spare moments which come in every day, and which are illed away unnoticed. If leisure moments are profitably and pleasantly employed, they are not only utilized but also enjoyed, and that they can be profitably and pleasantly applied to breaking a very brief experience will demonstrate beyond question. A single trial will satisfy the most sceptical, as it has satisfied others in the past, and it is to render such trials successful that we shall now give the plan of breaking which we have found the best in a long life of field experience.

\section{BREAKING, HOW DIVIDED.}

Breaking is properly divided into that of the yard and the field. The former includes bringing the dog under control, teathing him to understand what certain orders mean and to obey them. 'The latter covers work in the field upon game and the application of the preliminary instruction to such work. This course is adiuted to dogs that have never been handled and that have no confirmed fiults, to 
young dogs in fact; but beyond this something must be said of the rebreaking of dogs which have been badly handled, and which through lack of proper control, and the promptings of their own inclinations, have acquired habits destructive to field efficiency.

\section{FORCE $v s$. COAXING.}

At the outstart we must say we are no supporter of what may be called the "coaxing" system, in other words, playing with the pupil and coaxing him into doing what is desired. Work and play are two very different things and cannot be profitably mingled. The one involves persistent performance in the face of whatever inconvenience may be encountered, the other is a matter of mere pleasure, and is discontinued the moment it is orerbalanced by pain. The idea of making play of work appears well in theory, but it will not stand practical test. It is a favorite theory of inexperienced persons, and of those who are morbidly sensitive upon humane principles. It is an exaggeration of opposition to eruelty, and, like other exaggerations, is out of proportion with common sense. Men do not play at the work of their lives. Necessity applies a force which they recognize and obey. If this force was not present there would be very little work done, but being present, it controls their lives. The same prineiple may without hardship be applied to our control of animals, for they too have their work, and an intelligence proportional to the demands upon them, by which they recognize force and are led to yield to it, doing their best under reasonable and sensible compulsion. Men find their rewards in success and the approbation of their fellows, and brutes theirs in the approval of the master, an approval they appreciate, and which makes up, evidently, the sum of their greatest happiness. Nothing in such forcing as we alvocate approaches cruelty, nor is there any lack of reward, but it simply means teaching a $\operatorname{dog}$ to do a certain thing because he is ordered to, even if it clashes with his inclination, and for obedience we provide ample recompense. In short, the system is one of rewards and punishments, doubly appealing to the dog's intelligence, and making him a far better and more efficient servant 
than he would be if admitted to equality with his master, so far as to be allowed option in the performance of his tasks.

\section{YARD BREAKING.}

The lessons which come under this hear are: 1, yielding to control; 2 , obeying the whistle; 3 , stopping at command; 4 , charging; 5, following at heel; 6, retrieving; 7, beating the ground and quartering. Each of these must be thoroughly taught before passing to the next, or they will be confounded, and the dog led into mistakes while doing his best to obey. The breaker must make up his mind to many vexations, and to bear these with patience, never allowing his temper to control him, even when punishment is most deserved. With intelligence and manly perseverance he can conquer his dog, but if he is lacking in these attributes which mark his superiority to the animal, the struggle will degenerate into one of brute with brute, in which the most stubborn will win.

Six months at the earliest is the age at which the dog's instruction should begin, and another six can be profitably added to this if the breaker has experience, or is willing to encounter a little more trouble. Many men begin very early with their dogs, but with a force system some development of the intelligence is necessary to prevent fright, and beyond this is the fact that field work should follow as closely as possible on that in the yard, and very young dogs are apt to be overworked and discouraged if taken into the field before they are old enough to stand fatigue.

\section{TEACHING CONTROL.}

To teach a dog to yield to control we tie him up, using for this purpose a broad collar and rope, as the rattling of a chain will only add to his fright. The rope is about six feet long, and is fastened to a stont ring in a fence or the side of a building, so that the dog cannot wind himself up. We bring him quietly to the place of confinement, as we desire to avoid resistance till the lesson is fairly begun, and also to have that lesson given by the confine- 
ment and not by ourselves. When secured, we leave him to jump and pull upon the collar till he finds escape impossible, and that resistance only gives him pain, then, when he submits to the incvitable and lies quietly down, we release him, and by encouragement restore his confidence. We find it better to tie the dog than to hold the cord in hand as some men do, because the restraint being an entirely new experience awakens fear, and if this is associated with ourselves, we are put to the trouble of overcoming it. before we can proceed to firther instruction. The time required for this lesson varies according to the character of the individual, some being more difficult to conquer than others. Very few indeed are satisfied with a single experience, and most require several daily repetitions; but thoronghness in this preliminary, remote as it appears to be from what is generally considered breaking, is really of great importauce, and is a great help to the later instruction.

TO OBEY THE WHISTLE.

As the first step in this lesson we accustom the dog to lead well by the cord. This also serves to prevent lugging upon the chain when he is taken about later in life, the most common and one of the most disigreeable faults a dog can have. When he leads well we face him, and saying "come," give him a gentle pull, and if he does not obey, a sharper one, increasing the strain till he yields to it, then when he approaches we pat and reward him by encouraging words. When he minds quickly with the short cord we substitute a longer one, and allow him to play about, oceasionally calling and making him come promptly. This lesson is a very important one, since, if the dog does not know he must come under all circumstances, he will never be under proper control, and will run away if at any time there is oceasion for correcting him. If thoroughly taught, the dog will come to be whipped, fearing even more to disobey the call. Under no circumstances should he ever be coaxed to come for punishment, as this will involve treachery which he will appreciate, and so lose all confidence in his master.

'The second step is to substitute the whistle for the call, which is 
easily done in the same way, the pull upon the cord showing that the blast of the whistle is equivalent to the conmand. 'To avoid confusion later, the whistle call to come should be of a special character. That is, when at field work, it will often be necessary to attract the dog's attention to stop or drop him, or to change the direction of his beat, and for this purpose a single blast is most convenient, lience the call to come should be two quick sharp blasts. The dog will quickly notice the difference, and with a little practice will simply look round in one case, and come in in the other.

\section{STOPPING.}

To teach this we lead the dog, having him well in hand, and after walking a few steps come to a sudden halt, and with the command "ho," bring him to a stop, keeping a stearly strain upon him, and repeating the command if he attempts to move. The halt on our part gives significance to the strain upon the cord, and thus our wish is explained in a twofold manner, appealing both to the dog's natural inclination to imitate and also to his recognition of the cord. If he attempts to come in, we control him by a pull in the opposite direction, which his position by our side renders easy. Many breakers use the command "toho," but the more brief and decided the commands can be made the better they are for use and for the $\log$, hence we prefer the single syllable to two.

As soon as the dog will stop quickly and maintain his place, we work him at a little distance, and practise him under all variety of circumstances, making him stop without the cord, while we are still walking, and while we walk away from or around him, thus teaching him that our own actions are no longer to be imitated, and that they are entirely independent of the command to him.

Next comes the substitution of signals for words. The signal to stop is given by raising the open hand at arm's length above the head, and must at first be accompanied by the "ho" as explanatory, the word being dropped as soon as possible. The order to advance from the stop is simply "on," and is given from the first with a for. 
ward wave of the hand, thus in this instance teaching obedience to two commands at the same time. We do not combine commands and signals in other cases, because in them we impose restraint, and the orders should therefore be as simple as possible; but in this the dog's inclination prompts his understanding, and thus time can be saved.

\section{CHARGING.}

We now take the $\log$ by our side, and with the command "drop," force him down by pressure upon the shoulders. This word is better than the more common ones "charge" and "down," because a command should never be given except for the purpose of exacting a certain action, and this too by those authorized to demand it. It is a very common practice with persons who do not know the harm they do to give a friend's dog orders for their amusement, and as he naturally does not obey a stranger, he thus in some degree becomes indifferent to commands, but if broken to words and signals not in common use, the sanctity of the true order is preserved and less injury done to him.

The position in which the dog drops in the first few lessons is not material, provided it is not upon the side, in which case he should be gently turned upon his belly. Later, if he does not take a natural posture, the hind legs must be tucked under him and the front extended. He will generally, however, correct all defects himself after the first fear is past. He must be pushed down till he will drop promptly, then worked at a distance, gradually increased, but always within easy hearing of the voice till perfect.

The command to rise is "up," accompanied by an upward wave of the hand, the two being combined for reasons similar to those given for the order "on."

The signal to drop is given by a down wave of the hand, and should not be used till the dog obeys the word unhesitatingly, the word and signal being combined till the dog understands that both have the same meaning.

Under ordinary circumstances the dog when dropped may be allowed to hold his head up, but this is sometimes injurious to sport, 
and to meet such contingencies he should be taught to put his nose down between his paws at the command " elose," or when at a distance, by a second down wave of the hand after he has dropped to the first.

Having thoroughly drilled the dog thus far, we now practice him in both stopping and dropping till he fully distinguishes between them. It often happens that he will drop at "ho" or the raised hand after being worked in dropping. In such cases we walk up and raise him to his feet, giving the "ho" and emphasizing it by a slap under the belly. No advance in instruction must be made till both stop and drop are thoroughly learned.

\section{FOLLOWING AT HEEL.}

For this we again put the cord on the dog, and taking him up short, with hand behind our back, compel him to follow, repressing all attempts to push forward by the order "back," and a light tap on the nose with a switch. The two great points in this lesson are to make the dog follow, and also to keep up with us. If the latter is not taught, the dog will get into a habit of stopping to play with others he meets, or to pay attention to anything that attracts his notice. The first is taught as we have shown, and the second may be by a sharp twitch upon the cord whenever he loiters, accompanied at first by the order "come."

The signal to come to heel is given by a backward wave of the hand.

\section{RETRIEVING.}

More dogs are ruined by bad systems of teaching retrieving than by all other errors in breaking. Some are played with and coaxed into it, and so are made hard-mouthed, or are led to consider it mere sport, and refuse when circumstances strip it of pleasure. Others are forced by spike-collars or the whip, hy which some are made obstinate beyond control, and others are so frightened that they never obey except under evident protest, that utterly destroys all beauty of action. Upon good retricving a large por. tion of the sportsman's success depends, and it cun be so taught 
that the dog will always perform willingly and efficiently, yet be always under perfect command.

We shall not stop to show the utter worthlessness of the systems we have referred to, but give that which we have used for many years, and which we have never known fail in either our own hands or in those of any person who has given it a fair and intelligent trial. It is, as will be seen, a force system of the most absolute character, yet we have never known of a dog being permanently cowed by it, or one that was not made tender-mouthed and careful in seizing and bringing his game.

As a preliminary the dog must be taught to sit upon his haunches, and hold his head up at the command "sit up." To this end we take him by the under jaw with one hand and lift his head up, while with the other we bend his hocks, thus forcing him into the desired position, and repeat this with the command till he obeys readily.

Having progressed so far, we next take a hard, tightly-rolled woollen cylinder, about four inches long and an inch and a half through, with the edge well sewed down; this being easily grasped by the dog, yet of a character that does not incline him to bite it. With this in hand we make the log sit up before us, and, opening his jaws with one hand, insert the roll and close his teeth upon it, with the command "pick it up." He will probably throw it out immediately; but for this we care nothing, as taking, not holding, the roll is what we desire to effect. After presenting it two or three times in this way, without the dog making any attempt to take it, we then catch him by the nose and upper lip with the right hand, and with a strong overtwist, as if trying to tear the nose off, force him to ery out, thus causing him to open his mouth, into which we slip the roll with the other hand. This action ronses the dog's will and temper, but regardless of both, we continue repeating the command and tristing his nose till he begins to open his mouth when the roll is presented, which submission we immerliately reward by encouragement, and as soon as it becomes decided we end the lesson for the day. 
The length of this first fight depends upon the dog's character, some resisting much longer than others. We have conquered some in half an hour, and have had to work nearly a day with others, but we always push the first lesson to submission, no matter how long it takes, because if we stop short of this the dog naturally supposes he has got his way, and this makes him more stubborn at the next trial. Where a breaker cannot give so much time to a lesson, he must make up his mind to more trouble, but he will win if he persists, though it will be harder for both him and the dog.

It must not be supposed that the dog maintains his sitting posture during the first lesson; on the contrary, he makes every possible effort to escape, and if he finds this impossible, as it should be, he throws himself upon the ground. No effort should be made to keep him sitting up, the benefit of that position will be discovered later, and we have only taught it thus early to prevent having to diverge from the direct line of instruction in retrieving. It is proper to say here that, no matter how enraged the dog may become, there is no danger of the breaker being bitten if he keeps his eye upon the dog while twisting him, as the hand upon the nose cannot be caught, and in addition to this immunity it serves to keep the teeth away from other parts of the person.

The submission already gained is seldom permanent, and at the next trial we generally meet with refusal, when we immediately apply the twist till the dog gives up; and as the first experience was a severe one the second struggle is comparatively brief, but we persist, rewarding every hesitation with a twist and every obedience with approval, till the dog opens his mouth promptly.

We next teach him to hold the roll till ordered to give it up, which is done by first closing the jaws with the hand, giving the order "hold," and when resistance to this ceases, we simply give him a slight slap under the jaw if he attempts to drop it. By this method and encouragement he is som taught to retain the roll as long as we desire; but we make the time brief, as we desire now to 
relieve the dog of all discomfort not absolutely necessary to overcome his will. The order to surrender the roll is "give," at which we take hold of it, and if necessary at first gently open his jaws. This part of the lesson must be thoroughly taught or the dog may, when he takes pleasure in retrieving, refuse to surrender, and bite his birds badly in the effort to retain them.

To confirm what we have already taught we next practice the dog in taking the roll from the hand in all positions, high, low, and on one side, pushing his head gently towark it, and increasing the distance as he improves. There must be no coaxing in this any more than in other parts of the instruction. The head must be pushed till the dog comprehends what is wanted, and then if he does not move towarls the roll at the order the twist must be applied and the liead turned at the same time, but approval and encouragement should he marle very marked, that the dog may perceive the difference in the results of refusal and obedience.

The next lesson is in picking up from the floor, and if the last has been well tanght this will be comparatively easy. The roll must be dropped, and with the hand touching it the usual command given, and the twist applied if the dog refuses, dragging his head by the nose to it if necessiry, but he must at first be aided to get it into his mouth. If, as often happens, he seizes it with a savage crunch, which if allowed to become habitual will cause him to bite his birds, we must, as soon as he picks it up readily, say "carefully," and, slipping the thumb into his month under the roll, press it sharply up between the junction of the lower jaws just back of the teeth. The log will have no inclination to bite the hand, but, on the contrary, may at once release the roll ; but with a little patience he can be bonght to hold it while the thumb is in position, and will eventually become very tender-mouthed. He may now be taught to fetch by the breaker stepping back a step or two with the command "come," and, if necessary, holding his hand under the dog's jaw, with the ustal command if the dog attempts to drop the roll. A few hours' practice at different times will teach him to carry well, and proper encouragement will make him take great pleasure in 
doing so, besides preparing him well for the next step,-fetching from a distance.

We throw the roll at first only a step or two, and, with a wave of the hand and an encouraging "pick it up, good dog," advance with him if necessary, make him pick it up and return with us to the place from whence we started. As he improves the roll can be thrown farther and farther, till he will fetch it from wherever it falls. Up to this time we have encouraged him to start immediately when the roll is thrown, but as this will incline him to break shot to retrieve when in the field, we now, as soon as he becomes eager to fetch, stop him by the "ho," and make him stand till ordered on by "pick it up." We do not use the usual command to advance in this case, because we wish the object of the advance to be present in his mind, and to insure this we remind him of it. If necessary to restrain him, we simply take him by the collar, throw the roll, and, after a very brief pause, at first send him for it. Later the pause may be made longer, and any attempt to advance immediately checked, till the dog understands he must not start till ordered. All kinds of light objects must now be substituted for the roll, and the dog familiarized with them, forcing him to pick then up as before; lastly, a freshly killed bird must be used. Care must be taken to see that he brings everything tenderly, aud a sharp "carefully, sir," be instantly given if he appears in the least inclined to crush what he brings.

Heretofore we have accustomed him to fetch oljects in sight, and we come now to hunting for them, which will oblige him to depend upon his nose. To this end the object used must have scent imparter to it, and this may be done either by carrying the roll in the pocket, or by rubbing it lightly with a piece of raw meat. We throw the roll a short distance when the dog is not looking, call him up, and saying, "find it, good dog," stoop and pretend to search for" it ourselves, thus by example prompting him to hunt. We gradually work him to where the roll lies, and when he funds and fetches it, reward him by expressions of pleasure and encouragement. An intelligent dog will soon get the idea, and will persistently hunt for 
and find objects under increasing difficulties, till his certainty of discovery becomes almost wonderful. When brought to this point in his education, the dog cannot be worked too frequently, with, of course, reasonable regard to fatiguing him. He should be taken frequently for a walk, and practised in all the various lessons he has been taught, and the more attention and encouragement he receives the greater will be his progress, and the greater return will he make when he comes to field work. If properly handled so far, he will have lost all the fear which the forcing to retrieve has awakened, and will be a courageous, willing performer of all he knows.

As we have said, the time necessary for instruction will vary in proportion to the character of the $\log$ and the intelligence of his teacher. We have had dogs that would retrieve perfectly in two weeks from date of the first lesson, while others have cost us a month's hard work. No period can therefore be named within which a man may expect to succed, but, speaking from experience, we say the system we have given is not only the best, but also the quickest in producing results of all we have seen tried.

\section{BEATING AND QUARTERING.}

The last of our yard lessons is in beating and quartering the ground. We have divided it in this way because quartering means simply a systematic right and left range, and under certain circumstances, as on the edges of thickets, or along fences and hedges, where birds resort when scattered, such work is not needed, as the ground to be covered is so limited that a straight forward beat will bring the dog to all the birds, and save him the fatigue of unnecessary labor.

To teach quartering, we take the dog into an open field and send him on, then by a single blast of the whistle attract his attention, and by a wave of the hand in a direction at right angles to our course endeavor to turn him, turning ourselves if necessary, and walking on the new line. W'hen the dog has gone a short distance we again whistle, and with a wave of the hand turn him so as to go 
in the opposite direction, as far on the other side of our original line of advance as he has come on this. When this style of range becomes confirmed, we can walk down the centre of a field, and the dog will cross us right and left, going from fence to fence on either side.

To beat ground in straight lines, he must be taught to stay in the cover and to move forward. To this end we take the dog to such ground, say, "in there" with a wave of the hand, and when he gets in stop him, and wave the hand in the direction he must go, sending him back if he comes out of cover, and calling him by whistle if he goes too deep into the thicket. These two lessons will call for considerable practice, but when fully taught, the dog will have a system in his work which will insure him against missing auy game on the ground gone over. Quartering is highly prized in field trials, and is certainly effective with dogs of average noses, but some dogs of very keen scenting powers display a natural instinct for keeping to the leeward of the ground, and thus catching the scent borne on the wind, by which they are led straight to the birds. Such work, though less showy, is fully as effective, and is not as hard upon the $\log$ as systematic quartering, because it involves less labor. Dogs capable of it are comparatively rare, but when found and proved to be grood game-finders, we would strongly urge our readers "to let well enough alone," for they certainly cannot improve upon their dogs, and may only injure them by attempting to control intelligence by rigid rules for its display.

In this lesson, and also when the $\log$ is at exercise, it is well to allow him to trail a light cord, fifteen or twenty yards long, as it may be needed when he comes to field work, and by accustoming him to its drag at this time it will not distract his attention later if it has to be used.

\section{FIELD-BREAKING.}

Having perfected the dog in all preliminaries, we come now to the practical application of these in the field, and the first step is the introduction to game, which should be effected without the gun, as excitement will make the dog somewhat heedless of orders, and 
the breaker will have all he can attend to without attempting to shoot.

Providing ourselves with a light cord with spring snap, we take the dog to ground where we know there are birds, and our first object is naturally to get him

\section{TO POINT.}

This is natural to all dogs worthy of breaking, but the excitement of the scent will often induce a high-couraged one to press so near the birds that they flush, and persistence in this will make him permanently headstrong, if it does not overcome his inclination to point. As soon, therefore, as we see he is making game, we get near him and stop him by the "ho," giving him time to quiet down a little before advancing. If in spite of us he flushes, we catch him, take him back to where he should have pointed, make him stop, and then taking him by the collar lead him a few steps forward over the trail, with occasional twitches on the collar, and rating him with "take care, sir," in a low tone, then make him stop and remain standing for some moments. If a few experiences of this kind do not bring him to pointing, we then hook the cord to the collar-ring, and let him drag it till he again makes game, then get hold of the cord, and by sharp twitches and the verbal warning make him go slow till he shows by his actions he is near the birds, then stop him by the raised hand if possible, and if not, by the word. We let him stand without approaching him for some moments, then walk up carefully so as not to flush the birds, and take a place by his side. After standing a while we advance and flush, keeping a sharp eye on the dog to see he does not break point and follow, facing him instantly if he attempts to do so, and checking him by the raised hand and a sharp imperative "ho." Some dogs are naturally cautious, roading their birds carefully, and pointing from the first. With such all that is necessary is to confirm them in this by care and whatever restraint is required. In all cases we eudeavor by cautious conduct on our own part to show the $\log$ there is need for great care and watchfulness in the work. 
All dogs are imitative, and more or less so in proportion to their intelligence, so that a display of caution by the breaker acts as a constant warning to them.

\section{STANCHNESS.}

Upon the steadiness with which the dog is made to hold his first points his later stanchness depends. He should therefore be invariably compelled to stand as long as pnssible without fatiguing him, provided the birds are not evidently running. The breaker must exercise good judgment in deciding this, and must be guided by the circumstances of the ground, the probability whether the birds have been alarmed so as to move them or cause them to lie up, and also by the dog's actions. So long as his attention is evidently fixed, and the dilation of his nostrils shows that the scent is strong, the birds may be supposed to lie before him, but when his attention flags, and he becomes uneasy, this is prima facie evidence that the scent is growing weaker, because the birds have run. An advance is therefore necessary, but must be made with great care, so as to establish another point if possible. In all cases the birds must be flushed within a reasonable time, that the dog may be rewarded for his point, while his interest is keen. Some allowance must also be made for the dog's character. Those which are easily cowed may be discouraged by being kept too long on point. In fact, in this as in other matters the brealier must study his dog, and use common sense in working him.

\section{CHASING AND BREAKING POINT.}

These are both destructive to good work, and must be repressed. Sometimes, if the dog does not show proper interest in birds, he may be allowed to chase a few times, but should not be encouraged to do so, or he will come to think this is proper work. If inclinced to chase, and uncontrollable by the "ho," the cord must be used emphatically till he gives up. If the birds rise either through the dog's fault or their wildness, the dog must be instantly stopped by the raised hand if he is where he can see it, or by word if he can- 
not see it or refuses to obey. In cases of decided refusal he must be punished, but this should be done in the same way as in yardbreaking, by twitches upon the collar rather than by the whip, which in fact should, with the great majority of dogs, be never used till they are well advanced in field work. Breaking point should never be allowed with a young dog, and any attempt at it should be promptly restrained. Later, when the dog has gained experience and become thoroughly reliable, he may be trusted to determine his actions by his experience and his nose.

UNDER THE GUN.

When the dog can be depended on to road cautiously, point stanchly, and not to chase, he may be shot over. Many breakers accustom their dogs to the guu before putting them to field work, and if at all inclined to shyness, this is proper so far as to overcome such timidity, but apart from this, we have found it best not to use the gun till the dor is sufficiently advanced for its use to bring him a reward for his exertions in the form of killed birds. When the $\log$ points, the breaker should walk quietly up to him, and after a reasonable time flush and lill a single bird, not more, for this is a new experience, and the sight of the falling bird and its possible tumbling about on the ground if only wounded, will be very likely to excite the dog, and the breaker will have enough to do to prevent his breaking point without attending to more shooting. This is the time to teach the dog to drop to shot, or stand in his place, whichever the breaker prefers. If the former, the command "drop" must be given instantly upon the shot. If the latter, all that will be necessary is to see the dog does not move from his point, and stop him if he attempts it by a sharp "ho." Experience will soon teach him to be steady under fire, and to drop or stand without orders.

It is bad practice to send a young dog to retrieve a wounded bird when first shot over, and the breaker will do far better by killing it with a second barrel. For the command to retrieve we like "dead bird," accompanied by a forward wave of the hand, 
better than the "fetch," which is used in yard-breaking, as the former is more distinctive in character. The breaker must watch closely to see that the dog does not seize the bird roughly, or crush it in carrying, and must be careful to make him sit up and deliver into hand, thus insuring stylish work, and what is even more important, the possible escape of a wounded bird when, after a time, the dog is allowed to retrieve such.

\section{BACKING.}

ITe do not believe in working a young dog in company of others till fully established in his own work, for the reason that if he finds his companion by greater experience finds more birds, he will be apt to depend upon him instead of hunting independently. It is essential, however, that he be worked in company after a time, not only to overcome or prevent jealonsy, but also to teach him to back, or, in other words, point his companion when pointing. This is not merely a stylish performance, as it is of practical value. If a dog does not back, but, on the contrary, rushes up to the pointing dog, the latter will, unless very steady, be made jealous, and may be induced to break his point. Birds too, if at all wild, are very apt to rise when the second dog comes up, thus destroying all chances for a shot, except in those exceptional cases when the sportsman happens to be near the dogs. It is very necessary, therefore, that the back be as prompt and steady as the point, and no dog can be considered properly broken that is not thoroughly reliable "before and behind."

Backing is taught by stopping the dog the instant it is evident he notices his companion's point, and keeping him standing till the birds have been flushed, fired upon, and retrieved if killed. If the dog has been taught to drop to shot he should of course drop, and remain down till ordered up, otherwise the standing position must be maintained. It is often difficult to keep the backer steady while the sportsman advances and shoots. It is well, therefore, to give the first lessons with the help of another man to do the shooting. By all means, also, the pupil should be worked in company of the 
same dog till confirmed in this lesson, as the change of companions will be certain to rouse his jealousy. Another important thing is to select for second dog one as free as possible from false pointing, as the pupil must gain confidence in the point being upon game, or as he advances in game-finding ability he will proportionally lose respect for a companion that points false.

If the sportsman is shooting alone he should not take inexperienced dogs out together. One must be stearly and reliable, so that the entire attention ean be given to the pupil, and in advancing to shoot while the pupil backs, the sportsman must keep an eye on the latter, and instantly repress any attempt to advance, in the same manner as he would an attempt to break point. Stanchness is as essential in one case as in the other, and both are taught in the same way,-by patience and perseverance.

When the pupil can be depended on to back his regular associate, he should be taken out with others, as the sportsman will have frequent opportunities for shooting with different friends, and if his $\operatorname{dog}$ does not perform well under all circumstances, he will destroy sport and discredit his breaker.

\section{FALSE POINTING.}

Young dogs that are "full of point" will often point small birds, and this, though allowable at first, must be broken up as soon as possible, as it is very annoying for the sportsman to walk half across a field in expectation of a shot only to find the dog stiff upon something that is not game. Intelligent dogs will generally give up this practice when they find their points are not rewarded by shots, and it is for this reason that we prefer correcting this error under the gun, rather than in the preliminary instruction. When the dog persists in making false points, he must be taken by the collar and pulled off of his point, with the command "come away, sir," accompanied by a sharp twitch. Care must also be taken to prevent him from pointing whenever possible, by this command given as soon as he appears to notice anything not game. 


\section{NOT TO CROSS FENCES.}

Another important matter is to teach the dog he must not cross any fence without orders. His proper place when a fence has to be crossed is at heel. When ranging he must be recalled by whistle and wave of the hand if he attempts to pass out of the field, and must be ordered to heel when the sportsman comes up to the fence. He must also be thoroughly taught never to jump over after his master till ordered, as serious accidents may result from his jumping against his master or the gun. If he persists, he must be taken by the collar and pulled roughly away from the fence with the command "back," and if too eager to follow, he must be restrained by the "ho," or if necessary, by a light blow on the nose.

\section{GENERAI، HINTS TO BREAKERS.}

It must be evident that it is much better to prevent errors than to correct them. Correction involves a greater or less degree of intimidation, and the less restraint the dog recognizes, beyond that necessary for proper control, the more free he will be to exercise his instincts and faculties in his work. A breaker must, therefore, watch his dog as closely as possible, and by proper warning stop him before he is really guilty of a wrong act. Such supervision is doubly beneficial, viz.: it educates the man in attending to his dog, and it impresses the dog with the idea that he is constantly under his master's eye, and cannot escape detection, the result of which is he becomes more careful in his work and less inclined to yield to impulses of a bad character. It may be accepted as a truism that a careless, negligent sportsman will always have a careless or badworking dog. The most perfect performers, other things being equal, are those owned by the most careful and attentive men. There is no justice in holding the $\operatorname{dog}$ responsible for the errors of the man, or in punishing him for wrong acts actually encouraged by his master's neglect. We cannot, therefore, impress too strongly upon our readers the advantages and necessity for watehfulness, and 
we assure them they will find this greatly to their advantage in both breaking and subsequent working of their broken dogs.

\section{BREAKING OLD DOGS.}

It is seldom a paying matter to attempt breaking an adult dog $a b$ initio, because such have almost invariably such strength of will and confirmed habits that it is very difficult to get them under thorough control, and the work necessary to break an old dog is much greater than that necessary for a young one, which when developed may easily be a better performer. Simply saying, then, that the same system of instruction must be followed in all cases irrespective of the age of the pupils, we shall confine ourselves to directions for correcting faults in adult dogs resulting from imperfect breaking or bad handling. Many dogs of naturally fine abilities have, through the fault of their handlers, acquired bad habits, yet are worth rebreaking, and must be rebroken when they pass into the hands of men who appreciate fine work, and will not be satisfied with anything else, and it is to this class of cases that we shall devote our present attention.

\section{WILDNESS OR LACK OF CONTROL.}

Dogs of this character must of course be taught to obey before they are taken into the field, by the same course as that used with younger ones, but it often happens that some will obey well out of the field, yet under the gun are headstrong, disobedient, or beyond control in their range, so that when taken into cover they cannot be restrained within the limits necessary for effective cover work. Such dogs need sharp correction, and for this purpose we use the spikecollar and cord, compelling them to obey the "ho" and whistle promptly, also to go slow at the command "steady." It is folly to attempt shooting over such dogs till they are under good control, as the breaker will have all he can do to make them mind, and if his attention is given to anything else, they will take advantage of it to act as they like. In using the spike-collar it will of course be necessary to allow the cord to trail, so that it can be caught up at 
any time when needed, yet not restrict the dog's range unduly. If the $\log$ is very headstrong it is well to let the cord trail, and punish him frequently by catching in bushes and stones, by which the spikes will prick the neck and admonish him to save himself by moderating his rate of going, but if he does not need such sharp treatment, and also as he begins to yield obedience, a plain collar should be put on in front of the spikes, and the cord looped to this by a piece of twine strong enough to stand ordinary drag, yet weak enough to break when the cord is jerked by the breaker for punishment.

\section{CHASING AND SHOT-BREAKING.}

These are very common faults with badly-broken dogs and must be corrected by the spikes, used in the same manner as the plain collar is used with a pup, to enforce the "ho" or "drop." Some dogs will, however, break shot only when a bird falls. With such it is well to take an attendant to hold the cord when the dog points, while the breaker advances to shoot. The attendant should not, however, attempt to give orders, but simply enforce those of the breaker, by spiking the $\operatorname{dog}$ if he does not obey promptly. If sharply applied, the spikes will quickly teach even the most confirmed shot-breaker that he must abandon the practice, and when once subdued, the command and proper punishment by whip will keep him right.

\section{BITING BIRDS.}

Nearly all dogs that have been badly taught to retrieve will mangle birds. Ordinary punishment is useless, because it is difficult, if not impossible, to make the dog understand for what he is corrected. The quickest and most effectual way is to run a number of small wires through a bird, so that they will stand out just under the feathers. This must be thrown when a bird is killed, or at any time the lesson is given, and as the dog seizes it, the breaker should if possible catch him by the upper and lower jaw, and shut them together so that the wires will prick sharply, with the command 
"carefully." Very often the dog will drop the birl as soon as he pricks himself, and in this case the breaker should put it into his mouth and prick him, with the command. The command should also be given when the $\log$ is in the act of picking the bird up. If the dog has been forced to retrieve, he can always be compelled to bring the wired bird; but if, on the other hand, he has not been forced, he will probably refuse to bring, and then must be rebroken by the force system used with a pup. In any event, a confirmed biter hould never be allowed to retrieve a wounded bird till fully cured and firmly established in his improved retrieving by long practice. This is one of the most difficult of all faults to correct, because there are so many circumstances that prompt a dog to it, and these circumstances must be appreciated and avoided by the breaker if he expects to make him tender-mouthed:

\section{A LAST WORD.}

It is impossible to provide by any system for all contingencies. Dogs, from their varying dispositions and characters, require in some measure different treatment. Some, too, will display faults uncommon and peculiar to themselves. All can, however, be broken by the system we have given, more or less sharply applied according to circumstances. Brealiers must exercise patience and discretion, study their dogs, and vary the system to suit them. If peculiarities or faults which we have not mentioned are displayed, their cause must be investigated and removed. We claim that by the system we have given any dog can be broken by even an inexperienced man. We mean by this any dog that is breakable. Some will, of course, give more trouble than others, and some men will find more difficulty than others in applying the system. All we pretend to. give is a thoroughly good general rule, and we must leave to our readers the intelligent application of it. The great secret of success is thoroughness and frequent practice in the lessons, with firmness but good temper on the part of the breaker. With these any man can break a dor but without them he is not fit to attempt it. 


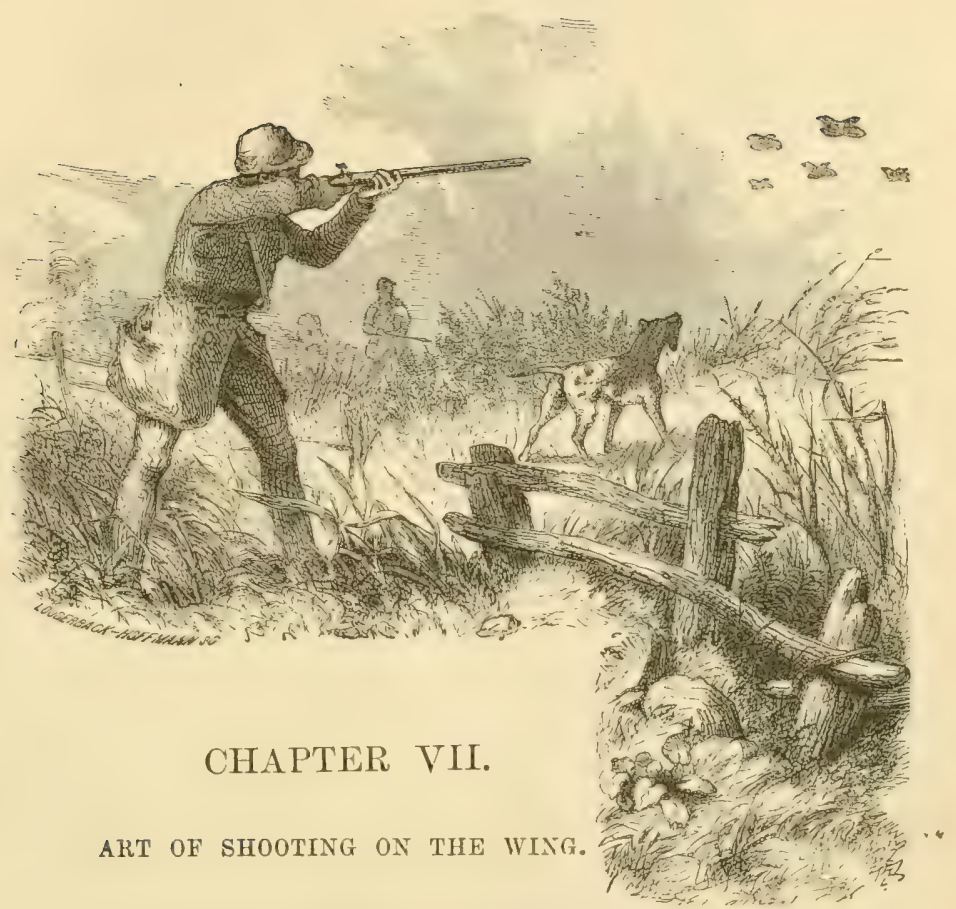

"All the spo:ts of the field are delightful, 1 own,

But none can with shooting compare;

'Tis a joy that entices the king from his throne,

'Tis a joy that the wisest may share.

The voice of the hound on the breeze of the morn,

The note of the bugle, may please;

The songr of the wild bird is sweet from the thorn,

But the gun has more music than these."

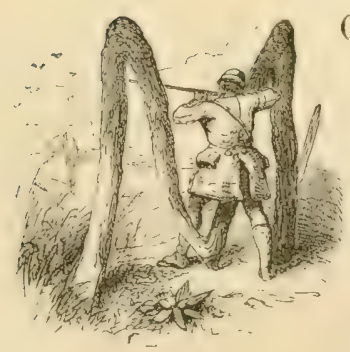

OST persons unconversant with the use of the gun are naturally led to believe that there is some great mystery or some extraordinary sleight-of-hand work connected with the art of shooting birds when on the wing. This opinion is often so firmly engrafted on the minds of certain sensitive individuals that they are ever unwilling even to make a trial of their own dexterity in 
this way, fecling satisfied that they could never arrive at any degree of perfection in an art so difficult to acquire. Or, if they should be tempted to venture in the field with some one of their associates more experienced in the use of the gun, expecting a day's enjoyment, they become so discouraged at their want of success, as well as perplexed at the inability of their sporting companion to give them any definite or systematic instruction for shooting, that they not unfrequently witlıdraw from the field completely mortified and disguster with cvery thing appertaining to the sport; when, by a little perseverance and a few well-timed hints from their companion, they might soon have arrived at that pinnacle of fame to which all sportsmen aspire; we mean-a good shot!

We ourselves do not pretend to be a great shot, but, on the contrary, are very modest in our claims upon this point; but because we cannot kill every bird we fire at, that is no reason why we may not instruct others, so that they, by longer practice, may arrive at this degree of excellence, if they wish it, but to which we have neither the ambition to aim nor the time at our disposal to acquire. It is no uncommon circumstance in the study of the arts and sciences for the pupil to excel the master; and we suppose, or rather we flatter ourselves, that we may yet look forward to encountering some one of our own pupils in the field who will not hesitate to snub our nose whenever an opportunity offers. If such should be the case, we shall be happy in the knowledge of having done some good for our country, and more particularly for the sports of the field.

The first grand desideratum to be considered by the pupil is the possession of a good gun, of which, however, we will speak more particularly under the chapter on fire-arms. The next great aequisition to be sought after is coolness and deliberution, for without these qualities you might as well leave the gum in its case, and walk into the fields with a dog at your heels, and a shootingcracker in your hand ready to throw at the birds as they rise from the stubble, in the vain hope of frightening them to death 
by the noise of the explosion, as to fire a gun over them without perfect self-possession and composure. Without coolness and deliberation, a young shooter, or even an old shooter, can hope to accomplish but little in the field. In fact, we have seen the best of shots miss bird after bird during a whole day's excursion, owing to some unexpected but perhaps trifling oceurrence which lad interrupted their natural equanimity of temper, and thereby lestroyed that coolness and deliberation which are so essential for the proper handling of the fowling-piece. Success in shooting, all the paraphernalia being equally good, is dependent in a great measure upon coolness and deliberation; the first and most important step, therefore, to be taken by a young shooter, is the resolution to acquire as soon as possible a perfect control over all his morements during the excitement consequent upon the springing of a covey of partridges, the whir of a woodeock, or the sudden and irregular flight of a snipe. This mastery over his feelings being once acquired, there will be no difficulty in the way of a rapid progress in the art of shooting on the wing. Having selected, with the assistance of a sporting friend, a gun, made by the most approved gunsmith, practise the handling of it in your own room; be sure that it comes up to the shoulder right, and that the eye runs along the barrel with facility. Bring it up to your shoulder ever and anon; take sight along its barrel at some small object placed in the farthest corner of the room: a red wafer, or a piece of colored paper stuck on the wall, will answer this purpose. By practising in this way for a short time, a certain degree of ease in the handling of the gun will be acquire $\mathrm{l}$, and then it will be as well to crack off a few caps by way of accustoming the ear and eye to the explosion, as also familiarizing the finger with the touch of the trigger. Having occupied the leisure moments of a few days in this kind of sport, it will be high time to sally forth to the fields and spend a portion of the day in practising the art of shooting on the wing any of the small birds that we may meet in our rambles over the country: Many young sportsmen exercise their skill upon swallows. 
But it is not a good practice, and cannot be attended with any particular benefit to them, as the swallow's flight is so entirely different from any known game-bird that one might soon become expert in killing these harmless but useful little creatures without ever being able to bag a partridge, a woodcock, or a snipe.

Swallows fly with considerable swiftness and great irregularity, and cannot be easily killed except when they stop or rather poise themselves for an instant in the air to seize their prey, and while in this position the veriest bungler that ever handled a gun can soon become expert in knocking them over. Any of the smaller and less interesting birds that fill the groves during the spring and autumn months have flights resembling that of partridges much more than that of the swallow does, and more improvement may be derived from shooting a few of them than the slaughter of one-half of all the swallows found about a large farm. For, after all, the shooting of swallows is nothing but a knack, acquired by a little observation and practice, just as any other kind of shooting or in fact sleight-of-hand work; but then it should be remembered by the young aspirant that he may spend much labor and time both in acquiring this knack, without in the least benefiting limself so far as the shooting of partridges or any other kind of game-bird is concerned.

Nicety in shooting exclusively at some particular objects, in some particular mode, may be carried to a degree of perfection scarcely to be conceived of, as witnessed in the feats of the brothers Toomer, as described by several English mriters.

Of these two celebrated marksmen, Blaine remarks that Richard and Edward Toomer, with their rifles and a single ball, killed eight pigeons out of twelve, shooting alternately; and one of the pigeons that did not drop, had a leg carried off by the ball. They likewise with a single ball struck twice, out of four shots, a cricketball thrown into the air; and Richard at a cricket-match, his gun being loaded with shot, struck the ball twelve successive times, when bowled by one of the sharpest bowlers in all England. Our backwoodsmen years ago brought rifle-shooting to so high a state 
of excellency that their ordinary performances secmed marvellous even to the German Jägers, who have always been esteemed the very best marksmen of the Old World. Killing with a single ball squirrels from the tops of the highest trees, as well as cutting off the head of a wild turkey or other large bird at the distance of one hundred yards or more when in full flight, was a common feat with these hardy huntsmen. In fact, so expert were the keel-boat. men of the Mississippi in handling the rifle, that they did not hesitate, in a spirit of playfulness, even at a long distance, to cut the pipe out of the hat-band of a companion, or unexpectedly upset a cup of whiskey that might at lunch-time be for the moment resting on some one's knee. Driving the nail at forty paces, snuffing the candle at fifty, and shooting an apple or other small objects from the heads of each other, were the favorite amusements of these daring marksmen.*

It is also not an uncommon circumstance to meet with persons who can lay a double-barrelled gun, cocked, on the ground, throw two pennies up in the air and strike them both, before touching the ground. This same degree of nicety in handling the gun and perfecting the eye may be acquired in pigeon-shooting, as witnessed in the wonderful exploits laid down under this head by numerous English authors, and as detailed from time to time of our own shooters in the columns of the Spirit of the Times. But all these various kinds of shooting, though exhibiting much skill and perfection in the art, will not qualify a person for taking the field with an experienced sportsman; as the killing of game is quite a different thing from knocking over the tame, quiet, and phlegmatic house-pigeon, that, rising from the trap with a certain degree of regularity, although with a sudden impetus imparted to it by the operations of the spring, and most frequently taking a bewildered though easy flight, is brought down with the greatest facility by those accustomed to its usual course of action at such times. 
How tame, how vastly different is all this to the sudden and unlooked-for spring of the vigorous little partridge, as with a startling noise he bounces up from under our very feet, and, long before any save the initiated one can recorer from his bewillerment and bring his piece to bear upon the affrighted bird, has fairly soared far beyond his reach-yes, even beyond his sharpest vision. And then, again, the deep, sonorous, and still more perplexing whir of the ruffed grouse, as he goes booming off through the entangled thickets bordering the mountain streams; or the delveresounding start of the lonely woodcock, as he rushes through the marshy brake, all in the full vigor and freshness of his native freedom; or the still more confusing zigzag flight of the fickle snipe, as he springs wildly from the oozy marsh.

The whirring noise consequent upon the springing of a covey or even of a single bird is not a little trying to the nerves of a young shot; and it requires some considerable time to accustom his ears to this startling sound, which, however, will wear off by degrees, no matter how nerrous he may be at first. When the dogs have come to a stand, advance noiselessly and with firmness towards the spot indicated, holding the gun cocked, and with the muzzle in such a position that its contents could not injure any one of the company, even if it should by any mishap go off before you have the proper range on the birds. Be careful, above all, not to shoot the dogs; which accident, by-the-by, has happened more than once to heedless beginners. When the birds are flushed, raise the gun with perfect coolness and deliberation; single out first one bird and then another, if you have a doublebarrelled gun, as every sportsman should have, and be sure not to pull trigger upon either of them till they are well covered. That is, when looking down the barrel-plate, the cye, the sight, the point, and the bird, are all in the same line: this, then, is the moment to fire; do not hesitate an instant; do not dwell upon the object after it is once covered, or you will ineritably lose the point of sight, and the load will pass under the bird.

The eye in a correct light is seldom wrong in its calculations, 
seldom deceived as regards distances or positions; seldom, in fact, at fault in any one particular; it is to some one of the many other circumstances upon which the proper handling of the fowling-piece is dependent that we must attribute the frequent habit of missing; such, for example, as a want of self-possession, over-anxiety, careless loading, hurry, nervousness, or some such cuuses. Be careful not to shut both eyes just at the instant of pulling the trigger, as some beginners do; neither throw the muzzle of the gun up or down with a sudden jerk, but let it lie perfectly free in the grasp. By following these few instructions, although you may miss your bird over and over again during the first day's shooting, still, we are confident that you will attain in a very short space of time to some considerable cleverness in the art. When there is a fair and open shot and the bird not killed, you may depend upon it that it was not properly covered; or, if it was, the gun, by some imperceptible movement, must have been carried from its proper direction at the instant of firing, or the bird might have perchance varied its straight course at the critical moment of being covered. One of these three things must have taken place provided the gun was loaded properly, otherwise the bird would have inevitably been brought down. We do not pretend to say that every one on going for the first time into the field will acquire in an incredibly short time this beautiful accomplishment of shooting on the wing by the mere committing to memory of any set of rules for the handling of a gun. But, on the other hand, we must assure the novice that without pretty constant practice and great attention he will never attain the art; but when once acquired it is seldom lost, except temporarily, so long as the visual organs are perfect and the physical powers sufficiently strong to carry him into the field in pursuit of game. No doubt thousands of sportsmen arrive at great excellence in shooting without ever reading a line on the subject or receiving a word of advice from the more experienced; but still, their progress has been very slow and up-hill kind of work, and their object accomplished at last only by long practice and observation. We do not, however, wish our readers to under- 
stand that any one can acquire the art of shooting on the wing without patience, practice, and study, as we do not believe any such thing, and would be sorry to attempt the promulgation of such a fallacy. But we do assert that the young beginner will much sooner, and with much more pleasure to himself, arrive at this desirable end, by giving heed to the experience of those who have gone before him, no matter whether the instruction be imparted orally or by means of the pen. That there are certain fundamental rules for acquiring this accomplishment no one will deny; and these rules should be made as simple and as ferr as possible; in fact, reduced down to a few words of caution, which may be embodied in the following line:-Be cool and detiberate, and never draw the trigger till the bird is well covered. We do not wish to bother the novice with a long array of written instructions for shooting, as information obtained in this way is too often a mere matter of rote, and cannot be of any great practical utility; we desire, however, to impress upon his memory a few short rules that will secure him from the commission of many faults and prerent him from falling into the common errors of most beginners. This end being accomplished, we abandon him to the practical operations of the field, which of themselves will soon make him skilful, if he possess any of that aptness for sport which seems inherent in many of those who follow the dog and gun as a source of the most healthful and exhilarating amusement.

Although by strictly adhering to the golden rule, be cool and deliberate, and never draw the trigger till the bird is well covered, the novice without doubt will miss many birds, as they will often get beyond the reach of his shot long before he has fairly covered them, more particularly if shooting in thickets or woods, nevertheless, he will find, at the conclusion of the day, that he has not made out so very bad, and, we can assure him, much better than if he had shot at every bird before it had flown ten steps from the spot whence it sprang. To-be-sure, he will often feel mortification and disappointment at the sight of a partridge sailing off untouched by his fire, although well covered by the gun: this chagrin, how- 
ever, will be of short duration, as, on the springing of the next bird, he will involuntarily strive to be somewhat smarter in his movements, but at the same time adhering strictly to the golden rule of coolness and deliberation; and his efforts on this occasion will perhaps be crowned with greater success. The bagging, then, of this one bird will recompense for many others lost, and at the same time impress upon him the importance of sticking to the principles upon which he entered the field, and make him a firm convert to the absolute utility of giving heed to our instructions; for he will find that as often as he departs from these rules and fires his gun at random, just so often will he be disappointed in the result, and will also learn that the chances of killing birds at random shots are very few, even when fired into a large covey; for how frequently have we seen even the most experienced sportsmen shoot into coveys without ruffing a feather, owing entirely to the circumstance of the birds all rising, as it were, in a mass together, and confusing him by their proximity and numbers; or, in other words, throwing him off his guard, and depriving him momentarily of that coolness and deliberation of which we are speaking! It is very difficult, at times, even for an old sportsman to suppress a feeling of anxiety, a kind of nervous trepidation that involuntarily creeps over him when advancing upon a covey that he feels certain is spread out around him, but at the same time entirely ignorant of the exact spot from whence the birds will spring. Under these circumstances, the heart of an old shooter is apt to palpitate with a slight but agreeable emotion, while the warm blood of the tyro rushes through his system with a velocity that often makes his whole frame quiver with excitement. If, then, he misses his bird, it is not to be wondered at, as the confusion and noise consequent upon the flushing of a covey of frightened birds is no small affair, but, on the contrary, is well calculated to upset his already-shaken nerves and throw him entirely off his guard; insomuch that he mechanically raises his gun and bangs away, harum-scarum, without the least aim, and then is mortified as well as astonished that 
he did not kill half a dozen birds from among so many immediately under his nose.

It is to steel the heart of the novice against this emotion that we wish to impress upon him, in the most forcible manner, the importance of coolness and deliberation in all his actions; for rest assured that without these two chief requisites he will never make a good shot, but always be a bungler and a dangerous person to go out with, as he will be sure some time or other to shoot either himself, a friend, or his dog.

\section{CROSS SHOTS.}

We have in the previous pages been endeavoring to explain more particularly the rules for plain or straight shooting; that is, when a bird is going directly from us, as partridges most generally do when a covey is flushed. We will now speak of the rules for cross shooting.

Many persons can kill birds with a great deal of certainty when they are flying from them; but, for want of a little attention to the subject, are constantly at fault when they come to pull upon birds that are either crossing to the right or the left, more particularly the former. The first thing to be observed by the sportsman when considering a "cross shot" is the velocity with which the bird flies, and the distance it is off from him at the moment of firing. These two circumstances must be determined upon in his own mind in a moment of time, as it were, by intuition; for when the game is on the wing there is no opportunity for the exercise of inductive reason to arrive at these points. This faculty of rapid discrimination or rightly judging the distance that the bird is from us, or the velocity with which it is moving through the air, every shooter must soon acquire by practice; otherwise he can never become a superior marksman, but will constantly find himself missing the fairest cross shots. The American partridge, more particularly when frightened, or rather startled by the sportsman, flies with amazing velocity, perhaps swifter and stronger than any other game-bird in the world. The 
rdinary flight of the English partridge is nothing to compare to it in point of speed-we mean, of course, a full-grown December bird. This being the fact, there is no doubt that our bird requires much more calculation and precision to bring it down when crossing.

When flushed, partridges, except in sections of the country where they are seldom or never hunted, boom off at the top of their speed; and if they attain a distance of forty, fifty, or sixty paces before we succeed in fairly covering them, it will be necessary to sight the gun a little in advance of them in the regular line of their flight. If the birds are very large and strong, which, by-the-by, most generally is the case in November and December,-it will be better to allow a still greater distance between the bird and the point of sight, and then perhaps we shall not unfrequently have the mortification of seeing our intended victim move off unlurt save the loss of the tail feathers. If the course of the bird should be oblique, as is often the case, the same rules for shooting will apply, save that the point of aim should be about half the distance in advance of the bird, as if it were flying directly across. There is another point in cross shooting which we must not forget to impress upon the attention of our readers, otherwise all our previous remarks on the subject will prove nugatory and go for nothing. What we refer to is the absolute necessity of accustoming the hand and eye to keep up the lateral motion imparted to the gun when sighting it on the object till after the piece is discharged. If attention be not paid to this point, and at the moment of pulling the trigger the gun is arrested in its onward progress, the whole load will most inevitably pass behind the bird; as the time intervening between the pulling of the trigger and the passage of the shot through the air to the intended victim is quite sufficient to allow of its getting beyond the point of sight first caught at by the eye.

The distance intervening between the bird and the point of sight is the space granted the bird for flying through the air during the passage of the shot from the muzzle of the gun to the point of sight, and not for the pulling of the trigger, ignition of 
the powder, and the escape of the load from the barrel. All this, to-be-sure, appears only to be a momentary, if not an instantaneous affair; but such is not the fact, as every shooter can testify to; for it is a self-evident fact that some time must elapse between the accomplishment of these two acts-the pulling of the trigger and the escape of the charge from the gun. This time will be regulated in a great measure by the quality of the powder and the construction of the gun, which, however, will be spoken of particularly uniler a more appropriate head. If, therefore, the motion of the gun be stopped during the time of pulling the trigger and the escape of the load, the bird will inevitably have got beyond the reach of the shot, unless we should allow double the distance to intervene between the bird and the point of sight, and this kind of shooting would be very uncertain. Therefore, we repeat again that it is of the utmost importance that the gun should continue its gentle movement in the line of flight at the proper distance in advance of the game till after the pulling of the trigger. Most young shots have a strong inclination to arrest the progress of the gun when pulling the trigger, which, if not early corrected, degenerates into a settled habit that is very diffcult to be overcome.

A bird crossing to the right is generally considered more difficult to shoot than when going to the left, and very justly so; as the gun, being balanced on the left hand, can be carried towards that side with more ease and freedom than it can towards the right. If any of our readers are dubious on this point, let him take a gun in his hand and place himself in the usual position to fire, and he will readily perceive what we mean, as upon trial he will find it difficult to take sight on an object even at right angles with his right side, whereas he will be able to turn himself with ease so far to the left that he can shoot in a direct line behind his person.

A bird when crossing is much easier killed, if struck, than when going straight from you or coming towards you, as the vital parts are somewhat protected in the first case by the rump, and in the second the shot is very apt to glance off from the thick 
feathers of the breast. When a bird is flying towards you or over your head, you will be very apt to miss it: the better plan is to wait till it has passed, and then turn and take a fair shot at it. If, however, you prefer shooting as the bird advances towards you, aim for the head, or rather the bill, when he has arrived at a fair shocting distance. If coming very swiftly, as they most generally do when frightened, it will not be too much to aim even a fost or more before the bird. When shooting at long distances, be careful to hold the gun full high; as shot, after going a certain distance, has, as a matter of course, a downward tendency. The most common fault committed by sportsmen generally is the too frequent habit of shooting under their game; and we are satisfied from repeated observation that where one bird is missed by shooting too high, ten are missed by shooting too low. When, however, the game is flushed on the side of a hill and takes a downward course, the point of aim should then be at the feet, or the load will pass over the object, as it must be recollected that the bird is now descending-quite the opposite of its usual habit. To obviate the inconvenience arising from the smoke of the first barrel, or, in other words, to prevent the smoke of the first barrel interfering with the shooting or sighting of the second barrel, more particularly when a covey rises, we would advise our readers to get as many cross shots as possible. This can be done by either heading the dogs or by flushing the birds from the side, and not going directly on the game from the dogs, which practice, bythe-by, most generally is bad.

\section{COVERT SHOOTING.}

In covert shooting the same rules are applicable as we have already laid down for open shooting; the only difference is, that we must be more fully on the qui vive to take advantage of all and every chance, as we often see the bird for a moment only, and then it is lost to our sight among the trees or thick underwood; and, as before remarked, we constantly kill birds in thick coppices without ever seeing them at all. 
A snap shot is more successful in the woods than a plain shot; and the reader should recollect that in firing snap shots the fault most generally committed is shooting under the bird, forgetting that the bird is on the rise, almost always, when first flushed.

Never beat the bushes with your gun, or you may shoot a favorite dog, or perhaps, what would be a hundred times worse, you may shoot a friend; the habit is an unsportsmanlike and dangerous one, and should never be tolerated in a companion. You cannot be too careful with your gun in covert shooting; its position should be watched with the most jealous attention, and never for one moment neglected, more especially if shooting in company; for a twig or a bough may catch the hammer or trigger at any moment, and commit perhaps irreparable injury either to yourself or friend. Be ever cautious also in climbing ferices or jumping ditches.

\section{BOTH EYES OPEN.}

Some shooters fire with both eyes wide open. This practice is a mere peculiarity acquired by some ready shots, but which does not possess a single advantage over the old style of closing the left eye to recommend it to our notice. But, on the contrary, we are convinced that no one, except by very long practice, can shoot with the same degree of certainty with both eyes open as he can when one is shut in the usual way. The manner of acquiring this knack is to hold the eyes steadily upon the olject, bring the gun up to the proper position, and draw upon the trigger without sighting down the barrel, the hand and finger actually obeying the promptings of the eye without there being any actual collusion, or, rather, concert of action, between the two organs. Some sportsmen, however, recommend the norice to begin shooting with both eyes upon the game, insisting that this practice is the best. Although we differ with these gentlemen upon this subject, we do not wish our opinions to be considered faramount, or more worthy of creilence than theirs, but, on the contrary, are willing to believe all they say upon this head, not- 
withstanding our own personal experience teaches us quite the contrary. For "snap shooting" this plan certainly answers a very good purpose; but a "snap shot" is generally a very disagreeable companion to shoot with, and we would not advise any of our friends to be ambitious in this particular. The birds are usually, under the hands of a "snap shot," horribly mangled, and frequently fired upon before his companion has time to put up his piece, which, to say the least of it, if often repeated, is ill-bred on the part of the shooter and mortifying to his companion.

Although we do not admire a "snap shot," we trust that our readers will not understand us as recommending a "poking shot" to their attention; for we most heartily detest a "poking shot," who brings up his gun ever and anon, and dwells upon his bird, following it in its course for several yards before drawing the trigger, or perhaps takes his gun down without firing at all, complacently remarking "that he could not cover it to his satisfaction." Such a poker usually prides himself upon his excellent shooting; that is, notes down with unexampled minuteness the exact number of shots he has made in the course of the day without missing a bird. Such kind of shooting we entirely escherr, and consider it beneath the dignity of a true sportsman; as for ourselves, we would rather miss three shots out of five, all day long, than go pottering about in this style, picking our shots. If the art of shooting is to be reduced to such a systematic piece of business that we are never to shoot except when we are sure of killing our bird, we for one would be glad enough to abandon the field altogether, as one-half, if not all, the pleasurable excitement consequent upon the pursuit of game consists in the uncertainty, the doubts, the disappointments, and hopes, that we encounter. If on the one hand we suffer some personal chagrin owing to our carelessness in missing a fair shot, we reccive on the other hand double gratification in killing on a doubtful chance; and the results of the day's shooting will always be in favor of the man who shoots at all and every chance, though he may have missed three times as often as the tedious "potterer." 
Avail yourself of every opportunity to shoot, more particularly when the birds are scattered in thick cover early in the season, as you will acquire by this means a knack of killing the birds even when they have passed entirely from your sight behind the thick foliage. This knack is a very necessary one in early autumn shooting, before Jack Frost has sufficiently nipped regetation with his icy fingers. This kind of shooting requires considerable prac. tice, a quick eye and a ready hand, and is the style of shooting that all American sportsmen have to attain; and it is in this particular more especially that they excel the great field-shots of England. Most of the shooting in the Atlantic States is done in the wood and thick cover, through which the birds at some seasons can scarcely force their way; and we are not astonished that English sportsmen speak so disparagingly of its pleasures, as partridge shooting with us is quite a different affair from going out after them in the rich stubbles of their preserves; and what is still worse for them, when they have found our birds, they discover, greatly to their mortification, that they cannot kill them near as often as they do their own varieties, without first serving something of an apprenticeship to the sport, under the guidance of some one of their friends more skilled in the craft of our game. When shooting in the open stubble-fields, we are enabled to see the game, and correctly judge of position, distance, bulk, \&c.; but in the woods and coppices of our country we do not actually see, but learn to guess at all these necessary circumstances; and that, too, without the exercise of thought in the operation, if such a thing were possible; as the arm in most instances seems to obey a sudden and irresistible impulse, no time being allowed for any action of the mind upon the subject, for in thicket-shooting we often kill birds without ever seeing them. The difficulty of killing partridges is not the only thing that the English sportsman has to complain of, as will be seen in the following extract, taken from the journal of a traveller who appears to have been both discouraged and disappointed in his expectations of sporting in America :- 
"Hares and pheasants there are none, and partridges are scarce; woodcocks and snipes are uncertain, both as to season and situation. It is true that great quantities of other birds may sometimes be killed,-for instance, wild ducks and pigeons, which are seen occasionally in flocks of many miles in extent; but, after all, and much as $I$ have heard of American shooting, in my opinion it is poor, insipid diversion, compared with the English, being pursued without any kind of system or science, and reminding me more of the onsets of our mechanics and shopmen, let loose at Christmas and on holidays, to range the fields no matter where, and pounce upon all, no matter what, than of any thing worthy the name of shooting. Let no English sportsman think to better himself by emigration in this respect. I'll answer, upon trial, for his total disappointment."

In reply to the above, we must say that Mr. Fowler's remarks are calculated to give his countrymen a very unjust and unfavorable idea of sporting in the States. He must have been very unfortunate in the selection of his shooting-grounds when among us, to be forced to assert that partridges are scarce in America, or that woodcocks and snipes are uncertain both as to season and situation; for all three of these birds are to be found in almost every State of the Union in considerable abundance, at the proper time, as will be found by referring to our articles on these subjects. It would be folly in us to waste time in refuting all that has been said by Englishmen in reference to our sporting; and we therefore pass the matter over without further comment, as we are satisfied that the contents of this book will tell a different tale from what many of them have written.*

* What would Mr. Fowler's readers think of the following extract, taken from one of our daily Western papers, of March, 1855? -

"N. Powers, of Fayette County, Iowa, lately drove into Dubuque with a load of game, consisting of one thousand partridges, one thousand prairie-hens, (grouse,) one hundred hares, eight deers, five wolf-skins, two bear-skins."

Or of this, from the "Cleveland Leader:"-

"Dr. Short and his son shot two hundred and nineteen English snipe in one and a half days on the borders of Mud Creek, near the head of Sandusky Bay. When 


\section{KILLING CLEAN.}

Be not satisfied with wounding your game only, but aspire to become a nice, clean shot, as it will save you much trouble and vexation, and make your dog show to more advantage. For instance, if a covey rise, and we wound two birds and see them fluttering on the ground before us, we feel great anxiety as to their fate; and, fearing lest they might get off, or secrete themselves so that the dogs cannot find them, we can with difficulty suppress the strong desire that naturally rises in our mind to quit our position, before loading, to secure them; much less, then, can we hope to overcome this impulsive inclination on the part of our dogs. In spite of repeated castigations, the excited animals will rush after the fluttering birds, and persist in eatching them, in opposition to all our endeavors; and the consequence is the flushing of one or two laggers, who often remain behind when the coveys spring, and both of which might have been bagged if our

we consider that these birds are only shot singly, and only on the wing, we consider this extraordinary shooting. They found the ducks rather scarce, as they only bagged about fifty in two days."

Or this, from the "Lancaster Herald," of Grant county, Wisconsin, of January, 1856 :-

"Game is very plenty with us, this season, in all parts of the State. Venison is sold daily in our streets as common as pork and beef, and at the same price. Prairie-chickens (pinnated grouse) and pheasants (ruffed grouse) are offered for sale by the boys at our doors at one dollar to one dollar and a quarter per dozen, partridges at forty cents per dozen, hares at one dollar per dozen, wild turkeyg twenty-five cents each."

Or this, from the Philadelphia "North American," of January, 1856 :-

"WiLd Game fron the West. - $\Lambda$ week ago two hundred boxes of partridges, averaging, probably, one hundred birds to a box, were shipped eastward from Janesville, Wisconsin; and a short time previous to the 8th inst. two hundred deer were shot in the neighborhood of Sparta, in the same State, and sent eastward."

Or this, from the same journal, of a little later date:-

"The 'Vincennes Gazette' notices the arrival at that place of two thousand four hundred hares, six harrels of partridges, fourteen whole deer, twenty-five sadlles of venison, one hundred and forty-four prairie-hens, (grouse,) together with wildgeese, wild ducks, wild turkeys, squirrels, \&c. Sc. to an almost incredible extent: making, in all, five wagon-loads." 
piece had been loaded. Much time is also lost in hunting up wounded birds, to say nothing of the labor and worriment attending it; for we know nothing more provoking than to see a bird fall and flutter within a few feet of us and not be able to lay our hand upon it. Every bird, therefore, should be killed dead at from twenty-five to thirty paces and under, with a good gun and the proper ammunition: we occasionally have knocked birds down at much greater distances, even as far as fifty, sixty, and seventy paces by actual measurement; but we esteem all such lucky shots as mere accidents.

Not only on the score of vexation and trouble should the sportsman strive to become a clean shot, but for humanity's sake also, as a bungler in this respect will mutilate and abandon to a lingering death more birds in the course of a day than he will actually bag. A bird with a broken wing or a torn leg dangling from its body may live in misery and pain for several days, skulking about solitary and alone, half-starved and parched with thirst, and ultimately fall a victim to a prowling serpent, or be taken off by a hawk or some other one of its enemies.

\footnotetext{
"As glory more than gain allures the brave To dare the combat loud or louder wave, So the ambition of the sportsman lies More in the certain shot than bleeding prize; While poachers, mindful of the festal hour, Among the covey random slaughter pour, And, as their number press the crimsoned ground, Regardless reck not of the secret wound, Which borne away, the wretched victims lie, 'Mid silent shades, to linguish and to die. Oh let your breasts such selfish views disclaim, And scorn the triumph of a casual aim;

Disdain such rapine; of your skill be proud, The object singling from the scattering crowd."
}

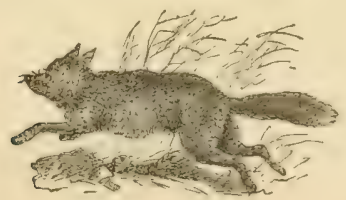




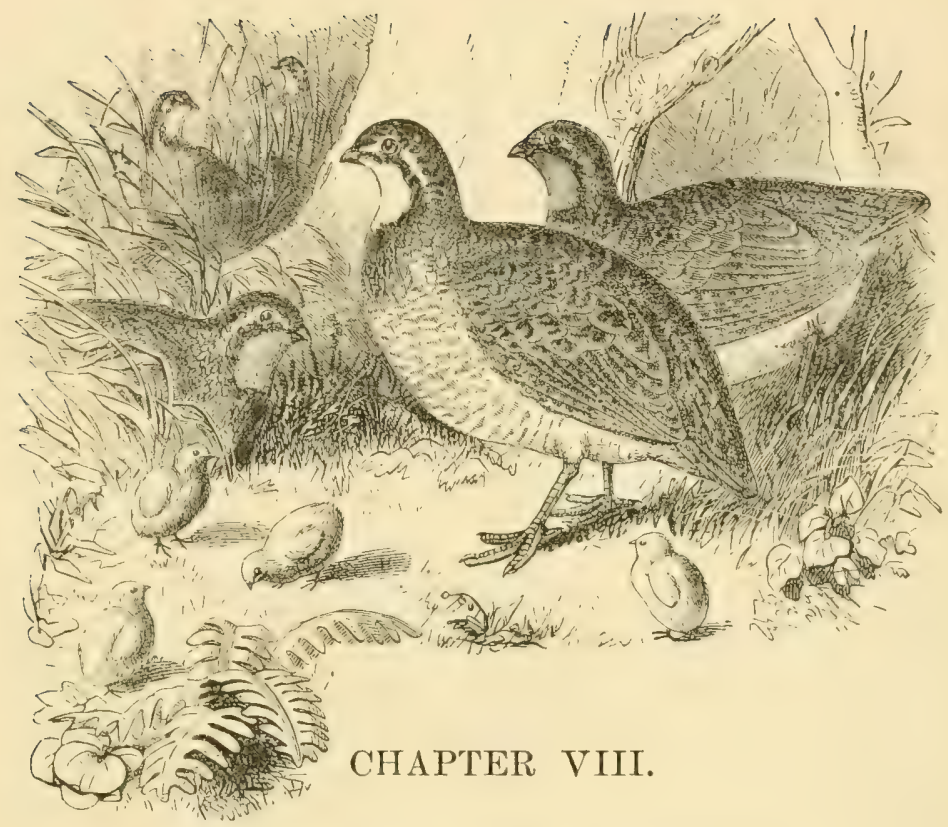

THE PARTRIDGE. PERDIX VIRGINIANUS.

"How beautiful they look! with outstretched tails, With heads immovable and eyes fast fixed, One foreleg raised and bent, the other firm, Advancing forward, presses on the ground."

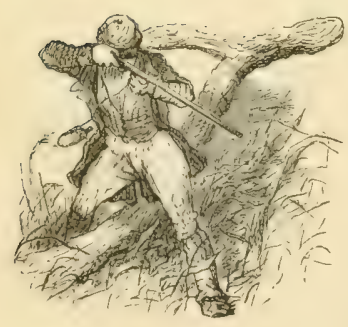

HIS beautiful bird, so well known and eagerly sought after by all the sportsmen of our country, is found in considerable abundance in almost every State of the Union, extending from the extrems parts of Canada even to the southernmost banks of the Rio Grande. The inhabitants of the Northern States call it quail; in the Middle or Southern States it is more familiarly known as the partridge, or Virginia partridge.

The habits and natural history of the American partridge having already bren so amply descanted upon by many able 
ornithologists who have graced this country by their presence and enriched our libraries with their splendid works, that it would seem superfluous, if not really hopeless, in us to attempt to add any thing further upon a subject thus dwelt upon by others far more competent to the task. However, as we propose bringing to the notice of our readers the practical experience of shooters in general, in connection with the more scientific observations and researches of ornithologists, regarding all those birds of our country which properly belong to the sportsman's catalogue, we must be pardoned, ex necessitatê rerum, for going over much ground already touched upon by other writers in the many excellent works already published on this branch of Natural History.

"The partridge is nine inches long, and fourteen inches in extent; the bill is black; line over the eye, down the neck, and whole chin pure white, bounded by a band of black, which descends and spreads broadly over the throat; the eye is dark hazel; down neck and upper part of the breast, red-brown; sides of the neck spotted with white and black, on a reddish-brown ground; back scapulars and lesser coverts, red-brown intermixed with ash and sprinkled with black; tertials edged with yellowish-white, beautifully marked with numerous curving spots or arrowheads of black; tail, ash sprinkled with reddish-brown; legs, very pale ash.'

The above accurate description, (as well as the major part of the other scientific descriptions of birds in this work, taken from Wilson, being so perfect in itself, there remains notling to add, except that the female bird is distinguished from the male by its diminished weight and size, and also by its plumage being somewhat yellowish-brown about the chin and sides of the head

\section{HABITS.}

Partridges, in sections of the country where they are much troubled by sportsmen, become extremely shy and wild, seldom venturing far into the open fields, but confining themselves to the edges of close cover, to which they take at the slightest alarm; secreting themselves in the thickets, and not unfrequently perch- 
ing upon the branches of the largest forest-trees. The act of perching upon trees is not, however, a natural habit of this bird, but appears to be solely the result of fright, or, perhaps, a precaution of safety which circumstances have taught it to adopt to escape from its pursuers. In hilly and mountainous districts, partridges are much more apt to fly to the trees than in other parts; and in such a locality we knew of a whole covey betaking themselves to a tree and remaining there, perfectly concealed from view, for some considerable time, greatly to our mystification, and that of our dogs also.*

In their natural undisturbed state, partridges delight in the open country, frequenting without fear the stubble-fields appertaining to the well-cultivated farms of our agriculturists, where they can obtain a plentiful supply of loose grain. The morning and evening is the time when partridges feed. When the weather is favorable, they leave their roost at an early hour of the day, and, being very industrious feeders, they are soon able to retire from the open fields to some favorite and secluded spot, to bask in the mid-day sun or roll themselves in the dust to rid their plumage of the vermin with which all birds are more or less infested.

Partridges are not strictly migratory birds, as the greater portion of them remain distributed throughout the northern portions of our country during the whole winter, and not unfrequently suffer immensely from the intense cold and deep snows; still, at that period of the autumn known as the "running season," large numbers abandon their former haunts, and, continuing along the borders of our rivers, take up their abode for a time in the lowlands, hundreds of miles, perhaps, from their breeding-places. Of this peculiarity we shall, however, speak more fully hereafter, - under a separate head. In the northern sections of our country, the ground is frequently covered for weeks with snow; and, all access to food being thus cut off, these poor birds, driven by stern

* In such situations, it is not unusual to find numbers taking to the trees wnen frequently disturbed. 
necessity, often become quite tame, visiting the barnyards, and even mixing with the poultry, to gain a scanty subsistence, which not unfrequently preserves them from actual starvation.

Besides thus falling victims to the inclemency of the weather, large numbers are now destroyed, not only by the gun, but by the aid of traps, nets, and other ingenious contrivances; and we have seen, in former times, the Philadelphia markets, and the villages of the interior, fairly overstocked with live birds, taken in various ways by the farmer-boys.

When this is the case, it behooves every sportsman living in the country, or residing in the city, to purchase all birds thus offered for sale, and keep them till the breaking-up of the winter, when they may be let loose upon a friend's estate, or turned out into some neighborhood where he is in the habit of shooting, and where, from the nature of the country, they will be apt to remain during the breeding season. By pursuing this course, the provident sportsman will be richly repaid for all his trouble and humanity, at the coming shooting season, by the number of birds that will thus be produced in some favorite shooting locality, as the fecundity of the partridge is extraordinary, and the coveys raised from a few couples of old birds, in a favorable season, will be sufficient to afford sport for several days' moderate shooting.

\section{PERIOD OF PAIRING.}

Partridges commence pairing in the month of March, early or late, according to the state of the weather; and, even after separating for the purposes of procreation, it is not unusual for them to reassemble in coveys as before, provided the weather should again become stormy and cold, as is often the case in our changeable climate. There is no doubt but there are more male birds hatched than females; and this rather singular circumstance gives rise to fierce battles between the cock birds for the possession of the hens at the coupling season; and to such extent are these encounters carried that they sometimes result in the death of ond or both of the rival combatants. This fact is so well established 
in the English variety, that it is no uncommon thing for the owners of some choice preserves to have the partridges on their manors netted, soon after the pairing season, and to destroy the surplus males, or old bachelors, as they are facetiously termed. This precaution prevents those strifes, and at the same time insures a larger produce of young birds; for, if the female be pursued by several cocks during the period of incubation, she has no opportunity to form a nest, but drops her eggs about in various places, no two, perhaps, together. Partridges generally complete their nests in five or six weeks after pairing. A small tuft of grass, sheltered by a bush or a tree, the corner of a worm fence, or the foot of an old stump, are the spots usually selected for the building of their nests, which are composed of leaves, dry grass, and a few feathers plucked from her own person. The little habitation is rudely but often ingeniously constructed; and, being so nicely concealed from observation, it not unfrequently bils defiance to the searching glances of the most inquisitive eye, as well as affording ample protection on every side from the inclemency of the weather. The eggs are white, and average from fiftcen to twenty in number, anct, in some rare instances, greatly exceed that quantity. If the birds be in their prime, and the season very favorable, it is not improbable that the hen may deposit twenty-five or even thirty eggs; but such cases are anomalies; and we should be more disposed to attribute the unusual increase of eggs to an occasional propensity that some birds have of laying in each other's nests. Mr. Daniel, speaking of the amazing fecundity of the English partridge, which is closely allied to our species, states that a nest was discovered with thirty-three egrs in it, another with twenty-eight, and another with thirtythree. The greatest number we have ever seen in the nest of the American bird is twenty-four; but we have often been told by farm hands that twenty-five is no unusual number. For the truth of these vague assertions we cannot, however, vouch. The perior of incubation is about twenty-one days. Some contend for a longer period; but we believe the former statement the more correct, 
although, in proof of the latter assertion, it has been argued that it requires four weeks to hatch the eggs when placed under a common hen. This, however, proves nothing, as the disparity in the time may be accounted for by the circumstance of the partridge setting much closer than the domestic forl, and, consequently, generating a larger amount, if not a ligher degree, of animal heat.

The hen bird during the period of incubation becomes quite poor, and undergoes the process of a partial moult, which provides a few downy feathers to assist in keeping the eggs warm during her absence from the nest in quest of food. The young birds are quite strong when they first burst from their narrow confines; and it is no very uncommon thing for them to be seen running about with a portion of the shell adhering to their backs. While the hen is setting, and even after the birds are hatched, her mate may often be seen early in the mornings, or late in the afternoons, perched on a fence-rail or low limb of a tree, whistling with all diligence for a half lour at a time, as if to cheer the female in her arduous and solitary duties. Partridges are strictly monogamous; and it is supposed by some that the cock assists the hen in covering the nest; and we incline to the opinion that these birds, in common with many others, do share the cares of hatching the little brood.

If the weather remains dry and mild after hatching, the young birds will be able to fly in the course of three or four weeks; if, on the other hand, the season should be backward and inclement, the tender little brood gains strength but slowly, and great numbers consequently will fall victims to the damp and cold while being led about in search of food.

\section{LEAVING THE NEST.}

As soon as the anxious mother abandons the nest, attended by her nimble little progeny, she is joined by the cock partridge, who gives all his attention to the searching for food and protecting the active little brood from any danger that may beset them. At 
the first alarm, the young birds instinctively skulk in the deep grass and remain perfectly motionless, while the old ones resort to every artifice within their power to ward off the impending danger.

It is interesting to observe the earnest solicitude with which both the parents watch over their young, and the wonderful instinct they exhibit in guarding them when surprised by the huntsman before they are sufficiently fledged to fly off. The old birds take to the wing, and the young ones run with all speed into the nearest thicket, or conceal themslves in the brushwood, or long grass that abounds at this season on their feeding-grounds. The hen, after flying a few hundred yards, alights, and returns by a circuitous route to the place she just abandoned; and, calling in subdued tones, she soon collects around her the scattered progeny, and quickly leads them off from the scene of danger. The cock partridge at the same time is using every effort to distract the attention of the intruder by flying or rather tumbling confusedly before him, running along the ground, hanging his wings, fluttering as if badly wounded and unable to escape his every grasp. By such like artifices, the male bird strives to delude the eager observer, and deceive, perchance, lis no less anxious dog; for, leading them both away, step by step, from the young covey, sufficient time is gained for the female to perform her important task. When the danger is passed, the hen bird, by her joyful call, directs the mate to her retreat.

It is not only in devices of this kind that partridges display a strong and lively affection for their young, but where there appears a probability of success they will not hesitate to attack any enemy that assails them; and it is no uncommon thing for the old ones to be seen flying up at hawks, or other birds of prey, screaming and fighting with all vigor to defend their helpless offspring. Several years ago we witnessed a desperate battle between a cock partridge and a black snake, which rather singular combat would, however, have soon proved fatal to the former if we had not so opportunely come to his rescue, as the serpent had alrearly caught the exhausted bird by the wing; and so deadly was the grasp that 
he even held on to his affrighted but nevertheless courageous rictim after we had broken his back with a blow from a large stick. On searching around in the grass, we discovered two very young partridges, somewhat mutilated, and nearly dead; both of which, no doubt, had been seized by his snakeship as a dainty meal, which he was not, however, permitted to enjoy, owing to the bold attack of the parent bird.

Such encounters between birds and serpents, we are convinced, are not uncommon, but of daily occurrence, as few of us at all familiar with country life but have witnessed like incidents in our rambles over the fields. We also believe that similar conflicts between the parent birds and these ruthless desecrators of their nests have given rise to the popular fallacy that snakes possess the power of charming birds, or, in other words, transfixing or drawing them within their reach by the use of certain mesmeric manipulations of their tongue and eyes. We give no credit whatever to this boasted power of fascination on the part of snakes, but regard it as one of those vulgar errors which spring up in the minds of the ignorant, from their inability to explain or investigate many of the everyday phenomena of nature.

Dr. S. Gilman, the author of a very interesting article on the Venom of Serpents, published in the St. Louis Medical Journal, is a firm believer in the occult power possessed by serpents of fascinating small animals, and hints at the probability of the king-snake exercising some power besides mere physical force by which he overcomes, even when fangless, the most venomous of his fellowreptiles.

Dr. Gilman states that he succeeded in making seven venomous serpents fraternize and dwell amicably in one den. A beautiful pair of long-bodied king-snakes, known to be fangless, and consequently without venom, were duly installed as members of the family. The older members manifested some uneasiness, but made no attempt to destroy the intruders; and the next morning four of the venomous serpents were found dead, and a fifth was gasping in the suffocating coils of the king-snakes. The two others re- 
mained stupid and apparently indifferent to their fate, and could not be made to offer the slightest resistance to their enemies. One of the king-snakes was afterwards inoculated with the poison of a rattlesnake which he had destroyed, and died immediately, thus evincing that they must have exercised some power besides physical force to overcome their fellow-reptiles.

II. Raspail explains the mystery of fascination, apparently very much to his own satisfaction, by supposing the serpent to possess the power of emitting two streams of a poisonous and stupefying gas-one on each side of its mouth-which proceed to unite above the head of the bird, producing asphyxia, \&c. \&c.

\section{DOMESTICATION.}

The wild nature of the partridge renders its domestication almost impossible, though in some instances, where the eggs have been placed under the common hen, they have been hatched and reared with as much success as if the progeny were of her own species. The young brood, however, though perfectly familiar with all the other occupants of the farmyard, and apparently reconciled to their unnatural mode of life, still exhibited the wandering and restless disposition of their race, and in most instances have flown away to their native haunts at the pairing season of the following year. The American partridge, in common with those of other countries, cannot bear close confinement; they may appear for a time to thrive, still, if too much restricted in their movements, invariably die. We unfortunately, during the last winter, lost several fine birds that were presented to us by our friend G. D. Wetherill, Esq., owing, we suppose, to the smallness of the cage in which we had temporarily placed them.

\section{TWO BROODS.}

It is a common opinion among sportsmen that the partridge produces two broods during each season. Whether this be true or not, we are not prepared to say positively; but one thing is certain, that the hen is often discovered setting during July, in our 
Middle States, and birds too small to be shot are constantly met with in October, and even in November.

This circumstance may nevertheless be accounted for on other grounds, as it is well known that the female, if disturbed during the period of inculation, or the eggs be destroyed by some one of her many enemies, will build another nest and commence setting afresh. We do not doubt, however, that, independent of these accidents, in a very favorable season the hen may be induced occasionally to raise two broods of young, more particularly in the Southern States; but we are not inclined to believe the habit a natural instinct of the bird, and rather attribute these instances to causes such as above enumerated.

The period of warm weather in the Middle and Northern States is rather too short to allow partridiges generally to raise two broods in a season; and, if they should succeed in hatching them, the second brood, being small and delicate, and not sufficiently well grown before the cool weather sets in, are unable to enclure the rigors of our boisterous winters, and consequently soon perish, either from want of food or exposure. These are the birds which are first caught in traps and sent to market.

\section{FULL-GROWN.}

The birds, being full-grown towards the close of Septernber, will be found associated in coveys from ten to twenty-five; and, in portions of the country where food is plenty, much larger coveys may be met with, perhaps two or three broods joining together in perfect harmony. The call of the male bird during the season of love, which is thought to resemble the notes produced by pronouncing the words $A h B o b$ White in slow and measured time, is now seldom heard except when the covey is flushed and separated; and then this plaintive call, in connection with the usual cry of the species, will be recognised at occasional intervals, collecting the terrified members of the fumily together again. The call of the partridge is a clear whistle, composed of three notes; the first clear, loud, and sonorous; the second less loud, and the third, 
though louder than the second, not as loud as the first. These call-notes are perfectly familiar to every sportsman, as they are often resorted to, to decoy the poor birds from their lurking-places. If the birds be young, they will soon reassemble or be decoyed by the imitative whistle of the sportsman; if, howerer, they be old and cunning, each one will remain perfectly quiet for a long time, and not venture to call each other till towards the close of the day, when all danger is removed. A low, twittering sound is frequently heard issuing from a covey when terrified and about to spring from before the dog; this sound somewhat resembles the chirping of a brood of young chickens when nestling themselves under their mother's wings towards nightfall.

ROOSTING.

Partridges, when pursued, as before stated, generally take to the woods and thickets for protection; but instinct and long habit, on the other hand, have taught them that the open plain is a more secure place for roosting during the night, and consequently they almost invariably choose a little mound of rising ground in the centre of a cleared or stubble-field for this purpose.

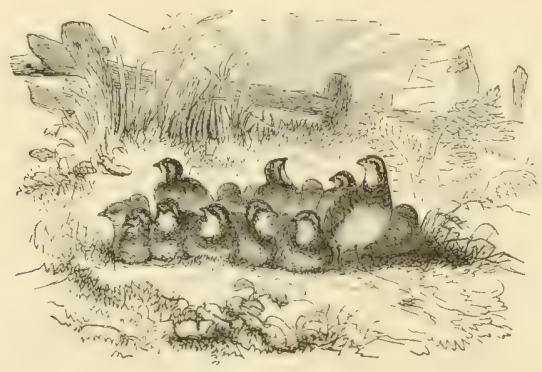

To afford greater security and prevent a surprise, we imagine, partridges roost in a circle, with their heads all turned outwards, and their tails joining each other in such a manner that they present a guard on every side; and when thus disturbed the whole covey are enabled to fly off in a direct course without interfering with each other. If undisturbed, they are apt to resort to the 
sume spot for several successive nights. We have often observed these birds arranged in this curious manner, and, when kept up during winter in cages, they will be found to place themselves in this position every night about roosting-time, or even when huddling together during the day.

FOOD.

The partridge is granivorous, and, in the words of the old poet-

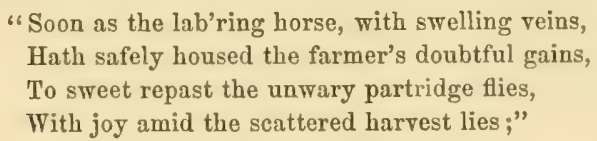

thus delighting in the open and cultivated districts, feeding upon all and every species of grain, and thought to be particularly partial to buckwheat. Some suppose that birds shot from the stubble of this latter grain are superior in flavor to any others. Mr. Skinner, we find, is of this opinion; and we are also disposed. to agree with this accomplished sportsman, although we must acknowledge that, in making the assertion, we may be arrogating to ourselves too great a nicety in the gastronomic art; for the delicacy of these birds is such that it is, perhaps, impossible to draw so nice a distinction regarding their flavor, no matter where shot, in the fore part of the season.

Partridges are very fond of Indian corn, and in a state of captivity we have seen them eat it in preference to all other kinds of grain save buckwheat. They are not, however, as often met with in the cornfields during the shooting season as they are in the wheat-stubbles; but this may be attributed, in a great measure, to the want of sufficient cover in the former, rather than any greater partiality for the latter. Small insects, ants, grasshoppers, \&c. are eagerly sought after by these birds; and in the midst of winter, when the ground is entirely shrouded for many inches in depth with snow, partridges as well as grouse are forced to eat the fruit, leaves, and tender buds of the mountain laurel, (kalmia latifolia.) 
This well-known evergreen flourishes in every section of our country, being particularly abundant on the sides of hills and mountains. There is also another variety, known as marsh laurel, (kalmia glauca, that inhabits the lowlands and possesses nearly the same properties as the other species. Some animals partake of these evergreens with impunity, while others are fatally poisoned by the use of them. The partridge and grouse both eat of their foliage and berries without any ill consequences to themselves; but their flesh, it is said, has often been poisoned to such an extent by long indulgence in this food, that death, in some rare instarices, has resulted from persons partaking of them while in this noxious state.

Doctor Shoemaker published, some time back, an account of two cases of poisoning arising from the eating of a pheasant whose craw was stuffed with laurel-leaves when shot. The most prominent symptoms in these cases were intolerable nausea, partial blindness, severe pain in the head, difficult breathing, feeble pulse, \&c. Great relief was obtained for these unfortunate patients by the free exhibition of mustard and warm water, in quantities sufficient to provoke vigorous vomiting.

\section{OLD AND YOUNG BIRDS.}

The bills of young birds are soft and brown, the legs yellowish or bluish white; the old birds have hard black bills, and legs dark and scaly. The young birds are somewhat smaller than the old and full-grown ones of the previous season. In some sections of country partridges seem to thrive and grow much larger than in other parts. Those shot in the neighborhood of the Tapahannock marshes, in the State of Delaware, are generally very heavy and remarkably fine birds.

Geo. D. Wetherill, Esq. - a zealous and ardent sportsman, bythe-by-informs us that he once shot, in the neighborhood of Mount Holly, New Jersey, ten brace of birds that averaged eight ounces each. 


\section{THEIR NUMBERS IN DIFFERENT LOCALITIES.}

After a favorable season, partridges are found in abundance throughout the Southern, Middle, and Western States; and, if the reports of those who have gunned in the West can be relied on, their numbers in these latter territories must be enormous,-quite beyond any idea we have of them in the Atlantic States. We have never yet been so unfortunate as to meet with partridges, on any of our shooting excursions, in such large bodies as necessarily to destroy, by their superabundance, all zest for hunting them; and we are rejoiced that there is only a comfortable scarcity in these localities, at all events a scarcity sufficient to make us all work hard and exercise a becoming skill in both hunting and shooting our game, which excitement, by-the-by, constitutes the chief pleasure attending the sports of the dog and gun.

The mere sallying out in a country overrun with birds, and sauntering lazily about for a few hours, loading and firing with little or no discrimination or exercise of skill in hunting up the game, remind us very strongly of the battues in the overstocked manors of the Old World, or perhaps the tameness of a pigeonshooting in our own country.

\section{DIFFERENCE BETWEEN THE ENGLISH AND AMERICAN BIRD.}

The American partridge differs from the English variety in several particulars, although it greatly resembles it in habits and disposition. It is smaller by one-third than the English; the plumage is somewhat different, and the call entirely dissimilar; its flesh, however, is equally white and delicate.

We receired a couple of brace of English partridges, a few dars since, from a friend residing in the mother-country; they arrived in good condition, and, we should think, were remarkably fine specimens, as they weighed $1 \mathrm{lb} .13 \mathrm{oz}$. each brace. The wings struck us as being singularly small and short for the size of the body. We invited some of our sporting friends to be participators in this rather novel and rare feast; and we believe that they were unanimous in 
pronouncing them not superior, but rather inferior, to our native bird in point of delicacy of flavor; and, furthermore, we all came to the conclusion that we could knock them down, right and left, like smoke, if we were once let loose in the overstocked preserves of "merry old England."

\section{AMERICAN PARTRIDGE NOT A QUAIL.}

It has been stated that the Perdix Virginianus is more closely allied to the European quail than to the English partridge; but such is not the fact, as the partridge of our country resembles the quail in no one particular save in the habit of partial emigration that it exhibits every autumn at the running season. The meat of the European quail is dark, and oftentimes loaded with fat, while that of the partridge is white, and invariably lean. This alone is almost sufficient to establish the difference between the two birds. Another circumstance still more striking in the habits of these two birds, and better calculated to prove most conclusively the difference between the two species, is the well-known fact that our partridge is monogamous, while the quail is polygamous. Although the American partridge may be termed a hardy bird, in one sense of the word, the quail is still more so, as it depends almost entirely on itself for support, eren a few days after being hatched; and, if kept among others of its own brood for a few weeks, fights most obstinately, the battle frequently ending in the death of one of the combatants. As early as four months old, the young quails are sufficiently strong to accompany their parents on their distant migratory flights. Quails seldom form themselves into coveys. The cock bird being polygamous, and at the same time very salacious, confines his attentions to no particular mate, and consequently assists but little, if any, either in the construction of the nest or the care of the young brood. 'The quail is also less prolific than the partridge. When quails migrate, they assemble together in large numbers; but, as soon as they arrive at their destination, they separate, each seeking his own food and guarding his own safety; they travel invariably at night. How 
widely different is all this from the habits of our birl! And still further dissimilarity, no doubt, might be remarked if the subject had been properly considered by those more conversant from actual observation with the point of contention than we pretend to be.

The quail may also be termed, in some respects, a nocturnal bird, and in this particular also differs from the partridge. The migrations of the quail, as before stated, are almost entirely per. formed during the hours of darkness, and, by way of compensating nature for this loss of repose during the hours allotted to it, most generally sleeps in the middle of the day, which time is always occupied by the partridge in scratching and pruning his plumage. This being the case, we trust the American sportsman hereafter will give our partridge its proper appellation and rank, and no longer confound it with the quail, a bird fir inferior whether in the field or on the table.

Although the ancient Athenians eagerly sought after and even reared quails for the purpose of employing them in combat with each other, they were not esteemed as an article of food, but, on the other hand, were erroneously considered unwholesome, from the circumstance of their feeding on hellebore. This vulgar notion, as many others of like character, is now entirely exploded.

\section{RUNNING SEASON.}

At the commencement of autumn, the partridges of America abandon the high grounds, and resort, in immense numbers, to the large river-courses, where they remain for a few weeks, and then travel back to their former haunts. At this period the birds are said to be running or travelling, and will not lie to a dog; and to pursue them is lost time, as it will be found utterly irnpossible to keep up with them, no matter with what speed you attempt it. In the fall of $18 t 5$, we, in company with a brother sportsman, encountered an immense drove of these running birds in the neighborhood of Elk River. When first discovered, they appeared to be holding a conference as to the proposed route they should take, 
or perhaps quarrelling with their leaders as to the propriety of proceeding firther on, as they had all come to a stand in a secluded little hollow on the borders of a pine forest, and were all whistling and twittering as fast and as loud as possible, insomuch that we distinctly heard the general turmoil at a distance of several hundred yards. Upon approaching to ascertain the cause of this rather unusual noise, the whole company took to their hecls in double quick time, hundreds running up the opposite bank of the hollow and disappearing in a few moments in the thick forest of pines and underwood. We followed on after them for a short time, but neither ourselves nor dogs were able io keep up with their retreating ranks. This company of royagers, we should think, contained several hundred individuals, and was the largest party we ever met with. These migrations of partridges to the sea-coast and river-shores are performed almost exclusirely on foot, as they seldom or never fly, except perchance to cross a small rivulet which opposes a barrier to their onward progress. The cause of these migrations is not satisfactorily explained by writers, if, in fact, any have attempted the solution of this rather mysterious movement on the part of these birds. We do not know what to attribute it to, and are even at a loss to renture an opinion. If the birds did not commence running quite so early in the season, we might be disposed to believe that a scarcity of food in their previous haunts impelled them to wander in search of it in clistant localities, like others of the feathered race; but this can hardly be the motive, as they are found on these excursions as early as October, when the weather is not often sufficiently serere to shut up the usual chamnels of food, but, on the contrary, is generally such as is most congenial to the habits of the bird.

\section{FLIGHT OF THE PARTRIDGE.}

The partridge, when full-grown, is a very vigorous and powerful bird, flying with great rapidity, and, like other's of the gallinaceous order, when on the wing, makes a loud whirring noise, which often not a little disconcerts the tyro, who, alarmed at the sudden 
springing of a large covey, knows not where to turn or in what direction to point his gun. This startling-but, to the ear of a sportsman, agreeable-sound is produced by the shortness, con cavity, and rapid motion of the wings, as they fly by a succession of quick flaps, and then sail till nearing the ground, when they break their fall by a few more flaps. When partridges rise on wing of their own free will, the whole covey takes the sarne course; when disturbed, they all seek safety by separating. When compared with the weight of the body, there are few, if any, game-birds, in any portion of the globe, that fly with the same rapidity or force, and consequently require such quick action on the part of the sportsman, as the partridge of America. They spring suddenly, and dart off with a celerity and regularity of purpose that appears almost impossible for any bird to possess, pursuing a rapid and headlong flight through the mazes of our thickest forests and impenetrable coverts; and we hardly suppose that any of our brother sportsmen ever saw one of these birds either entangled or otherwise impeded in its progress through the rank and poisonous vines that so often intercept the flight of other less strong and clear-sighted birds. The American bird flies with much more vehemence, and to much greater distances, than the English variety. It is no uncommon thing for sportsmen to see whole coveys, when wild from frequent flushing, take wing and fly entirely out of sight over the highest of our forest-trees. The English bird is stationary, and has neither the inclination nor strength sufficient for migrating from one portion of the country to another, hundreds of miles apart. The English bird is longer lived than the American. The average duration of life in the former is said to be seven to ten years; in the latter, three to five.

\section{CHANGE OF PLUMAGE.}

A few partridges, owing to some inexplicable freak of nature, change their plumage to a pure or mottled white. Many of such singular-looking birds have been shot in England. Mr. Daniel states that there was a covey of seven partridges netted at South 
Cave, four of which were of a most beautiful clear white color, three were pied, and that they were preserved alive for a long time as great curiosities. We have heard of several being shot in the State of Delaware, one of which remarkable birds is mounted and in the possession of the author. It is not purely white, but pied, and differs in no other respect from the common partridge. There is also another liandsome specimen in the possession of David Gratz, Esq., which most of our shooting friends, no doubt, have seen. There is also a very handsome specimen in the Academy of Natural Sciences.

There are several specimens of these singular birds in the English Museum; and Buffon states that ten or twelve partridges, entirely white, have been seen at once among others of the usual plumage, and that they had the pupils of the eyes red, as common to the white hare, rat, ferret, \&c.

What this alteration in the plumage of birds is to be attributed to we are at a loss to discern, as it has occurred in climates that could not be suspected of exercising any influence towards this change. Such anomalies, however, are not so very rare in the feathered race as we should at first be led to suppose; for it is no very uncommon circumstance to hear of crows, as well as blackbirds, having changed their lustrous jetty plumage for one of snowy white. We have also seen a white snipe, and a yellow reedbird, both of which will be spoken of under their proper head.

Since the publication of the first edition of our book, we have reccived at the hands of our friend, the late Mr. H. H. Stockton, who, by-the-by, was a most zealous and experienced sportsman, a remarkable, and, no doubt, perfectly unique, specimen of the American partridge. The plumage of this rara avis in terra is totally different from any thing that we have yet seen or heard of. Independent of the color of the plumage, the bird has every characteristic of the Perdix Virginianus, and, no doubt, is a veritable partridge, without any admixture of foreign blood, as some of our sporting friends would have us infer. If this hird had not been shot in the section of country where it was, and in company with 
other ordinary partridges, we might, perhaps, very naturally aave supposed it to belong to another variety; but, all the circumstances taken into consideration, we must regard it only as one of those lusis naturce that we occasionally meet with in every branch of animated creation.

In the specimen before us, the bill is black; line over the eye and down the back jet-black, with an occasional grayish-white spot; whole chin ashy-white, mottled with black, extending slightly over the throat, which is jetty, interspersed with a few reddishbrown spots; upper part of the breast exhibits a few pure white feathers; the lower portion dark-cinnamon or red-brown, fringed with black; sides of the neck reddish-brown; in fact, the balance of the plumage, save the admixture of black and cineritious tints, may be set down as reddish-brown, or rather dark-cinnamon color; legs of same hue; the irides hazel.

This very peculiar bird was killed in Pennsylvania, a short distance from Philadelphia; and, what is somewhat remarkable, there were others of similar plumage in the covey from which this one was secured. We went in quest of these birds with Mr. Stockton, on a subsequent occasion, but were unsuccessful in our search.*

THE IMPORTANCE OF STUDYING THE NATURAL HISTORY OF GAMEBIRDS.

We have already devoted much space-perhaps too much-to the natural history, habits, and peculiarities of the partridge, but, we trust, not without benefit to our readers, as no one can expect to become an accomplished sportsman without studying very closely the individual characteristics of every species of game that he pur.

\footnotetext{
* This remarkable bird is perhaps more worthy of being represented perched upon a tree, than the white one referred to by an English author, who states that one of this character, being shot, was sent to a Mr. Pugh, a good artist, but no sportsman, who, to make the delineation, as he thought, the more effective, first painted a large nak, and then very artistically placed the white partridge on one of the branches. When told that these birds always sat on the ground, he naively replied, "That might be; but it looked so much the more picturesque to have a' landscape in the background that he would not alter it; for an extraorelinary bird ought to have an extraordinary situation: it exalted him above his fellows."
} 
sues. For it is by this knowledge, either gained through great labor in the field, or acquired from the writings and associations of those who have devoted the leisure of years to this healthful recreation, that one shooter is seen to excel another in the style of hunting and bagging his game.

Many individuals, from a lack of personal observation on their part or the want of a suitable preceptor to instruct them in the field, will continue to hunt a lifetime in an awkward or hap-hazard way, without ever bringing into requisition any of those many little manourres and field-stratagems so familiar to the crafty old sportsman, and which he oftentimes selfishly endearors to conceal from the knowledge of the rising generation of shooters, fearing lest his teaching might raise up around him too many youthful aspirants, ever ready to pluck from his brow the hard-earned laurels of a long apprenticeship to the tricks of the field. If any of our readers, however, should only aspire to the office of pothunter, we would advise him to put this book aside, as we can assure him that he will not be interested in many of its details, except, perhaps, those portions of it devoted to the trapping and netting of game, or the different methods to be pursued by the shooter when anxious, from some particular circumstance, to make a large count. But, even then, a mind such as this selfish character possesses is often too obtuse to understand or practise the principles laid down for the guidance of a gentleman sportsman.

Of all the disagreeable characters that a well-bred sportsman is likely to be thrown in contact with, that of a pot-luunter is the most disgusting, the most selfish, the most unmanly, the most heartless; a being who alone can pride himself in a ruthless desire to destroy, and, as it were, to lay waste, all animated nature, by every and any means within his grasp, without regard to etiquette, humanity, law, or even the common decencies of life. Such are the real feelings of a pot-hunter, in the true sense of the word; and his boasted motto, Fill the bag, and damn the means, should be chalked upon his craven back in well-defined characters, as a warning to all young sportsmen to shum his company and leteat 
his vices. Perhaps our readers may think we have portrayed a being so base, so low, as seldom or never to be met with, except among those mercenary scamps who shoot for the markets. But rest assured, my gentle friends, that the picture is not overdrawn, for there are dozens of just such fellows in erery shooting community; and perhaps we can even find some such among our own sporting acquaintances, who hesitate at nothing to fill their bags, in season or out of season, and, in reality, practise in secret the open and avowed motto of the professed pot-hunter. We have met with such characters, and doubt not but our sporting friends have done the same, and perhaps been alike distressed and mortified at their behavior in the field. When caught, however, with such would-be sportsmen, we have but one course to pursue-resign the field for the day, or take our dogs and quietly put off in another direction to pursue our sports solitary and alone.

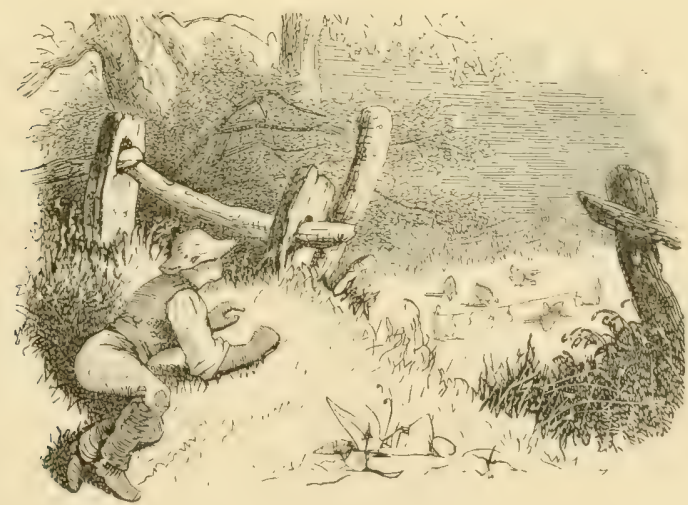

FURTHER HINTS.

We shall now enter upon some particulars more familiar to the practical sportsman, and in which he will take especial interest, and no doubt feel competent to compare our olserrations with the results of his own experience, and thus be able to judge of the truth and importance of our information, not only to himself, but 
to the young tyro. In compiling this work, it is our earnest desire to bring the young sportsman forward so rapidly in all that relates to the crafts of the field, that, with a little industry and ordinary attention, he may, in the second season of his debut, possess the same skill in hunting and bagging game as it would have required five or six years of regular apprenticeship for him to arrive at.

As before stated, partridges are formed into coveys, and are sufficiently large to shoot, in the month of October, which is the time appointed by legislative enactments for the killing of this game in several of the States; New Jersey, however,-lhaving in view the preservation of the second brood, we suppose,-prolongs this period to the following month. But few partridges are taken at this early season in traps, owing to the great abundance of grain, seed, and insects to be found in the stubble-fields and cloverpatches; nevertheless, incalculable numbers of running birds now fall victims to the nets set by farmer-boys and the regroes of the adjoining States. A gentleman residing on the Chesapeake Bay, a short distance from Havre de Grace, informed us, not long since, that his immediate neighbor caught in this way, during one season, on his own estate, no less than nine hundred partridges, which he kept in coops, and gave out to his negroes as ordinary food during the running season, besides supplying his friends in the city with considerable numbers. This account may seem incredible to those not familiar with the fecundity of partridges, and still less acquainted with the immense armies of these birds that congregate together during their migratory trips, and the regularity and pertinacity with which they pursue their course, sometimes passing through the heart of villages that obstruct their way. The estate upon which this large number of birds were captured is peculiarly well situated for intercepting the progress of these royagers, it being a neck of low land, bounded on one side by the bay and on the other by a wide stream of water, thus forming a kind of peninsula, encompassed by high lands, upon which the birds congregate for the purposes of incubation, and which they abandon again for the 
river-courses early in the autumn. We do not doubt that, with properly-devised instruments, much larger numbers might have been taken during the same season at this spot, as the birds were very abundant indeed, and the materials used in their capture were of the simplest and roughest character, and very little or no attention given to their skilful adjustment by the parties setting them. We need not, however, make any further comments as to the probability of this number being captured in one season, when it is well known that the quails of the Old World (not more prolific than the American partridge) assemble in such innumerable bodies, at the same period of emigration, that one hundred thousand have been taken in one day, within the space of four or five miles, along the western coast of the kingdom of Naples. About the time of their first appearance at Alexandria, after crossing the Mediterranean, such multitudes are exposed for sale in the markets that three or four may be bought for a medina,-a piece of money less than two cents in value. Whether there be such numbers of quails in these parts at present we are not able to say; but a few years back such was the case; and a writer informs us,_- "That so completely surfeited with this game have the crews of merchant-vessels become, that they were forced, in some instances, to prefer com. plaints against their captains, at the consul's office, for the purpose of obtaining other kinds of food; or, in other words, for a return to their salt junk and bean-soup."*

The nets commonly used by our country-people are very simple in their construction, often nothing more than an old fish-net rudely fixed up for the purpose and set about in different parts of the plantation where the birds are most apt to pass; sometimes a trail of grain leading to it conducts the unsuspecting birds into captivity before they are aware of their proximity to danger.

* Since writing the above, we find, in the "Spirit of the Times," a letter from a correspondent in Iowa Territory, stating that he netted, in one senson, ten thousand partridges, in the neighborhood of Burlington, a town of that country, the truth of which we do not fur a moment doubt, for it only confirms the reports that we have before heard of the immense numbers of these birds in those localities. 
Nooses of horsehair are also attached to twigs of low bushes or frames set up for the purpose, across the path most likely to be traversed by these armies; and considerable numbers are taken in this way.

Great numbers of partridges, as well as pheasants,-more properly speaking, ruffed grouse,- - are taken, by the aid of horsehair nooses, in New Jersey and Pennsylvania, more particularly in the district of country adjoining our city; and it is no unusual circumstance for sportsmen to come across long cords of several feet in length, stretched from stake to stake, on the borders of some farorite feeding-ground, hung with five, ten, fifteen, or twenty hair nooses, and even many more, with corn, wheat, or other grain, strewn about for the purpose of luring the poor victims into these deceptive and fatal snares. The birds are most usually caught around the neck, and thus strangled to death; but not unfrequently by the wing, and sometimes leg. Our dogs have often come to a stand upon the poor victims thus entrapped, and we never scruple to help ourselves to the spoils on such occasions.

As the winter progresses and food becomes scarce, the common figure-of- $t$ trap, constructed of laths, corn-stalks, or other suitable material, comes into requisition by every idle farm-hand and lazy negro boy, and thus again large numbers of these birds are mercilessly destroyed. It is no uncommon thing to take corey after covey, in these rude traps, during severe weather, without allowing one single member of the family to escape; as these birds, more than any others, are disposed to run in clutches, and are seen constantly crossing and recrossing each other when feeding, and when alarmed instinctively cluster together and follow blindly their leader, no matter what course he adopts. As we cannot approve of this wholesale slaughter of game, any more than we can justify the robbing of their nests for the purpose of eating the eggs, as is pursued to a considerable extent by the negroes in the slaveholding States, and often with the full connivance of their masters, we will not dwell longer upon the subject, or be more particular in describing the method of making or setting these traps, which 
already, unfortunately, is familiar to every one residing in the country. We sincerely trust that every one perusing these pages will discountenance, as far as lies in his power, the cruel practice of eating the eggs of the partridge, and prevent the negroes or others about his farm from desecrating the nests of these interesting birds.

This season of 1855 and 1856 has been particularly destructive to the feathered race. in consequence of the long-protracted and intensely cold weather which has so generally prevailed throughout our broad expanse of country. This severe spell, coupled with the deep, hard snow which has thrown its chilling mantle over so wide an extent of land, penetrating even far into the regions of the sunny South, has driven all descriptions of game to great extremities in search of food.

The havoc and slaughter, not only by the mercenary and cruel, but by the thoughtless and improvident, have, consequently, been very great, both of birds and animals. Thousands of buffaloes, deer, and hares, hundreds of wolves, panthers, and bears, as well as myriads of partridges and hecatombs of grouse, have been slain and trapped. The markets of all our principal cities have been most bountifully supplied with every description of game-in fact, filled to repletion with partridges and grouse; not, howerer, as many suppose, with birds alone coming from the far, far. West, but by incredible numbers of half-starved victims snared in our own and the neighboring States, or mercilessly shot down, whole coveys at a "blow," as they sit huddled together on the treacherous snow, stupefied and benumbed with the chilling blasts of the North.

At such times, when every vestige of herbage is entirely hidden from view, and the scanty underbrush of the thickets afford but little secrecy or protection to game of any kind, every thoughtless and mercenary lounger in the country shoulders his rusty weapon and wanders lazily forth to kill and destroy whatever of animated nature may lucklessly cross his path.

What a shame! what a pity that we have no laws rigidly enforced to protect from such foul play not only the game-birds at 
this inclement season, but the whole race of insectivorous birds and feathered songsters which enliven our brakes and forests with their melodious strains during the spring and autumnal months!

If the snow which has now shrouded the country for several weeks should continue much longer, we fear that the partridges will be almost exterminated throughout the Northern and Eastern States; as they are not only being trapped and shot down by thousands, as above stated, but immense numbers are absolutely stiffening and dying in consequence of the excessive cold and hunger, even in districts as far south as the central portion of Virginia. But, what is eren more shameful than the wholesale destruction of game by mercenary individuals, and most reprehensible on the part of the city authorities, now, on the sixth day of February, 1856, we, as well as scores of others, are cognizant of partridges and grouse being publicly hawked about the streets of Philadelphia, as well as clandestinely exposed for sale in the cellars and at the stalls of game-hucksters, in direct violation of both the municipal and State ordinances. All this illegal traffic appears to be carried on without any special interference on the part of the officers or clerks of the market; who, one and all, strange to say, seem possessed of lynx-eyes in ferreting out a pound of rancid butter which should perchance be under weight, but are as blind as bats in full noonday on the subject of the game-ordinances.

This illicit traffic we have noticed for several years past; but this season, in particular, our attention has been called to it, from the circumstance of those engaged in it having apparently thrown off all efforts at concealment, and exposing their unlawful wares with the most brazen effrontery, without let or hinderance. The numerous eating-saloons and club-houses, also, of this vast city, openly, without a shadow of disguise, serve up all kinds of game, in season or out of season, just as it suits their purpose or pleasure, without the slightest interference on the part of the constituted authorities. But, what is still more to be reprobated, and what we consider more scandalous than all these open infringements of the 
laws by those who are tempted from mercenary considerations, we have seen the tables of many of our most worthy-but, at the same time, most thoughtless, on this point at least-citizens fairly groaning under the weight of partridges, as well as ruffed and pinnated grouse, during the month of February,-a portion of the interdicted period for the sale of all these descriptions of game.*

As long, then, as such open transgressions of the law are permitted by the authorities and such glaring derelictions of duty indulged in by our otherwise best citizens, it were useless for us to hope any thing on the score of humanity towards the preservation of game by our thrifty farmers. For they, unfortunately, with the rest of mankind, are deeply inoculated with the "auri sacra fames" of the present day, and cannot withstand the temptation of gain when so alluringly held out to them.

That section of the city ordinance to which we refer is as follows:-

"That no person shall sell or expose to sale, within the city of Philadelphia, any grouse, partridge, or pheasant, between the 1 st of February and the 1st of October, nor any roodcock between the 1st of February and the 1st of July, under penalty of five dollars and of forfeiting the articles so sold or exposed for sale."

The act of Assembly is of similar import, and prohibits the killing of these birds within the prescribed periods, under a penalty of ten dollars for each infringement of the law.

Analogous legislative enactments are in existence in the adjoining States of Delaware, New Jersey, and Maryland, but, we fear, are quite as nugatory in their action as those of Pennsylvania. Now, in conclusion of this subject, we sincerely trust that all sportsmen and others interested in the preservation of this charming bird, which enlivens the spring and summer months by his

* By the game-laws of Illinois and others of the Western States, crery person is liable to a fine of fifteen dollars who shall kill, ensnare, or trap any deer, fawn, wild turkey, grouse, prairie-chickens, or partridges, between the 15th of January and the 1st of August. How then can the authorities in Philadelphia permit, or our citizens countenance, the sale of such game, coming, as it does, from these States during this period of prohibition? 
plaintive but most musical whistle, will discourage, as far as is in his power, the shooting or trapping of them during the next season at least,-we mean the season of 1856 and 1857. Not a bird should be killed, under any pretext, in our own or the neighboring States, during the next twelve months, as their numbers have been so thinned the past winter that it will require one or two seasons of undisturbed quiet, coupled with their prolific powers of procreation, to replenish their now almost exterminated ranks.

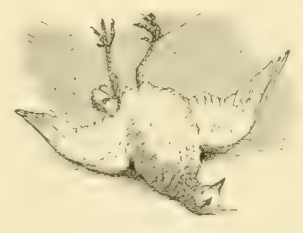

\section{DRIVING PARTRIDGES.}

Another mode of catching partridges, not less fatal to their propagation, if pursued by thoughtless individuals, is much practised by the residents of Virginia, North Carolina, and other Southern and Western States, where these birds are very abundant. It is called driving, or netting. This method is so minutely and correctly described by Audubon, in his valuable work on Ornithology, that we will quote his own words on the subject:-

"A number of persons on horseback, provided with a net, set out in search of partridges, riding along the fences or thickets which the birds are known to frequent. One or two of the party whistle in imitation of the call-note, and, as partridges are plentiful, the call is soon answered by a covey, when the sportsmen immediately proceed to ascertain their position and number, seldom considering it worth while to set the net where there are only a few birds. They approach in a careless manner, talking and laughing, as if merely passing by. When the birds are discovered, one of the party gallops in a circuitous manner, gets in adrance of the rest by a hundred yards or more, according to the situation of the birds and their disposition to run, while the rest of the sportsmen 
move about on their horses, talking to each other, but at the same time watching every motion of the covey. The person in advance, being provided with the net, dismounts, and at once falls to placing it so that his companions can easily drive the partridges into it. No sooner is the machine ready than the net-bearer remounts and rejoins the party. The sportsmen now separate to a short distance, and follow the partridges, talking and whistling, clapping the hands, or knocking the fence-rails. The birds move with great gentleness, following each other, and are kept in the right direction by the sportsmen. The leading bird approaches and enters the mouth of the net; the others follow in succession, when the net-bearer leaps from his horse, runs up and secures the entrance, and soon despatches the birds. In this manner fifteen or trenty partridges are caught at one driving, and sometimes many hundreds in the course of a day. Most netters give liberty to one pair out of each covey, that the breed may be continued. The success of driving depends much on the state of the weather. Drizzling rain or melting snow is the best; for in such weather partridges, and gallinaccous birds in general, run to a great distance rather than fly; whereas, if the weather be dry and clear, they generally take to the wing the moment they discover an intruder, or squat so that they cannot be driven without very particular care. Again, when the coveys are found in the woods, they run off so briskly and so far that it is difficult for the netbearer to place his machine in time.

"The net is cylindrical, thirty or forty feet in length by about two in diameter, excepting at the moutl or entrance, where it is rather larger, and at the extremity, where it assumes the form of a bag. It is kept open by means of small mooden hoops, at a distance of two or three feet from each other. The mouth is furnished with a semicircular hoop sharpened at both ends, which are driven into the ground, thus affording an easy entrance to the birds Two pieces of netting, called wings, of the same length as the cylindrical one, are placed one on each side of the mouth, so as to form an obtuse angle with each other, and are suypnited by 
sticks thrust into the ground, the wings having the appearance of two low fences leading to a gate. The whole is made of light and strong materials."

This account coincides exactly with the description giren us of this sport by several gentlemen residing in the South. Care should be taken, however, to liberate a pair or so of birds from each covey, so as to insure a continuation of that abundance which furnishes such a profuse and epicurean delicacy for the table.

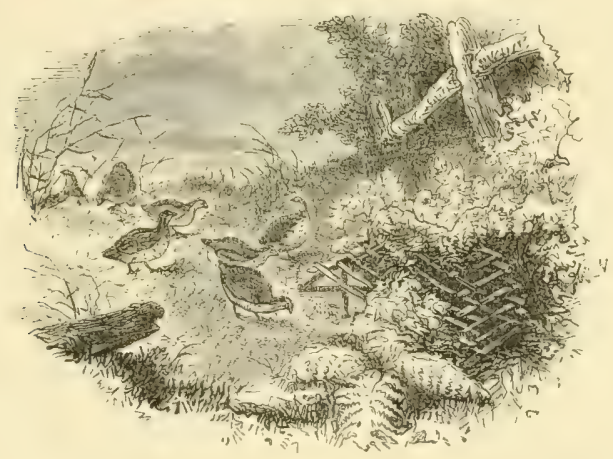

INTRODUCTION INTO ENGLAND.

Frequent attempts have been made to introduce the American partridge into England; but these efforts have, we believe, gene rally proved abortive, from the circumstance of our birds being so very pugnacious that they destroyed or drove off the English variety, which is a much larger bird, and considered finer eating in that country;-chacun à son goût.

\section{ACTIONS OF OLD AND YOUNG BIRDS.}

There is a great difference between the actions of old birds ana a covey of young ones. The former are up to all kinds of tricks, while the latter soon become confused and unable to avail themselves of any manouving whatever to save themselves from the persecutions of the dog and sportsman. The young birds, if not 
made wild by previous hunting, lie well to the dogs and make but short flights, and are consequently soon come up with again, and, being scattered about in close proximity, can be picked off one by one, without much trouble to the shooter. The old birds, on the other hand, when hunted, often lie badly, are extremely cautious, and run away from before the $\operatorname{dog}$ as soon as they observe his approach; and when they spring they take immediately to the thick cripples or disappear over the tops of the highest woods. An old bird, when shot, will often carry off several pellets of lead with him, if not struck in some vital part, and even with a broken wing will frequently escape the pursuit of both huntsman and dog.

\section{BEST TO BREAK DOGS ON.}

The partridge, most unquestionably, is the finest bird we have to break our dogs on; and, being once broken to this kind of shooting, they can soon be taught to seek for any other kind of game, such as woodcocks, snipes, or grouse. In hunting these birds, the dog learns a degree of boldness as well as care that cannot be acquired on any other kind of game, as none feed so widely, or leave so long a trail of scent behind them, which the dog winds a considerable distance off, and thus learns caution, ease, and delicacy in approaching his victims, knowing full well, from sad experience, the chastisement that would follow any heedlessness or undue precipitation on his part; but rather

\section{"Against the wind he takes his prudent way,} While the strong gale directs him to the prey; Now the warm scent assures the covey near: He treads with caution, and he points with fear."

GAY : Rural Sports.

\section{COVEYS THAT WILL NOT LIE.}

It is seldom attended with much success to follow after coveys that will not lie close, but are continually rising and flying straight away at the least alarm. Such birds are sure to be either a travelling party, or they have already been shot at a great deal too much to afford any sport. The only likely way of getting a shot at 
them would be to circle entirely around them, and then the chances are much against your being able to close on them before they again take wing.

RETAINING SCENT.

It has frequently been observed by every sportsman that the very best of dogs, at times, cannot find partridges, eren when marked down in the most open ground and are known to be secreted immediately around the spot where the dogs are put to hunt. This fact has been a mystery for years to some sportsmen, and many a valuable dog has been grossly and unjustly censured for his want of nose in not finding the birds under these circumstances. This seeming deficiency, however, in the olfactory organs of our canine favorite, is now easily accounted for by the presumed existence of a singular provision of nature, which endows the American partridge with the extraordinary faculty of withholding, for a time, the emanation from its body of that peculiarly strong odor that betrays its proximity to the dog. This phenomenon was very particularly inquired into, some years since, by $\mathrm{Dr}_{1}$. Smith, of Baltimore; and the results of his inquiries were published, at that time, in the form of a letter to Mr. Skinner, which interesting communication we take pleasure in bringing again to the notice of sportsmen by its insertion in these pages. We are constrained to do this from the conviction that nothing has been written, since its publication, that further elucidates this subject; and, if we rere to attempt to give our own views and observations upon the phenomenon, it could not be done in a more practical and satisfactory manner than Dr. Smith has accomplished it; and we therefore give place to its insertion with all pleasure:-

Mr. EdrTon:-A close scrutiny of every subject in natural history discloses some marvellous power given to inferior creatures for their preservation from the hostility of man and his various and numerous agents. It is surprising how many striking facts are forced upon us for contemplation before any doctrine is 
thoroughly admitted as truth. How long, for instance, has it been observed, and with regret, by sportsmen, that the best dogrs could not discover certain birds of value, such as partridges, in places where they were seen to settle themselves! and yet years have rolled away without a single individual advancing the only rational idea of the proper cause. The truth never reached them that these persecuted little creatures had been granted the power of withholding odor, to preserve them from their ruthless destroyers. Noble dogs have been censured as wanting or careless, when the often-repeated fact, in almost every day's hunt, made it manifest that the fault did not lie with them. Many years ago I noticed this fact, and after frequent and earnest observation I adopted the conclusion already given.

I will state some of my observations and experiments. Precise dates are of no consequence, as the facts are general, and open to the study of all who are interested. It is now twenty years since I was one day in company with my friend and companion, the late learned ornithologist, Alexander Wilson, assisting him in his endeavors after the birds of this country. We encountered a well-appointed party of gentlemen, who were shooting partridges. They had seven dogs, apparently of the best quality. They were in a large stubble-field, having small patches of low bushes and briers in several places. From one of these was flushed a very large covey of partridges, which, after having been rigorously fired upon, settled nearly in the centre of the field, in a place slightly depressed, where the stubble was unusually high, with rank clover underneath. The sportsmen pursued with due caution, giving the proper instructions and ample time to the dogs. Some of the birds were put up and killed, but not near as many as had taken refuge there. After considerable search, the party left the ground. Why so few of the birds were roused puzzled me exceedingly, and $I$, in common with every one, censured the dogs. Immediately adjacent to the stubble was a body of open woodland, in which Mr. Wilson was several hours engaged in his usual ardent study into the habits and manners of a number of small birds sporting 
in it. On our return home, we crossed the stubble directly past the spot where the partridges had been hunted by the sportsmen. As we approached it, a bird flew up, and soon after another, and another, until five went off. I expressed my surprise to Mr. Wilson, who dismissed the matter by supposing that the stronger scent from the feet of so many men had transcended that of the birds and bewildered the dogs. Having been an anxious witness to the whole scene, I was not satisfied with this explanation, but believed the dogs to have been in fault. After the lapse of a few years, I became exceedingly given to field sports, and was in possession of several fine dogs. It often happened that many dogs could not find partridges, even when I had marked them settle and conducted them to it, especially when the cover was of thick and matted grass. In 1821, I obtained a pup of high pedigree, and took the charge of his education upon myself. No animal of his kind ever surpassed him, but even with him I was often unable to flush a scared partridge. I now first admitted the idea that these birds were endued with the occasional power of holding that efluvium which exposed them to their direst enemy. My remarks were general, but tended to strengthen the opinion I had adopted. For instance, I excursed very many times with large parties, where they might be said to be a pack of dogs from their numbers, and most of them approved hunters. Often have I seen, in large clearings, five or six coveys of partridges flushed, amounting probably to a hundred birds, and, although scarcely a brace of them would leave the open grounds, not more than a fifth part of them could be recovered. 'The sportsmen did not seem to think of their failure, and no one would disparage the truth of the charming Venuses, Junos, Dianas, and Coras, so sedulously engaged for his amusement. After such a field, I have made it a practice to return alone to it after the lapse of sufficient time, and I always found that the birds had not left it, but that, having resumed their natural or usual habits, were easily flushed. In October, 1824, I became assured of the truth of my doctrine. I was then, in company with five gentlemen, in a fine partridge country. We 
had eleven dogs (setters and pointers) of approved value. The party concluded to range a field or two before breakfast; but I did not go out with them. I soon heard rapid firing in a new cleared ground in sight of the tavern-house. I hurried to join them. There was a small meadow-land and a little brook intervening between us. On the margin of this meadow stood a large pine stump, covered with running-dewberry vines, and surrounded by small oak-shrubs. I was within sixty yards of it, and parallel to it, when two partridges came directly towards me, across the meadow. Having but one barrel charged, I fired upon the nearest bird, and killed it. The other made a sudden dart from its line, and took refuge among the shrubs and briers about the stump. I had my favorite dog and a very valuable pointer-bitch with me. Having recharged, I approached in guard upon the marked bird; but the dogs gave no point. This was the proper time to test my belief; I therefore called off the dogs, and waited till I could have every one on the ground brought to the spot. This was done; but there was no intimation given that there was a bird near us. We left the ground without remark or explanation, and retired to breakfast. In an hour we took the field for the day. I requested the gentlemen to indulge me again by an advance upon the stump, leading the van myself with the pointer-bitch. She instantly pointed, and the other dogs backed her. The bird was flushed and shot. I now explained myself fully, and Mr. Edward Tilghman, well known to most American sportsmen, was greatly struck with it. He expressed great pleasure too at it, as he said it would save many valuable animals from unmerited censure. He told me, moreover, that he had more than once noticed the same fact with pheasants and grouse. I think it highly probable that these birds are endowed with the same power; but I have not had sufficient experience to speak of them with any certainty. Last week, on one of our steamboats, Colonel S. B. Davis, formerly of the United States army, a great sportsman in his day, asked me, without any. previous conversation on the subject, why the best dogs could not sometimes find a single partridge in open ground. The fact was 
forsed upon him, but he had no thought of the solution here advanced.

Yours, respectfully, Samuel B. Sirth, M.D.

Although this communication occupies some space in our work, we are satisfied that every one will feel pleased with its perusal, as it presents a plain unvarnished relation of facts that admit of no doubting or misunderstanding. So far as our experience has enabled us to judge of this matter, we are inclined to coincide with Doctor Smith in his original notions on the subject; and we also might enumerate many instances of like nature with those advanced by him, and as fully corroborative of what he wishes to establish. But, having already devoted much space to the subject, we must pass on to other less obscure points in the habits of this bird.

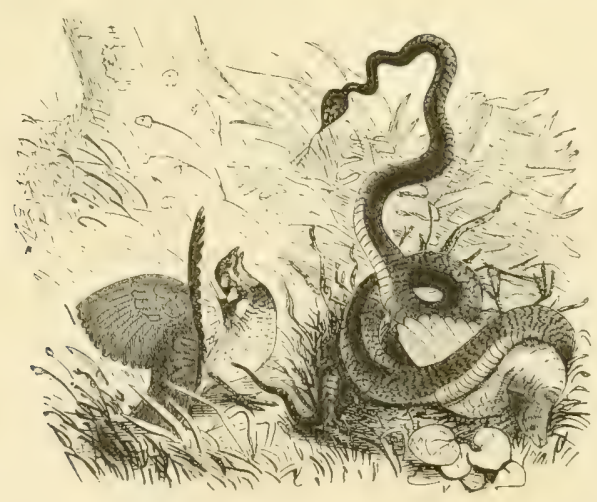

ENEMIES OF THE PARTRIDGE.

Man is not the only enemy that partridges have to fear, as there are several animals-such as the fox, raccoon, weasel, polecat, serpent, hawk, crow, \&c.- that not only, when pressed for food in the winter season, destroy the old birds, but also devour great quantities of the young, and consume numberless eggs during the period of incubation.

Among the foes of their own species there are none more 
destructive than the sparrowhawk, pigeonhawk, and goshawk, who follow after and destroy great numbers of them early in the autumn, when they are comparatively weak and unwary and not sufficiently alert to elude their grasp by rapid flight to the thick coverts. The pigeon-hawk, being much larger and stronger than the former, does not hesitate, on a favorable occasion, to dart down and carry off the oldest and strongest birds. Nothing terrifies a covey so much, when feeding in the open country, as the appearance of this formidable marauder. Skimming along the tops of the stubblefields, so near to the ground as scarcely to be discovered, he comes stealthily upon his unconscious victims, and fastens his deadly talons in their very vitals, bearing them off screaming to the nearest tree, to satisfy his cruel appetite. The covey, startled at his approach, fly in every direction, secreting themselves in the thickets of brushwood, deep grass, and almost impenetrable cripples. When partridges have been frightened in this way, they take a long time to collect together again, as they dare not give utterance to a single note-call, while dreading the presence of their relentless foe.

We have often come across birds disturbed by this fearless freebooter, and found them extremely wild and shy, not permitting a dog to come within a hundred yards of them. When the winter is severe in the middle and northern latitudes, these hawks, more particularly the goshawks, a larger species, are driven to great extremities for food, as most of the small birds, their usual prey, have left for more congenial climes; and then it is that the formidable goshawk visits the barnyards in search of plunder, and does not hesitate to carry off the largest chickens. It is no uncornmon thing for shooters to see this daring depredator dip down into a covey when within a few yards of his own person; and a gentleman informs me that he has seen them pounce upon and carry off partridges which were brought to the ground a few moments before by the gun, and that, on a certain occasion, he actually shot 'ne when in the very act of making off with a bird which he had serzed the moment it was knocked down at a long shot. 
The goshawk also destroys immense numbers of passengerpigeons, as well as the different varieties of ducks, such as mallards, teal, black-duck, \&c. Audubon mentions having seen this hawk strike and carry off all these fowl, and we imagine that alnost every sportsman must be familiar with their extreme boldness and daring. After seizing mallards, they turn them belly upwards and eat the flesh off their breasts, disdaining all other less tender and juicy parts of the body when food is so plentiful.

The sparrowhawk is also a most outrageous poacher upon all kinds of birds, and, being extremely dainty in his taste and habits, we doubt not that he also destroys numbers of young partridges, if not the old ones. We have over and over again witnessed him in the act of carrying off smaller birds.

Sportsmen should never fail to kill these birds of prey whenever met with, as they answer no particular good purpose, and often materially interfere with their recreations. It is no uncommon thing for a hawk, in severe weather, to linger about the haunts of a covey of birds for several days together, picking off one or two whenever a suitable opportunity presents, until the whole covey is destroyed.

\section{PREDICTIONS REGARDING GAME.}

An observant sportsman will, or rather should, be able to predict, with some degree of certainty, the probable abundance or scarcity of game, according to the mildness or severity of the previous winter, the dryness or wetness of the spring, and the many other concomitant circumstances which influence the habits of game-birds in different localities.

\section{HAUNTS OF PARTRIDGES.}

If the day be fine and clear, the birds will be found on the wing at a very early hour; if, on the other hand, it be wet and cold, they seem very loath to leave their roosting-places, delaying their flights as long as possible, even until the day is fur advanced. And if rain should set in, they will most generally desert the 
open fields entirely, and take to the woods and thickets for protection.

\footnotetext{
"Or when the country floats with sudden rains, Or driving mists deface the moistened plains, In vain his toils the unskilful fowler tries, While in thick woods the feeding partritge lies."
}

If the weather has been dry and warm for several days previous to going out, it will be perfect folly to hunt on the hills where there is a scarcity of water. And, in like manner, if the season has been wet, it will be equally irrational to wade through the low grounds, as these birds neither affect very dry situations nor wet localities, but, on the contrary, prefer rich stubble-fields in the immediate vicinity of a clear running stream, to which they love to resort to quench their thirst after the morning's feeding, and preen themselves for a while in the noonday sun. If the weather be boisterous and windy, without rain, partridges may most frequently be found on the edge of close cover, or on the sides of rising ground, where they betake themselves for shelter. On such days they will lie very badly, and will not suffer the approach of a dog, although a quiet old pointer will occasionally get right on top of a covey, owing to the wind carrying all noise off from the birds, provided he hunts up wind, as all dogs should be taught to do.

If, besides being stormy, a drizzling, drenching rain should set in, we would advise the sportsman to withdraw at once from the field, and wait patiently until the elements prove more propitious; otherwise, he will not only run the risk of an attack of rheumatism, but also of ill-humor, while his dogs will soon become jaded and his game-bag continue empty. It is of no use to kick against the pricks, neither is it of any avail to get out of temper and make fight with the elements, as rain it will in spite of all our scolding and bad-humor; and it will be much better to hold ourselves perfectly resigned to the will of the Fates, and endeavor to preserve our minds unruffled by conning over to some good and patient listener the numerous wonderful achievements of our gun and dog in former days. If, however, you are of a taciturn dispo. 
sition, and take no delight in these interesting and often romantic recitals, what shall we advise you to do to pass the time when, perhaps, quartered away in some dreary, sequestered spot, out of the reach of books, newspapers, or any thing else whereby to satisfy an inquiring and active mind? Ah! we have it. Call for the family Bible; for where can you find a household, in our favored country, that does not possess one of these time-worn testimonials of bygone days? Turn to the register of births, deaths, and marriages, and you will soon find yourself lost in deciphering the lieroglyphics of these important family records, and perhaps thus while away an hour or two in studying some long genealogical table, gravely proving that the ancient founder of the American Smith family first landed at Plymouth with the pilgrims from the old World, and afterwards emigrated to these parts, where he built a log-cabin on the identical spot now covered by the house you are in, and which still, even to this day, continues in the possession of the lineal descendants of the said Smith family. What a discovery! Before fully awakening from your surprise, the rain, perhaps, will have ceased, the sun broken forth, and you can again joyfully sally forth to the fields. If this, perchance, will not engage your attention, draw a chair up to the hickory fire that blazes and crackles at your feet, plant your broad back against the chimney, look sullen, kick the dogs, and go to sleep as soon as possible. Or, if it suits you better, walk up and down the room for an hour at a time, making the whole house shake and tremble with your heavy tread, scolding, and staring out of the windows every few moments, to see if the lowering clouds are blowing away, or to halloo after the hostler or farm-hands, whenever you espy them about the premises, demanding their opinion as to the state of the weather, which, nine times out of ten, will be very cheering:- -such, for example, as, "Well, I can't say, sair; it looks pretty black out in this 'ere direction." "Indeed, it's very hard to tell, sair; but it sometimes clears up when the wind shifts around to that 'ere quarter;" pointing to the west, and the wind still blowing a perfect gale from the east. 


\section{GOOD WEATHER.}

In fair weather, partridges will be found out in the stubble, clover, or corn-fields, near to a hedge or some other cover. If a buckwheat-patch be in the neighborhood, it must of course be visited; for if there be any birds in those parts, they will most likely be about this field in preference to all others. As we have stated before, they are very partial to this kind of grain. Partridges generally feed until eleven or twelve o'clock, and are then either quiescent for an hour or two, or resort to some favorite watering-place or gravelly bank, where they scratch and pick themselves while basking in the sun. We have often found them, at this time, on the sunny side of the trunk of a fallen tree, in a fresh clearing, and always make it a point to hunt around all such places, more particularly if a purling stream should be in the vicinity.

\section{HINTS FOR THE SPORTSMAN.}

It behooves the shooter at this hour of the day to desist for a while from his labors, and refresh himself as well as his dogs with a little quiet and a small snack of something to eat and drink. He need not be fearful of wasting time by this trifling suspension of his sport, as both hinself and dogs will hunt with more vigor and energy after this truce, and the birds will have had time to collect together their scattered forces, ready for another onset, provided he should retrace his steps over the morning's grounds. Fresh birds will also have left their watering-places, and be busily occupied in the stubble-fields feeding. A selfish disposition is to be despised in any one; but when it occupies a large space in the heart of a sporting character, it is more frequently and disgustingly displayed than in any other person: at least, such is our opinion of the matter; and when a shooter has such a wild furor for killing birds that he cannot remain quiet for half an hour during this period of the day, or suffer his faithful dogs to snatch a few moments of respite from their arduous duties, but, on the contrary, 
considers such an intermission of his sport as an actual loss of time, we are forced to class him with that unenviable race of beings known as pot-hunters, or, at all events, but one degree above them, and, of course, mean and narrow-minded in the extreme.

"Some greedy elves-

Pot-hunters vile!-appear to grieve

If forced a single bird to leave.

Such men avoid, and be your pride

With those that soon are satisfied."

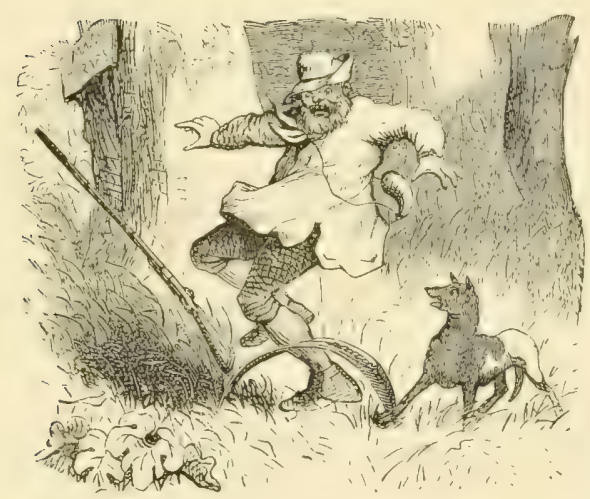

EARLY DAWN.

Before leaving their roosts in the morning, partridges appear to welcome the return of a new day, and to congratulate themselves on the general safety of the family circle, by a low, shrill, twittering noise, somewhat resembling the sounds produced by young turkeys, or perhaps more cheerful and harmonious than that often heard issuing from a covey when in the act of springing, if disturbed while feeding in an open field. These mutual greetings at an end, the covey take their flight to some favorite feeding-ground, most generally the adjoining field, or perhaps run off in quest of food immediately around them; but they are not very apt to ronst in the same field where they habitually feed.

The reason why partridges seldom or never roost in the same field where they feed is perhaps owing to a natural instinctive pre- 
caution which they possess; that is, the dread they have of leaving a trail behind them by which they could be traced or scented nut by some one of their numerous enemies during the night, and suddenly pounced upon either by the prowling fox, raccoon, polecat, or any other nocturnal animal common to the districts of country which they frequent. To prevent this trail being left behind them, which would necessarily be the case if they ran to roost, they very cumningly take a short flight to an adjoining field, and settle down for the night immediately about the spot where they alight. By this device they entirely free themselves of the treacherous trail which otherwise would follow them to their unprotected retreat.

SNOW.

If it should snow, the birds keep close huddled together under some brushwood, in the deep sedge, or in the corners of what are called snake or worm-fences. They never go about during a snowstorm, and consequently are often covered completely up by a deep fall, and find great difficulty in freeing themselves from their cheerless prison when the tempest has abated. When the weather threatens to be severe and the snow very deep, in the interior of the Atlantic States, partridges betake themselves to the neighborhood of the sea-shore, where it is usually milder, and the snow but seldom lies over a day or two. There is also generally a great abundance of thick sedge in such localities, in the depths of which they find shelter and plenty of food. In the autumn of 1845 we met with great numbers of partridges in the sedge on the sea-shore, and witnessed some excellent shooting by a companion, a memorandum of which we published at the time in the Spirit, and now avail ourselves of this opportunity to transfer it to these pages.

\section{PARTRIDGE SHOOTING IN DELAWARE.}

Eriday, Nov. 28-Fair, but blowing a gale; bagged....................... 42

Saturday, Nov. 29-Good day, but over the same ground................. 33

Cuesday, Dec. 2-Blowing a stiff breeze, and over the same ground, with

little variation.................................................. 35

Total........................................................ 110

Or, within a fraction of 37 birds per diem. 
Nearly if not every bird was killed singly, as we were particularly unfortunate in shooting into coveys, never having bagged over two at any one time; but most generally we tipped the first two that rose when flushed.

Since writing the above account for the Spirit, we have heard of some shooting that far exceeded this count in the number of the slain; but we doubt very much whether the shooting in itself was beaten, for, taking the state of the weather, the quantity of birds, and all other attendant circumstances, into consideration, we think there are very few of our crack shots that could have done as well, and many we are sure would not have accomplished as much. The best shooting, however, or rather the biggest shooting, on partridges, that we have yet heard of, is that of three gentlemen living in the neighborhood of Lynchburg, Virginia, who bagged over one hundred partridges each during one day's shooting. This season of 1851 and 1852, partridges have been unusually plenty, more particularly along the large watercourses, owing to several circumstances, all of which an observant sportsman will readily understand.*

Firstly. The previous winter having been remarkably mild and open, few or no birds were destroyed by exposure to cold; neither were they driven by the scarcity of food into the deceptire traps or still more cruel tunnel-nets.

* Game Abundant. - We learn from the Upper Mississippi country, that the prairies in the vicinity of Keokuk and Rock Island are teeming with partridges in unheard-of abundance. Large numbers are now brought from those places to the New Orleans market. A few days since we noticed, on board of a steamboat, coops containing one hundred and forty dozen of these birds. Also, the steamer Saranak, on her last trip down, brought one hundred dozen. A gentleman informs us, that a party with nets left Keokuk lately, and repaired to the island below that town. They took four hundred birds in a single afternoon. Partridges sell in this market at from 75 cents to $\$ 1$ per dozen. In Keokuk they can be had at from 40 to 50 cents per dozen.

The St. Louis Evening News also states that large quantities of grouse, partridges, deer, and other game, are daily sent from that place, almost every steamer carrying out as many as it can accommodate. They are shipped to various points on the Ohio, aud in many instances have been sent as far as Baltimore, Philadelphia, and New York. So large has this export been this season, that these articles are now commanding an unusually high rate at St. Louis. 
Secondly. The following spring and summer months werc unusually dry, and especially suited for the purposes of hatching and rearing the young brood, which often suffer so lamentably from the effects of a long-continued wet spell, as we have before remarked under a different heading.

Thirdly. The drought having extenderl through the summer and even autumn months, all the smaller streams and inland watercourses became entirely dry; and those sections of country thus failing in water were abandoned en masse by all the birds; and this will account for their location among the hills and stubblefields adjacent to the large river-courses. We met this season with great numbers of partridges on the large and beautifully-cultivated islands of the Susquehanna, but found it rather difficult to shoot them, in consequence of the birds on the first alarm darting along and under the high river-banks, where they conceal themselves so securely that it is quite impossible to drive them out. Our friend C. T. Phillips, Esq., killed this season sixty-one birds in one day, which of itself is sufficient to prove how numerous they must have been; - not wishing, however, by this remark, to detract in the least from our friend's skill in shooting; for every one who has been out with him in the field knows that he is one of the very best shots that goes forth from our city; but in ordinary seasons it is not very often that the most industrious and persevering sportsman will get sixty-one shots in a day, much less bag so many birds.

One of Mr. Skinner's correspondents, detailing some of the particulars of a day's shooting, states that his companion fired forty-three times, killed thirty-eight, and wounded four, only missing clearly once; and, what is most remarkable of all, this accomplished sportsman, with a double-barrelled flint gun, whirled and fired five times with hoth barrels, in different directions, lilled nine times, and wounded the tenth. This we consider the best record of shooting that has as yet come to our knowledge; and we agree with the chronicler of these worthy deeds that it required "a ready hand and a quick eye" to accomplish it, when we recol- 
lect, as before observed, that the American partridge, sans doute, is the most difficult of all game-birds to be brought down. This, too, is the opinion of Frank Forrester, and all others equally competent to judge.

A friend of the author's, a genuine sportsman, at our particular request very kindly furnished us with a leaf from, his shooting. register for the year 1854, which exhibits the following results:-

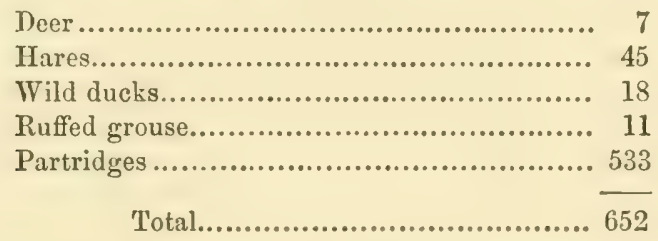

All of the above were bagged within the limits of Pennsylvania except the deer, which were killed in the State of New York during one hunt, circumstances having prevented any other expeditions.

Provided with one dog only, and in the same neighborhood-in fact, almost over the same ground each day, this accomplished sportsman brought to bag as follows:-

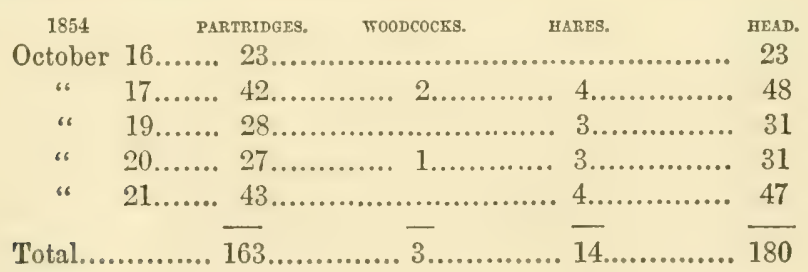

\section{THE FIELD.}

"See how the well-taught setter leads the way:

The scent grows warm. He stops; he springs the prey, The fluttering coveys from the stubble rise, And on swift wing divide the sounding skies. The scattering lead pursues the certain sight; And death, in thunder, overtakes their flight."

It is now quite time that we should proceed to the field, which we will endeavor to do with all possible despatch, accompanied by all the paraphernalia necessary for the legitimate and sportsmanlike 
way of bagging game, and properly equipped, or rather suitably dressed, as every gentleman should be under all circumstances, whether in the ballroom, encompassed on every side by a gay throng of sparkling eyes, not less fatal in their glances oftentimes than the reeking shot that is sent whirling from his unerring gun, or in the wide-extended stubble-field, surrounded by his faithful setters, stanch pointers, crafty marksman, and jovial companions. The uncleared state of our country, and a comfortable scarcity of game in the Middle States, render it necessary to have two dogs; at all events, it is much better to have them, and, from our experience, we are led to recommend one to be a pointer and the other a setter. The weather in the early part of the season is often very warm and dry; and the setter, if overworked, will most assuredly give out if not lavishly supplied with water, which, bythe-by, it is often impossible to obtain in some districts of country; while the pointer, on the other hand, will suffer very little or no inconvenience either from the heat or thirst. The setter, however, is peculiarly serviceable at this period of the season: being well protected by his long shaggy hair, he does not for a moment hesitate to penetrate the closest coverts, to which the birds are so apt to take when disturbed. It is quite impossible for the smoothhaired, wiry pointer to insinuate himself into these brakes or fastnesses; and if, in his eagerness to keep up with his companion, he is forced into such places, he always retires from them with his body and tail dreadfully lacerated by the thorns and briers that are now flourishing so thick and rank.

Having provided ourselves with dogs and all necessary ammunition, we will now imagine that we have arrived, at a late hour in the afternoon, at the tavern or farm-house from which we purpose to sally the next morning in pursuit of game. The first thing to be attended to by every sensible sportsman is the welfare of his dogs, as most of his enjoyment depends upon their exertions, and therefore no trouble on his part should be spared to keep them in proper condition. The dogs being well fed and comfortably boused, the sportsman may then think of his own comfort. We 
never trust any one to feed our dogs, no matter how fatigued wo may be, but make it a positive rule, from which there is no appeal, to attend to this duty ourselves, and most generally superintend the cooking of their suppers as well as sharing it out to them when done; for where can we find an ignorant country-servant or farm-hand willing to bestow the necessary attention upon the preparation and serving-up of food for an over-fatigued and perhaps delicate pointer? Besides all this, there is another reason, equally important, why the sportsman should feed his dogs himself: it attaches the animals to him, and consequently makes them the more subservient to his will, and therefore the more anxious to do that which will merit his caresses and kind treatment. This is really far more important than many careless owners of dogs suppose; it is a feature in sporting that should not be overlooked, and we wish particularly to call the attention of our friends to its operation. For, after all, the pleasures resulting from the field are almost entirely dependent upon the good and gentle behavior of our dogs; for without their exhilarating presence and cheerful assistance, the hunting of most game would be not only very tame, but very uncertain amusement.

Having partaken of our supper, smoked our regalia, and sipped perhaps a glass of warm punch,- - but only one, and that very light,we retire to our own room at an early hour, unpack our carpet-bag, and arrange all the shooting-apparatus ready for the morrow's expedition. This being done, we go to bed, sleep soundly, and get up at the first dawn of day, big with expectations and ready for action. Every thing being arranged over-night, we find all the shooting-accoutrements at our very finger-ends, and consequently are enabled to dress very leisurely, without bustle or confusion. Breakfast being despatched,-which, by-the-by, should be a very substantial repast, - we call our dogs around us, give them a light feed without flesh, and then, with a chosen companion, away to the fields,

"Soon as the eastern skies display

The rosy tints of welcome day." 
Do not be in too great a hurry for the first half hour. Go along leisurely, and give the dogs an opportunity to empty themselves, clear their nostrils, and tune their olfactory apparatus to a fine degree of nicety by snuffing the untainted morning breeze.

It is always better to engage the services of a person to act as marker. He can also carry on his arm a small basket containing extra ammunition and a few nicely-prepared sandwic., for luncheon.

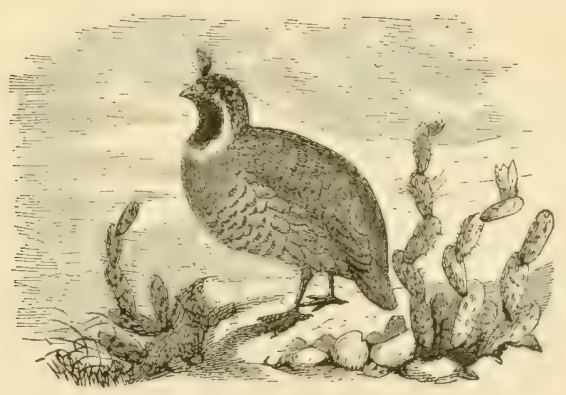

MODE OF HUNTING DOGS.

Having already given a very minute and detailed account of the partridge, as well as carried the sportsman into the field and conducted him to the spots where he would most likely find the game, it now remains for us to talk with him upon a subject of the utmost importance,-namely, "the proper manner in which to hunt his dogs."

In the first place, let me warn you against venturing into the field for a day's hunt with half-broken dogs, more especially if ir. company, as you will only worry yourself and annoy your friends; but rather stay at home, or go alone attended by such torments. If you go in company, you will not be able to teach them any thing, owing to the ill-temper either of yourself or friends; whereas, on the other hand, if you go alone, you will soon break them in, after a few disappointments, and perhaps have a fine day's shooting. An old stanch pointer is the best field mentor for 
young dugs,-far preferable to a setter, no matter how superior he may be, as the pointer makes a far more honest and unmistakable stand than the setter, and at all times is more certain in his behavior.

Young and heedless dogs at all times are great pests in the field, and we are often led to suppose that they ought to be broken thoroughly before taken out; at all events, they should be under perfect control, so far as coming and going, before we force them into the company of our friends' dogs to run and caper over the fields, flushing and tearing after the birds, perfectly reckless of the consequences. However, we have not much fear of a well-bred dog, while under our tuition, disturbing the sport of our friends while in the field, after we have once made him understand the gross impropriety of running after birds; for we are satisfied that few or none will ever repeat the offence a second or third time after they have escaped from our perhaps cruel hands. If they do, we are willing to pass them over to the keeping of some one else far more patient and tender than we pretend to be with obstinate and reckless animals.

Good dogs should be procured by provident sportsmen before the shooting season comes around; they can be had far cheaper at such times, will become familiar with their new master, and learn to understand his every look and gesture. Always purchase young dogs in preference to old ones, even if they should not be so well broken. Old dogs are contrary, or rather self-willed, and if they have perchance any vices, they are difficult to be got rid off. Young dogs are far more pliable, and if intelligent will soon accommodate themselves to your peculiar habits and modes of hunting, and, what is very important, will not require replacing as soon as old dogs. You should not expect the dog to study your character alone, but recollect that it is equally the duty of the master to strive to understand the disposition and temper of his faithful coadjutor. If timid and wanting in confidence, he must be cheered rather than reproved; if bold and full of action, he must be restrained within proper bounds; if negligent of commands and regardless of 
instruction, he must be flogged, and that soundly, till brought to a proper appreciation of your supreme authority.

Some dogs, as individuals, require far more correction than others; the lash, consequently, should be employed with a tempered hand; no dog ought to be punished except he is made perfectly sensible of his misconduct, and, being once fully apprised of his improprieties, should never, through negligence or sickly sympathy, be allowed to escape the most condign and immediate chastisement.

The fear of punishment at the hands of man has a wonderful influence over the actions of all animals; but over none is this controlling power more forcibly exercised than in the canine race. The castigation, to-be-sure, may oftentimes be of the lightest character-an angry look, a liarsh word, or a single blow; still, the faithful creature feels it all, and that very acutely, and by his meek submission expresses repentance, and by his servile crouching acknowledges the utter helplessness of his position.

It were quite unnecessary for me to tell the sensible sportsman never to kick or strike a dog with a heavy bludgeon; but we fear lest there may be some of our readers who have not properly thought over this matter, as we have occasionally witnessed scenes in the field that have fairly thrilled us with horror. A reckless, headstrong dog, we grant, is quite enough to try the temper of the most self-governed man in the world, but nevertheless should not be quite sufficient to cause him to kick him in anger or shoot him in desperation and rage. If we cannot control our own actions by the aid of education and our reasoning faculties, how should we expect a dumb brute to do it, who has had so much less tutoring and possesses but a tittle of the intellectual strength bestowed on us!

The natural instinct or bent of inclination is, we all know, very powerfully coercive in its operations over the actions of the brute creation: how difficult then must it ever be for a high-strung, fullblooded dog to suppress the spontaneous impulse that urges him to spring upon game when under his very nose, or race after it when 
on the wing. The act of pointing game, it must be recollected, is not a truly automatic instinct of the animal, as many suppose, but the beautiful result of discipline and long training in one special branch. The habit, however, has now become so confirmed, through this persevering education on the part of sportsmen, that each generation of pointers, more particularly those of pure breeds, seem to possess an involuntary desire to practise those actions that have been inculcated by the lash in their forefathers.

Many breeds of pointers have this faculty of standing game so early and powerfully developed that it is analogous to second nature; for we often see whole litters of pups stop so instinctively at the first scent of game, that they point the moment they come upon partridges, without the least tutoring, and without knowing the why or the wherefore.

There may be, however, more instinct in this practice of pointing than we are at first willing to suppose, as we know that most predatory animals either lie in wait for prey or creep crouchingly towards it for the purpose of surprise. In the pointer, therefore, the habit may be somewhat instinctive in itself; but, as now perfected and propagated in the whole breed, is the result, as before stated, of nice education. It is better in throwing the dogs off to give them the wind, which they afterwards will be very apt to keep, if taught to quarter their ground properly. Dogs should be spoken to as little as possible in the field, and as much should be accomplished by signal as can be; the eye and the hand should do far more than the voice. If well broken, they may be allowed to range pretty widely, so that they remain in sight. Young dogs must always be within hearing; otherwise they commit some gross errors without being reprimanded at the proper moment. When the dogs come to a stand, approach as noiselessly as possible, and, if the grass be deep, lift the feet high and tread as lightly as you are able; and, if the birds are wild and lie badly, incline the body forward, so as to keep it somewhat out of view. Flush the bird yourself, by advancing, if necessary, even before the dogs, as it is a bad practice to encourage the dogs to do it by hieing them on. 
Young dogs can never stand such training, as they are not able, or at all events, being so very eager, are not willing, to comprehend the wide difference between flushing the game when their master is directly behind them and doing it for their own particular gratificaticn when he is entirely out of gunshot. Old dogs may be hied on occasionally, when circumstances seem to demand it, but young dogs never, except we wish to spoil them and consequently give ourselves a world of trouble in breaking them.

When the game is sprung, do not fire at random into the covey; if you do, you will be sadly disappointed at your want of success. On the contrary, carefully select one bird, on which draw, and then give the other barrel to another, perhaps one of the stragglers last up. Never mind the dead birds; your dogs ought to be able to find them. Watch the covey, if you have no marker, and see exactly where they alight; and follow, if practicable, as soon as your gun is loaded. It is better not to stir from the spot where you are standing till your gun is charged again, as there may have been one or two stragglers left behind when the covey flew. Endeavor at all times to be on the qui vive for such as may be termed chance shots, which will amount to a great deal in the course of a day's shooting.

A dog that will industriously and perseveringly hunt up wounded or dead birds when so ordered, we consider absolutely a sine quâ non in shooting. In truth, a dog that will not assist his master in this important service we would almost consider worthless for partridge-shooting in some particular sections of country. Every dog can be taught this duty without much trouble, although at first it is often necessary to exercise, with young and high-strung animals, considerable patience and perseverance, so as to confine their attention to the particular spot where the game is supposed to have fallen, thus giving them a fair opportunity of catching the scent of the bird if dead, or of getting upon the track of it if only wounded. When a dog, more particularly a well-bred setter, has once acquired a tact and fondness for this particular duty, he is most invaluable to the sportsman, and will save from prolonged 
suffering many a poor bird that would otherwise linger and die from its fatal wounds. Upon the score, then, of humanity alone, we should teach our dogs this important service, and never permit them to abandon a disabled bird till after the most diligent search. We have already spoken on this subject under the head of "killing clean," and cannot too strongly impress these remarks upon the minds of our readers.

Never lose a bird, if possible, which you have once marked down, but hunt the dogs closely about the spot, kicking the stubble or brushwood, if there be any. Do not be in too great a hurry to get over the ground, and by a little patience you will often get many shots which your companion in his anxiety has left behind him. It is by such manœurres that good sportsmen always obtain garne, no matter how scarce it may be.

We doubt not that many of our readers will have observed the habit which partridges have of lying very close till the sportsman has passed by, and then suddenly flirting up, and making off behind lim, before he has time to turn around; therefore, we repeat again, do not be in too much of a hurry. Recollect also that the partridge of America has been pronounced the most difficult of all game-birds to find, or to kill when found, and that frequently they give forth no scent whatever for several minutes after they alight, and consequently will defy the cleverest dogs to point them. Do not, therefore, be discouraged either at your want of success in getting birds up, or your want of skill in bringing them down, on all occasions; but take things coolly, and hunt your dogs patiently, more particularly when the birds have flown to close cover.

It is not always prudent to follow birds immediately into a thick covert overgrow with rank underbrush, as they will give forth a better odor in ten, fifteen, or twenty minutes after settling than they would at first. Some birds, however, run the very moment they have struck cover, and thus may be lost altogether, as they move along pretty briskly when frightened, and after a lapse of fifteen minutes may be a mile off from where they alighted.

Your dogs will naturally, or rather soon learn to hunt along 
the sides of the fields adjoining cover, as partridges do not frequent the middle of the fields except in portions of the country where they are seldom or never hunted after.

When the dog comes to a point, if possible, place yourself between the birds and the cover, and, if practicable, face the wind, as the covey when rising will furnish a much better shot.

Dogs should not be too severely rated for making false points, as the best dogs will do it at times; those that back him, of course must be entirely exonerated. Dogs possessing the very nicest noses are occasionally at fault, and will overrun and flush single birds, more especially in hot, dry weather, and should not be treated too harshly for such mishaps. Much advantage is gained by the mode of approaching your dogs when they have come upon a covey; and every shooter should be able to judge of the position of the birds by the actions of the dog.

English dogs, we are satisfied, from personal observation,-in fact, from actual experiment, for we have imported several,-cannot at first find our partridges with the same facility with which our dogs do; and we might go further, and say there never was an imported dog over the age of two years that ever acquired the art of finding the American partridge equal to our own breed of pointers and setters.

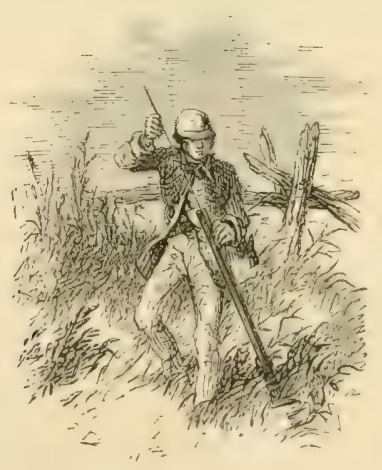




\section{MEMORANDA.}

1. Partridges are not migratory birds, although great numbers show a disposition to shift their quarters at the running season.

2. The American partridge is not a quail, either in habits, appearance, or the flavor of its flesh

3. Partridges commence pairing in March; period of incubation, three weeks. The young are capable of locomotion as soon as freed from the shell, and are able to fly in three or four weeks.

4. Not susceptible of domestication to any great extent.

5. Partridges are granivorous, and said to be very partial to buckwheat.

6. It is not uncommon for them to produce two broods in one season.

7. Young birds have soft bills, and the legs yellowish or bluish, and lack the cunning of the old birds.

8. The English bird is much larger than the American variety.

9. It is of no use to follow running birds, as they will not lie to the dogs.

10. Partridges the best game to break dogs on.

11. Partridges are said to have the power of retaining their scent

12. A dry spring will generally produce plenty of birds the following autumn.

13. If the weather has been wet and boisterous, look to the high ground for birds; if, on the contrary, dry and warm, seek the lowlands.

14. If the morning is fair and clear, the birds will be on the move at an early hour; if wet and cold, they are loath to stir.

15. Take the field at as early an hour as possible. Do not be in too great a hurry to get over the ground; keep cool, and take your time.

16. Dogs should be taught to hunt up wind and quarter their ground without being bellowed at. 
17. Pointers are better adapted for early shooting than setters; but, when the weather is cool, give us the never-flagging, never-tobe-stopped setter.

18. Flush the game yourself; never allow your dogs to do it.

19. Mark the covey as it goes off. Pay no heed to the dead birds; your dogs ought to find them.

20. When a bird towers and falls suddenly, he is struck in the head.

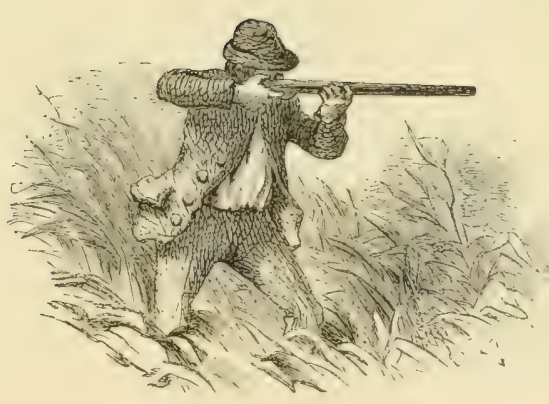




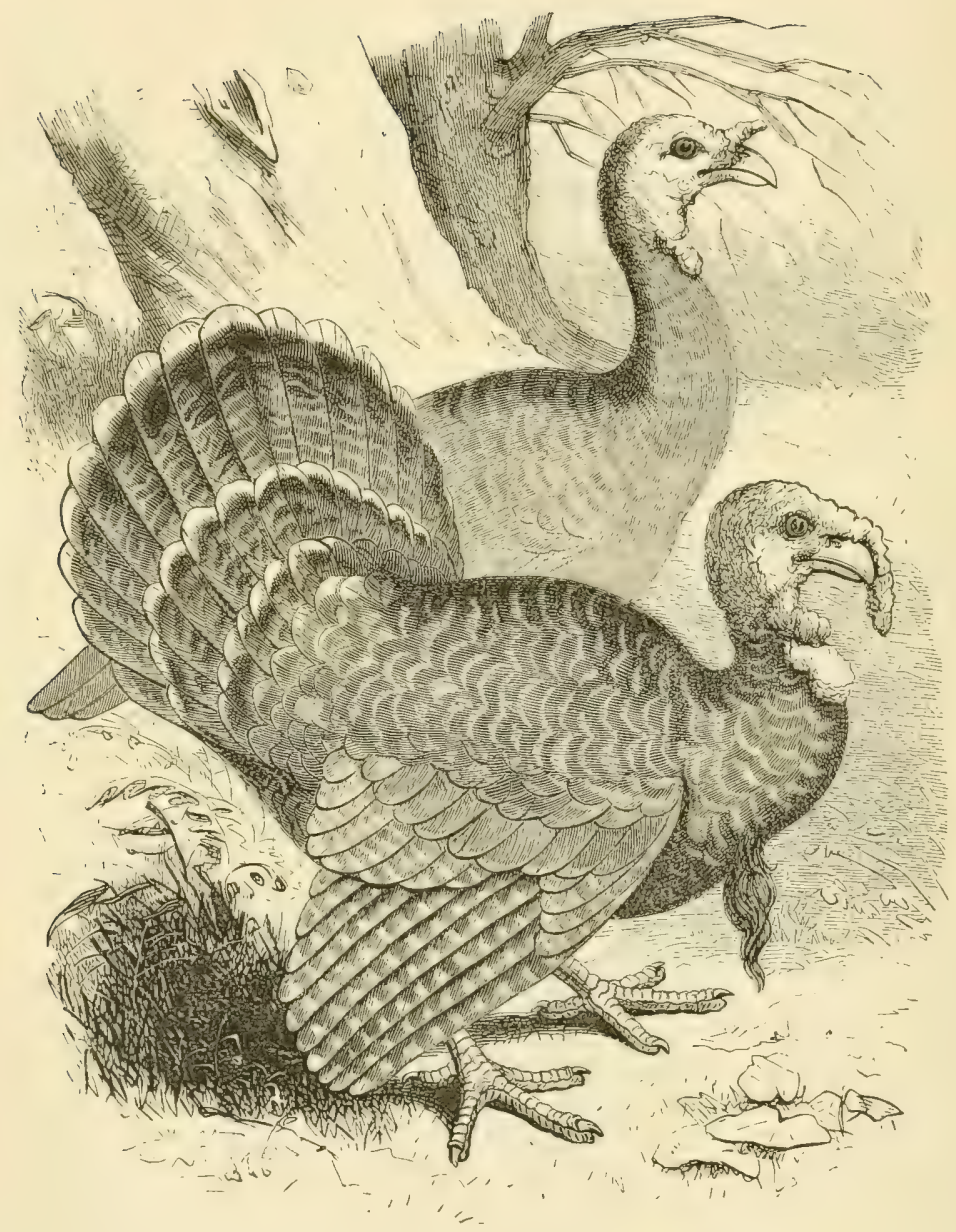

\section{CHAPTER IX.}

THE WILD TURKEY. MELEAGRIS GALLIPAVO.

"On the top

Of yon magnolia the loud turkey's voice

Is heralding the dawn: from tree to tree

Extends the wakening watch-note far and wide, Till the whole woodlands echo with the cry." 
DESCRIPTION. ADULT MALE.

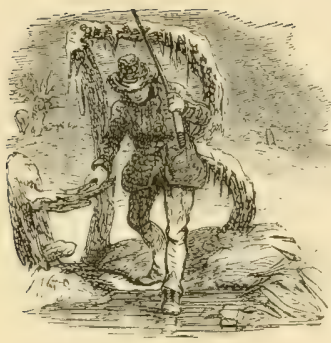

ILI shortish, robust, slightly arched, rather obtuse, the base covered by a bare membrane; upper mandible with the dorsal outline arched, the sides convex, the edges overlapping, the tip a little declinate; under mandible somewhat bulging towards the tip, the sides convex. Nostrils situated in the basal membrane, oblique, linear, covered by a cartilage.

Head small, flattened above, with a conical, pendulous, erectile caruncle on the forehead. Neck slender. Body robust. Feet longish and strong; tarsus covered anteriorly with numerous transverse scutella, scaly on the sides, scutellate behind; toes scutellate abore, scabrous, papillar, and flat beneath; hind-toe elevated, half the length of the lateral toes, which are nearly equal, and much shorter than the middle toe; claws slightly arched, strong, convex above, obtuse flat beneath. A conical, rather obtuse, spur on the tarsus, about two-thirds down. Conical papilla of the forehead rugose, sparsely covered with bristles. Head bare and corrugated, the skin irregularly raised, and covered with a few scattered bristles.

External ear margined with short and slender thin feathers. Neck also bare, corrugated, beset anteriorly and below with a series of oblong, irregular, cavernous caruncles, interspersed with swall, bristly feathers.

Plumage in general compact, glossy, with metallic reflection. Feathers double, as in other gallinaceous birds, generally oblong and truncated. A pendulous tuft of long bristles from the upper part of the breast. Wings shortish, convex, rounded, consisting of eighteen broad, rounded feathers, capable of being erected and expanded in a permanent manner when the bird is excited, and reaching nearly to the ground when the bird stands erect. 
Bill yellowish-brown. Frontal caruncle blue and red. Rugose and carunculated skin of the head and neck of various tints of blue and purple, the pendulous anterior caruncles of the latter, or the wattles, bright red, changing to blue. Iris hazel, legs and toes bright purplish-red; claws brown. Upper part of the back and wings brownish-yellow, with metallic lustre, changing to deep purple, the truncated tips of the feathers broadly margined with velvet-black. On the middle and lower back, the black terminal bands of the feathers almost conceal the bronze color. The large quill-coverts are of the same color as the back, but more bronzed, with purple reflections.

Quills brownish-black, the primaries banded with grayish-white, the secondaries with brownish-white, gradually becoming deeper towards the proximal feathers, which are similar to the coverts. The lower part of the back and the coverts are deep chestnut, banded with green and black. The tail-feathers are of the same color, undulatingly barred, and minutely sprinkled with black, and having a broad, blackish bar towards the tip, which is pale-brown and minutely mottled. The under parts are duller. Breast of the same colors as the back, the terminal black band not so broad; sides dark-colored; abdomen and thighs brownish-gray; under-tail coverts blackish, glossed with bronze, and at the tip bright reddishbrown.

Length, 4 feet 1 inch; extent of wings, 5 feet 8 inches; beak, $1 \frac{1}{2}$ inches along the ridge, 2 along the gap; tarsus, $7 \frac{1}{t}$; middle toe, 5 ; hind toe, 2 ; pectoral appendage, one foot.

The female is considerably inferior in size, with the vattles much smaller, the tuft on the breast comparatively small and only in old birds, the color of the plumage duller, there being bu: little of the refulgent hues of the male, and the lower parts browni.sh-black. The young, before being fledged, are pale, brownish-yellow above, pale yellowish-gray beneath, the top of the head brighter, narked in the middle with a longitudinal pale-brown band; the back and wings spotted with brownish-black, excepting the smaller wingcoverts, which are uniformly dull brown. 
The above will at once be recognised as Audubon's description of this magnificent bird.

\section{NATURAL HISTORY AND LOCALITIES-WHERE FOUND.}

The wild turkey, the largest of all the fowls that have been reclaimed from the primeval forests of this or any other country and made subservient to the never-ceasing wants of man, stands pre-eminent among the game-birds of America.

In former times this noble bird wandered in undisturbed peace and quiet, in vast armies, from one end of our remote country to the other, having little or nothing to dread from the savage inhabitants of those wild regions, abounding in game to them of a much more attractive as well as useful character. Then it was, before the pristine forests and luxuriant plains of this vast continent had been invaded by the devastating foot of the white man, that this proud and beautiful fowl roamed in joyous security, unmolested, unharmed, in its native haunts. Then it was that the haughty, vainglorious gobblers, in conscious freedom, decked in the most gorgeous plumage, with outstretched wings, quivering bodies, and blustering heads, pompously strutted and puffer in mimic grandeur, as it were, to win the favor of their amorous but still unyielding mates, or meeting in battle array with sanguinary fury, avenged their jealous desires. Then it was, hidden amay in some choice umbrageous copse, that the anxious mother, without fear, without restraint, patiently hatched and reared her tender brood, and brought them forth with careless solicitude, to feed and wander crer the fruitful plains.

How changed is all this! Scarcely a bird is now to be cncountered on the whole northern and eastern Atlantic seaboard. The destroying hand of the white man is stretched forth, and his rictims are vainly seeking an asylum far beyond the confines of the "Father of Waters;" and the time is fast approaching, we fear, when we shall hear of the wild turkey as one of the almost extinct species of our land.

Few or none are to be met with, at this present time, north or 
east of Pennsylvania, and few-very few-in some of the remotest portions of this latter State. Small flocks are found in the wild and roody regions of Virginia, larger numbers in Ohio, Indiana, Illinois, and Kentucky, but only in considerable congregations in the unsettled tracts far beyond these localities. During the last autumn, while shooting in the interior of Virginia, in company with Andrew Staley, Esq., we encountered several of these birds; but they were in such straggling parties and so very wild that little or no inducement was offered to hunt them. We were informed, however, that a sportsman in that district, who followed this particular kind of game with great zeal and ardor, had killed some twenty or more during the previous season; but even this success, we are well assured, was only accomplished at a great expense of time, patience, and real labor. Of all this, however, we need not speak, as the sportsman, no doubt, in his own mind, was richly repaid for all he endured.

In the wilder portions of Tennessee, Arkansas, Louisiana, Mississippi, and Alabama, they are still to be found in some abundance, are more scarce in Georgia, Florida, and the Carolinas.

We are greatly indebted to our esteemed friend, Doctor R. Percy Sargent, who resides in the neighborhood of Natchez and devotes much of his leisure to shooting and the study of the habits of game-birds, for a letter containing much useful as well as practical information regarding the wild turkey. From this article, so kindly furnished us by the doctor, we shall in the course of this compilation make some considerable extracts, as well as from Audubon, to whom we owe nearly all our knowledge of the bird under consideration; for we must frankly confess that our own opportunities of studying them in their native haunts have been very limited.

The doctor informs us that wild turkeys are still met with in small numbers in the cypress-swamps, thick forests, and wild ridges of the neighborhood around Natchez. They are, of course, very wary, cunning, and watchful of the approach of man, and are only to be killed by those long experienced in hunting 
them and practically familiar with their habits and secret haunts. Although these birds in the settled districts occasionally come out into the open meadows and frequent the grain-fields, still, they generally secrete themselves in the depths of the forests, and are seldom to be approached within gunshot, save when on the roost at early dawn or when drawn into ambush by the deceptive call of the huntsman.

\section{INCUBATION.}

The season devoted by the wild turkey to propagation and incubation is a very interesting period for the lover of natural history to study the habits and characteristics of this truly magnificent bird.

These promptings of nature to perpetuate her creations are observed in the turkey as early as the month of March, and, if the weather be favorable, even as soon as the middle of February. The first change that takes place in its ordinary habits that seems to mark the near approach of this sexual desire is the partial separation of the females from the males, accompanied by the almost incessant gobbling of the latter. The turkey, like others of the gallinaceous order, is very salacious, and does not by any means confine his attentions to one hen, but oftentimes becomes the mate and protector of several, and is ever ready to give battle at the slightest token of intrusion on the part of less favored rivals.

These conflicts, too, are often contested in the most desperate manner, insomuch that death to several of the combatants not unfrequently results from a general engagement.

Audubon remarks on this head:- "I have often been much diverted, while watching two males in fierce conflict, by seeing them move alternately backwards and forwards, as either had obtained o. better hold, their wings drooping, their tails partly raised, their body-feathers ruffled, and their heads covered with blood. If, as they thus struggle and gasp for breath, one of them should lose his hold, his chance is over; for the other, still holding fast, hits 
him violently with spurs and wings, and in a few minutes brings him to the ground. The moment he is dead, the conqueror treads him under foot, but, what is strange, not with hatred, but with all the motions which he employs in caressing the female."

The period of sexual intercourse continues for several weeks, when the female, towards the middle of April, begins to make arrangements for placing her eggs in security. She now sees far less of her mate, being anxiously occupied in securing a favorable site for the nest, which is formed on the ground in a very slovenly and artless manner.

A dry situation is always selected for this purpose, most generally a mere hollow scooped out in the ground by the side of an old stump, moss-covered log, or fallen tree, hidden from casual view by the intervention of thick and tangled bushes, and the approach protected by the rank growth of creeping vines and matted briers.

They also form their nests occasionally in the small thickets or briery patches of the open fields, (Dr. Sargent informs us that such is most generally the case about his neighborhood,) as well as within the edge of the canebrakes. Audubon states "that the eggs, which are of a dull cream-color sprinkled with red dots, sometimes amount to twenty, although the more usual number is from ten to fifteen."

The hen is very cautious when approaching her nest, so much so that she seldom goes to it more than once by the same route; and when she leaves it, for the purpose of feeding or seeking the company of her mate, she carefully conceals the eggs from observation by covering them over with leaves.

The turkey-cock does not assist in the duties of incubation, but, on the other hand, is ever eager to discover the nest and destroy the eggs, so that he may insure for himself the further company of the hen. This latter circumstance, therefore, is one of the strongest incentives which urges the anxious mother to conceal the locality of the nest from her jealous and treacherous mate. Several hens, we are informed, occasionally deposit their eggs in the 
same nest in beautiful harmony, and, being thus intimately associated, pursue their maternal duties in perfect congeniality and increased security from the attacks of wild animals, birds of prey, or lurking serpents. Audubon mentions having discovered three sitting on forty-two eggs.

When on the nest, the hen is noiseless as death itself, but watchful as her keen vision and acute hearing can possibly make her; and with equal sagacity, though trembling with terror for the safety of herself and eggs, will permit the unconscious intruder to pass within a few paces of her, without moving from her seat.

When the full period of incubation is drawing to a close, the hen will not leave the nest under any contingency; she will rather sacrifice her own life than abandon the offspring just about bursting into existence. Indeed, so resolute is she in her nearly-accomplished purpose that, Audubon states, she will even allow an enclosure to be built around her, rather than forsake them at this critical juncture!

How marvellous, how powerful, how impressive the instinct which thus sways the actions of an otherwise timid, cautious, and wary bird, that under ordinary circumstances takes alarm at the slightest token of danger, not only fleeing the presence of man, but driven into precipitate flight at the very sound of his voice!

Wet weather and low, moist grounds are very detrimental to the well-being of the young turkeys; insomuch that an inclement spell, about the period of hatching, is very destructive to the tender brood. The hen at such seasons, doubly solicitous for the preservation of her sensitive offspring, seeks the high, dry grounds, and, further to ward off the ill effects resulting from exposure to rain. Audubon tells us that she, with instinctive ingenuity, feeds them upon the buds of the spicewood-bush.

The young continue to nestle on the ground for two or three weeks; they are then sufficiently strong to take to the low limbs of trees, where they roost under the wide-extended wings of their ever-anxious parent. The plunage of the young bird grows with 
considerable vigor, and they increase in size and strength rery rapidly, provided the weather continues propitious.

As early as the month of August, the young turkeys are quite able to take care of themselves as well as fly to the tops of the highest trees. Our author, from whom we have already quoted so liberally, informs us that about this time "the young cocks show the tuft on the breast, and begin to gobble and strut, while the young hens pur and leap."

The wild turkey, as a general habit, rears but one brood of a season; but if she forsakes or is driven from the nest, or the eggs are destroyed by some one of her numerous enemies, she seeks her mate and makes preparations for another setting.

During the period immediately succeeding that devoted to sexual enjoyment, "the males become greatly emaciated, and cease to gobble, their breast-sponge becoming flat. They then separate from the hens, and one might suppose that they had entirely deserted their neighbors. At such seasons I have found them lying by the side of a $\log$, in some retired part of the dense woods and canethickets, and often permitting one to approach within a fer feet. They are then unable to fly, but run swiftly, and to a great distance."

Several weeks elapse before the gobblers entirely recover their condition, when they all reassemble, old and young, males and females, and move off to some more favored feeding-ground.

\section{FOOD.}

The wild turkey is not very particular in the choice of food; but little comes amiss. They partake indiscriminately of all the forest-fruits, such as nuts and berries; also consume considerably of grass, herbs, buds, seeds, \&c., as well as beetles, grasshoppers, tadpoles, worms, and even lizards. When feeding on the plains, they feast on strawberries, dewberries, blackberries, and all similar productions.

Audubon states that they are particularly partial to the pecannut and winter grape; they also eat largely of the fruit of the oak 
and beech, as well as of all kinds of grain, when to be obtained without too much exposure.

\section{MIGRATIONS.}

The turkey is principally influenced in its movements after the breeding-season by the abundance or non-abundance of fool. They often wander in enormous droves, at certain times, over a wide extent of country in search of mast, on which they principally feed during the late autumn and winter months. When they encounter a river during these peregrinations, they mount the loftiest trees on the banks, and after a general conference, which sometimes, strange to say, lasts a day or two, the whole party, at a given signal from the leaders, take flight and reach the opposite shore without much difficulty.

Should any, however, from want of confidence or strength, fail in the effort and fall into the water, they swim with considerable dexterity, and soon gain the land.

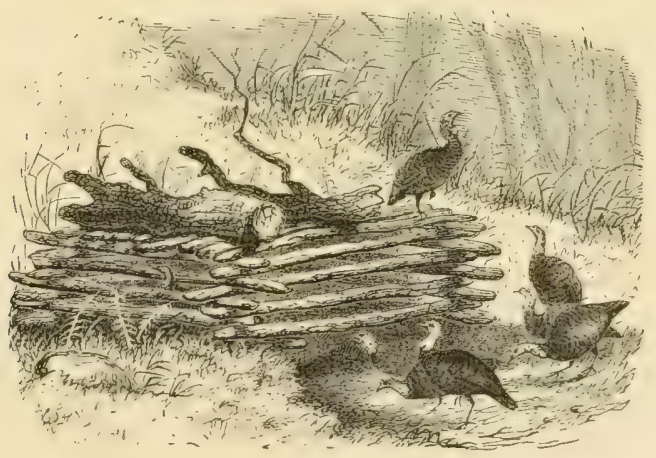

THEIR DOMESTICATION.

The wild turkey is a native solely of the New World; it is indigenous to the wilds of America, and the progenitor of the domestic fowl so generally distributed over the whole civilized globe.

It is, then, to the forests of our country that the old World is 
indebted for one of the most common, but at the same time one of the most choice, of all the barnyard-fowls that have, by the ingenuity of man, been reclaimed from their native haunts to minister to his daily wants.

"In a state of domestication, the wild turkeys, though kept separate from tame individuals, lose the brilliancy of their plumage in the third generation, becoming plain brown, and having here and there white feathers intermixed."

Wild turkeys often, when opportunities offer, associate with tame ones, and with great advantage to the latter, as it improves the stock, making them more hardy, and consequently less difficult to raise.

It is a subject of somewhat curious interest to examine the various notions or theories that have been broached by different writers, by way of explaining in a satisfactory manner how this fowl, entirely indigenous to the Western Hemisphere, should have received the appellation of Turkey; for this name would very naturally seem to imply that the bird was a native of the East, rather than of the New World.

This seeming paradox may, however, be reconciled by a reference to the history of the period of its introduction into England. The Turks were then in their zenith of glory, or, rather, were in their most lawless state of rapine and plunder; insomuch that the whole nation was dreaded as well as despised throughout all Christendom.

Their ships, almost unmolested, swept the waters of the Mediterranean, while their fleet galleys laid waste the sunny shores of Italia, as well as carried devastation along the coasts of Hispania and the adjacent countries. As a nation, they were nothing more than a horde of barbarians, a band of pirates, leagued together for the purpose of carnage and pillage; their very name a byword to all the more civilized people of the Old World, - a token of contempt, a symbol of cruelty, cowardice, and oppression. Such was the period of the advent of this bird in England; and, coming as a stranger from distant parts, no one knew or cared whence, they 
were regarded as fancy fowls alone. Most probably their introduction was through the medium of some of the British cruisers from the coast of Spain, where, no doubt, many of the birds had already been brought from the newly-acquired Spanish possessions in the New World, and dubbed Turkey, or Turkey-Bird, in a spirit, perhaps, of irony or contempt for its irascible and pugnacious disposition, as evinced in its blustering attitudes, unmeaning struttings, and senseless gobblings. And this title seemed the still more appropriate for the pompous stranger, owing to the pectoral appendage resembling so much the huge tufts of beard which the Turks were so remarkable for cultivating.

The singular misnomer of this fowl seems conclusive evidence that the bird was not brought to England direct from America; and, whether there be any truth or not in the above conjecture, there is certainly much plausibility in the deductions. However, let all this be as it may, it is a well-known fact that, about the period of its introduction into England, during the reign of that monster Henry VIII., the British merchants carried on a consider:able traffic throughout the Mediterranean, and even extended their voyages as far as Smyrna on the one side and Constantinople on the other; and it is not improbable that their vessels, on their return voyages, stopping for trading purposes at the different Spanish ports, may have brought home, as mere fancy fowls, some of these birds lately arrived from the Western World.

And thus alone, from the mere circumstance of arriving in England through the medium of these same Turkish traders, ignorant, perhaps, themselves of the true history of the fowl, it was very naturally presumed by the uninitiated to have been brought from the most remote region that the vessels visited, which was Constantinople, and consequently received the cognomen of Turkey or Turkey-Bird, without any particular allusion to the peculiar condition of the Turks at this period.

With the exception of the hen and goose, the turkey is by far the most valuable addition which has been made to our domestic fowls; and it is somewhat strange that the history of its trans. 
plantation across the waters should have become involved in so much obscurity that more than one eminent author has striven to establish an Asiatic or African origin for it.

But such efforts at imposition could not long stand before the ever-ready pen of the closely-investigating Buffon, who soon, by a few researches, cleared away the mist by which these specious writers had enveloped the early history of the bird, and proclaimed it a fowl indigenous to the wilds of America alone.

Prescott, in his Conquest of Mexico, makes frequent mention of the turkey, not only in its wild state, but as domesticated among the Aztecs; in fact, it was more common than any other kind of poultry among this strange people. And as a proof of this assertion we need only state that, along with other items enumerated in a list of yearly household expenditures of the Tezcucan monarch, was an almost incredible number of turkeys, being no less than eight thousand.

\section{THEIR FLESH.}

The flesh of the wild turkey assimilates very closely to that of the tame fowl, but is darker, more juicy, and, of course, has more of a game flavor.

\section{TRAPPING TURKEYS.}

In parts of the country where these birds are numerous, the most effectual mode to procure a supply is to catch them in traps, or rather pens.

Audubon states that tney are constructed thus:- "Young trees of four or five inches in diameter are cut down and divided into pieces of the length of twelve or fourteen feet. Two of these are laid on the ground, parallel to each other, at a distance of ten or twelve feet. Two other pieces are laid across the ends of these, at right angles to them; and in this manner successive layers are added, until the fabric is raised to the height of four feet. It is then covered with similar pieces of wood, placed three or four inches apart. and loaded with one or two heavy logs to render the 
whole firm. This done, a trench, about eighteen inches in depti and width, is cut under one side of the cage, into which it opens slantingly and rather abruptly. It is continued on its outside to some distance, so as gradually to attain the level of the surrounding ground. Over the part of this trench within the pen, and close to the wall, some sticks are placed so as to form a kind of bridge about a foot in breadth.

"The trap being now finished, the owner places a quantity of Indian corn in its centre, as well as in the trench, and, as he walks off, drops here and there a few grains in the woods, sometimes to the distance of a mile. This is repeated at every visit to the trap after the turkeys have found it. Sometimes two trenches are cut, in which case the trenches enter on opposite sides of the trap, and are both strewn with corn. No sooner has a turkey discovered the train of corn, than it communicates the circumstance to the lock by a cluck, when all of them come up, and searching for the grains scattered about, at length come upon the trench, which they follow, squeezing themselves, one after another, through the pas-. sage under the bridge. In this manner the whole flock sometimes enters, but more commonly six or seven only, as they are alarmed by the least noise, even the cracking of a tree in frosty weather.

"Those within, having gorged themselves, raise their heads, and try to force their way through the top or sides of the pen, passing and repassing on the bridge, but never, for a moment, looking down, or attempting to escape through the passage by which they enter. Thus they remain until the owner of the trap, arriving, closes the trench and secures his captives. Dr. Sargent informs us that it is usual, in his part of the country, to make these pens in the corners of the worm fences."

\section{SHOOTING TURKEYS.}

Various plans are resorted to by huntsmen to kill turkeys, dependent in a great measure upon the particular locality shot over.

If the country be new and wild, and the birds abundant, as well as seldom pursued, much less stratagem is necessary to approach 
them than if the region is thickly settled and the turkeys proportionately scarce and wary from previous hunting; for in this case it requires much labor, skill, and cunning, to entice them within gun or rifle-shot.

A good turkey-dog is of great consequence, Audubon remarks, in the pursuit of these birds, as they not only scent the game from a great distance, but, when up with it, perform the most essential service in running into their midst and forcing them to take flight to the trees in the utmost confusion, thus procuring for the sportsman the most desirable shots.

If the turkeys were not thus scattered by the dog and made to take to the trees in disorder and terror, they would all make off in a body with such suddenness and precipitancy that it would be impossible for the sportsman to come up with them.

The wild turkey runs with amazing celerity, vigor, and bottom, insomuch that they soon outstrip both dog and rider; even when badly winged, it requires a swift dog to overtake them.

Turkeys are easily killed if shot in the head or neck; when hit only in the body they most frequently make off and are lost to the hunter.

It is a common practice in some localities to shoot these birds on their roost on moonlight nights, when they can be distinguished quite easily on the trees.

Dr. Sargent states "that wild turkeys commence gobbling a little before the break of day, and continue on their roosts until broad daylight; during this interim, the hunter can cautiously glide within shooting-distance of the tree upon which they are perched, and, silently and patiently awaiting till the dawn has broken, secure his game without further trouble. This march upon our victims, however, must be accomplished in the most stealthy manner; otherwise, the wary gobbler will be alarmed, and seek safety in the most inglorious flight." If such should be the case, the doctor further remarks that the sportsman must now remain perfectly calm and quiet for twenty minutes or so, and then, perhaps, by a few well-timed yelps, may be able to draw the 
wary but still amorous swain within the deadly ambush. Another artifice has also been resorted to by the doctor, to secure this wary bird, by placing a tame turkey in a suitable position, with a long cord attached to his leg, by pulling which the uneasy captive is made to cluck from time to time, so as to attract the notice of any wild ones that are known to be concealed or feeding in the immediate vicinity; for a gobbler, on hearing this call or cry of another, instantly rushes forward to meet him, and is thus easily shot down.

\section{ENEMIIES.}

The wild turkey is pursued, harassed, and preyed upon, by quadrupeds innumerable, as well as by the larger species of birds of prey. The wolf, fox, lynx, cougar, opossum, and wild cat, all prowl about, destroying their nests as well as their tender offspring, or, lying in wait, pounce upon the full-grown birds as their lawful prey.

Audubon remarks, on this head, that "the lynx sucks their eggs, and is extremely expert at seizing both young and old, which he effects in the following manner:- When he has discovered a flock of turkeys, he follows them at a distance for some time, until he ascertains the direction in which they are proceeding. He then makes a rapid circular movement, gets in advance of the flock, and lays himself down in ambush until the birds come up, when he springs upon one of them by a single bound and secures it. While once sitting in the woods, on the banks of the Wabash, I observed two large turkey-cocks on a log by the river, pluming and picking themselves. I watched their movements for a while, when, of a sudden, one of them flew across the river, while I perceived the other struggling under the grasp of a lynx."

The larger species of owls, as well as hawks, are said to attack and destroy the full-grown birds as well as those of a more tender age.

The lurking and noisome serpent also plunders the nest, ar.d secures the helpless brood when first merged into existence. 
MEMORANDA.

1. Turkeys were formerly very abundant throughout the whole continent of North America.

2. The gobbler does not confine his attentions to one hen, but oftentimes has several under his protection.

3. The hen sits very close, and endeavors to conceal the nest from the cock bird.

4. The young brood is sufficiently strong to take to the trees in the course of two or three weeks after hatching.

5. Wild turkeys are not very particular as to the choice of food: they partake indiscriminately of all the field and forest-fruits, as well as the various descriptions of insects and small animals which they encounter.

6. At certain seasons turkeys wander over a wide extent of country in enormous droves.

7. The turkey is solely a native of the New World, and the progenitor of the domestic fowl.

8. Most probably introduced into England through the medium of Spain.

9. The turkey has almost entirely disappeared from the Atlan. tic seaboard States.

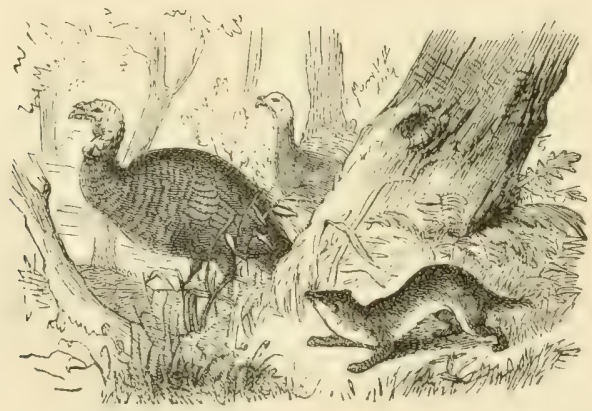




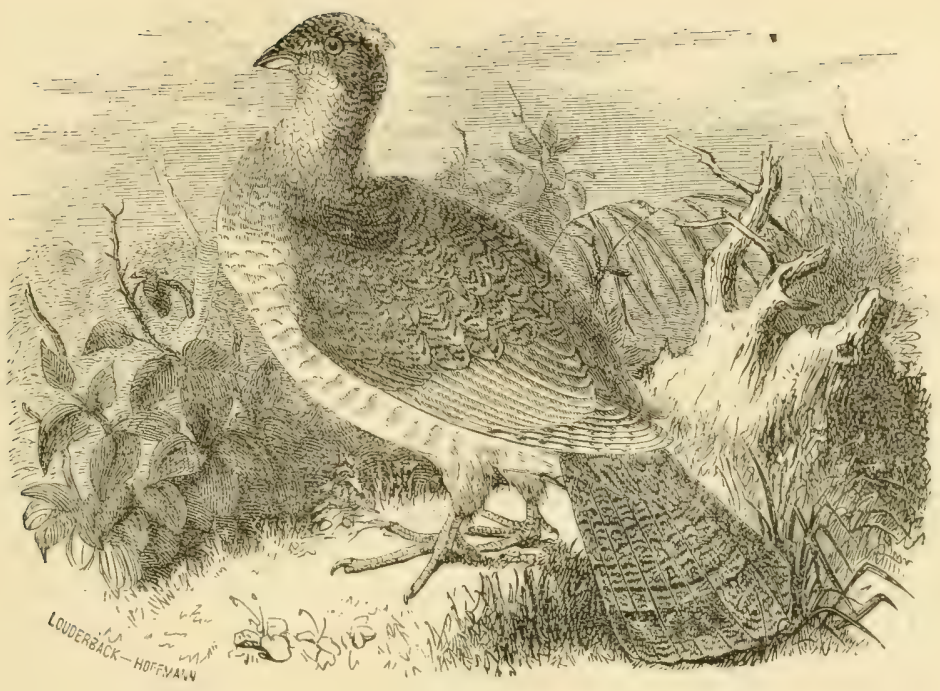

\section{CHAPTER X.}

THE RUFFED GROUSE, OR PHEASANT. TETRAO UMBELLUS.

"Two whirring pheasants swept across our path, And swift as lightning flew the fiery death."

\section{THEIR LOCALITY.}

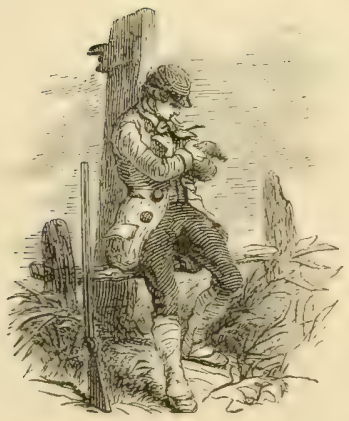

$\mathrm{N}$ almost every section of our country. from the northernmost latitudes even as far south as Georgia, ruffed grouse are to be met with. At times they are very abundant in the pines of Jersey, as well as the mountainous ranges of the Mississippi and Columbia Rivers.

Numbers of grouse were formerly found in the higher elevations of the burrens of Kentucky and Tennessee; and some remain there even at the present time, although far less abundant than they were a few years since. This particular section of comtry afforded 
fine protection and plenty of agreeable food for these birds, and the regular temperature of the climate was at all times such as was most congenial to their habits.

\section{NOMENCLATURE.}

The ruffed grouse derives its name from the peculiar construction of the plumage on the neck,-" a large space being left destitute of feathers, but covered over by an erectile ruff of elongated feathers, of which the upper are silky, shining, and curved forward at the end, which is very broad and rounded."

Like most others of our game-birds, the ruffed grouse has several local appellations: it is called partridge in the Eastern States, pheasant in the Middle, and grouse in the Western. So general is it with us all to call this bird pheasant in Pennsylvania, and by no other name, that it really would appear like a piece of pedantry to give it its proper appellation of grouse; in fact, most of our shooters would not recognise the bird at all by this name.

\section{DESCRIPTION.}

The pheasant is eighteen inches long and twenty-three in ex. tent; bill a horn-color; eye reddish-hazel, immediately above which is a small spot of bare skin of a scarlet color; crested head, and neck variegated with black, red, brown, white, and pale brown; sides of the neck furnished with a tuft of large black feathers, twenty-nine or thirty in number, which it occasionally raises; this tuft covers a large space of the neck destitute of feathers; body above, a bright rust-color, marked with oval spots of yellowishwhite, and sprinkled with white spotted with olive; the tail is rounding, extends five inches beyond the tips of the wings, is of a reddish-brown, beautifully marked with numerous waring transverse hairs of black, is also crossed by a broad band of black, within half an inch of the tip, which is bluish-white, thickly sprinkled and speckled with black; body below, white, marked with large blotches of pale brown; the legs are covered half-way to the feet with hairy down of a brownish-white color; legs and 
feet pale ash; toes pectinated along the sides, the two exterior ones joined at the base as far as the first joint by a membrane; vent yellowish rust-color. The plumage of the female is less beautiful, the ruff smaller and more of a brownish color; the bar of black on the tail is also of a lighter color, and the plumage generally of a lighter shade.

Many persons confound the ruffed grouse with the prairie-hen; but this is quite wrong, as there is a striking difference between the two birds, not only in their plumage, but also in their modes of life. The former variety, it is well known to every one at all familiar with its habits, delights in the mountainous districts of our country, and is particularly partial to craggy sides of the hills, and the steep, rocky, and almost inaccessible banks of rivers or small streams; while, on the other hand, the prairie-grouse feeds entirely upon the open plains and clear countries of the West, and never, except when disturbed by the huntsman, forsakes these situations for the woods.

\section{THEIR GRADUAL EXTINCTION.}

The ruffed grouse, as well as the pinnated, is fast retiring from before the destructive hand of the whites; for, notwithstanding the broods of the former are so very prolific and their haunts so retired, the demand for them in our cities increases so fast that every encouragement is offered to the ruthless netters and trappers who are ever at work thinning their numbers, in season or out of season, as may best suit their convenience or the pampered palates of their guilty customers. There are, however, considerable numbers of grouse in some portions of New Jersey, and many more in Pennsylvania and New York; but every season sends forth a myriad of gunners to shoot them down, while the deep snows of our long winters drive them, half-famished, into the fatal traps and snares that are so thickly scattered over their haunts. We need hardly speak at this particular time of the unsportsmanlike and barbarous custom of shooting game out of season, or offer any comment upon the subject, as we have already said much thereon under another 
head, and, we trust, quite enough to induce every sensible man to discountenance such proceedings as far as lies in his power, whether he be a sportsman or not; for, unless some attention is given to this matter by the people generally, we may soon expect to find our whole Atlantic seaboard entirely destitute of game of every description.

\section{INCUBATION.}

The pheasant begins pairing in March and April, and the nest is finished in the course of two or three weeks. The most solitary situations are selected for incubation, and the nest itself is formed even more rudely than that of the partridge, but of pretty much the same material, and generally at the base of a small bush, tree, or old stump. The hen generally drops from five to twelve eggs, of a dull-yellowish color, without spots, and nearly the size of those of a Polish chicken. The nest, notwithstanding the secrecy of its situation, is often plundered, during the absence of the hen, by the crow, raven, and other cruel enemies, that are constantly on the watch to seize upon such delicacies as it contains. In this case the hen is very apt to court again the society of the cock birds, form a new nest, and go to laying a second time; which fact, as in the partridge, has given rise to the idea of two broods in a season. The young leave the nest almost as soon as hatched, and follow the mother in quest of food; if surprised during these perambulations, they skulk in the grass as young partridges do, while the hen resorts to the same artifices to allure the sportsman away from the vicinity of her tender offspring. Wilson mentions that on one occasion, having accidentally come upon a hen pheasant in company with her brood, she flew up, evidently much alarmed, fluttered for a few moments before him, and then darted down and seized one of the young in her bill and bore it off to a place of safety, leaving him, of course, greatly surprised at the extraordinary incident.

The young birds are sufficiently strong and well grown to fly a short distance in the course of a very few days. The cock birds 
do not assist their mates in the care of the broods, but associate themselves together in small bands till the autumn, or rather the commencement of cold weather, when they all again mingle indiscriminately together, young and old.

\section{DRUMMING.}

Early in the spring, the forests resound far and wide, in certain portions of our country, with the drumming of the cock pheasant, who adopts this rather singular method of calling the hen into his presence; in fact, the making of this peculiar noise is the only sure plan that he has of wooing his mate from her close retreat during the period of incubation. This operation is a very singular manœurre, and we know not better how to explain it to our readers than in the words of Audubon:-

"The male bird, standing erect on a prostrate decayed trunk, raises the feathers of its body in the manner of a turkey-cock, draws its head towards its tail, erecting the feathers of the latter at the same time, and, raising its ruff around the neck, suffers its wings to drop, and struts about on the log. A few moments elapse, when the bird draws the whole of its feathers close to its body, and, stretching itself out, beats its sides with its wings in the manner of the domestic cock, but more loudly, and with such rapidity of motion, after a few of the first strokes, as to carse a tremor in the air not unlike the rumbling of distant thunder."

This rumbling sound is called the drumming of the pheasant, and in clear weather may be heard a long distance off. The cock resorts to the same spot, if undisturbed, during the whole breeding season, for the purpose of performing these singular manocuvres, as may very easily be proved by the large deposits of excrement and feathers that are always found in places suitable for this purpose.

During the pairing season, fierce battles often take place between the males for the possession of the females. The cocks are not confined entirely in their attentions to one mate, but often have several hens under their protection. 


\section{MIGRATIONS.}

Like the partridge and wild turkey, pheasants are said to perform partial migrations, from northwest to southeast, at the approach of winter; but their excursions are neither so general nor extensive as those of the partridge. Pheasants fly with great ease, and do not hesitate to cross the widest rivers that obstruct their way during the season of migration. Audubon, speaking of these migrations, remarks that "no one who pays the least attention to the manners and habits of our birds can fail to observe them."

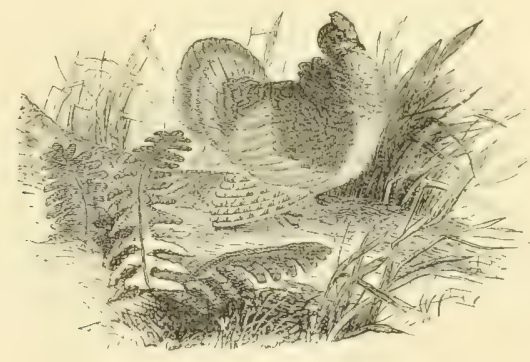

FLIGHT.

This bird, like most others of the gallinaceous order, when disturbed, flies with a loud whirring noise, even louder and more startling than that made by the springing of a large covey of partridges. They usually fly away in a direct line, and seldom or never either cross the shooter or fly behind him.

When not put to flight from fear or any other exciting cause, they move off slowly and rather stiffly, flapping their wings for a few seconds, and then sailing ahead. They seldom go farther than a few hundred yards at a time. Audubon does not think that any of the gallinaceous tribe, when moving through the air perfectly free from excitement, necessarily make a whirring sound; but, on the contrary, supposes the noise is produced by the unusual rapidity in the motion of the wings, owing to the over-anxiety of the bird to escape the suspected danger. He also states that he has observed pheasants, as well as partridges, rise and fly off of . 
their own free will without making the least noise, but, on the contrary, moving as lightly and silently as other birds.

\section{HABITS.}

The ruffed grouse, as before stated, is a very solitary bird, commonly found in small packs of four to eight, in sections of the country where they are not too much hunted. If frequently disturbed, it is rare to find more than a single pair together. They delight in high, elevated districts, and love to roam about in dense and secluded forests, watered by some large stream, upon the precipitate banks of which they can repose in silence or wander about in search of food. At a very early hour in the morning they usually leave their secluded haunts and repair to the roads that traverse the forests, where they busy themselves in picking up gravel and scratching for grain in the droppings of horses. Ruffed grouse are also particularly partial to most kinds of seeds, berries, and grapes, and are always in good condition when they can procure a supply of wild strawberries, dewberries, and whortleberries, and will not hesitate to roam long distances from their retreats in search of these delicacies when in season. In the spring, grouse feed on the tender buds of various trees, and are perhaps less wild then than at any other period of the year, but they are generally very poor and tasteless. In the winter season, grouse, as well as partridges, are driven to great extremes for food, and when the snow is very deep they depend almost entirely for sustenance on the buds and leaves of the mountain-laurel, (kalmia latifolia,) which food is said to poison their flesh so much that it is dangerous to partake of them.

We have already spoken of this circumstance when treating of the partridge, and avail ourselves of this opportunity to say that we are very sceptical on this head, and doubt very much whether a fresh-killed pheasant could possibly poison any one partaking of it, no matter how long the bird had been forced to feed upon portions of the shrub. We are disposed to attribute these instances of poisoning referred to by writers to other circumstances than the mere living 
on this evergreen, and would rather consider them as the consequence of indulging in these birds when half putrid from age, or even when preserved perfectly sweet for a long while after death, with the craws stuffed full of this plant, which might possibly render the flesh poisonous by the absorption or impregnation of its noxious juices. Such, in fact, is the opinion of most of the ornithologists who have given the subject their attention. As for ourself, we would not, and never did, hesitate to feast upon pheasants at all seasonable times, and often with a full knowledge of their craws being stuffed with the leaves of laurel, provided we were satisfied that the birds had been lately killed or that they had been drawn soon after being shot.

The pheasant roosts on the ground in the thickets, or by the side of a tree, old log, or stump, and not unfrequently, as the partridge, makes a short flight previous to settling down for the night.

\section{ENEMIES.}

The pheasant, as well as the partridge, has many enemies independent of man. Polecats, weasels, raccoons, opossums, foxes, crows, \&c., all prey, when an opportunity offers, either upon the eggs or the young birds. The weasel attacks the old birds on their roosts, and the fox does not hesitate to pounce upon them when feeding. The larger species of hawks also destroy them; and none are more fatal in their attacks upon all kinds of birds than the red-tailed and Stanley hawks.

\section{DELICACY OF THEIR MEAT.}

The flesh of the ruffed grouse is white, and is considered far more delicate and juicy than that of the prairie-hen, which is dark. We most cheerfully subscribe to this opinion, and doubt very much whether we have any game-bird superior to the ruffed grouse in point of excellency of flavor. Some of our readers, perhaps, will differ from us in this assertion. However, we assure them that we could make many converts to our opinion, provided they were willing to act on our hints for cooking them, as detailed under 
another head. Much depends upon the science of the cook for the delicacy of all game; but in no kind of game is the superiority of cooking shown more than in the serving up of pheasants, which may be rendered as tough and dry as a chip or as delicate and juicy as a reed-bird. It is no unusual thing to receive English game on this side of the water during the winter months in perfect condition. A few days since we dined* off both English pheasants and grouse, brought out by one of our steamers; both were in excellent order. The meat of the English pheasant is white and the flavor very similar to that of our bird,-more juicy, perhaps; but we could not, or, it may be, would not have perceired any difference in the flavor, had we not been previously informed that they were English birds. They are larger than the American species. The grouse were larger than our prairie-hen, the tetrao cupido, and the meat dark and very juicy.

\section{MODES OF SHOOTING.}

Several plans are resorted to for obtaining a supply of pheasants for the markets of Philadelphia and New York. Many are caught in nets and nooses, others in traps, and numbers are shot down by being decoyed into ambuscades by trails of grain laid on the snow. These birds are extremely wary, except when pushed by the cravings of hunger, when they become more bold and venturesome. In districts where they are hunted after, it requires great caution and perseverance on the part of a shooter to bag them. When suddenly come upon, they often squat and lie close till you have passed by, when they spring up and make off at a tremendous speed. They generally take to the thickest cripples, or perch themselves in the highest forest-trees, so buried in the foliage that it is impossible to get sight of them, and there remain perfectly motionless till all danger has passed. Shooting grouse, where they are not too scarce, is very lively sport, but is usually attended with great toil, more especially in the vicinity

* At the kind invitation of our friend, Andrew Staley, Esq. 
of long-settled districts, when the sport is generally precarious and uncertain. If a grouse is missed after being sprung, it is seldom that we can get a second shot, as they are extremely wary, and will not let the sportsman again come sufficiently near to insure a fatal coup-de-fusil. The young birds fly very short distances, and hardly ever rise higher than the tops of the laurels, where they are most frequently met with.

When pheasants are raised on the declivity of a hill, they dive apparently for its base, but, after going a short distance, usually turn off in another direction; and by this trick, as it may be called, they are very apt to mislead the inexperienced shooter.

Audubon denies the commonly-received opinion that several of these birds can be shot from the sime tree without disturbing the others, provided you commence with the lower ones first and proceed regularly up. He states that, after repeated trials, he never succeeded, except in some very few instances, when there was a heavy fall of snow; and even then he only obtained three or four in this way. In the winter season, when the snow is very deep and soft, pheasants, when hard hunted, will occasionally bury themselves in it, or rather dive into it, and emerge again at a few paces in advance.

During the drumming season, these wary birds can be decoyed from a considerable distance by imitating this peculiar noise, which may be done by striking a large inflated bullock's-bladder with a small stick, being cautious to preserve, as far as possible, the marked time in which the cock bird beats. The ruffed grouse being naturally so shy and retiring in its habits, it is not strange that it should not lie well to a dog; and we do not know exactly what suggestions to offer on this point, as we have never had much experience in the sport, and very few of our shooting friends are sufficiently au fait in the matter to give us much useful information. 'Those worthies who shoot for the markets generally go after them accompanied by a small mongrel terrier, or cur, which is taught to range through the thickets and brushwond that these birds usually haunt. He gives voice as freely and as lively as a well-trained 
cocker would do, and, by following after the bird, designates its course, or, perhaps, stopping under some tree where the game has pitched, betrays it to the shooter. This latter is called "treeing pheasants." Many of these apparently worthless little curs are very fond of this sport, and, by practice, become wonderfully expert in the business, and will often discover pheasants where no other eye could distinguish them. They are also at times taught to retrieve, and will pursue a wounded pheasant with a perseverance and courage that would often put the owners of the finest dogs to the blush. A dog of this kind, to a shooter for the markets, is worth his weight in gold, in a neighborhood where these birds are plenty; and so one of them expressed himself to us, when extolling the qualities of his ugly little brute, a short time since. And well he might brag upon the merits of his shooting companion, if he could perform one-half of the deeds attributed to him; for, in a word, he was a capital watch-dog, a good-natured playfellow for his children, a superior pheasant-dog, a courageous ducker, an excellent pigger, unequalled ratter, fair on snipe, and useful on partridges, \&c.

If a setter be used for pheasant-shooting,-and he certainly is far preferable to a pointer for this sport, - -he should be old and steady, and contented with a point at twenty or even thirty feet, as it is almost impossible for a dog to make a nearer approach, even in the closest cover, as these wild birds are constantly on the alert, and will make off at the first intimation of danger, either by taking wing or running. Early in the season, however, when grouse are young, they will lie much better, and are always in fine condition for the table, owing to the great abundance of wild fruit which they can obtain. The cocker, spaniel, and springer, as stated in our edition of Youatt, are, no doubt, the proper dogs with which to hunt this game. When the presence of grouse is suspected, great caution and absolute silence are necessary to approach them, as it is a singular circumstance, but nevertheless a well-established fact, that grouse will bear the presence of a dog, or even the report of a gun, much better than they will a single sound of the 
human voice,- - the truth of which any one can test whenever an opportunity offer's for him to raise them when pointed by his dog. A single word spoken will always be sufficient to do it.

\section{SNARES, ETC.}

Many pheasants are snared and entrapped by the same means resorted to in taking partridges; and we may safely say that full one-half of the birds brought to market are obtained in this way, and not by the gun. Pheasants, when feeding, resemble the woodcock in one particular; and that is, their intolerable aversion to clamber or fly over any trifling obstruction which may be placed in their course through their feeding-grounds; and this singularity is taken advantage of by the country-boys, who place a barrier across their haunts, a foot or more high, with small openings at short distances apart, set with horsehair snoods, as before de scribed, and thus take large numbers in the course of the season.

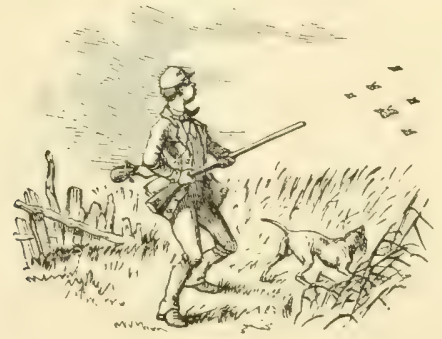

MEMORANDA.

1. The ruffed grouse, or, as we have consented to call it, the pheasant, is found in all the wild and mountainous districts of our country, from the most northern latitudes as far south as Georgia.

2. They are called partridge in the Eastern, pheasant in the Middle, and grouse in the Southern States. There are no pheasants, properly speaking, in America.

3. These birds commence pairing in March and April. The nest usually contains from five to twelve eggs. 
4. The cock pheasant is not faithful to one mate alone; neither does he assist in incubation, or in the care of the brood. They associate together in small bands till the young are full-grown, when they all pack indiscriminately together.

5. The cock bird attracts the attention of the hen, and allures her from her nest, by making a peculiar noise, termed drumming.

6. At the drumming season they are very pugnacious, and fiequent battles take place among the males at this time.

7. The prevalent opinion that the flesh of the pheasant becomes poisonnus by partaking of the leaves and berries of the mountainlaurel is all fallacious, and may without hesitation be classed among the list of vulgar errors.

8. Pheasants are partial to wild strawberies, dewberries, whortleberries, \&c.-in fact, all kinds of fruit: their flesh is white, and far more delicate than that of the prairie-hen.

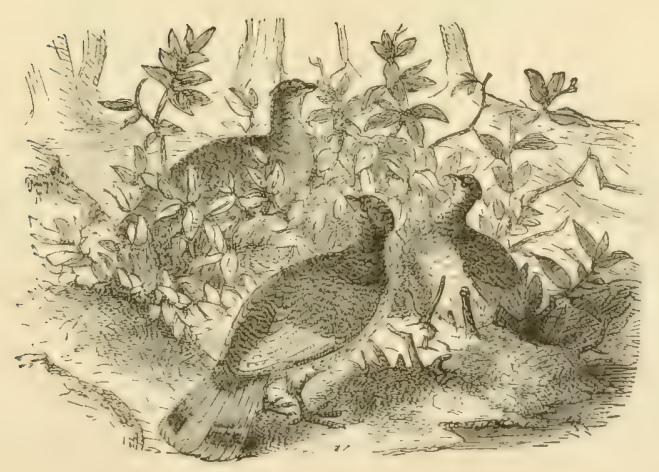




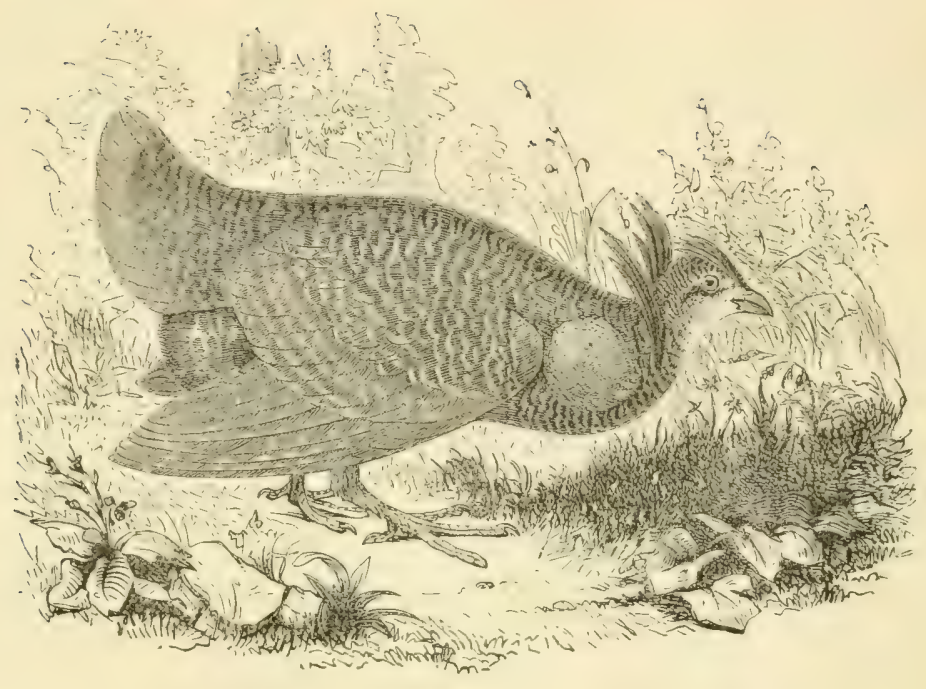

\section{CHAPTER XI.}

PINNATED GROUSE, OR PRAIRIE-HEN. TETRAO CUPIDO.

"Hurrah for the prairie: No blight on its breeze, No mist from the mountains, no shadow from trees."

DESCRIPTION.

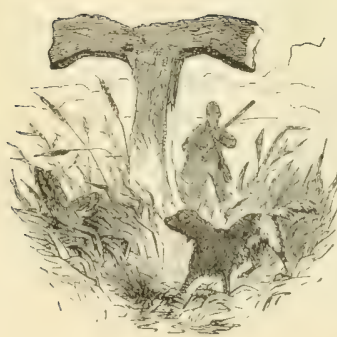

HIS species of grouse is very different in many respects from the last-mentioned variety. Its appearance, habits, flesh, are all quite dissimilar, and we regret never having had very full opportunities for studying these interesting birds in their natural haunts,-the rich prairies of the Far West. However, we, as many others, have this pleasure still in anticipation, and in the mean time will endeavor to lay before our sporting friends all the information upon this head which we have culled from reading and conversing with those who have been in the habit of hunting these birds for 202 
years past, and trust, at all events, that we shall succeed in making this chapter as interesting as some others which we have compiled for the benefit of sportsmen.

Wilson thus describes this bird:-The pinnated grouse is nmeteen inches long, twenty-seven inches in extent, and when in good order weighs about three pounds and a half; the neck is furnished with supplemental wings, each composed of eighteen feathers, five of which are black and about three inches long, the rest shorter, also black, streaked laterally with brown, and of unequal length; the head is slightly crested; over the eye is an elegant semicircular comb of rich orange, which the bird has the power of raising or relaxing; under the neck-wings are two loose pendulous and wrinkled skins, extending along the sides of the neck for twothirds of its length, each of which, when inflated, resembles in bulk, color, and surface, a middle-sized orange; chin creamcolored; under the eye runs a dark streak of brown; whole upper parts mottled transversely with black, reddish-brown, and white; tail short, very much rounded, and of a plain brownish soot-color; throat elegantly marked with touches of reddish-brown, white, and black; lower parts of the breast and belly pale brown, marked transversely with white; legs covered to the toes with hairy down of a dirty drab-color; feet dull yellow, toes pectinated; vent whitish; bill brownish horn-color, eye reddish-hazel. The female is considerably less; of a lighter color, destitute of the neckwings, the naked yellow skin on the neck, the semicircular comb of yellow over the eye.

\section{LOCATION.}

The prairie-hen was, no doubt, at one time widely disseminated over our whole country, more particularly in those portions interspersed with dry, open plains surrounded by thin shrubbery or scantily covered with trees. Unlike the ruffed grouse, this bird delights in the clear, open prairie-grounds, and will desert those distriets entirely which in the lapse of time become covered with forests. These birds are very rare-in fact, may almost be con- 
sidered extinct in the Northern and Middle States. Within a few years they were quite abundant on some portions of Long Island. They were also to be found in Burlington county, New Jersey, and in some few other places. There are, however, still a few to be found on the Jersey plains, and every season we hear of some of our sporting acquaintances exterminating a small pack. We know of ten braces being killed this season, (1848,) and about the same number last year, by the same party; and, as usual, in both instances these scarce and beautiful birds were butchered long before the time sanctioned by the strong-or rather the weak-arm of the law.

Thus it is that the destructive hand of the would-be respectable poacher, as well as the greedy gun of the pot-hunter, hastens to seal the fate of the doomed prairic-hen in these Eastern regions; and we may predict with great certainty that ere long not one will be found save upon the rich plains of the West; from which, also, in course of time, they will be driven, and ultimately perish, root and branch, from before the uncrring guns of their ruthless destroyers. We understand that there are still a few of these birds to be found in Pennsylvania, we believe in Northampton county, where the pine forests are thin and open, and the country about them such as prairie-hens delight in. They have always been abundant in the barrens of Kentucky and Tennessee, as also in the balmy plains and fertile prairies of Louisiana, Indiana, and Illinois. So numerous were they a short time since in the barrens of Kentucky, and so contemptible were they as game-birds, that few huntsmen would deign to waste powder and shot on them. In fact, they were held in pretty much the same estimation, or rather abhorrence, that the crows are now in Pennsylvania or other of the Middle and Southern States, as they perpetrated quite as much mischief upon the tender buds and fruits of the orchards, as well as the grain in the fields, and were often so destructive to the crops that it was absolutely necessary for the farmers to employ their young negroes to drive them away by shooting off guns and springing loud rattles all around the plantations from morning till night. 
As for eating them, such a thing was hardly dreamed of, the negrees themselves preferring the coarsest food to this now muchadmired bird; while the young sportsman exercised his skill in rifle-shooting upon them, in anticipation of more exciting sport among the other prized denizens of the plain and forest. Prairiechickens have not only deserted Long Island, Martha's Vineyard, Elizabeth Island, New Jersey, and their other haunts to the eastward, but they have also removed even farther west than the barrens of Kentucky, and are no longer to be found abundant save in Illinois, and on the extensive plains of the Missouri, Arkansas, and Columbia Rivers.

\section{PERIOD OF PAIRING.}

As soon as the winter breaks up, the pairing season commences, generally in March or early in April; then it is that one can distinguish the well-known booming sound of the male bird, known as the "tooting" of the cock. This singular noise is produced by the inflation and exhalation of the two small bags which are found on the neck, and appear to be formed by the expansion of the skin of the gullet, which, when not filled with air, hangs in loose, pendulous, wrinkled folds.

Audubon remarks:- "When the receptacles of air, which, in form, color, and size, resemble a small orange, are perfectly inflated, the bird lowers its head to the ground, opens its bill, and sends forth, as it were, the air contained in these bladders in distinctly-separated notes, rolling one after another from loud to low, and producing a sound like that of a large muffled drum. This done, the bird immediately erects itself, refills its receptacles by inhalation, and again proceeds with its 'tootings."

This "tooting" can be heard at times as far off as a mile, more particularly on a clear, mild morning. If the air-cells be punctured with a small, sharp instrument of any kind, they canmot, of course, be again inflated, and the "tootings," consequently, are at an end.

These birds, like the ruffed grouse, are extremely pugnacious at 
these times, and during the early period of incubation the males meet at early dawn at particular spots termed "scratchinggrounds," where they toot and strut about with extended wings and wide-spread tails, much in the pompous style of turkey-gobblers; and, after a little while thus spent in expressing their wrath and defiance, they engage in the most obstinate and sanguinary conflicts, not inferior to the battles often witnessed between gamecocks.

During these encounters, they spring up in the air and strike their antagonists with the utmost fury, and oftentimes with the greatest effect; feathers are freely plucked from each other's bodies, and their eyes are not unfrequently seriously injured before one or other of the combatants gives way and flies to the roods for shelter. A friend of the author, who is very familiar with the habits of these birds, informs him that last spring he witnessed, for over an hour, a series of battles between a number of these birds upon a farorite "beat, or scratching-ground," and declares that, after they had all retired, he might have picked up a hatful of feathers which they had torn from one another.

The nest is formed upon the ground, in a very secret spot upon the open plain, or perhaps at the foot of a small bush. It is rudely constructed with a few leaves and particles of grass, and contains from eight to twelve eggs of a brownish dirt-color, and somewhat larger than those of the Tetrao umbellus. The prairie-hen sits eighteen or nineteen days.

The birds are able to run a very short time after hatching, and the mother alone attends upon them, supplying them with food, calling them around her by a cluck, and nestling them under her wings at nightfall or when the weather proves unfavorable, rery much in the style of the common barn-hen. When the young leave the nest the hen separates from her mate. The pinnated grouse is not so retiring and secluded in its disposition as the other variety, and is not very difficult to domesticate even when taken wild, as it soon becomes tame and accustomed to the presence of man. 
Audubon cut the tips of the wings of sixty of these birds towards the close of the summer, and turned them out into an enclosure, where they remained quite contented the whole winter through, and soon became sufficiently gentle to feed from the hands of his wife. They appeared quite unmindful of their former state of freedom, and conducted themselves very similarly to the tame fowls, with which they often mingled on the most friendly footing. In the spring, they "tooted" and strutted about in the most pornpous style imaginable, even as much so as if they were still in their native haunts, and even coupled and hatched many broods. Their pugnacious tempers would not permit them to quail even before the threatening presence of the largest turkey, and they would not unfrequently take a round or two with the dunghill-cocks of the poultry-yard. The pinnated grouse, as the other variety, hatch but one brood each scason, except when disturbed, as they are frequently, by the crows, hawks, polecats, raccoons, and other animals. When wandering about with their young, if interrupted, they resort to the same artifices as the partridge to protect their young. Their food consists of seeds of the sumach, grapes, grain, wild strawberries, cranberries, partridge-berries, whortleberries, blackberries, and young buds. They also partake of worms, grasshoppers, flies, and insects generally. In the winter season they eat acorns, the tender buds of the pine, clover-leaves, and, when convenient to their haunts, will frequent buckwheat and other stubbles.

They are said to remain stationary during the whole year round, and show no disposition to migrate or travel, as the ruffed grouse or partridge. They affect the dryest situations, and avoid as far as possible marshy or wet places, and partake very sparingly of water ; in fact, depend entirely for a supply of this fluid from the morning dew, which they collect from off the leaves of plants. So dry are the situations which these birds generally frequent, that it is absolutely necessary to carry water along for the dogs; otherwise, they will soon be entirely overcome by thirst. 


\section{FLIGHT.}

If surprised, the pinnated grouse rises with a moderate whirring sound; but, if they discover the sportsman at a distance, they run off with the utmost speed, then squat and remain perfectly silent till passed by or put up by the dog. Their flight is strong, regular, and tolerably swift, and at times, according to Audubon, protracted to several miles without intermission. They fly less rapidly than the ruffed grouse, and often repeat two or three cluckings when about to spring or when on the wing; they also frequently take to the branches of the highest forest-trees, and, if then shot, they fall and turn round and round with great violence, not unlike a common chicken, till dead. If slightly wounded only, they run with great swiftness, and hide themselves in some secluded spot, where they remain motionless.

\section{FEEDING AND ROOSTING.}

Prairie-chickens resort to their feeding-ground at a very early hour of the day, and retire towards noon to preen and dust themselves in the ploughed fields or along the roads, and do not come out again till late in the afternoon.

They do not, as a general thing, roost on trees, but, like the partridge, they select a little eminence of ground in the open field, and squat about within a few feet of each other; at all events, such is their usage during a greater portion of the year.

When the several broods have united and formed packs, they are said to resort to the trees and fences to roost, which habit they continue till the following season of pairing.

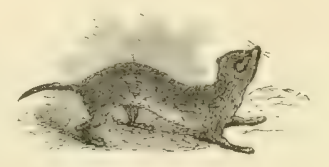


TIME FOR SHOOTING.

The pot-hunter who shoots for the markets hunts these birds long before the broods are well grown; the real sportsman, however, does not think of going after them before the middle of $\mathrm{Au}$ gust, when the young birds are so large that it is even difficult to tell them from the old ones, save by their bills and feet.

The various broods remain separate and distinct till the latter part of September or early in October, when they unite together, forming packs in many instances containing several hundred.

As observed under the following heading, prairie-hens are not much esteemed during the winter months, and consequently are not generally sought after by the epicurean sportsmen, who deem it but just and right that our game should be killed only at those periods when it is in its best condition.

\section{THEIR FLESH.}

The comparative merits of the meat of these.two varieties of grouse are often a subject of discussion among sportsmen and epicures, whose opinions are often entirely at variance. We know very well that the tastes of people are much influenced by circumstances, and we are all apt to relish that most which it is most difficult to obtain; and the residents of those parts where prairiehens are abundant, as a matter of course, generally prefer the white and delicate meat of the ruffed grouse, while those that live in the Atlantic States, and seldom or never see a prairie-hen, greatly prefer the dark meat of the latter bird, as it is to them a greater novelty and luxury than the other. They are considered a great delicacy at the East, and, when exposed for sale, command extravagant prices,-seldom less than five dollars a brace; although we have purchased superior ones in the Philadelphia markets for two dollars, and even less.* We do not think them equal, by any

* The price of these birds, since the opening of the various direct arenues to the West, is very much reduced, and will continue so till the Eastern demand causes them to be exterminated at all accessible points. 
means, in point of flavor to the ruffed grouse. We should remember, however, that the flesh of the prairie-chicken is far more tender and juicy during the months of August and September than at any subsequent period. We at the eastward, therefore, seldom if ever partake of them in their best condition, as the weather is then too warm to admit of their transportation.

At this time the flesh of the prairie-fowl is also light-colored, whereas in the winter season, when we usually receive them from the West, it becomes very dark, and is but little esteemed by those accustomed to hunt them.

\section{OTHER VARIETIES.}

There are other varieties of grouse found within the limits of the United States, two of which we will merely mention. They are occasionally met with in the wilds of Maine and Massachusetts, but are more common in Canada. Their haunts are very secluded, and they seldom encounter the form of a human being, and consequently are not much alarmed at his presence. Their flesh is dark, and resembles that of the prairie-hen:-Tetrao saliceti, willow grouse; and Tetrao Canadensis, the spotted or Canada grouse.

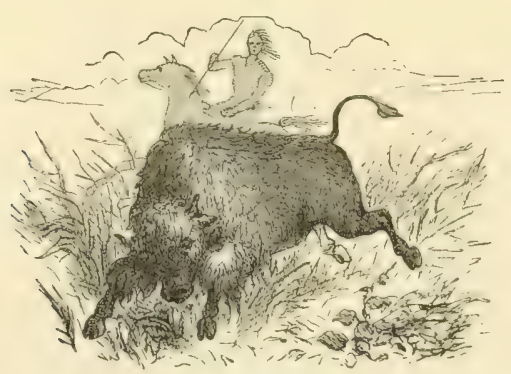




\section{MEMORANDA.}

1. The prairie-hen is now almost exclusively confined to the open champaign countries of the West.

2. Their habits and modes of life are very different from those of the ruffed grouse; the one seeking the seclusion of the deepest forests, while the other delights only in the open plains.

3. The time of pairing, period of incubation, number of young, and habits of male birds, all much the same as the ruffed grouse.

4. The cock birds at the pairing season are heard "tooting" instead of "drumming;" they are very pugnacious, and fight with great spirit among themselves during the period of courtship.

5. Unlike the ruffed grouse, the pinnated are easily domesticated, and will pair and hatch in captivity; they exhibit no disposition to migrate, as the other variety does.

6. Their meat is dark, and inferior to that of the ruffed grouse.

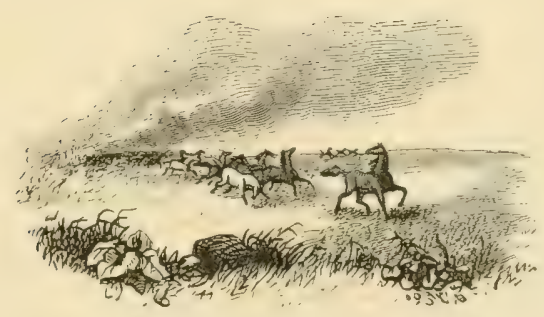




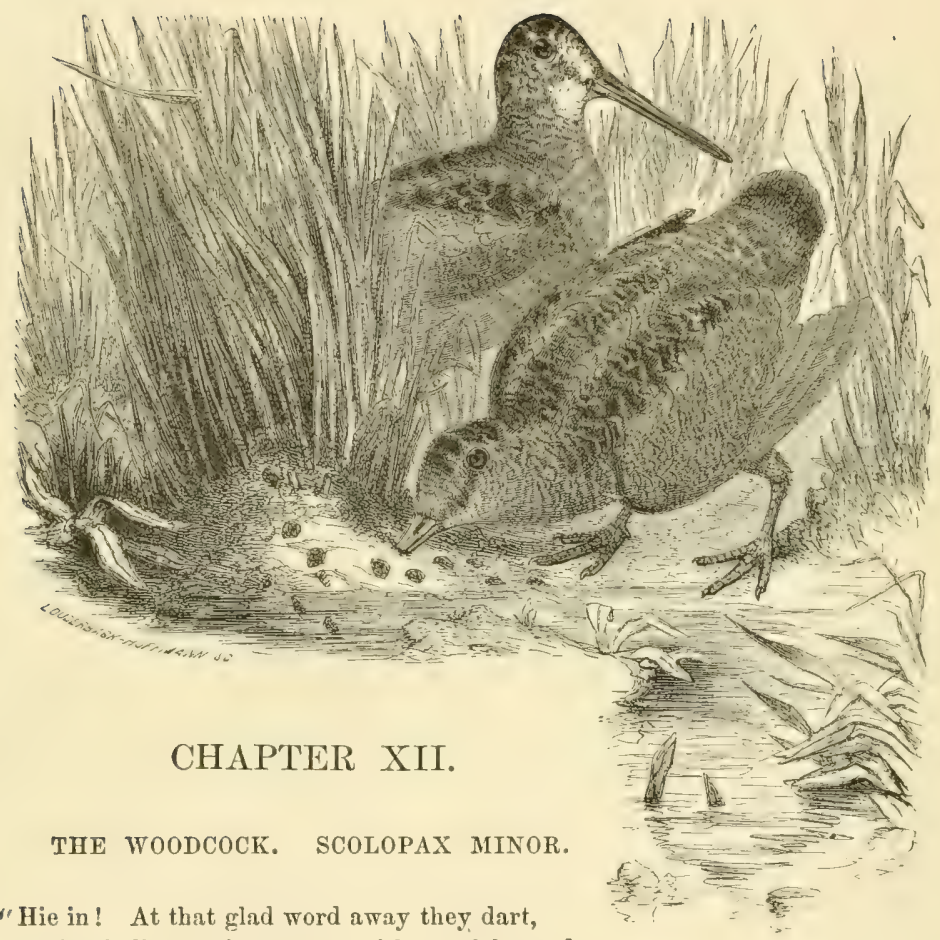
And, winding various ways, with careful speed Explore the cover. Hark! that quest proclaims The woodcock's haunt."

THE CLAIMS OF THE WOODCOSK.

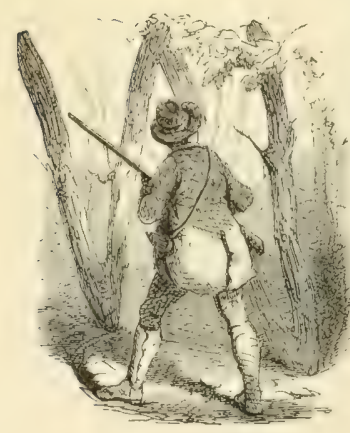

HAT bird is there in the catalogue of the American sportsman which surpasses the woodcock, whether we consider the beauty of its plumage, its general contour, the richness and delicacy of its meat, or the pleasure derived from shoot ing it? Sportsmen eagerly pursue this interesting and noble bird in every quarter where he makes his appearance, and ex perience more gratification in the display of a couple of woodcocks than they would in the triumphant exhi212 
bition of double or treble the same number of partridges, or any others of the feathered tribe. There seems to be something peculiarly attractive to the true sportsman in the very appearance of this bird; for how often do we observe him examine with delight the long and slender bill, variegated plumage, tapering legs: and large, mellow black eyes of each innocent victim, before consigning him to the game-bag, and even exhibit more than ordinary care in smoothing down and arranging his ruffled and bloody feathers.

We, with the rest of shooters, both American and English, are quite an admirer of this bird, and derive more satisfaction from killing a few couples of them than we do in the slaughter of a multitude of rails or a fair proportion of partridges. Why we have this feeling we will not pretend to explain; but we know that we have it, and have noticed it in others, and have more than once watched, with some degree of astonishment, the eagerness with which most of our friends seek to bring down a solitary woodcock, that perchance is seen to flutter across their patl when in pursuit of other game, and, if successful, they always evince more self-satisfaction than if they had bagged two or three brace of partridges. In England, where these birds are much less plentiful than they are with us, "cock-shooting" is highly prized-in fact, is considered by many as the "fox-hunting" of shooting; while all lovers of the dog and gun regard a good day's woodcock-shooting as the very ne plus ultra of sport; and Watts, in his versificution of field-sports, thus cautions the anxious shooter when in quest of this game:-

"Have patience; recollect my words:

A couple of these precious birds

Yield more delight to sportsmen true

Than any other game can do."

These doggerel lines, though they do not in themselves make any great pretensions to the chaste harmony of poesy, are, nevertheless, sufficiently expressive to show the estimation of this bird in the eyes of the English gentry. 


\section{THE NOMENCLATURE OF THE WOODCOCK.}

The nomenclature of the woodcock, like that of most other of our game-birds, is somewhat confused, being known in rarious sections of our country under the different appellations of mud-snipe, blind snipe, big-headed snipe, marsh-plover, and woodhens. The latter title, however, is not often applied to this bird, except by the over-fastidious and scrupulously chaste huckster-women of our market-houses.

\section{DESCRIPTION.}

The male woodeock is ten inches and a half long and sixteen in extent; bill, brownishr flesh-color, black towards the tip; the upper mandible ending in a slight knob, which projects one-tenth of an inch beyond the lower, two inches and a half long, and grooved; forehead, line over the eye, and whole lower parts reddish tawny: sides of the neck inclining to ash; from the fore part of the eye backwards, black, crossed by three narrow bands of brownishwhite; back and scapulars deep black, each feather tipped or marbled with light brown and light ferruginous, with numerous fine zigzag lines of black crossing the lighter parts; quills, plain dusky brown; tail, black, each feather marked along the outer edges, drab-color above, and silvery-white below; lining of the wing bright-rust; legs and feet a pale-reddish color; eye very full and black, seated high and very far back in the head; weight, five ounces and a half, sometimes six.

"The female is twelve inches long and eighteen in extent, weighs eight ounces, and differs also in having the bill very nearly three inches in length; the black on the back is not quite so intense, and the sides under the wings are slightly barred with dusky."

\section{COMPARED WITH THE ENGLISH VARIETY.}

This bird is considerably smaller than the foreign variety; in fact, weighs fully one-third less, seldom exceeding six or nine 
ounces; while the ordinary weight of the English cock is never less than twelve or fourteen ounces, and two are mentioned by writers as having been killed weighing sixteen and seventeen ounces respectively. We have never met with an American birc? heavier than nine and a half ounces, save in one instance, although we have been induced to test the weight of many birds of our own shooting, as well as those exposed in the markets, that seemed to us remarkably fine specimens and perhaps above the usual standard in point of size, but have generally been disappointed in the results; for they have seldom reached eight ounces. A sevenounce bird makes a fine show, and must be full-grown, and in good condition, to weigh this much. We shot a very fine cock last season that weighed over ten ounces, and it now adorns our cabinet.*

The plumage of these two varieties is also considerably different, and the flesh of the American bird is pronounced superior in richness and juiciness to the English.

\section{ONE SPECIES ONLY.}

Many of our sporting friends believe that there are two species of woodcocks indigenous to America, - a large and a small variety. This, however, is not the case, but an error-and a very natural one-arising from the great disparity in the respective sizes of the male and female bird. The latter, strange to say, is much the largest, and not unfrequently weighs two, three, and even four ounces more than the male bird.

\section{HABITS OF WOODCOCKS.}

The habits of woodcocks are very interesting, and in sorre measure mysterious. They are migratory, and extend their journeyings as far north as the Canadas and as far south as Florida.

* G. D. Wetherill, Esq., informed us, a few days since, that a gentleman sent him, a year or two ago, a woodcock that weighed fourteen ounces, which was shot in New Jersey, and it was his intention to have had it mounted, but, owing to the negligence of the party who brought the bird, it was too far gone before he recerved it. 
They breed and rear their young throughout the Middle and Northern States, and at the approach of winter move off to the Far South, in quest of the rich and loamy soil of. those temperate climes. Notwithstanding the greater mass of these birds migrate south, there is but little doubt that numbers of them remain in Pennsylvania, Jersey, and Delaware, during the whole winter through, as it is no unusual circumstance to shoot an occasional cock at all periods of the cold weather in these States. Early in the spring, woodcocks abandon their winter-quarters in the South, and betake themselves to the Northern States for the purpose of incubation; some few, however, it is not unlikely, remain in the higher elevations and marshy solitudes of the South the whole summer through, and there accomplish those promptings of nature which impel so many of their brethren to seek the cool alder-swamps of the Far North.

\section{FORMATION OF THE HEAD.}

The formation of the head is somewhat remarkable, and is a striking peculiarity of the woodcock. It is large and triangular. The large, prominent black eyes, set far back in the temples, a considerable distance from the bill, give it rather a strange but bold and expressive appearance; and there are few pictures more pleasing to the eye of a sportsman than the sight of a startled woodcock just on the point of springing, or rather when in the attitude of fear, arising from the stealthy approach of the shooter. Notwithstanding woodcocks possess such beautiful large eyes, their vision in full day is very incomplete; in fact, they are incapable of supporting a glaring light, and consequently see much better in the twilight than at any other time.*

Woodcocks are essentially night-birds, and remain concealed, during a greater portion of the day, in secluded thickets, or hid

* M. T. W. Chandler, Esq., informs us that he knew of two instances in which woodcocks flew in bright day against a brick dwelling and were killed.

These two facts are of themselves sufficient to prove the imperfect vision of this bird in the drytime, or they certainly would not have made such a mistake in their course. 
away in the rank tussocks of the marshes, and only feed freely in the open grounds at early dawn or towards sunset. This will be seen more particularly when we come to speak of the habits of these birds along the ridges of the Southern rivers. When favored by moonlight, woodcocks wander about in search of food during the whole night, and at such times, like rails, become very fat. We do not pretend to assert that woodcocks feed only during the hours of twilight or moonlight, but that, from the peculiar position and construction of their eyes, they are far better calculated to move about at these times than any other.

The darker and more dense the covert, the better is it suited for the haunt of woodcocks, as, their eyes being so very large and set so far back in the head, they are enabled to collect every faint ray of light which penetrates through the thickest and most entangled foliage: and in such places they may be seen running about and feeding during the bright sunshine.

There is no bird of which country-people are more ignorant than of the woodcock, as they are seldom seen by any except those who go in quest of them in their wet and often dreary haunts; and the confiding and inquisitive sportsman will often be led astray if he listens to the silly reports of our agriculturists respecting them, and perhaps find himself on the track of a company of sandpipers, woodpeckers, or other less dainty and interesting birds.

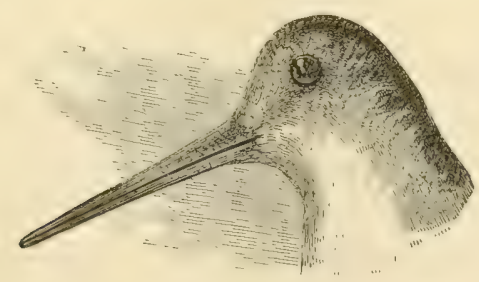

FOOD.

This timid and unsocial occupant of our woody delves and rank marshes does not, as is erroneously supposed by many, live by means of suction; but their food is composed of worms and several spe- 
cies of larve, which they find concealed under the leaves and turf of tine thickets, as well as in the open bogs. Some sportsmen assert that when cocks are feeding they strike their long bills into the soil, and then, raising their bodies high on their feet, they open their wings and flutter round and round until they have sunk their bills sufficiently far into the ground to reach their prey. We do not know positively whether cocks perform these rather singular gyrations, or, more artistically speaking, "pirouettes," but must confess that we are rather dubious on the subject, as, with our liberal opportunities of observing the habits of game-birds, we have never yet been able to discover a woodcock thus employed, although on one occasion in particular we watched a couple feeding for more than an hour, and only noticed them dexterously turn over the withered leaves, and every now and then probe, with the greatest facility, the rich loamy soil with their long slender bills. We are inclined to believe that this report of the feeding of the woodcock is more the result of imagination than of actual observation, like many other vulgar errors respecting natural history. It is possible, however, that these birds might be tempted to resort to some such process as the above to enable them to bury their slender bills deep into the earth in some particular spots where the soil is extremely dry; but, unfortunately for the support even of this hypothesis, woodcocks are never found in such places, and even if they were, they could not hope to extract from such a soil their usual food, no matter how deep their pirouetting might enable them to bore. We would, however prefer abandoning entirely this fanciful idea, and should not perhaps have given it as much attention as we already have, had we not found the subject referred to by a very respectable writer of our country, who seems, from his remarks, to give some credence to the report.*

The American cock, without doubt, feeds in the same way as the European variety, and which is minutely described by a close observer, who had a fair opportunity of studying the habits

* We refer to the remarks of J. S. Skinner, Esq., on this head. 
of these interesting birds, in the aviary of St. Ildephonso, in Spain.

"There was," sayș Mr. Bowles, "a fountain perpetually flowing to keep the ground moist, and trees planted for the same purpose; fresh sod was brought, the richest in worms that could be found. In vain did the worms seek concealment when the woodcock was hungry; it discovered them by the smell, stuck its bill into the ground, but never higher than the nostrils, drew them out singly, and, raising its bill into the air, it extended upon it the entire length of the worm, and in this way swallowed it smoothly, without any action of the jaws. The whole operation was performed in an instant, and the motion of the woodcock was so equal and imperceptible that it seemed doing nothing. It never missed its aim: for this reason, and because it never plunged its bill beyond the orifice of the nostrils, I concluded that smell was what directed it in search of food."

With the foregoing quotation we will dismiss the subject, trust. ing that some of our friends may yet enlighten us if they should ever catch a woodcock engaged in these evolutions.

THE BILL.

The bill of the woodcock is well supplied with nerves, and is so extremely sensitive to the touch that few worms can hope to escape its searching explorations, if within two or three inches of the surface of the soft earth into which they delight so much to bore. Woodcocks are very greedy, or rather we should say voracious, birds, and are both vexatious and difficult to keep in a state of captivity, owing to the trouble consequent upon obtaining a sufficiency of their usual food for them. An English writer observes of this bird:- "A woodcock in our menagerie very soon discovered and drew forth every worm in the ground, which was dug up to enable him to bore; and worms put into a large gardenpot, covered with earth five or six inches deep, are always cleared by the next morning, without one being left. The enormous quantity of worms that these birds eat is scarcely credible; indeed, it 
would be the constant labor of one person to procure such food for two or three woodcocks. The difficulty of procuring a sufficiency of such precarious aliment determined us to try if bread and milk would not be a good substitute; and we found that by putting clean washed worms into the mess, the bird soon acquired a taste for this new food, and will now eat a basin of bread and milk in twenty-four hours besides the worms it can procure."

We quote these remarks in support of our assertion as to the voracity of these birds, and also for the information of any one Tho may have a fancy to keep one of them, either as a pet, or for the more laudable purpose of observing its habits. This singular voracity on the part of woodcocks is no doubt one of the principal causes of the unsocial and solitary lives which the whole species seem to prefer, as no one spot, however rich in worms or larvæ, is capable of producing sufficient food for any length of time for more than one of these greedy cormorants.

\section{INCUBATION.}

Woodcocks begin laying in April, sometimes much earlier: the nest is formed in a very artless manner, generally composed of a few dried leaves or small portions of grass, and situated at the foot of an old stump or tussock, within a copse or thick wood. It usually contains three, four, or five brown-spotted eggs, over an inch long. The period of incubation is about the same time with the partridge-three weeks; and the young leave the nest a short time after escaping from the shell, but are not by any means as expert at running as young partridges, it being no uncommon circumstance to catch young cocks, but very difficult, on the other hand, to make captive a young partridge, even when only a day or two old.

At this season of the year the male bird is said to perform, at times, more particularly about early dawn, some very singular manourres: rising by a kind of spiral course to a considerable height in the air, uttering a sudden or sharp "quack," till, having gained his utmost elevation, he hovers round in a wide, irregular 
manner, making a sort of murmuring sound, and then descends with the same rapidity that he arose. This movement, accompanied by the short, discordant note or "quack," is the call of the male to his favorite female.

We must not forget to mention one other peculiarity of these birds, and that is the somewhat extraordinary habit they have of carrying their young on their backs from place to place. We have never been so fortunate as to see a woodcock adopt this novel mode of conveyance for her young, and must confess that we are rather skeptical on the subject, although we have heard it from others who have witnessed it, - at least, they told us so, and of course we could not doubt their word, though we might have thought of the "traveller's privilege." Notwithstanding the improbability of the whole affair, it is well supported by the assertions of Viellot, in his Galerie des Oiseaux, for he states that such is the fact, and, moreover, that he has seen them do it "plusieurs fois."

Many persons believe that woodcocks raise two broods each season. Whether or not this is the case in the Northern States, it is difficult to say; we do not doubt, however, that such is often the fact, when circumstances exist similar to those that drive the partridge to a second incubation. "Frank Forester" expresses himself quite positively on this point, and we know no one in whose opinions upon such matters we ought to place so much confidence, as this accomplished sportsman has certainly had ample opportunity, as well as inclination, to ascertain such interesting facts.

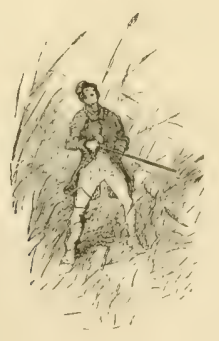


He says:- "The ordinary number at a hatching is four birds, and if the first brood gets off early the parents immediately proceed to a second incubation, the male bird in this case taking care of the first brood until the second gets off, when all associate together until the moulting season, when all ties are dissolved, and they know thenceforth neither kindred nor kindness." If the season is very forward and mild, woodcocks' nests may be found even as early as March or perhaps the latter part of February.

\section{TIME FOR SHOOTING COCKS.}

If the weather continues favorable during the breeding season. many young birds are large enough, throughout the Middle States, to shoot in July, but many more half-grown ones will be found.

If we could hope to exert any influence over the shooting propensities of the sporting community, we would advise them to abstain from hunting these birds till late in September, or rather October, when their age and increased size render them not only a savory dish for the table, but the rapidity of their flight insures them some chance of escape from the ever ready gun. No sportsman can take any particular credit to himself for the wholesale slaughter of young cocks during the month of July, as at this time many of their victims can scarcely fly over a few yards, and might as well be knocked down with a long pole as fired at with a gun. However, both custom and the laws have sanctioned the barbarous habit of shooting these birds at a much earlier period than October; in fact, have given license for their destruction when only half Tedged, and when, perhaps, the old birds are still engaged in the satching or rearing of a second brood. By the passage of these injudicious enactments, our State legislators actually adopt and encourage a certain plan to render this species of game, as well as other kinds, nearly extinct throughout the country, in the course of some few years. All we might say upon this subject would avail but little, without the cheerful assistance of more wise legislation. We therefore pass it by with these few observations to all intelligent and liberal sportsmen, trusting that no gentieman 
who follows the sports of the field as a manly and noble pastime will henceforth be so recreant to the cause of humanity, and so blind to the high duties of the craft, as to be seen with a gun in his hand, at all events, in the month of June, in quest of the feeble young cocks.

At this early period all will acknowledge that woodcocks are under the parental care, and generally are too weak to raise their tender limbs above the tops of the lowest thickets, and not unfrequently they drop dead from mere fright on the discharge of the fowling-piece.

Such conduct on the part of shooters who ought to know better is disgraceful in the extreme; and we cannot understand what pleasure can be derived from killing these miserable little birds one moment before the time set apart for their destruction, as they are too small and insipid for the table even in July; and honorable sportsmen should not take any pride in doing that which they are forced to do by stealth, as is necessarily the case if they go after them in the latter part of June. Every day-nay, every hourof existence is of the utmost importance to woodcocks at this period of the year: the destruction of a single old one may involve the loss of a whole brood of young ones, which, if a few days older, would have been able to take care of themselves. We know of several sportsmen in our city who are in the habit of slipping off a few days before the close of June, to have, as they term it, "the first crack at the cocks;" and we hope that their eyes may meet with these remarks, and that they may relish them in the right spirit and mend their ways accordingly.

The law does not sanction the shooting of these birds, in our Northern States, before the fourth of July; and it would have been far better if the framers of those legal enactments had prolonged the term of prohibition through the months of July and August. Some sportsmen, in justification of their wanton amusement, will tell us, no doubt, that cocks are a migratory and uncertain bird, and if we do not kill them in the summer we may not have the opportunity of doing it in the autumn, as they will abandon their 
old feeding-grounds for the Far South, or other spots equally remote. This is not the case; for woodcocks, as before mentioned, remain with us till the cold weather sets in, and if they were not slaughtered in such immense numbers during June and July we should have an abundance of them in the months of September and October. But the fact is, they are nearly all killed during these months, and the few which are left unharmed have become so wild and cunning that they are difficult to be got at. We all know that it is no very unusual thing for even a tolerable shot to bag fifteen or twenty couples of young cocks in the course of one day's shooting; and well may he do it, and make a brag of it besides, when he goes after birds which may be shot on their nests, or are being led about by their anxious parents in quest of food.

The game-laws of most of our States are a "mere bagatelle," that no one regards; in other words, they are all a dead letter, as there are no appointed agents intrusted with the care of them, and there are few if any persons willing to take upon themselves the trouble and responsibility of enforcing them, or calling wilful offenders to account for their many misdeeds. Hundreds of transgressors consequently escape year after year, unwhipped of justice, until at last they lose sight of the law, if there be any, entirely, and stalk boldly over the country, destroying game in season and out of season, just when it suits their fancy or inclination. Why do the inhabitants of New Jersey, Delaware, Pennsylvania, and other States, allow those reckless shooters, just let loose from the purlieus of our cities, to overrun their grounds and kill woodcocks two or three weeks before the time allowed even by law? Is there no one among the respectable and worthy agriculturists of those States possessing sufficient energy or moral courage to make a few examples of these lawless fellows, who sally forth to destroy these noble birds for mere wanton amusement, as the most of them are unsuitable for eating, or any other good purpose, at this early season?

Legislation most assuredly sanctions the "slaughter of cocks" at a sufficiently early day, and every shooter should discounte- 
nance, both by precept and example, the barbarous habit of going after them one hour before the appointed time, as every moment of existence, both to the old and young bird, is of immediate consequence. Many old birds are yet sitting on their nests; while hundreds of young ones are running about, too feeble to take care of themselves, and consequently soon perish if depriver of the protection of their parents. Some of our farmers are fond of shooting, and really enjoy the sports of the field in a fair and legitimate way; and we are astonished that these do not interest themselves so far in this matter as to have the prohibitory time for cock-shooting extended beyond July; for under the present regulations they can never hope to enjoy this sport, as they are always too much occupied during this month in housing their crops to think of devoting any portion of their time to cocking, and the birds are pretty much all killed before their leisure hours come round.

We do not wish to stir up any unfriendly strife between the farmers and citizens; there is already too much jealousy existing on kindred subjects between them; but, at the same time, we do not hesitate to declare that we have no objection to see the former assert their just rights, and maintain them in all matters of this kind, provided they are influenced by a proper spirit. There are, however, many headstrong and selfish farmers in our rural districts, who put us very much in mind of the far-famed fable of the Dog in the Manger, as they neither have a desire or fancy to kill the game themselves nor will they permit any one else to do it. No one, we conceive, has a better title to game generally than the farmer, as it is on his ground that the birds are bred and reared, and it is from the rich gleanings of his stubblefields that they thrive and grow fat.

We would, therefore, respectfully urge the farmer-sportsman to have the enactment regarding cock-shooting changed; for, as it now reads, it is framed only for the benefit of the city shooters. And, when changed, we would also impress upon him the necessity of seeing it duly enforced. 
INGENUITY OF THE HEN IN CONCEALING HER YOUNG.

The hen woodcock, like the partridge, exhibits great ingenuity in her efforts to conceal her young and to draw off the sportsman or his dog from the spot occupied by the nest, or, perhaps, little brvod. She flutters along the ground, dragging her body heavily after her, as if wounded and incapable of flight, until the dog is nearly on her, when she makes off again to a short distance and repeats the same manœurres as before. When she has succeeded in enticing her pursuers a considerable distance from the starting-point, she suddenly takes wing, greatly to the surprise of all, and flies off in beautiful style, and in a very short time returns by a circuitous route to the spot where she abandoned her offspring.

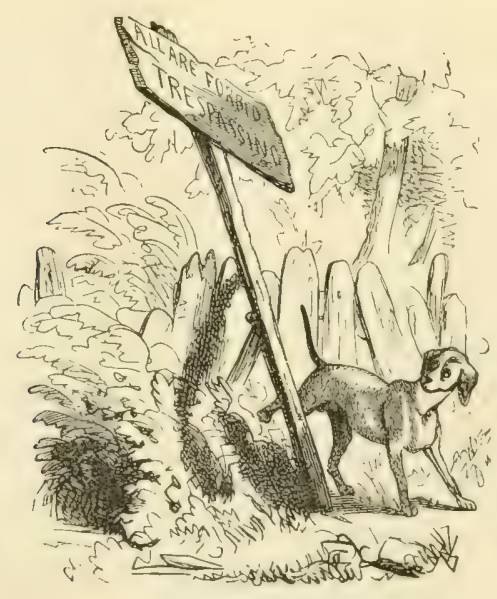




\section{WHERE TO FIND COCKS.}

\section{"Startled by the report, a woodcock springs}

From the low marsh, flitting with nimble wings:

In vain he flies; he feels the fatal lead,

Curves flapping down, and falls with pinions spread."

These birds, as before observer, delight in a wet, loamy soil, and are seldom or never found in the upland districts, but most frequently locate themselves along the marshy willow and alderborders and extensive flats of our rivers. They also secrete themselves in the dense thickets of underbrush along the margins of smaller streams, or hide themselves in the rank grass and luxu. riant fern of our wet meadow-lands. In fact, wherever there is good boring-ground and a certain degree of seclusion, there will be found woodcocks in the month of July, many or few, according to the nature of the soil and the favorable or unfavorable state of the breeding season.

When there has been a long continuance of dry weather, it is quite useless to examine light and open coverts or sparse woods in quest of cocks, as at such times they will be found either on the open wet bottoms, if such spots can then be met with, or more likely in the deep, impermeable thickets and entangled brakes, where the ground seldom or never entirely loses its moisture. On the other hand, when the weather has been extremely wet for some days, woodcocks will betake themselves to the hill-sides or elevated grounds, as they are not by any means partial to too much water, although a certain degree of moisture is absolutely necessary for their very existence. When the weather begins to get cool, they may also be found in the open woody glens or clearings, enjoying, as it were, the mild warmth of the autumn sun, as the feeble rays from time to time pierce the sparse foliage of the overhanging trees, or actively engaged boring in the mossy banks of the warm rills which so often spring up from such sheltered situations. In sections of the country where these birds resort, we can scarcely visit a spot of this kind early in October without 
finding a couple or so of cocks, provided the ground is not too often overrun with shooters.*

Still later in the season they may be met with in the more deep and sheltered wood-swamps, where the insects, larræ, and earthworms, protected in a measure from the biting frosts of more exposed situations, are enabled to remain near the surface during the severest weather. Here it is that the sportsman will discover the perforations or borings of this lonely bird.

The warm and almost impenetrable cedar-swamps are also favorite resorts for such woodcocks as remain in the North during the cold weather, as the springs in such situations seldom freeze, and there is always to be found a scanty supply of suitable food even in the depths of winter. These birds, however, like the snipe, are very uncertain in their movements, being governed a good deal by the state of the weather and the consequent condition of the soil in their natural haunts for boring.

Woodcocks are very abundant in Jersey and Delaware, particularly after a dry spell of weather, as they congregate there from the interior of the country and spread themselves over the wide extent of meadow-lands and marshy cripples so congenial to their habits, and which are so general in the lower portions of these States. Cock-shooting in these districts is as laborious as snipeshooting, if not more so, especially if pursued-as is, we may say, universally the custom - during the oppressive hot weather of July and August. In wandering over these extensive marshes, or, as they are vulgarly called, mashes, it is necessary for the

* Our friend, M. T. W. Chandler, Esq., mentioned to us a few days since, in course of conversation, that he had noticed that cocks are seldom or never found in the swamps of an iron-district. He also stated that he considered their absence from such places owing to the general acidity of the soil, which always, in these iron regions, contains a large proportion of oxygen; a fact, by-the-by, well known to all intelligent farmers, who always spread quantities of lime on such places, to sweeten the soil, as they say, and make it in a condition to produce. We know from our own observation that but few or no worms can be found in these sour marshes, and the vegetable products themselves are coarse and ill-flavored.

Mr. Chandler also states that cocks are rare in the coal-regions, owing, no doubt, to the noxious gases that oftentimes are generated in such soils. 
sportsman to exercise considerable dexterity in stepping from tussock to tussock; otherwise he will often be doomed to a sudden plunge into the filthy oozes that surround him on every side. The excessive heat of the weather is another strong objection to the shooting of woodcocks in the month of July, as the temperature is often so oppressive that the birds will spoil in the course of a few hours after being shot, and, in some instances, even before leaving the field for the day. As for hoping to keep the birds over a day or two, to carry home, such a thing is quite impossible, and the sportsman, consequently, is forced to throw them away sometimes when only a few hours old, if he cannot procure ice to pack them in, which article, by-the-by, is not always to be had in the country.

We have noticed, with sentiments of sorrom, a very prevalent but at the same time very unfortunate ambition on the part of many of our sporting friends, - to boast of quantity rather than quality of game killed.

This braggart feeling should be at all times discouraged and reprobated among gentlemen, as quantity is not by any means a safe test for a superior shot, neither is it the just criterion of an accomplished sportsman. But, on the other hand, quantity not unfrequently goes to prove that he who elaims this distinction has been more eager, more greedy, more selfish, than his companion, and perhaps less courteous and gentlemanly in the field than he should have been. This foolish ambition as regards quantity is often displayed in its most deplorable form in the wanton and reckless destruction of young woodcocks, which, as before observed, are shot by hundreds when too feeble to save themselves by flight, when too young to afford suitable food for the table, and under circumstances, oftentimes, when these desolators of our fields and forests know full well that they can make no use of them. How mortifying, how degrading, in the eyes of humanity, that such a crucl, reckless, and thoughtless propensity for the taking of life should exist in our very midst,---should be encouraged by the example of some of those with whom we daily associate,-and eren ke discovered 
lurking in the breasts of men whom, in our ordinary intercourse with the world, we would fain pronounce amiable, humane, and considerate! We agree with Mr. Skinner when he remarks that "a great fault in sportsmen is the ambition of killing for quantity, which occasions them to protract their hunt until many of the birds are spoiled by the heat and delay. The sportsman should have a spice of chivalry in his composition; he should not be merely a wanton and reckless destroyer. He should always spare the hovering bird, and confine his efforts to others, to the number he can carry in order to his home, for his friends or himself. I have known this pernicious system of shooting for quantity pursued on the grouse, and, to gratify the false pride of killing more than any other party, the time protracted until all the birds killed on the first day were spoiled and had to be thrown away. You should raise your voice against this growing and vicious ambition, and establish it as a rule among sportsmen, that credit should be given only for such game as each returned with in good order.

"Our Indians look upon this habit of the whites with the utmost horror. 'He kills and wastes,' say they, 'without object; and riots over life as if it were a thing of no value. The game vanishes from his desolating path, and the ground is covered by his destroying hand with that which he does not mean to use. The bounteous gifts of the Great Spirit are the mere objects of his wanton destruction.' We should redeem ourselves from this just reproach, and infuse some prudential consideration and moral feeling in our hours of sport."*

* We are glad to observe that the supervisors of our public squares are disposed to encourage the presence of squirrels and birds within these enclosures, by affording them the necessary protection from the many thoughtless and inconsiderate youth who frequent these places of resort. They have also very latterly permitted the introduction of some beautiful peacocks, that seem already contented and quite at home in their new quarters.

The habitual presence of the numberless birds that now build their nests, rear their young, and enliven our parks with their melodious strains, - the presence of the ever-welcome, lively, and frolicksome squirrels which will soon abound in these safe retreats, - the presence of the elegant, graceful, and gorgeous peacock, as he struts majestically about over the greensward, will have perhaps a far more ex- 
Few, we think, can expect to derive much real pleasure or benefit from the exposure consequent upon a cock-shooting expedition, exposed as they are, for hours together, not only to the burning rays of a July sun, but also to the inhalation of the poisonous gases that are always engendered in these miasmatic situations during the summer months. These two circumstances alone, independent of any other reasons, ought to be sufficient to prevent any sensible sportsman from entering into the amusement at this season of the year. However, the temptation to go after woodcock at this time, we must acknowledge, is often very strong; and we are not surprised that but few can resist it, particularly when the law encourages it, and almost every one hears his sporting friends around him boasting of their great success and wonderful deeds the day previous.

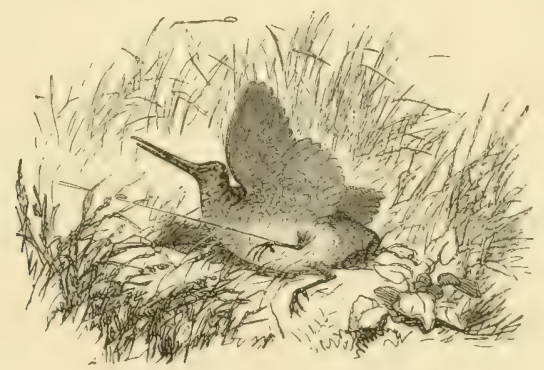

\section{DISAPPEARANCE OF WOODCOCKS.}

During the period of moulting - the latter part of August and the month of September-woodcocks disappear, or are said to disappear, for a short time, from their usual haunts, and retire either

tended, a far more beneficial influence over the community than the city fathers at first supposed or intended.

May we not confidently hope that their presence in these places will engende). in the bosoms of our youth a better appreciation and a more becoming respect for these lowly but still very interesting oljects of creation? will foster and cultivate the kindlier feelings of the heart? will give rise to and encourage a love for the beautiful and a taste for the study of natural history, and perhaps do more than any other plan could towards crushing, as it were, in the very germ, that disposi:ion to kill and destroy which unfortunately is so characteristic of Anerican youth? 
far north, entirely out of the reach of our sportsmen, or congregate, as has been asserted by many, on the wild and rugged hills of the mountain-ranges, and there live a lifo of deep seclusion and indolence during this annual sickness. We have heard, and even read, much upon this disputed point, as to the whereabouts of these birds at this time, and have come to the conclusion that they do not all follow the same biddings of nature, but that some remain closely concealed in their old grounds, others, perhaps, go far north, and many betake themselves to the high grounds of the interior. By the expression of this opinion we are sure not to go far astray from the truth, and at the same time we do not compromise ourselves, or offend the peculiar doctrines of any sportsman upon this subject, as we freely confess our belief, or rather partial belief, in nearly all the theories yet advanced.

In the getting up of this work for the benefit of sportsmen, we wish them all to look upon us more in the light of a compiler than of an author, as our great aim has been to collect from all and every source the greatest amount of information to elucidate the various subjects under discussion, not relying solely upon our own experience and observation, but culling a little here and there from every one that chance or design threw in our way.

It is not an unusual circumstance to find cocks in the wet and rich cornfields during the moulting season. Here they frequently escape the notice of sportsmen, who, by-the-by, generally have a repugnance to liunt in these places, not only on account of the disagreeable walking, but because it is no easy matter to shoot birds when the corn is standing two or three feet higher than one's hear, for the moment the cock is up he is out of sight. We would, however, advise all inquiring shooters to hunt out every moist cornfield that comes in their way at this season, and they will soon be satisfied of the truth of our assertion. In saying this, however, we do not wish to be understood as aiding and abetting the hunting of cocks at this time, for we heartily disapprove of it, even more than we do the shooting of them in July, as they are now in a measure diseased, and not at all suitable for the table: 
but we advise the exploration of the cornfields by the inquiring sportsman or naturalist, for the confirmation of our statement regarding the habits of these birds.

However, when we take into consideration the immense slaughter of cocks during the month of July, it is not very hard to account for their scarcity during the following month, even if it were not the season of moulting; and we see no reason why we should be racking our brains to account for their disappearance.

\section{FLIGHT OF WOODCOCKS.}

The flight of young cocks is slow and regular, and seldom protracted in a cripple to a greater distance than fifty yards. They merely skim over the tops of the reeds or bushes, and drop suddenly and heavily to the ground, with a kind of impetus that sends them running forward several yards.

In July, young cocks are very tender and easily killed, one or two small pellets being quite sufficient to bring them down. Later in the season, having gained strength and muscle, cocks fly with much more vigor. They may then be seen darting off, with a shrill piping note, in sharp and rapid zigzags, even over the tops of the highest trees; and it requires the steady hand and piercing eye of the long-practised shooter to stop them in their headlong career.

When found on the open grounds and meadows, it is easy enough to shoot woodcocks; but it is quite another affair in the high woods and thickets, as they rise, not unfrequently, in an almost spiral, perpendicular direction, twisting and turning with such rapidity that they gain the tops of the trees and dart off before they can be fully covered even with the sharpest eye and readiest hand.

\section{FIRE-HUNTING OF COCKS.}

There is a mode of taking woodcocks in Louisiana, which is practised, perhaps, in no other section of the country; it is termed "fire-hunting," and was, no doubt, introduced by the French population of those parts. A full description of this sport, from the graphic pen of T. B. Thorpe, Esq., will be found in Porter's 
republication of "Hawker." Fire-hunting is almost entirely confined to a narrow strip of country running from the mouth of the Mississippi up the river about three hundred miles. Woodcocks resort in great numbers to the interminable swamps of this region, and, according to Thorpe, even remain in these solitudes during the spring and summer months, to breed and rear their young. It is perfectly useless for the sportsman to attempt the pursuit of cocks in these fastnesses, overrun as they are with deep and matted grass, high cane, and rank vines. Although many cocks remain in these marshes during the warm weather, still, the greater number of them go off to the North for the purpose of incubation, and, at the approach of winter, return with increased forces to pass the cold months in these secure and favored spots. It is then that the "fire-hunting" takes place, and continues during the months of December, January, and February. Though the marshes at this time are crowded with these quiet and secluded birds, it is almost impossible for the shooter to get a sight of one of them; and this fact, together with their immense numbers, is perhaps a palliation for the unsportsmanlike practice of "fire-hunting."

The sport is carried on in this wise:-The shooter, armed with a double-barrelled gun, and decked with a broad-brimmed palmetto hat, sallies forth on a foggy night to the "ridge," where the cocks are now feeding in wonderful numbers. His companion on these expeditions is generally a stout-built negro, bearing before him a species of old-fashioned warming-pan, in which is deposited a goodly supply of pine-knots. Having arrived on the ground, the cocks are soon heard whizing about on every side; the pine-knots are quickly kindled into a flame, and carried over the head of the negrn. The shooter keeps as much as possible in the shade, with his broadbrimmed palmetto protecting his eyes from the glare, and follows close after the torch-bearer, who walks slowly ahead. The cocks are soon seen sitting about on the ground, staring wildly around in mute astonishment, not knowing what to do, and are easily knocked over with a slight pop of the gun, or more scientifically brought to the ground as they go booming off to the marshes. 
The lurid glare of the torch only extends to a distance of twenty yards or so around the negro; the sportsman must, therefore, be on the qui vive to knock the birds over as soon as they rise, otherwise they will immediately be shrouded in the impenetrable darkness of night.

These excursions are carried on with great spirit, sometimes continue the whole night through, and the slaughter of cocks is often very great; with an experienced "fire-hunter" it is no unusual occurrence to bag in this way fifty couple before morning. This plan of taking woodcocks is very similar to that pursued ages ago by the fowlers of England, and is termed "bird-batting." Instead of the gun, they made use of nets to throw over the birds, and bludgeons to knock them down whenever a favourable opportunity presented itself. It was also deemed very necessary in these "bird-battings" for the torch-bearer to ring a loud bell without intermission, as its sound at the dead hour of the night was thought to bewilder or stupefy the birds to such an extent that they became transfixed to the ground, and therefore offered an easy mark for the fowler. If the ringing of the bell was for a moment discontinued, the birds were very apt to arouse themselves from their lethargy, fly off, and consequently frustrate the fowler's designs.

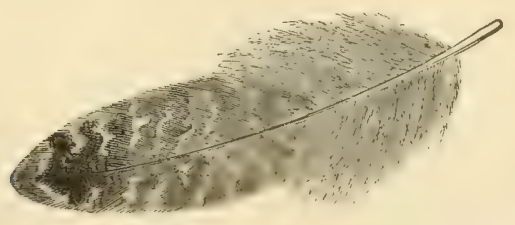

NETS AND SNARES.

Formerly, when cocks were much more plentiful in England than they are at present, multitudes were taken in glade and spring-nets, which were hung in the moist places where their "marking and meutings were observable." These birds are very loath, while. feeding, to pass over any obstruction that may lie in their way, but would rather pursue a confined and tortuous path than turn 
from their course for the purpose of scrambling over the slightest barrier that may obstruct their progress.

This peculiarity of woodcocks has been taken advantage of by the fowlers and poachers of England, who are said to place their nets between the tufts of heath, with avenues of small stones formed on each side, leading up to them, and by this contrivance are successful in taking great numbers. They are also captured by these gentry by means of horsehair nonses, set about in their feeding-grounds, similar to those referred to when speaking of the partridge.

Woodcocks are quite abundant in Ireland, and numbers of the English nobles resort there annually to shoot them. It is usual to hunt them in this country with the assistance of men and boys, termed "springers," who penetrate into the thickets and woody glens, hallooing and beating the bushes on every side, so as to flush the astonished cocks from their close retreats. The sportsmen, while this is going on, move about in the clearings, and watch every opportunity to knock the poor birds over as they endeavor to escape from one cover to another.

This method of killing cocks, no doubt, is quite exciting, but cannot compare with the regular way of hunting them with dogs, and would not be resorted to by English sportsmen except $e x$ necessitate rei.

\section{DOGS FOR COCK-SHOOTING.}

Cocks lie well to dogs, and, if their habits of life did not force them to select such inaccessible places to feed, they would afford as much sport as partridges. If cocks were left undisturbed during the summer months, and not hunted till October, we should have plenty of them at this agreeable season, and certainly in much better condition. The English derive much more pleasure from cock-shooting than we do in this country, as the whole charm of this pastime is destroyed with us by the barbarous custom of shooting the old ones in the months of June and July, when sitting on their nests, and frightening the young ones to death by the roar 
of guns, placed in the hands of every awkward booby that can raise sufficient means to purchase a few pounds of shot.

Cock-shooting in England, some of our readers will be surprised to learn, is most generally pursued with the aid of cocker spaniels. We are content to hunt them with our setters and pointers, mary of which are celebrated for their skill and prowess in finding this game. It is particularly necessary that dogs used for cock-shooting should be very stanch, and not over eager, otherwise they will soon be lost to view in the coverts and brakes which these birds most generally frequent, and flush bird after bird without ever being seen or corrected for it.

As for attempting to shoot woodcocks to half-broken spaniels, we should consider such an undertaking too laborious and tormenting to venture upon, although, with good cockers, we can easily imagine that the sport must be much more spirited and enlivening than when pursued with setters and pointers. Cockers, from their size, are much better adapted by nature to the pursuit of this game than either the setter or the pointer, which latter cannot insinuate themselves into the recesses of our briery coverts, no matter how welldisposed for the sport they may be, but are forced to back out of such impassable places, where the courageous little cocker would glide through without suffering the least inconvenience from the thorns and briers.

It is not unusual, in England, to attach small, plaintive bells to the collars of dogs hunting woodcocks, so that their exact position may be known. This practice is a very good one, and, when the covert is very thick, will save the sportsman much hallooing and whistling. When used for pointers and setters, the silence of the bell will announce the point of the dog. The tinkling of the bells, if light and melodious, will not disturb the birds, but rather en. liven the gloom and dulness of the woody glens, and add new spirit and life to the sport.

The bells should be of different tones, so as to distinguish the dogs from each other. We are satisfied that the use of bells conld be made very advantageous in partridge-shooting, in some sections 
of our country, more particularly early in the season, when the coverts are so very thick. We would recommend to those having a fancy to try them, to put a small ring to the dog's collar, to which they might attach the bell by means of a spring-hook, simjlar to those now so generally used for fastening the guard-chain to the vest button-hole. Arranged in this way, the bell can be removed or put on at a moment's notice, according to circumstances.

We are certainly an admirer of the little cocker spaniel, and would advise gentlemen, more particularly those residing in the country, who pursue shooting as a pastime, and not for the mere wanton gratification of bagging large quantities of game, to try their hands with these active little creatures, as we are sure they will be delighted with their boisterous and exciting style of hunting, giving subdued tongue when on the scent of game, and then bursting forth with joyous acclamations when the bird is flushed and on the wing.*

If the reader should ever be so fortunate as to possess a cocker spaniel to whom he can, in good faith, address the following four lines of an epitaph, he may consider himself thrice fortunate indeed:-

"Alike the woodcock's dreary haunt,

Though keen to find amidst the shade,

Ne'er did thy tongue redoubled chant,

But mark quick echoed through the glade."

\footnotetext{
* For the tuition and management of spaniels, see our edition of Youatt on the Dog.
}

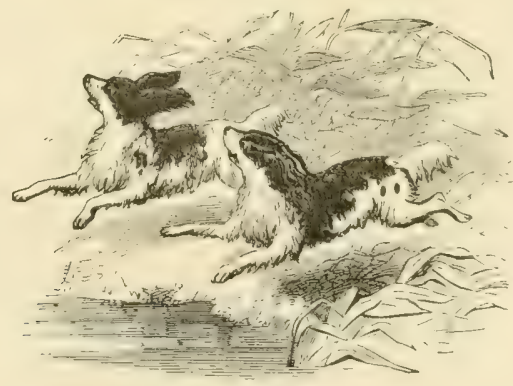




\section{MEMORANDA.}

1. The male bird is much smaller than the female; the former usually weighs from five to six ounces, the latter from six to eight.

2. The American woodcock is much smaller than the English.

3. There is but one variety of woodcock in America.

4. Woodcocks are migratory, and extend their wanderings from the Canadas even as far south as Florida.

5. Their food consists of worms and larvæ, and they are all voracious feeders.

6. Woodcocks breed in the North, and commence laying, if the weather is favorable, even as early as February. The period of incubation is about three weeks.

7. Woodcocks moult in August and September, and at this time they lie very close.

8. Woodcocks frequent moist places, and are seldom met with in other situations.

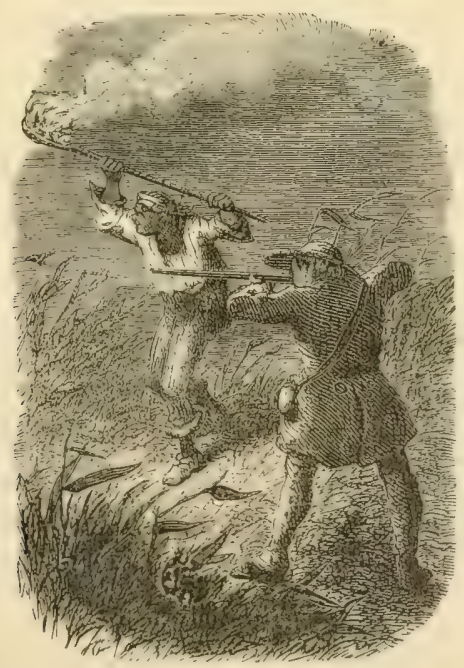




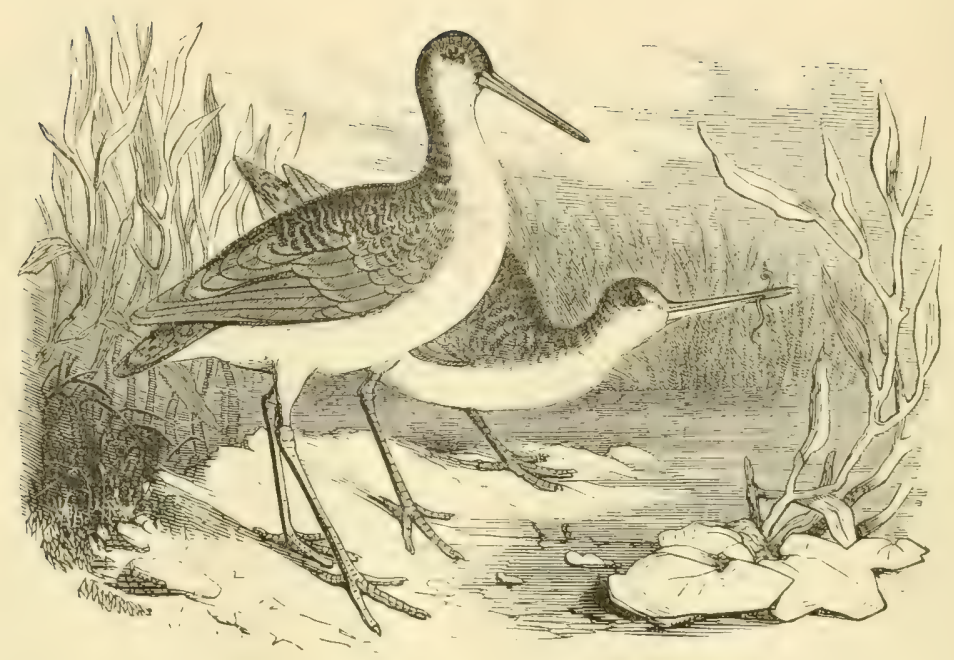

\section{CHAP'TER XIII.}

WILSON'S, OR ENGLISH SNIPE. SCOLOPAX WILSONII-SCOLOPAX GALLINAGO.

"To-day we spring the snipe, And, with an eye as keen as does the bird Himself, by hungers's strongest law compell'd, Explore each shelter'd drain or hollow ditch."

THEIR DISTRIBUTION OVER THE WORLD.

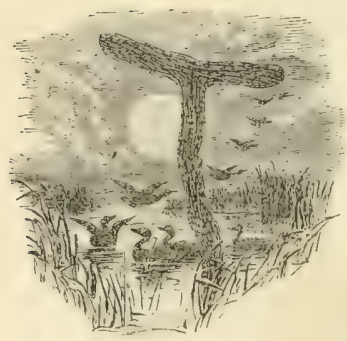

HERE is no game-bird so widely distributed over the whole world as the species now under consideration. They are found in all countries, from the extreme points of Siberia even to the uttermost limits of the South. The West India Islands, as well as Ceylon and Japan, are annually visited by this little fowl, while the rice-plantations of the Carolinas and the fertile meadows of Egypt alike swarm with their multitudes. So numerous are these birds in the rich country of the Pharaohs, that it is 240 
no unusual thing, after the harvest of rice, to sit quietly in one place and shoot a large basketful of them in the course of a few hours. Snipes are equally esteemed in all parts of the world where they are known, and the richness and delicacy of their flesh may be considered as second alone to that of the roodcock; we need not add, therefore, that hunting them is a favorite pastime with the American sportsman.

\section{VARIETIES.}

There are several game-varietics of snipes known in the old World, and all equally sought after by sportsmen; there are also many species in our own country, but only one that attracts much attention from our shooters. In Russia there is a large snipe which occasionally wanders as far as England, and is known there, we believe, as the horseman's snipe, from its superior size and fine appearance. This bird affords much sport to the Russian noblesse, as well as a savory dish for their tables. The double, or solitary snipe, (Scolopax major,) although quite rare in England, is very common in Sweden; it is nearly twice as large as the common snipe, and offers attractive amusement to the inhabitants of that country, who pursue field-sports with as great zest as the sportsmen of our own country. The Scolopax gallinago, or English snipe of America, is closely allied to the common snipe of the Old World; it resembles it in plumage, size, and habits; a little difference, perhaps, may be conceded to the latter variety in point of weight. The observant Wilson, in his usual style of close investigation, discovered a very marked distinction between the English and American bird; and, in consideration of this discovery, Temminck and other European naturalists have very justly dedicated the American snipe to this distinguished ornithologist, by bestowing upon it the title of Scolopax Wilsonii, or Wilson's snipe,-a compliment not less deserved than generously awarded. Wilson states that the American snipe has the same soaring, irregular flight in the air, during gloomy weather, as the snipe of Europe; the same bleating note and occasional rapid descent; springs from 
the marshes with the like feeble "squeak," and in every respect resembles the common snipe of Britain, except in being about one inch less, and in having sixteen feathers in the tail instead of fourteen. Audubon, however, informs us that the notes of the two varieties are quite dissimilar, - in fact, as different from each other as those of the American crow and the carrion-crow of Europe, and expresses some surprise that Wilson should not have mentioned this difference.

Frank Forrester, on the other hand, observes that the cry of the two varieties is perfectly identical, and in this statement he further remarks that he is corroborated by the judgment of several English sportsmen, with whom he has frequently shot.

This snipe is known in Britain as the common snipe, snite, or heather-bleater, and with us is called English snipe, or Wilson's snipe. In Louisiana, the Creoles term it cache-cache, the derivation of which, we imagine, arose from the well-known retired or lurking habits of the bird.

"The snipe is eleven inches long, seventeen inches in extent; the bill over two inches and a half long, fluted lengthwise; brown color; black towards the tip, crown black, divided by an irregular line of pale brown; another broader one of the same tint passes over each eye; from the bill to the eye there is a narrow dusky line; neck and upper part of the breast pale brown, variegated with touches of white and dusky; chin pale; back and scapulars deep relvety black, the latter elegantly marbled with waving lines of ferruginous, and broadly edged exteriorly with white; wings plain dusky, all the feathers, as well as those of the coverts, tipped with white; shoulder of the wing deep dusky-brown, exterior quill edged with white; tail-coverts long, reaching within threequarters of an inch of the tip, and of a pale rust-color, spotted with black; tail rounded, deep black, ending in a bright ferruginous bar, crossed with a narrow waving line of black, and tipped with whitish; belly pure white; sides barred with dusky lines; legs and feet a very pale ashy-green; sometimes the whole thighs and siles of the rent are barred with dusky and white. The 
female differs in being more obscure in her colors; the white on the back being less pure, and the black not so deep."

\section{THEIR IOCATION AND FOOD.}

The snipes of America spend the winter in the Southern States, resorting to the ricefields of the Carolinas, where they often congregate in immense numbers, and are said to be quite tame compared with what they are when they stop with us at the North on their way to more elevated districts for the purpose of breeding. Audubon states that in the South he has seen them in fifties and hundreds in small fields of a few acres in extent. They are also numerous in the wet swamps of Florida during the winter season, but move off at the first approach of spring, tarrying on their way to the North, for a few days, in the various sections of country which they pass through. They arrive in Pennsylvania, New Jersey, and Delaware, in the month of March, according to the state of the weather, but are not often abundant till the following month of April.

Like most other migratory birds, they are quite poor when they first arrive among us, but soon become extremely fat from feasting upon the profusion of animal as well as vegetable food that they find scattered over the extensive marshes of these States. Their nourishment consists principally of worms and larvæ, which, like the woodcock, they extract from the rich, loamy soil by boring into it with their long and slender bills. It was formerly very generally believed by sportsmen, and others who pretended to a knowledge of such matters, that snipes, as well as woodcocks, supported themselves by suction. This, of course, is as erroneous in the one case as in the other. These birds also partake of the tender roots of aquatic plants, and in captivity will feed greedily upon corn-meal and worms, and after a few trials will also learn to relish bread and milk.

In the spring season the snipe performs some very singular manouvres, not very unlike those that are noticed in the woodcock during the period of incubation. If the sportsman should, 
at early dawn, or even at mid-day, visit the low meadows frequented by these birds, he will probably see one or both of a pair mounting high in the air in a spiral manner, beating their wings or sailing around in rapid circles, until they have gained a hundred yards or more in height; then, clasping each other, they whirl around, flapping their wings with great velocity, and then, dropping in micl-air, give utterance to a low twittering or rather rolling sound, supposed to be produced by the action of the wings upon the air in their rapid descent. We have seen them perform this manœurre more than once, but at no other period of the year than the spring.

Towards the close of April, if the weather continues warm, snipes desert the oozy marshes of Delaware and New Jersey and commence moving farther north, where they spread themselves throughout the interior of the upland countries for the purpose of breeding and rearing their young. They are most generally mated when they take leave of these parts. Like other nomadic birds, a few of them, owing to one peculiar circumstance or another, remain with us in the low marshy fallows during the whole summer, and even hatch and rear their young broods. It is no very uncommon circumstance for our shooters to kill an occasional young snipe, as well as old ones, when in pursuit of cocks in the months of July and August.

In the month of May, 1846, while wandering in company with Mr. E. Lewis over his extensive estate in Maryland, we sprang a Wilson's snipe from the midst of an oatfield, and, being surprised as well as attracted by its singular manœuvres, we made search for its nest, which we soon found, with four eggs in it. The situation selected for incubation could not have been better chosen in any portion of country, as it was on a rising piece of ground, with a southern exposure, and protected in the rear by a large wood, and at the foot of this high ground was a considerable extent of low marsh-meadow, watered by a never-failing stream, along the borders of which the anxious parents at any time could obtain a bountiful supply of food. 


\section{PERIOD OF INCUBATION.}

In the State of Maine and other portions of the count:y far north, snipes are very numerous during the summer months. They are also abundant in the Canadas and Nova Scotia, but are not known in Newfoundland or Labrador. In these northern latitudes, snipes inhabit the marshy portions of the hilly districts, as the spots most secure and favorable for incubation. The nest is constructed in a most simple manner,-being, in fact, nothing more than a hollow made in the moss or grass, lined, perhaps, with a few feathers. The brood generally consists of four, and, like the young of the woodcock, are capable of motion as soon as sprung from the eggs. At this tender age, owing to the softness and delicacy of their bills, the young snipes are unable to probe the slimy bogs for worms, and therefore are forced to content themselves with collecting the larvæ, small insects, and snails, that are found on the surface or hid away in the grass or moss. At the expiration, however, of a few weeks, they are sufficiently strong, and their bills quite hard enough, to penetrate into the moist grounds in search of more savory food.

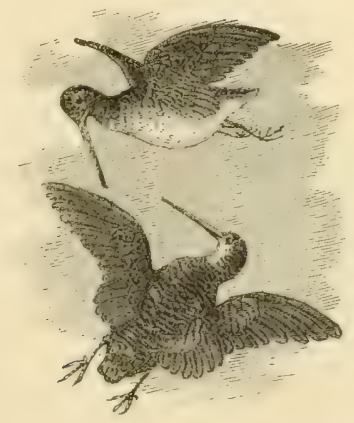

RETURN TO THE SOUTH.

Snipes commence returning to the South in the month of September, accompanied by their young, and of course stop for a while in all their old haunts along the route. They remain during 
several weeks in New Jersey and Delaware, and get very fat while feeding on the marshes. Although they most frequently appear very suddenly and in large numbers in eertain localities, they are not gregarious, but perform their migrations singly, or in rery small wisps, seldom exceeding four or five.

The flight of the snipe, even when going to a considerable distance, is very irregular and devious; they must, howerer, fly with rapidity, as they spread themselves over so wide an extent of country in so short a space of time.

Snipes are, without doubt, very fickle and uncertain in their movements, resorting in great abundance to certain spots on one day, and entirely abandoning them on the following, without any apparent cause, save perhaps a trifling change in the wind or weather. They seem to possess a restless spirit, which impels them to seek on one day the high and open grounds, and on the next the low and sheltered marshes. The presence of a slight and almost imperceptible frost, or the springing up of a northeasterly wind during the night, influences the wanderings of these birds at early dawn; and their sudden appearance at or absence from certain localities is often a source of astonishment to the shooter, who, luxuriating on his downy couch, dreams of the morrow's sport, little heeding the insidious mutation in the elements that drives the sensitive snipe from the farored feeding-grounds of the previous day, and thus frustrates all his bright anticipations.

The snipe family in general has very justly been pronounced the most meteorological of all birds, for their appreciation of atmospheric changes is certainly very remarkable, and far beyond that of any other of the feathered tribe. Their perception of cold or moisture must be exquisitely nice, far beyond any thing which we can form an idea of, as their abrupt shiftings from place to place are governed, we presume, in many instances, by the variations in temperature which are scarcely discernible to the sportsman. For we cannot attribute these sudden rorings on their part to any other cause than those alterations in the atmosphere, unless we believe that they are solely the result of a capricious disposition, 
which oftentimes induces them to abandon the very best of feeding-grounds to go in quest of like spots elsewhere; and this to us appears a very unnatural as well as untenable supposition.

Snipes, like woodcocks, are most voracious feeders, and require an immensity of food, and consequently are obliged to shift their ground much more frequently than many other kinds of birds. This circumstance alone is quite sufficient in most cases not absolutely dependent upon the weather to account for their erratic propensities. When feeding in situations where there is a plentiful supply of food, it is often a very difficult task even for the most zealous sportsman to drive them off; and we have more than once been quite surprised at their apparent tameness, as indicated by their short flights after repeated harassing over some one of these favored feeding-grounds.

In all their peripatetic vagaries snipes are seldom or never found in the woods, but delight in the low, wet meadow-lands, or along the margins of the secluded streams which are so numerous throughout our country; they may occasionally be found in the cornfields, more particularly if the weather is rainy, as well as in the thin woods and even briery thickets, but they do not frequent these situations except under peculiar conditions of the atmosphere.

\section{DIFFICULT TO BE SHOT.}

The flight of the snipe, together with its shyness during its sojourn at the North, and the disagreeable nature of the ground that it alone frequents, renders it the most difficult as well as the most fatiguing and vexatious of birds to hunt. When sprung, it takes wing very hastily, and flies off in rapid zigzag lines for a few paces, in such a confused, irregular, and tortuous course that it is almost impossible even for a snap-shot, during this time, to cover the bird for an instant while performing these elliptical gyrations.

Snipe-shooting, not only in England but also in our own country, may very justly be pronounced the "crux jaculatorum" of sportsmen, as there is no game which requires more skill and judg- 
ment in bringing to bag, or demands a greater share of labor and perseverance to follow. A sporting writer-no great admurer of this diversion, however, we imagine-remarks that "snipe-shooting is a pastime the best calculated (grousing excepted) to try the keenness of the sportsman, to ascertain his bottom, and if he can stand labor, water, mire, swamps, and bogs. He should be possessed of a strong constitution, not liable to catch cold, and have all the fortitude as well as exertion of a water-spaniel; he should be habitually inured to wet, dirt, and difficulties, and not be deterred by cold or severe weather."

This statement, although a little overdrawn, is not far wide of the real truth, as every snipe-shooter knows full well; and, when entering on the sport, each one should be willing to repeat within himself, Audax omnia perpeti. Notwithstanding the numerous ills attendant on this recreation, it has many ardent admirers, who, in spite of wind and weather, cold and rain, mud and mire, are at each succeeding spring and autumn found ready at their posts, all eagerness to commence the fray; and, at the close of every season, each one has a long list of adventures to relate, not, perhaps,

"Of moving accidents by flood and field,

Of hairbreadth 'scapes i' the imminent deadly breach,"

but of many mishaps and hardships encountered during the campaign on the filthy marshes, the most of which, though grievous at the time, in reality added zest to the diversion, and will ever remain imprinted on the memory of the true sportsman as agreeable sourenirs by which to recall the scenes of much past enjoyment.

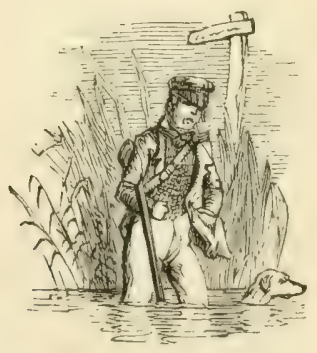




\section{DIFFERENT PLANS FOR SHOOTING SNIPES.}

"Next for the snipe you must prepare

He darts like lightning through the air,

With devious wing; a moment wait,

You'll see the rover travel straight."

There are many ways in vogue for overcoming the exaggerated difficulties attending the shooting of snipes; in fact, every sports. man has some particular rule of his own to guide him, and recommends it in the strongest terms to every tyro panting to reach that desirable goal, "a good snipe shot." However, laying all means and modes aside, every one is well satisfied if he reaches home at the close of a long day's tramp with a few couples of these wary birds. When, however, snipes are very abundant on our marshes and the weather favorable for shooting, it is no unusual thing for an experienced shot to retire from the field with fifteen or even twrenty couples of them.

All the various systems for bagging snipes may be reduced to the two following plans:-_"snap-shooting" and "deliberate shooting;" both diametrically opposed to each other in practice and theory, but the same in their results, as either will be found to answer equally well in the present case. The snap-shot kills the bird as soon as sprung, and before he enters upon the zigzag course previously described; the deliberate shot poises his weapon, and coolly waits till these perplexing meanderings are at an end, and then pulls the trigger upon his victim with a certainty of fetching him to the ground. The irregular flight of the snipe is discontinued if the bird be allowed to pursue its course for a short distance, and its motion becomes uniform and steady long before it is out of reach of the gun, as it is very easily killed, requiring but a shot or two to bring it down.

The following anecdote, just met with in the columns of the racy "Spirit," is rather amusing:-

"It is known to all snipe-shooters that when the bird rises he makes a kind of screaming noise, something resembling the sound of the word escape. A noted shot of our acquaintance invariably 
exclaims, before pulling the trigger, 'I'll be d-d if you do!' giving as a reason that it affords him time to take his aim coolly and collectedly. The plan appears to succed with him, for a snipe rarely escapes from his merciless barrel."

The curious twisting flight of the snipe, when suddenly come upon, is not altogether natural to the bird, but is rather the result of circumstances, and has very justly been attributed to fright and the great anxiety of the bird to make off; and perhaps their indistinct vision in the glare of the day also renders their course, as it were, undetermined and contorted.

"Whene'er you beat for snipes, implore

Old Æolus o'er marsh and moor

Boldly to breathe; yet always mind

You turn your back upon the wind."

Snipes almost invariably fly against the wind: it will therefore be important for the shooter to have the wind at his back; for by this arrangement the bird presents a much better mark when coming towards him, and he is also in the proper position to take advantage of all the cross shots. These birds lie better in windy weather than at any other time; but are more difficult to shoot, perhaps, when on the wing, as they fly much farther and swifter than if the day be warm and mild, when their flight is short and easy.

This latter assertion seems rather strange, too,-that they should fly "farther and swifter on a windy day than on a mild one;" for, considering that they always proceed directly against the wind, it would be very natural for us to infer that, in consequence of this singular habit, their flight ought to be proportionably shorter, slower, and more labored, owing to the powerful resistance offered by a stiff breeze; such, however, is not the case, as every snipeshooter knows.

If, however, snipes have been much hunted after, and are wild, they make long flights even in the calmest and clearest weather; and are, as said before, very difficult to be got at, in consequence of this very "calm and clearness of the atmosphere," as they pos- 
sess very acute organs of hearing, and take wing at the slightest noise which is "wafted gently o'er the moor," from all quarters and from very great distances; and when one rises, if in wisps of two, three, or more, the alarm most usually becomes general, and the example is followed by all the others in quick succession.

Notwithstanding these birds are, perhaps, more difficult to be killed on a windy day than a mild one, there are but few snipeshooters that would not prefer a moderately blustering day to a calm one, as the points in favor of the former certainly overbalance all that can be said of the latter condition of the elements, and that very considerably. In this opinion we presume that we are sustained by nearly all our sporting friends; however, there are some of our acquaintances-one at least, and, what is more surprising, a very acute observer, too, of all things in general, and more particularly of every thing appertaining to the sports of the field-who will, at times, contend for the opposite, and strive most pertinaciously to support this erroneous opinion, in spite of all the powerful arguments brought to bear against it by men not his inferiors in any point of view as sportsmen.

The only argument worth alluding to-and which, in fact, is not an argunent, but merely a position or assertion that these advocates of calm weather adduce in support of their opinion-is the fact "of the shooter so frequently overwalking the birds on a windy day, and seeing them get up far behind him after he has passed over the places where he expected to find them." This circumstance, however, is not owing to the state of the atmosphere, but is rather the consequence of his own ignorance and bad manage.ment in not quartering the ground properly, which is of the utmost importance in snipe-shooting, when pursued without the assistance of a dog. When we say that the sportsman must hunt down wind, we do not mean that he should walk directly with the wind on his back, but rather that he should proceed in an oblique course, so as to quarter the ground in such a manner as to travel within hearingdistance of every snipe which may be feeding around. By following this plan, the birds rise on a windy day within ten, fifteen, or 
twenty feet, as the case may be, circle about for an instant, and then make invariably towards you or by you, and thus present the very best shot that could be desired.

When raining; snipes are very uneasy, wild, and difficult of approach.

Snipes always lie better in the autumn than they do in the spring, as they are far more restless, and even shy, at this latter season than they are when they return from the North, accompanied by the young birds, which necessarily are far less cautious and timid than the old ones, and require more quiet to recruit themselves after long flights.

\section{DOGS FOR SNIPE-SHOOTING.}

There are few dogs which we have ever had the good fortune to meet with that can be employed with much success in snipe-shooting; and, when the birds are abundant, most of our shooters prefer going to the field alone. However, when there is sufficient cover on the marshes, and the dog is accustomed to his game, snipes will frequently lie well, and suffer a cunning animal to approach within a few feet of them.

The dog, however, must be very careful, and not too fast; otherwise he will overrun his game, and do much more harm than good. The English, or rather Wilson's snipe, as every one should call it, gives forth a strong game eflluvium; and it is no uncommon circumstance for a careful dog to draw upon one at a distance of twenty, thirty, or even sixty feet. When the birds are very numerous and somewhat confined, owing to the locality and small extent of their feeding-grounds, we would advise a persevering shooter to leave his four-footed companion at home, provided he is willing to travel backward and forward over the cover and get all the birds up himself; for by so doing he will have a fairer chance to bag them than if he had the best dog in the world; such, at all events, has been our experience.

A snipe dog should be stanch, and had better be too old than too young, as hunting young dogs on these birds is very likely to 
prove injurious to them, having a tendency to make them slow, and perhaps lazy, as they find the birds so easy and the points succeed each other so fast that they are unwilling thereafter to put themselves to any great deal of trouble to find other game, which will generally prove much more difficult to be got at. If you must, however, take a canine friend along with you,_-and there are, we know, some shooters who cannot stir on an occasion of any kind without two or more of these favorites,-please recollect that one, at all events, is quite sufficient. We have seldom found dogs of much account in snipe-shooting-perhaps because we never had a particularly good one for this sport-except a first-chop retriever; and he can make himself very useful, provided he be intelligent and well trained to cross the ditches and bring his bird without coaxing or scolding.

As snipes invariably fly against the wind, it is a good plan to go around the dog when on a point, and, by thus facing him, we may get a much better shot when the bird rises. It is hardly necessary for us to add that you should look out for your dog, otherwise you may shoot him; such accidents have occurred, and may happen again.

To prove more forcibly this assertion in reference to the danger apprehended from shooting our dogs in the field, it may not be amiss to mention that we have just this moment received the sad intelligence of the accidental death of a favorite pointer dog which we presented as a mark of regard to a sporting friend, whom we know to be scrupulously particular in the handling of his gun, but nevertheless not sufficiently cautious in this one instance to bring upon himself the reproach of having, I may say, carelessly taken the life of a good and faithful animal. In his letter to us, commenting upon the painful mishap, this gentleman very feelingly remarks:"Birds were very plenty, but after the sad accident I felt no disposition to shoot, and consequently killed but two, missed one, and retired quite dispirited from the field, as well as mortified and distressed at this my first and only misadventure with a gun."

If, therefore, this careful and very watchful sportsman could accidentally shoot this $\log$, - for it was an accident, and we may 
say, without any intention of being censorious, a heedless accident; at all events an accident that should not have occurred,- - how much more does it behoove all young sportsmen to look to their dogs when in the field, and never endanger their lives by any species of negligence whatever; in fact, should never hold their weapons so that they can come in range with them !

\section{ADVANTAGES OF SNIPE-SHOOTING: "DULCIUS EX ASPERIS."}

Notwithstanding the mud and mire, trouble and vexation, we consider snipe-shooting a most pleasant diversion, more especially on account of the great number of shots to be had in the course of a day, as well as their rapid succession; and we are acquainted with no kind of sport that so rapidly improves an indifferent shot as this does. So much quickness, and at the same time so much judgment, are so absolutely necessary to hit upon the exact moment for drawing upon the trigger, that the tyro, with a little practice, will soon have complete control over all his movements; and it is also necessary for him to be ever on the qui vive, as nearly every bird that springs presents a different shot.

WHITE SNIPE.

Mr. Copple, an old shooter, showed us, a few days since, a very beautiful specimen of a pied or white snipe that he had shot the day previous in New Jersey. This is the first and only specimen we have heard of. It has been mounted, and we believe is now in the possession of Mr. Stirley.

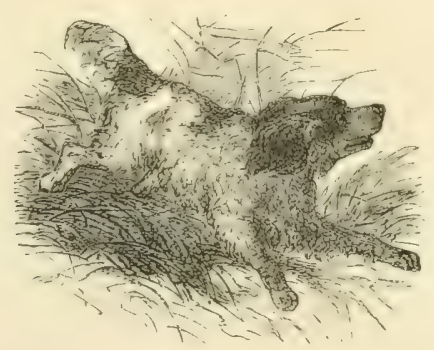




\section{MEMORANDA.}

1. Snipes are widely distributed over the world, and are cqually esteemed in all parts for their game qualities.

2. 'To Wilson belongs the honor of describing a marked distinction between the American and English variety.

3. The snipe is a migratory bird, breeding in the elevated districts of our Northern States, as well as Canada.

4. They arrive in Pennsylvania about the middle of March, and soon become fat.

5. Their food consists of worms, insects, larvæ, and the tender roots of aquatic plants.

6. Snipes move farther north towards the close of April.

7. The young brood generally consists of four.

8. Snipes almost invariably fly against the wind; therefore hunt them with the wind on your back.

9. Old and slow dogs are most suitable for this sport when the birds are plenty; when scarce, a fast but cautious, as well as experienced, dog is most serviceable. Young and heedless animals are far better at home under either contingency.

10. Snipes fly in "wisps," and not in flocks; therefore say a "wisp of snipes," and not a flock.

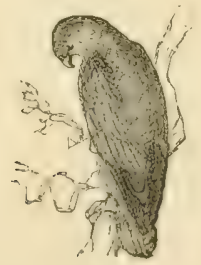




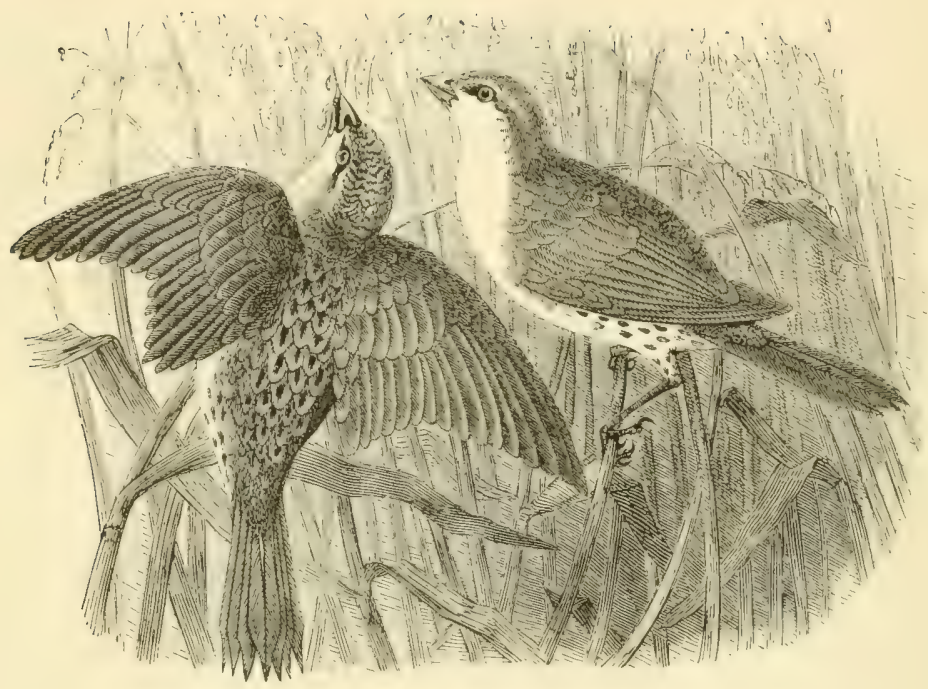

CHAPTER XIV.

REED-BIRD, OR RICE BUNTING. EMBERIZA ORYZIVORA.

THEIR HISTORY AND NOMENCLATURE.

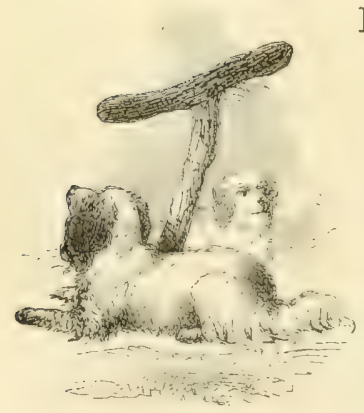

HIS delicate little bird is well known throughout the whole extent of our country, and is also a winter visitant to the West India Islands. In no quarter of its rambles, however, is its coming hailed with more delight than in the neighborhood of Philadelphia. In the Eastern and Northern States it is callerl bobolink, from the peculiar note which it almost incessantly emits, whether it be flying, or perched upon the tops of the bending reeds. In Pennsylvania they are known only as reed-birds; in Carolina they are styled rice-buntings; and in Louisiana, meadow-birds.

"The rice-bunting is seven inches and a half long, and eleven 256 
and a half in extent. His spring dress is as follows:-upper part of the head, wings, tail, and sides of the neck, and whole lower parts, black; the feathers frequently skirted with brownish-yellow, as he passes into the colors of the female; back of the head a cream-color; back black, seamed with brownish-yellow; scapulars pure white; rump and tail-coverts the same; lower parts of the back bluish-white; tail formed like those of the woodpecker genus, and often used in the same manner, being thrown in to support it while ascending the stalks of the reed: this habit of throwing in the tail it retains even in the cage; legs a brownish flesh-color; eye hazel. In the month of June this plumage gradually changes to a brownish-yellow; bill reddish color; legs and eyes as in the male. The young birds retain the dress of the female until the early part of the succeeding spring; the plumage of the female undergoes no material change of color."

THEIR MIGRATIONS.

The reed-bird breeds and spends the larger portion of the sum. mer months in the Northern States, extending its peregrinations in this direction as far as Lake Ontario and the river St. Lawrence. Their nests are built upon the ground, usually in a field of grass, wheat, or barley, and contain from four to six eggs, of a bluish-white color, irregularly spotted. They raise but one brood in a season, and, as soon as the young are able to leave the nests, they associate with other broods, and thus in a short time form large families, which are seen making their way over the country from all quarters towards the banks of the streams and large rivers, where they feed upon the reeds or plunder the grainfields of our farmers. Although so very small and insignificant in appearance, they often do serious injury to the crops, more particularly to the oatfields of New England, which they visit in countless multitudes. Towards the middle of August, forsaking their feeding-grounds in the North, the familiar "clink" of the reedy is heard on every side in the neighborhood of Philadelphia, and may be distmetly recognised on a still evening, as they pass 
in multitudes over the city. During the first few days of their appearance in these parts, they seem to confine themselves to the cornfields and upland meadows, waiting as it were the further ripening of the reeds; after this, they descend to the banks of the Delaware and Schuylkill, which are now overrun with the rank growth of the wild oats, Zazania aquatica, which produces a small seed in great profusion. Feasting luxuriantly for several days on this nutritious food, they soon become extremely fat,- -in fact, nothing but compact balls of delicious meat, each one a dainty morsel for the eager palates of our epicurean citizens.

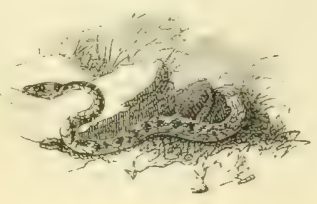

SHOOTING THEM.

The war of musketry is now heard incessantly from bright morning till dark night, all along the banks of our rivers, and the markets are soon overstocked with the innocent victims of many a rusty old barrel, only brought into requisition once a year, in reed-bird season. If the weather should be very warm, as it most frequently is at this time of the year, the birds spoil very soon after being killed, and consequently remain but a short time in the hands of the hucksters and game-ilealers, who are very glad to dispose of them at from twelve to twenty-five cents per dozen, according to the returns of the previous day's shooting, which, of course, depends in a great measure upon the wind and weather.

Reed-birds are shot on the meadows below our city, or in the reeds from a boat. Great numbers are often brought down at a single shot, as they generally congregate in enormous flocks towards sunset; it is no uncommon thing to kill four or fire dozen from the well-directed fire of a double-barrelled gun. It would appear incredible to state all the numbers that have been reported as killed at one discharge of an old musket, or other heavy gun; 
we will, therefore, confine ourselves to one single instance, in which thirteen dozen were picked up, - the result of a raking fire poured into a flock from an old fowling-piece that "scattered most confoundedly." This is not by any means the largest number we have heard of being bagged at one coup de fusil; but the account is well authenticated and within bounds of credence, and we give it to our readers as such, for we have no reason to doubt the veracity of the party who told us.

\section{NETTING REED-BIRDS.}

During the last year or two, a French gentleman of our city has been amusing himself in netting these birds upon the meadows, and has been quite successful in the sport, catching immense numbers, oftentimes several hundreds at a single draw of the net. The process of taking reed-birds in this way is very simple; but, as we are opposed to all kinds of poaching and unsportsmanlike modes of taking any kind of winged game, we will not dwell longer on the subject.

\section{COMPARED WITH THE ORTOLAN OF EUROPE.}

The flavor of the reed-bird is extremely juicy and rich, and assimilates as near as possible to that of the ortolan of Europe, which interesting fact we very unwittingly tested at a celebrated café, in company with some others of our green countrymen who were in Paris at the same time, and, greatly to our surprise as well as indignation, were forced to pay for the information at the rate of a dollar per head for these delicate little morceaux. At this rather recherché but expensive feast-for we devoured the poor ortolans in nearly the same numbers as we were wont to do the reed-birds at the height of the season in our own city-we think that the flavor of the French bird was indelibly stamped upon ow palate in about perhaps the same ratio as the impression made at the time upon our purse, which, en passant, wis not very light, we can assure the reader, as we were all Philadelphians, and consequently death on reed-birds, and, in course, ortolans 
also. As far as we can recollect the particulars of this déjeuner à la fourchette, —which, by-the-by, afforded us all much merriment for a long time afterwards,-the company, pretty generally, when partaking of the feast, in the goodness of their hearts, or rather in the joy of their stomachs, were quite loud in their praises of the far-famed ortolan; and all pronounced its flavor much superior to that of the poor unpretending reedy of America. But, before leaving the café, we must acknowledge there were some long faces and short purses in the "crowd," that seemed rather disposed to disparage the well-merited compliments which were previously so lavishly bestowed upon the French bird; and several were even so ungrateful, after stowing away a brood or two of them in their stomachs, as to draw invidious comparisons between the two rivals for gustatory repute. After mature reflection, however, the whole party, one and all, declared in favor of the reed-bird of America, at twenty sous the dozen, over the French bird at one dollar a piece.

\section{PROGRESS SOUTH.}

As soon as the frost makes its appearance in Pennsylvania, the reed-birds as well as rails take their departure for the South, and it is seldom that we find either of them with us longer than October. After they leave our rivers they continue their course south, visiting the ricefields of the Carolinas and Georgia, and often commit great havoc in those regions. Although thousands upon thousands of these birds have been destroyed in their route from the North, still, thousands upon thousands of them yet exist, and every gun is again brought into requisition in their new quarters, to thin down their inexhaustible numbers; but all to no purpose, as they still continue their flight in immense bodies as the winter advances, and ultimately arrive at the termination of their long royage in the West India Islands. In Jamaica they are called butter-birds; and there, as in all other parts where they make their appearance, they are highly esteemed for the delicacy and richness of their flavor. 


\section{CURIOUS FACTS.}

Audubon states that when these birds migrate south in the autumn their flight is diurnal, but when returning in the spring they travel mostly at night. Such, however, has not been the result of our observations, as we have noticed the flight of reed-birds, many times during the autumn, in the still hours of the night; and in the spring we have also seen them travelling during the day. Another interesting particular respecting the reed-bird is the singular change which takes place in the plumage of the male. This change begins in June, and by the close of the following month the color has approached so nearly to that of the female that it is very difficult to distinguish one from the other. This circumstance, in connection with the fact that the plumage of all the young birds also resembles that of the females, has given rise to the vulgar notion that the male birds never return from the North; but what becomes of them every one of course is unable to conjecture.

\section{AS A CAGE-BIRD.}

The plumage of the reed-bird is variegated and pretty, and he makes a very sprightly and contented captive for the bird-fancier: soon forgetting his former life of freedom, he resigns himself to his lot, and sings merrily and cheerily for several months in the year. His notes are agreeable, and capable of much improvement by associating him with the canary-bird, with which we have been told he will pair.

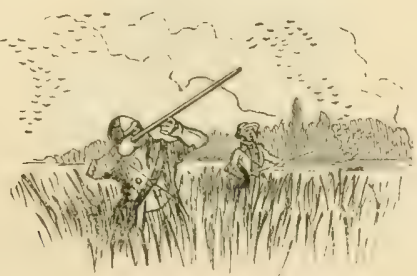


CHANGE OF PLUMAGE.

We were shown, a few days since, a reed-bird, the plumage of which was a perfect canary-color; and, if we had not recognised the bird from its general outline, we should have pronounced it an overgrown canary, so complete was the change that had taken place in its appearance.

MEMORANDA.

1. Reed-birds breed in the North, pass the summer in the Middle States, the autumn in the South, and the winter in the West Indies.

2. In the North they are called bobolinks; in Pennsylvania and Delaware, reed-birds; in the South, rice-buntings or meadow-birds; in Jamaica, butter-birds.

3. They build their nests on the ground, and raise but one brood in a season, consisting of from four to six young.

4. The plumage of the males during the summer resembles that of the females so closely that it is difficult to tell them apart; the young bird at this season also assimilates the female in its plumage.

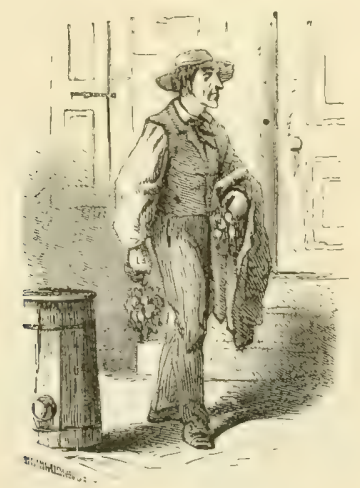




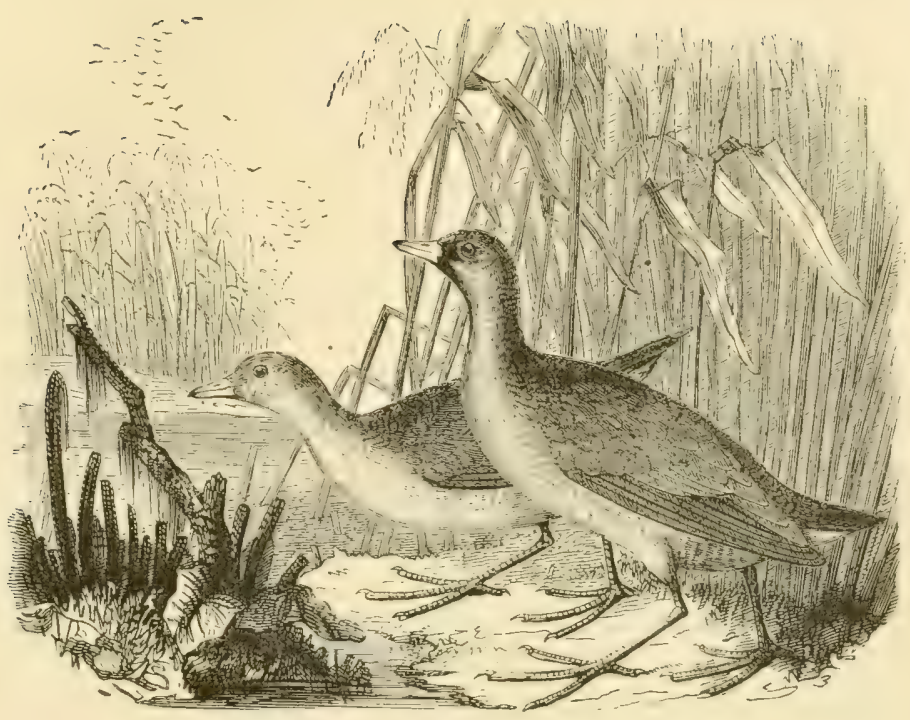

CHAP'TER XV.

THE RAIL, OR SORA. RALLUS CAROLINUS.

\section{DESCRIPTION AND NOMENCLATURE.}

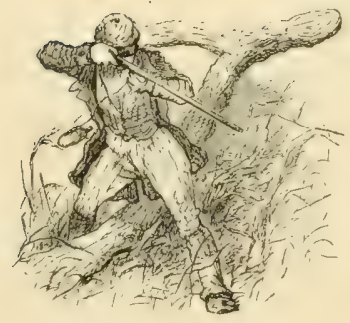

HIS somewhat mysterious bird, so well known throughout certain portions of our country under the appellation of rail, sora, or coot, resembles very closely both the water-crake or spotted rail, and the land-rail or corn-crake of England, not orly in its habits, but also in its general appearance. There are few, if any, species of birds in our country that offer more tempting amusement to the young sportsman, or a more agreeable delicacy for the table, than the timid little fowl which now engages our attention. We will detain the reader for a few moments while we transfer to our pages an abridged ornithological description of this shy bird, and will 
then pass on to a consideration of some of its habits, more particularly those within the range of our sporting friends, many of which instinctive peculiarities have very justly been termed by casual observers mysterious; all of which mysteries, however, we hope to make perfectly plain to every one before the close of this article. "The rail is nine inches long, and fourteen in extent; bill yellow, blackish towards the point; stripe down the throat black; sides of the crown, neck, and upper parts generally, olivebrown; streaked with black on a brown-olive ground, and edged with white; wing plain olive-brown; tertials streaked with black and long lines of white; tail pointed, dusky olive-brown streaked with black; lower part of the breast marked with semicircular lines of white on a light ash-ground; belly white; vent brownish-buff; legs, feet, and naked part of the thighs yellowish-green; eyes reddish-hazel. The female bird has little or no black on the head; the throat is white, and the plumage generally is of a lighter color, and more inclined to olive, than in the male."

\section{HISTORY.}

The first thing to be noticed regarding this bird is the circumstance which renders the term "mysterious" particularly applicable to the species. The regular migrations of the feathered tribes are well known to naturalists, and the favored time and peculiar conditions under which these voyages from distant parts are consummated by game-birds have been observed by most sportsmen; but in the case of the sora every one is more or less at a loss, both as to their coming and departure from among us. Whence they spring, or whither they go, both naturalist and sportsman have been equally at fault, as each is unwilling to grant that a bird whose flight is apparently so sluggish and feeble, scarcely rising above the tops of the reeds, should be capable of a long-continued volitation, or be sufficiently strong to encounter the fatigues of a journey from the Far North, like other migratory birds. Nevertheless, it is an evident fact that rails must come from a distance; and when they depart from our rivers, they must also travel to still more 
remote parts, if perchance they do not (as has been sagely surmised by some enthusiastic inquirers after truth) bury themselves in the mud of our river-banks or become changed into frogs. But who was ever so fortunate as to dig up a petrified rail or come across an unfinished metamorphosis of this description? Wilson, however, informs us that this latter theory, ridiculcus as it may seem, had its originator and firm supporter, who boldly asserted that the transmigration of the sora into the frog was the true secret of the sudden disappearance of this bird; and, moreover, that he, the author of the strange notion, had in his possession for several days an animal of an extraordinary kind, neither a rail nor a frog,-in fact, something between the two; but, unfortunately for the progress of science, not being accustomed to captivity and the over-kindness which was lavished upon it by its lucky owner, the animal died before the change was complete, and this remarkable lusus naturce was thus lost to the investigations of the curious in such matters.

What rendered this singular hypothesis more striking, and cor. firmed the originator in his preconceived notions, was the circumstance of the frogs generally ceasing to croak about the time of the coming of the rails in our rivers. This opinion, however, has gained but little ground, as few persons are to be found so credulous as to place any faith in a notion so extremely absurd. There are several species of rails known in England. They arrive there in the spring in the same mysterious manner which they do with us in the summer, and depart at the first approach of frost for more southern climes, in a like unceremonious style, seldom or never being seen on their passage either to or from the countries where at certain seasons they abound. So very shy is this bird, that, although almost every meadow and clover-field in England resounds during the spring with the eternal crek crets of the landrail, very few are shot, and the bird itself is scarcely known to the country-people, notwithstanding they constantly hear its wellknown crek erek whenever they go into the fields. For such is the secret, skulking, and solitary habits of this little bird, that it 
very seldom takes wing, even when hotly pressed by a dog; and all our sportsmen know how difficult it is to spring the rail, even with the assistance of a boat, and a long pole with which to beat the reeds.

Notwithstanding the different notions respecting the movements of our soras, it is certain that these birds, like many other species, perform regular migrations from North to South, and return in the same way during the following spring; and it is also probable that their flights take place in the night, owing to their instinctive desire to court concealment. Wilson tells us that it was formerly no very unusual thing to find young rails on the meadows of the Delaware and Schuylkill. Mr. Bartram, a gentleman well acquainted with this bird, states that he has often seen and caught young rails on his own meadows in the month of June; that he has also seen their nests, usually in a tussock of grass, containing four or five spotted, dirty, whitish-colored eggs, and that the young ran as soon as they escaped from the shell, being quite black, and glided about through the grass like mice, and during this particular period they resembled the "corn-crake of England." This circumstance alone proves that the origin of soras is not involved in so much obscurity as many persons are anxious to make it appear, and satisfies us that these birds follow the general laws of nature during the migratory season, and that some few of them, like other birds of similar habits, remain with us in these latitudes during the summer, for the purposes of breeding.

Although our sportsmen are unwilling to acknowledge the power of soras to fly any considerable distance, we have several instances on record that go to show that this bird is capable of great endurance and of very extended flight, and that in common with other birds it is possessed of foresight and strength sufficient to enable it to go in quest of distant climes, congenial to its feelings and modes of life. Mr. Skipwith, our consul several years since in Europe, when returning home, off the capes of Chesapeake, caught several rails that alighted on the ship, and, being well acquainted with the bird, declares that they were the same as those usually killed on the James River; and Wilson has also been assured by many gentle- 
men and captains that they have often met with these birds between the mainland and the islands.* These facts, certainly, are sufficient to convince us that rails are capable of very long flights, and would also lead us to believe that many of them even pass their winters in as remote districts as the West India Islands.

\section{SINGULAR CHARACTERISTICS OF THE RAIL.}

The mysterious coming and going of the soras is not the only singular characteristic attributed to the species, as it has been surmised years ago, by a gentleman of respectability and worth of this city, that rails are subject to bursts of vehement passion, occasioning fits analogous to epilepsy, and relates several instances in which this singular effect was produced. We never witnessed any thing of this kind; but some of our sporting friends may have done so in their shooting excursions, and we should be glad to hear from them on the subject. It has also been observed, by "Brewer," that the various species of rails possess a certain power of ventriloquism, which is more particularly developed in the corn-crake of England; and that when crying they often remain stationary, and throw their voices in opposite directions, at one time as if within a few yards of the spot where the observer is standing, and in a second or two appearing in an entirely different position.

We should, perhaps, never have noticed this remarkable fact in the rail species, if our attention had not been called to it by the observations of "Brewer." We are induced to place much confidence in his views upon this subject, from our intimate knowledge of the habits of the rails of our own country, which we believe also to be somewhat endowed with this singular power; and the mere mention of it in this article may possibly throw some additional light on the subject. It is not at all impossible that nature may

\footnotetext{
* May 10, 1851. - We were invited by our friend George H. Bryan, Esq., to go on board of the packet-ship Michael Angelo, just arrived from Liverpool, to see a rail caught at sea some days previous. The captain assured us that the nearest land at the time the rail was captured was Cape Sable, distant about three hundred miles.
} 
have bestowed this power upon these birds for some goou purpose, as well as upon other animals. Captain Lyon, in speaking of the Arctic fox, states that "it is a singular fact that their bark is so modulated as to give an idea that the animal is at a distance, although at the very moment he lies at your feet;" and he supposes that these foxes are gifted with this species of ventriloquism in order to deceive their prey as to the distance they are from them.

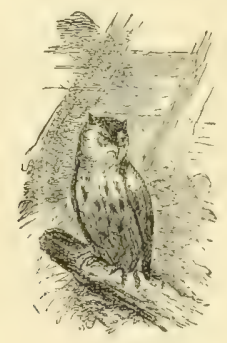

THEIR FOOD, ETC.

The soras, like the rice-buntings, are excessively fond of the seeds of the Zizania aquatica, or wild reed, that grows in such luxurious profusion along the muddy shores of many of our rivers, and will be found secreted in the midst of these flourishing plants as soon as they have acquired their full growth. The Zizania aquatica grows to a great height and spreads over immense tracts of tidewater shores, extending for miles along the rivers, and oftentimes rising to a height of ten or twelve feet and the stems so strong and closely interwoven with each other that they defy every effort to propel a boat through them. The seeds of this plant begin to ripen, in the Eastern and Middle States, early in August, and the rails soon find their way to the different rivers whose shores produce it in any considerable abundance. When they first arrive, they are poor and unpalatable, but soon gain flesh, and become extremely fat and delicious to the taste. In truth, we are very partial to this bird, and, when in good condition, prefer it to most other kinds of game; at all events, we can eat more 
rails, and partake of them more constantly without feeling sated than of any other game-bird. They are particularly tender, rich, juicy, and delicate, and do not cloy the stomach by quantity or pall the appetite by daily indulgence. At this season the reeds along the Delaware and Schuylkill swarm with these timid little birds, that pursue their solitary ways in silence and dread, seldom giving utterance to a single note, if undisturbed. Should a stone, however, be thrown into the reeds, a sharp and rapid crek, crek, crek will be heard resounding in every quarter; but still not a rail is to be seen, although hundreds are gliding about through the reeds in every direction, within a few feet of where we are standing. If we should be so fortunate as to spy one skulking in the dense field of reeds before us, he will most probably be seen jutting up his tail and running with astonishing speed between the stalks of those plants, more like a water-rat than a feathered denizen of the air. The flight of this bird being so regular and feeble, it presents an easy mark to the young sportsman, and perhaps is the best game-bird that we have on which to commence the art of shooting on the wing, although it will require considerable experience to make the tyro proficient in the science of balancing his body in the boat while it is being pushed through the reeds.

The sora seldom flies more than fifty or a hundred yards at a time, and often not so far. They merely rise with extended legs, and flutter, as it were, lazily over the tops of the reeds, and then drop down again. We have, however, observed them, when hard pressed by numerous shooters, direct their course across the Delilware, and seemingly gain strength and energy as they pursued their venturesome way.

When wounded, rails exhibit wonderful cunning, and frequently display decided ingenuity in their efforts to escape. The swim with ease, and dive very expertly, occasionally remaining under water for some moments, clinging to the reeds with their feet; and we have often observed them secreted and perfectly. motionless under the sides of the boat, or floating under the broken recds, with the point of their bill protruding above the surface of 
the water, to enable them to breathe, in which position they will continue until an opportunity offers for escaping from their pursuer.

In the month of July, the soras are found farther north; and we hear of them being shot upon the marshy shallows in the neighborhood of Detroit, where another species of reed, to which they are also partial, is seen to grow; and no doubt there are many places along our northern frontier that are visited by these birds in their annual migrations. Rails are very sensitive to cold, and seldom remain with us longer than the month of October; and it is quite useless to go in quest of them after a smart frost or two, even if it should occur quite early in the season, as they will generally be found to have abandoned their haunts as suddenly as they came to them. The season of 1846 was a remarkably favorable one for the stay of the soras in our rivers; and we understand that until November 25th of that year they lingered in considerable numbers among the reeds, luxuriating upon their tender seeds, and awaiting the first brumal spell to speed them on their tedious journey to the South.

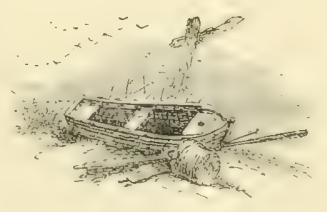

SHOOTING RAILS.

The sport attending the destruction of rails is exciting and exhilarating in the extreme, but perhaps more fatiguing and less beneficial to health than any other kind of shooting. It is carried on in this wise:-

Being furnished with a small, flat-bottomed canoe, and a good, broad-shouldered boatman, yclept "pusher," from the peculiar duty that he performs in propelling the bateau through the reeds by means of a long pole, the sportsman stations himself on the railground and anxiously awaits the coming of the tide. The water 
having risen to a sufficient height to allow the passare of the boat through or over the reeds, the shooter places himself in the bow of the little craft, surrounded by all the necessary paraphernalia for loading with expedition and safety, and, being ever on the qui vive, knocks the poor birds down right and left as they rise a few yards before the boat as it gently glides among the reeds.

It is better to have two double-barrelled guns; for when the birds get up lively it will be necessary to load and fire so rapidly that the gun will soon become too hot to handle or charge without danger, and the chambers and barrels will get so clogged with powder and leaded with shot that it will be almost impossible to load with the necessary expedition. It will also be proper to provide yourself with a good, stout ramrod, which can be handled with facility and thrown down anywhere in the boat without fear of being broken. To prevent accidents and insure despatch in loading-upon which latter circumstance the grand result of the day's sport almost entirely depends, even with a moderately good shot-it is absolutely necessary to be provided with shot-cartridges, which, together with the caps and powder, may be placed in a handy box, and set on the bow of the boat, directly in front. The kind of box we generally make use of is made of tin, about twelve inches in length, six in width, and five in depth; it is divided into two equal compartments, - one for powder, and the other for shot or cartridges; and the latter apartment has a small shelf or division at one end of it, sufficiently large to hold a quantity of caps or cut wads. If cartridges are used, there will be no occasion for wads; and, as we employ them altogether when shooting rails, we have so division in our box for holding wads. The box should be made of good, stout tin, well soldered together, with a cover or lid sufficiently large to close up either apartment, and so made that when thrown from the powder it will fall over and corer up the shot or cartridges, and when the shot is exposed to view the powder will necessarily be covered up, and thus prevent accidents, and the provoking consequences arising from the small seeds, stems, and dirt falling into the powder, when the boat is being. propelled 
through the high reeds. It is better not to have a handle to the box, as it would necessarily have to be square, and over six inches high from the top of the box, so as to allow the lid to pass under it; and, being made in this way, would have a clumsy appearance, and be of no particular benefit, but rather interfere with the motion of the hands when loading with rapidity. If the box is filled with the necessary ammunition before leaving the house, it may be very conveniently carried to the boat by tying it up in a stout handkerchief, or a leather strap may be attached to the box is such a way as to serve the purpose of a handle. But we prefer taking all our accoutrements to the boat in a small basket, and then transferring them to the box, before leaving the shore. The basket also answers a very good purpose for carrying the birds in from the boat on our return, as they dry much better, and the plumage looks far more nice than when dangling to a long string, upon which they become soiled and ruffled, by dragging on the ground or pitching about in the boat. Howerer, if a stationary handle is convenient on some accounts and inconvenient on others, it is easy enough to have a shifting one put on, that may be taken off at pleasure; but we prefer the old cotton handkerchief or basket, and so does a valued friend of ours, a veteran sportsman, from whom we took the idea.

Thus equipped, and provided with a good portion of ice, to allay the parching thirst that gencrally attends this sport during the hot days of summer, the shooter takes his position in the bow of the boat, with gun in hand, left leg forward, and his borly firmly balanced. Being rightly placed, the sportsman now trusts himself to the skill and management of the "pusher" to carry him through the reeds wherever the rails are most likely to be fecding.

Great dexterity and muscular power are required in a pusher; for without the former the shooter may be splashed from head to foot, and perhaps rudely knocked overboard by the awkward handling of the heavy pole by which the boat is made to shoot through the reeds; and, without the latter requisite, the skiff, instead of proceeding in a regular, steady course, will start and quiver with an uneasy motion, that renders the footing so unstable 
that he may be thrown down, perhaps overboard, - at all events, be often prevented from shooting when a rail presents itself.

Another important requisite in a "pusher" is that he be a good "marker," otherwise one-third of all the birds shot will be lost, as the eternal sameness of the green reeds precludes the possibility of an inexperienced hand finding them, when, as is often the case, there are four or five rails down at one time. Who among our Philadelphia shooters has not heard of Old Pike, Fowler, and Bill Rump, of rail-shooting notoriety, all of whom have served an honorable apprenticeship to the arduous task of "pushing," and are not yet to be excelled in these parts? How eagerly are these three veteran "pushers" sought after, and how frequently, almost universally, do their boats bring in the largest number of birds, without regard to the skill of the sportsman himself!-as an indifferent shot, with these men, will have double the number of chances that a better marksman with another "pusher" will get on the same tide, and consequently may miss a third of his birds and still be even with the party. The first time we went out railshooting, we employed "Bill Rump;" and, to our great satisfaction and surprise, on counting our birds, found that we had beateu several old stagers at the sport, although-we are loath to confess it-we missed enough of fair shots to quite discourage, if not at times to totally disgust, our zealous "pusher."

However, speaking of "beating others at this kind of sport" reminds us of the great opportunities that those who participate in this amusement have of chiselling each other regarding the number of rails actually killed on one tide. To show the fallacy of betting on the results of such shooting, without the parties are much closer watched than they usually are at the present time, we will merely state that there are some individuals, "begging their pardons," nothing remarkable for their shooting qualities, who never can be beaten, or never will be beaten, upon a trial-match at rail-shooting, no matter how great the number their antagonist kills, for the simple reason that they are leagued in with their friends and "pushers" to provide them with the birds when concealed from 
observation in the reeds, even if the stern or bow of the boat is not stuffed full before leaving the landing; or perchance he may find a dozen or two cunningly staked out in the reeds, which will so considerably augment his numbers that no shot, no matter how good, can easily overcount him.

We know that such tricks have been practised upon our friends, "and we consider it our duty to expose them, and thus put the green ones" on their guard, or, at least, on an equal footing with these wonderful "rail-shooters," who every season perform such miracles and make loud boasts of their slaughter and carnage.

As the boat passes through the reeds, the rails usually rise singly a few feet in advance of the bow, and, flying slowly in a direct line, present a fair mark for the sportsman. It is seldom that more than one bird is killed at a time, although two are occasionally brought down with one barrel, when they spring fast and cross each other in their flight.

It is the duty of the "pusher" to mark the birds which are killed, as also to notice where those that escape drop down; and when a rail springs on either side of the boat, he should call out "Nark!" so that the shooter may be on the alert to bang away in every direction. The higher the tide the better the sport, as the boat will glide more freely over the reeds, and the birds, having less shelter, are obliged to spring more frequently when come upon. The reeds around the boat should be constantly beaten with the pole, as rails are often concealed within a few feet of our track and will not stir without being driven to "wing" by this method.

The tides are regulated very much by the wind; and the moon, also, has no small influence in the production of high tides commonly called "spring-tides," which may occur both at the full and change, as at both these periods she acts on the earth in conjunc tion with the sun.

For rail-shooting in the Delaware or Schuylkill, and, in fact, in all the tributaries of the former, a southerly or southeasterly wind will produce the best tides; but we have seen good tides when the wind was from quite a contrary direction, and no doubt every rail- 
shooter has occasionally been deceived in his calculations on this head. We have known excellent tides in our river when the wind was blowing fresh from the northeast.

It is a common observation that soras are fatter during the increase and full of the moon than at any other time, which has been accounted for by the fact that the bird is at this time able to feed both by day and night; and, moreover, the high tides that prevail frequently at this period enable the rails to get at the seeds better, and a much greater deposit of them is also left on the mud at low water, by the breaking down and shaking of the reeds during the ebb and flow of the water. If the day be somewhat hazy, it will answer the purpose of the sportsman much better than a clear sky, as the reflection of the sun from the water upon one's face, in connection with the beaming hot rays upon one's head, for several hours together, is not the most pleasant position that a shooter can place himself in.

The sport continues without intermission till the receding tide warns the "pusher" that all his efforts will soon prove unavailing to propel the boat through the thick reeds that encompass him on every side.

It is useless to attempt to give any instructions as to shooting these birds; as we are convinced that any one who keeps his eyes open, and points the gun towards the rail, will be sure to kill them, as they seldom or never deviate from a direct course. but pursue a bee-line for a few yards and then pop down again. The only thing necessary to make an expert rail-shooter is a little quickness in handling the gun, as the bird must be covered as soon as on the wing, otherwise he flutters for a moment or so and then drops in the reeds, and, as before remarked, when down after being flushed, he lies very close, and is difficult to be got up again.

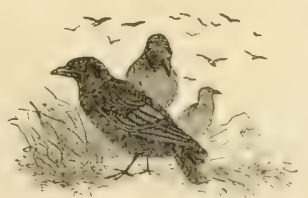




\section{NUMBERS KILLED,}

The number of rails often killed on a single tide by one shooter is almost incredible, when we take into consideration the circumstance that the birds are all shot singly; and, if we had not most authentic information regarding these statements, we should hesitate to publish them. But, having obtained the memoranda for 1846 from a reliable source, we cannot for a moment doubt its correctness, and our own observations lead us to believe that the accounts are not at all exaggerated. The great abundance and luxurious profusion of the reeds along the shores of the Delaware below Philadelphia, and the extensive mud-flats which are covered for miles with these plants, make our river the favorite resort of rails, as well as reed-birds, and the multitude that are slaughtered each season are beyond computation. The following extract is taken from the paper furnished us and carefully compiled by Major Price, of the National Hotel, Chester, and we select from it the best shooting of the season of 1846 :-

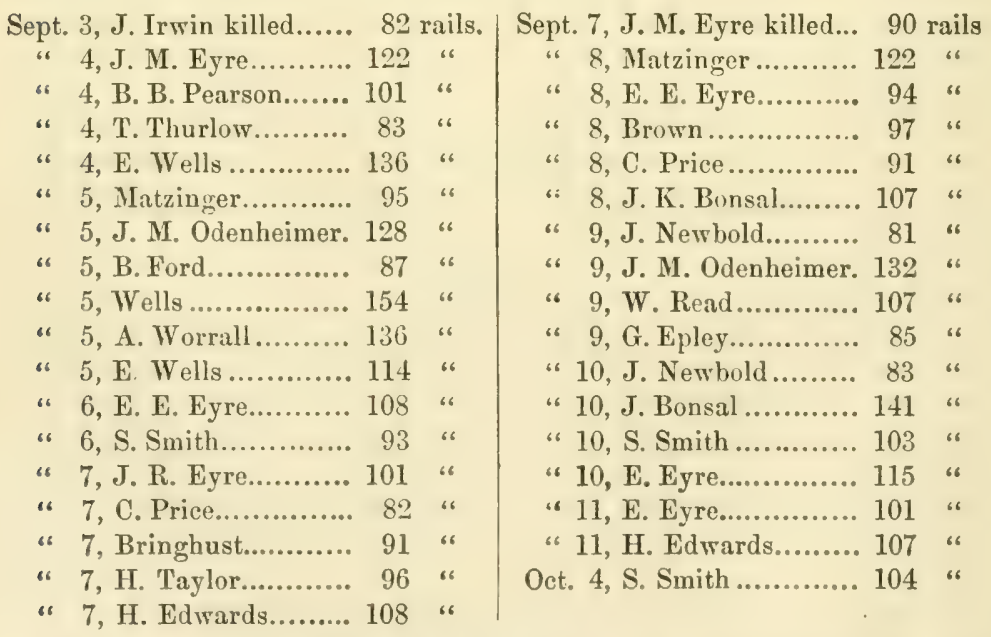

But the greatest exploit of all is yet to be chronicled. On the 8th of September, Mr. J. M. Eyre killed on one tide the surprising number of one hundred and ninety-five rails, which is 
forty more than ever was bagged by one shooter on our river, if we except, perhaps, the shooting-match that took place many years ago between Mr. Hubbell and a friend, at which time, we believe. the former gentleman got one hundred and seventy-five rails. The birds were very numerous, as we may suppose, on this day, and the tide very high, insomuch that the rails were obliged to seck shelter on the meadows, - a very uncommon circumstance. Mr. Eyre lives in Chester, and is considered one of the very best of shots on rail, and is ever on the spot rearly to avail himself of all the high tides that make up our river during the rail-season.* The most indifferent shot may often kill from thirty to forty rails on a good tide, and fair shots always calculate on sixty or eighty.

\section{SHOOTING RAILS IN VIRGINIA.}

Although soras are generally killed in the way we have endea. vored to describe above, they are taken along the shores of the James River, in Virginia, in much greater numbers, by a very singular process, with which, however, we are not practically acquainted, but will lay it before our readers in the words of Wilson. The operation of this method is the same as the "fire-hunting of woodeock" in Louisiana:- "A kind of iron grate is fixed on the top of a short pole, which is placed like a mast in a light canoe, and filled with fire. The darker the night the more successful is the sport. The person who manages the canoe is provided with a light paddle ten or twelve feet in length, and, about an hour before high-water, proceeds through among the reeds, which lie broken and floating on the surface. The whole space for a considerable way round the canoe is completely enlightened: the birds stare with astonishment, and, as they appear, are knocked on the head with a paddle and thrown into the canoe. In this manner,

* During the season of 1849 , rails were very abundant, and great numbers were killed; over one thousand were brought into Chester alone during one day of a very good tide. 
from twenty to eighty dozen have been killed by three negroes in the short space of three hours."

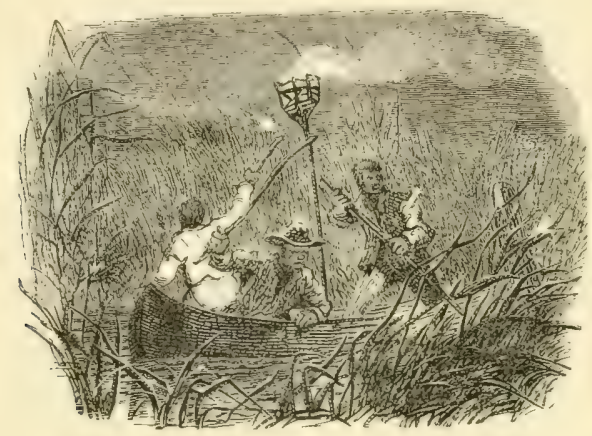

NETTING RAILS.

We have been informed that a French gentleman of our city conceived the project of driving rails into nets set in the reeds; but we believe that he was not very successful in the undertaking, at all events, not as much so as he has been in the capture of reedbirds by a somewhat similar process.

\section{FISH PREY UPON RAILS.}

Wherever rails abound, eels and catfish are said to resort in great numbers, anxiously awaiting every opportunity to prey upon all those that escape the eye of the marker after being killed, or that die from wounds. It is no uncommon thing to find portions of these birds, and even whole rails, in the stomachs of cels.

\section{PLACES TO SHOOT RAILS.}

It is difficult to say where, upon the Delaware, sportsmen can find the most rails, as every spot teeming with the Zizania aquatica is filled with these little birds, and great numbers are killed in the neighborhoods of Trenton, Bristol, Bordentown, Burlington, Bridesburg, Gloucester Point, Penrose Ferry, Marcus Hook, Lazaretto, Chester, \&c. This latter place is perhaps as good as any, 
being at a convenient distance from the city, and good pushers and boats are to be had without much difficulty.

\section{EXPENSE ATTENDING RAIL-SHOOTING.}

This amusement is somewhat expensive to the sportsman,-at all events, much more so than partridge-shooting. Food pushers command high prices for their arduous services, and few, if any of them, are contented with less than $\$ 250$ or $\$ 3$ a tide; but if they perform their duty well, we do not consider these amounts too much, as their work is of the severest kind. If the generality of them, however, drank less and pushed harder, it would be a salutary change for the better among this class of men.

Some of our friends who live upon the river in the vicinity of the rail-ground take turns in pushing each other during the shooting season, and thus enjoy in a quiet way this sport, without the expunse of employing "regular pushers."

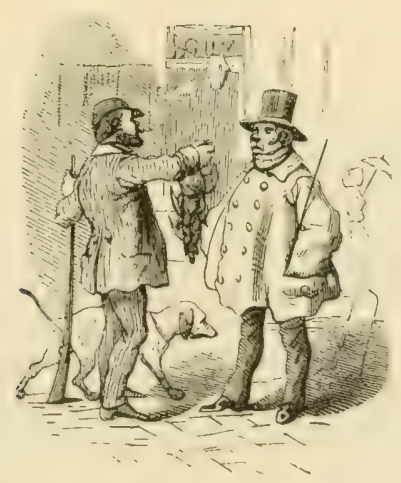




\section{MEMORANDA.}

1. Rails migrate regularly, as many other birds, and pass the breeding season in the North and the winter in the Far South.

2. These migrations are invariably performed under cover of night, and hence the mystery of their sudden appearance: they are capable of long flights, and have frequently been caught far out at sea.

3. Like the reed-birds, they are very partial to the seeds of the Zizania aquatica, and consequently frequent the river-shores where this plant flourishes in the greatest profusion.

4. Rails make their appearance in the Delaware and Schuylkill Rivers early in August, and remain till the frost warns them to seek the sunny South.

5. Rails are easily killed; two pellets of small shot are quite sufficient to knock them down. When wounded, they swim and skulk with great skill.

6. The greatest number of rails as yet killed on any one tide is one nundred and ninety-five.

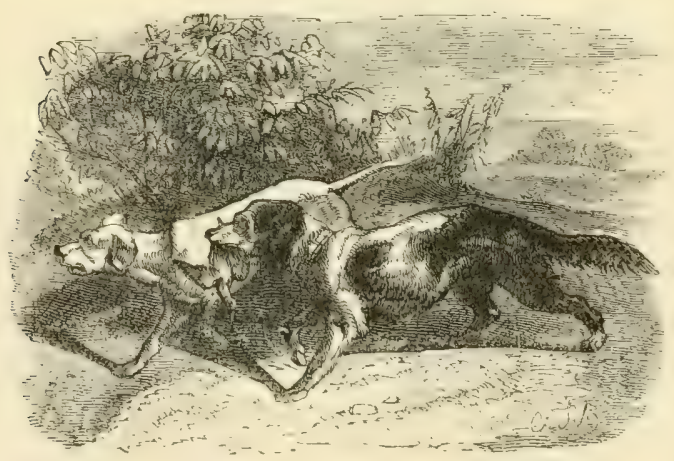




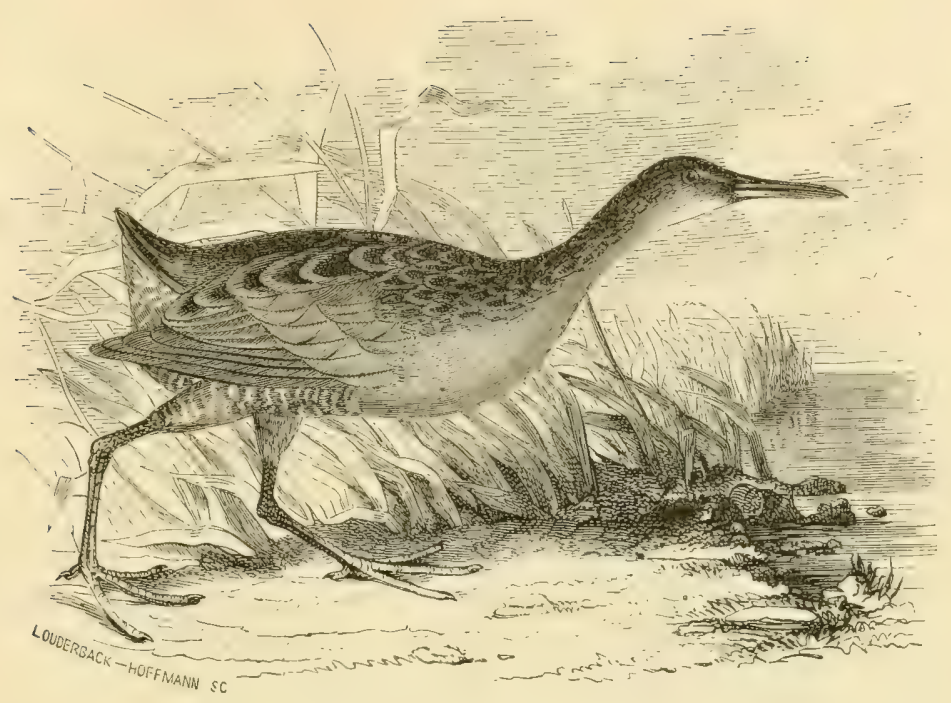

CHAPTER XVI.

GREAT RED-BREASTED RAIL. RALLUS ELEGANS.

LOCALITY AND DESCRIPTION.

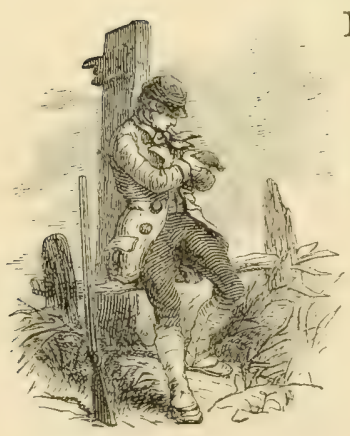

$\mathrm{N}$ his work on the birds of Long Island, Giraud thus describes this beautiful fowl:- "Bill along the gap, two inches and three-quarters; length of tarsi, two inches; sides and forepart of neck and the breast, bright orange-brown; iris, bright red." Total length of the specimen before us, seventeen inches; wing, six and three-quarters. Adult, upper part of head and hind-neck dull brown; from the base of the upper mandible over the eye a dull white line terminating with brownish-orange; lower eyelids white, loral space and a band behind the eye dusky; upper part of the body brownish-black; the feathers broadly margined with light olive- 
brown; wing-coverts dull chestnut; primaries dark brown, inner secondaries and tail-feathers same as the back; throat white; forepart and sides of the neck, with the breast, bright orangebrown; abdomen and sides of the body dark brown, faintly barred with dark brown; lower tail-coverts white, with a black spot near the end; the middle feathers black, barred with white.

The Rallus elegans is well known to the Delaware rail-shooters as the king-rail. They frequent the fresh-water marshes of the interior, and seem to feed upon similar food with the sora rails, as they are generally found in the same localities. The red-breasted rail is far more common in the South than it is to the eastward, being seldom met with beyond the reedy sheres of the river Delaware. The specimen before us is a very beautiful one, and was obtained while shooting soras below Chester last season.

The flesh of the king-rail is very analogous to that of the sora, perhaps not quite so delieate, but at times equally as juicy and tender. The Rallus elegans affects fresh-water marshes only, never being found on the seaboard; it penetrates far into the interior, and has the same wild and skulking habits as the other variety; its flight is short and apparently labored, and it requires but a slight "rap" to knock it over. This bird swims and dives, when wounded, with great dexterity, and resorts to the same artifices to conceal itself beneath the water as the sora rail.

We shot one of these birds on an upland marsh in the midst of a heavy wood, in the interior of Maryland, during the month of July.

The king-rail is also known as the fresh-water marsh-hen, in contradistinction to the clapper-rail, which is often spoken of as the "salt-water marsh-hen."

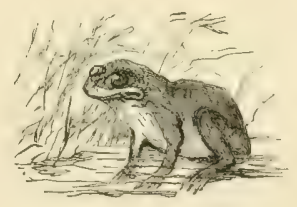




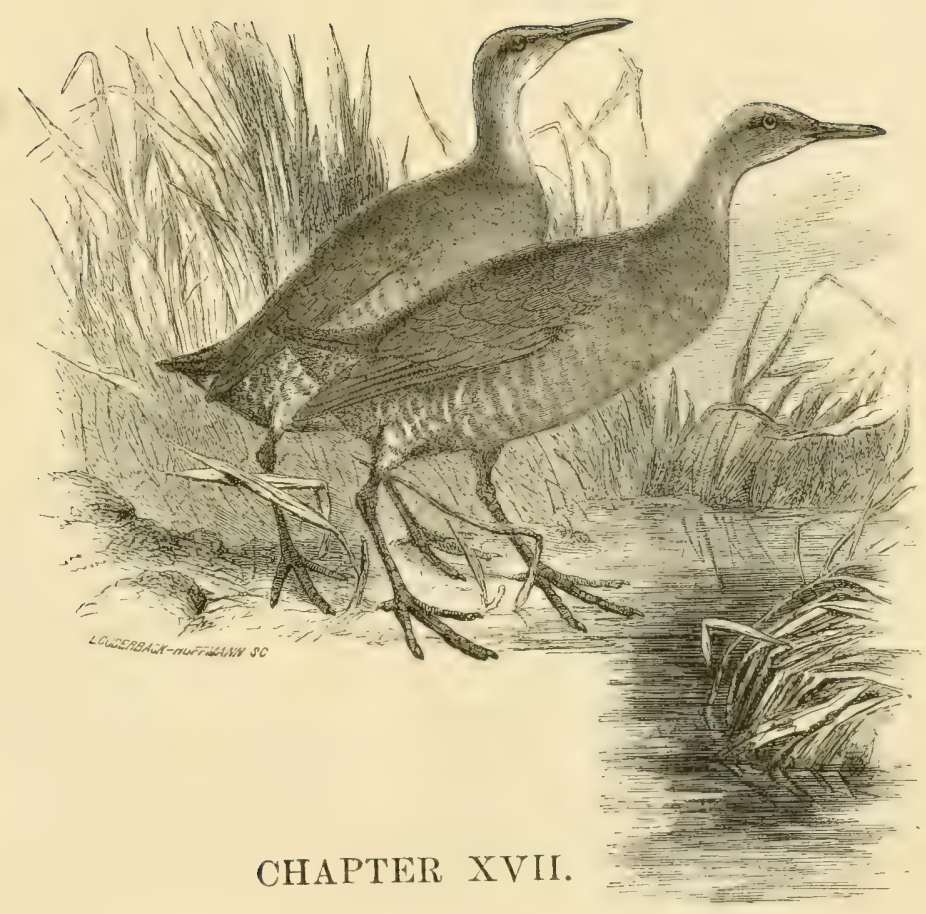

CLAPPER-RAIL, OR MUD-HEN. RALLUS CREPITANS.

NOMENCLATURE, ETC.

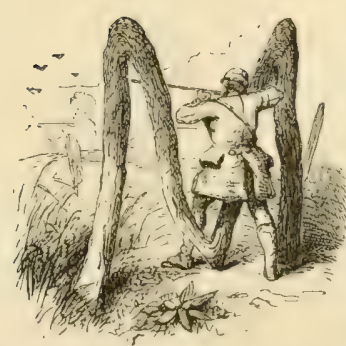

UD-HENS, meadow-clappers, or big rails, (for by these appellations this fowl is more familiarly known to the coast-shooters, ) are met with along our whole Atlantic board, from the southernmost extremities of Florida even as far north as the New England States. The clapper-rail is a large bird, and affords at times considerable sport to the shooter: the flesh, however, notwithstanding all the arts of the maitre de cuisine to the contrary, is universally 
insipid, dry, and sedgy. This fowl is not known in Europe, but it somewhat resembles the moor-hen (Furtica chlorophus) of England, both in its habits, size, and the savorless character of its meat.

Clapper-rails are extremely shy and secret in their habits, and are only to be found along the salt marshes of the sea-shore and the large rivers of the Atlantic States. They are always abundant in New Jersey and Delaware, and sometimes quite numerous in the brackish fens of Long Island. The mud-hen is a migratory bird, and arrives from the South on the coast of New Jersey and the neighboring States about the middle of April. Though coming unobserved in the stillness of the night, they soon make their presence known to the inhabitants of those districts by the sound of their harsh and never-ceasing cackle, somewhat resembling the well-known tremulous cry of the Guinea-fowl. Although the marshes and sedgy meadows, in the course of a very few days after their first appearance, resound on all sides with the unmelodious notes of these skulking birds, few or none of them are to be seen, as they seldom take wing, and when pursued run with amazing rapidity through the tangled weeds and high grass which always grow so luxuriantly in the haunts that they affect. In our youthful days we have had many a race after a wounded clapper, and know full well that our powers of speed and endurance were often most fruitlessly taxed in the arduous chase.

The mud-hen commences laying towards the close of May; the nest is simple, but often artfully contrived for concealment, having the long grass twisted and plaited over it in the form of an arch, so as effectually to conceal it from the glance of an inexperienced observer. Eight or ten eggs are usually found in their nests: we have seen as many as fifteen. The eggs are eagerly sought after by the residents of these parts, who, in fact, consider them far superior in delicacy to those of the domestic hen. The wholesale robbery of their nests is not the only interruption that the clapperrail meets with during the period of incubation, as the marshes are occasionally overflown during the continuance of a northeast gale, and thousands of eggs as well as old birds are destroyed. 
Wilson mentions an instance where this calamity took place twice during one season, and, notwithstanding these sad misfortunes, this persevering fowl commenced building anew the third time, and in two weeks their eggs appearet as numerous as ever. On these occasions, hundreds of mud-hens are destroyed by the ruthless hands of idle boys, and even grown persons, many of whom avail themselves, as before observed, of every opportunity to sacrifice the lives of the inferior animals, from a mere love of cruelty, or to gratify a montrous propensity for shedding blood.

The clapper-rail swims expertly and dives with considerable facility, often remaining under the water for several minutes at a time, holding on to the roots of the marine plants that grow at the bottom of the inlets and guts which intersect the marshes whereon these birds congregate.

It is almost impossible to flush them; and the only chance the sportsman has to shoot them is by going on the marshes in a light boat during a high tide, when, from want of shelter, they are obliged, like the soras, to seek safety in flight, and are then easily knocked over. When the tide is not sufficiently high for this sport, many may be killed by moving noiselessly along the guts in a boat and keeping a sharp look-out on all sides for the many clappers that will ever and anon be seen stealing down to the water's edge, to drink, or to pick up the small shell-fish and aquatic insects which are deposited upon the banks. A good retriever would prove a useful dog in these expeditions, to recover and bring to hand the wounded birds, as when only slightly struck the clapper-rail is very tenacious of life, and runs with so much ease through the reeds and matted grass that few sportsmen, no matter how agile they may be, can overtake them. The dog should be as small as possible; otherwise he will not be able to follow the bird through the twistings of the pathways, or rather archways, which it forms all through the reeds.

The flight of the clapper-rail is very similar to that of the sora; and being, if any thing, even more slow and labored, it requires but an indifferent shot to bring them down. We have killed these 
fowls often, when in pursuit of other coast-birds, on the marshea about Cape May and Cape Henlopen, but never thought it worth while to go a foot out of our way to procure them, as they are at best but an unsavory dish for the table; and we trust that we have never encouraged the weasel-like propensity to take life from sheer fondness of carnage, or perhaps to indulge a morbid taste to make a great display by the magnitude of our game-bag.

\section{DESCRIPTION.}

"The clapper-rail measures fourteen inches in length and eighteen in extent; the bill is two inches and a quarter long, slightly bent, pointed, grooved, and of a reddish-brown color; iris of the eye dark red; nostril oblong, pervious; crown, neck, and hack, black, streaked with dingy brown; chin and line over the eye brownish-white; auricular dusky; neck before, and whole breast, of the same red-brown as that of the preceding species, wing-coverts dark chestnut; quill-feathers plain dusky; legs reddish-brown; flanks and vent black, tipped or barred with white. The males and females are nearly alike.

"The young birds of the first year have the upper parts of an olive-brown, streaked with pale slate; wings pale-brown olive; chin, and part of the throat, white; breast ash-color, tinged with brown; legs and feet a pale horn-color."

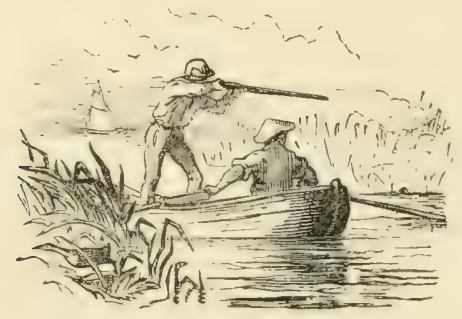




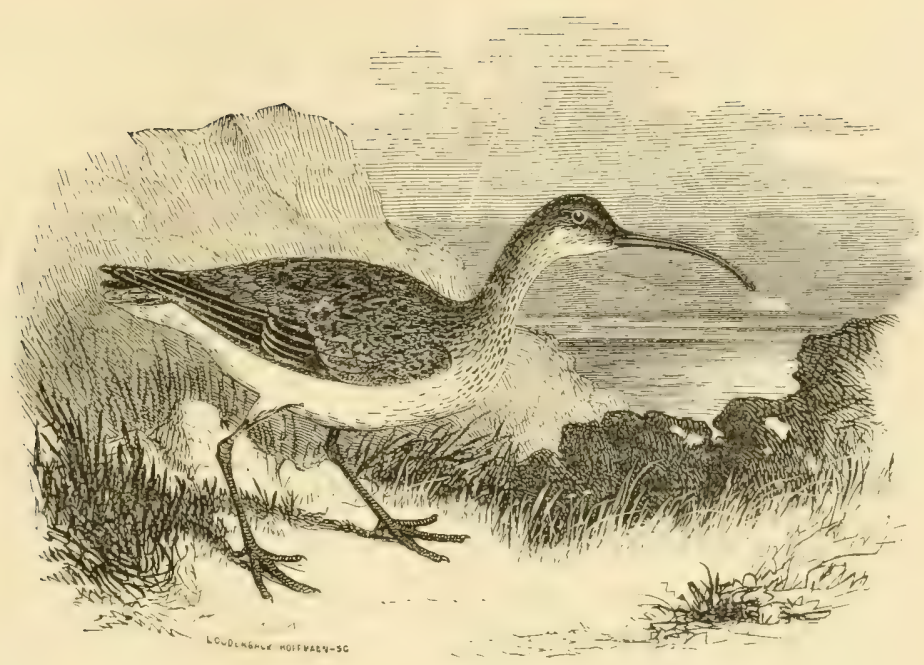

\section{CHAP'TER XVIII.}

\section{ESQUIMAUX CURLEW, OR SHORT-BILLED CURLEW. SCOLOPAX BOREALIS.}

"Soothed by the murmurs of the sea-beat shore,

His dun-gray plumage floating to the gale,

The curlew blends his melancholy wail

With those hoarse sounds the rushing waters pour."

\section{NOMENCLATURE AND DESCRIPTION.}

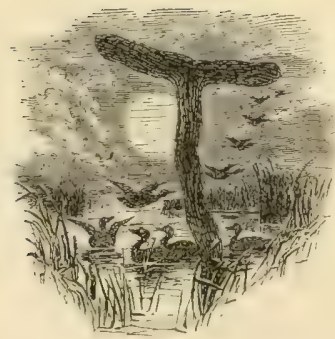

HIS large and handsome bird is known to our shooters as the jack curlew, or shortbilled curlew, in contradistinction to the other variety, the Numenius longerostris, or long-billed curlew.

"The Esquimaux curlew is eighteen inches long and thirty-two inches in extent; the bill, which is four inches and a half long, is black towards the point, and a pale, purplish flcshcolor near the base; upper part of the head dark brown, divided 
by a narrow stripe of brownish-white; over each eye extends a broad line of pale drab; iris dark-colored; hind part of the neck streaked with dark brown; fore-part and whole breast very pale brown; upper part of the body pale drab, centered and barred with dark brown, and edged with spots of white on the exterior vanes; three primaries black, with white shafts; rump and tailcoverts barred with dark brown; belly white; vent the same, marked with zigzag lines of brown on a dark cream ground; legs and naked thighs a pale lead-color."

This bird, like most others of our sea-fowl, is migratory, arriving in the Middle States from the South early in the spring, and remaining a short time, feeding on the mud-flats and salt marshes, in company with various others of the feathered race. After this they take up their line of march for the Far North, where they spend the summer in breeding and rearing their young. The short-billed curlews travel in large bodies, and keep up a constant whistling during their journeys. It is possible that some few remain the whole summer through in the marshes about Cape May, for the purposes of incubation: such, indeed, is the opinion of those employed in shooting these birds for the markets. We have often met with them in the neighborhood of Cape May early in July.

During the breeding season, curlews collect in immense numbers on the Labrador coast, where they remain till the months of August and September, and then leave in large companies for the South. During these months, and until the commencement of cold weather, curlews are very numerous on the coast of New Jersey and Long Island, frequenting the salt marshes and flats, where they find abundance of food, such as marine worms, shell-fish, and various species of aquatic insects, all of which they partake of greedily. On these mud-flats, where numberless varieties of seabirds collect, are great quantities of a particular kind of shell or craw-fish, vulgarly called fiddlers, upon which the larger fowls prey and soon become fat. This dainty food, however, though very nutritious and excellent, does not improve the flavor of the 
bird, as their meat soon becomes coarse and sedgy after their arrival among us. In the North, they keep more to the open grounds of the interior, and consequently feed chiefly on seeds, insects, and berries. Their flesh at such times is pronounced delicious, and even delicate. We have shot them within a few days after their arrival among us from the North, and always found them more palatable than at any other time. When these birds associate with field-plovers and frequent the meadow-lands, their flesh is quite passable, and even sometimes quite savory; but it is not often that they are found in such good company. Curlews are very shy, and require much caution to approach. They fly with great rapidity when frightened, and require a good blow to bring them down. There are many ways of shooting this bird: the favorite plan is rowing through the inlets and guts in a boat, and killing them as they fly backward and forward to their different fecding-grounds, or coming upon them by stealth, when, unsuspicious of danger, they are socially feeding, in company with other waders, on the insects and shell-fish that they find on the bars and points along the creeks. Great caution, silence, and a considerable degree of manouvring, are necessary to follow this sport with much success, as these birds are extremely shy and easily put to flight. When approaching them, keep near to the shore, and also under cover of the land: it will also be frequently necessary to get out of the boat and make a long detour, so as to get in the rear of the birds: we have often obtained a raking shot at beachfowl in this way.

If one be wounded, he should be made use of as a decoy for others, as they are very kindly in their feelings, and show a great desire always to assist a distressed companion, whom they will fly around for a considerable time, and thus offer many opportunities to kill several before leaving the spot. For all kinds of coastbirds, when shooting from a boat, it is best to have a gun in reserve, as the most of them are enticed within reach by the cries of a winged bird, and the second volley in such cases is oftentimes the most destructive. 
The great mistake that city shooters make in pursuing coastbirds is in the size of the guns which they make use of. Partridgeguns are not suitable for this kind of sport; neither are the full duck-guns the proper weapon. A medium-sized gun is the proper instrument: it should not be too light, or the bore too small, and above all it should be forged to throw the shot with great force at long distances. When going along the inlets in a boat, keep a bright look-out on the marshes adjoining the stream, and you will often discover two or three suspicious-looking heads peering up from among the high grass, within a short distance of the banks, offering an easy shot to the marksman. We have obtained many a good shot in this way which otherwise would have been passed by. This bird is not the same with the Scolopax phaepus, or whimbrel of England, as originally supposed, but proves to be an entirely distinct species.

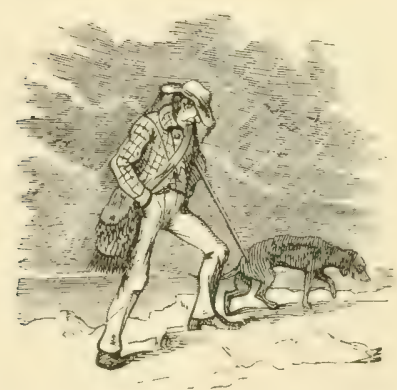




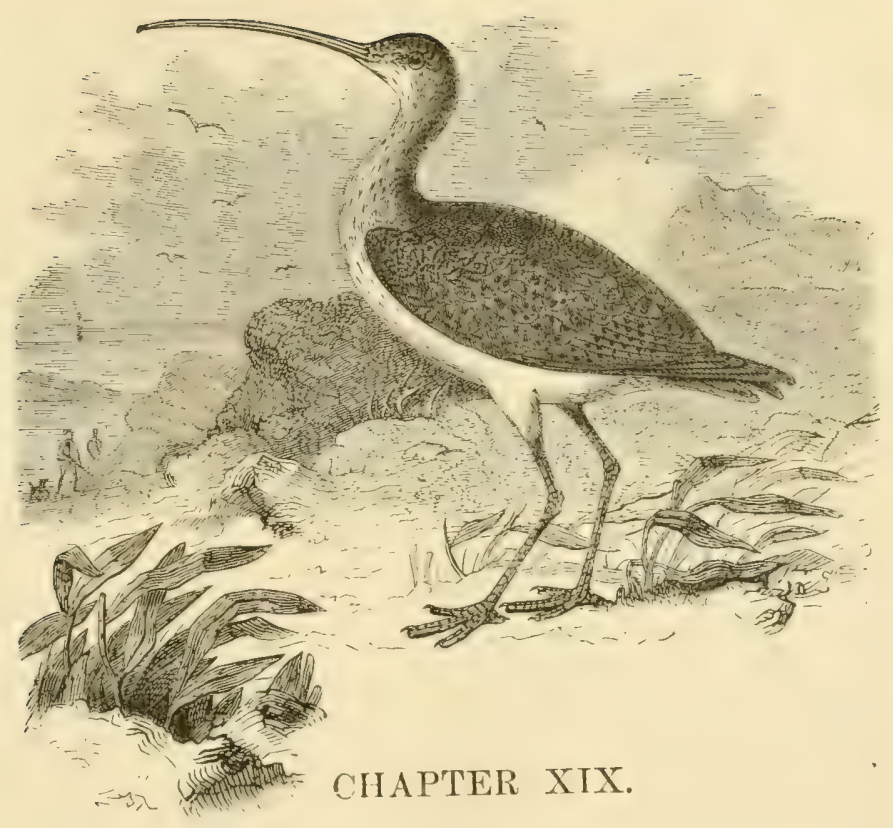

LONG-BILLED CURLEW, OR SICKLE-BILL. NUMENIUS LONGIROSTRIS.

\section{HABITS AND DESCRIPTION.}

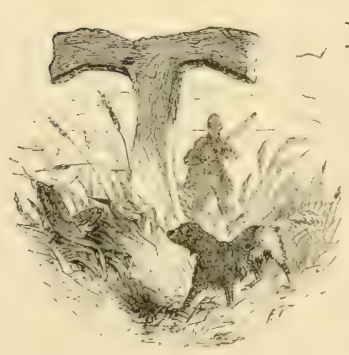

HIS variety of curlew is larger than the preceding species, but not, perhaps, as numerous; it is a beautiful and noblelooking bird. The habits of the sicklebills are very similar to those of the short-billed; they frequent the salt marshes and sea-shore about the same time as the other bird, and we are surprised to learn from Mr. Giraud's work that numbers of them remain on Folly Island, near Charleston, during the season of nidification, for the purposes of procreation.

"The long-billed curlew is twenty-five inches in length and three feet three inches in extent, and when in good order weighs 
about thirty ounces; but individuals differ greatly in this respect. The bill is eight inches long, nearly straight for half its length, thence curving considerably downwards to its extremity, where it ends in an obtuse knob that overhangs the lower mandible; the color black, except towards the base of the lower, where it is of a pale flesh-color; tongue extremely short, differing in this from the snipe; eye dark; the general color alone of the plumage above is black, spotted, and barred along the edge of each feather with pale brown; chin, line over the eye, and round the same, pale brownishwhite; neck, reddish-brown, streaked with black; spots on the breast more sparingly dispersed; belly, thighs, and vent, pale, plain rufous, without any spots; primaries black on the outer edges, pale brown on the inner, and barred with black; legs and naked thighs very pale light blue or lead-color; the middle toe connected with the two outer ones as far as the first joint by a membrane, and bordered along the sides with a thick, warty edge; lining of the wing dark rufous, approaching a chestnut, and thinly spotted with black. The male and female alike in plumage, \&c."

This bird resembles somewhat the English curlew, (Scolopax aquata;) but the difference in the plumage and length of the bill is sufficient to mark it as a distinct species. The English curlew weighs about the same with the American; the bill, however, is two inches shorter. During the season of brambleberries, the curlews sometimes desert the marshes and fens, and resort to the old fields to partake of this fruit, and are then free from that strong, sedgy taste which they acquire while feeding on fiddlers, snails, shell-fish, and other strong food.

These birds, like all their congeners, are very shy and hard to approach. They are often shot down when in company on the sandflats with other less wary fowls; they are easily decoyed, while flying, by imitating their whistle, with which most of our coastshooters are familiar, and who often draw them a considerable distance from their course by sounding their expressive notes. All seabirds should be fired upon while going from us, as they are more easily killed by striking them with the feathers than against them. 
The long-billed curlew requires a very hard rap to bring him down, and will often carry off several large pellets with him. They usually fly very high and with great velocity, and, when in companies, adopt the wedge form, like ducks.

These birds are pursued upon our coast like other sea-fowls, either in boats or by tramping over the marshes. A pit dug in the marsh adjoining some favorite feeding-ground or point is ar excellent plan to shoot all kinds of bay-fowl.

Another variety of curlew, known as the doe-bird, is often shot by the bay-shooters; it is smaller than either of the two preceding varieties. It is also termed the jack-curlew. Its habits are the same, and it associates with the other two species.

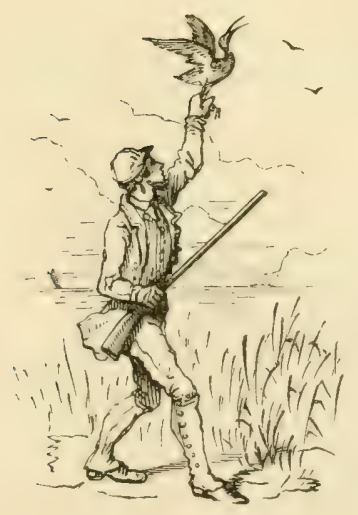




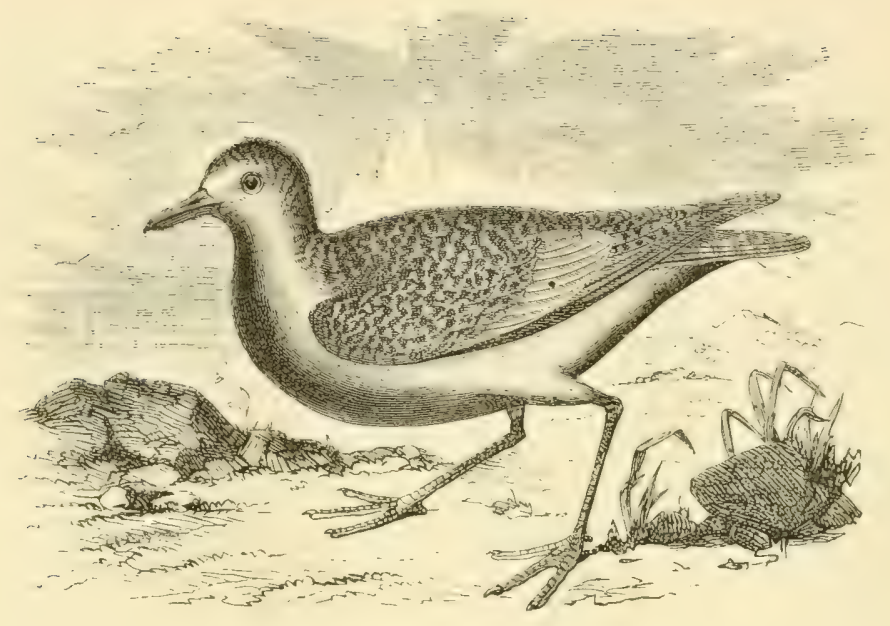

CHAPTER XX.

BLACK-BELLIED PLOVER. CHARADRIUS APRICARIUS.

"O'er the flat marsh we mark the plovers sweep,

And, clustering close, their wheeling courses keep."

THEIR HABITS, ETC.

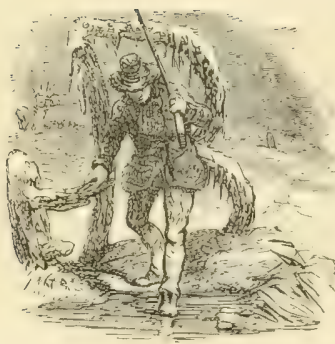

LACK-BELLIED PLOVERS, being well known to most of our sportsmen, are eagerly sought after wherever they make their appearance. These birds return from the South early in May, and remain but a short period upon the seacoast; they then retire to the high upland districts to breed and rear their young, and during this season feed upon berries, grasshoppers, and various insects, and become very fat and good-flarored. At this time more particularly they are known as the old field-plover, or whistling plover. Towards August or September, in company with the young birds, they resort to the sea-shore, and soon be294 
come sedgy from the change of food. The plumage of the young bird is quite dissimilar to that of the adult bird, in fact so much so that they are frequently considered a distinct species, and are then known as the "bull or beetle-headed plover." Plovers generally fly high, and keep up an incessant whistling, which being repeated be the sportsman, the birds are easily decoyed within gunshot. They are very shy when feeding, and extreme care is requisite to approach them. When on the sea-shore, they may be shot by the same artifices resorted to for the killing of curlews or other seabirds. When on the open plains, where they are still more difficult to be got at, the use of a stalking-horse is an excellent plan by which to circumvent them, and is recommended as a highly successful mode of killing them.

A most capital manœurre, and one adopted by some of our sporting friends in the country, is to approach them in a careless manner, either in an old wagon or cart, or on horseback, as they seldom take alarm at a horse or a vehicle of any description.

Plovers require a very hard rap to bring them down. This variety is known in England.

As soon as the cold weather sets in, these birds move off to the South.

\section{DESCRIPTION.}

"This species is twelve inches long and twenty-four inches in extent; the bill is thick, deeply grooved on the upper mandible, an inch and a quarter in length, and of a black color; the head and globe of the eye are both remarkably large, the latter deep bluish-black; forehead white; crown and hind-head black, spotted with golden yellow; back and scapulars dusky, sprinkled with the same golden or orange-colored spots, mixed with others of white; breast, belly, and vent, black; sides of the breast whitish; wingquills black; middle of the shafts white; greater coverts black, tipped with white; lining of the wing black; tail regularly barred with blackish and pure white; tail-coverts pure white; legs and feet a dusky lead-color; the exterior-toe joined to the middle by a broad membrane; hind toe very small. 
"From the length of time which these birds take to acquire their full colors, they are found in very various stages of plumage. The breast and belly are at first white, gradually appear mottled with black, and finally become totally black. The spots of orange or golden on the crown, hind-head, and back, are at first white, and sometimes even the breast itself is marked with these spots, mingled among the black. In every stage, the seemingly disproportionate size of the head and thickness of the bill will distinguish this species."

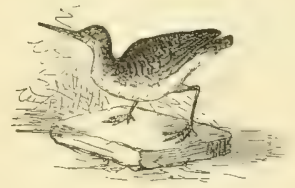

GOLDEN PLOVER. CHARADRIUS PLUVIALIS.

HABITS, NOMENCLATURE, ETC.

THese birds are more beautiful in their plumage than the latter variety, but somewhat smaller; they are also far less numerous. Their habits, however, are pretty much the same, perhaps more gregarious, as they are often seen in considerable flocks on the seaboard. The notes of the golden plover are less shrill and piping than those of the black-bellied plover; they are less timid, and more easily decoyed. These birds are often taken for the young of the other variety. They are known as "frost-birds" in the neighborhood of New York, from the circumstance of their being more abundant about the time of the early frosts of autumn, when they are also in good condition. The golden plover resorts to the upland meadows in search of berries and grasshoppers, to both of which it is very partial. The flesh of these birds in the early 
autumn is most excellent, and they always command a good price when exposed for sale in our markets. As the weather gets cold they pass on to the Far South. They breed in regions beyond the United States; they are never very numerous in the Middle or Eastern States, and, their flesh being savory, they are highly prized.*

\section{DESCRIPTION.}

"The golden plover is ten inches and a half long and twentyon inches in extent; bill short, of a dusky slate-color; eye very large, blue-black; nostrils placed in a deep furrow and half covered with a prominent membrane; whole upper parts black, thickly marked with roundish spots of various tints of goldenyellow; wing-coverts and hind part of the neck pale brown, the latter streaked with yellow; front, broad line over the eye, chin, and sides of the same, yellowish-white, streaked with small pointed spots of brown olive; breast gray, with olive and white; sides under the wings marked thinly with transverse bars of pale olive; belly and vent white; wing-quills black, the middle of the shafts marked with white; greater coverts black, tipped with white; tail rounded, black, barred with triangular spots of golden-yellow; legs dark dusky slate; feet three-toed, with generally the slight rudiments of a heel; the outer toe connected as far as the first joint with the middle one. The male and female differ very little in color."

There are several other varieties of plover known to our gunners; the flesh of the most of them is equally good, and when in season is highly prized by the epicure. The two above described, however, are the largest and most distinguished of the species: the others are known as the ring-plover, piping-plover, kildeer-plover, Wilson's plover, grass or field-plover, \&c.

The last-named variety, Tringa bartramiana, is not a coast or

* The golden plover frequents tae sea-const of the Middle and Eastern States in the spring and early summer; during the autumn they resort to the prairies and interior feeding-grounds. 
marsh bird. They are found most commonly on the inland meadows and old upland fields, where they feed on grasshoppers, beetles, and the various insects that inhabit such situations. They are very much esteemed by epicures, their flesh being delicate, juicy, tender, and high-flavored. The whole species are wild, wary, cunning, and difficult to be approached.

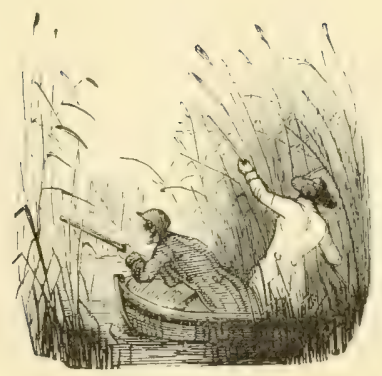




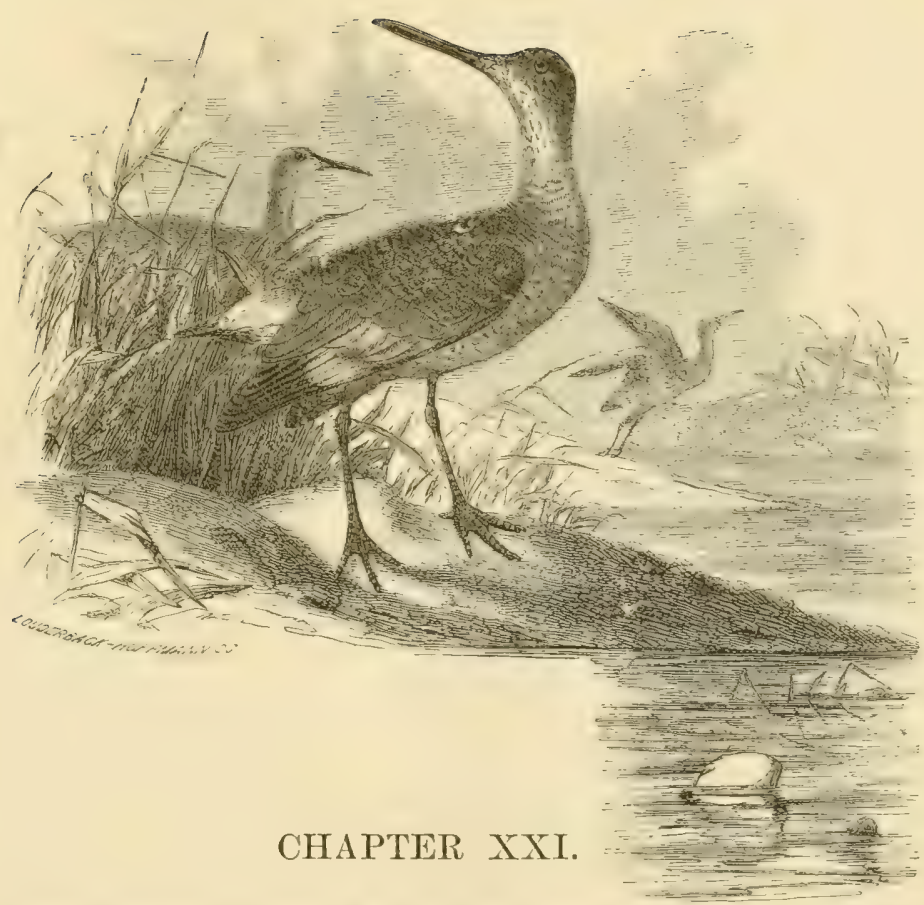

SEMIPALMATED SNIPE, WILLET, OR STONE-CURLEW. SCOLOPAX SEMIPALMATA.

HABITS, DESCRIPTION, ETC.

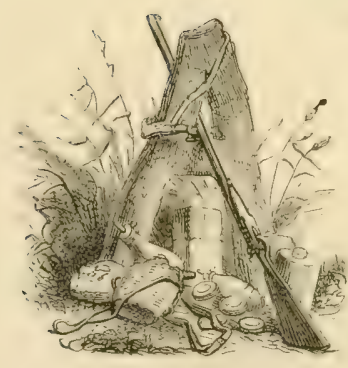

$\mathrm{S}$ before stated, the snipe family is extremely numerous throughout this country, and the number and variety of birds of this species that flock to our sea-coast during the summer and autumn is almost incredible.

Among these shore or bay fowls there is none more conspicuous or more sought after than the one now under consideration. The shrill and incessant cry of the willet is well known to 
every frequenter of the salt marshes throughout the States of New York, New Jersey, and Delaware; and this familiarity with the peculiar call of this wary bird is turned to terrible account against them, as they are easily deceived and decoyed within reach of the treacherous gun by the skilful imitations of the shooters.

The willet is not known in England, nor is there any bird in the country with which it may be said to correspond. Temmick, however, notices it as an accidental straggler among the birds of Europe. Willets come from the South about the middle of April, and soon make preparations for laying; their nests are built in the marshes, upon the tussocks and other little eminences of earth and herbage that are scattered about in the dryer places. The nest generally contains four tapering dark-colored eggs, which, like those of the mud-hen, are said to be good eating; in fact, we know them to be very excellent, as we have partaken of them, although we did not assist in the destruction of the nests from which they were filched. This bird, with most others that build on the marshes, suffers greatly during the period of incubation from the attacks of crows, weasels and foxes, and other animals, which devour numberless eggs as well as young willets.

These fowls feed on small shell-fish and the innumerable variety of aquatic insects and worms found on the marshes; the flesh consequently is sedgy, though not fishy. Young willets are juicy and tender, and perhaps more esteemed than any other of the shore-birds; and, when cooked properly, are quite passable when no other kind of game is to be had; in fact, we have heard many of our sporting friends really extol these birds when served up, and hunt as eagerly after them as if they possessed the delicacy and game-flavor of the woodcock.

Willets remain with us till October and November, and sometimes later, if the weather continues agreeable. They are shot during low tide, on the marshes and flats, and when flying are easily decoyed by imitating their whistle, which is thought to resemble the following combinations:-Pill-will-willet, pill-willwillet 
Shooters most frequently go after these birds in small boats, on the inlets and guts that intersect the marshes which they, in common with curlews, plover, \&c. frequent.

\section{DESCRIPTION.}

"Length fifteen inches; extent thirty inches; upper parts dark olive-brown; the feathers streaked down the centre and crossed with waving lines of black; wing-coverts light olive-ash, and the whole upper parts sprinkled with touches of dull yellowish-white; primaries black, white at the root-half; secondaries white, bordered with brown; rump dark brown; tail rounded, twelve feather's pale olive, waved with bars of black; tail-coverts white, barred with olive; bill pale lead-color, becoming black towards the tip; eye very black; chin white; breast beautifully mottled with transverse spots of olive on a cream ground; belly and vent white, the last barred with olive; legs and feet pale lead-color; toes half-webbed.

"Towards the fall, when these birds associate in large flocks, they become of a pale dun color above, the plumage being shafted with dark brown, and the tail white, or nearly so. At this season they are extremely fat, and esteemed excellent eating. Experienced gunners always select the lightest-colored ones from a flock, as being uniformly the fattest. The female of this species is generally larger than the male.'

Willets, as other shore-birds, have a strong affection for their young, or for a companion in distress, and are ever ready to turn from their course to offer assistance at the first call for aid, regardless of all consequences. 


\section{RED-BREASTED SNIPE. SCOLOPAX NOVEBORACENSIS.}

HABITS, NOMENCLATURE, ETC.

THus snipe resembles very much in size and plumage the common snipe, more particularly when in its winter plumage; it is, however, altogether different in its habits, as well as in the flavor of its flesh. The English or Wilson snipe frequents fresh-water marshes only, while the present species confines itself almost exclusively to the salt marshes of our Atlantic States. The English snipe is mostly a solitary bird, while the red-breasted snipes congregate in immense flocks upon the mud-flats and sand-bars. This snipe, we believe, is known to our coast-shooters as the brown back, or dowitcher, and we have at times found it more palatable than any other kinds of sea-bird, although considerably smaller than the curlew, willet, or plover. Being so much smaller than these birds, this snipe is not so much sought after as some others; we, however, never let an opportunity pass to bring them to bag, when on these excursions, oftentimes in preference to the other birds, which are always far more sedgy, and not unfrequently fishy besides.

The red-breasted, or, as they are also called, the quail snipes, arrive on the coast of Jersey from the South on their way to their breeding-grounds farther north, about the first week in May, remain a short time, and then stretch off, for the Canadas. Towards the middle of July they commence returning in increased numbers, and remain feeding on the marshes till the commencement of the cold weather, when they take themselves to the South. These snipes fly in large flocks, and feed in thick masses upon the points, and will often allow a boat to approach sufficiently near to give them a raking shot fore and aft, that not unfrequently spreads death and destruction through the greater portion of their affrighted ranks. We were present on one occasion when twenty-three of 
these birds were killed at one discharge of a large-sized fowlingpiece; and we have killed, repeatedly, six or eight at a shot.

They are certainly far less wary than most other shore-birds, and when feeding in company are always the last to take the alarm; they are easily deceived by the bay-shooters, and many fall victims to the treacherous decoys.

Their food consists of small snails, and aquatic insects that are washed up by the tide.

\section{DESCRIPTION.}

"The red-breasted snipe is ten inches and a half long and eighteen inches in extent; the bill is about two inches and a quarter in length, straight, grooved, black towards the point, and of a dirty eel-skin-color at the base, where it is tumid and wrinkled; Iores dusky; cheeks and eyebrows pale yellowish-white, mottled with specks of black; throat and breast a reddish-buff color; sides white, barred with black; belly and vent white, the latter barred with dusky; crown, neck above, back, scapulars, and tertials black, edged, mottled, and marbled with yellowish-white, pale and bright ferruginous, much in the same manner as the common snipe; wings plain olive, the secondaries centred and bordered with white; shaft of the first quill very white; rump, tail-coverts, and tail, (which consists of twelve feathers, white, thickly spotted with black; legs and feet dull yellowish-green; outer toe united to the middle one by a small mernbrane; eye very dark. The female is paler on the back and less ruddy on the breast."

\section{OTHER VARIETIES OF SHORE-BIRDS.}

There are several other varieties of the snipe species that sports. men eagerly seek after while shooting on the sea-shore marshes; it cannot be expected of us, however, to describe all these birds. We shall, therefore, be forced to pass them by with two exceptions. namely, the 
SCOLOPAX FLAVIPES- YELLOW-SHANKS SNIPE; AND SCOLOPAX VOCI. FERUS-TELLTALE SNIPE, GODWIT, OR GREATER YELLOW-SHANKS SNIPE.

Bотн these birds are well but not favorably known to the market shooters of Philadelphia and New York, as they are extremely shy and very vigilant, and often give notice, by their shrill whistle, of the approach of the pot-hunter when he would not have been observed by the less wary fowl feeding around. This habit of timely warning their careless companions of the danger that is encompassing them has given rise to their respective appellations of Greater or Lesser Telltale. Notwithstanding their uncommon vigilance, they are, nevertheless, often brought to bag, and in the autumn their flesh is not unfrequently very savory. These birds resemble each other so very much in their general appearance and plumage that the difference in their size alone is the most rlistinguishing characteristic.

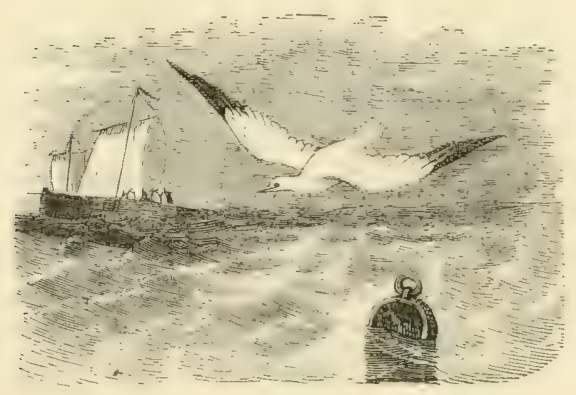




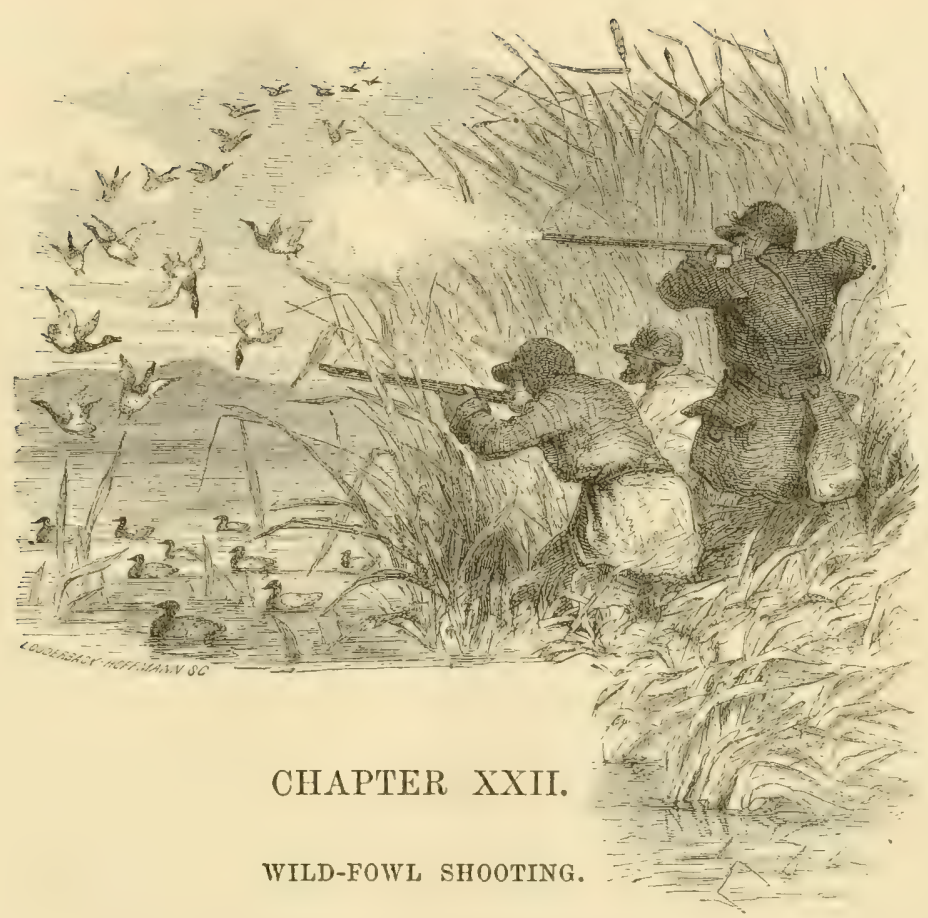

"But hark! what sound is that approaching near?

'Down close!' The wild ducks come, and, darting down, Throw up on every side the troubled wave,

Then gayly swim around with idle play."

THIS AMUSEMENT IN AMERICA.

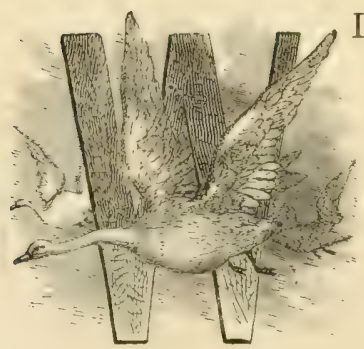

ILD-FOWL shooting, though not as popular or followed with the same zest by the sportsmen of America as it is by those of England and other countries, is nevertheless every season attracting increased attention to its real merits as a manly and exciting sport; and no doubt, as the conveniences for visiting our bay and sea-shores become more widely diffused throughout the various portions of our Atlantic States, by the opening of new steamboat and railroad routes, our pleasure-loring and norelty-sceking 
people will flock to the secluded haunts of the wild forl much more generally than they do at present. When a fondness for this kind of sport is once awakened among us, we may expect to see our shooters excel those of any other portion of the world, owing to the great abundance of this kind of game, the freedom with which they can pursue it, and the enthusiasm with which they will take it up. This sport, at present, is almost entirely confined to the hands of those who follow the occupation of killing wild fowl not from motives of pleasure or healthful recreation, but as a means of subsistence for themselves and families; and the tables of our epicures are generally supplied from this source.

Some few of the New York sportsmen occasionally sally forth during the ducking season to spend a few days in shooting upon the neighboring shores, but the sport is not considered sufficiently enticing to carry them very often on such expeditions. We also have a few amateurs in Philadelphia who are fond of visiting the wild-fowl regions, but none that are ver'y enthusiastic on the subject, like Colonel Hawker and many other Englishmen, who have devoted so much time and talent to the perfecting of this branch of sport.

Duck-shooting, to-be-sure, is no child's play; but, on the contrary, is often attended with many mishaps, great hardships, and constant exposure to the elements, and withal frequently results in fisherman's luck, so often quoted. No true lover of sport, however, should be intimidated, or, in fact, object to these petty inconveniences, as it is these rery circumstances that afford the chief enjoyment and give a keener relish to this pursuit, which will in time inure him both in body and mind for the accomplishment of greater and more lasting benefits than the mere destruction of game. We cannot expect to arrive at perfection in any employment without a becoming share of labor and perseverance; and in the pursuit of ducks the shooter will find a wide field open for the exercise of both these virtues, as well as many other qualifications alike necessary for the attainment of nobler deeds. It is indeed necessary for a sportsman, to enjoy this kind of amuse- 
ment, to become accustomed to all kinds of hardships, - to care neither for the peltings of the rain, the driving of the snow, whistling of the wind, or the freezing of the water. All such accompaniments to his pursuits must be despised, and not regarded as barriers to his enjoyments; but, as before intimated, their presence must be viewed as imparting a keener zest to the pleasure of the sport. With feelings akin to these, the sportsman is prepared to enter upon the hardy and exciting occupation of wild-fowI shooting in all its branches during the cold winter months of our northern country; and such a choice spirit will derive both pleasure and healthful recreation in the pursuit.

It is almost unnecessary to tell the sportsman that he must be provided with many essentials to assist him in holding the elements at defiance, and resort to every expedient to protect his ammunition from dampness, his gun from rust, and his own person from the effects of the cold and rain to which he will often be exposed during these excursions. Water-proof boots, water-proof coats, woollen shirts, drawers and stockings, and warm gloves, are all necessary accompaniments to a ducker's wardrobe; and, without these essentials and a strong heart besides, he had better not enter upon the rough-and-tumble sport of wild-fowl shooting as followed by an old campaigner.

A flask of good spirits is also an important accompaniment to the other necessaries, but which, by-the-by, should be resorted to as seldom as possible; for the use of liquor during active exercise often creates an unnatural thirst, which, if indulged in to an extent sufficient to produce a flush on the cheek or a glow on the body, will most assuredly make the eye uncertain or the hand unsteady, and, moreover, prove otherwise injurious by opening the pores of the system and making the shooter more susceptible to the effects of cold. We have spoken more fully on this subject in our hygienic directions. 


\section{CHESAPEAKE BAY.}

"Above, around, in numerous flocks are seen

Long lines of ducks o'er this their favorite scene."

There is no place in our wide extent of country where wild. fowl shooting is followed with so much ardor as on the Chesapeake Bay and its tributaries, not only by those who make a comfortable living from the business, but also by gentlemen who resort to these waters from all parts of the adjoining States to participate in the enjoyments of this far-famed ducking-ground. All species of wild fowl resort to these waters in numbers beyond credence or computation; and it is really necessary for a stranger to visit these regions if he wishes to form a just idea of the wonderful multitudes and numberless varieties of ducks that darken these waters and hover in interminable flocks over these favored feedinggrounds. It is not, however, the variety or extraordinary number of ducks on the Chesapeake that particularly attracts the steps of so many shooters to these parts, as there are other rivers and streams, equally accessible, where wild fowl also abound. But the great magnet that makes these shores the centre of attraction is the presence of the far-famed canvas-back, that here alone acquires its peculiar delicacy of flavor while feeding upon the shoals and flats of these waters. It is in quest of these noble ducks that so many repair annually to the shores of the Chesapeake and its numerous tributaries, regardless of the myriads of other fowl which are seen around on every side. The shooter alone taxes all his energies for the destruction of this one variety, regarding all others with contempt, and as hardly worthy of powder and shot. The month of October has hardly set in before the immense host of ducks commence arriving from the North in the waters of the Chesapeake. Among the first of these welcome visitors will lie seen the Anas albeola, commonly known as the butter-ball, and whose sharp and quick note-quack! quack! quack!-is soon heard throughout the neighboring streams and marshes, as they ever and anon spring up and dart off with amazing velocity. Now may be 
seen the Anas boschas, known as the wild drake or mallard; the Anas glacialis, south-southerly or long-tailed duck, with its singular and discordant notes; and a few others. As the season progresses, the cold blasts of the North bring down in regular succession the sprightly little Anas mavilla, black-head or bluebill; the cunning Anas Americana, American widgeon or ball-pate; the poaching Anas ferina, or red-head; the wary Anas Canadensis, or. Canada goose; the graceful Cygnus Americanus, or American swan; and, last, but not least, the Anas valisineria, or canvas-back. Now it is that the waters of the Chesapeake are filled to repletion with the armies of ducks that collect on the flats and shoals where the juicy blades of the valisineria flourish in the greatest profusion. Now it is that the shores are thickly strewed with the remnants of this aquatic plant, pulled up from its soft bed. Now it is that the waters of the bay are darkenerl by the flights of the winged host travelling hither and thither in search of food. Now it is that the ordinary quiet employments of the residents of these regions teeming with abundance are abandoned for the more exciting and lucrative occupation of duck-shooting. Every old musket and rusty fowling-piece is brought into immediate requisition. All is bustle and confusion among the duckers; and now it is that the neglected water-dog, who has wandered idly about, uncared-for and unfed, for the past nine months, is called familiarly and even kindly to the heels of his selfish master. The bay shore for miles and miles, long before the dawn of day, is alive with shooters; and every point is occupied with eager marksmen, who stand prepared with murderous weapons to give a passing volley to every canvas-back that heedlessly ventures within range. The before quiet and peaceful shores of the bay now resound with the deafening volleys of the toling parties concealed behind the various blinds erected along the banks, while the guns from the boats and masked batteries send booming over the placid waters their echoing notes of death and destruction. The wary canvas-backs, startled in every quarter, fly here and there, scarcely knowing where to repose in safety or feed in peace. 


\section{HINTS FOR DUCKERS.}

Wild fowl are ever on the alert, and always ready to take alarm at the least indication of danger, and therefore must be approached with the utmost precaution or waited for in the profoundest silence. The plashing of an oar, the rattling of a pebble, the rustling of a leaf, the bobbing up of a head, the exposure of a leg, the raising of an arm, or the utterance of a loud word, will often put to sudden flight a whole flock of ducks a few minutes before feeding in fancied security almost within reach of our smallest gun; therefore, "be as still as death itself, yet watchful as life can make you."

The sense of smell is singularly developed in wild ducks, and, when approaching them on the water, it is necessary to get to the leeward of them. Colonel Hawker very justly remarks, on this point, "In following wild fowl, it is easier to get within twenty yards of them by going to leeward than a hundred and fifty directly to windward, so very acute is their sense of smelling." This fact of their being able to scent an enemy a long distance off is well known to the men employed in attending on the decoyponds of England and France; and, for the purpose of destroying or counteracting the odor emanating from their persons, they always hold a piece of burning peat in their mouths when visiting their nets.

\section{DISTANCES ON THE WATER.}

It is very difficult for the inexperienced to judge of distances on the water, and the eye is consequently often deceived on such occasions; and a young sportsman not unfrequently will fire away at wild fowl securely feeding far beyond the reach of a gun double or treble the calibre of the one he is using, and then express great astonishment that the load should have fallen far short of the mark, or, perhaps, have scattered harmlessly in the very midst of the intended victims. Experience and observation will alone correct this fault. 


\section{VELOCITY OF FLIGHT.}

When wild fowl are travelling against the wind, it causes them to fly low and closer together than when going with it. The velocity with which ducks cleave the air is very great, and argues strongly the necessity of having the best of guns and ammunition, to be successful in this kind of sport. The barrels of duck-guns should be of sufficient calibre and length to bear a large proportion of powder, so as to throw the shot thickly and with great force to a long distance. Under ordinary circumstances, unassisted by the wind, ducks fly at the rate of eighty to one hundred miles an hour, as has often been proven by actual experiment; and the following plan, adopted by Major Cartwright, to ascertain this fact to his own satisfaction, is both ingenious and conclusive in its results, and we therefore give it in his own words:- "In my way hither, I measured the flight of eider-ducks by the following method,- - viz.: on arriving off Duck Island I caused the people to lie on their oars; and when I saw the flash of the guns which were fired at a flock of ducks as they passed through the latter, I observed by my watch how long they were in flying abreast of us. The result of very many observations ascertained the rate of their speed to be ninety miles an hour." This celerity of flight is not only wonderful, but seems almost incredible; nevertheless, the fact is well substantiated by the observations of other writers respecting the movernents of birds even less rapid than those of ducks. For example, it is not an uncommon occurrence to shoot wild pigeons (Columba migratorna) in the forests of Canada, with their stomachs filled with perfect, or rather whole, grains of rice, which must have been gleaned from the rice-fields of the Southern States, at a distance, perhaps, of one thousand miles or more from the spot where they were killed. Now, allowing several hours of active exercise to be sufficient to digest this article of food, or, rather, granting the inability of these seeds to resist the action of the stomach for a longer time than a few hours, it is but fair to conclude that the birds must have flown with astounding velocity 
to have arrived at such a distance from the rice-plantations even before its last meal was digested. Still further to elucidate this subject, we will mention another well-authenticated circumstance that has already been referred to by more than one writer. It is stated that a falcon belonging to Henry the Fourth, King of France, escaped from Fontainebleau, and was captured again at Malta, a distance of nearly fourteen hundred miles, in less than twenty-four hours from the time of its liberation from its former prison. Now, if we suppose this bird to have been in motion during the whole of the time intervening between its escape from Fontainebleau and its recapture at Malta, the rate at which it travelled would exceed sixty miles an hour. This supposition, however, is neither correct nor rational, as this species of bird never flies in the night; and we must therefore grant it the hour's of darkness for repose, and calculate the actual velocity of flight accordingly. Allow, therefore, that the falcon enjoyed eighteen hours of light, which is more than a fair proportion of the time in opposition to our argument, and also grant that the bird was seen the monent of its arrival at Malta, which is also somewhat improbable, the speed with which it must have flown is equal to eighty miles an hour, or within a fraction of that amount.

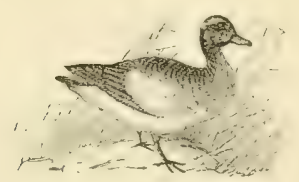




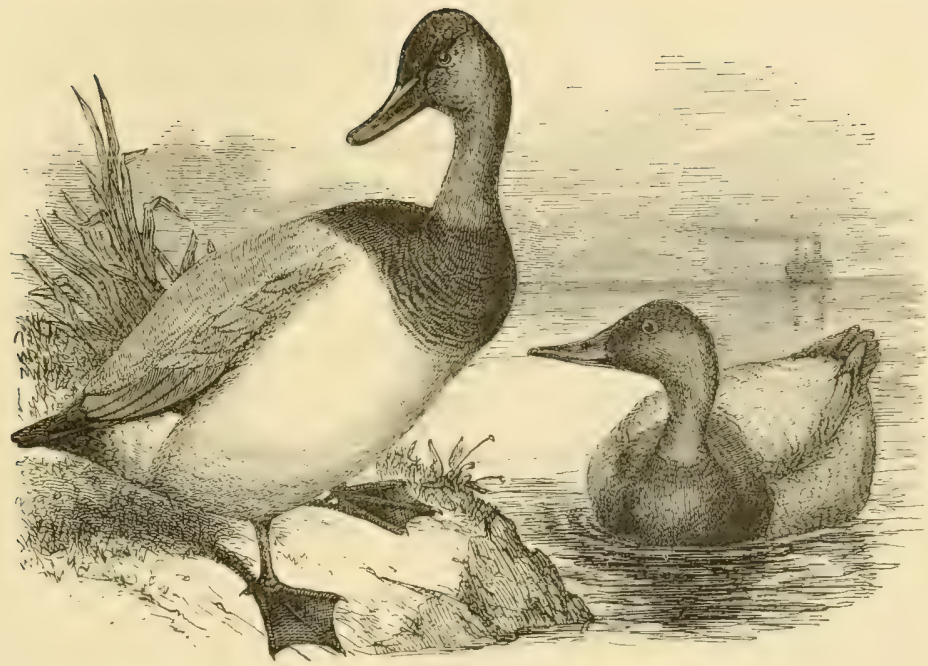

CHAPTER XXIII.

CANVAS-BACK. ANAS VALISINERIA.

"Now all around us rising trains appear;

Wild whistling wings on every hand we hear;

The alarm of death amid their legions spread,

In files immense they winnow overhead."

THEIR HIGH ESTIMATION.

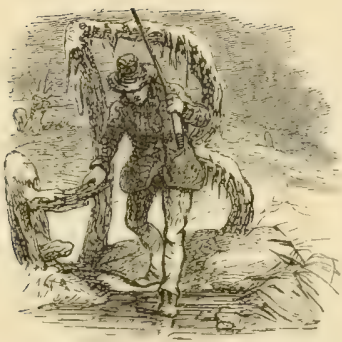

OTH with sportsmen and epicures the far-famed canvas-back stands forth preeminent for the richness and delicacy of its flesh; in fact, it is conceded in all quarters that no wild fowl in any portion of the globe can vie in flavor with the canvas-back of the Chesapeake or Potomac. No variety of duck is more eagerly sought after by the sportsmen of our country, and no viand contributes so largely to enhance the enjoyments of the table among the luxurious followers of Epicurus as the presence of this delicious 
fowl, served up piping hot, all redolent with the captivating fumes of its savory flesh; and, in the words of Wilson, "canvas-backs not only grace, but dignify, the table; and their very name conveys to the imagination of the eager epicure the most comfortable and exhilarating ideas."

The beautiful appearance, large size, immense numbers, and juicy tenderness of these ducks, during their stay on the Chesapeake and its tributaries, cause them to be persecuted with an unrelenting ardor by shooters collected from all parts of the neighboring States, urged on not only by a healthful desire for sport, but doubly stimulated by the more selfish motive of gain. Although thousands of these ducks are annually sent to the markets of Philadelphia, Baltimore, New York, and even as far south as Charleston, the demand for them at these places is ever the same; and the exorbitant price that they readily bring-two or three dollars per pair-is of itself a sufficient proof of the high estimation in which our citizens hold them.

\section{KNOWN ONLY IN AMERICA.}

This duck we are proud to claim as solely American, there being no fowl as yet described in any portion of the world, except perhaps the pochard of England, that at all resembles the canvasback. This duck, however, is much smaller, and weighs at least one-third less; and the delicacy of its flesh, though good, is far inferior to that of our species.

Before going further, we will make the reader familiar with this beautiful duck by the introduction of Wilson's description:-

"The canvas-back is two feet long and three feet in extent, and, when in good order, weighs three pounds; the bill is large, rising high in the head, three inches in length, and one inch and three-eighths thick at the base, of a glossy black; eye very small; irides dark red; cheeks and foreparts of the head blackish-brown; rest of the head and greater part of the neck bright, glossy, reddishchestnut, ending in a broad space of black that covers the upper part of the breast and spreads round to the back; back, scapulars, and 
tertials white, faintly marked with an infinite number of tranverse waving lines or points, as if done with a pencil; whole lower parts of the breast, also the belly, white, slightly pencilled in the same manner, scarcely perceptible on the breast, pretty thick towards the vent; wing-coverts gray, with numerous specks of blackish; primaries and secondaries pale slate, two or three of the latter of which nearest the body are finely edged with deep velvety black, the former dusky at the tips; tail very short, pointed, consisting of fourteen feathers of a hoary brown; vent and tail-coverts black; lining of the wing white; legs and feet very pale ash, the latter three inches in width, - a circumstance which partly accounts for its great powers of swimming.

"The female is somewhat less than the male, and weighs two pounds and three-quarters. * The crown is blackish-brown; cheeks and throat of a pale drab; neck dull brown; breast, as far as the black extends on the male, dull brown, skirted in places with pale drab; back dusky white, pencilled like the back; wings, feet, and bill as in the male; tail-coverts dusky; vent white, waved with brown."

\section{NATURAL HISTORY.}

Very little or nothing is known of the canvas-back during the period of incubation; in fact, the history of the whole duck tribe during this interesting season is but little known, as they retire at the breaking up of winter to the far regions of the Arctic, and there, in those solitudes never trod by the wandering footsteps of man, they unmolested breed and rear their young.

Audubon, however, informs us that they breed in considerable numbers on the borders of Bear River, in Upper California; also

* We are just in receipt of two couples of canvas-backs, from the Chesapeake, the aggregate weight of which is twelve pounds and a half, being three pounds and an eighth to each fowl; as they are paired, male and female, the weight is rather unusual. We occasionally hear of a seven-pound couple; but such ducks are very rare, even in the height of the season. We have seen some couples that weighed within a fraction of eight pounds; but such are still more rare. 
in the marshes and along the banks of streams in many parts of the Rocky Mountains.

Canvas-backs first make their appearance on our waters in the months of October and November. During the time of migration a few are encountered upon the Hudson and Delaware, and other rivers, but the great body of ducks generally take up their line of march straight for the Chesapeake and its tributaries, the Susquehanna, Potomac, James, Elk, North-East, Bush, Gunpowder, and some other smaller streams.

It will now be very naturally asked by the uninitiated but inquisitive reader, Why do these ducks resort so particularly to the above-mentioned waters in preference to the hundreds of others of our noble rivers? This question is easily solved when we inform him that a peculiar kind of aquatic plant on which they delight to feed grows luxuriantly in these streams, and that it is seldom or never found in other localities; and, if met with at all, is generally in such small quantities that it would not furnish food sufficient for these numberless ducks for more than a few days. They, therefore, instinctively, or perhaps led by the older members of the flocks, wend their way from the bleak climes of the North in a direct course to these favored regions of abundance, and where, previous to the coming of the white man, the feathered tribes remained all winter, feeding unmolested and undisturbed by the never-ceasing reports of the terrible duck-guns which now spread death and destruction on all sides. When the canvas-backs first arrive in our waters, they are rather poor and unpalatable, but soon become fat and juicy, as they are very industrious feeders, and partake largely of the roots of the valisineria, or wild celery, which is very tender and extremely nutritious. This species of aquatic herb, from which the canvas-back so appropriately derives its scientific appellation, grows in great abundance on the exten. sive shoals of the Chesapeake, as also on the numerous flats of all the rivers that empty their waters into this estuary. The plant attains several feet in height, and has a small white root very much resembling young celery; and it is upon this delicate portion alone 
that the dainty canvas-back regales his fastidious appetite, disdaining the green blades, which are left to float off and strew the shores of the bay for miles and miles. There are several species of ducks that are as equally fond of the roots of the valisineria as the canvas-backs; but, not being as strong as this fowl, they are not able to dive deep enough to seize the stock sufficiently near the bottom to insure pulling the plant up by the roots. These ducks, however, are always seen feeding with the canvas-back, and supply this deficiency in their physical construction to the arlaptation of their wants by a singular boldness and ingenuity. For acting the part of skulking poachers, they attentively watch every opportunity to seize upon the dainty morsel the very moment the canvasback makes his appearance on the top of the water with the root in his mouth, and then, swimming off rapidly to a convenient distance, quietly enjoy the stolen repast, unmolested by their good-tempered opponent, who soon dives down again for another bonne-bouche.

Among these cunning pilferers, none are more conspicuous than the red-heads and bald-pates, both of which are always found feeding in company with the canvas-back, and at the height of the season are not very far inferior to these ducks; and it oftentimes puzzles the best judges to distinguish one from the other, when properly served. We have seen the epicurean taste of some of our sporting friends put to the test on this point more than once; and the mistakes which have been made on these occasions are conclusive evidence of the great similarity in the flavor of these three varieties of ducks during the particular period that they all feed exclusively upon the roots of the valisineria.

Although the canvas-backs are excessively fond of the bulbous portions of the Valisineria Americana, and prefer it to any other kind of food, they are not solely dependent upon this herbal production for subsistence, but are obliged to resort to other species of aquatic plants when driven from the rivers and flats of the upper bay, by the large masses of floating ice, into regions where this vegetable does not grow. When forced by this circumstance to quit their favorite feeding-grounds, the canras-backs betake themselves 
far down the bay, where the valisineria is thinly distributed and the shallows are more generally covered with a different variety of marine plant, known as eel-grass. At such times, the canvasbacks, being driven to partake of this rank grass, as well as small fish and many other less dainty articles of food, soon lose a great deal of that delicacy of flavor which alone seems to be imparted to their flesh by the use of this water-celery. If they should be confined to a different diet for any considerable time, their flesh becomes sedgy and savorless, and is not much superior to many other varieties of sea-coast fowl.

The fact of the fondness of the canvas-back for this bulbous root, and the knowledge of the peculiar savor imparted to their flesh by partaking of it, has been turned to useful account by some of our intelligent agriculturists, who coop and feed the common domestic duck upon the tops and roots of the garden celery for a few days previous to killing them, which plan is said to much improve their flavor and altogether destroy that rankness which is often observable in the barnyard fowl. A friend of the author, who has fattened ducks in this way, assures him that it was almost impossible to distinguish some of them from wild ones, their taste being so much improved.

The canvas-back extends its migrations as far south as Florida, and is known at New Orleans under the somewhat singular appellation of "canard cheval." They are much esteemed in that city for their delicacy, but are said to be far inferior to those killed on the Chesapeake. Canvas-backs are often met with in the markets of Charleston and Savannah; but they are commonly very poor, insipid, and at times fishy, and not as much esteemed late in the season as either mallards or teal. We are informed by a friend that these ducks are very numerous in Galveston Bay, and at times are most excellent eating.

In the neighborhood of New Orleans the canvas-backs resort to wet prairies and fresh-water ponds, where they feed upon the seeds of various plants, more particularly those of the wild oats and water-lily. This kind of food being somewhat analogous to 
that which they partake of in the Chesapeake Bay, it is not improbable that the canvas-backs of that particular region may be but a trifle inferior to those shot on the fresh-water shoals of the North, where the Valisineria Americana flourishes in such profusion.

\section{THEIR SHYNESS.}

The canvas-back is an extremely shy and wary fowl, and very difficult to approach, except by means of some cunningly-devised stratagem, as there are always sentinels on the look-out for intruders, whether the mass of ducks be sleeping at night or feeding during the daytime. When on the water, they may be distinguished at a great distance from other ducks by their constant habit of diving, and when on the wing they fly in a wedge-like form, with considerable velocity, and generally at a great height. When wounded, they dive very deep and swim immense distances under water, thus baffling every effort of the most skilful dogs to overtake them; and the sagacious animals that are trained to this kind of sport are perfectly aware of this circumstance, as they seldom or never show any disposition to go after wounded canvas. backs; for they know full well, from hard-taught experience, the utter impossibility of catching them, no matter how fast they may swim or how deep they may dive in the pursuit.

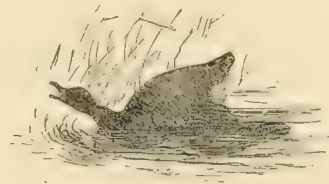

\section{MODES OF TAKING CANVAS-BACKS.}

In detailing the various schemes and describing the innumerable contrivances that the ingenuity of man has prompted him to adopt for the purpose of circumventing and destroying this much-prized duck, we will, ere finishing the subject, have pretty much ex+ hausted the whole material appertaining to wild-fowl shooting; as it is to the taking of this particular variety that the energies of 
the whole shooting craft are devoted in those portions of the country where they, in common with numberless other ducks, congregate.

\section{TOLING DUCKS.}

We will first speak of a most curious process resorted to by the shooters on the Chesapeake Bay, at the beginning of the season, for the purpose of decoying canvas-backs from the flats within gunshot of the sportsmen, who lie concealed from observation behind blinds erected all along the shore at convenient intervals. This practice we have already described in our edition of "Youatt," under the head of Newfoundland Dog, and as there put down will transfer it to these pages, with some additional observations :-

"This may not be an inappropriate place to speak of the wonderful mode of decoying ducks, termed toling, so extensively practised upon the Chesapeake Bay and its tributaries, where the canvas-backs and red-heads resort in such quantities every autumn. A species of mongrel water-dog, or often any common cur, is taught to run backwards and forwards after stones, sticks, or other missiles, thrown from one side to the other along the shore. In his activity and industry in this simple branch of education, within the comprehension of any dog, consists the almost incredible art of toling the canvas-back. With a dog of this character, the shooting party, consisting of several persons, all prepared with heavy double-barrelled duck-guns, ensconce themselves at break of day behind some one of the numerous blinds temporarily erected along the shore contiguous to the feedinggrounds of these ducks.

"Every thing being arranged and the morning mists cleared off, the ducks will be seen securely feeding on the shallows not less than several hundred yards from the shore. The dog is now put in motion by throwing stones from one side of the blind to the other. This will soon be perceived by the ducks, who, stimulated by an extreme degree of curiosity, and feeling anxious to inform themselves as to this sudden and singular phenomenon, raise their heads high in the water and commence swimming for the shore 
The dog being kept in motion, the ducks will not arrest their progress until within a few feet of the water's edge, and oftentimes will stand on the beach, staring, as it were in mute and silly astonishment, at the playful motions of the animal.

"If well trained, the dog takes no notice whatever of the ducks, but continues his fascination until the quick report of the battery announces to him that his services are now wanted in another quarter; and he immediately rushes into the water to arrest the flight of the maimed and wounded, who, struggling on erery side, dye the water with their rich blood.

"The discovery of this mode of decoying ducks was quite acc1dental, being attributed to a circumstance noticed by a sportsman, who, concealed behind a blind patiently awaiting the near approach of the canvas-backs, observed that they suddenly lifted up their heads and moved towards the shore. Wondering at this singular and unusual procedure on the part of this wary bird, he naturally looked round to discover the cause, and observed a young fox sporting on the river-bank; and the ducks, all eagerness to gaze upon him, were steering their course directly for the shore.*

"These ducks will not only be decoyed by the dog, but will often come in by waving a fancy-colored handkerchief attached to the ramrod. We have seen a dog fail to attract their attention till bound around the loins with a white handkerchief, and then succeed perfectly well. The toting season continues about three weeks from the first appearance of the ducks, - often a much shorter time, as these birds become more cautious, and are no longer deceived in this way. The canvas-back toles better than any other duck; in fact, it is asserted by some sportsmen that this particular variety alone can be decoyed in this mode. There are

* Be this as it may, this peculiar faculty of fascination on the part of the dog has long been known and practised on the decoy-ponds of England, to a much more limited extent, to-be-sure, but still sufficient to show that these wild-foyl sliooters, or rather netters, understand the whole bearing of the operation. For further information on the subject we refer our readers to Bewick's account of the decoy-ponds. 
always numbers of other ducks fecding with the canvas-back, particularly the red-heads and black-heads, who partake of the top of the grass which the canvas-back discards after eating off the root. These ducks, though they come in with the canras-backs when toled, do not seem to take any notice whatever of the dog, but continue to swim along, carelessly feeding, as if intrusting themselves entirely to the guidance of the other fowl.

"As far as we have been able to judge, we are inclined to this opinion also, and do not recollect ever having succeeded in toling any other species of duck unaccompanied by the canvas-back, although we have made the effort many times. These ducks are a very singular bird, and, although very cunning under ordinary circumstances, seem perfectly bewildered upon this subject. We were one of a party several ycars since who actually succeeded in decoying the same batch of ducks three successive times in the course of an hour, and slaying at each fire a large number. We counted out over forty at the conclusion of the sport.

"Although the toling of ducks is so simple in its process, there are few dogs who have sufficient industry and persererance to arrive at any degree of perfection in the art. The dog, if not possessed of some sagacity and considerable training, is very apt to tire and stop running when the ducks have got near the shore but too far off to be reached by the guns, which spoils all, as the birds are very apt to swim or fly off if the motion of the animal is arrested for a few moments."*

Since writing the above, we have been assured by an experienced and somewhat veteran sportsman that both the black-heads and the red-heads tole with the same facility, and the former luck, if

* On some particular days, even in the midst of the toling season, without any apparent reason, the toler is obliged to relinquish his sport, as no artifice on the part of the dog will induce the ducks to come in, although on the preceding day they may have exhibited the greatest eagerness to satisfy their curiosity on this point. The immediate cause of this fickleness on the part of these forl it is difficult to explain, as it cannot be attributed to any sudden change in the weather or other concomitant circumstances which most generally influence the actions of the feathered race. 
any thing, even more easily than the canvas-backs. From further cbservation and more minute inquiry on the subject of toling, we are now inclined to think that very nearly all varieties of the wild fowl can be decoyed in the way above described; but at the same time we are more than ever convinced that the canvas-back is more susceptible to this strange influence than any other duck on our waters. The reason why we were at first led to suppose that the canvas-back alone could be influenced by these playful motions of a dog was owing to the circumstance of our never having at that time toled wild fowl on other waters than the Chesapeake, where the canvas-back is always to be seen foeding during the shooting season in company with all the other varieties that flock to this favorite resort; and we had not perhaps considererl how seldom it was that a bed of ducks could be seen on these waters that did not chiefly consist of canvas-backs, as the most of the other varieties keep company with these ducks for the purpose of feeding on the refuse of the celery which they, by their superior strength and dexterity, are enabled to pull up from the bottom of the rivers. We consequently may have been perfectly correct in our assertion "of never having succeeded in toling any other species of duck unaccompanied by the canvas-back;" but at the same time our inferences may have been entirely wrong, when we consider how seldom a bed of ducks is seen on these waters that is not principally composed of canvas-backs. And, moreover, when we consider the acuteness of vision and the never-ceasing watchfulness of the canvas-back, we need not be at all surprised that they should be most generally the first to notice the dog or the first to take the lead in the general movement towards the shore,-all the other ducks apparently following, although they may be equally under the magic influence.

This plan of killing ducks, though practised by all the gentry as well as pot-hunters who frequent the bay-shore, is not altogether recognised as a sportsmanlike way of bagging game, and is forbidden on some of the grounds in possession of the clubs that meet during the shooting season at different points in the bay. Against 
the utility of this regulation we will not venture an argument. The gentlemen composing these associations no doubt have good reasons for their restriction. We must confess, however, that we see no impropriety nor any thing unsportsmanlike in thus decoying this wary fowl within reach of our guns, more particularly in positions where all other modes of getting at them would surely fail; but, on the contrary, we have always found a great deal in the sport to admire, as it is not unfrequently attended with a high degree of pleasurable excitement, while witnessing the playful antics of the dog operating so strangely upon his bewildered and silly victims that so soon pay the forfeit of their idle curiosity in death. And, moreover, if we desired to act the part of a sage, we might also draw a pretty moral from the incident, in demonstrating to our brother sportsmen that a foolish and idle curiosity even in the brute creation often results in disastrous consequences to the parties concerned.

Along some shores on the Gunpowder and Bush Rivers, exclusively devoted by their proprictors to toling, the season for this sport continues very late, as the fowl are seldom or never disturbed upon their feeding-grounds far out in the stream, where they take immediate refuge after being fired at and remain in perfect security till enticed again within gunshot; and this may be accomplished several times during the same day, and the slaughter consequently is often enormous. This method of killing ducks is less injurious in its effects upon the movements of wild fowl than any kind of boat-shooting that can be practised, as it never disturbs them on their feeding-grounds, but attacks them only when foolishly wandering away from their usual secure haunts.

The proper and most destructive moment to shoot ducks, when they have been toled, is when they present a side-view.

Duck-dogs, when behind the blinds along the bay-shore, mark the flight of wild fowl as anxiously as the sportsman himself, and often by their manner give evidence of the approach of ducks before they are observed by those on the watch for them. 


\section{BOATING DUCKS.}

Another method of killing canvas-backs is that of boating them on their feeding-grounds in small skiffs, either in the daytime or during the still hour of night. The latter plan, of course, is the most destructive and terrifying to the fowl.

A large swivel, carrying several ounces of powder and a pound or more of shot, is placed on the bow of a light boat, and, by means of muffled oars and under cover of the darkness, it is carried into the very midst of the sleeping ducks, and, being fired into their thick columns, great numbers are destroyed as well as crippled. This plan of killing wild fowl, however, is very generally reprobated by all respectable parties interested in this sport, and is very properly restricted by legislative enactment. Notwithstanding, however, the general discountenance of the community and the severe penalties threatening the participators in this cruel plan of butchery, many unprincipled poachers, who shoot for the markets, boldly resort to this expedient to fill their slender purses, in spite of all law and the universal execrations of those who live in the neighborhood of the bay. These impudent and reckless fellows know full well the inefficiency of all such laws, owing to the disinclination, or rather want of energy, on the part of the people to enforce them; for, without the assistance of those interested in such matters, all legislative enactments in reference to the preservation of game soon become obsolete, and the laws are no more than a dead letter.

Strong efforts, however, were made at the last session of the Maryland legislature to do something towards the protection of the wild fowl on the Chesapeake, by the suppression of the surfaceboats and the use of large guns; but the enactment was of little avail as regards the surface-boats, owing to some unlooked-for defect in the framing of the act, and we now learn that there is some probability of its being repealed altogether, which we very much regret: we would much rather see it made more rigid and then strictly enforced. 
Nothing is better calculated to drive duclis from their accustomed feeding-grounds than the practice of boating them at night; for, being disturbed during their wonted hours of repose and security by an unforeseen enemy, they soon learn that there is no safety for themselves under any circumstances, and have been known to abandon such places almost entirely after being shot at two or three times in the quiet of the night, when perhaps the whole flock, perfectly unconscious of danger, were wrapped in deep sleep.

Boating ducks on their feeding-grounds, even with small guns during the daytine, will soon drive them from their accustomed haunts, and force them to find other spots at a distance where they can remain undisturbed. All modes of boating ducks are condemned by the sportsmen visiting these parts, as well as by those who reside in the vicinity of the bay-shore.

\section{NETTING DUCKS.}

A very ingenious way of taking canvas-backs was resorted to a few years since by a gentleman living on the bay, and which certainly, for its novelty, requires some notice on our part. This plan consisted in sinking gilling-nets a short distance below the surface of the water, so that the ducks in diving would get their heads and wings entangled in its meshes, and thus miserably perish by drowning.

Great numbers were secured by this method at first; but the canvas-backs soon entirely forsook the shoals where these nets were placed, and did not return to them again during the same season. But what brought this method more particularly into disrepute, even among pot-hunters, was the circumstance of the ducks secured in this way being so far inferior to those which were shot, owing to their being drowned and remaining so long a time under the water, as the placing of the nets occupied so much time and labor that it would not pay to examine them oftener than once in twenty-four or forty-eight hours; and many of the ducks, consequently, were under the water during a greater portion of this time. The flesh, under these disadvantages, became watery and insipid, and 
the ducks, moreover, were very hard to keep, except in excessively cold weather, on account of their bodies absorbing so much water. The whole system of gilling ducks is now entirely abandoned, and we only mention it as one of the things that have appeared and passed away. This method, however, of taking ducks is not altogether new, as a somewhat similar plan is resorted to on the coast of France for taking the scoter-duck, which little fowl resorts in considerable numbers to the sea-coast for the purpose of feeding on the shell-fish that there abound. The fishermen, or those engaged in taking wild fowl, spread their nets at low tide on the flats where these shell-fish are found, being supported two or more feet from the ground, so that the ducks, feeding in with the tide and diving after food, become entangled, as in the case of the canvas-backs, in the meshes of the net.

\section{DUG-OU'TS.}

Another very successful mode of killing ducks, and one which has been very much in vogue for many years on our rivers, is the use of the dig-outs or dug-outs, ${ }^{*}$ a small kind of boat moored over the flats, and concealed as far as possible from observation by quantities of eel-grass thrown over it. Thus fixed, and surrounded by large numbers of decoys that are previously anchored all around the little vessel, the shooter patiently awaits the approach of the wild ducks which are flying up and down the river, and are, of course, tempted to dart down upon the deceptive decoys, believing them to be others of their own species that are feeding in perfect security, notwithstanding the proximity of the greenish mass which conceals the shooter and his boat. As soon as the canvas-backs hare come sufficiently near, the shooter rises up suddenly and blazes away with his ponderous weapon, dealing death and destruction throughout the affrighted ranks of his unsuspecting victims.

* So termed from being constructed by excavating the trunk of a large tree sufficiently deep to allow the person of the shooter to lie concealed in it. 
When the weather is farorable and the ducks are flying, this plan succeeds rery well, and offers considerable attractions in the way of sport to those accustomed to wild-fowl shooting; but if the weather be cold and boisterous, none should attempt it but those inured to the roughest usage and who are perfectly regar lless of the state of the elements.

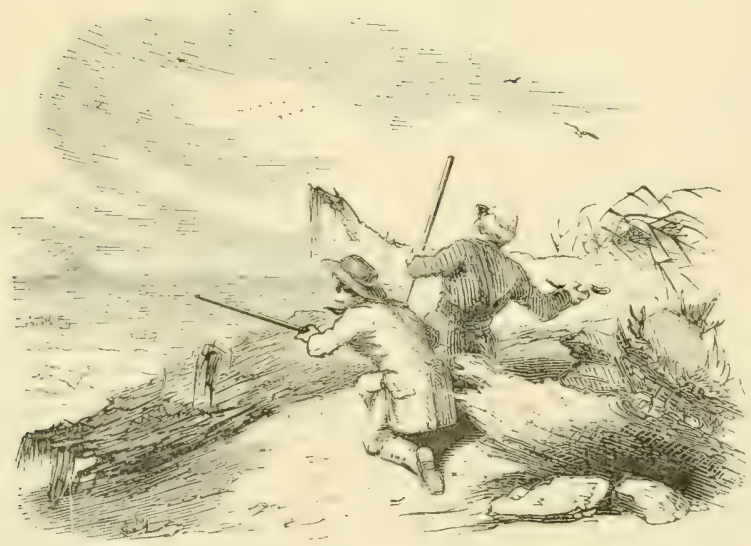



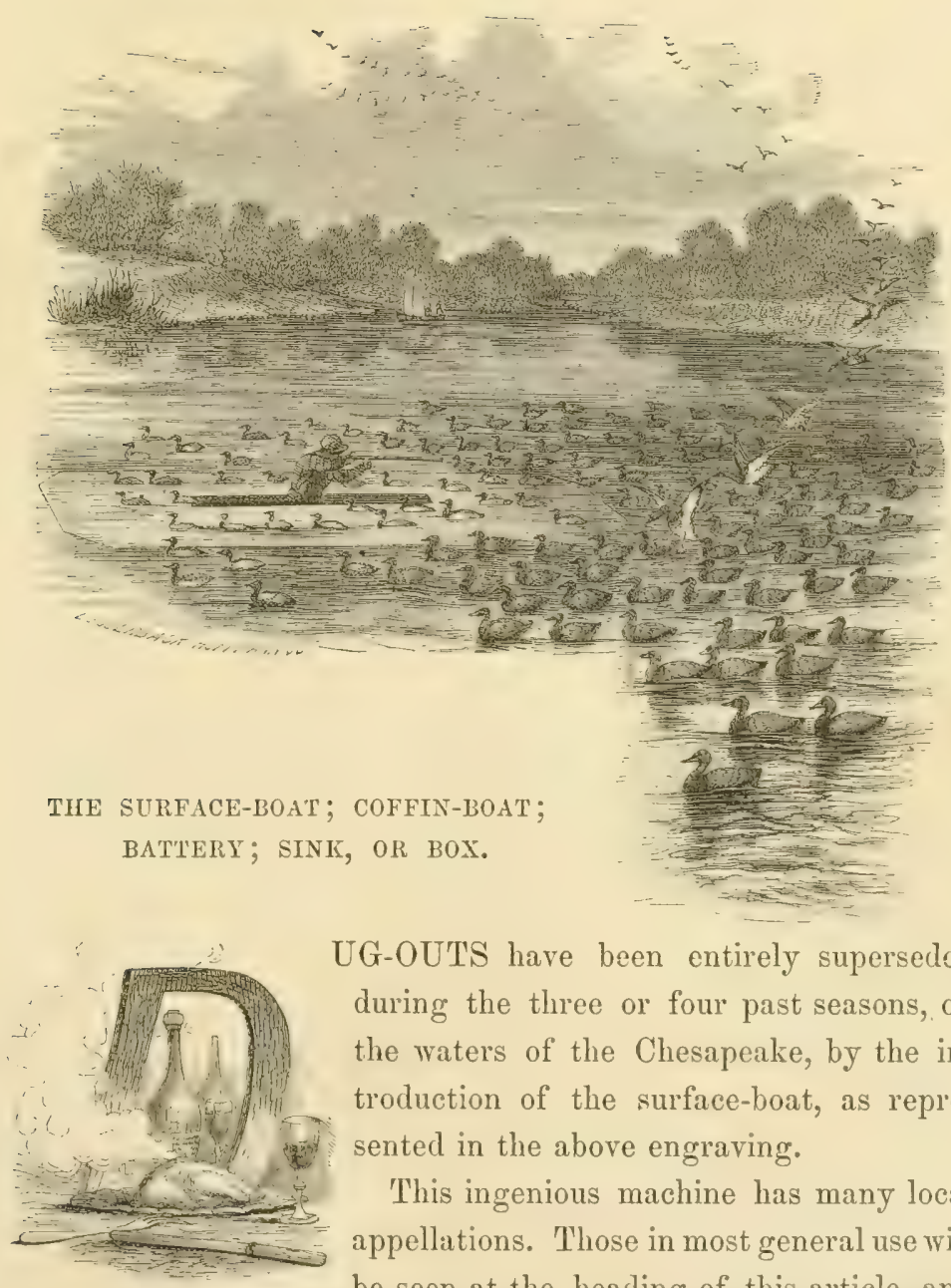

UG-OUTS have been entirely superseded during the three or four past seasons, on the waters of the Chesapeake, by the introduction of the surface-boat, as represented in the above engraving.

This ingenious machine has many local appellations. Those in most general use will be seen at the heading of this article, and at the close of it the reader will find explicit directions, together with a skeleton model of the same to be used as a guide in building one for his own use.

The boat is anchored out on the feeding-grounds, surrounded by innumerable decoys, resembling as much as possible the canvasbacks, and so balanced in the water that the most obscrvant eye 
can hardly distinguish them from the living fowl, as they ride gently on the surface and appear to be employed in feeding, owing to the constant motion of their heads and body imparted to them by the quiet rippling of the water.

The construction of this skiff is such that when anchored out, loaded with the shooter, his ammunition, and the necessary ballast, the water is on a level with the deck of the box; and when reclining, the occupant and all his paraphernalia are entirely concealed from observation, insomuch that it is next to impossible to distinguish any portion of this curious ambush, even when within a few hundred feet of it. We have often been amazed when gazing on the water in the direction of the flats, to see a black figure rise up suddenly, as if from the deep, and blaze forth a destructive volley into a flock of ducks about to alight, and then immediately sink again from view. The shooter, having delivered his welldirected fire, quickly reloads his gun or guns, and throwing himself again on his back, awaits another opportunity to repeat the sport, which almost immediately follows, provided the day be favorable for the flying of wild fowl. It is better, in fact usual, to have two or more double-barrelled guns in the sink, as a great many ducks are only winged at the first discharge, and need reshooting to secure them.

Thus, in rapid succession, immense numbers of canvas-backs, as well as other wild fowl, are killed, and the water for a hundred feet or more is erimsoned with the rich blood and covered with the mangled bodies of this far-famed duck. Those engaged in this profitable way of killing canvas-backs are always accompanied by a companion in a light sail or row boat, who keeps at a respectful distance, for the purpose of watching over the safety of his associate as well as rumning down upon the adjacent feeding-grounds and putting the ducks to flight, so that they may chance to join the decoys that are set to allure them as they pass up and lown the feeding-shoals. On the flats in the coves near to Havre de Grace and Spesntia Island, where this method of shooting ducks has been more particularly practised during the last three seasons, there is 
but little or no current during calm weather, and therefore is singularly suitable for this kind of sport. The ducks, after being shot, will remain nearly in the same place where they dropped for a considerable time without drifting away; the shooter, therefore, pays no heed to them until he has a large number killed, when he makes a signal to his companion to come and pick them up.

The amount of ducks killed in this way during the four past seasons is enormous,-almost beyond belief.

We are credibly informed that $\mathrm{Mr}$. W. W. Lery, a ducker well known on the Chesapeake Bay for his skill in this particular sport, has killed as many as one hundred and eighty-seven ducks in one day, and during the seasons of $18 \pm 6$ and $18 \pm 7$ actually bagged seven thousand canvas-backs.

This system of killing ducks, we believe, was introduced on the Chesapeake Bay by some of the experienced wild-fowl shooters from the vicinity of New York, and who now reap a rich harvest from their hardihood and ingenuity. It is no unusual thing for one of these men to kill as many as fifty couples of canvas-backs in the course of a day; and if the weather prove favorable for this kind of shooting, they have been known to fill a small vessel with ducks in two or three days, which they immediately despatch for the markets of New York, Baltimore, or Philadelphia. These worthies that pursue wild fowl for a living usually make their appearance on the Chesapeake Bay in small yachts, or rather illlooking sloops, in which they live and stow away their plunder, seldom or never visiting the neighboring shores, knowing full well the reception they most likely would meet with from the hands of those residents who also kill ducks during the winter season to sell, and consequently, from selfish motives alone, are very testy and jealous of those rights which the legislature has endeavored to guarantee to them, but which they from a lack of principle and moral energy are incompetent to enforce by legal measures.

When the wind is blowing pretty fresh and the ripple high, the ducks are more apt to notice the decoys than on perfectly mild days, and are also more likely to alight among them. When ducks 
are approaching the battery, the distance at which they are from it is often very delusive, insomuch that the inexperienced sportsman will find himself continually rising up to shoot before the fowl have got over the decoys, and even long before they have come within fair shooting range. This act of "rising up" too soon on the part of the shooter is a common fault with the beginner, and is fatal to his success in most instances; as the ducks, immediately on his appearance, take the alarm, and, making a sudden turn, sheer off in time to save themselves.

Ducks should be shot after they have alighted, or just when dropping their legs in the act of settling on the water, and not a moment sooner.

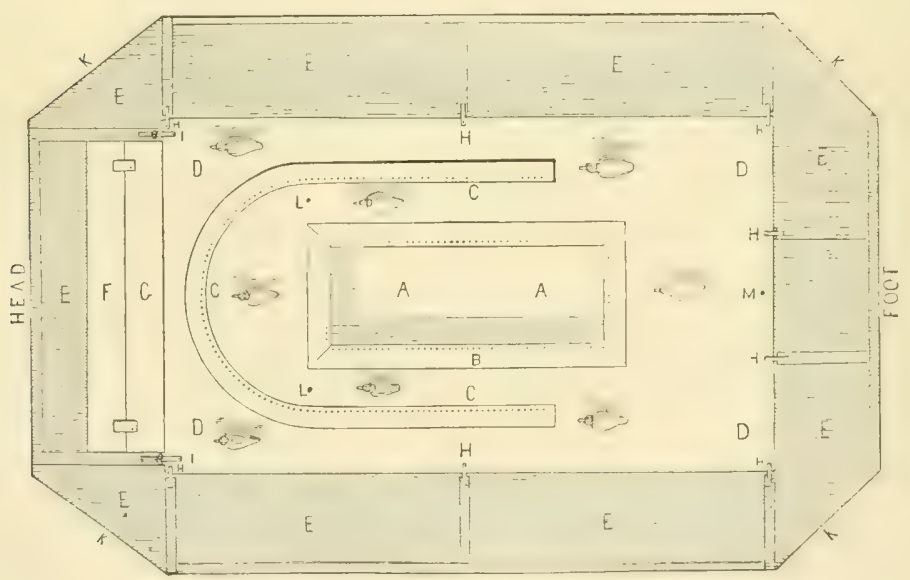

DESCRIPTION OF THE MODEL, WITH PARTICULAR DIRECTIONS FOR BUILDING A SINK, OR BATTERY.

$\Delta, \mathbf{A}$. The box in which the shooter lies concealed.

B. A rim of sheet-lead extending entirely around the box, to prevent the ripple from washing in upon the shooter.

c, c, c. Another rim of sheet-lead, as a still further protection from the ripple.

D, D, D, D. The platform, or false deck surrounding the box, sapported by carlings.

E, E, E, E, E, E, E, E, E. Muslin sheeting, or canvas, stretched over the wooden frames running around the platform. 
F. A board or frame attached to $G$ by leather hinges.

G. Another board or frame, secured to the deck by strong iron hinges.

II, I, Н, II, I, I, I, H. Leather hinges, securing the frames (on which the canvas is tacked) to the platform or deck.

r, I. Wrought-iron hinges, constructed with arms, so as to allow the endwing to fold over the side-wings, which are first drawn in upon the deck when the battery is to be removed from its position.

$\kappa, \kappa, \kappa, K$. Ropes extending from the extremities of the frames, and to which the canvas is also attached: this arrangement permits the wings to bs folded more readily upon the deck.

L, L. Points at which a rope is passed through the carlings supporting the deck, to the middle or bight of which rope the cable of the head-anchor is attrached.

3. Point at which the foot-anchor is attached to the carling supporting the deck.

Having given, we trust, a satisfactory explanation of the model, we will now proceed to give some special instructions as to the building of the battery. The timber most usually employed is one-inch white pine, except in the case of the head and foot of the box, which should be made of two-inch oak, or some other hard and durable wood. The side-boards and bottom of the box are attached to the head and foot; and the strength of the box, as well as the deck, is in a great measure dependent upon these oaken timbers.

The carlings, or small beams which support the platform or deck, are also made of oak, one and a half inch thick, five inches wide in centre, reduced at their extremities to one and a half inch, and secured to the ends and sides of the box by means of screw-bolts or large wrought nails.

The length, width, and depth of the box must of course ho proportioned to the size of the shooter; for an ordinary-sized individual, the following dimensions are amply sufficient:-

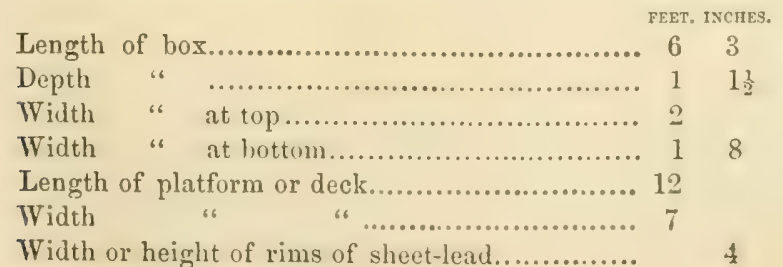




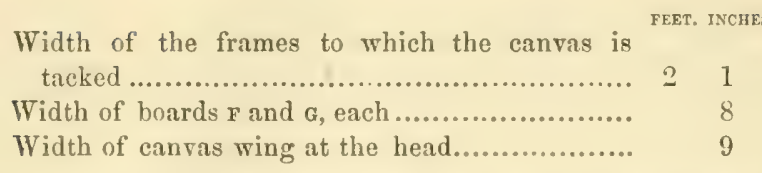

The deck is not a perfect plane, but declines, or rather is graderl off, from the box on every side to the extent say of one inch. This slope or dip of the deck permits the ripple to wash or play over the platform the more securely, having a constant tendency to the edges instead of the centre, where the box is placed,- - the opposite of which would be the case if the deck was a dead level.

The entire edge of the box is slightly elevated above the surface of the deck,- say an eighth to a quarter of an inch; to this edge the inner rim of sheet-lead is tacked, extending entirely around the box, and, being very pliable, is raised up at an angle of fortyfive degrees just before launching the battery into its position on the shooting-grounds, which precaution will prevent the ripple from washing into the box.

The outer rim of sheet-lead c, c, c, it will be observed, does not extend entirely around the deck, that being totally unnecessary, from the circumstance of the sea or ripple seldom or never being sufficiently violent to break over the foot or sides so as to endanger the comfort of the shooter; and when such should be the case it is time for the ducker to decamp for more secure quarters.

The head of the battery, it will be seen, has two eight-inch boards. The inner one $\mathrm{G}$, as explained abore, is attached to the deck by stout iron hinges $\mathrm{I}$, I, made with projecting arms, so that the whole head-wing may turn in upon the two side-wings, which are first folded up when the box is about being removed from its position. The other frame $\mathrm{F}$ is secured to $\mathrm{G}$ by strong leather hinges, as well as the balance of the frame to which the canvas is tacked.

The head of the battery is always anchored to the breezc, and, as a matter of course, is obliged to sustain the principal shock from the wind and waves, and of necessity is made differently as well as much stronger than the foot, by the addition of the frame- 
work $\mathrm{F}$ and $\mathrm{G}$, and which, from their peculiar construction and attachment to the solid platform; oppose a pliabie but at the same time safe resistance to the shock of the waves.

It is most important to know exactly how to attach the anchors to the battery, more particularly the one at the head; for without proper precaution on this point the whole machine would ride most unpleasantly to the shooter at the slightest puff of Old Boreas.

To explain this more fully, we have caused two points or dots - $\mathrm{L}, \mathrm{L}$ - to be placed on the model at the head of the box, to show the position of the ends of the rope to which the anchor is attached, and have defined above the manner in which the cable of the anchor is to be secured to the bight of this rope.

The advantages of this arrangement should at once be obvious to the greenest landsman; for the head of the platform, being in a measure free from restraint, is permitted to rise and fall with the swell of the sea, with an easy motion, thus protecting the shooter from the disagreeable consequences of the waves breaking in over the deck, which would be the inevitable result if the anchor was attached to the extreme end of the platform; as the head of the battery, during a heavy blow, would be pulled entirely under water, and the whole machine, even during a comparative calm, would be subjected to a jerking, disagreeable motion.

The position of the foot-anchor we have designated by the point $\mathrm{M}$, and requires no further explanation.

At the bottom of the box there is a false bottom, or drainageboard, which takes up an inch and a half of the original depth. Notwithstanding this additional loss of space, there is still sufficient room remaining of the thirteen and a half inches not only to accommodate, but absolutely to hide below the surface of the platform, the shooter himself, as well as the sheepskin or buffalo-robe upon which he reposes.

As to the amount of ballast necessary for a battery such as $\mathbb{6}$. nave described, that must be regulated by the state of the wind and waves, and other circumstances; it will vary, howerer, from 
fifty to one hundred and fifty pounds, increasing from the lesser to the greater amount in proportion to the violence of the elements. Portions of iron pigs are most convenient for ballast.

When these batteries are intended to be occasionally towed out to their position on the flats, they should be made sharp at the stern or bow by the addition of a false cut-water; otherwise it will require heavy pulling to get them along. Most, if not all, of those in the lands of the regular bay shooters are made square at the ends, and, thus constituted, answer their purposes perfectly well, for they move them from point to point only by hauling them on board of their large row or sail boats, which convey the whole party on these expeditions.

On looking at the drawing, several decoy-ducks will be noticed on the platform. The bodies of these ducks are reduced in bulk, or, in other words, are shaved down to one-third of their original thickness, and permanently fixed to the deck at suitable intervals, with movable heads, which are slipped on and off at pleasure by the ducker, as he takes his position in the box or retreats from it. The number of decoys set out around the battery is not often less than two hundred, and most generally two hundred and fifty, or even more. Each decoy has a string several feet long attached to it from a loop in the breast, and to the end of each string is tied a small piece of leaden pipe or other convenient metal, or eren a fragment of stone sufficiently heavy to anchor the decoy and prevent its floating off from its position.

The arranging or putting out of so great a number of decoys around the battery, on a cool, blustering December morning, is no child's play, we can assure the uninitiated reader, and is only equalled, or rather excelled, in point of discomfiture, by the pro. cess of taking them up again in the evening, when it is necessary to wind the wet and half-frozen strings around each one to prevent entanglement when placed together in the boat.*

\footnotetext{
* Decoys made of solid blocks, such as are universally used, can be had oi duckers on the bay, if ordered during the idle season, at a moderate price, rangin from twenty to thirty dollars a hundred.
} 
A small pad or pillow for the head to lie on should be placed at the top of the box, and in severe weather the shootor will find a woollen helmet, vizor, or mask, a very comfortable contrivance to protect him from the cold blasts.

We were formerly under the impression that much danger was to be apprehended from the accidental sinking of these batteries; but we are now satisfied, from further observation and the expe. rience of old duckers who have used these machines properly constructed, (for the early ones were susceptible of much improvement, ) that our fears are rather gratuitous.

Mr. W. W. Levy, of Havre de Grace, to whom we are indebted for a rough but very complete drawing of a battery from which the above sketch was taken, as well as much other valuable information upon this subject, assures us that a box built such as we have described could not, by actual experiment, be made to sink below the surface, when filled with water, loaded with two hundred and fifty pounds of pig iron and the addition of two stout men.

This experiment we cannot but consider a very extreme one, and the result most conclusive; and we shall no longer hesitate in recommending our sporting friends to consign themselves, without hesitation or fear, to one of these cunning machines whenever a fitting opportunity presents itself.

The ease with which one of these batteries rides on the surface of the bay, even during a heary blow, is very remarkable; we have been quite comfortable in them, when it required two strong carsmen to row a light gunning skiff.

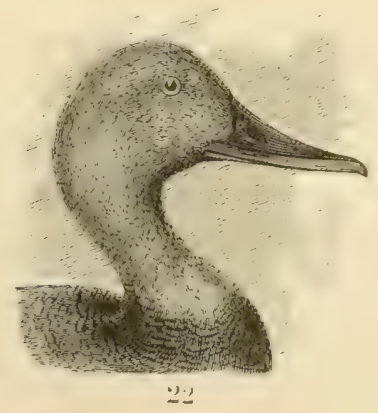




\section{AMBUSH ON THE FLATS.}

We noticed last season a very simple but at the same time rather ingenious contrivance erected on the flats in Elk Rirer, from which to shoot ducks. We have never seen any thing of the kind before, but presume something similar may have been adopted elsewhere by others.

This ambush or blind, as all such contrivances are termed in this particular section, was constructed in this wise:-

Some shooters, taking advantage of low tide, had driven intc the soft mud, in the very centre of the widest expanse of feeding ground, and in the very path of the ducks as they flew up and down the river, four strong posts, forming a square.

These posts or piles were perforated on their upper portion, which extended far above low-water mark, with large holes of sufficient capacity to permit the introduction of long hickory pins, which passed entirely through and projected several inches from the inside. Upon these pins thus secured was placed a light frame, sufficiently strong, however, to bear the weight of the shooter, who lay there completely concealed from observation by a profusion of cedar brush and eel-grass piled around him.

The numerous holes in the posts were necessary for the purpose of raising up and letting down the framework to suit the state of the ticle, which was very easily accomplished before the sportsman took his position.

This particular kind of blind was especially adapted for this river, as the narrow steamboat-channel is marked out in its whole course by long poles thrust into the mud on either border, each one of which was surmounted by a heavy piece of cedar-brush, with which the ducks soon become familiar while feeding, and therefore take no precaution to aroid while flying, which also was the case with the blind; and most excellent shooting at times was thus obtained from this cunningly-devised ambuscade.

The flats or feeding-grounds on Elk River are quite extensive, and occasionally attract enormous hosts of wild fowl, more espe- 
cially when they have been greatly harassed by the boats and batteries on the Susquehanna and Chesapeake, as both these modes of warfare are strictly interdicted upon this stream. During the season of 1850 , we had considerable sport shooting over decoys off the points on Elk River, the weather being mild, and the ducks, both canvas-backs and red-heads, being more numerous than we had ever before witnessed them on this water.

\section{STOOLING OFF POINTS.}

Another method of killing ducks by means of decoys is to anchor them off a short distance from some one of the many points along the bay or river-shores, more particularly on those points in the narrows of Spesutia Island. When the canvas-backs are flying and the weather is not too severe, this plan affords most excellent sport, and great numbers may be killed. This kind of shooting requires the assistance of a dog; and none but a Newfoundland or other hardy water-spaniel of some good breed will be able to stand the work, if the weather is very cold; as the frequent plunging into the water chills and stiffens the animal to such an extent that he is often barely able to walk or swim.*

When the weather is very calm and the surface of the river remains unruffled by a breeze, although the ducks may be flying, they will not dart to decoys, more especially off points, as readily as if they had a certain degree of motion imparted to them by the gentle ripple of the waters.

For when perfectly still the decoys, no matter how well made or proportioned, lose that lifelike appearance which they present when bobbing up and down as if in the very act of feeding; and, consequently, are wanting in their chief attraction for the ducks that may be on the wing in quest of more secure and fruitful feedingplaces.

* Decoys made of solid blocks of wood are preferable to those made hollow; they are less expensive and not so easily injured by the shot, and also require far less gentle handling. From fifty to one hunclred are necessary for point-shooting, - the more the better. 
We have before us a late number of the Spirit of the Times, which contains an excellent article on duck-shooting, wherein is described a very ingenious plan adopted by the writer for imparting this particular motion to the decoys on a still day; and, as the expedient is quite novel as well as practicable, we shall transfer the description of it in the words of the author to these pages, feeling sure that it will prove serviceable to some of our sporting friends under like circumstances :-

"Ducks not decoying well on calm days, of which we had quite a number in December, we hit upon a somewhat novel expedient to attract their attention to our decoys. A dozen stakes of about two feet in length were firmly driven into the soft bed of the river, at a distance of some forty yards from the blind, so that at lowwater their upper ends were quite a foot beneath the surface. Through the tops of these stakes, on which we had bored holes of an inch in diameter, having rings of stout iron wire inserted in them to prevent chafing, were passed strings of the proper length, one of the ends of which was carried into the blind, while the others were attached to the necks of the decoy-ducks. These latter were anchored by heavy anchors at such a distance from the stakes that, when pulled upon by the strings, the anchors remaining firm, they were suddenly drawn head-foremost beneath the water, representing very fairly the diving of the real fowl. The ends of the strings within the blind were attached to small sticks, four in number, being three to each, and one person could thus manage at the same time all or a portion of the decoys.

"Around these divers, (as we termed them,) which were scattered over a considerable extent of water, were set the usual number of decoys, taking care to place the latter so as not to interfere with the action of the strings of the former. Not being aware of its ever having been tried before, we were exccedingly anxious about the result of our experiment; and on the first calm day, all being prepared, we looked anxiously for the appearance of a flock of ducks with which to test its success. A bunch of canvas-backs passing down the river soon came in sight, but holding their way 
so far out that we despaired of attracting their notice. When directly opposite, however, we commenced vigorously working our divers, and, to our surprise and delight, the flock immediately turned in, and, passing back and forth two or three times, came up most beautifully.

"This success at once settled the question of the utility of our device, and during the whole of this day, on which there was not sufficient wind to ruffle the surface of the water, we had excellent sport, many fowl passing up and down the river, and almost every bunch that were not too far off to see our decoys came up fearlessly and without hesitation; with single ducks, or when only two or three were together, we were invariably successful. Day after day, the weather being mild and calm for this time of the year, we tried it with complete success, and to this simple expedient we owed decidedly the best portion of our shooting; its excellence existing not only with regard to the canvas-back, but also to the red-head and scaup-duck. The success with which we met was owing partly to the exceedingly natural appearance of the decoys, for this number of divers scattered through some seventy or eighty gave the semblance of life to the remainder, and, creating a ripple on the water, made them show much better; besides this, ducks passing at a distance frequently do not see decoys, and a slight motion among the latter is at once sufficient to draw their attention; this done, their coming up to such well-gotten-up affairs follows almost as a matter of course."*

\section{HOLES IN THE ICE.}

As the season advances, ducks are frequently obliged to abandon their favorite feeding-grounds in the upper bay, owing to the large masses of floating ice that are constantly coming down the Susquehanna and the smaller streams they are wont to frequent. The canvas-backs are now driven to great extremes to procure food, 
and are almost constantly on the wing in quest of suitable spots to dive down for the still tender roots of the valisineria.

At this juncture, a cruel adrantage is taken of the half-starved condition of the poor canvas-backs to entice them within the reach of the murderous guns of those who lie in ambuscade upor the shores of the Gunpowder, Bush, Elk, and the many other smaller streams which are now frozen over. A large hole of many feet in diameter is cut in the ice directly over some choice feeding-shoal, sufficiently near, however, to the land to allow of its being raked by the guns of those concealed behind a blind erected on the shore. Large numbers of wild fowl, more particularly the canvasbacks, may be killed in this way, and the shooter can lie still and bang away at the ducks all day long, as they will oftentimes continue coming and going as fast almost as he can load, provided they are driven to the extremity we have mentioned above. These seasons of searcity are not by any means unusual; and a friend of the author informs him that he has killed as many as one hundred and fifty canvas-backs over one of these feeding-holes in one day on the Gunpowder River.

\section{POINT-SHOOTING.}

Several of the above plans of shooting ducks may be said to be illegitimate ways of sporting, although pursued indiscriminately by all those of our friends who participate in wild-fowl shooting. The really sportsmanlike way of killing canvas-backs, however, is for the shooter to station himself on some one of the many points or bars along the bay-shore or its tributaries that the ducks fly over in their course to and from their feeding-grounds. Much depends, in this kind of shooting, upon the disposition of the elements; for neither pleasure nor success can be reasonably expected if the weather is intensely cold or the wind blowing fresh from a quarter that carries the ducks off from the point rather than on it.

On the other hand, if the wind and weather prove favorable and the ducks are flying briskly, there is not a more delightful way 
of enjoying one's self than in point-shooting. Great skill and judgment are requisite to strike the ducks; and when thus suddenly stopped in their rapid course, they present a beautiful sight as they come tumbling down with a heavy plash from a height of one, two, or even three, hundred feet.

It is this kind of duck-shooting that either displays the ignorance or dexterity of the sportsman; for, without long practice in this particular branch, the best general shooter in the country would appear to little advantage alongside even of an indifferent ducker.

The principal sites on the Chesapeake Bay where sportsmen resort for this kind of pastime are the points immediately about Havre de Grace, the Narrows of Spesutia, a few miles farther down, Taylor's Island, Abbey Island, Legoe's Point, Marshy Point, Bengie's Point, Robbins's and Ricket's Point, Maxwell's Point, and Carrol's Island. There are also some good points about Elk and Northeast Rivers, and a few on the western shore.*

Carrol's Island has long been in possession of a club of sportsmen, who regularly resort to this favorite spot during the ducking season, and seldom return home without being heavily laden with the rich spoils of their skill. Not only canvas-backs, but the larger species of wild fowl, are killed at Carrol's Island. Numbers of swans and geese are seen flying about these points; and the ambitious sportsman will often have an opportunity to bring down with his steady hand the most majestic as well as the most beautiful of all the feathered race. If any of our readers should feel this

\footnotetext{
* There is a consirlerable difference between bar-shooting and point-shooting. The latter we have already described; and, to make the former intelligible to our readers, we must premise our remarks by stating that, along the shores of the Chesapeake, the land stretching out into the bay to form these shooting-points is often a mere narrow peninsula, termed a $b a r$, over which the ducks are constantly passing and repassing to their feeding-grounds, without going out of their usual course to weather the points, as they would do uniler ordinary circumstances; most of the shooting, therefore, is perpendicular, and consequently far more difficult than when shooting directly off the point. Maxwell's Point is thus formed by a very narrow strip of land. The shooting-points on the Elk River are Locust Point, Plumb Point, Little and Big Welsh. Nearly all these shooting-points are rented out.
} 
laudable ambition-and where is the tyroho will not?-we trust that he may prove more successful than a did at our détut upon swan-shooting; having, much to our mortcation, fired both barrels of a heavy duck-gun from behind an abush into a noble flock of sixteen swans quietly feeding on the iter within sixty yards of us, without even as much as rumpling single feather of their plumage. But then there was a reason wh, as all sportsmen have good excuses for their bad shooting; at all vents, they strive very hard to concoct plausible ones, by which torull their companions. But in this case, unfortunately for our cret as a marksman, the gun was neither strange, bad, nor overloade; neither did it snap, lang fire, overshoot nor undershoot its mar; but the plain and simple fact is-shall we have recourse to so hckneyed a plea?-to cut the matter short and solve the mystery, whad no number B B shot in the barrels, one of our companions havig drawn the charge the night before, by way of affording himselt some amusement at our expense on the following day.

Jokers, however, often get hurt with the ecoil of their own reapons; and so it was in this case. As we rere entirely alone, and separated from the projector of this trick rhen we fired at the swans, we suspected something wrong, and did not relate the circumstance till after he had confessed drawing the load and expressed a desire to know the result of our first tro shots; and then, greatly to his chagrin, he learned that we might have had added to our lot of ducks several noble cygnets, if he had restrained his silly propensity to make us a laughing-stock for the company. Such an opportunity to distinguish ourself in the field of wild-forv shooting we never again expect to meet with, as we are satisfied that we should have killed, on this occasion, not less than six swans, and perhaps more; for they were all huddled together in such a manner, when we drew on them, that hardly one could have escaped from the effects of our fire.*

\footnotetext{
* We do not mean to assert that we might have bagged the whole sixteen by one "coup de fusil," or even with two ; but we do say, most positively, that scarcely one could have gotten off without carrying a few pellets of shot with', him.
} 


\section{ART OF SHOOTING DUCKS.}

We have now nearly drawn to a close the whole subject of wildfowl shooting; but little remains to say further, except, perhaps, an effort on our part to instruct beginners in the art of shooting ducks, both on the wing and water. Without some instructions on this head, and a great deal of practice besides, we can assure the most determined tyro that he would make but a poor show of shooting among the skilful duckers of the Chesapeake. He might, however, stand an equal chance with the oldest of them, provided he could ever be so fortunate as to meet with canvas-backs in the same predicament that a correspondent of the Spirit states that some punters found a flock of black and gray ducks on the ice of Little Creek, in Canada; that is, too fat to fly, and wanting in energy sufficient to get out of the way when pursued.

The particulars of this sporting incident being so very curious and unique, we think it worth while to transfer to our pages the extract of the letter containing the details, leaving it for naturạlists and sportsmen to explain the phenomenon as they best can. As for ourselves, we do not feel inclined to believe that ducks could become too fat to $\mathrm{fly}$, in the month of December, in the bleak regions of Canada, and doubt very much whether such an occurrence could be so general under any circumstances, no matter how plenty the most nutritious food might be. Might not the singular conduct of these fowl be attributed rather to sickness produced by some unnatural cause, or perhaps the eating of some deleterious substance forced upon them by the severity of the weather? However, here is the extract; we give it as we find it:-

"By-the-by, talking of cold, I have a most extraordinary circumstance to tell you in the sporting way. Two punters last week went to the Long Island marsh, which has been for some timo frozen up, for the purpose of trapping. Walking along the ice near the creek,-I think called Little Creek,-they saw a great number of ducks on the ice, and crawled up very cautiously to get a shot. They were, however, much surprised, on coming near them, to find 
that they did not appear at all alarmed, and concluded that they must be frozen, or something of the sort; they consequently did not fire, but continued to approach until they caught one. Upon this the others scattered, but did not attempt to fly; and a chase ensued, which ended in the capture of no less than seventy-six, all black and gray ducks, and one wild goose. The next day they came across some more in the same way, and took thirty-four: in all, one hundred and eleven. Did you ever see or hear the like of that?-a novel sort of duck-hunting! The birds were actually so fat that the punters attribute their success in taking them to their inability to rise in consequence."

Canvas-backs fly with great strength and velocity, and require a heavy blow to bring them down; if winged only, it is almost useless to pursue them either with a $\operatorname{dog}$ or in a boat, as they dive with so much celerity, and swim such great distances under water, that it is next to an impossibility to overtake them, or even to shoot them if within gunshot, as they only come to the top of the water for an instant, and duck down again before a snap-shot could get a range on them even with a light partridge-gun, let alone a heavy duck-gun. Dogs accustomed to duck-shooting soon learn this fact, as before stated, and will not be induced to follow after a wounded canvas-back if able to dive. The shooter will thereiore see at once the importance of striking canvas-backs in a vital spot. The head and neck are the portions we should always endeavor to hit, as a single pellet of shot lodged in these portions of the body will do as much execution as a half-dozen imbedded in the breast or other fleshy parts. To accomplish this, many circumstances must be taken into consideration, and must be run over in one's mind at a moment when there is not a second to ponder on the subject. For example, we should be able to tell at a glance the probable distance the ducks are from us, their height, the velocity with which they are flying, the course they are pursuing, \&c. \&c.; for without a just appreciation of all these particulars we shall be very apt to shoat over them, under them, before them, or behind them. This kind of rapid mental calculation, though very 
troublesome at first, will soon become a kind of intuitive habit by practice, and the gun will be found almost of itself to take the proper direction, seemingly unguided by any special will of the shooter.

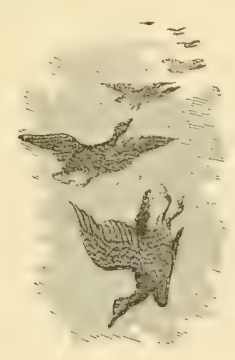

\section{FURTHER INSTRUCTIONS.}

Never shoot at ducks as they are coming towards you; wait till they are on a line with your person, or till they have passed you, as it is almost impossible for shot to penetrate through the thick plumage of a duck when presented in this position. As the ducks are approaching, raise your gun, take sight on them, and follow the foremost with the eye and weapon until they come immediately overhead, or rather in a line parallel with your body; then slide the gun with a quick motion a short distance in front of the flying column, being careful, however, to preserve its range directly in their course, and fire without stopping the motion of the arm.

The distance which the gun is thus thrown before the ducks depends entirely upon their probable distance from the shooter, the velocity with which they are flying, and the other points alreacly alluded to above, all of which must be ascertained in a moment of time, when the eye is resting upon the birds along the barrel of the gun. One or two feet will nearly always be necessary to insure success in bringing down canvas-backs, and sometimes even as much as ten feet is not too far in advance, if the wind is blowing fresh and the ducks travelling before it, as they most frequently do. It should always be borne in mind that most ducks 
fly with amazing velocity; and the great error committed by all beginners, and even by experienced shooters, is that they deliver their shot behind the bird. The range of the sight should be rather above than below the ducks, to prevent the pellets from falling too low before reaching their proper destination. The various points on the narrows of Spesutia Island are perhaps the most frequented of all localities in the upper bay for duck-shooting; and it is seldom that the sportsman will be disappointed in visiting these grounds, as the ducks are passing up and down these waters nearly all day, but more particularly in the morning and afternoon. Canvas-backs commence flying very early, and it is necessary for the sportsman to be up and on the ground betimes, as he will have an opportunity of trying his skill as soon as it shall be light enough to see the ducks which he will hear moving over his head in uninterrupted numbers for an hour before daybreak. The morning flights continue an hour or two after dawn, although, as before stated, many ducks keep in motion all day long; but the greater portion of them are busily engaged feeding after this time, and, if Aying, endeavor to avoid these exposed points, where they have every reason to apprehend danger. Canvas-backs, in fact, are disposed to keep clear of the shores at all times; but when impelled by a strong breeze that sets them towards these points, they are not easily turned from their course, it not being often necessary to employ any kind of device to screen the sportsman from observation, provided he remain motionless until the ducks have come sufficiently near to be in range of the gun. It is better that the dress should not be too conspicuous: a drab overcoat and cap of the same color is the most suitable for concealment; and, if possible, station yourself against a bush, tree, or some dark object, if there are no blinds erected.

When the canvas-backs are flying fast and in great numbers, an eager sportsman had better take two guns with him, and have an assistant to load while he fires; and in this way he will get double the number of shots, without the hurry and excitement of charging fast. 
Captain Hawker very justly remarks:- "Never look up while loading; you can do no good by it, and you will only put yourself in a flurry, and perhaps break your ramrod. If your man, (assistant,) knowing you have no gun loaded, says, 'Look out, sir !' why -I had almost said-knock him down."

\section{TO SHOOT DUCKS SITTING.}

Having learned the art of shooting flying, the tyro may feel disposed to treat with contempt any endeavor on our part to teach him so simple a thing as to shoot wild fowl while sitting on the water, within, we will say, fifty or a hundred yards of our ambush. Nevertheless, we can assure him that it is not such an easy matter as he supposes, and he will upon trial soon find to his satisfaction what we say to be true; and, without paying proper regard to our instructions on this point, he will often have the mortification of seeing the ducks escape from his fire, when he ought by due management to have killed at least a dozen or more. It seems to be a very simple thing to point the gun in a direct range of a flock of ducks, and cut a complete lane, as it were, through their ranks with a heavy charge of powder and shot; but such, unfortunately for the tyro, is not the case. The young sportsman generally commits one of two errors in shooting wild fowl; that is, he either undershoots or overshoots the game, according to the distance they are from him. If within thirty, forty, or fifty, or even seventy yards, the shot almost invariably passes orer the ducks; if beyond this distance, the load most frequently falls far short of the intended mark.

When the shot is first impelled from the mouth of a large duckgun held on a level, it has an upward tendency from a point-blank range, which it preserves for an indefinite distance, according to the quantity of powder used and the force with which the weapon shoots. When it has reached a certain distance it begins to lose the uprard impetus, and, therefore, must fall sooner or later before losing entirely its projectile force. Any one can easily ascertain this fact by trying the experiment on the water, if not 
convinced of it by previous observation. This being the case, the force of our assertion will be readily seen; that is, when the ducks are but a short distance off, the load will most likely pass over the spot within the point-blank range of the gun and be distributed some distance beyond; while, on the other hand, the ducks being much farther off, the shot will most likely fall short of their intended destination, or, in other words, drop within the point-blank range of the eye.

When the ducks are a short distance from our station, the foremost ones, if there be many, should be in full relief over the sight of the gun; and then, most probably, if shooting on a level, as is most frequently the case on the shores where wild fowl are pursued, the leader of the troop which we select for our guide will escape from the dire effects of our rolley, that shall spread death and destruction in his rear.

If, on the contrary, the ducks are a long distance off, be sure that the foremost ducks are entirely under the range of the barrels, and then we shall most likely rake the front and middle columns, if not sweep the whole mass. For other information regarding shooting ducks, we refer to our chapter on wild-fowl shooting in general, and beg to close the present subject, as some one has done before us, with the spirited lines of Wilson, descriptive of the shooting of these celebrated birds.

"Slow round an opening point we softly steal,

Where four large ducks in playful circles wheel.

The far-famed canvas-backs at once we know,

Their broad, flat bodies wrapped in pencilled snow:

The burnished chestnut o'er their necks that shone,

Spread deepening round each breast a sable zone.

Wary they gaze; our boat in silence glides;

The slow-moved paddles steal along the sides;

Quick-flashing thunders roar along the flood,

And three lie prostrate, vomiting their blood!

The fourth aloft on whistling pinions soared;

One fatal glance the fiery thunders poured;

Prone drops the bird amid the dashing waves,

And the clear stream his glossy plumage laves." 
THE PRESENT AND FUTURE NUMBERS OF DUCKS UPON CHESAPEAKE BAY.

"Still files of ducks in streaming thousands pour;

At every bend their rising torrents roar."

Notwithstanding the immense multitude of canvas-backs which annually resort to the waters of the Chesapeake Bay, they are now said to be far less numerous than they were some years ago. Of this fact we are not able to judge, but feel satisfied that the species, although killed in numbers still greater than they hare been heretofore, can never become extinct, as some persons apprehend. The greatest safeguard to the continuation of the whole duck race is the circumstance of their breeding in regions so remote. They are besides so prolific, that every succeeding autumn will bring down to their former haunts a wonderful increase to the great numbers of those that necessarily escape the general massacre. The large and increasing demand, however, for ducks from the Chesapeake in particular, and the ingenions methods resorted to to kill them, will no doubt eventually drive the larger portion of the canras-backs from their favorite feeding-grounds, and thus cause them to become more widely dispersed over the whole country. The comparative searcity of them on these waters will, perhaps, induce the erroneous belief of their speedy extinction; but such a thing we deem impossible, owing, as already stated, to the habits of the whole duck tribe during the period of incubation. During the season of 1850 and 1851 , canvas-backs were rery plenty, and, owing to the unusual mildness of the weather and the consequent increased slaughter of them from the surface-boats, they were sold at unprecedented low prices in our markets.

The early portion of the season of 1854 and 1855 was equally prolific of the feathered race, insomuch that greater slaughter of wild fowl was made on the flats of the Chesapeake and its numerous tributaries than in any previous year. No less than three thousand head of rarious kinds of ducks were killed in the vicinity of Havre de Grace alone on the first day which the duckers in a body 
agreed to make use of their batteries. The temperature during the months of Ociober and Jorember of the following season of 1855 and $155, f$ being uncommonlt moderate, but few canras-backs,

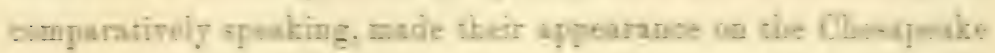
before Decemter. The weather scon after becoming intenselt cold, and continuing so for sereral meels, the destruction of ducks on

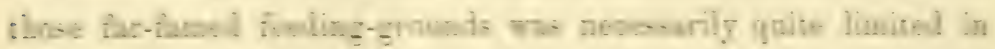

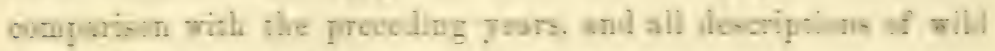
forl sold in our markets at rery high prices.

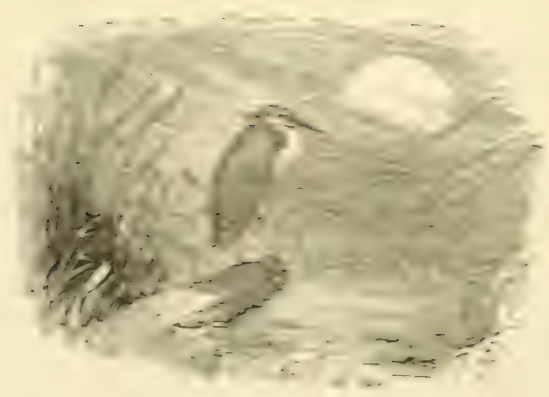




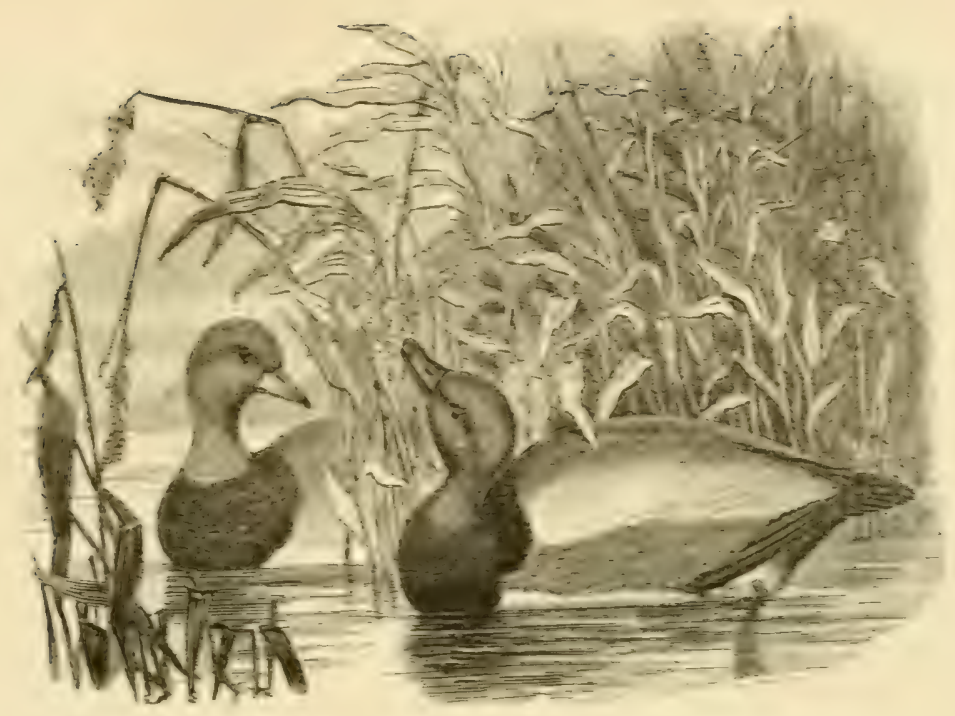

CHAPTER TAIT.

\section{DIFFEREII TARIETIES OF DECKS.}

\section{RED-HEADED DECE, OR RED-HEAD. ATAS FERIXA.}

- Berend a point, just opening to the riew.

A fleet of daclss collect their seattered crem:

Part, soon slarwed, with sulden splatering, soar.

The rest remaining, seet the farther sbore."

\section{HABITS, DESCPIPTION, EIC.}

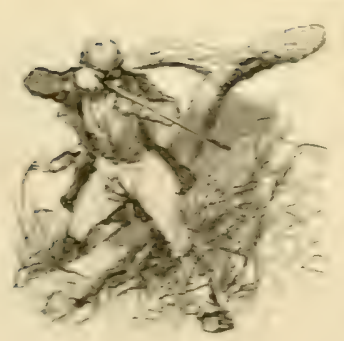

HE red-head, second alone in delicacr of flaror to the canras-back, will now clain? our attention. It frequents rers much the same grounds with the preceding rarietr, although not so exclusirely medded to the waters of the Chesapeake but that it can be found in other localities in considerable profusion, eren huring the luxurinace of the valisinerits. The rel-beal, the the

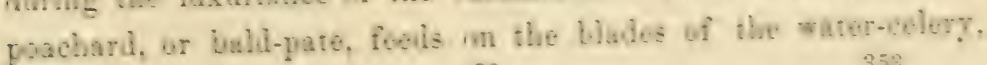


when it cannot filch the tender roots from the canvas-backs. It is often shot in the Delaware, Hudson, and other rivers, and visits the streams of the South as the winter progresses. The flesh of these fowls is so near akin to that of the canvas-backs, that the most delicate palate can hardly distinguish one from the other; and we have seen many amusing mistakes made by persons professing to be able to tell one duck from the other when served for the table.

"The red-head is twenty inches in length and two feet six inches in extent; bill dark slate, sometimes black, two inches long, and seven-eighths of an inch thick at the base, furnished with a large broad nail at the extremity; irides flame-colored; plumage of the head long, velvety and inflated, running high above the base of the bill; head, and about two inches of the neck, deep glossy reddish-chestnut; rest of the neck and upper part of the breast black, spreading round to the back; belly white, becoming dusky towards the vent by closely-marked undulating lines of black; back and scapulars bluish-white, rendered gray by numerous, transverse waving lines of black; lesser wing-coverts brownish-ash; wing-quills very pale slate, dusky at the tips; lower part of the back and sides under the wings brownish-black, crossed with regular zigzag lines of whitish; vent, rump, and tail-corerts, black; legs and feet dark ash." The female has the upper part of the head dusky brown, and the plumage generally is not so bright as that of the male.

The red-head weighs from a pound and a half to two pounds.

This duck resembles very closely the poachard, red-headed widgeon, or dun-bird, of England, and is considered by many as the same identical bird. The deseription of the one corresponds very much with that of the other, as will be seen by the following, taken from Daniel. "The poachard is about the size of a widgeon, weighs one pound twelve ounces; its length is nineteen inches; breadth two feet and a half; the bill is broader than the widgeon's, of a deep lead-color, with a black tip; irides orange; the head and neck deep chestnut; the lower part of the neck and breast, 
and upper part of the back, dusky black; scapulars and wingcoverts nearest the body of a grayish white, elegantly marked with narrow lines of black; the exterior wing-coverts and quills dusky brown; the belly ash-colored and brown; the tail consists of twelve short feathers of a deep gray; the legs lead-colored. The female has the head of a pale reddish-brown," \&c.

From the above description, and the investigations of naturalists, we are led to suppose that these two birds are identical; and therefore it will not perhaps be deemed irrelevant to the sulject to introduce a short history of the plan pursued in England for the capture of this fowl upon an extensive scale:-

"These birds (poachards), are eagerly sought by the London poulterers, under the name of dun-birds, as they are deemed excellent eating. The greater part of what appear in the markets are caught in decoys; but the construction and mode of working is perfectly distinct from that wherein the other wild fowl are taken. A decoy for dun-birds is called a flight-pond, and has nets fastened to tall stout poles twenty-eight or thirty feet long; at the bottom of each pole is a box fixed, filled with heavy stones, sufficient to elevate the poles and nets the instant an iron pin is withdrawn, which retains the nets and poles flat upon the reeds, small willow boughs, or furze; within the nets are small pens made of reeds, about three feet high, for the reception of the birds that strike against the net and fall down; and such is the form and shortness of wing in the poachard, that they cannot ascend again from their little enclosures if they would; besides, the numbers which are usually knocked into these pens preclude all chance of escape from them by the wing. A decoy-man will sometimes allow the haunt of dun-birds to be so great that the whole surface of the pond shall be covered with them previous to his attempting to take one. Upon such occasions, he bespeaks all the assistants he can get, to complete the slaughter by breaking their necks. When all is ready, the dun-birds are roused from the pond; and, as all wild fowl rise against the wind, the poles in that quarter are unpinned, and fly up with the nets at the instant the dun-birds begin to leave 
2 


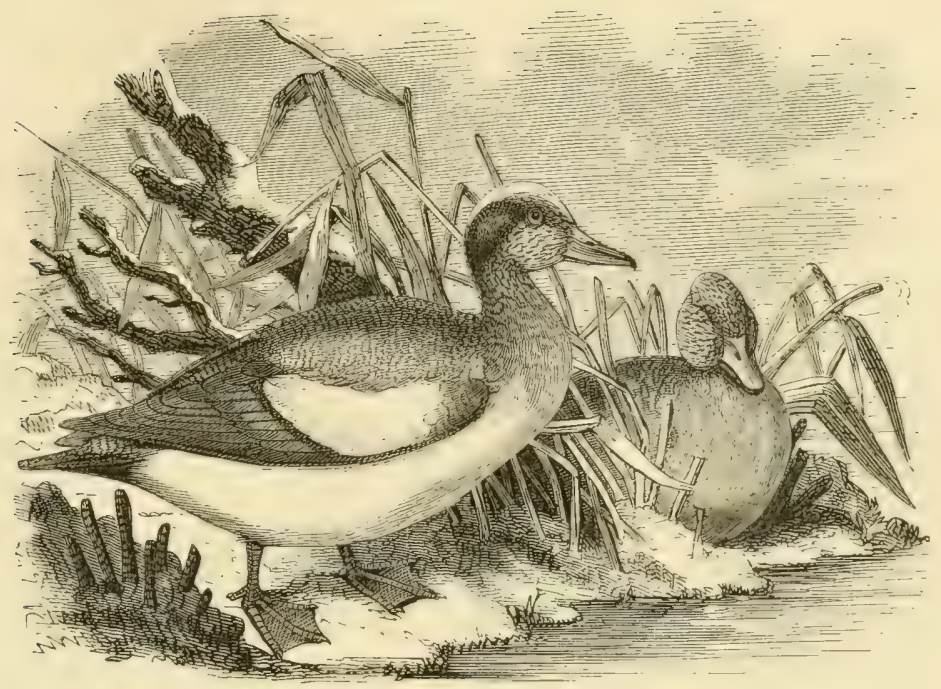

ANAS AMERICANA. AMERICAN WIDGEON, OR BALD-PATE.

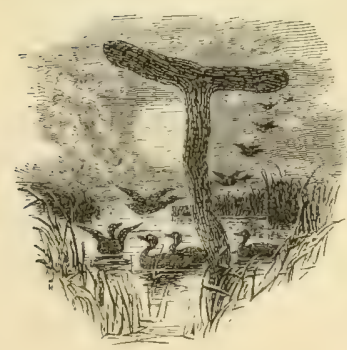

HIS fowl, like the red-head, during its sojourn on the Chesapeake and Potomac, is the constant companion of the canvasback, upon whose superior skill in diving it depends for a supply of the tender root of the valisineria, which it filches from these ducks as soon as they come to the top of the water with it in their mouths. The bald-pates, as these ducks are most commonly called on the Chesapeake, are not far inferior in flavor to the canvas-back, and when in good order it is not easy to distinguish them from the above duck. Those killed on other streams, though excellent eating, will not compare with those that feed on the flats of the Chesapeake. Widgeons are extensively scattered throughout the wnole of our Atlantic States, and are abundant in some of the West India islands; they are well known in the Delaware Bay. 


\section{DESCRIPTION.}

"The widgeon, or bald-pate, measures twenty-two inches in length and thirty inches in extent; the bill is of a slate-color; the nail black; the front and crown cream-colored, sometimes nearly white, the feathers inflated; from the eye backwards to the middle of the neck behind extends a band of deep, glossy green, gold, and purple; throat, chin, and sides of the neck before, as far as the green extends, dull yellowish-white, thickly speckled with black; breast and hind-part of the neck hoary bay, running in under the wings, where it is crossed with fine waving lines of black; whole belly white; vent black; back and scapulars black, thickly and beautifully crossed with undulating lines of vinous bay; lower part of the back more dusky; tail-coverts long, pointed, whitish, crossed as the back; tail pointed, brownish ash; the two middle feathers an inch longer than the rest, and tapering; shoulder of the wing brownish ash; wing-coverts, immediately below, white, forming a large spot; primaries brownish ash; middle secondaries black, glossed with green, forming the speculum; tertials black, edged with white, between which and the beauty-spot several of the secondaries are white.

"The female has the whole head and neck yellowish-white, thickly speckled with black, very little rufous on the breast; the back is dark brown. The young males, as usual, very much like the females during the first season, and do not receire their full plumage until the second year. They are also subject to a regular change every spring and autumn."

This fowl, it will be seen, resembles the English widgeon, whewer, or whim, both in appearance and habits. The American variety is, perhaps, a little heavier, and the plumage richer. Widgeons do not feed much during the day, but remain listlessly on the sand-flats or hidden among the herbage of the marshes; but as soon as night comes they are in motion, and may be heard repairing in considerable numbers to the various feeding-grounds which they are wont to frequent. These fowl are very abundant on the 
coasts of Great Britain, and the numbers slaughtered in the course of a season by the sportsmen and fowlers are enormous. They are much esteemed in London, and eagerly sought after by the poulterers as a ready article of sale. They are pursued by the English punters almost entirely by night; they lie in wait for them in those situations which they are most likely to visit or pass orer in their course to the feeding-grounds. The best weather for this sport is a clear, windy, half moonlight night, provided the wind does not blow from you, as the ducks may smell you: in fact, it is always necessary to get to the leeward of wild fowl of all kinds, as their power of scenting is very great. The English variety is casily "domesticated in places where there is plenty of water, and are much admired for their beauty, sprightly look, and frolicsome manners." The same is said of the American widgeon.

Bald-pates can be decoyed within gunshot by imitating their peculiar shrill note; are not apt to dart at decoys off points, except in foggy weather. They are migratory, and breed in the North, on the coast of Hudson's Bay; they visit the ricefields of the South during the winter in considerable numbers, and are much esteemed by the planters as an article of food.

For further information on the subject of widgeon, we beg to refer the reader to Colonel Hawker, the Magnus Apollo of wild. fowl shooting, as he has very justly been styled.

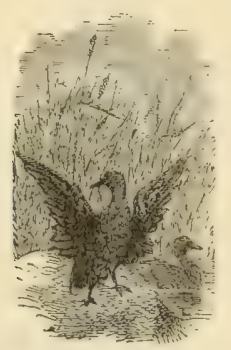




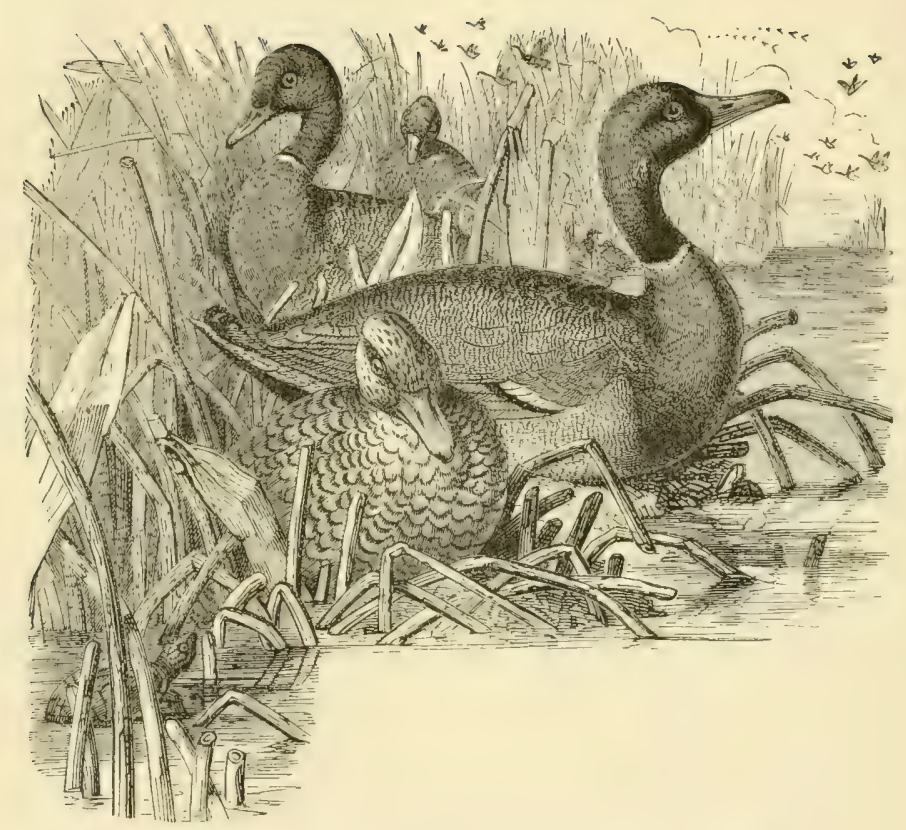

ANAS BOSCHAS. MALLARD, OR WILD DRAKE.

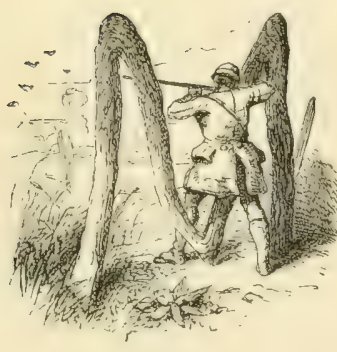

ALLARDS are widely disseminated over almost every habitable portion of the globe, and their flesh is alike esteemed in all parts; and wherever they make their appearance, sportsmen resort to all kinds of expedients to secure them. At a glance, it will be seen that the wild drake is the original stock from which is sprung the puddle-duck of our barnyards, as they differ but little in plumage and general form. The wild bird, however, is a much more noblelooking fowl than those of the same race that have been enslaved by man; and instead of the silly, discordant quack! quack! quack! lazy waddle, inactive life, and singular propensity for dabbling in the filthy oozes of the stable-yard, common to our domestic duck, they pursue a cunning, silent, active, and free life. 


\section{DESCRIPTION}

"The mallard, or common wild drake, is so universally known as scarcely to require a description. It measures twenty-four inches in length by three feet in extent, and weighs upwards of two pounds and a half; the bill is greenish yellow; irides hazel; head, and part of the neck, deep, glossy, changeable green, ending in a narrow collar of white; the rest of the neck and breast are of a dark purplisn chestnut; lesser wing-coverts brown-ash; greater crossed near the extremities with a band of white, and tipped with another of deep velvety black; below this lies the speculum or beauty-spot, of a rich and splendid light purple, with green and violet ruflections, bounded on every side with black; quills pale brownsh-ash; back brown, skirted with paler; scapulars whitish, crosserl with fine undulating lines of black; rump and tail-coverts black, glossed with green; tertials very broad, and pointed at the ends; tail, consisting of eighteen feathers, whitish, centred with brown-ash, the four middle ones excepted, which are narrow, black, gloged with violet, remarkably concave, and curled upwards to a complete circle; belly and sides a fine gray, crossed by an infinite nuraber of fine, waving lines, stronger and more deeply marked as they approach the vent; legs and feet orange-red.

"The female has the plumage of the upper parts dark brown, broadly bordered with brownish yellow, and the lower parts yellow ochre, spotted and streaked with deep brown; the chin and throat, for about two inches, plain yellowish-white; wings, bill, and legs, nearly as in the male.

"The windpipe of the male has a bony labyrinth, or bladder-like knob, puffing out from the left side. The intestines measure six feet, and are as wide as those of the canvas-back. The windpipe is of uniform diameter until it enters the labyrinth."

Like most wild fowl, the mallard breeds in the Far North, and makes its appearance in the autumn among the first of our ducks. It is common throughout all our rivers and fresh-water lakes, but is seldom met with on the sea-coast. As the winter 
progresses, large numbers continue South, and take up their abode among the ricefields of the Carolinas, where they become very fat and particularly palatable. Their flesh, at all times when the weather is not very severe, is good, as they feed on vegetable matter in preference to any other kind of food, and only partake of fish when they cannot obtain any thing else.

Mallards are easily brought within gunshot by means of decoys, used in the way already described under the head of canvas-backs. They are numerous at times on the Delaware, and numbers are killed by shooters hiding themselves in boats and the reeds within range of their stool-ducks, which are set out on the edge of the reeds. They are very fond of the seeds of the wild oats that flourish so profusely on the flats of the Delaware, and their flesh soon becomes delicate and juicy.

In England and on the Continent many singular contrivances have been invented to entrap these birds; and so successful are the fowlers now in this lucrative business that many hundreds are often taken at one draw of the net.

The most destructive way of trapping mallards is the plan adopted on the decoy-ponds of England and France. a full account of which may be found in Bewick's British Birds.

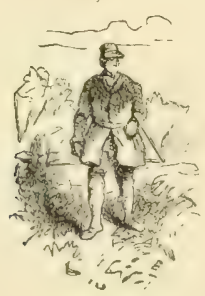




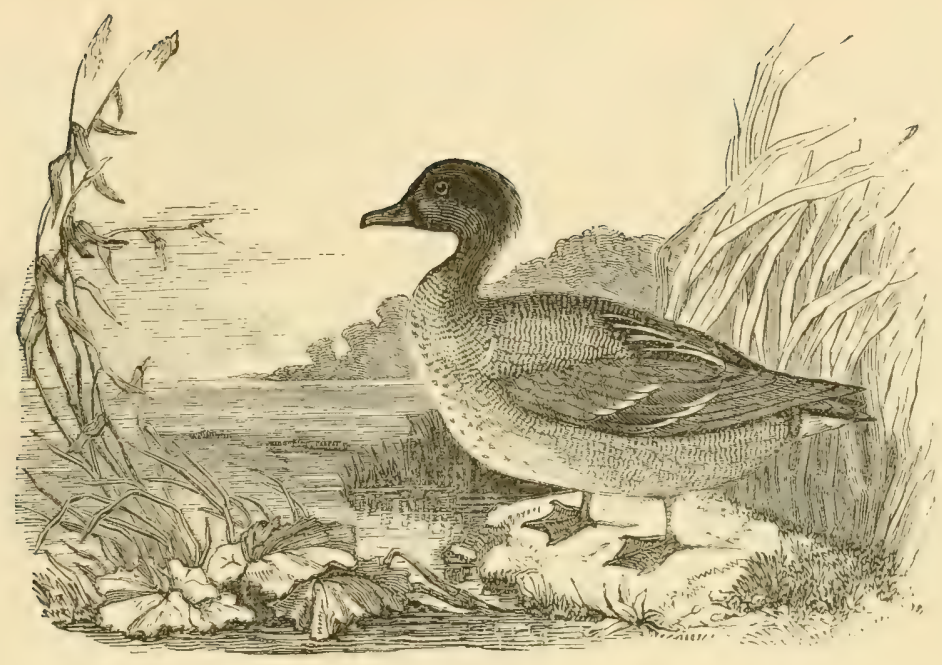

ANAS DISCORS. BLUE-WINGED TEAL.

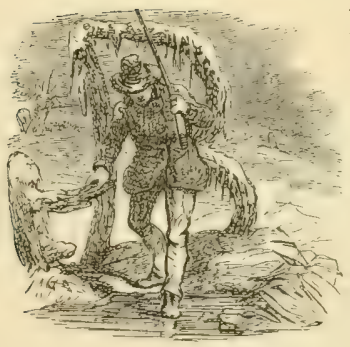

LUE-WINGED TEAL are among the first of the water-fowl that visit, the shores of the Delaware and Chesapeake from the far regions of the North. They arrive among us in September, and remain feeding along the fresh-water shores and mud-flats until driven farther south by the chilling frosts of these regions, as they are a very tender bird, and spend the most of their time in parts where the weather is mild. This little duck appears to be much less cunning than most other varieties of wild fowl, as it is not difficult to approach in a boat or under cover of any simple device.

The shooters on the Delaware kill great numbers from the reeds, over stool-ducks set out on the mud; they stool without difficulty, and drop down among the decoys and go to eating as if they were surrounded by busy companions like themselves.

They stool better if the decoys are set in the mud than if in the water, and in this respect differ from every other duck. 
They are fond of the seeds of the wild oats, and become very fat after feeding on them for a short time. In the South they also become very fat, and are considered most excellent eating; great numbers are shot as well as caught on the ricefields in traps set by the negroes.

The markets of Philadelphia abound with these ducks, which are sold for a mere trifle. They are considered best by epicures when split open and broiled, with a dressing of butter: we prefer them in this way to all other modes of cooking.

Blue-winged teal fly with great rapidity and considerable norse; they drop down suddenly among the reerls, much like a woodrock.

\section{DESCRIPTION.}

"This species measures about fourteen inches in length and twenty-two inches in extent; the bill is long in proportion, and of a dark, dusky slate; the front and upper part of the head are black; from the eye to the chin is a large crescent of white; the rest of the head and half the neck are of a dark slate, richly glossed with green and riolet; remainder of the neck and breast is black or dusky, thickly marked with semicircles of brownish white, elegantly intersected with each other; belly pale brown, barred with dusky in narrow lines; sides and vent the same tint, spotted with oval marks of dusky; flanks elegantly waved with large semicircles of pale brown; sides of the vent pure white, under the tail-coverts black; back deep brownish-black, each feather waved with large semi-ovals of brownish white; lesser wing-covert a bright light-blue; primaries dusky brown; secondaries blask; speculum, or beauty-spot, rich green; tertials edged with black or light-blue, and streaked down their middle with white; the tail, which is pointed, extends two inches beyond the wings; legs and feet yellow, the latter very small; the two crescents of white before the eyes meet on the throat.

"The female differs in having the head and neck of a dull dusky slate, instead of the rich violet of the male; the hind-head is also 
whitish; the wavings on the back and lower parts more indistinct; wing nearly the same in both."

\section{ANAS CRECCA. GREEN-WINGED TEAL.}

This variety is a little larger than the preceding, and resembles more closely the English teal-is, in fact, considered by naturalists as the same duck. Its habits and disposition are similar to those of the blue-winged, and its flesh of like quality.

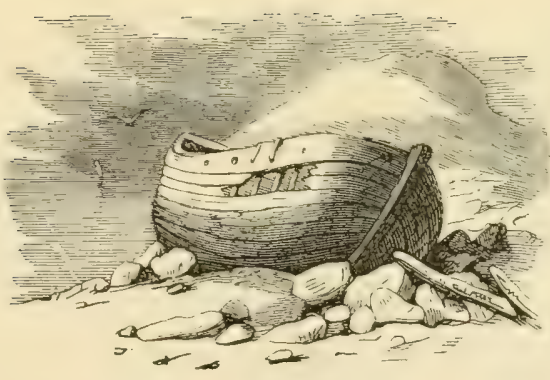




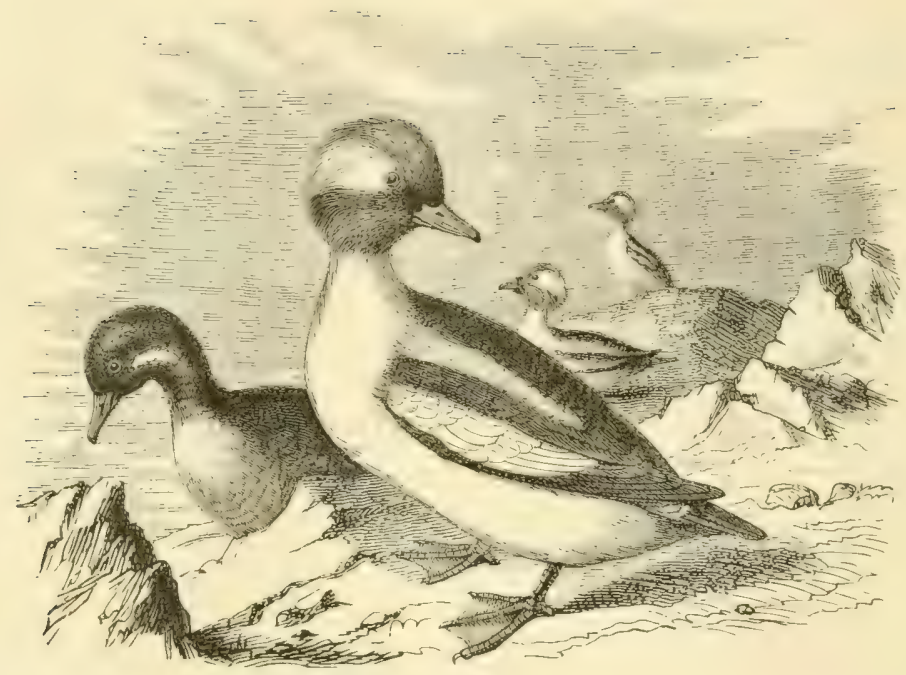

ANAS ALBEOLA. BUFFEL-HEADED DUCK, OR BUTTER-BALL.

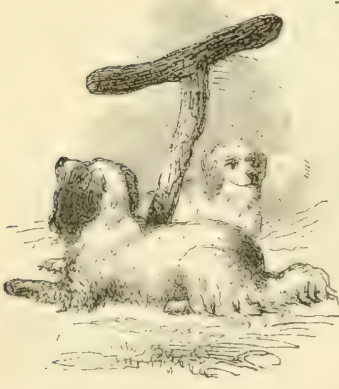

HIS little duck is more commonly known as the butter-box, or butter-ball, from the circumstance of its fat, plump little body. It is one of the very first ducks that comes from the North. Its flesh is rather fishy at times; but we have shot them on the Chesapeake and Delaware of very good flavor. It breeds in the North, flies with great velocity, and dives with considerable facility; and, when on the wing, utters a quick, guttural note-quack! quack! quack!

\section{DESCRIPTION.}

"The buffel-headed duck, or rather, as it has originally been, the buffalo-headed duck, from the disproportionate size of its head, is fourteen inches long and twenty-three inches in extent; the bill is short, and of a light blue or leaden color; the plumage of the head and half of the neck is thick, long, and velvety, projecting 366 
greatly over the lower part of the neck; this plumage on the forehead and nape is rich glossy green, changing into a shining purple on the crown and sides of the neck; from the eyes backward passes a broad band of pure white; iris of the eye dark; back, wings, and part of the scapulars, black; rest of the scapulars, lateral band along the wing, and whole breast, snowy white; belly, vent, and taii-coverts, dusky white; tail pointed, and of a hoary color.

"The female is considerably less than the male, and entirely destitute of the tumid plumage of the head: the head, neck, and upper parts of the body and wings are sooty black, darkest on the crown; sides of the head marked with a small oblong spot of white; bill dusky; lower part of the neck ash, tipped with white; belly dull white; vert cinereous; outer edges of six of the secondaries and their incumbent coverts white, except the tips of the latter, which are black; legs and feet a livid blue; tail hoary brown."

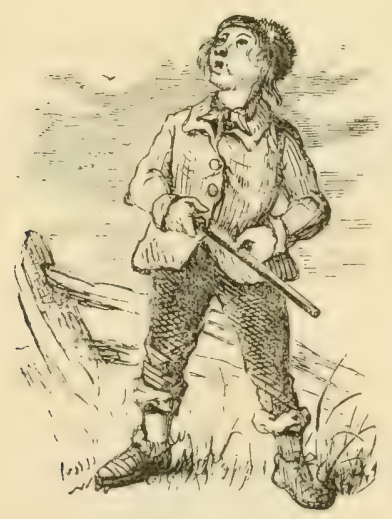




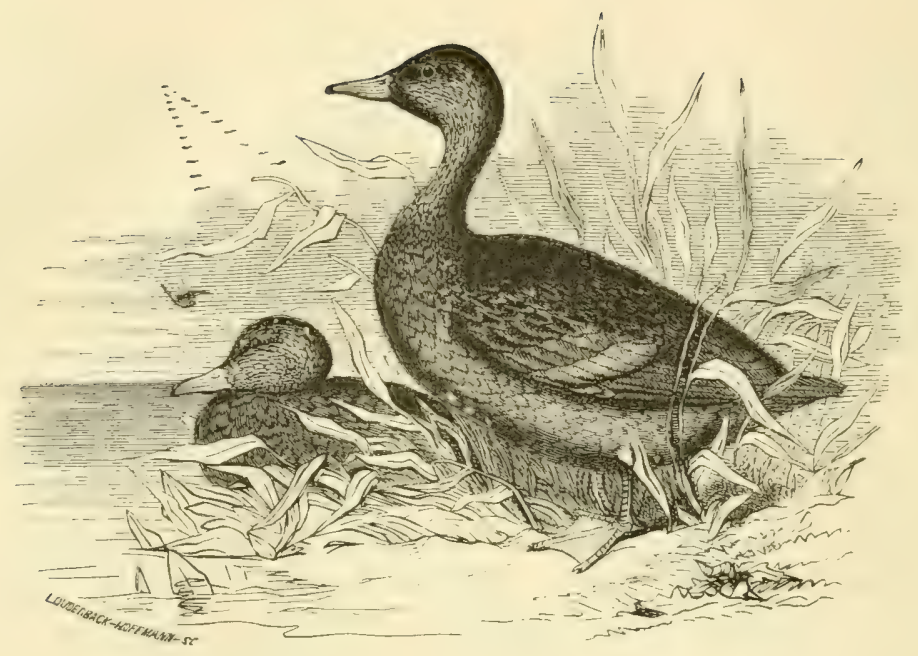

ANAS OBSCURA. DUSKY DUCK, OR BLACK DUCK.

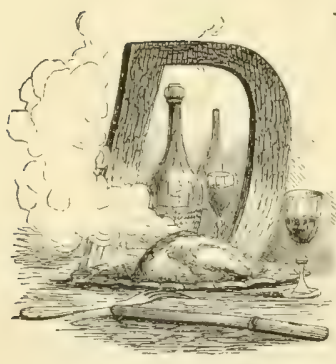

USKY or black ducks are known to all our sea-shore shooters, and innumerable quantities are brought to the Philadelphia markets. They meet with ready sale, although their flesh is far inferior to that of many other varieties of wild fowl. They are better known as the black duck, and are shot on the salt marshes of the Delaware. They are very wary, and will not stool. They feed on the small bivalves that are so abundant in these waters, as also along the shores of the creeks and inlets of the Middle States. Black ducks swim and fly with great velocity: their notes resemble those of the mallard, but their flesh is much inferior.

As before stated, wild fowl rise almost universally against the wind; black ducks, however, are an exception to this general rule, as they spring indifferently either with or against the wind.

Numbers of black ducks are killed by the gunners lying in wait for them in the route of their return from the sea to the marshes to feed after night. This kind of shooting is termed "dusking." 
and of course can only be practised with much success on a moonlight night.

When the weather is not severe and the ducks are plenty, "dusking" is an agreeable pastime. Black ducks are very wary and sagacious; and it is necessary to hold the most profound silence when dusking, as they change their course or tower high at the slightest noise.

\section{DESCRIPTION.}

"The dusky or black duck is two feet in length and three feet two inches in extent; the bill is of a dark greenish-ash, formed very much like the mallard, and nearly of the same length; irides dark; upper part of the head deep dusky-brown, intermixed on the forepart with some small streaks of drab; rest of the head and greater part of the neck pale yellow-ochre, thickly marked with small streaks of blackish brown; lower part of the neck and whole lower parts deep dusky, each feather edged with brownish white and with fine seams of rusty white; upper parts the same, but rather deeper; the outer vanes of nine of the secondaries bright violet-blue, forming the beauty-spot, which is bounded on all sides by black; wings and tail sooty brown; tail-feathers sharp-pointed; legs and feet dusky yellow; lining of the wings pure white.

"The female has more brown on her plumage, but in other respects differs little from the male, both having the beauty-spot on the wing.

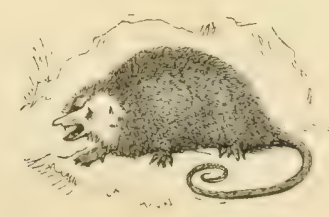




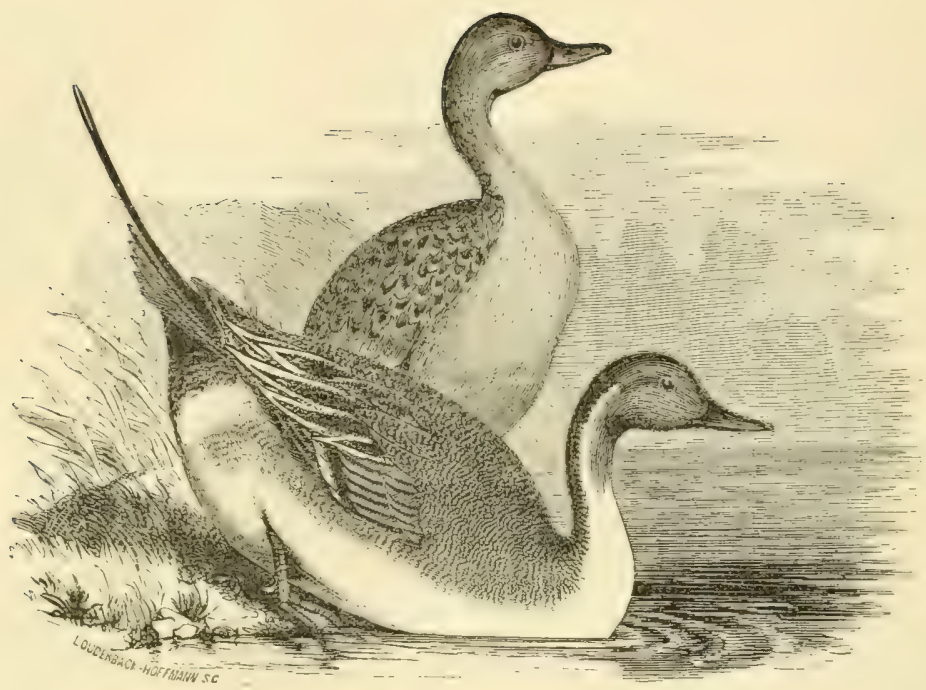

ANAS ACUTA. PINTAIL DUCK, OR SPRIGTAIL.

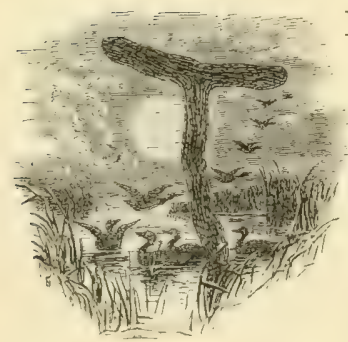

HIS handsome-looking duck is known to our shooters indifferently as the pintail or sprigtail. The latter appellation is perhaps the most common. They frequent the fresh-water streams of almost every section of our country, both inland and on the seaboard. They are not very partial to salt water. Sprigtails are shy and vigilant; when aroused, they fly confusedly together, so that the shooter has always a fine opportunity to rake the flock when on the wing. They remain with us all winter and breed in the North; their flesh is sweet and often delicious.

\section{DESCRIPTION.}

"The pintail duck is twenty-six inches in length and two feet ten inches in extent; the bill is a dusky lead-color; irides dark hazel; head and half of the neck pale brown, each side of the neck marked with a band of purple-riolet, bordering the white; 370 
hind-part of the upper half of the neck black, bordered on each side by a stripe of white, which spreads over the lower part of the neck before; sides of the breast and upper part of the back white, thickly and elegantly marked with transverse, undulating lines of black, here and there tinged with pale buff; throat and middle of the belly white, tinged with cream; flanks finely pencilled with waving lines; vent white; under tail-coverts black; lesser wingcoverts brown-ash; greater the same, tipped with orange; below which is the speculum, or beauty-spot, of rich golden green, bordered below with a band of black and another of white; primaries dusky brown; tertials long, black, edged with white and tinged with rust; rump and tail-coverts pale ash, centred with dark brown; tail greatly pointed, the two middle tapering feathers being full five inches longer than the others, and black; the rest brown-ash, edged with white; legs a pale lead-color.

"The female has the crown of a dark brown color; neck of a dull brownish-white, thickly speckled with dark brown; breast and belly pale brownish-white, interspersed with white; back and root of the neck above black, each feather elegantly waved with broad lines of brownish white-these wavings become rufous on the scapulars; vent white, spotted with dark brown; tail dark brown, spotted with white; the two middle tail-feathers half an inch longer than the others.

"The sprigtail is an elegantly-formed, long-bodied duck, the neck longer and more slender than most others."

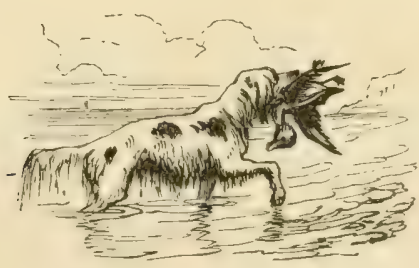




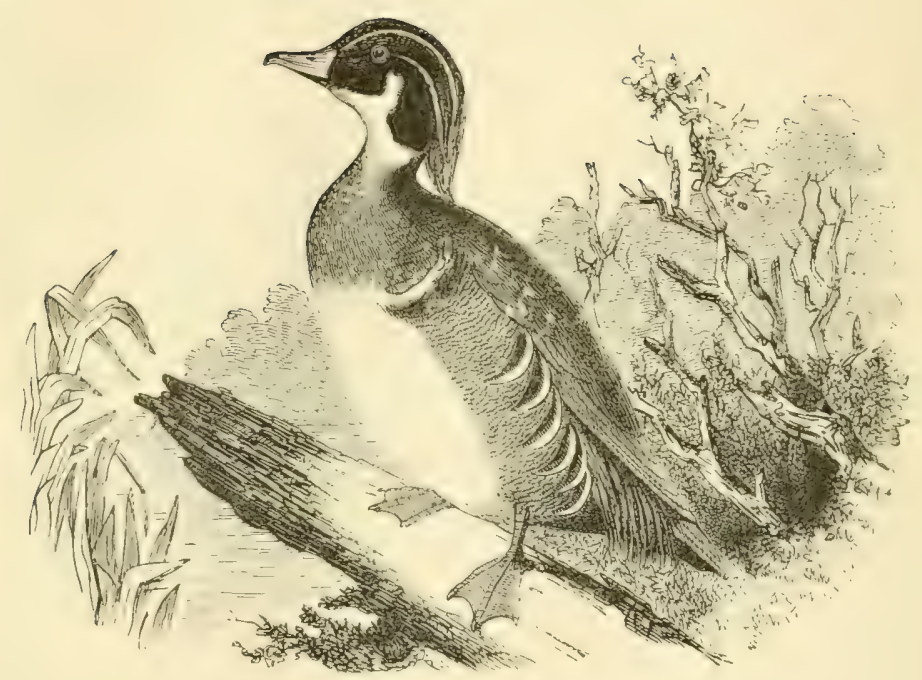

ANAS SPONSA. SUMMER-DUCK, OR WOOD-DUCK.

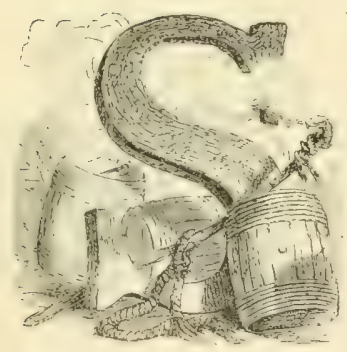

UMMER-DUCKS are remarkable for the richness and varied hue of their plumage, and are considered the most beautiful of all the duck tribe. It is spread throughout the whole extent of our country, breeding in almost every State of the Union, and familiarly known to country-people as the wood-duck, from the circumstance of its selecting the hollows of trees to breed in. This fowl delights in the small streams and mill-ponds of the interior, and is but seldom met with on the large rivers. They are not often met with in flocks, but are generally found in small families of two or three. The followers of Sir Isaac Walton are generally much more familiar with this fowl than the professed sportsman, ats they, in the pursuit of their favorite amusement, spend much of their time in the quiet and secluded haunts which 
these birds affect. Their food consists of seeds and insects, and their flesh at times is excellent. They are easily tamed when taken young, and soon become completely domesticated.

\section{DESCRIPTION.}

"The wood-duck is nineteen inches in length and two feet four inches in extent; bill red, margined with black; a spot of black lies between the nostrils, reaching nearly to the tip, which is also of the same color, and furnished with a large hooked nail; irides orange-red; front, crown, and pendent crest rich glossy bronzegreen, ending in violet, elegantly marked with a line of pure white running from the upper mandible over the eye, and with another band of white proceeding from behind the eye, both mingling their long pendent plumes with the green and violet ones, producing a rich effect; cheeks and sides of the upper neck violet; chin, throat, and collar round the neck pure white, curving up in the form of a crescent nearly to the posterior part of the eye; the white collar is bounded below with black; breast dark violetbrown, marked on the forepart with minute triangular spots of white, increasing in size until they spread into the white of the belly; cach side of the breast is bounded by a large crescent of white, and that again by a broader one of deep black; sides under the wings thickly and beautifully marked with fine undulating parallel lines of black, on a ground of yellowish drab; the flanks are ornamented with broad, alternate, semicircular bands of black and white; sides of the vent rich light-violet; tail-coverts long, of a hair-like texture at the sides, over which they descend, and of a deep black, glossed with green; back dusky bronze, reflecting green; scapulars black; tail tapering, dark glossy green above, below dusky; primaries dusky, silvery hoary without, tipped with violet-blue; secondaries greenish blue, tipped with white; wing-coverts violet-blue, tipped with black; vent dusky; legs and feet yellowish red; claws strong and hooked.

"The female has the head slightly crested; crown, dark purple: 
behind the eye a bar of white; chin and throat, for two inches, also white; head and neck dark drab; breast, dusky brown, marked with large triangular spots of white; back dark glossy bronze-brown, with some gold and greenish reflections; speculum of the wings nearly the same as in the male, but the fine pencilling of the sides and the long hair-like tail-coverts are wanting; the tail is also shorter."

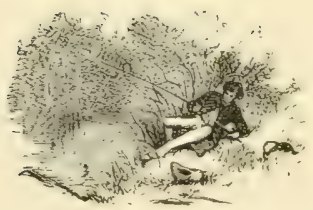




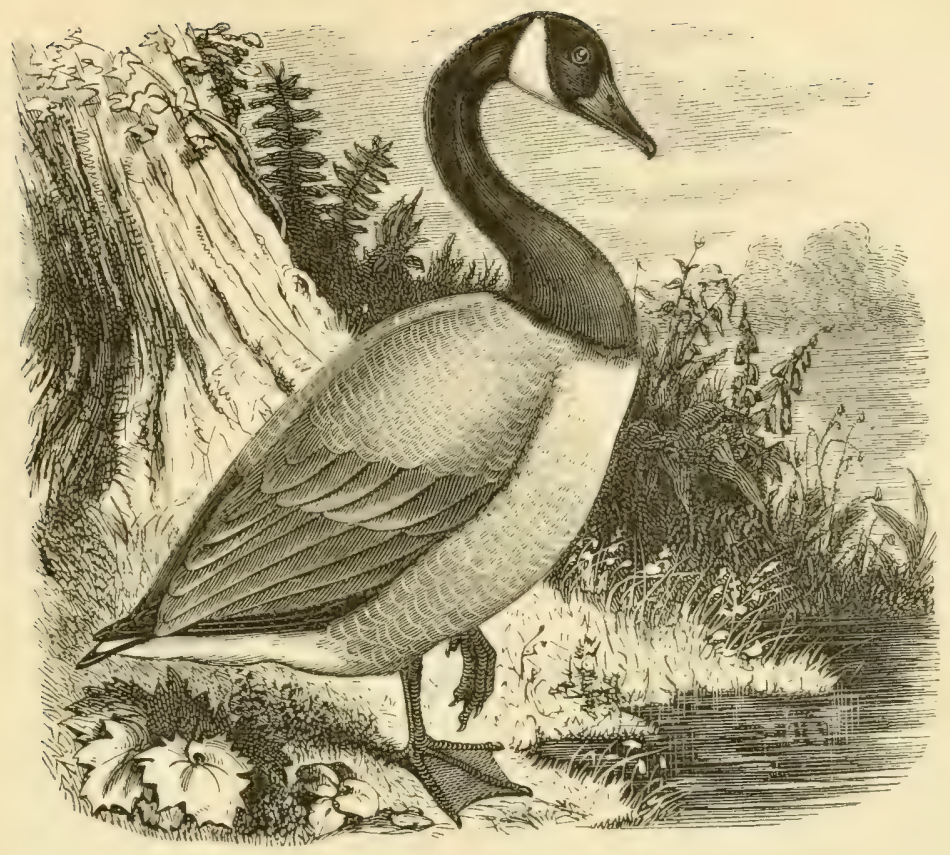

\section{ANAS CANADENSIS. CANADA GOOSE.}

"Hawnk! honk! and for'ard to the nor'ard is the trumpet-tone! What goose can lag, or feather flag, or break the goodly cone?

Hawnk: onward to the cool blue lakes where lie our safe love-bowers, No stop, no drop of ocean-brine, near stool or hassock hoary, Our travelling watchword is 'our mates, our goslings, and our glory!' Symsonia and Labrador for us are crowned with flowers, And not a breast on wave shall rest, until that heaven is ours.

Hawnk! Hawnk! E-e Hawnk!"

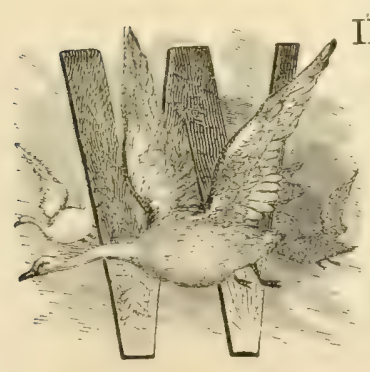

ILD GEESE are widely spread over the whole of the country; and there are few portions of the United States where the honking of the goose is not familiar to the inhabitants. These fowl, in therr migrations south and north, are considered the sure harbingers of dreary winter or the near approach of cheerful spring. They breed in the remotest regions of the North, even 
perhaps under the very Pole itself, where, undisturbed by the cruel hands of man, they rear their young in the most perfect security, and only leave those peaceful climes when driven from them by the severity of threatening winter.

Wild geese make their appearance on the Delaware and Chesapeake Bays in October; and when many are flying early in the season it is considered a certain prognostic of a long and hard winter, - a belief in which all the inhabitants of those parts which they visit place implicit confidence.

During their journey through the Canadas, their thick ranks are considerably thinned by the slaughter made among them by the Indians, who kill immense numbers for their own support and for that of the English settlements about Hudson's Bay.

The geese are cleaned and salted away for the winter's use, and afford the principal article of flesh that the people have to rely upon for several months in the year.

Mr. Pennat says, "The English at Iudson's Bay depend greatly on geese of this and other kinds for their support, and in farorable years kill three or four thousand, which are salted and barrelled. Their arrival is impatiently expected by the inhabitants, as they are one of the chief articles of their food and also the harbingers of spring; and the month is named by the Indians the Goose-moon. They appear usually at our settlements in numbers about St. George's day, and fly northward to nestle in security. They prefer islands to the continent, as farther from the haunts of men. Thus, Marble Island was found in August to swarm with swans, geese, and ducks,--the old ones moulting, and the young unfledged and incapable of flying. The English send out their servants as well as the Indians to shoot these birds on their passage. It is in rain to pursue them; they therefore form a row of huts made of boughs, at musket-shot distance from each other, and place them in a line across the parts of the vast marshes of the country where the geese are expected to pass. Each stand is occupied by a single person; these, on the approach of the birds, mimic their cackle so well that the geese will answer, wheel, 
and come nearer the hovel. The sportsman keeps motionless and on his knees, with his gun cocked, and never fires till he has seen the eyes of the geese. He fires as they are going from him, then picks up another gun that lies by him and discharges that. The geese killed he sets up on sticks, as if alive, to decoy others; he also makes artificial birds for the same purpose. In a good day (for they fly in very uncertain and unequal numbers) a single Indian will kill two hundred. Notwithstanding every sort of goose has a different call, yet the Indians are admirable in their imitation of every one."

The geese, on their return to the North, pass through the Eastern States in the months of April and May, early or late, according to the state of the weather. When in our waters they feed on the leaves, blades, and berries of different marine plants, and the roots of the sedge which grows so abundantly on the salt marshes. Their flight is heavy and laborious, and in the form of a triangle, the flock being led by an old gander. When wounded, they swim and dive with great facility, going long distances under the water. When taken alive, they are easily domesticated, and will breed readily with the tame goose. It is a very common circumstance to see flocks of these geese entirely domesticated in the neighborhood of the waters which they frequented in their original state of freedom. Although they may have become quite tame, and perhaps have reared a brood or two, they are all apt to exhibit symptoms of uneasiness as the period for migration approaches, and will sometimes fly off with the wild ones that they hear honking overhead. The Canadian goose is domesticated in England and France, and is considered superior to the common gray goose.

Many plang are resorted to by the shooters on our coast to decoy these wary fowl within gunshot, and none more successful than that of imitating their honkings, which most of them can do to perfection.

Domestic geese are also used to decoy the wild ones flying overhead; and they not unfrequently entice them from great heights. in the air to alight among them, supposing them to be some of their own companions feeding in safety below. 
They are also shot at night on the ponds and marshes where they go to feed.

Numbers are shot over decoys from the sand-flats, or points upon which are sunk boxes, in which the shooter conceals himself. When only wounded, they are difficult to capture, as they swim and dive well, and also possess the power of sinking their bodies in the water with the bill only projecting above the surface, and will continue in this position for some time.

Wild geese, when migrating South, sometimes lose their way, more particularly in foggy weather, when they have been known to alight in the immediate vicinity of the farm-houses, apparently much confused and wonder-struck at their peculiar and dangerous position. When feeding, sanding, or sleeping, they always place sentinels on guard, who are regularly relieved at the lapse of an hour or so. These sentinels are ever on the alert, with wideextended necks, and give the alarm to their companions at the slightest intimation of danger.

\section{DESCRIPTION.}

"The length of this species is three feet; extent five feet two inches: the bill is black; irides dark hazel; upper half of the neck black, marked on the chin and lower part of the head with a large patch of white, its distinguishing character; lower part of the neck, before, white; back and wing-coverts brown, each feather tipped with whitish; rump and tail black; tail-coverts and vent white; primaries black, reaching to the extremity of the tail; sides pale ashy-brown; legs and feet blackish ash.

"The male and female are exactly alike in plumage."

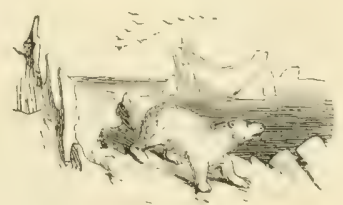


ANAS HYPERBOREA. SNOW-GOOSE.

"Hoarse, heary geese scream up the distant sky

And all the thunders of our boat defy."

This beautiful fowl is known upon our coast as the red goose, and makes its appearance in the rivers of the Eastern States early in November, and as the winter progresses proceeds farther South; it also stops with us on its return to the North early in the spring, or rather late in the winter.

Snow-geese are numerous on the coast of Jersey and in the Delaware Bay. They frequent the marshes and reedy shores to feed upon the roots of various marine plants,-more particularly that called sea-cabbage. Their bills being very strong and well supplied with powerful teeth, they pull up with great facility the roots of sedge and all other plants.

Their flesh, though not fishy, is strong, but, we think, better than that of the domestic fowl.

The same stratagems are used to shoot these fowls as are put into practice to kill the other variety.

\section{DESCRIPTION.}

"The snow-goose is two feet eight inches in length and five feet in extent; the bill is three inches in length, remarkably thick at the base, and rising high in the forehead, but becomes small and compressed at the extremity, where each mandible is furnished with a whitish rounding nail; the color of the bill is a purplish carmine; the edges of the two mandibles separate from each other in a singular manner for their whole length, and this gibbosity is occupied by dented rows, resembling teeth, these and the parts adjoining being of a blackish color; the whole plumage is of a snowy whiteness, with the exception, first, of the forepart of the head all round as far as the eyes, which is of a yellowish-rust color intermixed with white; and, second, the nine exterior quill- 
feathers, which are black, shafted with white, and white at the root; the coverts of these last, and also the bastard wing, are sometimes of a pale ash color; the legs and feet of the same purplish carmine as the bill; iris dark hazel; the tail is rounded, and consists of sixteen feathers; that and the wings when shut nearly of a length."

Wilson remarks that "the bill of this bird is singularly curious: the edges of the upper and lower gibbosities have each twentythree indentations or strong teeth on each side; the inside or concavity of the upper mandible has also seven lateral rows of strong projecting teeth; and the tongue, which is horny at the extremity, is armed on each side with thirteen long and sharp bony teeth, placed like those of a saw, with their points directed backwards; the tongue turned up, and viewed on its lower side, looks very much like a human finger with its nail. This conformation of the mandibles, exposing two rows of strong teeth, has probably given rise to the epithet 'laughing,' bestowed on one of its varieties, though it might with as much propriety have been named the grinning goose."

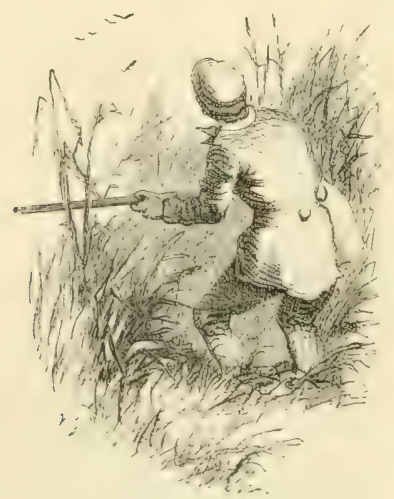




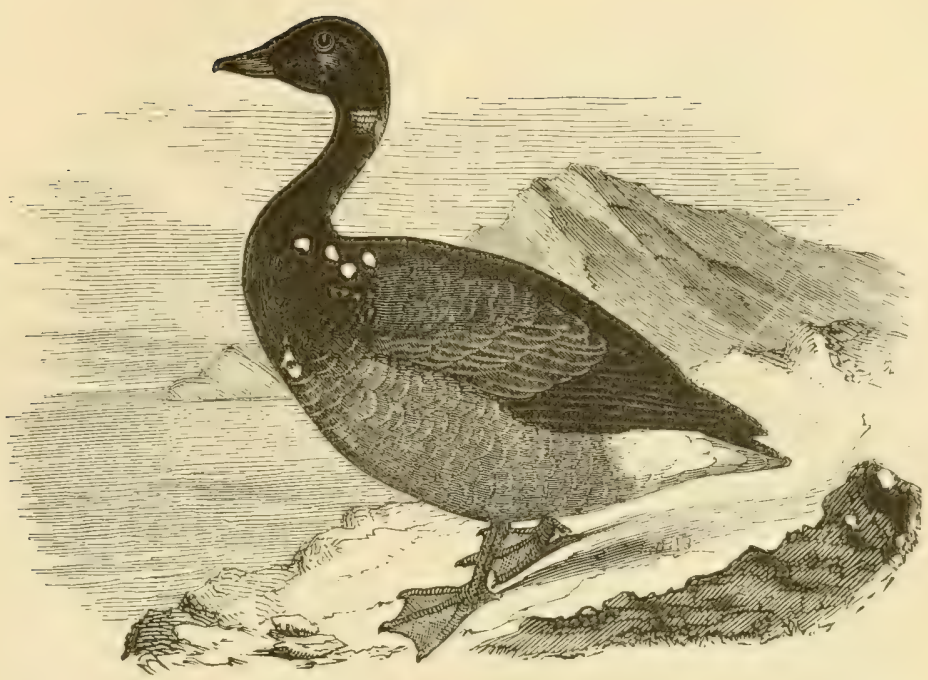

ANAS BERNICLA. BRANT, OR BRENT.

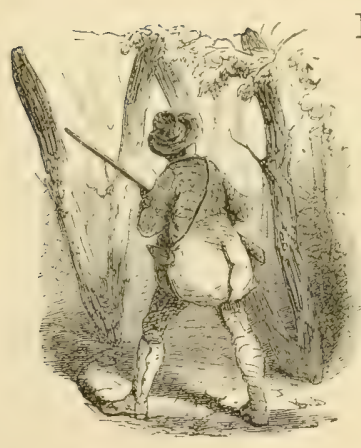

ILSON considers the brant and barnacle goose the same bird. Large flocks of these fowl arrive on the coast of Jersey in the latter part of September or early in October. They remain in these regions till the weather gets very cold, and then move off to the South. They feed on shell-fish and marine vegetables: their flesh is sedgy, and often extremely fishy. Our markets are crowded with brant in autumn and spring, and they sell for a mere trifle. They have a hoarse, honking, disagreeable note, and may be heard at a great distance. They are shy birds, and fly high and in long lines.

Great numbers of brant are killed about Long Island by shooters concealed in batteries somewhat similar to those used on the Chesapeake Bay for the capture of canvas-backs. Those shot late in the spring are much better eating than at any other time. Unsuccessful attempts have been made to domesticate them, but, 
owing to their wild and wandering disposition, but little has been accomplished towards this end.

\section{DESCRIPTION.}

"The brant generally weighs about four pounds avoirdupois, and measures two feet in length and three feet six inches in extent; the bill is about an inch and a half long, and black; the nostril large, placed nearly in its middle; head, neck, and breast black, the neck marked with a spot of white about two inches below the eye; belly pale ash, edged with white; from the thighs backwards, white; back and wing-coverts dusky brownish-black, the plumage lightest at the tips; rump and middle of the tail-coverts black; the rest of the tail-coverts pure white, reaching nearly to the tip of the tail, the whole of which is black, but usually concealed by the white coverts; primaries and secondaries deep black; legs also black; irides dark hazel.

"The only material difference observable between the plumage of the male and female is, that in the latter the white spot on the neck is less, and more mottled with dusky. In young birds it is sometimes wanting, or occurs on the front, cheeks, and chin, and sometimes the upper part of the neck only is black; but in fullplumaged birds of both sexes the markings are very much alike."

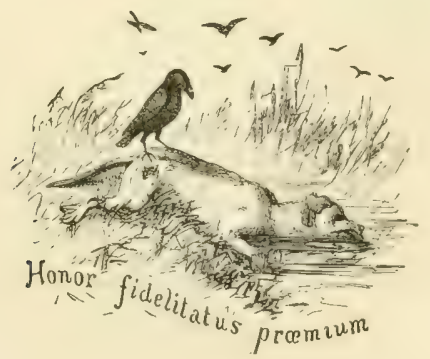




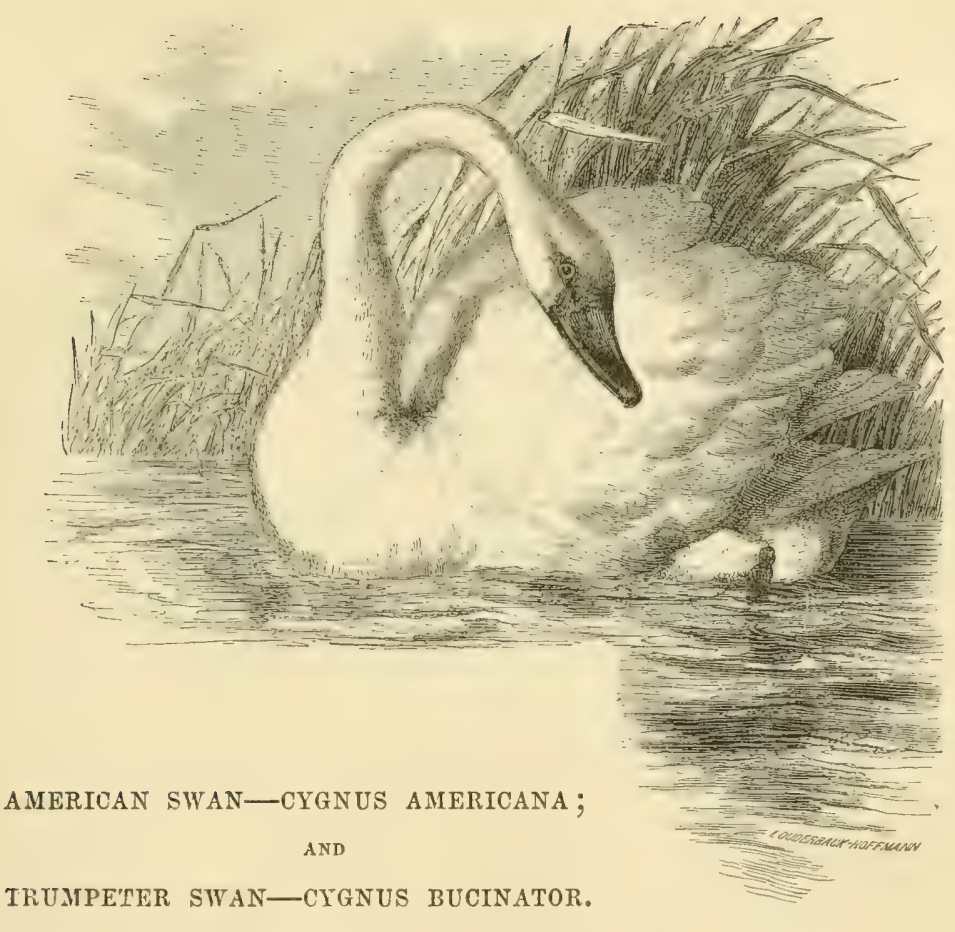

"The stately-sailing swan

Gives out his snowy plumage to the gale; And, arching proud his neck, with oary feet Bears forward fierce, and guards his osier-isle, Protective of his young."

\section{WHERE FOUND, ETC.}

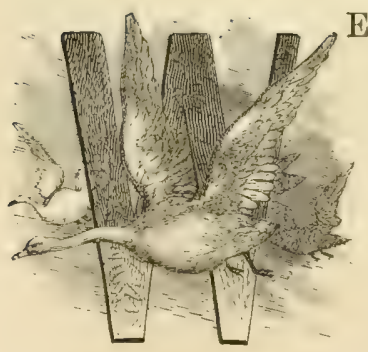

$E$ have two or more varieties of swans which visit the shores of our Atlantic States. At times they are quite numerous in the vicinity of Carrol's Island, more particularly if the weather continues boisterous for several days, when the retire from the mid-bay to seek food on the shallows of the coves or under the protection of the islands a considerable distance from the sea. 
Swans are very shy, fly high, and are not easily brought down unless struck in some vital part. The flesh of the eygnet, or young swan, is considered excellent. We have eaten of it frequently, but cannot say that we have any great predilection in its favor. One thing is certain, however: it is superior to the wild goose, but inferior to the canvas-back.

Swans are frequently-and, we may say, easily-domesticated; but they will not thrive save where they can pass most of their time on the water. In such favorable situations for their mode of life, they will breed and live for years contented and happy. Swans, par excellence, are the most beautiful, most elegant, most graceful, and most spotless of all fowl. Their plumage is perfectly white.

The Cygnus Americana is the species most commonly met with. The other varieties are but seldom shot in these parts. Swans, like the rest of the wild fowl, retire to the Far North in the early spring.

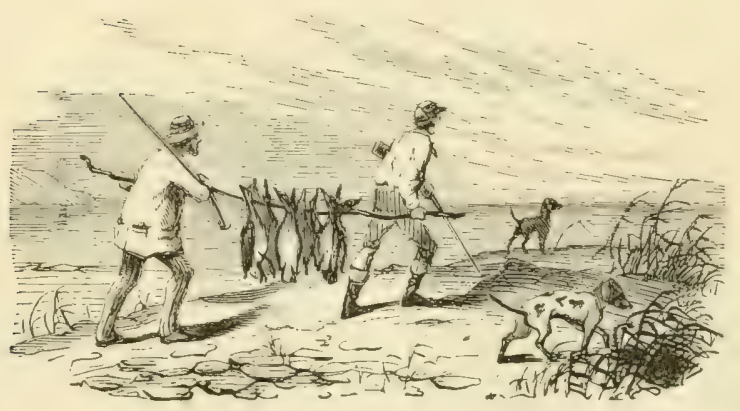




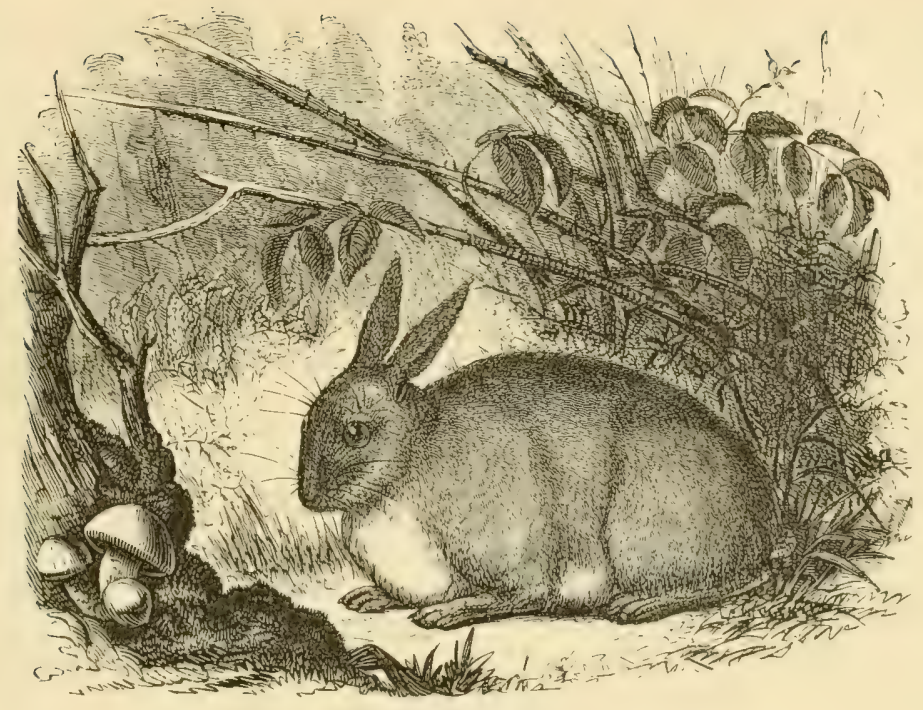

\section{CHAPTER XXV.}

AMERICAN HARE, OR GRAY RABBIT. LEPUS SYLVATICUS.

DESCRIPIION, HABITS, GENERAL CHARACTERISTICS, ETC.

\section{"SUMMER DRESS.}

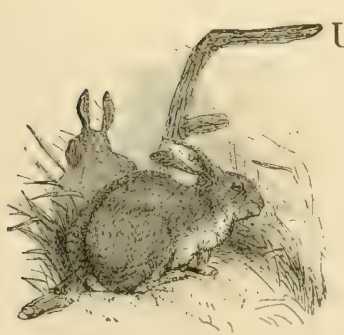

UP on the back yellowish brown; soft fur, from the roots to the surface plumbeous; the long hairs which extend beyond th? fur, and give the general color to the animal, are for three-fourths of their length lead-colored, then yellowish, and are tipped with black; ears dark brown on the outer surface, destitute of the distinct black border seen in the Northern hare, and not tipped with black like those of the Polar and variable hare; whiskers nearly all black; iris light brownish-yellow; a circle of fawn-color around the eye, more conspicuous nearest the forehearl: cheeks grayish; chin, under 
surface of body, and inner surface of legs, light grayish-white; tail, upper surface grayish brown, heneath white; breast light yellowishgray; behind the ears a broad patch of fawn-color; outer surface of fore-legs and thighs yellowish brown.

"WINTER COLOR.

"Very similar to the above; in a few specimens the hairs are whitest at the tips; in others black tips prevail. This hare never becomes white in any part of our country, and so far as our researches have extended we have scarcely found any variety in its color.

\section{"DIMIENSIONS.}

ADULT MALE.

INCHES. LINES.

"Length of head and body..... 150

"6 head........................................... 35

" ears.......................................... 3 (

" tail (vertebræ) ............................. 12

" tail, including fur.......................... $2 \quad 2$

From heel to end of middle claw..................... 3 .

Weight 2 lbs. 7 oz."-Audubos.

\section{IOCALITY.}

The gray rabbit is met with as far north as New Hampshire, and abounds in the Middle, Southern, and Western States.

\section{GENERAL CHARACTERISTICS.}

The timid and interesting little creature now under consideration, we may say, is universally known as the rabbit; this appellation, however, notwithstanding its general use, is a very unjust one, as will be learned from the following remarks on this head.

Those naturalists who hare studied the habits and characteristics of the genus lepus of America do not hesitate for a moment in placing all the varieties yet met with in their proper rank of hare. And, moreover, we shall, without doubt, surprise some of our readers when we tell them that we have no rabbit - that is, true rabbit-indigenous to this country.

The hare and rabbit so closely resemble each other in many 
points that it is not at all astonishing that they should often be confounded one with the other; in fact, nothing but the discriminating eyes of science could have pointed out the dividing-line between these two nearly-allied species.

The principal and most striking difference in the habits of these two species is the circumstance of one living in communities and burrowing in the ground, while the other lives singly or in pairs, and makes its nest upon the open surface; this peculiarity of the American hare is almost sufficient of itself to prove the entire identity of the species with that of the English hare, (Lepus cuniculus.)

We have, however, still stronger grounds than this for placing our rabbit, as it is termed, in the same rank with that of the European hare.

The American hare, as the English, breeds about three times in the course of a year; in the South they may possibly, owing to the effects of climate, liring forth more frequently. Their nest is of the rudest character, and constructed with little or no care for any thing like warmth or comfort; it is generally found upon the open ground, in an old field, perhaps protected somewnat from the weather and easy observation by the overhanging leaves of a shrub or other smail plant.

The rabbit, on the contrary, has several litters in the course of the year, and selects with some degree of care the choicest part of its burrow for the deposit of its young; the nest is made of the softest materials within the reach of the anxious mother, and she even plucks the downy fleece from her own body to furnish a soft and warm bed for the reception of her tender offspring.

The young of the Lepus sylvaticus, at birth, are covered with hair; their eyes wide open and ready for immerliate use: their eare fully developed and eager for action; their bodies supple and thein limbs pliant, even so much so that they possess sufficient strength to run almost at the moment of birth.

The young of the rabbit, on the contrary, are deposited in the dark recesses of the burrow, entirely destitute of any protection in 
the way of fur, their eyes shut up and their ear-flaps even closed; their bodies also are soft and delicate, and their limbs feeble; in fact, the litter is entirely dependent upon the anxious care of its parent for protection and support for a considerable time after birth.

The flesh also of the hare and rabbit is quite dissimilar; the former when boiled is dark, the latter white; there is also a gameflavor about the one that the other does not possess.

The rabbit is a lively, frolicsome little animal, delighting to pop in and out of its burrow at all hours of the day, to bask for a few moments in the sun and collect something to eat, and then away at the slightest token of alarm to the depths of its subterranean abode.

The hare is a timid, lonely creature, sitting motionless for hours, crouched up within its form,-a mere space the size of the animal upon the open ground,-or perhaps snugly stowed away under a pile of brush, stones, or rubbish of any description whatever.

The rabbit, when pursued by dogs, takes to his burrow as the only secure refuge.

The hare, on the contrary, trusts in a great measure to his speed and cunning to insure his safety; and when pursued by dogs the American species resort to the same method of escaping from their enemies as the English variety, - that is, doubling. The construction of the hind-legs is also the same in the one as in the other, being not less than ten inches in length, which is large in proportion to the size of the body; those of the rabbit are much smaller.

The American hare has from three to five young at a litter, sometimes six, and rarely seven. If it were not for the wonderful fecundity of this animal, the whole race would soon become extinct, from the constant and nerer-ceasing depredations of its numerous enemies. Nature, however, wise in all her plans, compensates for the waste on one side by an extraordinary fruitfulness on the other, thus balancing the losses from destruction by that of reproduction, in a ratio which is always sufficient to insure the prolonged existence of the race. 
The hare is peculiarly adapted for speed, not only on account of the general muscularity of its body, but also from the peculiar construction of its hind-limbs, which, being so very long, assist the animal greatly in going up-hill,-in fact, gives it considerable arlrantage over the pursuer, and of which, from cunning, or, more properly, instinct, it avails itself by taking to rising ground as soon as come upon. The hare is always in good ruming condition at that season of the year when it is most likely to be pursued by dogs or other less dangerous foes; this circumstance also we may regard as a peculiar provision of nature, for if the timid little creature were permitted to repose in ease and silence, entirely free from apprehension of danger except at the moment when really attacked, the body would soon become overloaded with fat, which would necessarily prevent it from taking adrantage of that fleetness which, when in condition, insures its safety.

The American hare has considerable speed, and can run for a short time without giving out; the hairy covering of its feet gives it a decided advantage over the dog in a race, during dry or frosty weather. When hotly pursued, hares most frequently take to holes, hollowed trunks of trees, or secrete themselves under brushheaps, old logs, or piles of stone. When first roused, the hare dashes off in good style, and at a speed that soon leaves its pursuers far in the wake; but, unfortunately, for want of sagacity, puss exhausts her strength long before the scent grows cold or the hounds begin to tire, and, if it were not for their taking to holes, piles of $\operatorname{logs}$ or brush, they would soon fall victims to almost any cur that has the bottom and perseverance to follow in their trail.

The construction and position of the eyes in the head are such as to enable the hare to encompass nearly a whole circle in its glance, with scarcely any motion of the head; the eyelids are never completely closed, not even in sleep. The ears also are so contrived as to collect the slightest sound arising in any quarter. With such endowments, it is seldom that a hare is come upon unawares. although he may spring up from beneath our very feet, or from before the nose of our dogs; he was well apprized however, of 
our close proximity, and only trusterl, as he had often done before, that, owing to the striking semblance between his color and that of the ground or surrounding herbage, he would escape unnoticed.

The hare may be termed a nocturnal animal, "as it is commonly at the earliest dawn, while the dew-drops still glitter on the herbage, or when the fresh verdure is concealed beneath a mantle of glistening frost, that the timorous hare rentures forth in quest of food, or courses undisturbed over the plains."

Although sportsmen meet with hares in considerable numbers at all hours of the day, it must be recollected that they are not found feeding, but, on the contrary, are generally roused from their forms, where perhaps they have been crouching for hours in undisturbed repose.

"During moonlight nights, the timorous hare may be seen sporting with its companions in unrestrained gambols, frisking with delighted eagerness around its mate, or busily engaged in cropping its food."

\section{THEIR FOOD.}

The hare is not a very dainty animal as to the choice of her food; every thing produced upon a farm or cultivated in the garden is alike palatable to her, and she not unfrequently makes great havoc with the autumnal turnip and cabbage-crops; she also frequents the cornfields to glean the scattered grains, and risits the orchards in quest of the juicy apple. The partiality on the part of the hare for the last-mentioned fruit is turned to fearful account against them by those who bait their traps and snares with it, for the dainty morsel thus laid in their very path seldom fails to entice an unwary hare within its deceptive clutehes.

Later in the season, when food is scarce and nothing more palatable is at hand, hares often become very destructive to the young nurseries, by gnawing the tender bark from the fruit-trees, which they greedily devour.

Hares are fond of every description of wild fruit and berries; and it is not until after the commencement of the frost, when all 
these various productions are ripe, that they become fit for the table.

In the North, they depend for support during the long winters upon the buds and bark of the pine and fir, upon which they grow fat.

THEIR FLESH.

The flesh of the American hare, when cooked, is dark and of a game-flavor, and, if it were not for their great abundance, would be highly esteemed as a delicacy for the table; but, so long as they can be purchased in our markets at twelve and a half cents apiece, the public will not think a great deal of them.

The hare is not in condition for the table until after several severe fiosts, when the meat will be found clean, delicate, juicy, and tender, provided it is cooked in right style and with the proper condiments. In the summer season, hares are not fit for the table at all; their flesh at this time is tough and stringy, and, moreover, their bodies, more particularly about the head and upper part of the neck, are infested with a species of oestrus, that lays its eggs in the skin, and which, when hatched, grow sometimes to an enormous size before leaving its nest; we have found them buried in the very flesh of the neck, as much as an inch long, and as large as the point of the little finger. Their presence must worry and torment the poor animal much, as we have always found those with these worms in them very lean, and to all appearance weak and sickly. We have shot them as late as Norember with these worms in them, but they generally fall out much earliee than this.

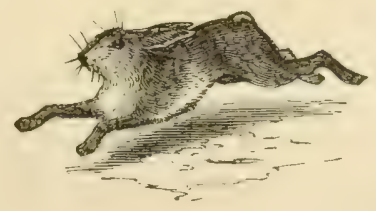




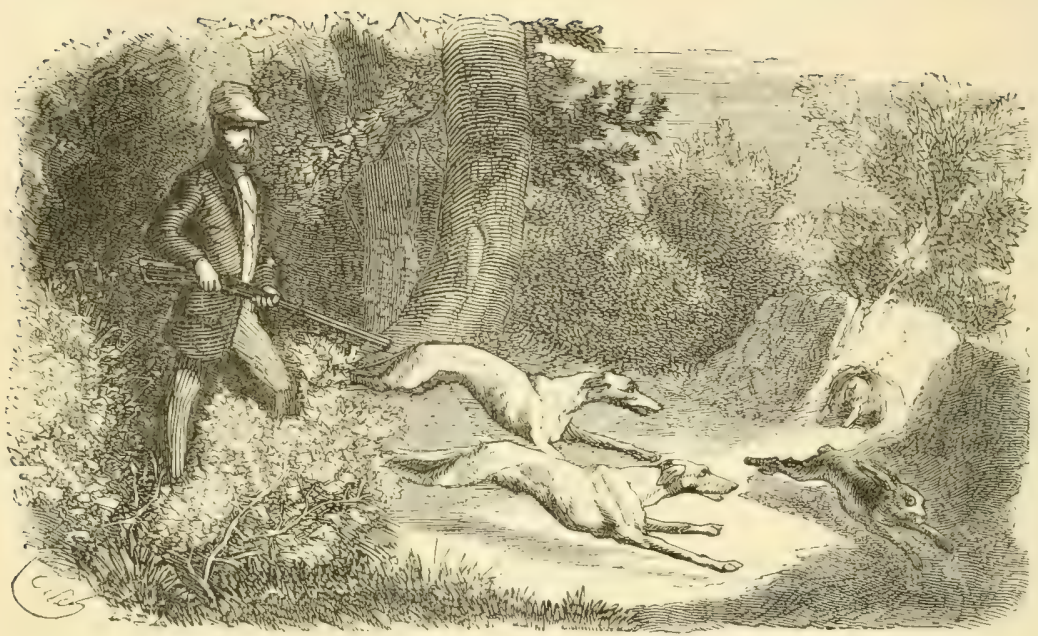

HUNTING HARES.

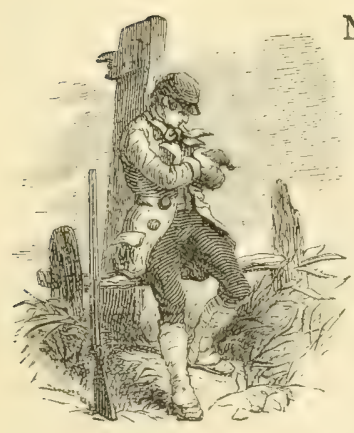

NSTEAD of coursing hares as they do in England and on the Continent, we either take them in snares and traps, or rousing them with a dog, shoot them as they make off. They are easily killed, and it will require but a few pellets of partridgeshot to bring a large one to bag.

They possess a strong scent, and perplex the dogs very much when in pursuit of partridges: the best of dogs can hardly refrain from chasing a hare, after pointing it and seeing it jump up and make off from before his very nose. They lie very close, and it will be necessary oftentimes to kick them up from their form when the dog points them; we have done so repeatedly. ILares affect marshy thickets, or rather the open fields adjoining thickets; as they retire to these situations for refuge as sonn as rouscd, and in fact remain there during the greater portion of the dity. They bound along with considerable speed and gene- 
rally in a straight course, but when hard pressed resort to the artifices of dotabling, - a manouvre practised constantly by the European variety. They will also hide themselves away in the trunk of a hollow tree, which they ascend by pressing the feet and back against opposite sides of the hollow.

The kind of dogs most gencrally employed in the pursuit of hares in this country is a small species of beagle, the production, we believe, of a cross and recross of the fox-hound and beagle. These animals, as well as most other mongrels found on our farms, become very foud of the sport, and acquire considerable sagacity and speed in the chase.

There are few dogs that live in the country but will hunt rabbits, or, more correctly speaking, hares; some of course are fir superior to others, according to their build and the intelligence bequeathed them by their ancestors.

\section{DOMESTICATED.}

American hares have in some few instances been domesticated, but, when confined in enclosures, are ever making efforts to escape; they will, however, breed in warrens.

\section{THEIR CRY.}

"This species, like all the true hares, has no note of recognition; and its voice is never heard, except when wounder, or at the moment of its capture, when it utters a shrill, plaintive cry, like that of a young child in pain; in the Northern hare this cry is louder, shriller, and of longer continuance."

\section{ENEMIES.}

It is not surprising that a timid, defenceless creature like the hare should have numerous sanguinary enemies; and among them none are more destructive than the weasel. This formidable and courageous little animal is constantly on the look-out for hares, and, tracking them, enters the holes, hollow trees, or other places where they are secreted, and dispatches them with the greatest 
ferocity. Skunks, wild cats, foxes, hawks, owls, snakes, de. all prey upon the hare whenever they can succeed in capturing him either by pursuit, stealth, or stratagem.

\section{DIFFERENT VARIETIES.}

There are several varieties of hares distributed over different sections of our extensive country. 'Their habits are generally very analogous to those of the Lepus sylvaticus.

Some varieties, however, are smaller, while others are larger; and those inhabiting the more northern latitudes change their sombre summer pelage during the winter months to a spotless white. Their flesh at the proper season is universally esteemed, and the timid creatures are consequently much persecuted by the inhabitants of the districts wherever they are found.

\section{MEMORANDA.}

1. The American hare is not a rabbit, but a bona fide hare, both in appearance, flesh, and mode of life: no naturalist disputes the point.

2. Different varieties of foreign rabbits have been imported into the country from time to time; but there is no species of rabbits a native of this continent as yet discovered.

3. American hares, like the European, live singly above ground, and never burrow; they also breed far less often than the rabbit, and have fewer at each litter.

4. The English rabbits live in communities, and form extensive excavations in the ground, termed burrows or warrens, where they mostly reside and deposit their young.

5. The young of the Lepus sylvaticus, as the foreign hare, are covered with hair at birth, their eyes open, and their limbs strong enough for immediate action.

6. The young of the true rabbit are quite bare of hair: when first brought forth, their eyes are closed and their limbs tender and weakly.

7. The American hare is a lonely, timid creature; the rabbit, 
on the contrary, is a social, frolicsome, bold or rather pert little animal.

8. The hind-legs of the Lepus sylvaticus are very long, and formed like those of the European hare, and are consequenty quite different from those of the rabbit.

9. The Lepus sylvaticus, when pursued by dogs, trusts in a great measure to her speed for safety, and resorts to the same devices to insure her escape (that is, doubling) as the English variety.

10. The rabbit, on the contrary, takes to her burrow as her only safeguard.

11. The flesh of the hare, when boiled, is dark; that of the rabbit, white

12. The hare is almost entirely a nocturnal animal; the rabhit but little so.

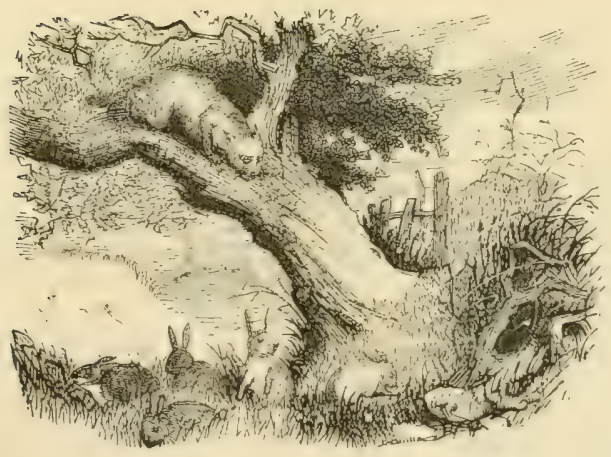




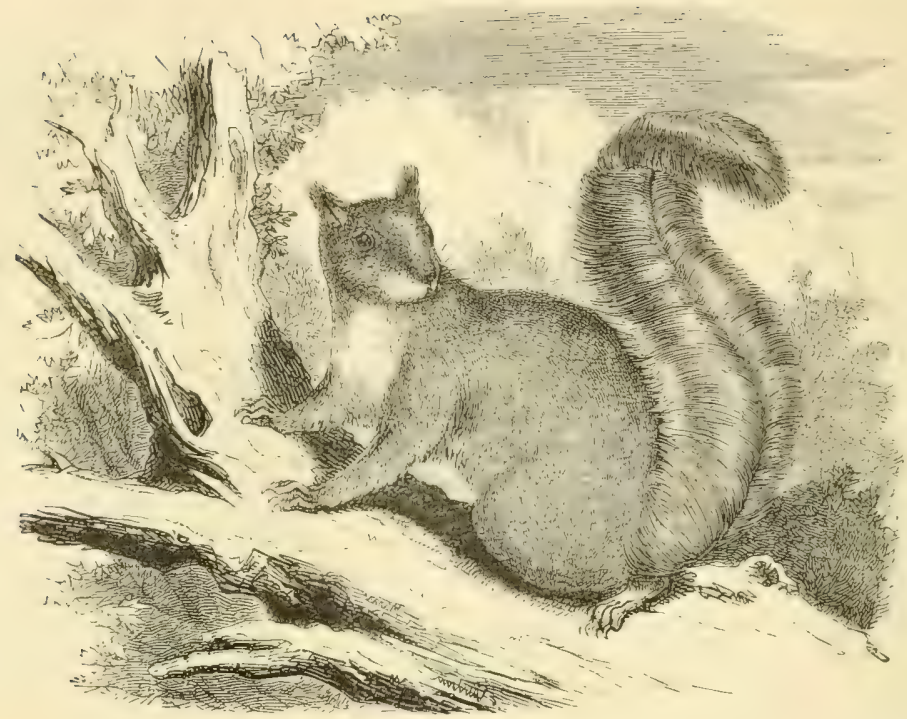

\section{CHAPTER XXVI.}

\section{TIIE SQUIRREL.}

"From bough to bough the scampering squirrels bound, But soon in smoky thunders bite the ground;

Life's gushing streams their sable furs defile."

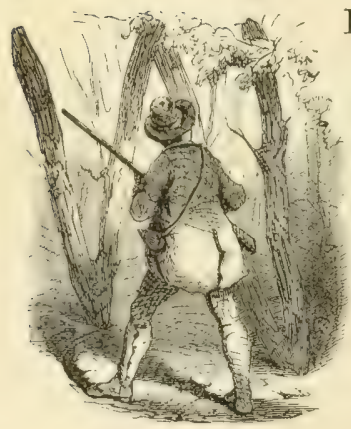

E hardly think it will be expected of us to include the subject of squirrel-shooting in this volume; however, as we know something about the matter, (perhaps nothing new, ) picked up during our early school-days in a great squirrel-country, it may not be amiss in us to devote a few pages to these interesting little creatures, that enliven the solitude of our deep forests with their frolicsome gambols.

Our friend Porter, in his reprint of Hawker,-by-the-by a most excellent work in itself, and made still more so by the valuable 
additions of the editor,-gives a most interesting account of squirrel-shooting.

If all our readers would peruse the articles referred to in the above publication, they would have nothing further to learn on the subject, save a few hints as to the habits of the animal.

\section{VARIETIES OF SQUIRRELS.}

"There are no less than sixty or seventy rarieties of this genus described by naturalists, of which twenty well-determined species exist in North America."

\section{HABITS, LOCALITY, AND GENERAL CHARACTERISTICS.}

The habits of the whole race of squirrels are nearly akin; and their bodies are covered with long, soft, and beautiful fur, ard furnished with a long, wiry, and bushy tail, which latter appendage adds greatly to their graceful appearance, as they are all alike remarkable for their sprightliness, agility, and elegance of firm.

Squirrels are at all times, even in a state of captiviı, of a restless, active disposition. In their native wilds they are ever frolicsome and gay, jumping from tree to trce. They pass their time in joyousness and unrestrained freedom in the midst of the rich abundance of our forests. When moving on the ground, the squirrel seldom runs, but advances by a series of jumps. They are of a sly, mercurial temperament, seldom remaining still for a moment, except when alarmed; then they will stretch themselves out at full length, on the topmost branch of a high tree, on the side opposite to the seat of danger, and thus remain perfectly motionless, as if a part or parcel of the tree itself, until the cause of the alarm has moved off.

They generally build large nests formed of twigs, moss, and leaves, in the notches of the highest forest-trees, or take up their abode in hollow trunks, or burrow in the ground.

The whole race of squirrels is very prolific; and some species increase so rapidly and to such a surprising extent in certain sections of country that they actually become a severe scourge to 
the furmer, who, with the assistance of all his family, is not able to protect his hard-earned crops from the depredations of these lawless little fellows, that swarm in the cornfield at such times by hundreds, and even thousands, consuming all within their reach, and destroying still more by throwing it down on the ground.

When eating, or occupied in listening, they sit erect on their hind-legs, with their long, bushy tail raised beautifully along the back as far as the shoulders, then falling in a graceful curve near the extremity, and hanging towards the ground. Their food is always held in their fore-paws.

The teeth of the whole race are remarkable for their sharpness, power, and durability; they cut with ease, in an incredibly short time, through the hardest hickory-nut, and have the sagacity to tell a withered or rotten nut from a good one by the mere feel or smell; and no sooner do they pick up one of these bad ones than they turn it round in their nimble paws and discard it. This fact we have again and again tested with the common gray squirrel. The gullet of the squirrel is said to be very small, or rather contracted at one point, to prevent the food from being disgorged when descending trees. We do not know if such is the fact, and we have no squirrel at hand at this present time to examine.

The whole race, with one or two exceptions, inhabit the thick woods, living upon the profusion of seeds, acorns, hickory-nuts, chestnuts, and the various other products of our rich and grand forests. Several varieties of squirrels, more especially those at the North, are very provident and thoughtful of the morrow, always collecting and laying up in secret storehouses the surplins food, which they partake of during the winter season, when the nuts are all shaken by the cold blasts from the trees, and perhaps covered up a foot or more in frozen snow. These well-stocked granaries are generally in the neighborhood of their nests, either in the hollow of a tree, in the bottom of an old stump, or in the wide fissure of an orerhanging rock. The quantities of nuts thus stowed away by a single squirrel is sometimes enormous. Tre have seen as much as a bushel of hickory-nuts, chestnuts, acorns, beech- 
nuts, chincapins, \&c. \&c. deposited in one of these spots. The Whole, howerer, may not have been put there by a single inclividual,- the stock, perhaps, having been collected together by several, who made this the general depot for all their contributions, each one laboring for the general good, and all, in turn, entitled to a full share of the booty. Each squirrel, most commonly, has several different storehouses, to which he respectively resorts according to circumstances. The fact of these industrious little animals providing themselves with more granaries than one for the guarding of their treasures is a striking example of that instinct which we so often see displayed in the inferior works of creation; for their storehouses are often discovered by the keen-scented hog, and the whole devoured at a single meal; strange squirrels, of a larger variety, will also sometimes locate themselves near one of these deposits, and not only rob it of all its provender, but even deny the anxious owner the privilege of sharing in the general division; a drift of snow, or some other mishap, will occasionally cover one up for weeks at a time. In either of such emergencies as we have described, the poor squirrel would have but a slim chance to get through the winter if he had not provided himself with other secret stores.

Squirrels are all very cleanly and nice in their habits and general appearance, and are seen frequently in the course of a day rubbing their faces with their paws, as if on purpose to wash them off.

\section{THEIR ACTIVITY AND STRENGTH.}

Squirrels are possessed of great muscular power, and leap with surprising agility and precision from tree to tree; and, when hotly pursued and unable to reach the adjoining tree so as to effect their escape, will not hesitate to drop themselves from tremendous heights to the ground, and then make off with rapid bounds to the next favorable cluster of trees that stands in their path.

Audubon remarks that "the squirrel is admirably adapted to a residence on trees, for which nature has designed it. Its fingers are long, slender, and deeply cleft, and its nails very acute and 
greatly compressed; it is enabled to leap from branch to branch, and from tree to tree, clinging to the smallest twigs, and seldom missing its hold. When this happens to be the case, it has an instinctive habit of grasping in its descent at the first object which may present itself; or, if about to fall to the earth, it spreads out in the manner of the flying squirrel, and thus, by presenting a greatcr resistance to the air, is enabled to reach the ground without injury, and recover itself so instantancously that it often escapes the teeth of the dog that watches its descent and stands ready to seize upon it at the moment of its fall."

\section{CAPTIVITY.}

In captivity the most of squirrels are gay, lively, and mischievous; they are easily tamed, and become very interesting pets; the most docile, however, will bite, at times, if worried; they are very destructive and troublesome if not perpetually confined to their boxes, as when at liberty they try their long and sharp teeth upon every thing within their reach; no article of furniture can escape them.

Squirrels, we have noticed, sleep very soundly, and are not easily aroused from their slumbers. They become attached to their keepers, and some of them will allow no other person to handle them. They are usually ligh-tempered, and are easily irritated.

Great alarm or sensation of pain is expressed by squirrels by a sharp, piercing cry; that of pleasure by a soft, rumbling noise, somewhat like the purring of a cat; when fretted or roused from their slumbers, they give forth a loud and angry growl.

Although, in a state of nature, nuts, seeds, insects, and grain of various kinds form their principal food, they soon learn to partake of almost every thing; several that we have had partook of bread and milk with the greatest relish.

They also become quite fond of sugar and all kinds of sweets, as well as fruits of every description; they are also very partial to locusts, which they tear to pieces and devour with the greatest zest. 
When wild, squirrels are said never to resort to the streams for Tater, but quench their thirst by sipping the dew and rain that collects on the leaves or in the hollows of trees; when domesticated, they drink freely and often: this may be occasioned by the difference in diet, as the sweets they eat in confinement will pro. duce a thirst in any animal.

\section{OTHER CHARACTERISTICS.}

"In the spring the squirrels shed their hair, which is replaced by a thinner and less furry coat; during summer their tails are narrower and less feathery than in autumn, when they either receive an entirely new coat or a very great accession of fur. At this season, also, the outer surfaces of the ears are more thickly and prominently clothed with fur than in the spring and autumn."

Some species of squirrels breed twice in the course of the spring and summer months; they all have several at a litter. In the northern latitudes, where the earth is shrouded for months in a chilling mantle of snow, the various species of squirrels indigenous to these inhospitable climes retire to their secure retreats, either in the ground, or in the fissures of rocks or hollows of trees, where, surrounded by their winter store, they pass the time in a state of sluggish and benumbed existence, not very far removed from the dormancy observable in many other quadrupeds. Some varieties, to a certain extent, live in communities, more especially during the time they pass in their winter quarters. Several species hare cheek-pouches, in which they can stow away an incredible quantity of nuts and seeds.

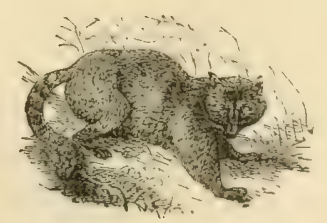




\section{THEIR ENEMIES.}

The whole tribe of squirrels, like the more timid and defenceless hare, have a host of enemies constantly on the look-out to make them their prey.

The fox, weasel, wild cat, and mink, are ever on the prowl, and ready to pounce upon the active little squirrel whenever they can secure him by stratagem or pursuit; the weasel is ever on the alert, and, following his victims into their otherwise secure retreats, attacks them with the most sanguinary spirit, and soon dispatches the anxious parent as well as her tender and unconscious litter, impelled alone to such savage deeds by an unquenchable thirst for blood, for he seldom partakes of but a small portion of that which he so wantonly destroys.

Several varieties of hawks, owls, and even snakes, capture squirrels, and prey upon their young.

\section{SQUIRREL-SHOOTING.}

In sections of country where squirrels are numerous and the pursuit of them is followed as a sport, they are killed entirely with a sinall-bored rifle. Our squirrel-shooters become surprisingly expert in the use of this weapon, and perform some wonderful feats with it during the squirrel season; they always aim for the head, so as not to injure the skin, which is valuable to the furrier if not perforated witl: a ball. It is seldom that they miss a squirrel, even when hiding in the topmost branches of our tallest forest-trees. In portions of country where they are not so numerous, it is necessary to repair to the woods attended with a squirrel-dog,that is, any kind of a terrier or spaniel mongrel which has been taught "to tree a squirrel," or, in other words, to rush about in the woods till he either sees a squirrel run up a tree or gets upon the fresh scent of one that has just taken to a tree. The dog stops at the foot, and, looking wistfully and knowingly up the tree, breaks forth into an incessant and musical bark that resounds through the woods and soon brings the huntsman to his side. The 
next thing is to find the squirrel, which, perhaps, is spread flat out on lis belly, on one of the topmost branches of the trec, the color of his fur assimilating so closely to that of the bark that it is almost impossible to discover him. In a few moments, however, the hawk-eyed shooter catches sight of his victim as he moves for an instant to hide himself more securely from observation; the sharp report of the rifle is immediately heard resounding afar in the distance, and down tumbles the once frolicsome little squirrel, a lifeless thing.

When pursued or watched, squirrels instinctively dodge around the opposite side of the tree occupied by the sportsman, and, by perseveringly pursuing this course, will often baffle the shooter till his patience becomes entirely exhausted; it is, therefore, always better to go in company when squirrel-shooting is the sport, so that either yourself or companion may contrive to get sight of every one that takes to a tree.

\section{BARKING SQUIRRELS.}

This original method of killing squirrels is pursued as a pastime by shooters inhabiting districts of country where these animals are numerous. The whole secret, or rather art, of barking squirrels, is to strike with the bullet immediately under that portion of the limb upon which the animal is stretched out, in such a manner that the blow will shiver the bark, and, killing the squirrel by the concussion, send it whirling in the air to the ground, "as if it had heen blown up by the explosion of a powder-magazine."

This is a very artistic way of killing squirrels, and many of our Pennsylvania hunters are very expert at it. The skin is not injured, nor the flesh torn, by this mode of shooting.

FLESH.

The flesh of several varieties of squirrels is most excellent. They should be voided and kept several days in cold weather. 


\section{SCIURUS MIGRATORIUS. MIGRATORY GRAY SQUIRRELE.}

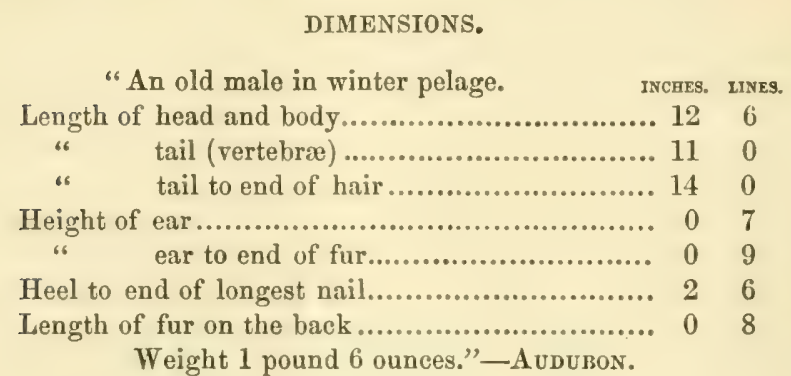

\section{LOCALITY.}

This species is the common gray squirrel of the North; it is found in considerable abundance throughout the wild districts of the Eastern States, and is very numerous in the mountainous regions of Pennsylvania, but does not exist farther south than the northern counties of Virginia.

HABITS.

The gray squirrel has few characteristics different from the whole genus as before described.

They are much sought after as pets by our youth, as they bear confinement with great good-humor, and soon become quite reconciled to a captive's life. Although mild and gentle, they are rather uncertain in their disposition, and will at times bite their keepers very severely. This species was formerly so abundant in the agricultural districts of Pennsylvania that they committed great depredations by invading the grainfields. To such an extent was this havoc carried during the period of the early settlements, that an ancient law existed, offering a reward of six cents for every squirrel destroyed; and Audubon informs us that in the year 1749 the bounty paid out of the treasury, in consequence of this 
enactment, was equivalent to 640,000 squirrels. 'I'h's circumstance alone will prove the amazing numbers of these active little animals. Even at the present time they are quite abundant in the less-cultivated districts of Pennsylvania; and it is no uncommon thing for a shooter to bring home a dozen or so, the result of a day's ramble through the dense forests.

\section{THEIR MIGRATIONS.}

During some seasons, in particular localities, squirrels, more especially the Sciurus migratorius, appear to be seized with an extraordinary desire to ramble or migrate from one section of country to another. Speaking of this peculiarity on the part of this species, Audubon remarks:- "It is stimulated either by scarcity of food, or by some other inexplicable instinct, to leave its native haunts, and seek for adventures or for food in some, to it, unexplored portion of our land."

At such times they collect together in multitudes and move off in immense droves; nothing can stop them in their onwảrd progress, and they never hesitate to swim the widest rivers which intercept their march. Great numbers are necessarily drowned in these bold undertakings, as well as destroyed by their enemies.

The circumstance of squirrels crossing rivers during their migration proves the indomitable energy of character that these active little creatures possess, as they are not at all partial to water in any form, and always keep within-doors during a storm; and, if they should accidentally wet or even soil their feet, they immediately stop to dry them by passing them through their bushy tails several times.

Godman remarks on this subject:- "While travelling through the State of Ohio, in the autumn of 1822, we had an opportunity of witnessing something of this sort. Parts of the country appeared to swarm with squirrels, which were so numerous that, in travelling along the highroad, they might be seen scampering in. every direction; the woods and fields might be truly said, in the country-phrase, to be 'alive with them.' A farmer who had a 
large field of Indian corn near the road informed us that, notwithstanding the continued exertions of himself and his two sons, he feared he should lose the greater part of his crop, in addition to his time and the expense of ammunition used in killing and scaring off the little robbers. This man and his sons frequently took stations in different parts of the field, and killed squirrels until their guns became too dirty longer to be used with safety; yet they always found on returning that the squirrels had mustered as strongly as before."

The following extract, taken from Porter, will also give a good idea of their numbers in Pennsylvania during a season of plenty :"These pleasant little fellows are at some seasons as scarce as specie; at other times they migrate in millions. A few seasons since, they perraded the northern part of Pennsylvania to such an extent, and in such numbers, that they did serious injury to the crops; and they were slaughtered as enemies,-not popped orer humanely after the manner in which we murder those we love. 'The squirrels were followed in due time by stately droves of turkeys; and, later in the season, the rear was brought up by scores of very serious half-famished-looking bears. A war of extermination was declared against the squirrels; and I am sorry to say that many overt acts of violence and bloodshed towards them preceded the formal declaration of hostility. A party of twenty-four, twelve on either side, all expert with the rifle, made a day's hunt, from sunrise to sunset,--the vanquished (that is, whichever side shot the fewer number of squirrels) to pay the forfeit of the best supper the town would afford, for all concerned; and they slaughtered fifteen hundred and sixty-eight! merely carrying the scalps to count with. A few days afterwards, a party of the same number went out, anxious to rival or eclipse the trophies of the first day, after having prepared themselves well, with clean guns, rifles of course, and all munition of war, their sights better regulated and their barrels better browned than those of the party who reaped the first day's victory; and they brought in eighteen hundred and nineteen! making about seventy-five apiece. One 
of the party in the last day's hunt shot one hundred and thirty. six, and that under unfavorable circumstances, being delayed three hours, during the day, in getting a bullet up which he could not ram down."

Further on the writer remarks again:- "We killed thirteen off one hickory-tree; and they were busily coming and going to and from it all the time, perfectly regardless of what was going on. All this immense importation of squirrels were either gray or black, and not one single fox-squirrel (which is common in Eastern Pennsylvania) was to be seen. During the whole afternoon it was nothing but loading and firing, until our rifle-barrels became so hot that we had to lay them down occasionally to cool. The mvriads of squirrels that are to be found on a few acres of farorable feeding-ground during the season of plenty is almost incredible to those who have never witnessed it. All the wholesale slaughter that was made during the season did not sensibly diminish their numbers; for the rear of their countless army poured in and filled up the places of the slain faster than were closed the thinned ranks of Napoleon on the field of Waterloo."

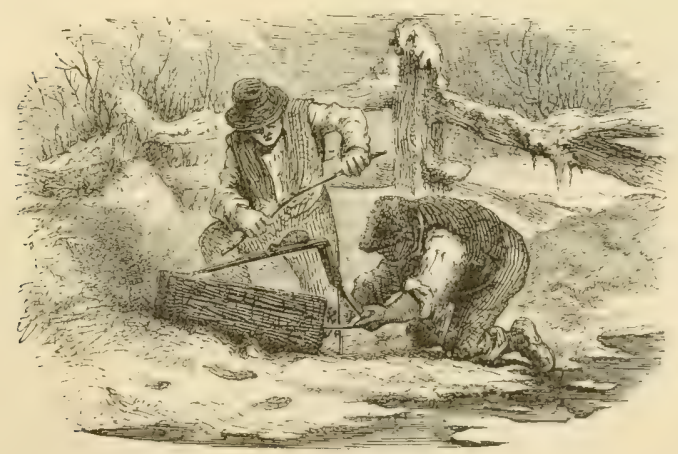




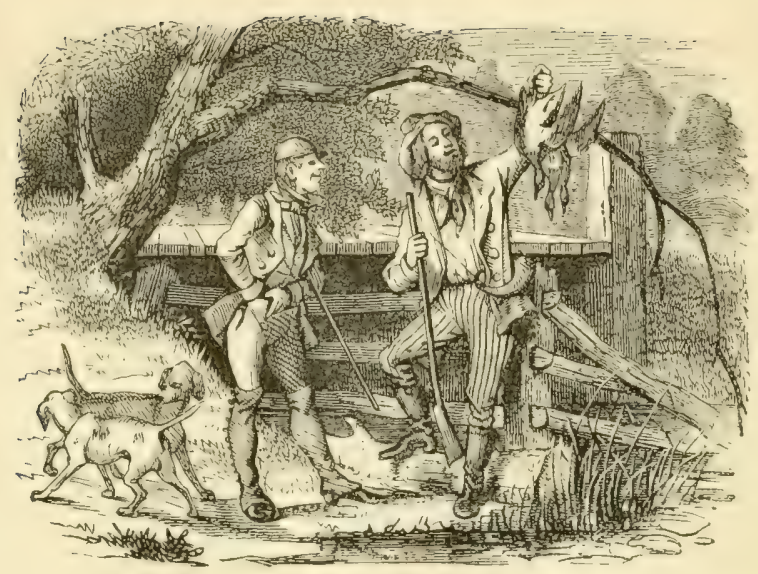

\section{CHAPTER XXVII.}

\section{MISCELLANEOUS HINTS.}

\section{USE OF GLOVES.}

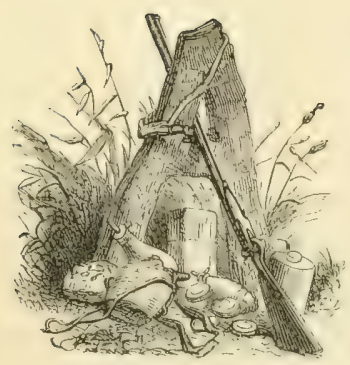

LL sportsmen whose occupation or rrofession makes it desirable that they should have white and smooth hands (and there are but few gentlemen whose employments do not require this) ought, ex necessitate rerum, to wear gloves when shooting, as nothing, to our eyes, looks more outr, if not vulgar, than a coarse, scratched, and scarred hand. Not only from time immemorial with the polished communities of the Old World, but even among the half-civilized inhabitants of other less-favored climes, a small, smooth, and delicate hand was, and is even at the present day, considered a special sign of nobility, or, at all events, regarded as one of the most striking features or tests of gentle breeding, education, and refinement. This feeling, to a certain extent, exists even in our country; and every intelligent sportsman, therefore, will understand our motives for calling his attention 
to what may be considered, by the mass, a very trite and silly matter. Howiever, no one, we imagine, even among this class of fault-finders, independently of the mere looks of the thing, could offer any particular objection to the protecting of his hands from the rude contact of the piercing thorns and poisonous briers that overrun our forests.

Old, half-woin kid gloves, that fit snugly but do not bind the hand, are the kind best adapted to this purpose. If the covering on the dexter-finger should interfere with the delicacy of touch so necessary for pulling the trigger, a portion of it should be removed. It will also be necessary oitentimes to relieve the stricture of the other fingers by making incisions lengthwise into the gloves.

\section{GRASPING THE BARREL.}

Guns are now made so light, and witha? so beautifully balanced, that there no longer remains any necessity, when presenting the piece, of stretching the left hand up the barrel to the extreme point of the stock; but it should rather be grasped close to the guard, so that the hand may be protected as much as possible, in the event of its bursting, from some of those untoward accidents which occasionally occur even in the hands of the most skilful. This mode of holding the gun was adopted some few years back by English sportsmen, on account of the frequency of such accidents, owing entirely to the inferior manufacture of the barrels for smallarms. The bursting of barrels in England, however, at the present time, is a very unusual occurrence, owing to the improvements in the arts, or perhaps more to the enactments of Parliament regulating these things; still, there are a great many worthless instruments imported into this country from abroad, which are constantly falling into the hands of every schoolboy, whose first lesson, therefore, in the use of the gun, should be the proper mode of presenting it, as there is no doubt but the hand is far more secure in this position than in any other. We have leard of several guns bursting during the last year or two, more particularly during the reedbird season, and several of the parties escaped without the slightes: 
injury, owing to this manner of holding the piece. If the hand, however, had been extended along the whole length of the stock, as formerly was the practice, we are satisfied, from actual examination of the shattered weapons, two or three of them would have lost nearly the whole hand, and some of them perhaps have died of tetanus, brought on by the severity of their wounds.

This plan of holding the gun cannot be so easily adopted by duck-shooters, as the length and weight of the barrels preclude the feasibility of rightly balancing the piece with the proper degree of steadiness without extending the hand farther along the barrel than the point of the guard.

This is rather unfortunate, as we know of no kind of shooting in our country that is attended with so many distressing accidents as the pursuit of wild fowl; and the most of these casualties arise from this one circumstance, - the bursting of the barrels, owing to heavy charging. We would therefore caution our friends against the use of a common duck-gun, and would also advise them to be particular in loading, as well as in keeping their person out of the bursting-range of a suspicious weapon in the hands of some one of their more reckless companions, who perhaps prides himself on being knocked over at every discharge of his piece. If the gun is not already too heavy for comfort, it may be rendered more manageable by loading the butt with metal, so as to make it balanse in the hands with more ease.

\section{COCKING THE GUN.}

In most kinds of shooting we are in favor of carrying the gun cocked in preference to half-cocked, for the following reasons:-In partridge-shooting, as before stated, the most of our hunting is done in the thick coverts, and when the birds are scattered about it is impossible to tell where or when they will get up, as the dog is lost to view one-half of his time, and the first intimation we have of his position, although within a few rods of us, is the whirring of a bird from under our very nose, and of which we only catch a glimpse in the distance as it rushes through the thick foliage or 
hanging vines. This opportune moment must be instantly cauglt at by the sportsman, or the game escapes; and we are convinced that no one, no matter how expert or ready he may be, can find sufficient time to cock his gun and fire in this short space of time. In snipe and woodcock-shooting it is also better to carry the gun cocked, as the game is so uncertain in its movements. And on the score of prudence, we would apprehend more danger from a companion cocking his gun on the springing of a bird behind him than if he were to have the piece already prepared to fire, as in the hurry and excitement of the moment he might not pull the cock sufficiently far back to make it catch the tumbler, and the consequence of this omission would be the discharge of the piece on at level with one's head, or perhaps the death of a valuable dog.

The gun, however, as before stated, should always be held in such a position that, no matter when or how exploded, its contents can do no mischief save the killing of a bird; and we would be loath to shoot in company a second time with any one who seemed thoughtless or hardy upon this subject, as life is too precious to be placed in jeopardy on every shooting-excursion.

\section{WADDING.}

Fatent wadding, or rather patent wads, have come so generally into use, and are so well known to all our shooters, that it would seem a waste of time to say any thing on the subject. These wads are made of a species of thick, elastic, porous pasteboard, and are numbered from one to twenty, so as to fit the bore of every description of gun. They are put up in boxes of from one hundred to three hundred, and are very convenient, compact, and serviceable.

Those living at a distance from the city had better always be provided with a "punch" for cutting wads, so that in case of need, or for economy's sake, they can be cut out of an old hat or stiff pasteboard or leather.

If the "punch" be of good metal, a thick, heavy piece of lead with a smooth surface can be used to cut the waddings on, without injury to the instrument; a piece of hard-grained wood, however, 
will answer the same purpose, and perhaps be more easily obtained.

The wadding over the powder should be forced down with considerably more violence than the one placed over the shot, so as to drive the powder into the chambers and nipple-hole and mould it into a compact form. If the wadding over the shot be forced down too hard, there will be a considerable recoil when the piece is discharged; this of itself will soon teach the novice better.

ONE BARREL USED MORE THAN THE OTHER.

The right barrel, in the hands of all sportsmen, is used more frequently than the left, and consequently in old guns is generally found to be far thinner than the left. This habit ought to be avoided as much as possible, and the novice should accustom himself to pull the trigger of the left-hand barrel with the same facility that he does the right. 


\section{SPORTING-KNIFE.}

There is nothing, at times, more useful than a sporting-innife, which comprises all the requisites for probing, examining locks. dividing luncheon, \&c. \&c. The knife should not be too large or complicated, but only contain those instruments which may at some time or another prove useful; for instance, it should not be deficient in a probe, a pivot-picker, a nipple-wrench, a turn-screw, a fleam for bleeding dogs, and one, perhaps, for horses also, as this noble animal is so frequently a necessary accompaniment to a shooting-trip that we should be provided with means to preserve his well-being in case of need; for instance, if he should be attacked with a fit of blind staggers, or any other affection requiring bleeding.

Such knives can be obtained at the gunsmiths' or fancy sporting stores, and should be as plain as possible in its appearance, and valuable for its intrinsic worth. If one-half or two-thirds of the price of the instrument is expended upon the finishing and carving of the handle or other fancy work, we cannot expect to find good metal in the blades.

\section{CARRYING GAME.}

The old-fashioned, cumbersome game-bag is now entirely out of use, and all kinds of game are carried in pockets appropriated to that purpose in the shooting-coat, of which we will speak more particularly under another head.

Before putting birds in the pocket, their feathers should be smoothed down; and, if the sportsman takes pride in the appearance of his game, the blood ought to be wiped from their plumage before it becomes hard and congealed.

\section{AUNNING-CLOTHES.}

Fustian undoubtedly makes the most serviceable coat for fieldshooting in these latitudes, and, although entirely of cotton fabric, 
is quite warm enough for all kinds of sport, even in the coldest weather, provided we are in motion.

A coat made of this material is rather warm and heavy for late snipe-shooting or cock-shooting, as the texture of the cloth is 80 rery close that it will hardly permit of the passage of the insensible perspiration from the body. For this latter kind of work we prefer a brown linen coat.

A fustian coat has an important advantage over all kinds of woollen articles, that it does not offer a harbor for moths during the idle season; and, moreover, having very little or no nap, it neither catches the briers so easily nor gets torn by the twigs or thorns.

We never had but one woollen shooting-coat; and that was fairly torn to pieces in one season, and the remnants eaten up the follow. ing summer by the moths.

The pants and vest should all be made of the same material, and have a sufficient quantity of pockets for all purposes. Our suit contains sixteen pockets, and we find them all more or less useful. The eap had likewise better be made of fustian: it will prove warm, strong, and in a measure water-proof; it should have a large front to protect the eyes, and a back to put down at pleasure, to turn the rain off from the neck and shoulders. A cap made after this style is called by the cap-makers the Napoleon cap.

The cap we use has no lining in it, and we find it quite warm enough without it for most kinds of shooting; if the weather, however, is very cold and boisterous during wild-fowl shooting, we place a quilted lining in the crown, which makes it as comfortable as need be. The fustian coat will not answer for wild-fowl shooting, as it is not sufficiently warm. Nothing but wool will do for this purpose,- to preserve which, in the summer season, from the annoying attacks of the moths, is no small affair; however, we will try to put our readers in a way effectually to defy thr orts of these little torments.

A bag sufficiently large to hold all the woollen shoot .g-clothes 
should be made of strong linen, and, before putting the clothing in it, it should be wrung out of turpentine and hung up to dry. The clothes, after being well beaten and brushed, are put into this bag with pieces of camphor distributed in the pockets. The bag is then sewed up and put away in some dark hole, and not opened until the return of the ducking-season, when all will be found right. Without this precaution, a whole suit will be riddled by these voracious little torments in the course of one summer. Fustian, as before said, being manufactured entirely of cotton, is, of course, not liable to the attacks of moths.

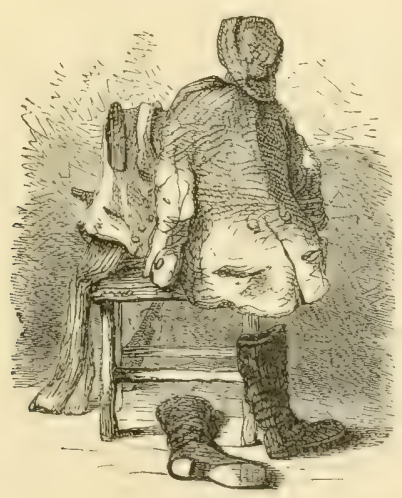

IMPORTANCE OF CLEAN GUNS.

Sportsmen cannot be too particular in cleaning their guns, so as to prevent the accumulation of any thing like rust. It would seem almost absurd for us to advise our readers never to put their arms away without washing them out thoroughly and rubbing them perfectly dry with a good supply of that very essential article vulgarly termed "elbow-grease." Nevertheless, this recommendation is a necessary precaution, as we were informed, a few days since, that one of our oldest and most experienced sporting friends is in the habit of laying his gun by at the conclusion of each shootingseason without even so much as swabbing it out; and, to make the matter still worse, he strongly recommends and insists upon this 
course as the proper plan to prevent the engendering of rust. Whether or not he also advised the standing of the barrels in a damp cellar for a month or so, we did not ascertain, but might be led to infer that he could not certainly object to this addition.

When a barrel is fired, the metal of course becomes heated, and the natural consequence of the application of this heat is a rapid condensation and accumulation of moisture upon the inside of the barrel, - the same as we often see collected upon the window-panes of our houses on a cool November morning. This fact may be clearly ascertained, if any one of my readers doubts the assertion, by merely thrusting the little finger into the muzzle a minute or two after firing, when it will be found that the inside of the gun is covered with a certain degree of dampness which increases the farther we go down the barrel. This moisture, in connection with some of the ingredients used in the manufacture of powder, soon creates a deposition of rust of a most corrosive character, which, if allowed to remain for several weeks, will materially injure the weapon.

When a rust-spot or flaw is once made on the inside of a barrel, it is very difficult to be got at; and even after the most cautious cleaning a small particle of moisture will be found clinging to its uneven surface, which will continue to corrode the barrel at this point, until at last a hole is actually eaten through, provided the gun does not burst before this takes place. A rust-flaw upon a fine sword-blade is a most difficult thing to get rid of, although easily got at, and will often defy the rubbing and polish. ing of the most persevering amateur.

Some shooters are in the habit of putting their guns away loaded and letting them remain in this condition for weeks at a time, and then fearlessly firing them off, little dreaming of the danger they run by this piece of negligence, owing to the accumulation of rust around the powder and along the barrel. That the corrosive action of rust is the frequent cause of those terrible accidents that often occur among ignorant and careless shooters no one will for a moment question; and all have noticed that the 
bursting of guns is far more frequent with those who reside in the neighborhood of the sea-shore than in any other part of the country, owing in a great measure to the fact that the salt moisture of the atmosphere produces rust with so much rapidity that it is almost impossible to keep the barrels clear of it, even with the most persevering industry. Of this, however, we will speak more fully under another head.

We are astonished that any sensible sportsman could for a moment entertain or endeavor to promulgate such a ridiculous notion as putting away a yun dirty to preserve it from rust! In fact, we cannot understand his motive or conjure up one single good reason for so doing; but, on the other hand, we are satisfied that such a course would be attended with the most injurious results.

\section{SHOOTING-BOOTS.}

How frequently have we seen one of our sporting friends victimized during a whole day's shooting by the tortures of a pair of badly-made and ill-constructed boots! and how often have we sympathized with him in his misfortunes, as well as laughed at his negligence in being caught in such an unsportsmanlike predicament.

Nothing adds more to the comfort and good-humor of a sportsman than a perfectly-fitting and well-modelled boot, and nothing is more easily obtained if recourse is had to a smart workman. If walking-boots are not made full, large, and easy, no comfort can be expected from them, as they will be sure either to cramp the feet, pinch the toes, gall the heel, skin the instep, or arrest the free circulation of the blood and fatigue the wearer almost to death. It is of no use, certainly, to enumerate any more of the miseries attending a pair of bad-fitting shooting-boots, as many of our readers no doubt, some time in the course of their lives, have had a practical demonstration of the matter, and perhaps can speak more feelingly on the subject than we can, as we have always been very particular in the choice of these articles, and consequently have seldom been caught in the unfortunate situation above alluded to. There are, however, some other objections attending the own- 
ership of a pair of tight boots, particularly when damp; that is, they are very inconvenient to get on, and, we might say, still worse to pull off. And, moreover, nothing injures the stiffening of the heels so much, and makes them perfectly good-for-nothing, as tugging at them with a bootjack or working into them with the toe of the other foot or over the cross-bar of a chair: the stiff sole leather with which the heel is braced becomes perfectly soft, anc consequently will be sure to run over on the next trial. What is more ludicrous than to see a bad-tempered man, half bent, dancing and prancing over a small bar-room, with one foot in a slipper and the other stuck fast half-way down a tight boot, striving in vain with all the energies of his body to force it on? Such scenes are not uncommon among sportsmen, and often give rise to much merriment on the part of the "knowing ones." That a tight boot is very uncomfortable, no one will deny; and a boot made too large for the foot has likewise its inconveniences, as it will be sure to ride up and down on the heel, and sooner or later will rub the foot into blisters of the most painful character. There is a happy medium betwcen these two evils of loose and tight boots, which every intelligent mechanic knows how to arrive at without any directions from the sportsman; "in a word, the boot should be made to fit the foot, and not the foot to fit the boot," as is too often the case.

Shooting-boots should be made of stout calfskin of the very best quality, with broad soles, square toes, wide, deep, and low heels. If the heels be made too narrow and high, the stiffening will soon give way when softened by the long application of mud and water, in connection with the pressure of the heel of the foot, which will soon be carried entirely over the frame of the sole; and we know of nothing more uncomfortable and fatiguing than to be forsed to walk all day long with a "run-over boot." This accident, bad as it is, can hardly be prevented with any degree of caution in snipe-shooting, as the stiffening of the heel becomes so very soft while wading about in the mud and mire, and the walking is so very uneven, that the heel almost invariably pushes itself by de- 
grees entirely over the frame, and we have abandoned all hope of ever having a decent-looking pair of boots for this kind of shooting. When, however, they have run over, they may be braced up rith pieces of sole-leather, and the heel itself slightly raised on the same side, so as to throw the weight of the foot in the opposite direction; in this way they will stand a great deal of hard work, and, with a little management, can be made to last a long while. We have been so much annoyed with our boots running over while snipe-shooting, that we proposed to our bootmaker to put in a metallic plate of some kind between the layers of leather usually employed for making this portion of the boot firm and unyielding to the pressure of wet and irregular walking; but he made so many objections to our proposition that we were forced to abandon the idea for the present. However, we intend to investigate the subject at some future time.

Some sportsmen recommend the use of low, laced boots for snipe-shooting, as they say it is impossible to keep your feet dry, no matter how careful jou may be, and therefore it is much better not to worry yourself with long and heavy boots, warranted to be water-proof. We have tried both water-proof boots and non-waterproof bootees, and have at times been as much disgusted with one as the other,-giving the preference now to one and now to the other,- - until we have at last nearly come to the conclusion that an old pair of easy walking-boots, with holes in them to let the water run out as fast as it flows in, is about as comfortable a kind of boot for snipe-shooting as one can wear, as the feet will get wet at all hazards, - at least our fect will; for if the boots be made high, even to reach far above the knees, we are sure, some time in the course of the day, to get into a ditch perhaps up to our middle; and as often as we have gone out with the determination of not getting our feet wet, just so often have we returned home with them soaking, and many a pang of rheumatism have we suffered in consequence of our want of care. We do not pretend to say that boots cannot be rendered water-proof, for we know to the contrary, and purpose giving some receipts for making even ordinary leather im- 
pervious to water; but we wish to say that, so far as we are concerned, we have never yet been snipe-shooting without wetting our feet; but, at the same time, must confess that we are not easily deterred from crossing a ditch, and neither are we a very expert hand at walking a rickety fence-rail or a slippery log.

Shooting-boots should never be made too heavy: it is a mistaken idea to have them made of the stoutest leather and with the heaviest soles, weighing perhaps several pounds apiece, independently of the mud which generally adheres to them. A pair of boots of this description, hanging like lumps of lead to one's feet, will tire and wear out any sportsman, no matter how lusty he may be, in just half the time that would have been the case if he had used a pair of strong and light boots.

Some of our sporting friends, however, who are as averse to getting their feet wet as a cat is to moistening her paws, insist upon water-proof boots with leggins of India-rubber cloth attached to the tops of them and made to fasten half-way up the leg. This plan, with some caution in picking out our way over the ditches and mud-holes, will, no doubt, succeed very well; but when we follow snipe we seldom have either the patience or time to hunt up good crossings or sound every quagmire for a firm footing, and therefore take it pretty much rough-and-tumble, just as it comes.

We have tried laced boots, but have discarded them entirely, as we dislike to have our legs exposed by rolling our pants up, and we have an equal aversion to have them dangling muddy and wet around our feet; we have, however, never made use of leggins, recommended in connection with laced boots for this kind of shooting; they, doubtless, would answer a very good purpose.

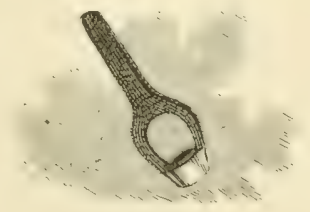




\section{DRESSING FOR SHOOTING-BOOTS.}

There are a great variety of receipts for making mixtures calculated to render boots water-proof; we will give some of them for what they are worth, leaving our friends to make a more thorough trial of their qualities than we have had an inclination to do as yet, for we have never been over-anxious to preserve our feet dry, and, when we did think worth while to make the effort, we have seldom found any preparations much superior to a good greasing with dubbing the night before going out, and stopping up the seams with a mixture of beeswax and grease melted slowly over the fire, or, if these ingredients are not at hand, the free use of a tallow candle at the moment of going out for the day, will generally answer the same purpose.

Porter's edition of Hawker furnishes us with much information on this subject; and we should pass the matter over without any further notice, if we were sure all our readers had provided themselves with this valuable work; in fact, we might with perfect justice to ourselves omit this subject as well as many others without a single comment, as they have already been largely dwelt upon in Hawker: and if a sportsman should read our unpretending volume without providing himself with the other far more valuable work, he does not deserve to be well posted up in sporting-affairs, as Hawker is considered the prince of sportsmen in England, and his editor, Porter, is too well known in this country to need any puffing from uf.

The best kind of grease for dressing boots is shoemakers' dubbing. We have used it for years in preference to all other mixtures: it repels the water, and keeps the leather soft and pliable. The boots should always be moistened before applying it, and it should not be put on too frequently, or the leather may be rendered too porous. Before grease of any kind is applied to boots, they should be rubbed quite clean and the hard mud taken from the seams; otherwise the leather, as well as the thread, will rot much faster and the boots repel the water far less than if they were perfectly clean when the grease is put on. 


\section{RECEIPT.}

Drying oil, (linseed, we presume,) one pint;

Yellow wax, two ounces;

Turpentine, two ounces;

Burgundy pitch, one ounce.

Melt these over a slow fire, and then add a few drachms of essential oil of lavender, or thyme; with this your boots are to be rubbed with $a$ brush, either in the sun or at some distance from the fire. The application must be repeated as often as the boots become dry again, until they are fully saturated.-Hawker.

This mixture is an excellent dressing for boots generally; it will not render them water-proof, but it will cause them to repel the rain extremely well.

An excellent dressing for shooting-boots, or any thing else that is exposed to foul weather, is a solution of gum caoutchouc, or India-rubber, as it is commonly called, in strong spirits of turpentine or ether. It is made as follows:-A piece of caoutchouc, the size of a walnut, is cut into small pieces and put into a widemouthed phial, with four ounces of turpentine or ether, and allowed to remain two or three weeks, according to the strength of the solvent, when it will become of the consistence of a thick varnish, and may be applied with a brush to every part of the boot, inside as well as outside. If ether is employed to dissolve it, it will require but a very short time to make this preparation. The phial should be tightly corked; otherwise the ether will lose all its strength, or, in other words, evaporate. This preparation, or one analogous to it, is the article sold for several years past as an application to old harness and wagon-covers, to make them flexible and water-proof.

Our friend Mr. Chandler sent us a quantity of water-proof dressing for boots, which we used on several occasions, and found to answer a most excellent purpose, so much so that we requested nim to furnish us with a receipt for making it, which he very kindly did, as will be seen from the following note:- 
"Dear Doctor:-I have had such an excellent opportunity for testing the good qualities of my water-proof preparation during a late shooting-excursion, that I can recommend it still more highly than before.

"The composition is as follows:-One-quarter of a pound of gum elastic, (caoutchouc,) with sufficient naphtha, oil of sassafras, seneka, or any other solvent, to completely liquefy it; after this is effected, a pound of tallow and three-quarters of a pound of beeswax should be melted together, and in connection with the dissolved gum should be kept over a slow fire until they are intimately commingled. When using the preparation, the boots should be slightly wet and warmed: if the mixture is then properly rubbed in, it is almost impossible for the water to penetrate. In addition to this, I generally have the soles of my boots soaked in copal varnish.

"This preparation, when used for common walking-boots or shoes, does not prevent a proper gloss being produced by blacking. I shall be glad if this is of any service to you, and am confident that it needs but a single trial to convince of its great efficacy.

"Very truly, yours,

M. T. W. Chandler."

Another:-

"For new boots, half a pound of beeswax, one-quarter pound of resin, and the like quantity of mutton-suet or tallow; boil them together, and anoint the boots well with the preparation lukewarm. If the boots have been used, beef-suet to be substituted instead of mutton."

Mr. Chandler informs me that he has his shooting-boots made straights, - that is, not right and left,-and finds that they wear longer, and are far less liable to run over, as they can be changed from one foot to the other as soon as they show a disposition to run either to the right or left. The idea is an excellent one; and we are somewhat surprised that it never occurred to us, more especially as we have had so much trouble with our boots in this very particular. 
Another:-

"A pint of boiled neatsfoot-oil;

Half a pound of mutton-suet;

Six ounces of beeswax;

Four ounces of resin.

"These ingredients are to be melted together over a slow fire and then freely applied to every portion of the boots, after warm. ing at the fire; this dressing is especially adapted to new leather."

Another:-

"A pint of boiled linseed oil;

Beeswax, one ounce;

Burgundy pitch, half an ounce;

Spirit of turpentine, two ounces.

"Melt the first three ingredients in an earthen pot, then add the turpentine; to be rubbed in when the leather is tolerably dry, before the fire."

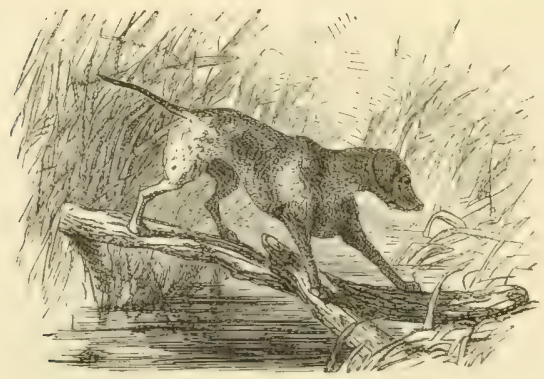




\section{SHOOTING-STOCKINGS.}

Woollen stockings are preferable for walking to any other kind. 'They should be regular made, - that is, woven without any seam; for, if they be joined together at their heels or toes with a needle, the irregularities of the seam are very apt to rub the parts and produce considerable uneasiness, and often blisters. Do not suppose that any common-made stockings, such as can be bought for a few pennies the pair, will answer every purpose and may then be thrown away at the termination of the trip. The plan, in the first place, is not an economical one, neither is it a convenient one; for with the addition of a few more pennies an excellent article, that would last a whole season, might be obtained, and, by always having them on hand, we would not, as is often the case when the stockings are thrown away, find our sporting-wardrobe partially, if not entirely, deficient of these essentials just on the point of starting. These low-priced common stockings are never regular macle, but are sewed together at the seams; they are also badly shaped, particularly at the heels, and generally uncomfortable to walk in, as well as very rotten, and in every respect unserviceable to a sportsman.

We are now using stockings sent to us by a friend from England, and said to be unversally used there for ordinary shooting: the soles, toes, and heels, are made of fine wool, the other parts of the stocking being formed of soft and stout cotton.

We have given several pairs of these stockings very hard service, and find them to answer admirably; in mild weather they certainly are preferable to stockings made wholly of wool, as they heat the feet less, absorb far less water, and get dry much sooner.

If our shooting-boots be too large, the difficulty will often be removed by wearing two pairs of stockings.

\section{CLEANING GUNS.}

The process of cleaning a gun, although simple in itself, is not, however, thoroughly understood, much less practised, by many of 
our sporting friends, as we have too often observed when on shoot ing-excursions. Not a few of them spend half an hour or more over their guns, rubbing and squirting dirty water about, when the whole might be completed in a few minutes if a certain system was adopted. Our method for this important duty towards our fowling-piece is as follows:-

The barrels are first to be removed from the stock; the learling to be loosened by the brisk friction of the wire-brush before spoken of.

Cold water is now to be poured into the barrels, and the rod, with the patent wiper attached to it, is to be used briskly for a few minutes in thoroughly rubbing the barrels.

This done to our satisfaction, rinse the barrels several times with cold water; then pour into them boiling hot water, being provided with a heavy eloth of some kind to grasp the barrel with, otherwise the hands may be blistered, as the metal soon becomes extremely hot from the applieation of the water ; make lively use of the rod for a few moments, then rinse out with boiling water, wipe the barrels off as dry as possible, and place the muzzle downwards before the fire to dry. A little olive-oil or other fresh grease may afterwards be used on the barrels to preserve their polish and keep from rusting. All this may be aocomplished in a very few minutes, certainly not exceeding fifteen. If hot water be used first, in place of cold, the powder adhering to the barrels will become soft and form itself into a kind of eake, which will be far more difficult to remove; therefore we particularly recommend the employment of the cold first and the hot afterwards.

If the gun is to be put away, not to be used for some time, a little more caution will be necessary in wiping the barrels perfectly dry, to prevent rust as well as preserve their polish.

This will require considerable friction with a piece of flannel or other woollen cloth.

\section{LEADING OF BARRELS.}

The Jeading of a gun is occasioned by the melting of the shot and the adhering of particles of the fused metal to the inside of the barrels. Perfect or smooth barrels are far less liable to lead 
than those which are rough and uneven in their surface. If a gun leads quickly and a great deal, it is certain evidence that it is imperfect in its bore, and will give the sportsman much trouble in rapid shooting, owing to the difficulty of loading his piece.

The wire brush we have before spoken of is an excellent instrument with which to free the barrels of the leading, and is the only one that will do it effectually; even washing will not relieve the barrels when they are very rough, as common guns generally are.

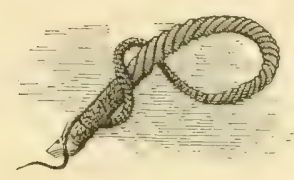

\section{TO PREVENT RUSTING.}

A great many different modes have been resorted to to preserve gun-barrels free from rust when laid aside for a season, more particularly by gunners living near the sea-shore, where the atmosphere at all times is strongly tainted with the oxidizing components. In our climate, under ordinary circumstances, remote from the seashore, there is little danger of rust collecting on the barrels in sufficient quantities to be of any particular injury to the metal, if proper care be taken to clean and oil them before putting away. The barrels should be rubbed perfectly dry inside and outside, and, as has been recommended by Blain, a piece of iron a little smaller in diameter than the bore of the piece may be heated to a fraction short of red-heat, and by means of a string let down into the barrels and moved up and down two or three times, so as effectually to dispel every particle of moisture that may be lingering in the interior of the gun.

This being accomplished to our satisfaction, the fowling-piece may be oiled very slightly, inside and outside, and the muzzles stopped up with a woollen cloth. Neatsfoot-oil is esteemed the best kind for this purpose. There should not, of course, be a particle of salt in the grease which is used to protect metal of any descrip- 
tion from rust, for reasons before stated. The nipples should be covered with a particle of shoemaker's' wax, or caoutchouc. This done, the gun is now to be laid away in a dry place; otherwise all our preventive treatment will prove abortive. It will be prudent to examine our guns from time to time when not in constant use, and rub them off occasionally with a linen cloth and a little oil.

If, however, the reader should reside near the sea-shore, it will be necessary to use some further precautions to protect his fowlingpiece during the idle season; and we know of no better plan than melting pure mutton-suet and filling the barrels with it, and also giving the outside a coating of the same, which may be easily done by pouring or smearing it over the gun when in a semi-liquid state; this plan, to-be-sure, is not a very nice one, but nevertheless it is a very effectual one.

Another plan, and perhaps a more acceptable method to many, is to give the barrels a light coating of simple varnish, which will protect them equally well from the action of the air.

If, however, the operation of filling the barrels with mutton-suet be not convenient or agreeable, they may be oiled, and filled with a rod covered over with a woollen cloth of some kind and made so as to exactly fill the calibre of the gun and by this means exclude every particle of air from them. The breeches should be removed for examination, and oiled before being put away.

Neatsfoot-oil is the only kind of oil admissible for these purposes. This unguent, however, is hardly pure or thin enough to be put on the machinery of the lock. We have been using latterly, as a general lubricating oil, a very beautiful French preparation by Adolphe Millochau. It is put up in small bottles of an ounce or less, and labelled "huile pour les armuriers," and can be purchased at most of the sporting stores on Broadway for a mere trifle. Mercurial ointment is highly recommended by Hawker for duck-guns, as also the following compound, taken from Daniels' Rural Sports. We have tried both, and found them equally efficacious in preventing rust. 


\section{RECEIPT.}

Three ounces of blacklead, half a pound of hogs' lard, onequarter of an ounce of camphor, boiled upon a slow fire; the gunbarrels to be rubbed with this, and, after three days, wiped off with a linen cloth. Twice in a winter will keep off the rust, which the salt water is otherwise sure to be continually bringing out from the iron.

In spite, however, of all these precautions, but more frequently 1)wing to the negligence of the sportsman, rust will sometimes accumulate on the surface as well as the interior of the barrels, which not only renders them unsightly, but is really very detrimental to the metal; therefore we are constrained to give in this place some instructions for the removal of this troublesome deposit and the restoration of the barrels to their original beauty.

THE SHAPE OF THE GUN-STOCK.

Until within a few years the gun-stock was made rather short, with a considerable bend or curvature in it; now we have gone to the other extreme, and every one is striving for a long and straight stock. This general desire for long stocks is not altogether judicious or reasonable, for what suits one sportsman in this respect will not necessarily suit all; but, on the other hand, each one should be guided by the "peculiar build of his own person" when ordering a gun stocked.

To exemplify what we mean, we may here state that the gunsmiths of England have arrived at such perfection in their profession that they actually measure their customers with as much precision as a flash tailor does a dandy, for the purpose of ascertaining the style of stock best suited to their handling: the length of the arms, neck, height, and general carriage of the body, are all noted, and the stock is made in accordance with the measurement. A clever gunsmith, who understands his business thoroughly, will also observe his customer's mode of raising and presenting the gun, his manner of holding his head while taking aim, and many 
other little indescribable etceteras which are always overlooked by a common workman, but which are sources of much information to a shrewd mechanic.

All sportsmen know the advantage of using a gun that "comes up to the shoulder right;" they also know the inconvenience as well as difficulty of shooting with a weapon the stock of which is formed differently from that which they have been accustomed to use.

It is natural to conclude that a tall, long-limbed man will require a longer stock than a shorter person; also that a straight stock will answer better for a short-necked, high-shouldered man than for a long-necked, low-shouldered person.

A stock rather long is decidedly better than one too short, and we would prefer a stock rather crooked to one too straight.

A straight stock is much more suitable than a bent one for a short-necked, high-shouldered person, for the simple reason that, in fast shooting, the point of sight at the end of the gun would come up to the range of the eye before the butt could be placed full against the shoulder, and the consequence would be that the piece, not being held firmly against the body, would recoil unpleasantly at every discharge.

Moreover, the gun not being held on a perfect level, but the point of the muzzle actually higher than the stock, the consequence will be that the load will be likely to be carried over the object. All this can be fully ascertained by a few trials; and, moreover, that with an over-straight stock it will be difficult to bring the head down to its proper level, even in deliberate shooting.

The fashion of having the stocks made straight and rather short is very much in opposition to the most determined efforts at good shooting on the part of sportsmen generally, and we beg to warn our friends against this error; they may rely upon our experience in this particular, as we have given the subject much attention, and are thoroughly convinced that reasonably high-mounted guns are far preferable to the "low-mounted."

By the term high-mounted we mean those guns which have long 
and considerably-bent stocks; by low-mounted we designate those pieces that have short and straight stocks.

Every sportsman, before deciding definitely upon the purchase of a gun, should, if possible, give the weapon a fair trial, which can be done very easily by firing at a mark, - not only to ascertain the force with which the barrels shoot, but more particularly to satisfy himself as to the mounting, as above explained.

If, for example, the shooter looks steadily at some object placed at a convenient distance from him, and throws the weapon up tc the proper range of his eye and fires at the very moment when he catches the sight, he will most undoubtedly strike the target, provided the gun is mounted to suit him. If such, however, should not be the case, the shot will be thrown most probably either above. or below the mark. If the former should be the case, he will know at nnce that the stock is too straight and too short, or, as we have before observed, the gun is too low-mounted for his handling. If; on the other hand, the shot should fall below the target, the stock may be too crooked, or, artistically speaking, the piece is too highmounted.

A long stock, as above remarked, is generally preferable to a short stock in the hands of most sportsmen, for sundry reasons, one of which we have not yet named, which is, that those having long stocks throw their fire with more power, from the circumstance that the butt is always pressed more closely against the shoulder of the shooter. Moreover, there is less recoil to be apprehended from a long stock than a short one, more particularly if the stock should be rather crooked as well as long. Many sportsmen ignorantly attribute their indifferent shooting to the barrels, when they should look alone to the stocking and mounting of the piece; as we are satisfied from long observation that "good shooting," in most cases, depends far more upon these contingencies than it does upon the shooting-properties of the barrels themselves.

The old habit of shaving off, or rather scooping out, the butt on one side, to allow the face to come immediately behind the line of the barrel, is perfectly unnecessary, -in fact, is opposed to good 
shooting, as we cannot but think that this shaping of the stock will cause the sportsman at times to shoot very irregular.

\section{GUN-LOCKS.}

Without a good lock, barrels of the finest workmanship will be of little avail, and the one is quite as difficult to be obtained as the other.

Gun-locks should be manufactured from the hardest metal, and all their parts filed and fitted in the most beautiful manner, with springs of the best construction and suitable strength; every portion of the machinery should work in perfect unison, and, when set in motion, should glide over each other with the same smoothness and evenness observable in the most elaborate pieces of mechanism.

Greener remarks on the subject in the following words, and we are sure that every sportsman will heartily respond to such sentiments:-

"I have always felt as great pleasure in handling a gun with a pair of good locks as some would experience in listening to the musical productions of the great Handel. There is to me a superior music in the tick of the scear on the tumbler, and the fine elasticity of the mainsprings, moving with a sort of fine, oily feel, though light, as sharp as the lightning playing in the heavens."

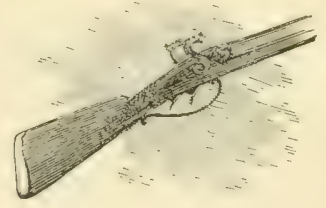

Good locks can only be obtained from the best artisans, and, to insure their quality, should be made to order by those only in whom we have the utmost confidence. There is no part of the gun that requires so much care and skill as the manufacturing of the lock, and consequently there is no part in which there is so much deception practised. It is impossible to judge of the quality of a lock by a mere examination of its structure, as the spring, swivel, or some nther portion of it, may soon grow weak, or give way 
entirely after a few days' shooting, if the metal used in its fabrication is not of the very best kind, and put together with the skill so well understood by an experienced and honest gunsmith. The attachment of the swivel and arrangement of the hole for the scear-pin are the two most important points in the construction of a lock, as the one controls the movements of the mainspring, while the other imparts the proper play of the scear on the tumbler, and produces that agreeable click which every sportsman delights to catch upon his ear when handling a good gun.

Locks can be purchased in England from a shilling to four pounds a pair. Great numbers of inferior locks are imported by our hardware-men.

GUNPOWDER-ORIGIN, ETC.

The discovery of this powerful compound, although generally attributed to a German named Schwarz, a student well skilled in alchemy, is nevertheless conceled by most inquirers into the subject to have been well known to some of the more enlightener nations of the ancients, and more particularly, at a very early period, to the ingenious inhabitants of the Celestial Empire, as we have stated in another place.

Some investigators of the subject assert that it was in use by the Chinese about or a short time after the commericement of the Christian era; and this curious people themselves even claim its invention and general use for ages prior to this period. Whether this be so or not, we believe that it is granted by all hands that Berthold Schwarz's discovery of the compound was perfectly original in himself, and that therefore he should not be shorn of the immortal celebrity that is and will ever be attached to his name. The ingredients used in the manufacture of gunpowder are pretty generally the same all over the world, each maker having, of course, his own ideas regarding the proportions of the three articles -nitre, charcoal, and sulphur-to be employed.

The best English, Scotch, or French sporting-powders are not so strong as the American. The average proportion of the ingredients 
composing the English powder, put up in small tin canisters or wrapped in cartridge-paper for the use of sportsmen, is as follows:nitre seventy-five parts, charcoal fifteen, sulphur ten.

Dupont's powder is more generally used by sportsmen throughout our country than any other; it is more powerful than the English powder, being compounded of-nitre seventy-seven parts. charcoal thirteen, sulphur ten.

This powder is put up in small tin canisters of a pound each, and in this way is entirely protected from the moisture that is so hurtful to it. Of its quality we need say nothing, as its long celebrity is a sufficient guarantee of its worth.

When packed as above, expressly for the use of sportsmen, Dupont's powder costs nearly double as much as it does when purchased in small six-pound kegs; but the universal satisfaction it affords, and the convenience and safety of carriage, give it a decided preference in the eyes of most sportsmen, notwithstanding the additional price asked for it.

\section{VARIETIES OF GUNPOWDER.}

The principal and most appreciable difference in the manufacture of gunpowder is its division into coarse and fine-grained, glazed and unglazed.

The first variety-the coarse-grained powder-is used principally for all species of large fire-arms, ant undoubtedly is the most powerful of the two kinds; at all events, we have arrived at this conclusion from experiments tried while duck-shooting, and we are supported in our observations by many respectable authorities; that is, we wish to be understood that an ounce of coarse-graned powder is more powerful than an ounce of fine-grained powder, both of the same manufacture and of equal proportions. The superior strength or projectile force of the coarse-grained has been accounted for on principles which, to our mind, are both reasonable and convincing, and may be explained by the perusal of the following extract taken from Greener's work on this subject:-"I have always thought and am quite convinced that powder is made 
too small in the grain. For what purpose it is made so, except to please the gunmakers, I never could imagine. I hare no hesitation in asserting that, if you obtain powder of fine grain and powder composed of the same quality of ingredients coarser grained, the latter will be found to be stronger than the former. This I have tried in various ways, both by the rifle and the musket, and the same quantity of the coarser invariably gives the longer range. Ii is owing, in my opinion, to each grain containing within itself greater force. When one is ignited, its effect is greater than that of several small ones. Four times the quantity of small-grained has to be ignited to generate the same force as is required of the larger-grained. Again, the small grain is generally coated with a sort of varnish, which must be injurious to its quickness. Another advantage the larger grain possesses is, that from its size it is less liable to be completely compressed into a solid state, and from the largeness of the interstices around them more atmospheric air is contained in a body, which must greatly benefit it in igniting; as without question (though it is possible to fire powder in vacuo) it will burn better with the assistance of atmospheric air."

The duck-shooters of our country, without exception, use the coarse-grained powder, not only because they know it to be stronger, but because it attracts, or rather absorbs, a much less quantity of atmospheric moisture than the fine. We recollect on one occasion, when shooting canvas-backs from one of the points at the Spesutia Narrows, by some unfortunate mishap both barrels of our gun became suddenly disabled, one from the flying off of the pivot, and the other from some trifling derangement in the machinery of the lock. The morning was a very fine one for the flight of ducks, and they were passing over our hearls ever and anon, in countless numbers and at a fair shooting-distance. Unhappily for us, however, we were forced, nolens volens, to be a silent spectator, and not, as was our wont, an active participator in the scenes around us. One of our sporting companions, a thorough hlood in this line, and we might term him a "duck-shooter by profession" as well as a "duck-shooter by education," as he had done little else 
but destroy ducks ever since he was big enough to shoulder his father's old musket and take sight over a "blind,"-having painfully injured the thumb of his right hand, we, having nothing better to do, volunteered to load his gun for him, on condition of a fair proportion of the spoils. Having our patent powder-flask with us, and being accustomed to its use as well as satisfied with its safety, we very naturally commenced loading from its contents, and continued so to do for a considerable time, while our friend was banging away at every moment, but, strange to say, bringing down scarcely a single victim, although those around us were heaping up piles about them; and so did our partner till we commenced load: ing for him. The old veteran could not account for his bad shooting, and attributed every miss to some new cause, first one thing and then another, cursed the gun, damned the ducks, and finally gave up in respair. We of course were equally as much surprised at his want of success, and even took the gun from his hands and essayed a few shots, but without much effect. The morning had now fully broken, and, upon closer inquiry into the cause of this barl shooting, our partner ascertained, to his no small horror, that we had been loading all the time with fine-grained canister-powder, instead of the coarse-grained article which all duckers prefer; in fact, they object to using any other kind.

The indignation of our friend was great when he made this discovery; and his vanity of shooting well, which had been on the wane for the previous half-hour, was now fully appeased, as he declared that "such stuff," meaning the fine powder, was not fit to make a squib of, let alone bring down a savory canvasback.

This powder, however, we had been using the day before on partritges, and had succeeded in killing five brace with it without much difficulty. This anecdote certainly goes to demonstrate how strong the prejudice is among duck-shooters in favor of the coarse powder, and at the same time proves conclusively that, though it would kill partridges at a reasonable distance, it had not force enough to carrv heavy shot as strongly as the common coarse- 
grained powder, such as is sold in the small country shops, from which source our friend always procured his supply; for as soon as he loaded with it the ducks came tumbling down right and left.

\section{GLAZED POWDER.}

Some powder is glazed and some not. The comparative strength of the two kinds is not much, if at all, affected by the process which it undergoes in glazing, as the grains are merely triturated with blacklead, to give them the glossy appearance which they present.

It is deemed absolutely indispensable that all military powder should be glazed, to prevent the formation of too much dust by affriction in its transport from place to place; as it is a well-established fact that a charge of powder compressed into a solid, dense mass, as it necessarily would be if its whole granular as well as angular construction was destroyed by pulverization, must lose some of its propulsion by the slowness of combustion.

As has been remarked by Greener, "though it is possible to fire powder in vacuo," still, the presence of a certain amount of air in the interstices of any combustible mass will greatly facilitate the rapid penetration of the flame through it, and consequently increase the projectile power dependent upon its instantaneous combustion. Commenting on Dupont's sporting-powder, Captain Mordecai, of the Ordnance Department, remarks as follows:"Dupont's very fine-grained sporting-powder, being thoroughly incorporated, free from dust, arıd composed of angular grains, although highly glazed, far surpasses all the other kinds in quickness." Further on, he again observes :- "The great and uniform superiority of Dupont's fine sporting-powder, even in large charges in the cannon, evinces the combined effect of the most careful preparation of the materials, their thorough incorporation, perfect drying, and high glazing, all of which are favorable not only to the production of the greatest inherent force of the composition, but to the quick 
combustion of the grains and to the rapid transmission of the flame through the whole mass of the powder."*

\section{TESTS FOR POWDER.}

English sporting-powder, when good, is found to impart scarcely any color to the hand when crushed in the palm with the thumb. Amcrican powder, to be perfect, should be equally free from all charcoal appearances. There is a simple method of ascertaining the quality of powder, which in some measure may be relied on. If a small quantity be placed upon a sheet of white paper and exploded, it should burn with a sudden white smoke, accompanied with a peculiar sharp report, or rather phiz, that the ear soon becomes familiar with and easily detects. There should be nothing left on the paper after the explosion if the powder be superior; if, however, the residuum be blackish matter, the probability is that there is too much carbon in the powder; if the paper should exhibit a dotted appearance, with little black splotches over it, we would be led to suppose that the sulphur or nitre was inferior in quality and badly incorporated.

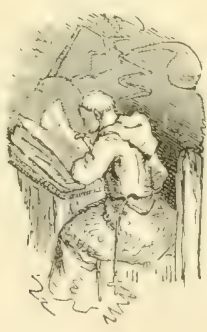

THE EPREUVETTE, OR POWDER-PROVER.

It is not an easy matter to ascertain the real pulsion of powder, even by subjecting it to the test of the epreuvette, - an instrument

* See report of experiments on gunpowder, made at Washington Arsenal by Captrin Mordecai. 
in common use in England, but scarcely known in this country, and on this account deserving of notice in this place.

The epreuvette, though the most perfect of all small instruments yet invented for the purpose of testing the strength of gunpowder, if not used properly will often give very unsatisfactory results. The construction of the epreurette should be perfect in all its parts, more particularly in the spring which controls the movements of the wheel on which the graduations are marked. The mouth-piece, or rather the piece which closes the muzzle of the epreuvette and is attached to the grading-wheel, should fit closely in its place, so as not to allow any space to be seen between the two surfaces when held up to the light.

One trial is not sufficient to test the momentum of the powder; it will be better to make several, and then take the average of the whole. The chamber should be nicely cleaned after each fire, provided we wish to obtain a close analysis.

\section{POWDER PRESERVED FROM MOISTURE.}

Powder should be kept dry and never exposed to a humid atmosphere, as it has a great tendency to imbibe moisture and will soon become unfit for service. If by any mishap it should become damp, it can be dried before the fire, or in the sun, on a metal dish; a coal fire is the proper kind of fire before which to dry it, - a wood-fire being rather dangerous, owing to the chance of sparks flying out, as they frequently do, more particularly if the wood be wet or green. We have dried our powder more than once by putting the dish which contained it on top of a brick placed on a stove.

The fact of the tendency of powder to absorb moisture may be very fairly and satisfactorily demonstrated by accurately weighing a certain proportion of the article, and placing it in a humid situation for a few hours, when it will be found that it has increased very perceptibly in weight, owing to the imbibition of the aqueous particles of the moist air. All circumstances being equal, smallgrained powder will necessarily absorb moisture more rapidly than large-grained, for the simple reason that, in a given weight of 
either, the smaller the grain the larger the surface exposed to the effects of the atmosphere. The projectile force of powder is considerably diminished by dampness, because, its combustion being much slower, a large proportion must necessarily be driven out of the gun before the whole mass is entirely consumed, and the explosion consequently must be weakened, as the phenomena attending the burning of gunpowder are accounted for by the sudden and rapid generation of an elastic fluid, which of course will not be properly created by the slow and unequal combustion of a lamp compound.

If the nitre used in the manufacture of powder is not perfectly pure and thoroughly embodied with the other ingredients, it will not burn with the rapidity necessary for the generation of the projectile force inherent in this compound when all its constituents are properly incorporated.

The mere circumstance of powder absorbing moisture when exposed to its effects, with more than ordinary rapidity, is a positive proof of its inferiority, and is a sure evidence that the nitre is not pure, and that it contains some portion of muriate of soda, which substance is generally found in combination with it in its natura] state, and which every one of the least observation is perfectly aware attracts humidity with singular facility.* If the powder is moist, besides losing a considerable portion of its strength, it soon fouls the gun, the grains become caked together, and will not enter the nipple-hole, \&c. For these reasons, the sportsman will be convinced that he cannot be too careful of his powder, and will take every necessary precaution to prevent the subtle compound from imbibing the particles of moisture with which the air is loaded during muggy weather, more particularly on the bay-shore, when

* Captain Mordecai, referring to experiments made with some powders manufac tured at the Eastward, remarks :- "In consequence of the impurity of the saltpetre in these powders, a great quantity of moisture is rapidly absorbed by them; the deliquescent salts in the nitre are dissolved, the grains become so moist as to hold in solution the nitre, which becomes separated from the other components, and the powder is soon rendered completely unserviceable." 
in quest of water-fowl. It should always be kept in tin canisters, and never be trusted to paper, which of itself has a tendency to absorb dampness, to say nothing of the danger of having packages of powder carelessly wrapped in old newspaper and lying about. A package of this kind, containing nearly half a pound of powder, we know of having been thrown into the fire by a thrifty housewife, who mistook it for a bundle of rubbish that she had collected up in a similar paper a few moments before, for the purpose of consigning it to the flames. The consequences of this umpardonable carelessness on the part of the sportsman might have proved very serious to us all, had not the accident been observed by a brother chum sitting close by, who, with admirable courage and presence of mind, seized the burning package with the tongs, and, rushing with it to the window, which had been opened a few moments before for the purpose of taking an observation of the weather, threw it out, where in a moment or two it exploded with a tremendous noise, but fortunately did no mischief.

It is almost useless for us to warn the sportsman to be careful, when drying powder, to expose as little as possible at a time to the fire, or he may blow the roof off the house, and perhaps blow himself out of the window. With proper caution, there is no more danger in drying powder than there would be in heating so much sand; but in the hands of a careless or reckless person the process would be rather hazardous.

\section{PROPERLY LOADING THE GUN.}

The art of rightly proportioning the charge for our piece is not so easy a matter as many suppose; but, on the contrary, it requires considerable judgment and experience to ascertain the exact quantity of powder and shot that a piece will best carry. If we wish to ascertain this fact conclusively, a series of experiments should be instituted immediately after the purchase of our gun; in truth, every sportsman should settle this important fact to his entire satisfaction at once, as we can assure him that much of his success in shooting depends upon the proper loading of his piece. 
If the gun be overcharged, as is much too often the case both with powder and shot, the whole load will be carried out of the barrel with an unequal, unsteady, and wild impetuosity, very different from the regular, easy, and determined motion imparted to it by a proper proportion of each. The gun, no matter how tightly grasped, if overloaded, will spring from the hand, and a recoil more or less serere will be felt at the shoulder. This should never occur in small fire-arms. In large duck-guns a slight recoil is excusable; but even in these pieces proper loading will alınost invariably remedy the evil if the gun is skilfully constructed; and if after judicious management it still proves incorrigible, the weapon had better be sold for want of use, or placed in the hands of some one who cares but little for a bruised arm and a sore shoulder.

As before said, a series of experiments should be instituted to find the exact charge that suits your gun best; that is, what proportion of powder and what proportion of shot will kill the farthest with the greatest certainty. This can be accomplished by firing at sheets of paper at a distance of forty yards with different-sized loads, and marking down the result of each discharge.

To make this chapter more complete, we cannot do better than introduce a few paragraphs from Greener on this subject, and at the same time remark that every sportsman will derive abundance of information appertaining to the gun by the perusal of that writer's highly instructive work:-

"I have repeatedly stated that all guns will burn a certain quantity of powder; you must, therefore, ascertain what that quantity is, which can only be done by practice. Suppose you begin with two drachms, and vary the charge one-eighth of a drachm each shot up to three drachms and a half, or as may be required, according to the length and bore of the gun, and, for precision, taking three shots with each charge at a sufficient number of sheets of paper; whichever you find strongest with the least quantity of powder, that is the best charge, as very likely 
the two next additions of powder will shoot equally strong, and yet not stronger, because more of it remains unburnt. Therefore, the least quantity which shoots equally strong is the proper charge, which having once ascertained, never change for any person's plan.

"Next as to the charge of shot. All guns, according to their bore and length, will shoot a certain weight and a certain size of shot best. A great deal of shot in a small bore lies too far up the barrel, and creates an unnecessary friction; and the shot, by the compression at the moment of explosion, becomes all shapes, - a circumstance which materially affects its flight. If of too great a weight, the powder has not power to drive it with that speed and force required to be efficacious, because the weight is too great in proportion. Those who reason with mathematical calculation will object to this doctrine. Say they, The greater the weight the greater the effect. No doubt it is so, if thrown with a proportionate force; but that cannot be obtained with a small gun. We must adapt the weight of projectile force to the power we are in possession of ; and, from many experiments, I am inclined to think that a fourteen-gauge two-feet-cight barrel should never be loaded with above an ounce and a bulf of shot, (No. 6 will suit her best,) and the utmost powder she will burn. A fifteen-gauge will not require more than one ounce and one-fourth; and no doubt No. 7 would be thrown by her quite as strong as No. 6 by the fourteengauge gun, and do as much execution at forty yards with less recoil; and, setting aside all other reasons, I should, on this account, prefer the fifteen-gauge gun, if both be of a length, finding I can do as much execution at the same distance with the one as with the other. To render a fourteen-gauge barrel superior, I think Colonel Hawker is right in stating that it should never be under thirty-four inches, which description of barrel I very much approve." 


\section{BURSTING OF GUNS. COMMODORE STOCKTON'S EXPERIMENTS.} RECOIL, ETC.

There are innumerable causes which tend to the bursting of gunbarrels, even those of the most approved workmanship; it is not astonishing, therefore, that those manufactured of inferior metal and put together by second-rate artists should frequently be torn to pieces while under the management of reckless and ignorant shooters. Although there are immense numbers of guns imported into this country, both from England and Germany, that could not stand the test of the proof-house, still, they are made of sufficiently good metal to bear the explosion of powder to a certain extent, and, if handled with caution, might perform many years of good service without endangering the lives of their owners. We do not, however, wish our readers to construe this concession of ours in reference to these trashy guns into a farorable notice of them; as we consider the use of weapons of a doubtful character, such as these are, as rather too hazardous an experiment for any one of our sporting friends to venture upon.

We will now endeavor to point out some of the causes that are calculated to produce bursting not only in barrels manufactured of inferior metal, but even in those forged out of the nost superior iron and wrought with the greatest care.

The first grand cause of bursting springs from the forge, as before stated; and every one knows full well that many manufacturers of guns use metal of very inferior description; and when the bars are being welded into barrels, the artificers themselves are guilty of most culpable negligence and recklessness, little heeding the limbs lost and lives sacrificed by their bad workmanship.

If a barrel be either welded, bored, or filed badly, even if it be made of good metal, it may nevertheless burst under the management of the most careful sportsman. If the thickness of the barrel is not uniform throughout its entire length, but weaker at one point than at another, owing to a flaw in the metal, overfiling, or rude boring, it will most probably burst, if overcharged, as the 
expansive force of the powder acts with increased vigor upon these weak points, owing to the resistance it meets with from the stronger portions of the tube.

If the subtle fluid generated by the inflammation of gunpowder be suddenly compressed or checked by a contraction in the calibre of the barrel, an undue proportion of the expansive force is exerted upon this point, and the result may be the bursting of the instrument. This fact will of itself show the folly of attempting to increase the shooting-powers of the gun by unequal boring of the barrel, or rather the contwacting of the diameter of the calibre at some given point in its length, as has been practised by some ignorant gunsmiths. We cannot imagine any cause better calculated to burst a fowling-piece than the contraction of its regular calibre from this erroneous method of boring, and would rather trust ourselves with a straight-bored barrel made of far inferior metal, than with one of these ill-shapen instruments forged of the very best stuband-twist. If the muzzle of the gun becomes stopped up with dirt or snow while in the act of springing over a ditch, or from a fall, and the extraneous matter should be of a consistency sufficiently hard to offer any considerable regree of resistance to the expulsive force of the powder, the barrel will be bursted without fail near its mouth; and the same accident will more readily occur if the mouth of the piece be sunk a few inches below the surface of the water, as the resistance offered by this fluid to the passage of the load under such circumstances is far more powerful than that presented by the thin sides of the barrel, and the weaker antagonism must necessarily give way to the stronger. That a gun will burst very readily if the muzzle be sunk a few inches under the water, we have not the least doubt; and an accident which happened to an acquaintance of ours, some years since, confirms us in the opinion.

A fowling-piece may also burst from bad loading; we do not mean entirely from overcharging, but sometimes from the want of proper precaution in ramming down the shot on the powder, or the moving of the wad of one barrel by the jar communicated to it by the explosion of the other. Bursting from this latter cause is 
occasioned by the sudden accumulation and increased expansion of the elastic fluid behind the object offering the resistance, or rather is the consequence of the sudden check given to its stearly exit from the barrel.

A ball thus impacted in the barrel of a small gun, musket, or rifle, will he most likely to burst the piece, if fired; such, at least, is the generally-received opinion.

This belief, however, like many other vulgar errors that have descended by repetition from one to another without any detail of experiments entered into necessary to establish the facts upon a certain and indisputable basis, may not be altogether correct.

Crmmodore Stockton, in his paper containing experiments on ordnance instituted by permission of the Nary Department, and Irtely read before the American Philosophical Society, opposes this long-received doctrine of explosion, and proves very conclusively, in some description of large guns at least, that they invariably burst with a smaller charge when the ball was nearer the powder than when it was at a distance; and, also, that the bursting took place with the shot at the shortest distance from the powder, after sustaining the same charges at a longer distance.

These experiments and their results certainly go to prove that such is the fact in large guns of equal calibre and size throughout their whole extent; but they prove nothing, in our judgment, in the case of small fire-arms of unequal strenyth and weight of metal.

Commodore Stockton also shows most conclusively that the greatest internal pressure at the moment of the discharge is at that part of the gun occupied by the powder.

Although the facts elicited from these interesting and highly instructive experiments are very conclusive, so far as they hare a bearing on large guns of one hundred pounds' weight or more and of like dimensions throughout their entire length, they do not certainly establish any thing, as before remarked, either yro or con., as to the old theory respecting small fire-arms; we are consequently forced to adhere to the ancient doctrine of explosion, and 
still believe that a fowling-piece is more apt to burst with a wad or a ball far up the barrel than if pushed home upon the shot or powder. This phenomenon we can account for in a way quite satisfactory, at least to our mind, by supposing that when the powder is ignited, and the expansive fluid generated by this inflammation is set in motion, and, striving to overcome the resistance offered by the sides of the barrel which enclose it, rushes forward up the barrel with that certain degree of propulsive force inherent within itself, and without having any positive obstruction in its way to arrest its onward course till it meets with the barrier opposed to its exit, in the shape of a wad, ball, mud, snow, or some other article which might be lodged in the barrel either by design or accident, this sudden check to its wild career creates a momentary yet a partial pause in its course, and consequently gives rise to an increased lateral pressure at this point in the barrels, which are proportionally thin as they approach the muzzle, and consequently, unlike the heavy breech, are unable to withstand this unequal and sudden shock, and therefore must give way. And thus we may say that bursting under these circumstances arises from the sudden accumulation and increased expansion of the elastic fluid behind the object offering the resistance and thereby preventing the free exit of the charge from the gun.

Why the same result was not obtained in the case of larger firearms, and why the experiments of Commodore Stockton should be diametrically opposed to this theory, we cannot, perhaps, satisfactorily explain, as we have no opportunities of making any practical observations upon the subject; we therefore leave it for the investigation of others, venturing, however, the following remarks:-

If, for experiment, the dimensions of the guns (as Commodore Stockton's all were) be of the same size throughout, and of a calibre sufficiently strong to withstand the shock of the powder used in the experiment, except at the very spot where the internal pressure is greatest, - that is, at the breech end,--and the metal be no stronger there than at any other point along the barrel, it is evi- 
dent to every one of the least thought that a certain charge of powder would have a very different effect upon a gun of this kind than it would on one constructed upon the principle of an ordinary fowling-piece, which has the weight of metal in the breech nicely harmonizing with the length and calibre of the weapon.

The experiments therefore cannot hold good in the one case as in the other; because, when the powder is exploded in the large gun, (such as used by Commodore Stockton,) the greatest pressure, as before stated, in this as well as in all other fire-arms, is at the point of ignition,- the breeches. Now, the breeches, or that portion of the barrel surrounding the chambers in the experimental guns, were exactly of the same size as the other parts of the barrel; and consequently, if the gun contained at any time sufficient powder to burst it, it would necessarily be burst at the point where the greatest pressure was exerted, and that of course would be at the breech, as already admitter. Again, when the ball is rammed home and the powder exploded, the force of the shock would of course be more confined to the breech than if the ball was far up the barrel. Moreover, the force expenderl on the breech at the instant of explosion under these circumstances-that is, with a regular home-charge - would be necessarily greater than that generated at the same point if the ball was not directly on the powder, for the ample reason that in the latter case there would be less positive resistance for the powder to overcome at the moment of ignition, owing to the absence of the ball from its ordinary position. The shock of the explosion would also be somewhat modified, in consequence of its first and most powerful effects having been exerted at the moment of combustion at the breech, and subsequently to a certain extent expended during the passage along the space intervening between the chamber of the gun and the point where the ball was impacted in the barrel. At this point the propelling fluid, we grant, would necessarily meet with a sudden check to its farther progress towards the muzzle, in consequence of the mechanical obstruction presented by the wedged ball. This check, however, would not produce, possibly, a shock 
equal to that generated at the first impulse of the burning powder, and therefore could not burst the barrel at this point, if it did not do it at the point of ignition, where the metal in the experimental guns was no stronger, and the force applied we assume to be much greater.

This position being correct, the gun would not be so readily burst from an explosion, under these circumstances, as it would if the whole force was exerted upon the one point, as is the case when the ball is rammed home upon the charge; and consequently it would require a larger proportion of powder to develope the same degree of force, without the immediate pressure of the ball, as would be generated if the ball were rammed tight upon the charge.

This, however, would not be the case with a fowling-piece, for the reason that the barrel being of unequal thickness, and the breech four or five times as heavy as the muzzle and in a proportionate degree heavier than all other parts of the barrel as you advance towards the mouth, if a ball therefore become impacted in it, and offer considerable resistance to the escape of the powder, the lateral pressure created by this shock might be more than sufficient to rend the gun in pieces at this point, when three times the same force would have no effect upon the breech end.

From the foregoing remarks, therefore, it appears evident to us that it would require far more powder to burst a small gun with a regular home-charge than it would to burst it, if, when set in motion, it should meet with a sudden and powerful resistance any distance up the barrel, either in the shape of a wad, ball, or any other accidental obstruction such as before mentioned.

Although the internal pressure first produced at the moment of ignition be not sufficient to burst the barrel asunder at the breech, the sudden shock occasioned by the resistance of the obstruction, though not equal to the first force generated at the breech end, might be, however, quite sufficient to tear the barrel to picces at the point of contact. 


\section{RECOIL.}

The recoil-or, as it is vulgarly called, "the kick一of a gun" may be produced by several causes, all of which, however, have their primary origin in the projectile force of the powder, or rather in the resistance offered to the expansive fluid generated by the ignition or explosion of a mass of powder. In all fire-arms of perfect construction the recoil is in proportion to the friction or resistance offered during the exit of the shot from the barrels; and it is only when this resistance, or rather the consequence of this resistance,- - the recoil, - becomes disagreeable to the shooter, that we look for the cause and the remedy, as there must, of course, under every circumstance, be some recoil in fire-arms, no matter how perfect the barrels may be in their construction.

Imperfections in the manufacture of the barrels are fruitful sources of reaction in shot-guns; and, if they are not perfectly symmetrical in their bore and smooth throughout their entire surface, the piece will rebound more or less severely at every discharge, no matter how small a quantity of powder may he used. If the barrel he wider at one point than at another, although this difference may not be perceptible to the eye, the repereussion will be greatly increased; as, the shot being somewhat arrested in its progress through the barrel, the impelling force of the powder exerts itself so much the more to orercome the barrier, and thus creates a back-action, which spends itself upon the breech. A recoil produced from such a cause is of a most dangerous character, and will eventually burst the weapon, as it is impossible for barrels of any orlinary thickness to withstand the oft-repeated and violent efforts of the powrler to force its way through the contracted point. For the same reason, a leated or foul gun, by offering a certain degree of resistance to the exit of the charge, will produce a recoil in proportion to the increased friction, which, even in the bestconstructed fowling-pieces, will often be very severe from such a cause. If the shot be too tightly rammed, or an over-quantity be used, the recoil, of course, will be increased in proportion to the 
resistance offered. A straight stock will feel the effects of this retro-action, or rather transmit those effects to the person of the shooter, much more severely than a crooked stock, as the latter, by receiving the force of the concussion in an oblique direction, breaks the shock before it reaches the extremity. Bad powder, particularly damp powder, adds greatly to the recoil; and no doubt some of our readers have remarked that there is always more recalcitration on a wet day than on a clear one; this is owing, to-be-sure, in part, to the barrels getting dirty much sooner, but principally to the dampness of the powder, which impedes the immediate ignition of the whole mass, and consequently retards the exit of the shot, which moves before the propelling force with a kind of jerking motion.

It has been asserted by some writers that the position of the touch-hole regulates in a great measure the power of the recoil. Suppose, for example, that the touch-hole communicates with the centre of the mass of powder: it is contended that at the moment of ignition the expansive force of the generated fluid is exerted as strongly backwards upon the breech as it is forwards or upon the sides of the barrel; but, on the other hand, if the powder is ignited from the base of the mass, the whole expulsive force will be directed forwards upon the shot, and the recoil consequently be much lighter. The less a gun reacts, the more certain and effective will be the delivery of its shot; as it is well ascertained that a piece made perfectly stationary in its bed will throw a ball much farther, and consequently with much more force, than one that is allowed to rebound at every discharge. A kicking gun, when grasped tightly and held firmly to the shoulder, will spring back far less than if lightly placed against it; it will also throw the shot much farther and with greater certainty. This fact may be very easily ascertained by a simple experiment.

Suspend, for example, a fowling-piece by two cords from a suitable frame, or from the limb of a tree, in such a manner as to permit an unrestrained recoil, having first charged it with the ordinary load of powder and shot; now fire the gun at a target 
properly arranged, and take especial note of the result; then load the piece as before, and secure it tightly, so that no rebound can take place; move the target some distance farther off, and note the result of this discharge. It will be observed that the last fire will be far more effective than the first, both as regards the strength and range, although the distance of the target has been considerably increased.

In support of the time-honored hypothesis relating to the effects to be apprehended from the presence of certain obstructions, intentionally or accidentally placed up the barrels of small fire-arms, we hardly know what to advance. Although we have not made any experiments to establish the position, still we feel quite sure in asserting that the old-received opinion is perfectly correct; that is, that there will be a greater recoil with the same amount of powder if there be some obstruction up the barrel, than there would be if the charge was properly rammed home.

This opinion, however, is quite contrary to the results obtained by Commodore Stockton; for he asserts that the recoil, as indicated by the motion of the timber to which the guns were fastened, was less when the ball was at a distance from the powder than when it was rammed home. This, certainly, is very much at variance with the popular belief.

If a gun be fired with an ordinary charge of powder, and be perfect in its construction, there will not be any retrograde motion of the piece, or in other words recoil, felt at the shoulder; or, if there be any, it will be of such a trifling nature that it is not worth noticing.

There is, however, a recoil ; and this recoil, as before observed, is deadened in proportion to the weight of metal in the breech, the shape and build of the stock, as well as in some measure by the mode of holding the weapon.

If, howerer, the charge in its exit from the gun should meet with any obstruction far up the barrel, where the metal is thin and the gun only lightly balanced in the hand by a grasp of the stock near the guard, the sudden shock given to it by the resistance of 
the obstacle encountered will communicate a jar or quick jerk to the weapon, which will be felt at the shoulder, and not expended, as in the other case, upon the breech or stock.

The reason of this, we presume, is that the retro-action imparted to a forling-piece by a regular charge of powder and shot is not a jumping, jerking rebound, but a regular and steady recoil, as it were confined to the thick chambers of the gun, and lost upon the stock before it reaches the shoulder of the shooter; but, in the other case, the motion imparted to the gun is a jumping or jerking recoil, which has not the heavy breech to break its immediate effects upon, and is consequently transmitted without interruption along the outside of the barrel directly to the person of the sportsman.

This action will be quite different in the case of the experimental ordnance-pieces, as has been already demonstrated; for there was neither a heavy breech nor long stock to ward off or receive the repercussion in those guns, and the whole force of the explosion consequently was transmitted immediacely to the timber to which they were all attached, and necessarily occasioned the conclusion arrived at by Commodore Stockton.

Commorlore Stockton's little pamphlet, the result of much care and ingenuity on his part in the prosecution of these highly interesting experiments, requires no notice from us: it speaks for itself. But we may be permitted to state that we were led to this partial review of some of its points from the interest we felt in the subject, and from the circumstance of a copy having been sent to us by a sporting friend, who requested our views on the norel as well as rather startling results.

In conclusion, we beg to remind our readers that we have not denied, nor have we attempted to disprove, any of the conclusions arrived at by the commodore; we have only endeavored to explain some of these results, and to show that they do not, in our judgment, affect the operations of sporting-guns, nor are they sufficiently conclusive to change our old-fashioned views on this subject. As far as the experiments go, they are quite satisfactory; 
and they certainly have developed some rather strange phenomena, - at all events have given rise to some very new ideas in reference to the matter, which we doubt not will prove hereafter of much practical utility in "gunnery."

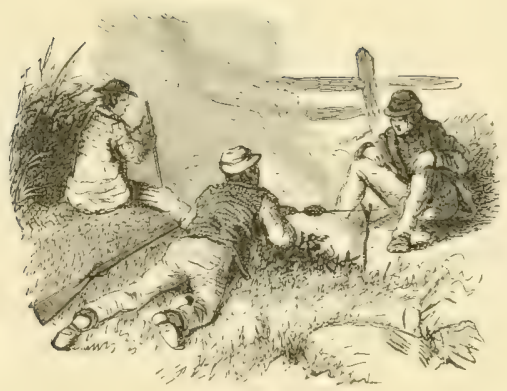




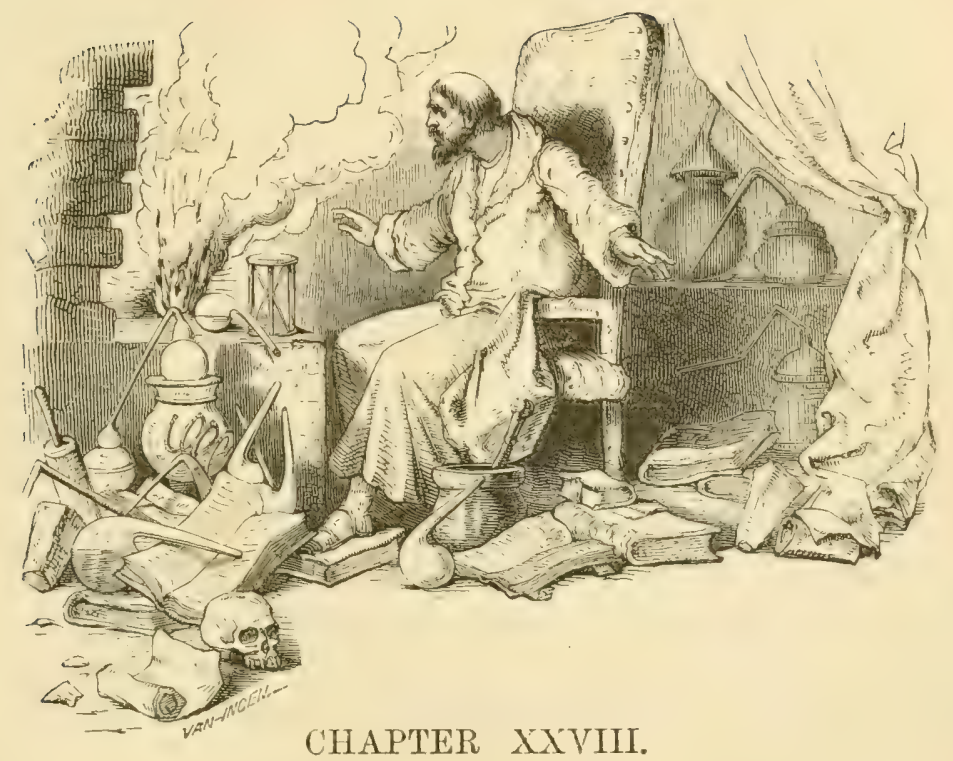

DISCOVERY AND INTRODUCTION OF GUNPOWDER.

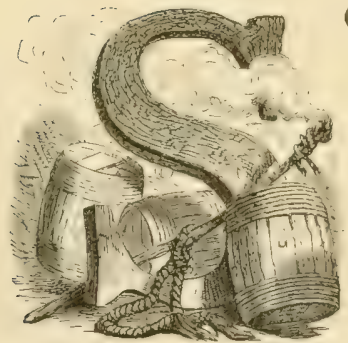

OME writers assert that the use of gun. powder, as well as ordnance, was well known to certain of the ancients as far back as the year of our Lord eightyfive; and in support of this hypothesis the following remarks of Uffano, on the authority of Robert Norton, the author of a work entitled The Gunner, printed in London in 1664, are often quoted, viz.:- "That the invention and use, as well of ordnance as of gunpowder, was in the eightyfifth yeare of our Lord made known and practised in the great and ingenious kingdom of China; and that in the maretyme provinces thereof there yet remain certaine pieces of ordnance, both of iron and brasse, with the memory of their yeares of founding engraved 455 
upon them, and the armes of King Vitney, who, he saith, was the inventor."

Another passage from Philostratus, the historian of Apollonius Tyanæus, about the commencement of the third century, has also been referred to by writers in favor of the antiquity of this invention. In speaking of a people of India called Oxydracx, this ancient authority remarks:- "These truly wise men dwelt between the rivers Hyphasis and Ganges. Their country Alexander the Great never entered, deterred, not by fear of the inhabitants, but, as I suppose, by religious considerations; for, had he passed the Hyphasis, he might doubtless have made himself master of the country all around them; but their cities he never could have taken, though he had led a thousand as brave as Achilles or three thousand such as Ajax to the assault, for they come not out into the field to fight those who attack them, but these holy men, beloved by the gods, overthrow their enemies by tempests and thunderbolts shot from the walls. It is said that the Egyptian Hercules and Bacchus, when they overran India, avoided this people also, and, having prepared warlike engines, attempted to conquer them. They made no show of resistance; but upon the enemy's near approach to their cities they were repulsed with storms of lightning and thunderbolts hurled upon them from above."

In the Opus Magus of Friar Bacon, who died about 1294, may be found a particular description of the effects of a certain compound of saltpetre and other ingredients, which, when ignited, gevo results analogous to those of thunder and lightning; and, furtlermore, it is stated when these elements are rightly amalgamated and properly applied, the force of the explosion would be sufficiently powerful to destroy not only an ariny, but even to overturn an entire city.

These remarks, together with some others even still more perspicuous on this head, have led most inquirers to conclude that the learned friar was at least well acquainted with the components and effects, if not well versed in the precise composition and application, of gunpowder. 
This information, it may very justly be presumed, was not orl. ginal with himself, but rather obtained from the others of his brotherhood, the monks, who had learned of its existence among the Chinese, as well as seen its operations during their missions in those far-distant regions, from whence they had then lately returned.

Some writers go so far as to suppose that the pious but wily monk was well acquainted with the composition of gunpowder, as well as its terrible effects, but at the same time assert that he was fearful of betraying the wonderful secret, knowing full weli that its introduction into the world would be attended with the most calamitous consequences; and, for humanity's sake alone, if not from other ulterior motives, he determined to keep the secret as long from the knowledge of man as possible.

Be all this as it may, there is no doubt that Berthold Schwarz, a German monk of the Order of St. Francis, was the first person who made the composition of this wondrous substance generally known to the world, and that the discovery, though ancient it might be, was nevertheless altogether original with himself.

The circumstances of the discovery are these:-Berthold Schwarz, a native of Freiburg, in the Grand Duchy of Baden, during his relaxation from monastic duties, occupied much of his time in the fascinating and absorbing pursuit of chemistry. During some of his manipulations, having pounded in a mortar an accidental mixture of charcoal, sulphur, and nitre, he was amazed and wildly astounded by its sudden and fearful explosion on the hap-hazard application of a spark of fire.

This terrible but at the same time novel exhibition of power in a simple compound like this very naturally aroused in the mind of the zealous student a spirit of investigation; and the result of further experiment was the discovery of that still mysterious composition known as gunpowder,-a discovery which has not only immortalized the otherwise obscure monk, but, since its general introduction and application to the use of fire-arms, has actually 
given rise to a new era in the workings of man, -in fact, has been the chief and all-powerful instrument in not only shaping the mighty affairs of great nations in times past, but must ever continue to exercise a decided influence over the destinies of mankind in all time to come.

All this happened about the year 1340; and the city of Freiburg has lately very properly commemorated the wonderful event by the erection of a handsome fountain, emblazoned with suitable inscriptions and surmounted by a statue of the fortunate discoverer.

\section{CANNON.}

Notwithstanding the reputed antiquity of cannon, they were little known in England before the fourteenth century, and were first employed as an engine of war by Elward III. At this early period of their introduction into military service, they were of rude construction and cumbersome proportions, and so continued, with little or no improvement, till the reign of Henry VIII. This monarch soon undertook the manufacture of ordnance, which was continued with spirit and energy by his persevering successor, Queen Elizabeth, and, during her reign, vast improvements were made in their fabrication. 'The "hand-goune" was next invented, -an instrument sufficiently rude in its construction when compared with the guns of the present day, but still, as a first effort in this branch of manufacture, a very serviceable weapon of attack as well as defence. This "goune" was made light enough to be carried about by one person, and was fired by the application of a match.

The stocked gun was the next improvement, which also was fired by the application of a lighted match to the prining, either through the medium of a match-lock or by the direct interposition of the hand.

The "wheel-lock" was the next invention, and approximated closely in principle if not in construction to the flint-lock of the present day, a spark of fire being produced and communicated to the priming by the friction of a notched wheel passing rapidly 
over the edge of a flint-stone. The flint-lock was the next step in order; and the percussion-lock, in its approved form, was the last and best of all.

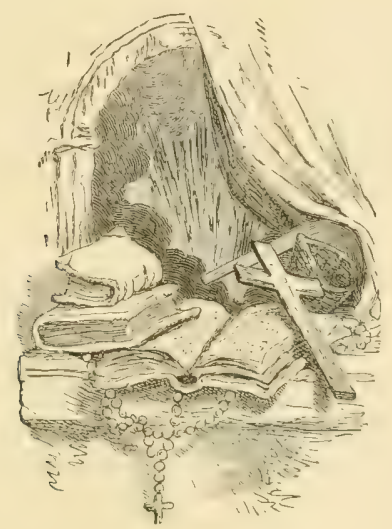

THE GUN.

The gun being the principal instrument by means of which the sportsman destroys his game, it seems proper that it should now claim our particular attention, as the proper knowledge of its manufacture, as well as its perfections and imperfections, should bo thoroughly understood by the tyro before entering upon the sports of the field. Without imparting this information, we cannot expect our sporting friends to be competent to provide themselves with such fowling-pieces as will come up to our ideal of beauty or answer the good purposes that we design to exhibit in a superior gun. Many of our readers will smile in anticipation of a long and tedious dissertation upon a subject in which they can take but little interest beyond the mere outward examination of an instrument the skilful making and putting together of which has occupied the minds of many of the most intelligent and ingenious spirits of the Gld World as well as the New. Many of our sportsmen are content to go to the field with a second-rate or third-rate gun, feeling well satisfied with its goodness provided it kills occasionally at long 
distances and does not burst when overcharged. The luxury of a superior gun, if we may so speak, is never dreamed of by these people; and they cannot conceive the possibility of shooting for years with the same fowling-piece without once seeing it the least out of order. A weapon so dangerous as a gun, even in the hands of the most careful, should certainly be of excellent quality, and all its parts made of such materials as to insure its safety at all times, under judicious management, and leave no room for those melaucholy accidents that so often occur from the bursting and going off of inferior guns when least expected, owing to impurity of metal or the imperfect structure of the locks or other portions of the machinery.

We do not intend to occupy, or rather bore, the reader with a long scientific dissertation upon gun-making, but merely wish to direct his attention to the subject in such a way that he will gain in a few pages all the practical information in reference to a gun that will be necessary to make him familiar with its history, manufacture, and construction.

Before the introduction of guns into England, the longbow and crossbow were the weapons mostly employed in war, as well as for the chase. The latter instrument was most in favor with sportsmen, owing to the greater strength and certainty with which it threw its arrows. Although the use of fire-arms, as before stated, was somewhat known during the reign of Elizabeth, as well as that of her predecessor, Henry the Eighth, and even as far back as Edward the Third, (1327,) who is said to have first used a specics of mortar for the purpose of ejecting large stones against the Scots when bombarding them in their native fastnesses, still, these rude weapons were of so unwieldy a character that it was not thought of introducing them into the chase. Even in the reign of Elizabeth, the muskets made under her directions for the use of the army were so large and heavy that it was impossible for the soldier to travel any great distance with them, or to hold them out at arm's length for the purpose of firing: but each one was obliged to carry a staff with him, which he stuck in the ground to rest the 
instrument upon while taking aim at his adversary. It was not till the reign of Charles the First (1625) that small-arms were made of such proportions as adapted them to the use of sportsmen; and even at this late period-nearly three hundred years after the introduction of gunpowder - the small-arms, though vastly improved, were still rude and cumbersome instruments, and suitable only for the pursuit of large animals, as they could not be handled or discharged with sufficient ease to enable the bearer to kill a bird on the wing. These weapons, like many other articles, have gone through a regular series of improvements, until at last they have in the present age arrived at a state of perfection beyond which it is difficult to conceive any thing superior.

Sportsmen should not hesitate between a doubtful and a superior gun on account of a trifling expenditure, as it is a purchase that is made only once or twice in a lifetime; and there is a certain degree of comfort and pleasure in going to the field for a day's amusement with the assurance of handling a weapon which no ordinary usage can injure, and that we have nothing to fear from accidents, which feeling of confidence richly repays us for all the unusual outlay.

The saving of a few dollars in the purchase of a gun would ill repay a shooter for the loss of a hand by an explosion, or perhaps the maiming of a friend or the death of a valuable dog by the going off of his gun, owing to poorly-made locks.

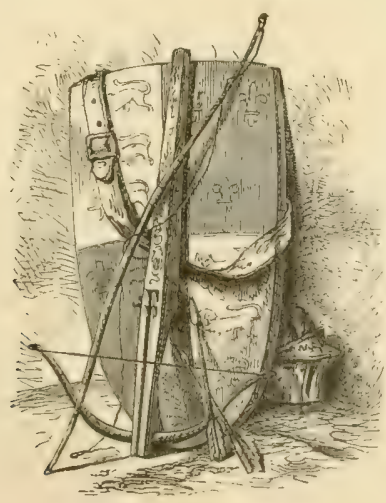




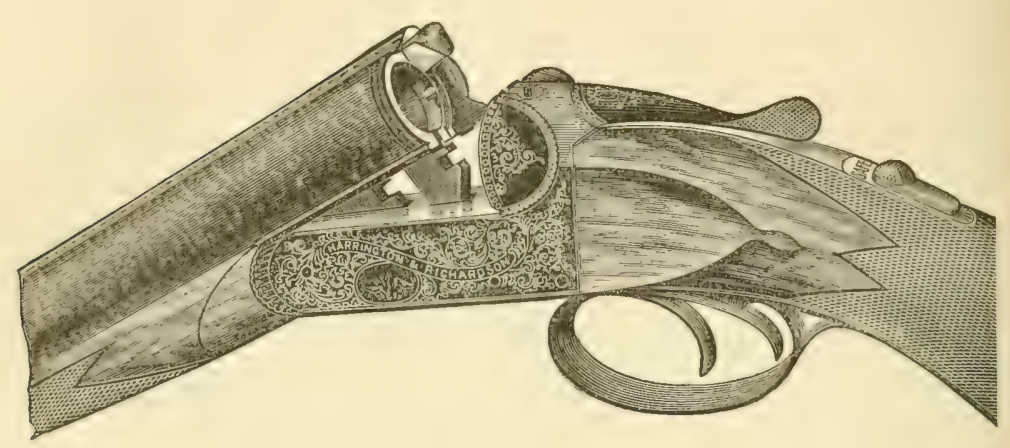

THE BREECH-LOADER.

Notwithstanding the improvements made from time to time to which we have referred, the muzzle-loader in its highest perfection failed to give satisfaction. The labor and time required for loading in the field detracted greatly from sport, to which was adcled the impossibility of changing the charges quickly if circumstances required, and over and above all was the danger of accident while loading one barrel over a loaded one, necessarily pointed directly towards the sportsman's hands, if not at other portions of his person. Recognition of these defects caused a demand for a more convenient and safe weapon, and led to the production of the modern breech-loader, which was, however, not a purely modern invention, but an improvement upon a crude form produced and discarded for its defects in the early ages of gunnery.

When first brought out, these new guns were very imperfect. The levers were inconveniently placed, the different parts badly fitted, and the bolting actions weak, so that the barrels soon became loose and shaky. The shells were as bad as the guns, being fired by pins which projected through holes in the breeches, and if not accurately struck by the hammers, were bent and failed to explode the caps. These defects were quickly remedied. The pin-shells were superseded by centre fire, the awkward levers changed for convenient ones, accuracy in fitting secured, strong actions invented, 
the hammers made rebounding, and snap-fastenings substituted for the fore-end bolts, and the gun thus improved was made the most perfect weapon ever offered to the sporting public, and for years fully satisfied all demands. One defect, however, still existed, viz., that of external hammers or strikers, which had to be drawn back before firing, and also were a source of danger through liability to catch in twigs or in the sportsman's clothing. This led to the invention of the so-called hammerless gum, from the fact that the strikers are situated upon the inner surface of the lock-plates, and the blow upon the firing-pin is delivered internally rather than externally. The hammerless system, regarded in a purely mechanical light, is a great improvement upon all past systems, because it permits of a lock consisting of less pieces, of more simple construction, and of consequent less liability to get ont of order, and in addition to this it also permits the locks to be cocked antomatically by the simple action of opening the gun to receive the shells.

As all new inventions meet with opposition until their value is proved beyond question, the hammerless guus were declared dangerous, because, as the strikers are concealed, the sportsman cannot tell at a glance whether his gun is cocked or not, and so may get a discharge unexpectedly. To offset this, we have the fict that the gun is known to be cocked every time it is opened, and remains cocked until fired, or the hammers are let down. Under either of these conditions it is as safe as any other gun can be, and when cocked, safety is specially provided for by automatic triggrer and tumbler-bolts, brought into action simultameously with the cocking of the gun, and remaining in action till released by pushing aside the safety-eatch. The position of this catch upon the upper surface of the gripe plainly indicates whether the locks are bolted or not, and by its action they can be bolted and released at any time, and as often as circumstances require. In addition to this, many gunbuilders have placed special indicators upon their guns, by which the position of the strikers is shown as plainly as by the old external hammers. In its present form, the hammerless gun possesses the great advantages over all guns of the past of being more safe, 
more convenient in operation, and less liable to give out with use. In point of simplicity and efficiency further improvement appears impossible, since every recognized defect in construction has been done away with. Critics still exist, doubting Thomases who can never be satisfied, but popular opinion is overwhelmingly favorable to the new gun, and the sportsman who seeks the most perfect weapon ever turned out, will find it in the hammerless gun of any - one of a dozen different builders.

It is true there are different hammerless actions, the inventions of different builders of repute. It is also true there are different bolting actions, and these all have their supporters and opponents. We do not propose to criticise or express any preference, as we believe the guns of the best English and American builders are any of them good enough for any sportsman's use, however they may vary in details. All are sound, well-proportioned, serviceable guns, guns which will last near a lifetime of ordinary shooting, and this being the case, it is, in our opinion, mere hypercriticism to make a choice.

BORING FOR SHOOTING QUALITIES.

No matter how perfect in construction a gun may be, if it does not possess the qualities of close, hard shooting, it is valueless for use. Various systems have been tried, from the perfect cylinder to the choke, but the results of careful, scientific, and extensive trials have proved the superiority of the chole-bore over all others. Choke-boring simply consists in reducing the diameter of the barrel as it approaches the muzzle. By such reduction the charge is concentrated, and delivered at the muzzle in more compact form than it leaves the shell in the breech. This reduction in diameter varies with different builders. Some bore their guns with a long taper extending back from the muzzle onethird or more of the length of the barrels, others bore a cylinder till within an inch of the muzzle, and then contract suddenly, and still others taper, relieve, and taper again. Guns of ali these styles of boring shoot admirably, but the muzzle-choke is less 
likely to be enduring than the taper, owing to the great friction, and to the comparatively small surface upon which it is exerted. The eloseness of the shooting depends upon the degree of contraction, and this is known as full or modified choke, the former being generally applied to duck-and trap-guns, and the latter to those generally used in the field. It is customary also to bore the barrels of field guns differently, one being less choked than the other, the open barrel being used for close shots, and for the first bird in doubles, while the other serves for long shots. This style of boring is open to the objection that it tends to induce the use of one barrel more than the other. The great majority of single shots are at short ranges, and for these the open barrel is used, as the choke cuts the bird up badly. The gun is thus subjected to an unequal strain, which will, in time, produce greater wear in the barrel most used, and in addition to this, the constant use of one barrel tends to weaken the sportsman's command over the other. Few men who use guns of this kind shoot equally well with both barrels, whereas by having both bored alike, and accustoming himself to the use of either by shooting them in regular order, irrespective of where the bird may be, the sportsman wears his gun equally throughout, and acquires a skill which he can depend upon at all times.

Choke-boring has given breech-loaders a great advantage over muzzle-loaders in pattern and penetration, as shown by careful targeting. Some muzzle-loaders have displayed exceptional shooting powers, but the best of them when subjected to the test of scientific trials, in comparison with choke-bored breech-loaders, have invariably failed to hold their own. Thus the improved breech-loader, in addition to all the other advantages we have named, possesses also shooting qualities superior to its predecessors.

\section{ENGLISH AND AMERICAN GUNS.}

Opinions differ upon the comparative merits of English and American guns. In this we ignore a certain class of sportsmen who appear to think that everything English is necessarily better 
than home productions, and refer to the unprejudiced class, that judges by intrinsic merit, and not by name or location. There is certainly no apparent reason why foreign builders shonld surpass us in the production of guns. In other manufactures we at least hold our own, and we have as intelligent mechanics, and as perfect machinery and tools, as any mation upon the face of the earth. It is true, gun-building is here a comparatively recent undertaking, but Americans have the faculty of profiting by the experience of others, and the guns turned out here show that this case is no exception to the rule. But few gun-makers in either country manufacture their own barrels, finding it cheaper and better to buy them in the rough from manufacturers who devote themselves exclusively to barrel-making, and this market is as open to American as to English makers, and our best guns are put up with barrels of precisely the same quality as those which appear in the finest English weapons. Some of our makers have lately forged as well as finished their barrels, and we are bound to say we have seen American barrels which for quality of material, shape, and perfection of finish equalled any we have ever examined bearing the best English names. 'The high reputation of any maker is very properly considered a guarantee for quality in his guns, since such reputation can neither be obtained nor perpetuated without it is fully warranted by the goodness of his work. The reputations of our best makers are national, and their guns are constantly gaining favor, and holding their own against those which are imported. This of itself is sufficient to show that in the opinion of a very large class, American guns will bear comparison with those made in England at the same price, and this is all that can be expected. There is in England a class of makers who build exclusively for the nobility and wealthy patrons, and who charge prices which are higher than any American builders ean obtain. The guns which they turn out possess a beauty and elegance of finish which is unequalled by cheaper ones on either side of the water. Practically they are no better than cheaper ones, built at prices which pay for thoroughly good work, but it is undeniable that, like other elegant 
articles, they are desirable if a man has the means to gratify his desire for the best. These guns are, however, placed above competition with others costing less, irrespective of plice of manufacture, and must, therefore, be regarded as out of the question, when comparison between American and English guns is made. Guns turned out by either American or English makers of high reputations may be relied upon to be of fine material, sound workmanship, and high finish, that will shoot well, and with proper care last for years of continual use. We have used many foreign and domestic guns, and have no choice between them, except such as is based upon a desire to patronize home products when of equal quality with the imported.

\section{MACHINE- AND HAND-MADE GUNS.}

English gun-makers decry American guns because most of them are made by machinery. The conservatism of the English character disinclines them to changes, and prejudices them against articles not produced in the old ways. So far these objections are at least honestly entertained, but beyond this, there is unquestionably the bias of national prejudices, the egotism of the English character, which forbids recognition of goodness in American productions, and the inability of hand-work to compete with machinework in point of cheapness. The popular idea of cheap English labor is erroneous when applied to certain classes. Skilled labor commands high pay in the best English workshops, and guns turned out in such must bring good prices to be remunerative. In addition to this is the duty on guns sent to this country, and the total cost is great when compared with that of guns made by machinery, so that to maintain a footing in the American market buyers must be taught to consider English guns the best, hence the belittling of American guns to which we refer.

Greener, from whom we have already quoted, and whose experience in gun matters makes his opiniou valuable when it is free from prejudice, has been most unjust in his criticisms of American guns, and his unfounded assertions have been repeatedly contra- 
dicted and disproved in our sporting journals. No man can with truth bring such charges against our guns as he has brought, and in the face of the undeniable fact that machine-work is more accurate and exact than any which depends upon human muscles, it is absurd to deny the high character of work performed by machinery as perfect as any ever invented. Greener, and all other foreign objectors, admit that no two guns can be made exactly alike by the most skilful hand workman. Some slight variation in the different parts will always be present, which utterly prevents interchangeability. The different parts of machine-guns, on the other hand, are duplicates of each other, and can be substituted in case of accident. Finish can be brought to greater perfection by machinery than by hand, and certainly the quality of metal is not affected by the manner in which it is worked. No sensible objection can, in short, be brought against American guns on this score, and the claims of foreign builders will be taken cum grano salis by men who judge from examination of the guns, and not from blind acceptance of prejudiced statements.

\section{THE COST OF A GOOD GUN.}

A gun, like any other article, has a value proportional to the quality of the material employed in its construction and to the work put upon it. This may be called the natural value, and in addition to this there will be a premium proportional to the maker's reputation. We do not consider this addition unreasonable within certain limits, as a maker is rightfully entitled to recognition of the effort he has made to acquire a reputation for good work, and that reputation is the buyer's security. Without doubt, this premium is in some cases unreasonable, that is, certain builders charge prices greater than those of men who turn out practically as good guns. As we have said before, rich men may patronize these high-priced makers, but the majority of sportsmen are not wealthy, and our object at this time being to consider the cost of a gun, sound, handsome, capable of standing the wear of service, and shooting well, yet within the reach of men of mod- 
erate means, these builders must be considered as out of the list.

Guns are offered on the market at prices varying from twentyfive dollars to four hundred and fifty dollars. We do not hesitate to say a safe and serviceable gun cannot be built at these lowest figures, even if no allowance for profit is made. The cost of materials for sound barrels, with that of careful forging, is sufficient to nearly cover the entire price. Cheap barrels are made of the poorest quality of iron, and the forging is so roughly and imperfectly done that flaws are left, which render the gun liable to burst at any time when severely tried. This weakness is in some degree compensated for by making the barrels heavier than good ones of the same gauge; but mere weight of metal is not sufficient, as the weak spots will at least partially give way, causing the inside of the barrels to become rough, and destroying their shooting qualities. Again, poor iron has not the toughness necessary to resist the friction of frequent firing, and barrels of this character do not retain their boring, so that a gun which at first shoots well will, in a little time, perform variably or bally. The hingepin and the different springs are also subjected to constant strain in opening and closing the barrels, and quickly wear away or break, causing the gun to become loose or temporarily useless. The stocks are imperfectly seasoned, and shrinkage opens still wider the inaccurate fitting of lock-plates, frame, and triggerguard, leaving spaces for decay under the action of dirt and bad weather.

From all these causes it must be evident guns of extreme low price are worthless, and the very lowest for which a gun wrorthy of the name can be bought, is seventy-five dollars, and this cost must be put entirely upon the materials and construction, learing nothing for engraving or ornamentation of any lind. A plain, serviceable gun can be got for this, but it must be bought from an American builder, as imported guns have to pay duty and dealers' profits, and at the figure named must of course cost the manufacturer much less than the American gun, and be proportionally less 
perfect. Foreign builders of gond reputations do not build gums at such rates, and the host of imported cheap weapons sold under apparently good names are the work of disreputable makers, who do not hesitate to palm off their trash upon the public by stamping it with names so nearly like those of noted builders as to deceive buyers who are not rell posted, and who are attracted by the glitter of cheap polish and tawdry engraving.

Every additional twenty-five dollars up to double the figure we lave named may be profitably expended, and for one hundred and fifty dollars a gun good enough for any reasonable man can be got from either good English or good home makers. It is noticeable that guns at one hundred and fifty dollars from English builders of repute are less highly engraved than those of American make, ornamentation being made to give way to sound work, duty and dealers' profits, so that the guns can be put upon the market at paying rates, yet sustain their makers' reputations. Under one hundred and twenty-five dollars we would prefer an American gun, but at this figure and upwards English guns may be admitted to competition, and a buyer may suit his fancy for either with confidence and safety.

THE BEST GUN FOR GENERAL USE.

There has been for a number of years a rage for guns of large bore and great weight, but the labor of carrying such in the field has produced a reaction that runs to the opposite extreme, and in place of ten bores weighing from nine and a half to eleven pounds, we find fourteen, sixteen, and twenty bores, some of them as light as five and a half pounds. Guns of both extremes may be admissible for special work, but we do not think them the best for general use, and after many years of practical experience in the field we have fixed upon a twelve bore weighing from seven and a half to eight and a half pounds, and with barrels twenty-eight or thirty inches long, according as the shooting is chiefly in cover or the open, as the best all-round gun a sportsman ean have. Properly bored and loaded it will kill all game shot over dogs, and on 
occasions will do good service at the trap or in a stand at ducks and geese, yet never be a burden that a man of ordinary strength cannot carry without fatigue. In pronouncing this the best gun for American sporting we are supported by a very large class of sportsmen, who have repeatedly expressed their opinions in our sporting journals, and we believe the day is not fur distant when it will practically supersede all others.

POWDER, SHOT, AND SHELLS.

Without good powder, shot, and shells the best gun will not kill game. For many years we have given different brands of powder extensive trials in the field, and speaking from experience we are bound to declare Hazzard's Electric the best we have ever used, with the exceptions of Curtis \& Harvey's and Pigou \& Wilkes's, both of which are imported from England. With either of these three the sportsman will get the greatest penetration with the least dirt and fouling of the gun, and the only objection to their use is their cost. All are high-priced, and this fact forces men to whom cost is a matter for consicleration to use cheaper grades. There are many such of about equal goodness, and we do not propose to discriminate between them, having expressed the above opinion upon the same principle as we spoke of the most costly English guns, viz., because they are practically out of competition. All black powder is open to the objection of smoke and dirt, and to remedy this many efforts have been made to discover some form of powder free from these defects. Several sorts of "wood powder" have been invented, but as yet none have given general satisfaction or come into general use. It is not necessirly, therefore, to speak of them in detail, but we are justified in saying the time will come when black powder, at least in its present form, will be discarded. The improvement in this line must keep pace with that in guns, and defects so great as those we have mentioned will prompt inventors to renewed efforts, which must ultimately be successful.

Two varieties of shot are now before the public, viz., the soft 
and chilled, the latter being hardened by a mixture of tin. There is no question that the latter gives greater penetration, as it does not bruise as badly in the barrel, and from its greater hardness breaks bones that would flatten or turn aside the soft. For all this the soft variety is most generally used in the field, and for small game does well enough. For wild fowl or at the trap, trial will satisfy any one that chilled shot is the better.

A great change has been made within a few years in the sizes of shot generally used. Formerly the large sizes were preferred, but experience demonstrates the at least equal killing powers of the smaller, from the greater number of wounds inflicted. In the smaller sizes the number of pellets to the ounce greatly exceeds those in the larger, and these extra pellets largely increase the chances of hitting the bird, and also of giving it many wounds, which, though not so large or deep as those inflicted by heavier shot, drain its life as effectually. For field-shooting Nos. 10 and 8 are now the favorites, and for ducks No. 6, with No. 2 for geese.

We do not hesitate to say we consider American shells fully equal to any imported. The primers and paper used in the Union Metallic, United States, and Winchester Companies' shells are sure fire and tough enough to stand repeated loading. For those who do not care to reload, the second-grade shells are as good as the first, and both are lower in price than the imported shells, which are no better. Paper shells have practically superseded metal, being lighter, more easily carried, and safer, besides costing so little that they can be thrown away after firing. The metal shells give slightly better penetration, and in shooting from a stand or at the trap may be used with advantage, but for field use the paper are good enough, and in such cases "it pays to let well enough alone."

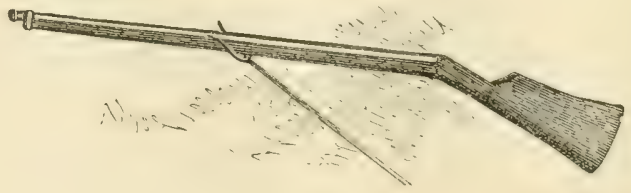




\section{WELDING BARRELS.}

The process for making common gun-barrels is very simple, and is done in the following manner:-A bar of iron is heated and hammered out into a thin flexible rod, resembling a good-sized hoop, of a length and thickness proportionate to the size and weight of the intended barrel. This rod is beat thinner at the muzzle-end than it is at the end intended for the breech.

This being arranged, the hoop is heated and turned round a mandrel, (a rod of tempered iron much smaller than the intended bore of the gun,) with the edges overlapping each other the half of an inch or so, and when welded together the barrels have the appearance of being manufactured or bored from a solid rod of iron. After being turned round the mandrel, the overlapping joints of the hoop are welded together by heating three or four inches of the tube at a time, and beating upon an anvil furnished with several semicircular furrows suitable for the various-sized barrels that are manufactured. This is the modus operandi adopted for forging common barrels, such as are used for exportation, and of which trash immense quantities come to this country through the hands of our hardwaremen.

The forging of barrels of a better description is quite a different operation, and requires far more labor and skill. The rod of iron is first heated to a red heat, a few inches at a time, and, one end being made stationary in a vice or other suitable contrivance, the other is seized by an instrument with a handle similar to an auger, by means of which it is twisted round a bar of iron (the mandrel) much smaller than the intended bore. By this operation the fibres of the metal are twisted in a spiral direction, which arrangement is known to resist the explosive force of powder much more than when the fibres all rum longitudinally. The hoops or rods are generally about half an inch or less in width, and consequently there will be over two spirals in every inch of barrel, when the twisting process is complete, as the joints are not made to overlap each other, but are forced to unite by a process termed "jumping," 
after the bar is entirely twisted. The greater the number of spirals to an inch, the more labored and perfect is the manufacture of the barrel, and the more expensive is the getting of it up. The rods for wire-twist barrels are extremely narrow,-only three-eighths of an inch, or less, in width; and the quantity of spirals is consequently increased.

After the hoops have been twisted round the rods, the spirals are joined together by heating the unclosed cylinder to a weldingheat and striking the end against the anvil, which springs them together so forcibly that, with a little hammering, the whole cylinder becomes welded as if formed of only one continuous piece. After the spirals are joined, the barrel is hammered in the grooves of the anvil to make it perfectly round.

It requires two, three, or four spiral cylinders, according to the length of the piece, to make one barrel; and great nicety and dexterity are necessary to join them together so that the barrel may appear to have been made out of one rod only. In common barrels this union of the rods may be distinctly seen upon examination before they are stained, and indeed very often after they come from the stainer's hands.

The next process in the manufacture of barrels is what is termed "hammer-hardening," which is accomplished by beating the metal for a considerable time in the grooves of the anvil with light hammers, for the purpose of closing the pores, increasing the density and elasticity, and rendering the texture more firm, flexible, and solid. This labor is not often bestowed upon ordinary barrels, got up merely for the home or foreign trade, but on ordered or show-guns only.

\section{BORING.}

The barrels are now submitted to the boring-mill for the purpose of giving them their proper calibre. This end is accomplished with the assistance of steam. The barrel being properly arranged on a frame, the boring-bit is introduced into the breech, and, by the application of the necessary power, is made to traverse 
the whole extent of the barrel, a stream of water playing upon the metal during the whole process, for the purpose of keeping down the heat that is engendered by the severe friction of the bit, and which, if allowed to increase to its full extent, might injure the quality of the metal.

The first or rough boring being finished, a bit of still larger size is now introduced, and the same process gone through with until the barrel is entirely freed from all unevenness and its whole internal surface made to shine like a mirror.

If the barrels, after repeated borings, should still exhibit an uneven surface and present flaws and depressions, they are rejected, and the metal returned to the forge, as it would be unsafe to bore them still thinner when the metal is so soft and frangible.

Some gunsmiths bore barrels by hand; and a good workman will make a beautiful instrument in this way, although it will take treble the time to finish it. The utmost nicety is requisite in the boring of barrels, as they should be perfect cylinders, and of exact calibre throughout their entire length. When they have passed the inspection of the lynx-eyed workman to whom this important process is confided, the barrels are handed over to the grinder, to be ground, turned, and polished.

GRINDING.

The barrels being bored, the grinder submits them to the friction of a revolving stone, for the purpose of freeing them from all the scales and roughness which cover them when they come from the hands of the welder.

\section{TURNING.}

A smooth surface being obtained by the application of the stone by the grinder, the barrels are next to be turned, which is accomplished either with a common turning-lathe or a self-acting machine.

A mandrel exactly fitting the size of the barrel is first introduced; the barrel is then placed in the lathe and the machine set 
in motion, and the whole process completed in a very short time, without any further interference on the part of the workman.

Turning by steam is far cheaper and even much superior to handwork, as the process of turning with a common hand-lathe is laborious in the extreme, and quite uncertain except in the hands of very superior and skilful mechanics.

The process of turning by a simple lathe is as follows:-The barrel being fixed in the lathe, an inch or so of the surface, both at the breech and muzzle end, is turned to the proper diameter; the rest is then removed to a distance of four or five inches from these points, and another inch or so of the surface at either end is removed, and so on; great care being taken, however, at each operation, to make the depth of the turning correspond with the size and calibre of the barrel. This part of the process being accomplished, the next step is to file away, by means of an instrument termed a "float," the projecting surfaces of the barrel intervening between the parts cut out by the lathe; the barrels are now ready for breeching and the tests of the proof-house.

\section{BRAZING.}

The barrels for double-guns are now filed away at the breech and muzzle, to make them lie against each other snugly, bound tcgether, and then brazed with hard solder or brass for several inches. The practice of brazing is highly censured by Greener, who asserts that by this process the strength of common barrels is diminished twelve and a half per cent., and that of hammer-hardened barrels to a still greater extent. His ideas on the subject are doubtless very correct, as the heating of the metal afresh to a white heat, for the purpose of brazing, must necessarily take away a portion of the tenacity or strength which it has already acquired during the process of hammer-hardening. 


\section{PROVING BARRELS.}

There is no department in the manufacture of a gun in which there is more deception than that of the proving-house. We do not wish to be understood to say that frauds upon the public actually take place under the eye and with the full cognizance of the companies to whom this important duty is confided; but we wish to inform our readers that large quantities of barrels are palmed off on the public, and particularly on the American market, having all the insignia of the London and Birmingham proof-houses, which never, at any time, were across the threshold of either establishment.

This is accomplished by forging the marks of these companies, and the deception is carried on to a very great extent; our readers, therefore, will see at once how much reliance can be placed on these marks when pointed out to them by the regular dealers as tests of the goodness of suspicious-looking guns.

The proving of gun-barrels was first introduced, according to writers on the subject, about the twelfth century, and originated with the company of gun-makers themselves. The enactments respecting the department, however, after a while became null and void, from a want of adequate means and a proper disposition on the part of the manufacturers to enforce them. Public attention, however, was again aroused to the importance of this matter early in the present century, owing to the discredit that had fallen on all English hand-arms, insomuch that sportsmen were obliged to seek their guns in other quarters than their own country, and considerable numbers were purchased in Spain and France for their use. In 1815, further legislation upon this subject made it obligatory upon all manufacturers to send their gun-barrels either to the London or Birmingham proof-houses to be tested, under a penalty of twenty pounds for every infraction of this ordinance; and the same fine was attached to the forging of the proof-marks of these companies. Previous to these enactments, thousands of guns rere manufactured for the foreign trade which were perfectly good-for-nothing, and the dealers themselves in these "sham-guns, sham-dam, park- 
palings," as they were termed, knew full well that they would most likely burst under the first explosion of a moderate-sized charge of powder and shot. Large numbers of these dangerous weapons were sent to this country; but they were furnished in far greater numbers to the slave-dealers for their nefarious and inhuman traffic on the coast of Africa. One of these worthless instruments, costing but a few shillings, was the usual price at that time of a human being; and what made the transaction still more unholy was the full knowledge, on the part of the traders, that the ignorant and degraded barterer in his own flesh and blood would soon pay the penalty of his wickedness, in the loss of a portion of his hand, if not his life, by the bursting of his ill-gotten prize.

In spite of the parliamentary enactments for the government of this important department, great frauds, as before stated, still continue to be practised upon the public, particularly upon foreign consumers.

If all the gun-barrels that come to our country were properly tested on the other side, we would not so often hear of the bursting of guns and the distressing accidents consequent upon these mishaps. The fact is, that the London and Birmingham proofmarks are not only forged in England, but they are even imitated in Germany; and large quantities of the latter trash, far worse than the most inferior English, are imported into our country, and may be bought at almost any price ranging from five to fifteen dollars for a double-barrelled gun of quite respectable appearance, and warranted in good faith by the ignorant dealers a regular stub-twist.

Greener gives a proof-scale of charges by which every barrel should be tested at the established proof-houses, and also furnishes a complete description of the whole business, which is quite interesting and instructive. All the respectable gunmakers of America test their gun-barrels themselves before they make them up for their customers.

The London proof-house requires that double-barrelled guns be joined together before testing, so that the gunsmith may be pre- 
vented from making them weaker by filing and brazing after the proof is stamped on them.

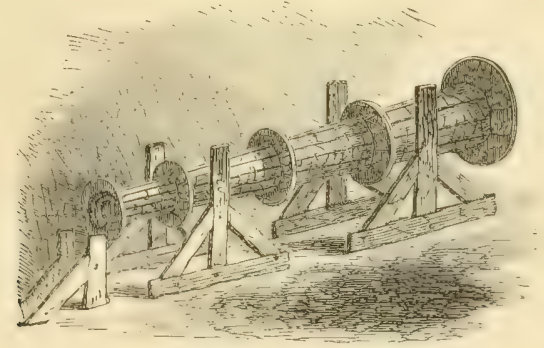

STAINING BARRELS.

There are a great many modes adopted as well as receipts given for the staining of gun-barrels: the basis of all, however, is the action of acids on the metal. Great numbers of inferior barrels are thus colored to resemble those of a superior quality, and these deceptions are very difficult to be discovered by inexperienced eyes. It was formerly supposed that the presence of "smoke-brown staining" was a positive guarantee of the quality of the metal from which the piece was manufactured: such, however, is no longer the case, as the gunsmiths are now enabled to produce this particular coloring even on the most ordinary barrels. In fact, so numerous and artful are the tricks now resorted to by the Birmingham people to deceive their customers, that the only safe plan left by which to secure a good and trusty gun is to order one of "a competent and honorable artist," of whom there are several on this side of the water as well as on the other.

\section{THE METAL USED IN THE MANUFACTURE OF GUNS.}

Very few sportsmen are acquainted with the peculiar kinds of iron used in the manufacture of gun-barrels. Although they frequently make use of the terms "stub-and-twist," "wire-twist," "Damascus barrels," \&c., they are generally quite ignorant of the real meaning of these terms, and know nothing of their import, origin, or application; in truth, they palaver often like parrots, 
without understanding the very phrases they make use of. This being the case, we shall endeavor to enlighten them on the subject in as short a space as possible, as we have so many other topics to treat of that we fear to dilate on any subject lest our work become too voluminous for our sporting friends to wade through.

\section{STUB-TWIST BARRELS.}

These barrels are very scarce,-that is, the real genuine stubtwist,-owing to the great difficulty of collecting the materials from which they are manufactured, the cost of working, \&c. This may at first sight seem a strange assertion to some of our readers, many of whom, no doubt, are under the impression that most of the guns in the possession of their friends, as well as those they have themselves, styled "stub-twist," are really and truly as genuine specimens as could be produced in any part of the world. Stop a moment, however, my incredulous friends, till you have learned from Greener of what a stub-and-twist barrel is compounded, and how it is wrought into a gun, and then tell me if you can expect to purchase one of these "rare gems" on this side of the water, or even on the other side, for the paltry sum of twenty-five or thirty dollars, lock and stock included.

"Old horse-nail stubs have, for a great number of years, been considered the best kind of scraps for the purpose of making the most superior gun-barrels. Numerous attempts have been made to find a composition of scraps to equal it, but so far without success. At what time the practice of using old stubs was adopted, we have no certain data. From the appearance of the oldest barrels, I should venture to say that it was coeval with their invention. It requires, however, no gift of prophecy to say that their use will not long continue, from the difficulty of obtaining them good, being only now to be procured from the Continent, and that with increasing difficulty.

"Before proceeding to manufacture them into iron, women are employed to sort and examine each stub, to see that no malleable cast-iron nails or other impurities are mixed with them. They are 
then taken and put into a drum, resembling a barrel-churn, through the centre of which passes a shaft that is attached to the steanengine, which works the rolling-mill, bellows, \&c. When the machine is put in motion, the stubs are rolled and tumbled over each other to such a degree that the friction completely cleanses them of all rust, and they come forth with the brightness of silver. The steel with which they are mixed, (generally coachsprings,) after being separated and softened, is clipped into small pieces, corresponding in size to the stubs, by a pair of large shears working by steam. These pieces are then, like the stubs, also put into a drum, in order to be divested of any rust they may retain, and are subsequently weighed out in the proportion of twenty-five pounds of stubs to fifteen of steel.

"After being properly mixed together, they are put into an airfurnace and heated to a state of fusion, in which state they are stirred up by a bar of the same mixture of iron and steel, until, by their adhesion, they form a ball of apparently melting metal. During this process, the bar has become sufficiently heated, to attach itself to the burning mass, technically called a bloom of iron, and by its aid the whole is removed from the furnace to the forge-hammer, by which it is reduced to a bar of iron of far less weight than the original mass, the weight lost being wasted in the process of welding and hammering. From the forge it passes to the rolling-mill, where it is reduced to the size wanted. By this mode of manufacturing, the iron and steel are so intimately united and blended that the peculiar properties of each are imparted to every portion of the mass, and the whole receives the degree of hardness and softness required. The process is admirable; and the mixture is calculated to produce a metal the best fitted, under the circumstances, to answer the purpose of manufacturing gun-barrels of the best description."

Spanish barrels, manufactured of the stubs of the nails used in putting on the shoes of the mules and horses, formerly had a great and deserved reputation among English sportsmen,-in fuct, commanding prices far beyond any guns produced in England. So 
great was the demand for these far-famed barrels, and so eager was every one to possess them, that it was not uncommon-so Blain informs us-for purchasers to be found at twenty, thirty, and even forty pounds for a single barrel.

The labor bestowed upon the manufacture of these barrels was excecded alone by that of the operatives on Damascus arms; and to such an extent was the hammering of the lusty smith carried, that it was not unusual for a mass of stubs, weighing from forty to fifty pounds, to be reduced by repeated beatings to a rod sufficient only to make a single barrel. By this long and arduous process the utmost ductility, tenacity, and purity were acquired, which rendered these guns superior for safety and shooting-powers to all other manufactures. Spanish barrels are no longer sought after with the same eagerness as in former times, owing to many circumstances that have operated to prejudice the public against them, as well as the present superior character of the stub-twist manufactured by English artists, and which, we opine, cannot be excelled by any barrels coming either from Spain or the East.

Great deception was practised in the getting up and sale of Spanish barrels as soon as it was known that there was such a demand for them in England,-a demand, in truth, which could not be supplied in the ordinary course of trade, as there was not sufficiont genuine stub-metal in all Spain to make these barrels fast enough for their foreign, much less their home, consumption. Inferior barrels consequently were imported from Spain, having the names of the most celebrated makers of Madrid engraved on thein. Nor was this the only deception practised upon the public, for Spanish barrels were actually counterfeited in the manufactories of Germany, and the country consequently soon became flooded with the most worthless and spurious trash imaginable, all purporting to be of real Spanish origin.

There is considerable difference between a stub-twist and a wire-twist, or a stub-twist and a plain-twist. All twists are not stub-twists; neither is it necessary for all stub-barrels to be twisted barrels. Although there is a wide difference between all these 
terms, it is very usual for our dealers in guns, as well as sportsmen, to make little or no distinction in their application. We do not, however, wish to find fault with our hardwaremen for the exhibition of such ignorance, when real, as they have but few, if any, sources from which they can obtain such information as would set them right on these subjects. There are, nevertheless, some importers as well as traders in guns among us who do know better than to impose upon their ignorant customers in the shameful manner in which they do, as they are well aware of the difference in cost, workmanship, and quality, between a genuine stubtwist and a wire-twist, and they should not boldly assert the one to be as good as the other, when they know what they say is false in every particular. Such conduct is very culpable, and more so when they are fully aware that the weapons they are selling are imperfect and often really dangerous to use.

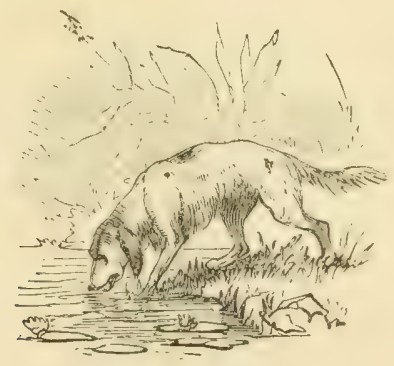

WIRE-TWIST IRON.

This is the next quality of iron used in the manufacture of gunbarrels, and the mode of making the bar of wire-twist is thus described by Greener :-_"Alternate bars of iron and steel are placed on each other in numbers of six each: they are then forged inte one body or bar; after which, if for the making of wire-twist barrels, they are rolled down into rods of three-eighths of an inch in breadth and varying in thickness according to the size of the barrel for which they are wanted; if for Damascus, invariably threeeighths of an inch square. When about to be twisted into spirals 
for barrels, care must be taken that the edges of the steel and iron shall be outermost, so that, when the barrel is finished and browned, it shall have the appearance of being welded of pieces the size of wires the whole length of the barrel." A little further on, our author remarks:-_"The objection made to the wire-twist is that, owing to the iron and steel being perfectly separate bodies, running through the whole thickness of the barrel, there is a difficulty in welding them perfectly, and of course there is a danger of its breaking across at any trifling imperfection. This objection is certainly well grounded, as many barrels break in the proving. I have myself seen a very strong barrel indeed broken across the knee without the slightest difficulty, while to all appearances it was perfectly sound. This is the reason why the manufacturers have ceased to make them, except for the American trade."

It is well known that every description of gun-barrel made in England that is deemed of a very inferior quality-in fact, too dangerous to be manufactured into a gun at home-is shipped to our country for sale. The knowledge of this circumstance should make all sportsmen rather chary in the purchase of guns from the hands of those who, from ignorance or want of principle, are ready. to palm upon them any kind of a weapon, no matter how inferior or how dangerous.

\section{DAMASCUS BARRELS}

"Are pretty to look at, but they possess no advantage over the wire-trist barrels; if any thing, they are inferior in strength and tenacity. The twisting which the barrels go through before they are welded together, for the purpose of forming into a barrel, instead of adding strength to the body of the metal, rather loosens the texture, by tearing asunder the parallel fibres, the close adhesion of which constitutes the power and strength of the metal."

These barrels are made as follows:- "When about to be converted into Damascus, the rod is heated the whole length, and the two square ends put into the heads (one of which is a fixture) of a description of lathe, which is worked by a handle similar to a 
winch. It is then twisted like a rope, or, as Colonel Hawker says, wrung as wet clothes are, until it has from twelve to fourteen complete turns in the inch. By this severe twisting, the rod of six feet is shortened to three, doubled in thickness, and made perfectly round. Three of these rods are then placed together, with the inclinations of the twists running in opposite directions. They are then welded into one, and rolled down to a rod eleven-sixteenths of an inch in breadth."

\section{CHARCOAL IRON.}

This species of iron, we believe, is the kind of metal from which most of the guns imported into our country by hardwaremen are manufactured. When we say most of the guns, we mean most of the best guns, as there are thousands of guns made of still more inferior metal than charcoal iron, expressly for the American trade. These barrels are generally palmed off upon the ignorant as the real stub-twist; they are, however, far inferior to the genuine article. The metal is composed entirely of old iron without any admixture of steel, and therefore is greatly deficient in the strength or elasticity of either the stub or wire-twist.

\section{OTHER KINDS OF METALS.}

There are several other varieties of metals or compounds from which gun-barrels are manufactured for foreign trade; they are generally far inferior even to charcoal iron, and are wanting not only in strength, but also in the tenacity and ductility so necessary for the making of an instrument which is intended to hold within bounds so dangerous and powerful a composition as gunpowder. Great numbers of these worthless weapons find their way to this country, and hundreds of individuals are crippled with them every year. A full description of all these metals will be found in Greener, as also a general exposé of all the deceptions sarried on in the gun-trade. 
WOOD FOR STOCKING.

Walnut is universally preferred in America for stocking; it is abundant, strong, durable, and handsome, and therefore combines many, if not all, the qualities calculated to recommend it to the gunsmith. Its natural beauty is very much improved by staining, and many useful points under this head may be learned from Hawker. The following method, however, we meet with in Greener's work; and, as we have tested its merits, we feel no hesitation in recommending it to our readers:- "After having got them (the stocks) dressed and sandpapered as fine as you possibly can for walnut, take a composition of unboiled linseed-oil and alkanetroot, in the proportion of four ounces of the latter to half a pint of oil. These, after being amalgamated for a week, will be of a beautiful crimson color, and will not fail to make walnut a handsome brown, on being laid on three or four times with a sponge."

Bird's-eye maple is also used for stocking, and is preferred by some to walnut on account of the greater beauty of its grain; we, however, and most other sportsmen, consider it far inferior to walnut. Greener remarks that maple possesses less "conducting principle" than any other kind of wood, and therefore is well calculated to lessen the recoil, and on this account is best calculated for gun-stocks. Of this argument, however, we think very lightly, for the reason that no partridge-gun properly loaded should recoil with sufficient force to give a disagreeable shock, whether the stock be made of walnut, maple, or any other kind of suitable wood.

The following method for staining maple, taken from the same source as the above, we have also used, -not on a gun-stock; however, as we have no gun stocked with this description of wood; but we tried it on some articles of furniture, and found it to answer a most excellent purpose,-in fact, imparting a beautiful and elegant appearance to the wood:-

"Mix an ounce and a half of nitrous acid with about the same quantity of iron turnings or filings. After the gas which is created by the mixture has evaporated, take a piece of rag and dip it in 
the liquid left, and wet all parts of the stock you wish to stain. Let it stand until it is quite dry; then lay on a slight coat of the oil and alkanet-root. Take a quantity of joiners' shavings: set fire to them, and pass the stock through the flame until it becomes quite black or the oil is quite burnt off. Re-sandpaper it, and you will find it, if possessing any figure, of a beautiful mottle. Add a few more coats of oil; it is then ready for varnishing, or any other way you may fancy to have it finished."

Maple stained in this way looks very beautiful, but we do not consider it either so handsome or so suitable for stocking as walnut; it is much more brittle and knotty, and is liable to break if roughly handled.

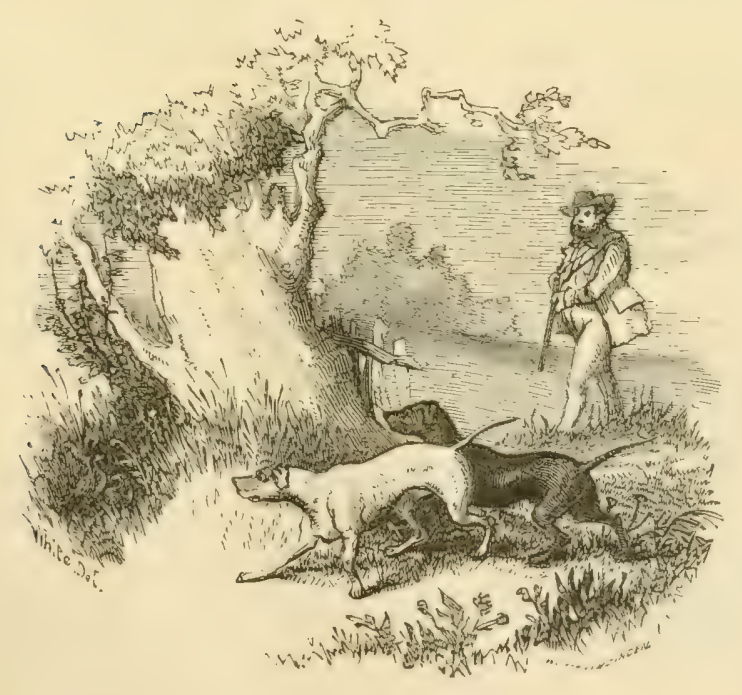




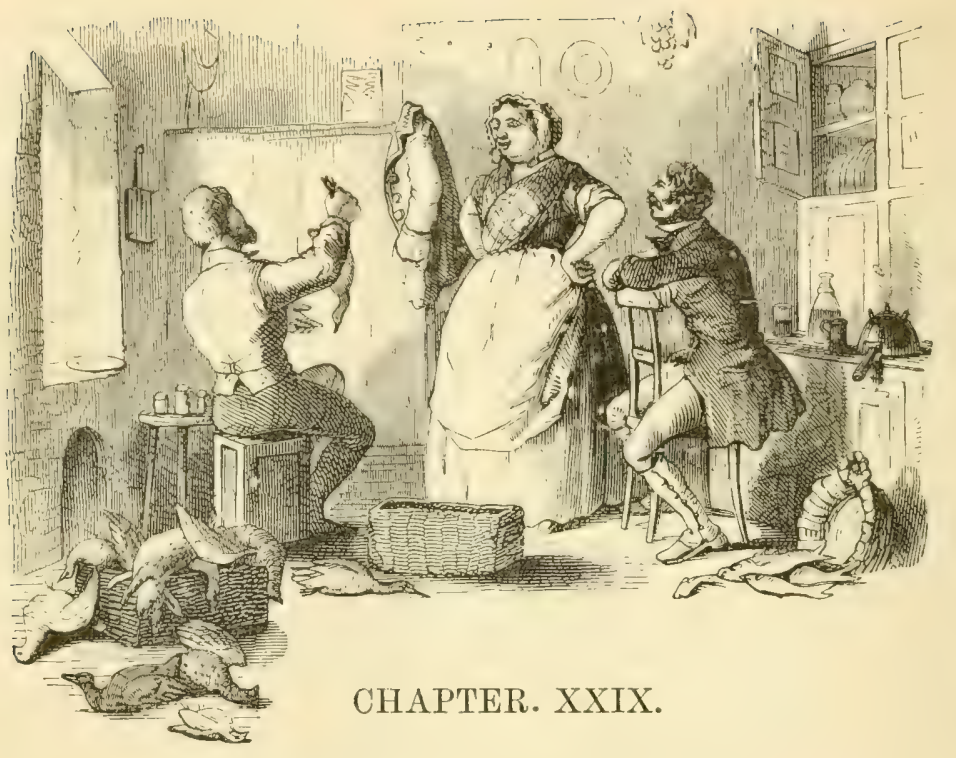

THE ART OF COOKING GAME

"God sends meat:"-who sends cooks?

Nequaquam satis in re unâ consumere curam:

Ut si quis solûm hoc, mala ne sint vina, laboret, Quali perfundat pisces securus olivo."

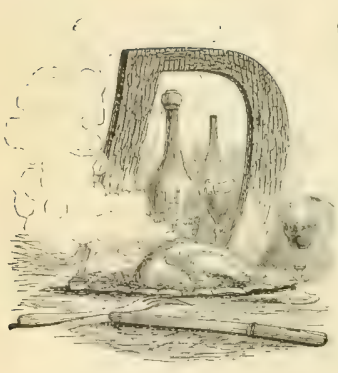

O not imagine, brother sportsman, that we are going to dive into all the mysteries and complicated paraphernalia of a cookerybook, or, as a scientific gourmand, that we are about to extol alone the pleasures, the delights, and the joys, of a well-spread table. In extenuation, or rather in support, of our trifling efforts to promote the happiness of our sporting friends when assembled around the convivial board with appetites made vigorous by the manly labors of the field, we beg to call their attention for a moment to the sage remarks of the philosophic Rumford when speaking on this subject:- "The enjoyments which fall to the lot of the bulk 
of mankind are not so numerous as to render an attempt to increase them superfluous. And even in regard to those who have it in their power to gratify their appetites to the utmost extent of their wishes, it is surely rendering them a very important service to show them how they may increase their pleasures without destroying their health." Dr. Mayo, in his "Philosophy of Living," also remarks that "man, unlike animals, is in best humor when he is feeding, and more disposed then than at other times to cultivate those amicable relations by which the bonds of society are strengthened."

Who among our readers will not cheerfully acknowledge the force of such sentiments, emanating, as they do, from men of study, reflection, and practical observation? Who among them will not concede, in the fulness of his heart, that "a good dinner is one of the greatest enjoyments of human life"? Who ever knew of a philosopher refusing to participate in the festivities of a banquet? And who ever encountered the still stranger sight of a disciple of Hippocrates living up to the dietetic precepts laid down for the guidance of his refractory patients?

Look around you on every side, ye carping cynics and snarling bigots, and see how many men of the greatest talents and rarest virtues, whether of the present day or of ages past, have sought pleasure in the innocent enjoyments of the table, and thus convince yourselves that these indulgences are not "incompatible with intellectual pursuits or mental superiority." Doctor Johnson, with all his wonderful attainments, did not consider a good dinner or a recherché supper beneath his attention; for we are informed by Boswell, his biographer, that "he never knew a man who relished good eating more than he did; and when at table he was wholly absorbed in the business of the moment." The doctor himself says, in his usual quaint and philosophic style, "Some people have a foolish way of not minding, or pretending not to mind, what they eat: for my part, I mind my belly very studiously and very carefully; and I look upon it that he who does not mind his belly will hardly mind any thing else." 
How perfectly correct and natural do these remarks appear to us, when we reflect for a moment on the intimate sympathy and peculiarly direct communication existing between the head and the stomach! If the least irregularity in the natural functions of the bowels takes place, with what rapidity is it followed by a proportional degree of malaise at the very centre of life,- - the brain!

In fact, the healthy operation of the whole natural economy is dependent in a great measure upon the state of the stomach; but the brain watches the actions of this organ with a most jealous eye, and in most persons is the very first to strike the alarm at the presence of gross or badly-cooked food; and it has been most justly remarked that "he who would have a clear head must have a clean stomach."

If such be the fact, (and no one certainly will dispute it,) how necessary is it that we should not only regard the quality of our food, but that we should have an eye to the proper preparation of it by the cook before receiving it into so important an organ as the stomach! We do not now address our remarks to those whose health is so robust, and whose habits and associations in life have been such as to force them to remain happy and contented with the coarsest fare, and whose stomachs consequently have attained the vigor of an ostrich or the capacity of an anaconda; such individuals, we know full well, would naturally accuse us of overrefinement and ridiculous nicety. Neither do we wish to encourage or uphold in their effeminate opinions those delicate and epicurean dandies who cannot enjoy a meal beyond the vile precincts of an eating-house or the luxurious saloons of a club-room, or whose pampered stomachs are never sated, save when tempted with all the niceties that the markets can produce, artistically concocted into savory stews, outlandish fricandeaux, greasy ragouts, highsounding fricassées, and dainty salmis.

Such fellows as these latter, "quibus in solo vivendi causa palato est," whose brains, (what little they may possess,) as well as their hearts, are located in their bellies, are objects rather of our commiseration, and wholly beneath the notice of any sensible man, 
save that, like peacocks at the grand congregation of the feathered race, they serve the purpose occasionally of adorning a dinnertable, of amusing the good-natured host by their senseless friponnerie, or perhaps, by the staleness of their wit and the dulness of their speech, of setting off the more cultivated jeux-d'esprit of some favored bun compagnon.

In fact, we have an utter abhorrence for a man in good health who cannot "rough and tumble it" in perfect good-humor for a few days when circumstances require it, whether it be to repose one's wearied limbs even upon a shaggy buffalo robe, under the wide canopy of a starless heaven, or to stretch them on the soft and downy feathers of a luxurious bed, surrounded by all the gaudy trappings of an ambitious upholsterer; whether it be to sit down to a mess of cold pork and brown bread, or to a round of juicy roast-beef: in fact, a sportsman should be ever ready in all cheerfulness to exclaim in the words of the ancient bard, "Rure meo possum quodvis perferre patique." But, at the same time, we must acknowledge, on the other hand, that we equally despise an ignorant, low-minded fellow, who affects to prefer salt pork to savory venison, or a barnyard duck to a Chesapeake canvas-back, or rotgut whisky to sparkling heidseck. Such a savage as this is more fit for the negro quarter than the banquet-room of the polished and refined.

The rational gratification of a natural appetite with such dainties as a kind Providence, in his infinite goodness, has given us in this world, cannot justly be called gluttony; nor can a proper attention or nice discrimination in serving them up be termed sensuality; as both the one and the other are the actual gifts of the Almighty, -the different varieties of viands on the one hand to tempt our palates, and the exquisite sense of taste on the other to enable us to appreciate them when laid before us. We have observed that those among our acquaintances who most frequently speak discouragingly of the pleasures of the table, and most vociferously disclaim all pretensions to what they significantly term good eating,-which, in truth, means nothing more nor less than having 
good food cooked in a wholesome and sensible manner,- - these same individuals, we say, when seated at the festive board, are the very foremost to find fault if the dishes are not served up in becoming style, or rather in accordance with their own peculiar and sometimes outlandish notions.

What gluttony, forsooth, or sensuality either, is there in preferring a plain roasted potato to a boiled one? And pray, what glut. tony or sensuality is there in preferring rich venison-soup to thin mutton-broth, or a larded partridge to a young squab, or mellow wine to tart cider?

Such differences as these are mere matters of habit or education; and a cannibal may with equal propriety be termed a sensualist when greedily devouring the tender flesh of a young infant, as a refined epicure when warmly extolling the gamy flavor of the leg of a grouse.

We do not profess to be a good cook, either practically, scientifically, or theoretically, nor do we aspire to so enviable a distinction, although the magnus coquus of princely establishments has always been an officer of considerable dignity; indeed, so highly was the profession esteemed among the luxurious ancients that a good cook, we are informed, was termed hominum servatorem,- the preserver of mankind.*

Notwithstanding all this high appreciation of culinary talents, we, like many others, would greatly prefer leaving the branch, with all its honors and practical operations, in the hands of those who have made the scientia popince their particular study and pursuit; though we cannot refrain from venturing a few remarks in reference to the art, so far as it concerns the comfort of the sportsman. We do not, however, consider the subject of cookery (as some foolish persons would affect) beneath our notice, but, on the other hand, regret exceedingly that our unavoidable ignorance on this score will confine our observations within a very limited sphere. 
Nothing is more annoying-at least to us, and no doubt generally to our friends-than to toil after game all day, even if this toil be our pleasure, and then have it totally ruined by the carelessness or ignorance of the cook; and, what is worse than all, perhaps disappoint a score of anxious guests, whom, in the goodness of our heart, we have asked to be partakers of our feast.

We are not a cook, brother sportsman, nor are we a glutton; but we may, perhaps, be a gourmand, or, in other words, an epicure, in all that relates to the cooking and serving up of game. There is, however, a wide distinction between these two characters. The epicure, by the acuteness of his palate in the exercise of that sense bestowed upon him by his Creator, is able to distinguish the good from the bad. The other regards not the delicacy or the quality of the food set before him, but rejoices alone at the quantity which he may be permitted to stow away in his capacious, ever-craving maw.

If a greedy, gormandizing fellow, unaccustomed to good living and moderate drinking, chooses to overload his stomach at a dinner-table, surely such beastly conduct is no argument against the rational enjoyment of eating in moderation, or against the seductions consequent upon good cookery and highly-seasoned food; for it is a well-known fact, as stated by Accum, that "savages, whose cookery is in the rudest state, are more apt to overeat themselves than the veriest belly-god of a luxurious and refined people,-a fact which of itself is sufficient to prove that it is not cookery which is the cause of gluttony and surfeiting. The savage, indeed, suffers fur less from his swinish excesses than the sedentary and refined gourmand; for, after sleeping sometimes for a whole day, having gorged himself with food, hunger again drives him forth to the chase, in which he soon gets rid of the ill effects of his overloaded stomach. Surely, cookery is not to blame for the effects of gluttony, indolence, and sedentary occupations; yet it does appear that all its effects are erroneously charged to the account of the refined art of cookery."

Although we may be willing to acknowledge ourselves in some 
respects a gourmet, still, we do not think that our love of the good things of this world could ever induce us, like Apicius, to offer our guests a ragout composed exclusively of the tongues of "peacocks and nightingales," or even of "partridges and reedbirds ;" nor would we desire, like Vitellius, to serve up for our brother, no matter how much beloved, a feast composed of two thousand dishes of fish and seven thousand of poultry. Neither is our taste so cultivated or refined as to hanker after the delicate flesh of young asses or the womb of a pregnant sow, * as served up on the festive boards of the luxurious Romans, or to relish the leg of a young puppy, as greedily devoured by the curious inhabitants of the Celestial Empire; nor is our palate so distorted that we could ever fancy, as some of our friends affect to do, the trail of a roasted woodcock or the contents of a snipe's stomach.

Nevertheless, if put upon short allowance, we might be glad to partake of any of the above dishes, as well as rattlesnakesoup, whale-blubber, and train-oil, without at the sarne time meriting the ignoble stigma of a glutton, since "necessitas non habet legem."

What, my delicate reader, would you think of a man that ate, at one meal,

$$
\begin{aligned}
& 4 \text { pounds of raw cow's udder, } \\
& 10 \text { " " raw beef, } \\
& 2 \text { " " tallow candles, } \\
& \text { Total, } \overline{16} \text {, }
\end{aligned}
$$

and washing the whole down with five bottles of porter? You would naturally, and very justly, remark, "What a hog! what a cormorant!" Strange as it may appear, however, such was the meal of Charles Domery, when a prisoner of war at Liverpool; and, although allowed the daily rations of ten men, he was not satisfied. 
It was not necessary that the science of culinary chemistry should be brought into action to provoke an artificial appetite in this individual: he was a glutton de facto. Nature made him such; and nothing but the strongest food could satisfy his inordinate cravings.

In fine, with the sentiments of Kitchener, and in the words of Accum, "the pleasures of the table have always been highly appreciated and sedulously cultivated among civilized people of every age and nation; and, in spite of the stoic, it must be admitted that they are the first which we enjoy, the last we abandon, and those of which we most frequently partake."

"Cookery is the soul of festivity, at all times and in all ages. How many marriages have been the consequence of meeting at dinner! How much good fortune has been the result of a good supper! At what moment of our existence are we happier than at table? There hatred and animosity are lulled to sleep, and pleasure alone reigns." These are the words, and such are the sentiments, of the illustrious Louis Eustache Ude, than whom no more accomplished maître de cuisine has ever lived.

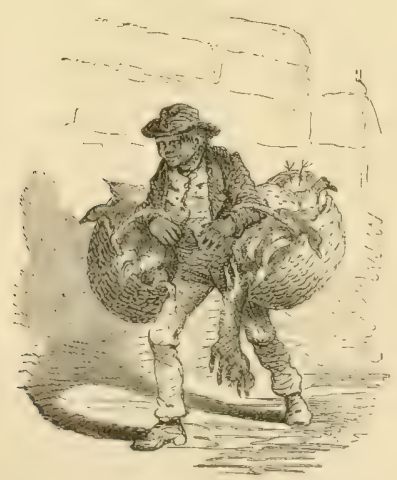




\section{TO SELECT GAME.}

The sportsman will often find it to his advantage to know how to select game, as well as to shoot it or cook it. We will, therefore, before entering more fully into the culinary department, give him a few hints upon this subject, which he may turn to good account as soon as a favorable opportunity presents itself.

There are three important points to be observed in the choice of game:-namely, the weight or size of the bird, the age, and the time of its being killed.

Those birds which are plump and heavy are, of course, preferable to those that are slim and light. A little practice will soon teach the sportsman to ascertain the comparative weight of birds by prising or rather weighing them on the first joint of his index finger.

Young birds are far better than old ones; their skin is much softer, and tears easily, their bills pliable, their legs and feet smooth and of a light color; their plumage is also lighter. The hen bird is generally preferable to the cock bird, being rnore juicy and tender.

When recently killed, the eyes are full and natural; the inside of the mouth, tongue, and throat, looks fresh, the skin white, and the whole body smells sweet.

If, on the contrary, the birds be old, they will be more tough and far less palatable, their bills hard, horny, and worn off, their legs rough and scaly, their feet ragged, and their nails short and blunt. If killed some days, the eyes will be sunk, their fulness gone, the inside of the bill, the tongue, and the throat, slimy and fetid, the vent soft and of a dark-bluish color, the legs and feet dry and husky to the touch.

So far as our experience teaches us, no kind of game-bird improves by keeping over two or three days, although in cold weather they may not be injured by it. Old and tough grouse (pheasants) may certainly become more tender by age, and perhaps may eat more palatably when in a state of half decomposition than when perfectly fresh; but this argues nothing, as the flesh was not good 
in the first place, and any change in its structure might, therefore, be for the better.

We do not, however, say that game should be eaten as soon after being killed as possible, for that would be wrong, except in the case of some water-fowl; however, we are satisfied that snipe, woodcock, plover, rail, and reed-birds, can be eaten with as mucb relish on the day that they are shot as at any subsequent period, and perhaps are never so good on the third day as they are on the first; at least, such is our notion on the subject, and perhaps we will be sustained in this opinion by some of our friends. We have no fancy for putting into our stomach half-decomposed substances of any kind; much less have we so distorted, so deprared a taste as to desire to partake of tainted, par-rotten game, or to chew up the half-digested leeches, worms, and bugs often to be found in their stomachs. Away with such mock refinement, such silly affectation!

In cold weather partridges will keep better than any other kind of game, provided they are hung separately and shielded from the rain and sun; those that are to be kept for any time should be as free from shot-wounds as possible. It is not necessary to draw them or pick them; if picked, there will be much more evaporation from the bodies of the birds, and they will consequently be far drier. A pinch of chareoal put into their mouths will assist much in keeping them sweet.

If frozen hard, game will keep for an indefinite period, but should be eaten as soon as convenient after being thawed; the best plan to thaw it for cooking is to hang it for a short time in the kitchen. No kind of meat should be put to cook before it is thoroughly thawed; otherwise, it will take double the time to cook, and at best will be tough, stringy, and tasteless.

The preservative effect of frost on dead animal matter is very remarkable, and is taken advantage of by the inhabitants of the far-northern countries on a very extensive scale, as may be learned from the following extract from Accum's Culinary Chemistry:"There is annually held at St. Petersburg and Moscow what is 
ealled the frozen or winter market, for the sale of provisions solidified by frost. In a rast open square the bodies of many thousand animals are seen on all sides, piled in pyramidal and quadrangular masses: fish, fowl, butter, eggs, hogs, sheep, deer, oxen, all rendered solid by frost. The different species of fish are strikingly beautiful; they possess the lustre and brilliancy of color which characterize the different species in a living state. Most of the larger kinds of quadrupeds are skinned and classed according to their species; groups of many hundreds are piled upon their hind-legs, one against another, as if each were making an effort to climb over the back of his neighbor. The motionless yet apparent animation of their seemingly-struggling attitudes (as if they had died a sudden death) gives a horrid semblance of life to this singular scene of death. The solidity of the frozen creatures is such that the natives chop and saw them up, for the accommodation of the purchasers, like wood."

\section{COOKING GAME.}

The more plainly and simply game-birds of all kinds are cooked, the better, save those of a sedgy or fishy nature. For these we shall give especial directions for disguising their disagreeable flaror.

No great art of culinary chemistry, in our humble opinion, can improve a plain roasted partridge, woodcock, or grouse. Nevertheless, to please the fancy or tickle the gustatory nerves of some of our dainty guests, it may be necessary to resort to some other more recherché method of serving them up.

To enumerate all the various modes of presenting game on the table, as practised by those versed in cooking, either for the ambitious purpose of exhibiting their skill in this branch or of whetting the appetite of some sickly epicure ever in search of novelty, would be at variance with the design of this chapter. We wish rather to confine ourselves alone to those simpler methods within the scope of every "family cook," discarding all useless and complicated dishes - such, in fact, as are within the comprehension alone of a mattre de cuisine, and which, by-the-by, need be served up but once in a lifetime. 


\section{TO ROAST GAME.}

To roast a partridge, grouse, or any other bird of the galli. naceous order, is as simple a process of cookery as can be attempted. The great error, however, which cooks most frequently commit in the operation, is that they place the birds too near the fire when first put down, and consequently cook them too fast, as well as too much in some respects. The surface becomes scorched and burnt before the flesh of the bird is actually warmed through; the juices are dissipated, the flavor lost, and the natural tenderness of the meat entirely destroyed. To remedy this evil, it will be necessary to caution the cook to place the spit at first at a considerable distance from the fire, so that the body of the bird will bccome thoroughly heated before the browning of the surface takes place; then to move it by degrees nearer the fire, so that the heat can penetrate thoroughly through the entire mass.

During this process it will be necessary to baste the birds occasionally with their own drippings or a small particle of melted butter, with which may be put a trifling portion of salt and black pepper. The drippings should be caught on pices of thin and crisp toast laid in the bottom of the pan: the crust of the bread should be pared off, and one small slice will answer for each bird.

When the birds are nearly cooked, they may be lightly dredged with flour, powdered cracker, or bread-crumbs, which, uniting with the juices exuding from every pore, form a beautiful brown crust. This process, before a brisk fire, should occupy about twenty minutes for a partridge, fifteen minutes for a snipe, woodcock, or plover, and twenty-five to thirty for a grouse;-a little longer, perhaps, for the last-mentioned bird, as it should be well done.

Scrve them up each on a slice of toast, on hot dishes and well covered.

This is the best and most simple method of cooking the greater variety of game-birds, and certainly within the ability of ans "plain cook," no matter how stupid she may be, or how lately" arrived from the "Emerald Tsle." 


\section{LARDED GAME.}

Game-birds of all kinds, when skilfully trussed, larded handsomely, and roasted brown, present a very beautiful appearance on the table; but we do not relish them so well as when served up perfectly au naturel. However, as before said, it is sometimes not only expedient but agreeable to us to consult the palates of our friends as well as to titillate their fancies by the variety of our set-out.

The process of larding is a very simple matter,* and may be learned from any cookery-book. The practice of it, however, upon small game in particular, requires some judgment and a great deal of nicety.

Before larding the birds, they may or may not be stuffed with a small portion of grated pork, bread-crumbs, and butter: the drippings ought to be received, as before, upon slices of thin toast. Roasted in this way, birds are certainly more juicy than when cooked perfectly plain, but are not, perhaps, so delicate to the palate of a true epicurean sportsman, as they have lost a portion of their natural gamy flavor, owing to the circumstance that the flesh and juices have become impregnated with the fat used in the larding, as well as that in the stuffing.

Larded grouse are better than larded partridges, larded partridges better than larded snipe, and larded snipe better than larded woodcock.

* Larding-needles may be had at the furnishing or hardware stores.

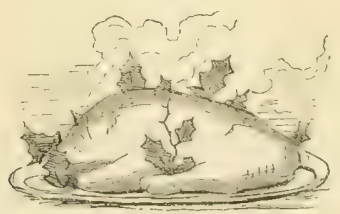




\section{BROILED GAME.}

Partridges, when split in the back and broiled over bright woodcoals, with a dressing of butter, salt, and a trifle of pepper, are very good; and this, perhaps, is the most convenient and safe way of having them cooked when from home. The cook should be careful not to burn or cook them too fast; the coals should not be too hot, or rather the gridiron should not be allowed to rest too near them, otherwise the surface of the body will be scorched black before the interior of the flesh is warmed through. If the legs of the gridiron are not long enough to protect the bird from the too direct effects of the hot coals, it is very easy to remedy the evil by putting pieces of brick under each leg.

\section{TO SPLIT AND BROIL PARTRIDGES BEFORE A COAL-FIRE.}

We recommend the use of the common beefsteak-roaster, which sits erect before the grate: we have partridges cooked in this way very often, and find them most excellent.

In all cases, game should be served up on hot dishes.

\section{BOILED GAME.}

Some epicures are very fond of larded and boiled partridges, as well as grouse. We are not very partial to either, although we can partake of both by way of variety, particularly if they be served up with celery-sauce, made without the admixture, however, of any kind of spice.

Birds should be boiled in a covered pot lined with china or tin, with just sufficient water to cover them nicely. They should be removed from the hot fire as soon as they begin to boil briskly, and allowed to simmer at the side till nearly done, and then permitted to boil up briskly again for a few moments before removing entirely. The lid should be raised now and then, and the scum, as it comes to the surface, skimmed off: this precaution is very necessary, as it adds much to the whiteness and consequent beauty of the birds when served up. A few grains of rice thrown into 
the pot will also assist in preserving the flesh white. The more slowly birds are boiled, the better; in fact, the whole process should be confined within a simmer: the more gradual the simmer, the more tender will be the flesh. It requires a longer time to cook game in this way than to roast or broil it.

\section{OTHER WAYS OF COOKING GROUSE OR PHEASANTS.}

Some persons have a fancy for cooking grouse, or rather basting them, with a rich gravy made of butter, spice, and Port wine. We have eaten them stewed in this kind of dressing, as well as stuffed with a variety of herbs or forced-meat balls.

These made dishes are all very nice in themselves, and calculated to please the fancy of many; but a pheasant stewed in Port wine and spices is no longer a pheasant, and therefore does not suit our palate; for, when we eat game, we like both to know it and taste it.

Pheasants are very passable when split in the back and broiled, as recommended for partridges. There are other modes for cooking grouse, which, however, are not worth referring to.

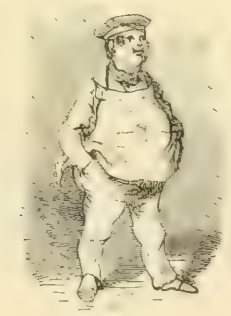

TO COOK A SNIPE, WOODCOCK, PLOVER, ETC.

As before said, the more plainly game-birds are cooked, the better. This observation applies particularly to the two former birds, as they each possess a rich gamy flavor which should be preserved unadulterated by any of the complicated arts of cookery.

A snipe may be larded and roasted; but a woodcock jamaisjamais! We regard a larded woodcock entirely outré,-a positive abomination. Yet there are some excellent cooks who will persist 
In serving them in this way, as well as some would-be cpicures who affect to relish them.

As for the disgusting and filthy habit of cooking these birds without taking out the gullet, gizzard, and stomach, we cannot speak in sufficiently harsh terms of it: we consider such a practice calculated rather to disgust even the depraved appetite of a cannibal than gratify the sensitive palate of a well-fed epicure. Those who are fond of half-cooked leeches, partly-digested ground-worms, tough viscera, and ugly insects of all kinds, can have them brought on the table in this way. For our part, we have no great penchant for such disgusting delicacies.

Audubon, in speaking upon this subject, very justly remarks, "Many epicures eat both snipe and woodcock with all their viscera, worms and insects to boot, - the intestines, in fact, being considered the most savory parts. On opening some newly-killed snipes, I have more than once found large and well-fed ground-worms, and at times a leech, which, I must acknowledge, I never conceived suitable articles of food for man; and for this reason I have always taken good care to have both snipes and woodcocks well cleaned, as all game ought to be."

Snipes are sometimes stuffed with herbs and baked. We consider such a dish on a par with partridge-pie.

Snipes, as well as partridges, are often roasted with a slice or two of fat pork wrapped around them, and then enclosed in sheets of writing-paper well greased with butter or fresh lard. The result of this process differs but little from that of larding.

Both snipe and woodcock require less time to cook than partridges, -in fact, should be rather underdone than overdone. From ten to fifteen minutes before a brisk fire is quite sufficient. When cut into, the blood should be seen on the elge of the knife, otherwise the juices of the bird have been dissipated by over-cooking. This should never be the case either with a partridge or grouse. The appearance of blood when carving these two latter birds is a sure indication that they have been taken from the fire too soon, and that the meat will consequently taste tough and raw. 


\section{TO COOK RAIL AND REED-BIRDS.}

Both these birds are best plainly roasted and basted with a trifle of butter, and served up on toast. Some of our friends speak in raptures of broiled rail. We cannot say that we admire them particularly when cooked in this way. Rail are a very juicy, tender bird, and require no larding; when roasted on the spit, enveloped in greased paper, they are very good. They should never be stuffed; they require about fifteen minutes to cook before a brisk fire. They are better eaten fresh, and never improve by keeping; in fact, they are generally shot during the warm weather, and when nothing short of an ice-house will preserve them longer than a few hours. They spoil very soon, particularly after being wet and pitched about in the bottom of the boat.

Reed-birds are best when roasted au naturel on the spit before a brisk fire. If enveloped in buttered paper, they cook more nicely, and there is less waste of the fat. Ten minutes is sufficient before a bright fire.

We have eaten reed-birds stuffed with crumbs of bread, butter, and a slight shade of herbs, and roasted in greased paper, which are very palatable for a change. They are also good when nicely broiled; some persons prefer them in this way to all others.

As to stuffing them with chopped oysters, or making them into dumplings with a thin crust of dough, and boiling them, we have nothing to say; and when any of our friends venture a word of commendation in favor of such abominable dishes, audio sed taceo.

\section{COOKING OTHER KINDS OF GAME.}

There are a great variety of other kinds of game-birds, known as fen, shore, or beach birds, which require very nice management to make them agreeable to an epicurean palate.

When these birds are known to be sedgy, they should be cleaned and rubbed with salt and corn-meal, and put to soak over night in cool water slightly acidulated with strong vinegar. They should then be stuffed with such herbs and spices as are best calculated to 
destroy, or rather disguise, their original flaror. If roasted and basted, or rather stewed, with a rich dressing of butter, spice, and Port or Madeira wine, their flavor is much improved; when served up, they may have a few drops of lemon-juice squeezed over them, to make the sauce more piquante. An old sea-gull, mud-hen, or any other tough fen-bird, may be made quite tolerable by such a process of cookery.

If, however, you should at any time be placed in a strait for something to eat, we would adrise Hawker's receipt for a "good mess," which may be made out of any thing in the way of a fowl, whether a tough old dunghill-cock, a cackling hen, a screaming gull, or a fishy dipper, as follows:-

"Have a fowl skinned and quartered;

Put it over the fire in a quart of cold water;

Boil it full two hours.

Then add two ounces (or a handful) of pearl barley, (rice will angwer ;)

Three blades of mace; about two dozen peppercorns, and

Salt to your taste:

Then let all boil together for one more hour."

An onion, or any other kind of regetable or strong herb, may be added ad libitum.

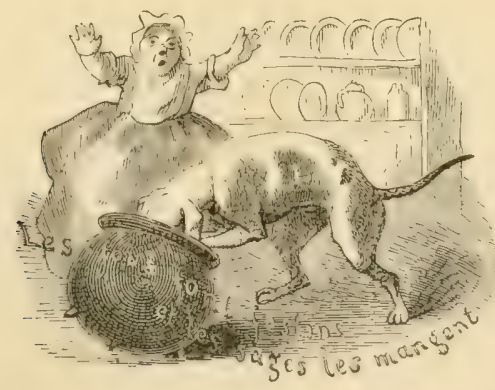




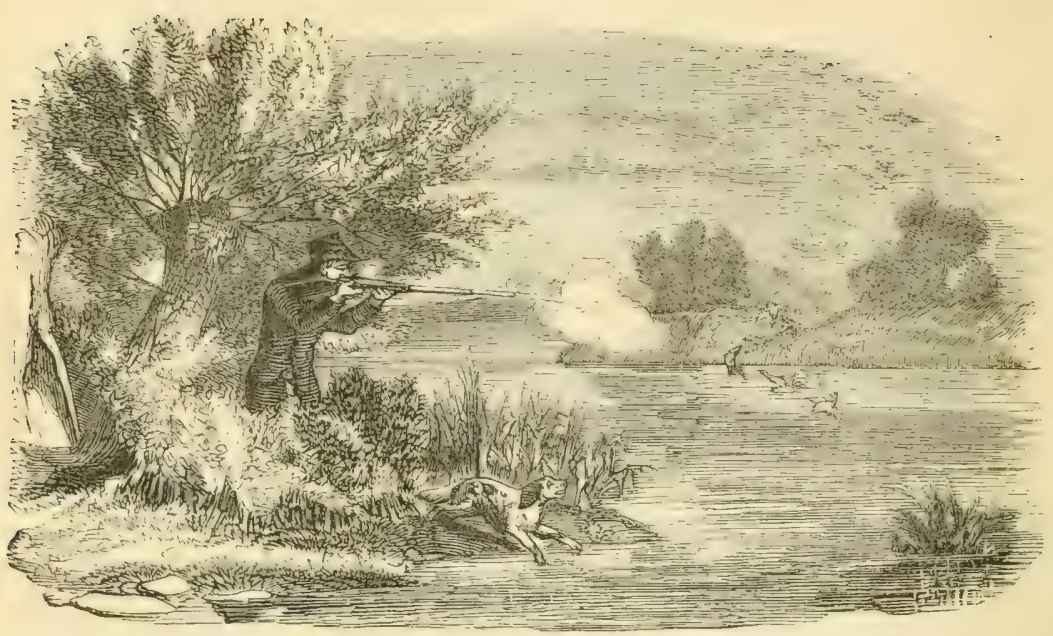

COOKING WILD DUCKS.

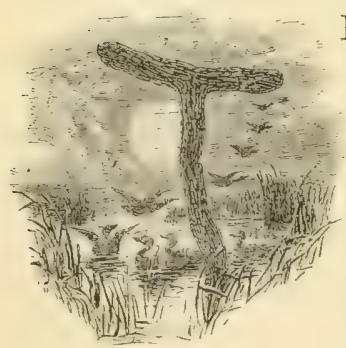

HE only admissible way for cooking wild fowl of every description is roasting on the spit, with the exception, perhaps, of teal, which may be broiled on the gridiron.

Those ducks that are fishy alone require any kind of stuffing; and, when stuffing is necessary to render them palatable, we consider a puddle-duck quite their equal, if not superior.

Ducks ought to be roasted on the spit, and never baked in an oven, as is too frequently done by careless and ignorant cooks. Baking renders them dry, rank, and tasteless, while roasting makes them juicy and tender.

Cooks are not generally partial to the cooking of game, as it is oftentimes attended with a good deal of extra labor, (picking and cleaning the birds, \&c.,) and, if not closely watched, will deceive their employers as to the mode of cooking it. They find it at 506 
times much more convenient to put a couple of ducks in an oven to bake than on the spit, owing to the low state of the fire or to the circumstance that the spit is used for some other purpose far less necessary. When this is done, the fowls are sure to be spoiled.

Ducks require but a short time to roast, and, when cut into, from every pore should exude a rich and high-colored blood; this will not be the case if the fowl be cooked too much, or baked in an oven. There should always be sufficient of its own drippings to baste it with; if not, however, a little butter and a little Port or Madeira will not in such cases harm them.

It will require about twenty-five or thirty-five minutes properly to roast a canvas-back. It should be served up with fresh crisp celery, potatoes mashed and baked, or plainly roasted.

Some persons like currant-jelly with these ducks. We do not; nor do we relish them so well when half-roasted and finished on the chafing-dish with jelly, \&c. We much prefer them perfectly au naturel. Canvas-backs should neither be picked nor drawn till a short time before they are to be cooked, nor should they 'bo soaked in water; in fact, they should not even so much as be washed out after being cleaned. Other kinds of wild duck, less delicate, may be picked and soaked in water two or three hours before cooking, without injury,-rather with benefit.

A small onion, or a few small slices of pared lemon, put in the inside of a strong fowl of any kind, will in a measure correct its disagreeable flavor and render the flesh more mild to the taste.

The following receipt, taken from Hawker, will be found an excellent sauce for all kinds of duck that require an artificial or made dressing:-

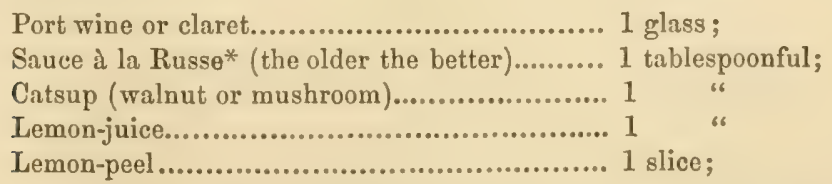

* See Francatelli's French Cookery, Receipt No. 35. If these herbs are not at hand, substitute others. 


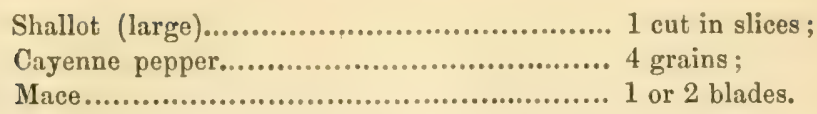

To be scalded, strained, or added to the mere gravy whict comes from the bird in roasting.

\section{FURTHER REMARKS ON THE SUBJECT OF COOKERY.}

Small game are generally cooked without cutting off the head or feet. Some persons are very partial to the brains. Independently of this, the birds look far better with their heads on, and they should never be removed by the cook.

Birds are far more tender if eaten immediately after being killed than if kept over night and then eaten; if kept, however, until the following or third day, they will most generally be as good again.

Ducks, if to be eaten soon after being killed, may be improved by burying them in the ground for a few hours.

As a general rule, thinly-sliced fried potatoes is the best accompaniment to game. They should be done brown and crisp; potatoes done à la mâtre d'hôtel will answer in place of celery-sauce for boiled game.

CELERY-SAUCE.

As we have recommended the use of celery-sauce with boiled game, it may not be amiss for us, before going further, to give directions for the preparation of it.

This sauce is the most palatable of sauces, and the only one we consider admissible as a dressing for boiled game; some even go so far as to recommend it for roasted birds; but we must confes? that we have no fancy or relish for it in this way.

Like all other nice sauces, celery-sauce requires some tact to make it. The celery should be selected with care, washed nicely, but not allowed to remain in water any time, for soaking it in this way, as is too often done, renders it tough, and destroys all that brittleness which makes the plant so relishable; it should then be 
pared,-not scraped or bruised, after the fashion of some ignorant cooks; then cut it into small pieces and boil in a small portion of water slowly, till quite tender; pour off the water through a colander, and boil it, or rather simmer it, again for a few minutes, with sufficient cream and a small particle of butter rolled in flour, and a pinch of salt and pepper.

The bowl in which it is serred should be warm; the sauce is to be poured on a slice of toast at the bottom. Raspings or crumbs of a French roll are also used in the same way, and answer an excellent purpose.

The cook should be very careful not to scorch the cream by putting it over a hot fire; it must be stirred gently while boiling. This sauce, as before said, requires to be made with some tact, and we cannot be too particular in our directions to the cook; for, if not made exactly right, it is neither palatable nor admissible for game. If burnt, which is the common error committed by stupid cooks in making it, it should be consigned forthwith to the swilltub, as six drops of such detestable stuff would spoil the flavor of a partridge or grouse.

If fond of spices, put in a little mace and a clove or two; we do not, however, recommend it. A shallot or so, a bay-leaf, lemonjuice, orange-peel, or a little parsley, might also be advocated by some of our friends.

\section{THICKENING FOR SAUCES OR GRAVIES.}

The foundation of all sauces and gravies is the white and browu thickenings of the French cookery-books. These thickenings are indispensable to a well-organized kitchen, and no dinner can be served up properly without their aid. They should always be in the larder for use, and are made as follows:-

\section{WHITE THICKENING.}

Take a small lump of butter, the size of course in proportion to the use you have for the thickening; melt it over a slow fire in a tinned or glazed stewpan; then drain off the buttermilk, and mix 
sufficient flour with the butter to make a thin paste, which keep on the fire for ten or fifteen minutes, being very careful that it is not scorched or colored; then set aside in an earthen jar for use.

\section{BROWN THICKENING.}

Take, as before, a small lump of butter, melt it slowly, get rid of the buttermilk, and make the residue into a thin paste with flour; then heat it gently over a mild fire until the whole mass becomes of a light brown color, when it is to be removed and put away for future use.

Both of these thickenings are useful in serving up game; the latter, especially, is suitable for mixing with the drippings with which roasted game is basted. These thickenings are the basis of many other sauces, which the skilful cook, with a little instruction, will soon learn to make subservient to her art.

\section{POTATOES À LA MAITRE D'HôteL.}

Steam or boil small, firm potatoes in the usual manner; then cut them into thin slices, and place them in a stewpan, pouring over them a small cup of cream in which has been melted a small piece of butter, seasoned with a little salt, pepper, chopped parsley, and lemon-juice; toss them over the fire for a moment, and dish them up piping hot.

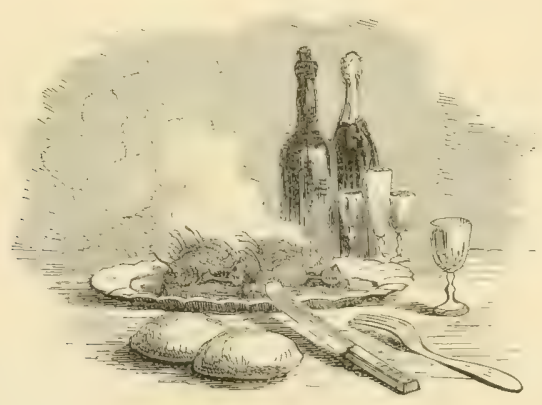




\section{VENISON-SOUP.}

The following receipt for making this most delicious of all suups we concocted a short time since, and we trust our friends will find it as palatable as we do. We are indebted to Frank Forester for sur first ideas on this subject.

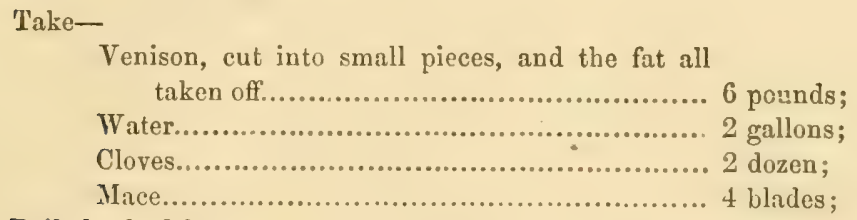

Boil slowly 2 hours.

Then add-

Venison, cut into small pieces an inch or so square......................................... 2 pounds;

Forced-meat balls.............................. 1 dozen;

Then boil 30 minutes.

Now add-

Cayenne pepper................................ 1 small pinch;

Black pepper..................................... "

Salt.............................................. 2 "

Lemon or lime-juice............................ half wineglass.

The soup-bowls - for it should be served in bowls - to be set before the fire, each contuining say half a pint of dry Port wine, and a thin slice or two of bread, toasted, if you choose, floating in it: the soup to be poured over the whole, each bowl covered up and served hot when seated at the table. This soup is equally good the second day.

Particular care should be had that the venison be quite fresh. and not in the least tainted, otherwise the soup will have a harsb Havor as well as disagreeable odor.

\section{SPORTSMEN'S BEEF.}

Take-

A large round of beef;

Saltpetre.......................................... $3 \frac{1}{2}$ ounces :

Allspice......................................... 1 ounce;

Cayenne........................................... 1 pinch ;

Rub in, and let stand 24 hours. 
T'hen rub in thoroughly-

Salt. several han Afuls.

Put it by for ten days, turning it and rubbing in the salt every day or two. Then put into a pan with-

Beef-suet... 4 pounds;

Dredge it slightly with flour, and bake slowly for 4 or 5 hours.

We have tried it; and we are satisfied that, with a little attention, it will keep during the whole of the cold weather. We also think that we can answer for its pleasing the most fastidious palate, and recommend it to our friends as an excellent and most convenient article of relish to have prepared for general use or in anticipation of a prolonged sporting-excursion. If the round is not very large, decrease the proportions somewhat, and take less time to prepare it. We met with this receipt in a very quaint and original book from the pen of General George Hanger, of the British army; we have altered it in some particulars, and, we think, for the better.

\section{FOR COOKING HARES OR RABBITS.}

Cut the hares into pieces.

The stewpan ought to be flat, so that every piece may touch the bottom.

First, heat the pan; then put into it about half a spoonful of lard; then place the pieces of hare into it so that every piece touches the pan: do not cover it. As soon as the hare begins to brown, turn the pieces and sprinkle over them two handfuls of flour, with two or three whole and very small onions. This must remain about five minutes over a moderate fire. Then pour over it about a pint of boiling water; add salt, pepper, two or three cloves, two or three allspice, and a very small portion of crushed garlic, (say about the size of a pea,) two laurel-leaves, (such as come in prune-boxes,) a small bunch of parsley, not cut apart, so that it may be taken out when the dish is served up. Let the whole boil, or rather simmer slowly, about one to one and a half hours. Then pour over the whole from one-half to one bottle of good claret wine, and continue to boil over a very moderate fire for two hours longer, when it will be ready to serve. 
Particular care is required not to have too much fire.

These proportions are for a dish of two hares. We are indebted to a friend for the above receipt, and we owe him many thanks for the opportunity he has thus afforded us of furnishing so desirable a dish for our gastronomic readers.

Squirrels may be served up in the same style, and will be found equally good.

"Nec sibi cœnarum quivis temeré arroget artem, Non priùs exactâ tenui ratione saporum."

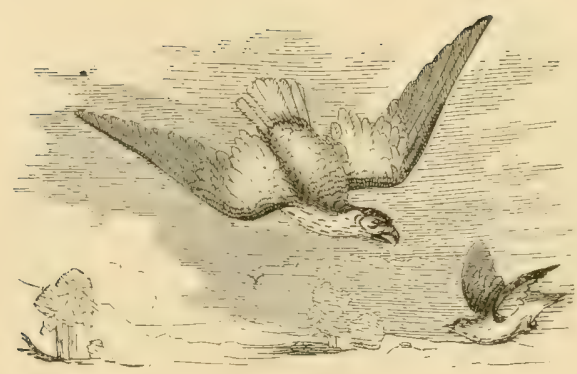




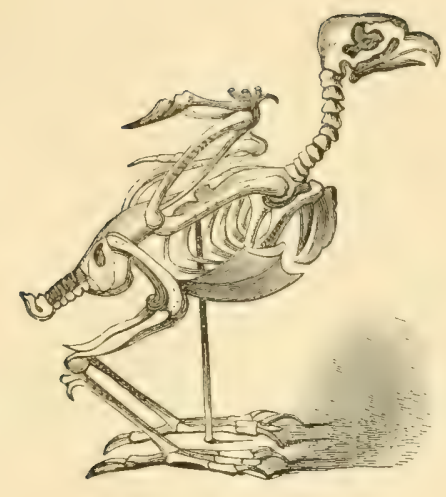

CHAPTER XXX.

SOME HINTS ON TAXIDERMY. THE ART OF OITAINING AND PRESERVING THE SKINS OF BIRDS.

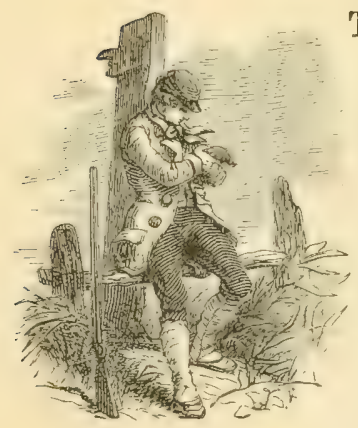

$T$ is often very important that the sportsman should know something in reference to the art of preserving and setting up the game he loves so much to pursue; for he may at any time, when a long distance from home and far away from help, come across some curious specimen, a rara avis,-a white partridge, a pied woodcock, or a mottled snipe, for example, - the preservation of which, for a place in his cabinet, would be a source of great satisfaction as well as pride. All this can be accomplished without any difficulty, provided the sportsman makes himself familiar with the very simple modus operandi of skinning a bird and the best plan of preserving the skin sweet till it is placed in the hands of an artist more competent to finish the undertaking.

The principal and most important object to be attained in the preservation of a specimen, after we have shot it, is the protection 
of its plumage. This is done by pursuing the following course:-If the bird is not shot entirely dead, the best and easiest plan to relieve it from its sufferings, as well as prevent any further displacement of its plumage by its painful struggles to escape from our hands, is to squeeze it across the breast, or under the wings, with the forefinger and thumb, but not with sufficient force to break the bones.

A small particle of cotton or fine tow should then be placed in the bill, to absorb any exudation that might run from the mouth and come in contact with the feathers. If the wounds show any disposition to bleed, they should also be lightly covered with the same material, to protect the plumage, as it is often very diffcult, and at all times requires very nice handling, to cleanse the feathers from coagulated blood.

This done, the bird should be lightly grasped in the one hand by the head, while the other is used in dexterously smoothing down the ruffled plumage; it should then be carefully wrapped up in a handkerchief or fine paper, and consigned to one of our spare pockets till the close of the day's sport. The following day or evening will be quite time enough to commence the operation of skinning, as the blood will not be completely coagulated till the lapse of several hours after death.

The process of skinning birds will at first seem very difficult and awkward to the novice; but we can assure him that a little patience and perseverance will soon overcome all the imaginary perplexities with which he surrounds the matter; and, before he has finished his sixth specimen, he will be surprised to find how easy a thing it is to skin a bird,- - even far less troublesome than to pull a rabbit out of his furry hide.

"In order to skin birds, we must pass a needleful of thread across the nostrils, tie it underneath the inferior mandible, (learing the thread the length of the bird,) to prevent the blood from coming out of the beak during the operation.

"We have before said that when a bird is killed we must introduce a little cotton into its beak; we repeat this injunction, be- 
cause the beauty of a mounted bird depends on the freshness of its head; it is easy to repair and clean the soiled feathers of the belly and back, but not those of the head without a great expense of time.

"These precautions taken, we stretch the bird on the table, the head turned towards the left of the operator; we divide the feather's of the belly right and left with small forceps, pull out the down which covers the belly, make an incision in the skin from the commencement of the sternum or breast-bone, until beyond the middle of the belly; raise the skin on one side by the forceps, and separate it from the muscles with a scalpel, approaching as near as possible to the wings; this done, we put a little floured or powdered cotton on the skin and flesh, that the feathers may not stick to them; we force up or push out the thighs within the body of the skin, cut them between the femur and tibia in such a manner that the former remains to be afterwards pushed back into the skin. By the help of the scalpel and the fingers we detach the skin as far as the rump, which we cut off. It is essential for this part to remain attached to the skin to sustain the tail-feathers. We then take the already uncovered part of the borly with the left hand, and continue to separate the skin from the two sides, eutting some little tendons, which we find before we come to the wings, with the scissors; we separate the wings from the trunk at the junction of the humerus with the body, and restore them to their proper place. We continue to skin the neck, thrusting the head from within, and we uncover it, taking care not to enlarge the opening of the ears, and, above all, to be particularly attentive not to injure the eyelids in taking out the eyes, which are easily picked out with closed points of the scissors; we replace the eye with chopped cotton, with which we fill the orbits.

"We separate the neck, take out the tongue, and carefully remove all the flesh which is between the two branches of the inferior mandible. We enlarge the occipital hole, to extract the brain, by means of an iron instrument resembling an ear-picker; and, to finish cleaning out the inside of the head, we pass cotton and flax 
Into it several times. We must, during the operation, besprinkle the humid parts with plaster of paris, or dry earth, from time to time, to prevent the feathers from adhering to them and becoming dirty, and also divide the feathers to the right and left, for the same reason.

"We then take out the wings, cut them off at the second joint, and, taking away the flesh, restore them to their place. This operation answers for small birds; and we anoint the wings in the parts which are destitute of feathers. We take away the flesh of the thighs, always preserving the bones of the leg, and put them back in their places.

"If the bird be of a larger size, we must carefully take away all the muscles which adhere to the skin, as well as the fat; and, if it has been killed by a gun, or holes are otherwise formed in the skin, they must be properly sewed up within.

"We fix a piece of thread to the first joint of each wing, drawing them together to the distance which they occupy when the bird is in the flesh. This precaution, which does not appear to be of great importance, infinitely abridges the operation; for, when the bird is mounted, the wings place themselves, provided they are properly tied' withịn."-Mrs. Lee's "Taxidermy."

The skins of some birds are far less elastic, after being dried, than others, and therefore require particular care in their stuffing. Those of the gallinaccous order, or game-birds generally, are very contractile and non-clastic, and consequently require full stuffing when green, to preserve them in their natural proportions, as it will be found very difficult to stretch them after being dried, even if submitted to the relaxing effects of steam, which softens their entire structure more than any thing else.

The skins should never be hung up to dry, as the weight of their bodies, if suspended by the head, will stretch their necks to an unseemly length; a somewhat similar result will be effected if they should be hung by the legs. The stuffed skins should be laid out on a plain surface, with their heads and legs gently extended in a line with their bodies. 
We saw a few days since a large box of pinnated-grouse skins nearly ruined in consequence of having been ignorantly suspended by the neck to dry.

To preserve the skins from the attacks of insects, more especially in warm weather, it will be necessary to powder thoroughly every portion of their inner surfaces with pure arsenic, or anoint with some of the arsenical soaps or other standard compositions. We prefer the free use of the arsenic itself: a weak solution of corrosive sublimate is the most convenient, if not the very best, of the liquid preparations. A teaspoonful of this poison to a quart of alcohol is about the proper proportion. The whole skin can be immersed in this solution without detriment, if it be deemed expedient.

With these few observations on this head, we will pass on to another kindred subject, which we also purpose to treat in the same summary manner; our object being merely to call the attention of the intelligent sportsman to these matters, with the hope of creating an interest in those animals which he pursues, beyond the mere shooting of them, - an interest that will most likely ultimately result in benefits to the cause of science. If this end is accomplished, our object is secured.

It could not be expected of us to enter largely into the subject of taxidermy, for it would require a volume of itself; and, moreover, there has been so much already written by those far more experienced than we could ever hope to be, that it would be absurd in us to collate such matters for our present book; we prefer calling the attention of our readers to the works of Mrs. Lee and Captain Brown, either of which contains all the information that one could desire upon the art of collecting, preparing, and mounting objects of natural history.

Both of these manuals have gone through a large number of editions, and contain a vast amount of information in a small compass. 


\section{PRESERVING EGG-SHELLS.}

To make his cabinet more complete, a sportsman may have a desire to preserve the nests and forms of the eggs of such gamebirds as he may meet with in his rambles over the country. The only effectual method of doing this is "to blow the eggs," as the shells are so very porous that no plan, however skilfully devised, will prevent the putrefaction, sooner or later, of their contents, if we attempt to preserve them whole. Baking, boiling, slow drying, immersion in spirits, varnishing, \&c. have all been tried without effect. To rightly "blow an egg-shell" is a process familiar to every truant-playing young urchin, and it would therefore seem unnecessary for us to enter into any detail upon so trite a subject; howerer, we may not go far amiss in instructing some one of our quiet readers who, perchance, never played truant or robbed a bird's nest in his youthful days.

The plan to be pursued is to make a hole in proportion to the size of the egg in the point and another in the butt; shake the egg well, or stir up the contents with a small wire or darningneedle, so as to break up the yolk; then apply the butt-end to the mouth and blow the contents out at the point. This done to your satisfaction, immerse the point in a cup of water and suck up a small portion into the shell; shake it well and blow it out; repeat this operation till the egg is entirely free from all the white or yolk that may adhere to its inside.

Eggs may also be blown by means of a small pipe constructed as exhibited in the following diagram.

These pipes, made of glass, can be had of the apothecaries. If made to order, however, either of silver or other suitable metal, they will answer a better purpose and last a lifetime: the glass ones are apt to get broken, and at all times require nice handling, as the points are necessarily so delicate and fine that the slightest knock will fracture them. With the use of this pipe it is only necessary to make one hole in the side, shake the egg for a moment or so, to break up the yolk, then insert the point (c) 
of the pipe, and suck the contents, by the application of the lips to the point $(a)$, up into the bulb $(b)$; then withdraw it, and blow the contents out by the same passage by which it was introduced; repeat this as often as necessary, according to the size of the egg; then suck up some water into the pipe and blow it into the egg; shake it up well as before, and draw off with the pipe, thus leaving the shell perfectly clean.

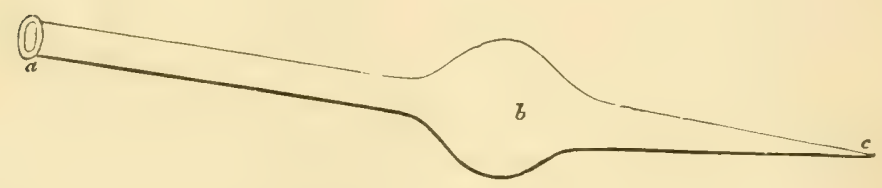

To preserve more effectually from corruption the scmi-membranous lining that covers the whole internal surface of the egg; the putrefaction of which would more or less affect the integrity of the shell, it is recommended to introduce into the egr, by means of the pipe, a small quantity of a strong solution of corrosive sublimate in spirits, which, being shaken up for a moment or so, may be drawn out as before. Care should be taken neither to draw too hard nor too suddenly upon the solution, as we may thus get a small portion of it in our mouth, which, by-the-by, will not prove so agreeable as a sip of golden sherry. A very little practice, however, in the use of the pipe, will make the operator quite skilful.

A handsome, semi-transparent appearance may be given to the egg by putting on, with a camels'-hair brush, a light coating of mastic or copal varnish. Colored eggs should be brushed over with a solution of gum arabic, as the varnish may impair the color.

\section{TO PRESERVE WINGED BIRDS FROM FATAL HEMORRHAGE.}

If we should wing a bird, and wish to preserve its life, it will be proper to examine it carefully, more particularly if it be a small bird, to see if the hemorrhage is likely to prove fatal. If such be the case, it will be necessary immediately to secure the blood- 
vessels by a ligature, which can be very easily accomplished by examining the following drawing and adopting the means to be described.

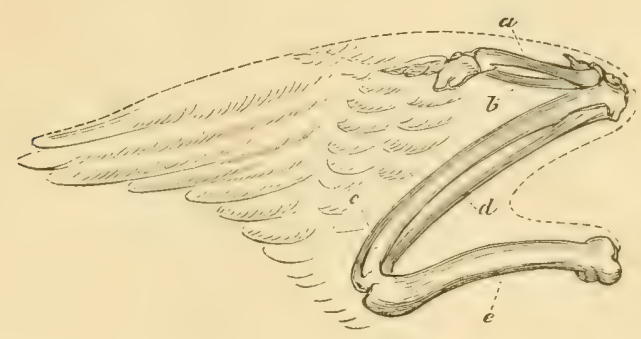

If the round be high up, at the point $e$, pass a needle, armed with a piece of waxed silk or thread, slightly under the skin, but near to the bone just above the wound, and, drawing the two ends together around the bone, tie them. The pressure thus exerted by the ligature on the humerus will be quite sufficient to prevent the passage of blood along the ressels that lie in close contiguity with the bone. This done to our satisfaction, the bird may be set at liberty, and the ligature carefully removed in the course of a day or two.

If the wound be below the second joint, as at $d$, pass the needle, armed as before, between the two bones and close up to $d$, and tie the large bone $c$, which will thus include the bleeding vessels.

If at $a$, below the third joint, pass the needle, as in the preceding case, between the bones, as near as possible to the small bone $b$; then pass it again on the opposite side of the bone $a$; now bring the ends together and tie them; this being done, the artery will be included in the ligature.

\section{TO PINION OR AMPUTATE A WING.}

If we should wish to pinion or amputate any portion of the wing, either on account of a fracture or to prevent the bird from escaping, it will be necessary first to put on a ligature just above 
the portion of wing to be taken off. This must be done according to the directions laid down above. The flesh is then to be cut down to the bone with a sharp knife, and the bone sawed through with a very fine saw, at a point just above the fracture. If a saw is not at hand, a pair of sharp shears may be used for cutting the bone.

Nipping the bones with shears, however, is very apt to fracture them and leave a ragged and uneven edge protruding from the wound, which will prove very painful to the bird and retard its recovery; the use of the small saw is far better. These operations, although very simple in themselves and such as any schoolboy can practise, still require some little skill and artistical cunning to perform properly. 


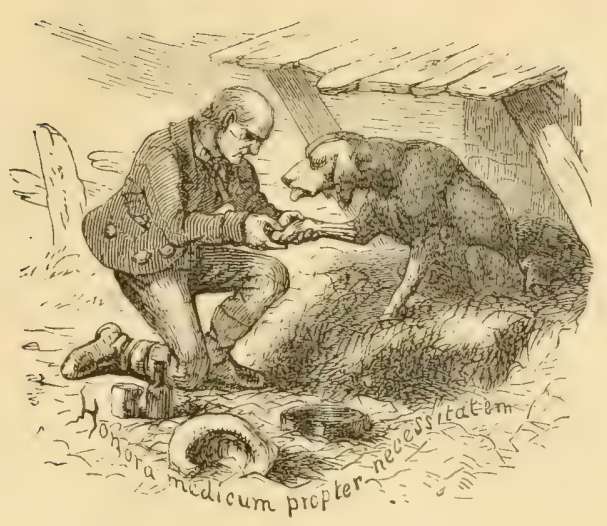

\section{CHAPTER XXXI.}

\section{GENERAL HYGIENIC REMARKS}

"The first physicians by debauch were made; Excess began, and sloth sustains, the trade. By chase our long-lived fathers earned their food; Toil strung the nerves and purified the blood; But we, their sons, a pampered race of men, Are dwindled down to threescore years and ten. Better to hunt in fields for health unbought, Than fee the doctor for a nauseous draught. The wise for cure on exercise depend:

God never made his work for man to mend."

\section{ATMOSPIERIC VICISSITUDES.}

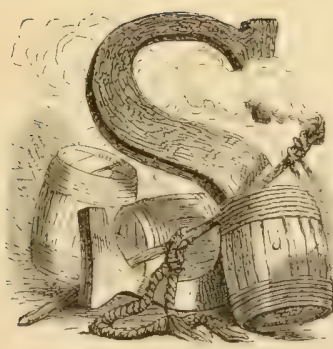

PORTSMEN should guard as far as pos. sible against the ill effects arising from exposure to the various atmospheric vicissitudes inseparable from their pursuits.

The clothing should be adapted to the season in which they hunt and the par ticular sport in which they are engaged; if the weather be warm, a heavy coat is a great encumbrance, and occasions much unnecessary fatigue; on the contrary, if the weather be cold and boisterous, a light coat 
would be equally inappropriate, and expose the wearer to a catarrhal affection, or perhaps an attack of rheumatism.

We cannot be too particular in this respect, although many old veterans may laugh at our remarks, as tending perhaps to effeminacy, and say that such precautions are suitable only for "dandy sportsmen," but quite beneath the notice of those accustomed to braving all kinds of atmosperic changes while in pursuit of game either by land or water, and perfectly regardless of heat or cold, wind or rain. To these we reply, in a hackneyed but nevertheless appropriate phrase, Chacun à son goût; at the same time we do not deny that there may be some who can brave all these extraordinary exposures, without apparently suffering any particular inconvenience at the time; but we may recollect, also, that many have passed through the impending dangers of a long and arduous campaign, and come out from its perils unscathed, perhaps to die from the prick of a needle or the scratch of a rusty nail. Thus it may be with some of those who ridicule such precautions as every sensible man should take to ward off the bad effects of imprudent exposure to the changeable and trying climate of our Northern and Eastern States.

"An ounce of precaution, at all events, is worth a pound of cure;" and no sportsman will do himself any harm by attention to the few hygienic rules that we are about proposing for his future comfort. He will rather derive much benefit from them, and bo able at an advanced age to exclaim,-

"Temperance, joy, and repose,

Slam the door upon the doctor's nose."

If wet after returning home, the clothing should by all means be changed as speedily as possible, and, if necessary, a little warm spirits may be taken. A cup of hot tea or coffee will often answer every good purpose, especially with those unaccustomed to the stimulus of strong drink. Nothing is more apt to produce a catarrhal or rheumatic affection than the pernicious habit of remaining in wet clothes after coming from the field, particularly the careless and common practice of keeping on wet stockings. 
Off with them at once, or your joints will ache long before you have seen twoscore and ten, and the sports of the field will no longer hold out any charms for your rheumatic limbs. Do not sit nodding and toasting your wet feet before the blazing fire, but off with those uncomfortable appendages to your lower extremities, and replace them with dry ones.

\section{OVERHEATED.}

When overheated from extraordinary exertion, avoid placing yourself in a draught of air, and shun the almost uncontrollable desire hastily to quench your burning thirst with the crystal waters of some sylvan stream that bubbles seductively at your feet; as a sudden checking of the perspiratory functions by these means often produces the most serious consequences, and death itself has followed in the track of such imprudence. Do not be tempted, no matter how great your fatigue, to remain quiescent for any time, while in a state of free perspiration, in a damp or wet place; do not sit down to rest your wearied limbs, but keep in gentle motion, until your skin has assumed its natural temperature, and then you may quaff freely and rest in safety. A professional acquaintance of the author, a few years since, fell a victim to his own folly by going into a damp cellar, and remaining for some time, by way of cooling himself during an excessively hot day in summer.

If hot or thirsty, mix a little wine, spirits, or vinegar,- the latter if you be a teetotaler,-with the water before drinking it: this precaution will counteract any bad effects arising from partaking of the fluid when in an excited state. It is also well to bathe the wrists and temples before drinking.

\section{STATE OF THE ATMOSPHERE.}

There is certainly a vast difference betreen the air of the mountains and that of the low, marshy districts of our country. The former is pure and healthy, while the latter is corrupt and often poisonous. The one contains all the natural constituents for supplying the respiratory functions with that food so essential to their 
well-being, while the other is tainted with the germs or exciting causes of numerous epidemic and endemic affections.

Therefore, if the sportsman should visit the malarious districts during the season of these poisonous exhalations, it behooves him to be extremely cautious how he exposes himself to their deleterious influences. He should not, in the first place, be too eager to sally forth to the fields before the morning mists are absorbed by the benign rays of the sun and all the malarious effluvia wafted off by the gentle morning breezes. Nor should he toil too much in the heat of the day, so as to enervate his frame to such an extent as to destroy the equable balance of health, and thus render his system more susceptible to the poisonous malaria engendered around him. Nor should he permit his love of sport to beguile him to remain out in the field after Father Sol has dipped below the horizon; otherwise, the evening's fog may shortly treat him to an unfriendly "shake." But, above all, he should avoid sleeping in malarious districts with open windows. If the weather be chilly, have a fire, if possible, in your bedroom, or fumigate it thoroughly with cigar-smoke before retiring: we say cigar-smoke, as this is generally the most pleasant mode of fumigation to which a sportsman has it in his power to resort. In the absence of this, however, have recourse to the burning of paper or rags, or adopt any other method that the ingenuity of the party may suggest. A little brown sugar or a handful of feathers thrown on a hot shovel will assist materially in disinfecting a sleeping-apartment in a malarious region.

The exhalations of a noxious country are all destroyed by the cold weather, and we may then visit those districts which are quite unapproachable during the spring and summer months, owing to the existence of this aeriform substance, termed "miasma," that is sure to fix upon a stranger who is so imprudent as to venture there in the sickly season. 


\section{DIET AND DRINK.}

"With relish would you taste your rich repast?

'Tis appetite must make that relish last;

If the great orator did right to say

That eloquence in action, action lay;

And will you ask me, Appetite comes whence?

A fortiori, I should answer-thence.

You want-what you may think an idle notion-

Perpetual exercise! perpetual motion!

A substitute for bread, your poorer neighbor;

But you require a substitute-for labor!"

"Eat and drink with moderation, if you wish to live long," is a saying not less applicable to sportsmen than to other persons; but to quaff lightly is absolutely necessary, not only for the comfort but for the success of the shooter, as much depends upon his temperance in all things appertaining to the bottle. It is impossible, as all will grant, (old topers not excepted,) that any one, no matter how hardy he may be, can take the field with a steady hand and sure eye on the morning following an evening's debauch; we will use even a milder term, and say after a night's frolic. Laying aside the headache and the general malaise that most usually attend excesses of this kind, the nervous system, even in the nost robust, must suffer more or less from the reaction that takes place on such occasions; and the muscular system, sympathizing with it in its derangement, renders the whole vital apparatus unstrung and unfit for arduous duty, such as the sports of the field require.

These conclusions are so evident that it requires no argument to support them; and we suppose no one will deny that such are the inevitable results of any excess in drinking.

No drink insures better health, and produces a more equablo tone throughout the whole system, than the exclusive use of unadulterated water,-nature's gift,-the only beverage to which all animated creation instinctively resorts to quench the natural cravings of thirst.

A fondness for other fluids, especially vinous liquors, is the effect of education and habit, as few persons like the taste of any description of spirits the first time they venture to apply 
their lips to the brimming bowl; moreover, there never was a drunkard made a sot in a weck; the dreadful vice is the consequence of a long and obstinate use of these liquors, which actually at first were very obnoxious to him. Water is the best solvent of all food taken into the stomach, and there is no drink that favors, or rather assists, the digestive apparatus so much, in a state of health, in the performance of its duties. It should therefore be used in preference to all other beverages by the sportsman, as well as by all others who wish to live to an advanced age. It is a wellknown fact that all those individuals who have attained a great age were and are water-drinkers; and it is seldom that we heur of an inebriate, or even of what are termed moderate drinkers, arriving at old age free from chronic affections.

If, however, it be necessary, either from habit or the peculiar condition of the constitution, to take a "little something" occasionally during our excursions, let that little be of the very best; and, in order to insure this, carry it along with you.

$\Lambda$ void, by all decent means, partaking of the poisonous drugs, called spirits, that are so generally found at the bars of our country taverns. Such liquors, most frequently, are not fit even to bathe the feet in, let alone putting into your stomach. A dose or two of such trash is often sufficient to upset a temperate man for days. To avoid the necessity of having recourse to this vile stuff, in case of sickness or otherwise, take, as before recommended, a small store of good spirits along with you, as a part and parcel of your necessary ammunition; but, as before observed, consider it as a medicine, only to be used when circumstances demand it.

It is often very difficult, either from motives of politeness, or of actual policy on the part of the sportsman, to avoid drinking at the bars of country taverns; in such cases, take as sparingly as possible of the liquor, and largely of the water, and then take as little of the abominable mixture as you can well get off with. We have more than once been placed in this unfortunate position, but have always succeeded in extricating ourselves by a little manæuvring, without suffering from an overdose of the nauseating drugs. 


\section{SLEEP.}

It is absolutely necessary that the wasted forces of the body should be restored by refreshing sleep. The amount of sleel should be proportioned to the fatigue undergone; therefore, after a hard day's hunt, retire as soon as possible, and do not sit dozing and nodding before the fire. Rest, so natural to all animal life, will soon restore the wearied functions to their normal state of existence, and impart fresh vigor and strength to the exhausted frame of the ardent sportsman, and thus make him ready for the pleasures or business of the succeeding day. Sleep acts as a balm to his excited system, and restores that just equilibrium of the vital functions so much deranged by long-continued efforts in search of game. Without a fair quantum of healthful repose, it is impossible for any one to pursue the sports of the field with that zest and ardor that every lover of the gun and dog should possess.

Sleep, however, to be beneficial, should be moderate and not indulged in to excess, but, as before observed, should be regulated by the amount of labour undergone. Excess of sleep relaxes the system, and even enervates the whole physical as well as mental apparatus. Less sleep is required in warm weather than in cold; and Nature herself seems to have regulated this fact by giving us the long nights of winter for sleep, and the short nights of summer for siestas only.

Some individuals require much more sleep than others. We are satisfied with six or seven hours under ordinary circumstances, and are led to believe that most persons can get along with a similar quantity. It is astonishing with what little sleep some persons of active disposition accustom themselves to, either from necessity or habit; while, on the other hand, many slothful drones, whose whole time is spent in strutting about like turkey-cocks up and down our principal streets, are not satisfied with double and treble-nay, even quadruple - the repose that many of our most active citizens require.

It is well known that many of the most distinguished com- 
znanders who have made the earth tremble with their great deeds allotted but two or three hours of the twenty-four to sleep, even during the fatigues of the most exciting campaigns. Napoleon and Frederick the Great are both instances of this fact.

\section{GALLED HEELS.}

If by any mishap your heel should get galled, the inconvenience can often be remedied by adopting the plan recommended by Hawker, but which we, as well as many others, adopted before reading it in the coloncl's work:-Take a small particle of goldbeaters' skin, and apply it over the rounded surface; when this is perfectly dry, and adheres well without wrinkling when the foot is set in motion from the ankle-joint, take a piece of court-plaster cut perfectly round, or, what is better, stamperd with a wadding-punch, so that there be not the slightest irregularity or inequality on its circumference; wet it with the tongue, and, holding it to the fire for a moment, apply it directly over the gold-beaters' skin. Hold the foot still till the court-plaster is perfectly dry, then rub it over with a little sweet-oil, tallow candle, or any other kind of grease more convenient; this latter application repels the moisture and consequently prevents the loosening of the plaster. A galled heel thus treated, with a change made in our boots, need give us no trouble, as the plaster will stick as tightly as possible through a whole day's hard work, if it be not immediately rubbed with a contracted heel, which will not allow the foot to go down into it, but keeps it seesawing up and down at every step we take.

If we should suffer from having our ankles occasionally galled mith a wrinkle in the boot, as we have suffered more than once, the plan proposed by Hawker will remedy the evil. We have tried it and found it to answer a good purpose. It is in fact the only plan to pursue. In the abscnce of the pad, one's own ingenuity can construct something analogous. The colonel says, "Get a square silk pad similar to a kettle-holder. Then have sewed on the opposite corners of it pieces of list long enough to go twice around and tie on the ankle. No wrinkle of a water-boot can 
then cut or bruise your 'tendo-Achillis,' or back-sinew, provided you secure the pad firmly by putting it over your common stocking and under your yarn stocking."

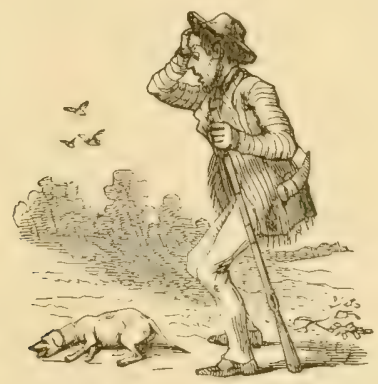

CORNS.

As writers on sporting-subjects, even those of the highest rank in this department of literature, have deigned to speak upon the subject of corns, it may not be deemed amiss in us to follow the precedent, although we may not be able to add much that is new upon the subject.

A corn is nothing more than a portion of hardened cuticle, generally produced by the pressure of the boot, or of one toe against another. Those formed by the latter cause are usually the most painful and difficult to be treated, as they are situated between the toes; and it requires much management to relieve the pressure sufficiently long to effect a cure, so long as the sufferer is obliged to incase his foot in a boot.

These formations on the feet are called corns, from the circumstance that a piece can be picked out very like a corn of barley, which fact no doubt many of our readers who are troubled in this way have observed. The curing of corns, in these modern days of improvement and charlatanism, has been promoted into a science by some few pretending worthies who have sprung into existence from the Lord knows where, and taken to themselves the highsounding title of chiroporlist to his or her majesty's big toe, we 
suppose! These fellows vaunt themselves much upon their skill in the treatment of these deformities, and even produce certificates from respectable sources in commendation of their great success, which certificates are oftentimes obtained from the various parties without proper consideration or the lapse of sufficient time after the operation to judge of its real efficacy. The public, however, is perhaps better able to judge of the merits of these scientific operations than we are; nevertheless, as far as our experience teaches us, these ignoramuses, with their high-toned titles and great pretensions, are a set of bunglers, and the most of them entirely unworthy of confidence. Some of them even go so far in their charlatanism as to succeed in gulling their victims into the belief that there is some great secret attached to the operation of extracting a corn, as they term it, and make a great ado in the matter, as it were to confuse the looker-on and involve their clumsy operation in a certain degree of mystery. All we have to say of these impudent humbugs is, that "the less our readers have to do with them the better."

If, reader, you have been foolish enough, or rather vain enough, to wear a tight boot in order to exhibit the beautiful proportions of your foot, and consequently have thus produced corns and brought upon yourself a good deal of suffering, the first thing to be done towards relieving yourself of these little tormentors is to call on an expert disciple of Saint Crispin and order forthwith a pair of easy, non-pinching boots.

This being done, procure some soft chamois-leather, and cut with your wadding-punch several pieces of it; through the centre of these pieces punch again another hole still smaller with a largesized shoemaker's punch: this hole should be about the size of the corn we propose to operate on.

These pieces of chamois may now be stuck together with a little thin glue or any other kind of strong paste, and as many thicknesses used as will be necessary to protect the corn from the pressure of the boot when it is laid over it. The under surface, or that part of the chamois-pad to be applied around the corns, 
should be spread with diachylon-plaster, (to be obtained from any apothecary,) and, when warmed at the fire, is to be nicely adjusted over the corn in such a manner that the hole in its centre will come immediately over the corn, and thus protect it entirely from the direct pressure of the boot and consequently permit the patient to walk with ease. This application will oftentimes not require readjusting for several days, and, if persevered in for a short time, the corn will entirely disappear. If the corn is between the toes, something of the same sort must be contrived for its relief. We suffered for several months with one of these formations in this situation; and we must confess that the treatment of it tried our patience and exhausted nearly all our skill before our efforts were crowned with success. We have heard of many empirical and old women's applications for the cure of corns, but do not believe that any one of them ever performed a cure if the primary cause of the deformity was not first removed,-that is, "the tight boot." This being done, any one of them may without difficulty effect a speedy cure.

The following recipe, picked up we know not where, we have used successfully on several occasions in the cure of corns, and therefore can recommend it with some degree of confidence:-The corn should be pared as close as possible, and the chamois-pad applied as above directed, and the mixture put on with a camels'hair pencil, every other evening, for a week or ten days; the pad should then be removed and the foot soaked in hot water, and the sorn again pared of all the softened cuticle that will come off without using any great effort or producing pain; the pad may be again applied and the mixture used as before. This will generally be sufficient to remove the enemy.

$$
\begin{aligned}
& \text { R.-'Tincture of iodine............... 3iii; } \\
& \text { Ioduret of iron..................... grs. xii; } \\
& \text { Chloride of antimony............. 3iv. }
\end{aligned}
$$

An excellent corn-salve, put up in little tin boxes, may be obtained from the great herb depôt in Dock Street. It appears to 
be of about the same consistency as the plaster known as Burgundy pitch. It softens the corn, and causes it to peel off.

Hawker furnishes the following recipe, which he recommends strongly. We have never had occasion to try it:-

"B.-Mercurial plaster;

Diachylon-plaster, with resin;

Diachylon-plaster. $\bar{a} \bar{i} 3 \mathrm{ij}$;

Sugar of lead grs. xx.

All mixed together and spread on leather.

"Apply a piece of this plaster for three or four days. Then soak the foot, and rub the corn with a piece of pumice-stone. Again repeat the plaster, and the corn will soon disappear.

"N.B.-The corn never to be cut."

TREATMENT OF A FALL, SPRAIN, BLOW, OR BURN.

If the sportsman, by any one of those mishaps incident to his pursuit, should meet with a fall and consequently sprain his ankle, wrist, or any other of the articulations of his body, the best and most convenient remedy, and one nearly always at hand, is the application of cold water, which should be poured on the injured part in a continuous stream for half an hour or more immediately after the accident. If the sufferer can get near a pump or by the side of a small waterfall, and place the limb directly under the stream, so much the better; otherwise, he will have to content himself with pouring the water over the parts from his hand or sporting-cup.

By pursuing this plan the pain will be diminished, the swelling prevented, and the inflammation of the parts powerfully opposed. The operation, however, to be of much advantage, should be commenced as soon after the accident as possible, and persevered in for a long time. The colder the water the better. The limb should not be used for some time after the accident,-in fact, so long as it feels tender and weak; otherwise, the cure will be retarded to an indefinite period. Sprains, apparently of the most trifling character, are sometimes attended with the most serrous 
consequences, perhaps laming the party for several months. Those affecting the ankle are the most troublesome and require great attention.

On one occasion, some time during our college life, we rather officiously proffered to hand a country-lassie from her carriage, which feat, by-the-by, she could have performed with far more ease, grace, and elegance, without our assistance, and perhaps have jumped clean over our head besides, if we had desired her so to do, or, rather, had bantered her upon her want of agility. The ground was slippery, with a high pile of snow on the side-walk directly in front of the vehicle. In her over-anxiety to grasp our extended hand, or rather in our great desire to support her delicate frame, she neglected freeing her garments from the projecting step, and the consequence was a trip up, and down she came on top of us with a perfect rush, knocking us over and burying our head and face almost a foot under the snow. In an instant she sprang to her feet, shouting and laughing at the top of her voice, at the same time plying us with handfuls of snow, as a reward; we presume, for our awkwardness. Without any complaint whatever she walked or rather ran into the house, standing a few rods from the street. In the course of half an hour or so she felt a slight pain in her ankle-joint, and discovered that the parts around were swollen. Little attention, however, was given to the matter that day.

On the following morning the ankle and foot were enormously swollen and painful; on the next day the swelling increased, and the inflammation was very great; and so it continued for days, and weeks, and months, and the upshot of the occurrence was a rigia confinement to the house for about nine months, with the dread at one time of losing the whole foot; and after the lapse of two years she had not entirely recovered the use of her limb, (so she informed me,) although we can vouch for her being now able to cross over, back to back, lady's chain, right and left, during a whole winter's. 'vening, without ever refusing a single proposition to dance from the country beaux. 
After the application of the water, and the limb being at rest, it will be well to bathe or rather gently rub the parts with some kind of opodeldoc. Sweet-oil, goose-grease, laudanum, spirits of camphor, hartshorn, brandy, alcohol, rum, whiskey, \&c. \&c. are the bases of all the mixtures known under the term opodeldoc. Any one or two of these substances, or all of them, may be employed. For the purpose of friction, the mixture should be stron $g$ enough to produce a smarting sensation and impart a certain degree of redness to the skin when rubbed in. Brandy and salt is a good application for this purpose, and can be obtained with convenience at almost any place.

This done, the parts may be bathed or kept wet with a solution of sugar-of-lead, made with equal parts of water and vinegar. If the limb, in spite of all these precautions, should be painful and continue to swell, it will ease it very much to apply a large poultice of flaxseed, corn-meal, onions, \&c. If it gets worse, send for a doctor, if within a hundred miles, and he will order the joint to be leeched and prescribe a dose of salts and magnesia.

Perfect rest to the limb is of the greatest importance, and without it no treatment will produce a cure. If the ankle is the affected joint, the foot should be kept up on a pillow, and never put to the ground till free of pain. A blow or bruise may be treated pretty much in the same way.

The following lotion for sprains and bruises we give as recommended by an old English sportsman and soldier, - General Hanger. The reason why we give this old-fashioned recipe in preference to any other of more modern date is that we adopted it several years ago as a kind of family cure-all, for man and beast, and found it to answer a most excellent purpose.

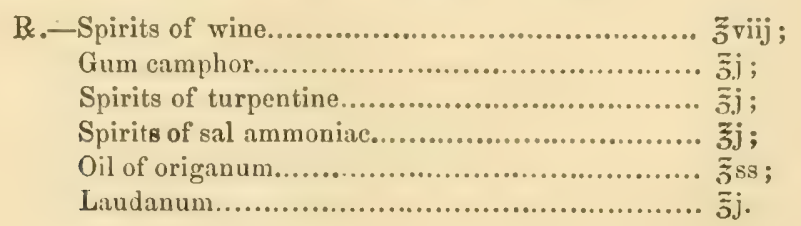


Dissolve the camphor in the spirits of wine first, then add the other ingredients. To be rubbed in with the hand, for a quarter of an hour, several times each day. This mixture will be found very efficacious in the case of men, women, children, horses, dogs, and cattle. If the surface of the wound be excoriated, it will not do to apply this mixture directly to the spot, as it will cause too much pain; it may be used, however, on the parts adjoining.

\section{BURN.}

The best application to a fresh burn is raw cotton dipped in sweet-oil or molasses; lime-water and sweet-oil also make an excellent dressing.

\section{WOUNDED EYE.}

If a bug, seed, or twig, should fly into the eye, it ought to be removed as soon as possible. If you have a companion along, make him explore the eye thoroughly till he gets it out, whatever it may be, with the corner of a handkerchief; else you will be tormented all day with it, and the eye will become irritated and inflamed from its presence. A small seed will sometimes bury itself in the lining membrane of the lids, and remain there for hour's if not removed by a skilful hand; to do this, it will be necessary to take a small pencil-case, or any smooth article about the same dimensions, in the left hand between the forefinger and thumb, (provided our patient's right eye is affected,) gently press the pencil lengthwise against the lower part of the lid, at the same time seizing the eyelashes with the forefinger and thumb of the right hand; with a dexterous motion the lid is everted, and its whole surface can be examined. This operation may appear diffcult to the reader; but we can assure him it is very simple, and can be performed by any one with a little practice.

Bathing the eye in cold water will often remove particles that may have blown into it, as well as afford considerable relief after the removal of such substances. The eye, during the evening, 
shlould be protected from the heat of the fire and the glare of the candle, not by bandaging it up, as some foolish persons would suppose, hut by shading it with a broad-brimmed hat, or, what is better, sitting with the back to both. A bandage will heat the eye and increase the inflammation.

The following is an excellent collyrium to be used in slight inflammation of the eye arising from wounds, colds, and similar causes.

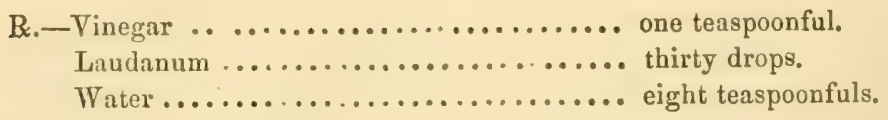

This preparation can be had at all times, as there is hardly a family in any part of the country that has not a little laudanum with which to dose a squalling child or to cure an attack of cholic.

SORE THROAT.

If the throat should feel sore, from exposure to wet feet or any other of those numerous causes to which all sportsmen are open during their excursions, have recourse to the following gargle, which we have used over and over again with perfect success in such cases. We have also recommended it frequently to our friends with like results:-

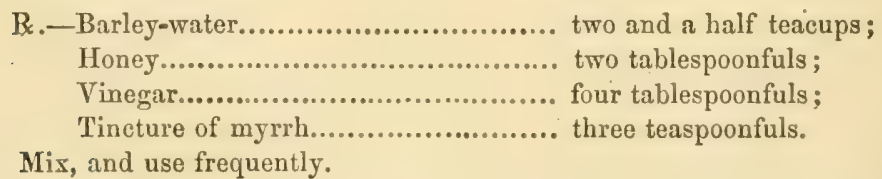

If these ingredients cannot be obtained, take equal quantities of vinegar and water with a sprinkle of Cayenne pepper, and gargle. The throat should be rubbed with hartshorn, oil, and laudanum; even goose-grease will help.

\section{TO STOP HEMORRHAGE.}

If by any accident an artery should be opened in any part of the limbs, the bleeding is very easily arrested by tying a hand- 
kerchief around the limb; it should be drawn tightly, and answers better if a knot is put in it, which is to be placed directly over the course of the bleeding vessel. By this means the pressure will be exerted more directly upon it. This bandage should not be re moved till a surgeon is present.

All the principal bloodvessels run on the inside of the limbs, and can be casily discovered by the pulsation.

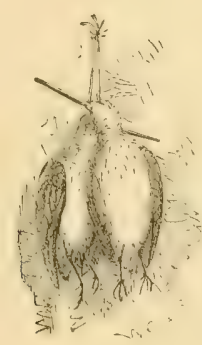

TO TELL THE AGE OF A DOG.

It just occurs to us how ignorant many of our friends are as to the mode of telling the age of a dog; we therefore give in this place a few hints on the subject.

Take, for instance, a puppy at one year old; open his mouth, and examine his front teeth; take no heed of the side or jaw-teeth, save to admire their ivory-like appearance.

These front teeth,-_or, more scientifically speaking, these incisors,-both in the upper and lower jaw, will be found jagged and uneven: this appearance may be termed the marks of the dor. The age of a dog may be determined by these marks with the same degree of certainty with which a jockey guesses at the age of a horse. These marks continue longer in the upper teeth than they do in the lower, and the jagged, uneven appearance notrced in the pup is half gone at the age of three or four years; when it has entirely disappeared and all the front teeth have becosue worn smooth and even, the dog is nearly or quite full six years oli. 
When the front teeth are not only worn smooth, but worn greatly away, the dog is well on to eight or even ten years; and we rnay then notice, in the majority of dogs, other signs of age which are not to be mistaken,- - such as the turning gray of the hair, about the eyes particularly, and which gradually spreads over the whole face. Dogs are seldom good for any sporting-purposes after ten years of age; and but few of them, even at this early period, if they have not had kind treatment and good attention, are worth taking to the field except for a few hours' hunt.

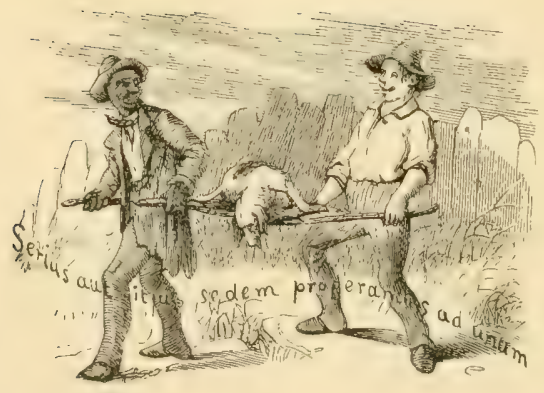




\section{N D E X.}

\section{A.}

Accum, 493.

comments on the gluttony of savages, 493.

comments on the pleasures of the table, 493.

comments on the frozen markets of St. Petersburg and Moscow, 497.

Achilles, the bravery of, 456 .

Act of Assembly, 141.

against killing game in Delaware, 141. against killing game in Illinois and other Western States, 141.

against killing game in Maryland, 141. against killing game in New Jersey, 141.

against killing game in Pennsylvania, 141.

Africa, guns made for, 478 .

Age of the dog, 539 .

Ah Bob White, 123.

A jax, the bravery of, 456 .

Alexander the Great: superstitious dread of gunpowder, 456 .

Ambush, erected on the flats, 338 . how constructed, 333.

Amputate the wing of a wounded bird, how to, 521.

Anecdote, snipe-shooting, 249.

swan-shooting, $3 \$ 4$.

punters', of frozen ducks, 345 . of Colonel Hawker, 348.

Apicius, extraordinary feast of, 494 .

A pollonius Tyanæus, refers to gunpowder, 456.

Philostratus, historian of, 456 .

Audubon, description of driving partridges, 142.

description of the wild turkey, 173.

observations on the migrations of squirrels, 405 .

comments on cooking game, 503 .

Auriculars, ear-coverts, their position and use, 26.

Auri sacra fames of the present day, 141.

Aztecs, wild turkey domesticated among, 184.

\section{B.}

Bacchus, Egyptian, repulsed with gunpowder, 456 .
Backwoodsmen of America, 99.

their exploits with the rifle, 99 .

killing squirrels and wild turkeys, 99.

Bacon, Friar, his knowledge of gunpowder, 456.

Bald-pate. 357. (See Widgeon.)

Barnyard ducks, fed on celery, 318 .

Barrels, leading of, how freed, 426 .

Bar-shooting, 343.

Bartram, statement respecting young rails, 266.

Bastard-wing, description of, 26.

Bats, acute sensation of, 30 .

Battery, description of, 329 .

great numbers of ducks shot from, 330 . mode of building, 332 .

explanation of the model, 334 .

Bears in Iowa, 111.

large numbers destroyed, 139.

Beef, sportsman's, how made, 511.

Beetle or bull-head, 295. (See Plover.)

Birds, batting, 235.

flesh of, made poisonous, 126.

measurement of, 28 .

moulting, 30 .

nocturnal, 29.

serpents, charming, 121.

technieal terms applied to, 25.

Black or dusky duck, 368 .

well known in the Philadelphia market, 368 .

habits and description, 369 .

Black-bellied plover, 294. (See Plover.)

Blow, treatment of, 534 .

Bob-0-link, 256. (See ReED-Bird.)

Boots, shooting, 477 . best kind, 418 .

receipts for dressing, 421.

Boswell, comments on Dr. Jolunson's eat. ing, 489.

Both oyes open, $10 \mathrm{~S}$.

Bowles, Mr., description of the feeding of woodcocks, 219.

Box, 329. (See BAtTeiry.)

Brace or couple, what is understood by a, 33.

Brant or brent, barnacle goose, 381.

Anas bernicla, babits, haunts, 381 .

how killed, description, 382 .

a gang of, 34 .

Breaking dogs, the science of. (See Doas.)

Breech-loading guns, 462 . 
Breech-loading guns, not a purely modern invention, 462 .

early defects of, 462 .

hammerless guns, 463 .

boring for shooting qualities, 464 . choke-boring, 464,465 .

English and American guns, 465. machine- and hand-made guns, 467 . the cost of a good gun, 468 .

the best gun for general use, 470 .

Breeding dogs, the science of. (See Dogs.)

Brewer, observation on the ventriloquism of rails, 267.

Brown, Captain, his work on Taxidermy, 518.

Brown thickening for game, 570 .

Bryan, George $\mathbf{H}$, a rail captured at sea, 267.

Buffaloes, great numbers destroyed, 139.

Butfel-headed duck, butter-ball, 366 .

Anas albeola, 366 .

habits, haunts, and description, 367 .

Buffon, opinion as to the origin of the wild turkey, 184.

statement respecting white partridges, 132.

Bull or beetle-head, 295. (See Plover.)

Burlington, Iova, 137.

large numbers of partridges netted in neighborhood of, 137 .

Burn, how to be treated, 536 .

Bursting of guns, 444.

Bush River, toling ducks on, 324 .

Butter-ball, 366. (See BUFFEL-IIEADED Duck.)

\section{C.}

Canada goose, 375. (See Goose.)

grouse, 210 .

grouse met with in, 210 .

Canard cheval, 318.

Cannon, antiquity of, 458 .

Canvas-back, 313

Anas valisineria, 313.

their great repute, 313.

testimony of Wilson as to their peculiar delicacy, 314.

known only in America, 314.

description, history, and habits, 314 .

their food and haunts, 316.

shyness and modes of taking, 319.

toling, boating, netting, 320 .

use of dug-outs, 327 .

batteries, surface-boats or sink8, 329 .

description of batteries, 332 .

decoys, 336.

ambush on the flats, 338

shooting off points, 339 .

holes in the ice, 341 .

point and bar-8hooting, 342 .

aneedote, 344 .

art of shooting, 345 .

verses descriptive of, 350 .
Cap, Napoleon, 414.

Carolina, reed-birds in, 260.

snipe in, 240.

Celery sauce, how made, $50 \mathrm{~S}$.

Ceylon, snipes in, 240.

Chandler, M. T. W., obserrations on woodcocks, 216.

observations on the haunts of woodcocks, 218.

receipts for making water-proof dressing for boots, 423 .

Charadrius apricarius, 294. (See BlackBellied Plover.)

Pluvialis, 296. (See Golden Plover.) Charles the First, small-arms in the reign of, 461.

Charming birds, serpents, 120.

Chesapenke Bay, partridges caught on the shores of the, 136.

as a resort of wild fowl, 308.

various kinds of ducks on, 308 .

exciting times on, 309 .

present and future numbers of wild fowl on, 351.

China, gunpowder known in, 455.

Chinese, gunpowder knuwn to, 455.

food of the, 494.

gunpowder used by the, 457 .

Citizens encourage killing game out of season, 140 .

should discountenance game suppers, 141.

Clapper-rail, 283. (See Rallus crePITANS.)

Clean guns, 415 .

Clerks of the market blind as bats, 140 .

Club-houses, encourage killing of game out of season, 140 .

Cont, made of fustian, 414 . made of woollen cloth, 414 .

Cocking the gun, 410 .

Cofin-boat, description of, 329 .

Collum, the neck, 28.

Columbia River, ruffed grouse on the ranges of, 189 .

pinnated grouse abundant about, 205.

Columbia migratoria, wild pigeon, 311.

Conquest of Mexico, wild turkey mentioned by Prescott. 184.

Constantinople, British cruisers visited, 183.

Cooking, art of, game, 485.

"God sends meat, who," 488.

Rumford's philosophic remarks on, 488 .

Mayo's, Dr., remarks on, 489.

importance of good, 490 .

author's viers and sentiments, 489 .

Johnson's, Dr., comments on, 459.

further comments on the importance of good, 490 .

author's remarks on, 491.

Accum's remarks on, 493 . among the Romans, 494. 
Cooking among the Chinese, 494. comments of Louis Eustache Ude, 495. to select game, and when to cook it, 496.

frozen game, 497.

to roast game, larded, broiled, 499 .

boiled game, and some other ways, 501.

snipe, woodcock, plover, pheasants, 502. reed-birds, rail, and other kinds of game, 504 .

wild fowl, 507 .

canvas-backs, 507.

further remarks on, 508 .

brown thickening for, 510 .

potatoes à la muître d'hôtel, 510 .

venison soup, 5 ll.

sportsman's beef, 511 .

hares, rabbits, or squirrels, 512.

Coolness and deliberation, necessity of, 96 . importance of, 100.

Copple, Daniel, white snipe killed by, 254.

Corns on the feet, how eured, 5:31.

Corona, crown of the head, 27.

Couple or brace, explanation of, 33 .

Covert-shootiug, rules for, 107.

Cross-shooting, or cross-shots, 104. rules for, 104.

Curlew, Esquimaux or short-billed curlew, 287.

Scolopax borealis, 287.

nomenclature and history, $28 \%$.

migrations, food, 288.

their flesh, and time to shoot them, 289.

Curlew, long-billed or sickle-bill, Numenius longirostris, 291

habits and description, 291.

Cygnus Americana, 383. (See SWAN.)

\section{D.}

Daniascus gun-barrels, 484 .

Daniel, Rev. Wm. B., fecundity of the English partridge referred to by, 118.

several white partridges mentioned by, 131.

description of English pochard, 354. receipt for gun-ointment, 429 .

Decoys, best kind, price of, 336 .

Deer, abundant in Iowa, 111. great numbers destroyed, 139.

Delaware, game ordinances, 111 .

woodcock in, 216.

good shooting, 157 .

snipes in, 246.

willets frequent, 300 .

reed-birds on river, 258 .

Diet and drink, effect of exercise on, 527. unadulterated water, 527 . eat and drink with moderation, 527. avoid debauch and various liquors,
Diet and drink, avoid bad liquors; how to avoid, 528 .

water-drinkers, $52 S$.

Distances on the water very deceptive, 310 .

Doe-bird, 293.

Dog, theories of origin, 35.

in his relation to man, 36 .

divisions into breeds, 36 .

the pointing instinct, 38 .

the setter, 41.

the pointer, 42,50 .

the spaniel, 42,52 .

the hound, 43,54 .

the retriever, 43,55 .

setter divisions, 44.

the English setter, 44

the Irish setter, 48 .

the Gordon, or black-and-tan setter, 49.

relative merits of the different breeds, 58.

Dogs, terms applicable to, 32 .

the science of breeding, 60 .

"like produces like," 61 .

no absolutely perfect dog exists, 63.

what to breed for, 64 .

how to breed, 68.

defects and their correction, 69.

uniformity, not "sortiness," $7 \mathrm{I}$.

the science of breaking, 72 .

yard and field work, 73 .

force 28 . coaxing, 74 .

yard breaking, 75 .

teaching control, 75 .

to obey the whistle, 76 .

stopping, 77 .

charying, 78 .

following at heel, 79 .

retrieving, 79 .

beating and quartering, 84 .

field breaking, 85 .

teaching the dog to point, $S 6$.

stanchness depends upon the first lessons, 87.

chasing and breaking point, 87 .

under the gun, 88 .

backing, 89 .

false pointing, 90 .

general hints to breakers, 91 .

breaking old dogs, 92 .

wildness or lack of control, 92 .

chasing and shot-breaking, y:3.

biting birds, 93 .

patience and discretion necessary, 94 . how to treat, 161.

feed them yourself; reasons for, 162. how to enter, on the field, 163.

proper manner to hunt, 163.

balf broken, young, and heedless, 163. good, young, and old, 164.

timid, bold, 164 .

correction of, 165 .

never kick or shoot, 165 .

act of pointing in, second nature, 166 . not to flush the game, 166. 
Dogs, should find the dead bird, 167. should hunt up wounded or dead game, 167.

how to bunt, 168.

when, come to a point, 169

occasionally at fault, 169.

accidental death of a, 253 .

to tell the age of, 539 .

Domery, Charles, celebrated glutton, 494. his wonderful feats of eating, 494 .

Down charge, 33.

Dubuque, immense load of game carried into, 111.

Ducks, art of shooting, 345 .

toling, 320 .

further instructions on shooting, 347 .

Duck Island, experiments at, 311 .

Duckers, hints for, 310 .

Dug-outs, description of, 327.

Dun-birds of England, 354.

Dupont, gunpowder made by, 434 . composition and superiority of, 434 .

Dusking, as applied to wild-fowl shooting, 369 .

Dusky Duck, 368. (See BuAck Duck.)

\section{E.}

East, wild turkey not a native of the, 182. Eating-saloons encourage killing of game out of season, 140.

Edward III, uses gunpowder, 458. guns in the reign of, 460 .

Eggs, enting partridge, 138 . should be discountenanced, 139 . preserving shells, 519 .

Egypt, snipe in, 210.

Egyptian Hercules, 456.

Elizabeth Island, pinnated grouse on, 205.

Elizabeth, Queen, uses gunpowder, 458. guns in the reign of, 460 .

Elk River, immense drove of partridges encountered in the neighborhood of, 129.

their singular actions, 130 .

England, efforts to introduce the American partridge into, 144.

woodeock-shooting in, 237.

land-rail or corn-crake of, 263.

water-crake or spotted rail of, 263 .

Epicurus, followers of, 313.

Epreuvette, or powder-prover, 438.

Eye, pupil of the, 27.

seldom wrong, 100 .

seldom at fault, 101.

how to treat a wounded, 537.

Eyre, J. M., exploits in rail-shooting, 276 .

\section{F.}

Feathers, rump or upper-tail coverts, 27. their position, character, and use, 27. stronger in proportion to the habits of the bird, 27.
Feathers, how formed in the woodpecker tribe, 27.

how formed in the water-fow $1,27$. acts as a rudder, 27 .

Feathers, vent or under-tail coverts, 27. their position and character, 27. longer on some birds than others, 27. how developed in the Rallus Carolinus, 27.

Feathers, sensation in, 29. delicate impressions conveyed by, 29. nice organization of, in nocturnal birds, 29 .

Feathers, shedding of, 30 . accidents to, 30 . moulting of, 30 .

Field, taking the, 160 . verses descriptive of the sports of the, 160.

Field or grass plover, 303.

Figure-of -4 trap, taking of partridges with a, 138.

Flexure, bend of the wing, 27.

Flight, velocity of, 311 . experiments to prove the velocity of, 311.

Florida, snipes in, 243. canvas-backs in, 318 .

Folly Island, numbers of curlew on, 291.

Fontainebleau, escape of a falcon from, 312 .

Forrester, Frank, opinion on woodcocks, 221.

observations on the note of the snipe, $2+2$.

Fowler, an English writer, 111. opinion of American sporting, 111. how unjust, 111.

Fowler, a celebrated rail-pusber, 273.

France, gun-barrels imported from, 477 .

Frederick the Great required little sleep, 530 .

Freiburg, monument erected at, 458 .

Frons, forehead, 27.

Frost birds, 296.

Frozen game, 497.

\section{G.}

Galérie des Oiseaux, Viellot's, 221.

Gallinaceous order, noise made by the, 130 .

Galveston Bay, canvas-backs in, 318.

Game of all deseriptions abundant, 139 . recklessly destroyed, 140 . illegal traffic in, 140 . ordinances against selling, 140 . ordinances a dead letter, 140. hawkers of, 140. their disregard of ordinances, 140 . predictions regarding, 152 . probable abundance of, 152 . probable scarcity of, 152 .

Ganges, the river, 456 .

Geese, terms applicable to, 34 .

Georgia, ruffed grouse in, 189. 
Georgia, reed-birds in, 260.

German jägers, good marksmen, 99.

Gilman, Dr., article on venomous snakes, 122.

curious experiments on snakes, 122.

Giraud, description of king rail, 281. statement about curlew, 291.

Gloves, use of, 363 . importance of wearing, 409 .

Gluttony among savages, 493.

Godman, comments on the migrations of squirrels, 405 .

Golden plover, 296.

food shooting, 160 .

Good shot, 96.

Goose, Canada, 375.

Anas Canadensis, 375.

habits and haunts, 375 .

great numbers killed by the Indians, 376.

Pennat's account of shooting, 376 .

easily domesticated, 377 .

how killed, 378.

description, 378 .

Goose, snow, 379.

Anas hyperborea, 379 .

habits and haunts, 379 .

description, 379 .

laughing or grinning, 380 .

Grass or field plover, 297.

Gratz, David, white partridge in his possession, 132 .

Greener, comments on gun-locks, 432. observations on loading guns, 442. remarks on brazing guns, 476 .

Grouse, terms applicable to, 33. numbers killed, 139. cooking, 502.

Grouse, pinnated, 202. prairie chicken or hen, 202.

Tetrao cupido, 202.

description of, 203.

location, 203.

period of pairing, 205.

tooting of the, 205.

Audubon's remarks, 205.

domestication of, 207 .

flight of the, 208.

feeding and roosting, 208.

time for shooting, 209.

other varieties, 210.

Grouse, ruffed, 189.

pheasant, 189.

Tetrao umbellus, 189.

locality and nomenclature, 189.

description of, 190 .

confounded with prairio chicken, 191.

their gradual destruction, 191.

incubation and drumming, 192.

their battles and migrations, 193.

flight of the, 194.

hubits, 195 .

their flesh poisonous, 195.

enemies of the, 196 .
Grouse, their flesh, 196

a feast of English, 197.

modes of shooting, 197.

treeing, 198.

shooting, with a setter, 199.

snares, etc., 200 .

Gun, selecting a, 97.

handling the, 97 .

nicety of shooting with, 99 .

exploits with, 99 .

proper handling of, 105 .

never beat bushes with, 106 .

cannot be too careful with, 106 .

importance of clean, 415 .

to clean, 425.

properly loading, 441 .

Greener's remarks on, 442 .

size and bore of, 443 .

bursting of, 444 .

experiments on recoil, 444.

recoil in, 450 .

Commoriore Stockton's experiments on recoil, 452.

author's views, 453 .

second-rate, 459 .

when first invented, 460 .

in the reign of Elizabeth, 460.

in the reign of Henry VIII., 460.

in the reign of Edward III., 460.

necessity of a good, 461 .

the breech-loader, 462. (See BREECHLOADING GUNS.)

welding barrels, 473 .

hammer-hardening, 474 .

boring, 474 .

grinding, 475 .

turning, 475 .

brazing, 476 .

Greener's remarks, 476 .

proving barrels, 477 .

forgery of the proof-marks, 477 .

Spanish barrels, 478 .

French barrels, $47 \mathrm{~S}$.

shain-dam guns, 478.

park-palings, 478.

made for the African market, 478 .

standing barrels, 479 .

metal used in the manufacture, 479.

materials from which made, 480 .

care and labor bestowed upon, 481 .

deceptions practised, 482 .

spurious, 482 .

wire-twist for manufacturing, 483 .

Damascus barrels, 485 .

charcoal iron, 485 .

other kinds of metal used, 485 .

wood for stocking, 486 .

staining woods for stocking, 486 .

Gunpowder, discovery of, 433.

to whom attributed, 433.

known to the Chinese, 433.

English, Scoteh, and French, 433.

Dupont's, 434 .

varieties of, 434 . 
Gunpowder, what kind preferred, 435. anecdote, 435.

glazed and unglazed, 437.

tests for, 438 .

epreuvette, or powder-prover, 438. to preserve from moisture, 439 . impure, 440 .

to dry damp, 441.

discovery and introduction, 455 .

well known to the ancients, 455.

remarks of Utfano on, 455 .

use of, in China, 455 .

used by King Vitney, 456.

referred to by Philostratus, 456 .

used by the $0 x y$ drace, 456 .

deters Alexander the Great, 456. employed against Hercules, 456 . employed against Bacchus, 456. used in India, 456.

known to Friar Bacon, 456. mentioned in the Opus Magus, 456. inquiries into the early origin of, 456 . known to the Chinese, 457 . discovery concealed, 457 .

reasons for concealment, 457 .

discovered by Berthold Schwarz, 457 .

monument erected in commemoration of, 458 .

used by Edward III., 458.

used by Henry VIII., 458.

used by Elizabeth, 458.

used in hand-goune, 458.

used in wheel-lock goune, 458 .

\section{II.}

Hand-goune, when invented, 458.

Hanger's, General George, lotion, 537. receipt for sportsman's beef, 512 .

Hare, American, 385.

gray rabbit, 385 .

Lepus sylvaticus, 385 .

description, 385 .

locality and general characteristics, 386.

not a rabbit, 386 .

the speed of, 389 .

a nocturnal animal, 390 .

food of, 390 .

flesh of, 391.

hunting, 392.

domestication, 393.

cry of the, enemies of the, 393 .

varieties, 394.

cooking the, 513.

Hares, terms applicable to, 34 . great abundance in Iowa, 111. numbers destroyed, 139.

Havre de Grace, partridges caught near, 136.

Hawker, Colonel, on wild-fowl shooting, 306.

comments on wild fowl, 310 .

the Magnus Apollo, 359.
Hawker, Colonel, dressing for shootingboots, 422 .

receipt for soup, 505 .

cooking of wild forv], 507.

Hawks, the quill-feathers of, 26.

conflicts with partridges, 120.

destroy numbers of partridges, 151 .

their boldness, 151.

the alarm they occasion, 151.

prey upon ducks, 152.

sportsmen sbould kill, 152.

Heels galled, how to treat, 530 .

Hellebore, quails feed on, 129.

their flesh poisoned by, 129.

Hemorrhage, to preserve wounded bird from, 520 .

to stop accidental, 538 .

Henry IV. of France, a falcon belonging to, 312 .

its rapid flight, 312 .

Henry VIII., wild turkey introduced in the reign of, 183 .

uses gunpuwder, 458 . guns used by, 460 .

Hercules, Egyptian, 456.

Hispania, coasts of, devastated, 182.

Hominum servatorem, 492.

Hound, description of, 54. (See DoG.)

Hubbell, great number of rail killed by, 277.

Hygiene, general remarks, 523 .

atmospheric vicissitudes, 523 .

caution to sportsmen, 523 .

proper elothing, 523 .

an ounce of precaution, 524 .

"temperance, joy, and repose," 524.

hot tea and coffee, 524.

catarrhs, rheumatism, 524 .

overheated, 525 .

death caused by imprudence, 525 .

state of the atmosphere, 525 .

malarious distriets, 526 .

precautions to be adopted, 526 .

noxious exbalations, 526 .

diet and drink, 526 .

exercise, perpetual motion, 527 .

headache and malaise, 527.

pure water the best drink, 527 .

fondness for vinous liquors, 527 .

avoid drinking bad liquors, 523.

\section{I.}

Illinois, game-laws of, 141.

abundance of grouse in, 204.

Indiana, grouse in, 204.

Indians regard with horror slaughter of game, 230.

kill great rumbers of geese, 376 .

Iowa, abundance of game in, 111.

partridges in, 111.

prairie chickens, 111.

hares, 111.

deer, 111. 
Iowa, molves, 111.

bears, 111.

great numbers of partridges killed in, 137.

great numbers of partridges netted in, 137.

Ireland, woodcock in, 236.

Iris irides of birds, 27.

Italia, her coasts devastated, 182.

\section{J.}

Jack-frost nips vegetation, 110 .

Jick curlew, 293.

Jamaica, reed-birds in, 260 .

Japan, snipes in, 240.

Jersey, ruffed grouse in pines of, 159.

Johnson, Dr., remarks on cooking, 489.

\section{K.}

Kalmia clauca, 125.

marsh laurel, 125.

grouse and partridges feed on, 125 . animals feed on, 126.

Kalmia latifolia, 125.

mountain laurel, 125 .

grouse and partridges feed on, 125.

animals feed on, 126 .

ruffed grouse feed on, 195.

author's comments on, 196.

Keel-boatmen of America, 99.

their exploits with the rifle, 99.

snuffing the candle, 99.

driving the nail, 99.

Kentucky, ruffed grouse in, 189. pinnated grouse in, 204.

Keokuk, numbers of partridges about, $15 \mathrm{~s}$ cooped and sent to New Orleans, 155 .

Kill-deer plover, 297.

Killing clean, importance of, 112. what distance in, 113.

for humanity's sake, 113. verses in support of, 113 .

King-snake, curious experiments, 122. their wonderful endowmonts, 123.

Kitebener, Dr., on the pleasures of the table, 495.

Knife, sporting, proper kind, 413 .

\section{L.}

Lake Ontario, reed-birds about, 257.

Laurel, mountain, 125. (See KALMrA LATIFOLIA.)

Laws, game, inere bagatelle, 22.

Leading of barrels, 426 . how freed, 427.

Lee, Mrs., directions for mounting birds, 515.

her work on Taxidermy, 519.

Legislative enactments as to killing game, 141 .
Lepus cuniculus, 355 .

sylvaticus, 376 .

Lesser coverts, situation and character, 26.

Levy, W. W., celebrated duck-shooter, 331. his draft of a battery, 337 .

Lewis, E., snipe's nest on his estate, 244.

Liquors, bad, to be avoided, 528 .

Locks of a gun, 432 .

importance of good, 432 .

Greener's remarks on, 432.

Long-billed curlew, 292.

Long Island, pinnated grouse on, 205.

Loral space, 27.

Louisiana, pinnated grouse in, 204. reed-birds, 256 .

Louis Eustache Ude, comments on cookery, 495 .

Lynx, attack on wild turkeys, 187.

Lyon's, Captain, views on the ventriloquism of the Arctic fox, 268.

\section{II.}

Mamnus Apollo, Colonel Hawker the, 359.

Marnus coquus of the ancients, 192 .

Maine, grouse met with in, 210 .

Mallard or wild drake, 360 .

Anas boschus, habits and haunts, 360 .

parent stock of tame duck, 360 .

description, 361 .

in the rice-fields, 362 .

on the Delaware, 362 .

in England, 362 .

decoy-ponds for netting, 362 .

Malta, falcon captured at, 312.

Mandibles, upper and lower, 27.

Markets in reign of Queen Elizabeth, 460 .

Martha's Vineyard, pinnated grouse on, 205.

Massachusetts, grouse found in, 210.

Maxilla, superior and inferior, 27.

Mayo, Dr., remarks on enoking, 489 .

Mensurement of birds, 28.

Mediterranean, Turkish eruisers in, 182.

Meleagris gallopavo, wild turkey, 172 .

Mentum, the chin, 28.

Mexicans, wild turkey domesticated by the, 184.

Migrations of partridges, 129. causes of their, 130 .

singular actions during their, 130.

Millochau, Adolpbe, gun-oil of, $42 S$.

Mississippi River, ruffed grouse on the ranges of the, 189.

Moon, effects on the tides, 274 . rails feed at the full of the, 274 .

Mordecai, Captain, $3 \mathbf{l}$. experiments and observations on powder, 440.

Moscow, frozen markets of, 497.

Moulting of birds, 30 . wise provision of nature, 30 . change in the plumage, 30 . protection from enemies, 30. 
Moulting in quadrupeds, 30.

cold modified by, 30 .

gradual in birds, 31 .

time of, 31 .

in water-fow, 31 .

in birds that incubate far north, 31 .

Mount Holly, partridges shot in the neighborhood of, 126 .

Mud Creek, good snipe-ground, 111.

Mud-hen, 2S:

\section{N.}

Napoleon required little sleep, 530 .

Natural history, importance of studying, 133.

Netting ducks, 326. partridges, 136.

New Jersey, game ordinances of, 141. numbers of rufied grouse in, 191. woodcock in, 216. snipes in, 243. willets frequent, 300 .

New Orleans, canvas-backs about, 318.

New York ruffed grouse, 191.

Nooses of horse-hair, 138. for taking game, 138.

North Carolina, driving partridges as practised in, 142 .

Norton, Robert, 455 .

\section{O.}

Oeciput, back of the head, 27.

OId World, batteries of the, 127 . quails of the, 137.

Opus Magus of Bacon, 456 .

Ordinance against selling game, 141 .

Origin of the dog, 35 .

Orismology, sporting terms a branch of, 32 . Ornithologists, terms used by, 25 .

Ornithologists who have graced this country, 115.

Ornithology, technical terms the A B C of, 25.

this information easily acquired, 26.

0 wls, sensation of feathers in, 30 .

Oxydrace, 456 .

\section{P.}

Panthers, numbers destroyed, 139.

Partridge, the springing of, 97. vigorous flight of, 100 .

when thushed, 105.

flies with amazing velocity, 105

flight compared with English, 105. great abundance of, in Iowa, 111.

Partridge, Perdix Virginianus, 114. verses descriptive of, 114.

their abundance, locality, nomenelature, 114.

description, habits, 115.
Partridge, perehing on trees, 116. not strictly migratory, 116. running season, 116.

during winter at the North, 116. eatching in nets, traps, etc., 117.

period of pairing, 117 .

building their nests, 118 .

number of eggs, 118.

fecundity of English, 11 s.

period of incubation, 118 .

the young, 119.

strictly monogamous, 119.

leaving the nest, 119.

solicitude of the hen, 120 .

artifices of the cock, 120 .

conflicts with hawks, serpents, etc., 120.

domestication of, 122 .

two broods, 122.

author's opinion of, 123.

call of the, 123.

actions of young, 124 .

roosting, 124

food, 125 .

shot on Tapahannock marshes, 126.

English, compared with American, 127.

not a quail, 128 .

how it differs from the quail, 128.

running season of the, $12 \%$.

immense droves, 129.

singular actions, 129 .

cause of these migrations, 130.

flight of, whirring noise, 130.

flight of English, 131.

change in color of plumage, 131.

white or pied, 131.

remarkable, in possession of author, 132.

hints on bunting, 135 .

formed into coveys, 136.

time for killing, 136.

taken in traps, 136.

abundant in Iowa, 137.

nooses of horse-hair to catch, 138.

eating eggs of, 138 .

numbers destroyed in 1855 and 1856 , 139.

game-ordinances disregarded, 140 . whistle of the, 142

driving into nets, 142 .

efforts to introduce into England, 144.

actions of old and young, 145 .

best to break dogs on, 145 .

retaining scent, 146 .

enemies of, 150 .

probable abundance or scarcity of, 152 .

haunts of, 152 .

where to find, 153 .

dry and warm weather, 153.

wet and boisterous weather, 153.

further hints on hunting, 155 .

early dawn, at noon, 155 .

when they feed, 155. 
Partridge, before leaving their roost, 156. seldom roost in same place, 156 . during snow, $15 \%$.

Partridges, shooting in Delaware, 157. in Virginia, 158. season of 1851 and ' $52,158$. numbers in vicinity of Keokuk, $15 \mathrm{~S}$. numbers taken in nets, 158 ,

Phillips, Clem. T., kills sixty-one, 159 . good shooting, 160.

Frank Forrester's opinion of difficulty of killing Ameriean, 160.

taking the field, 160 .

bow to act when hunting, 163 .

wounded birds, 167 .

most difficult of all birds to shoot, 168 .

frequently give forth no scent, 168.

to split and broil, $50 \mathrm{I}$.

Pectus, the breast, 28 .

Pennet's, Mr., account of shooting geese, 376.

Perdix Virginianus, 114. (See Pantridge.)

Pharaohs, suipe in the country of the, 240.

Phensant, or ruffed grouse, 159.

Philadelphia, game hawked about, 140. contrary to municipal ordinanees, 140.

Phillips, Clew. T., kills sixty-one birds, 159.

Pigeon, killing with a rifle, 98. exploits in shooting, 99.

Pike, celebrated rail-pusher, 273.

Plover, golden Charailrius pluviales, 296. babits, food, 295 .

how best killed, 297. description, 297.

Plover, black-bellied, 294.

bull or beetle-headed, 295 . grass or field, 297.

piping, 297. terms applicable to, 33 .

Pointer, description of, 50. (See DoG.)

Pointing instinct in $\operatorname{dogs}, 38$.

Poking shot not to be admired, 109.

Porter's, William T., account of squirrels, 406.

Potatoes à la maître d'hôtel, 510.

Pot-hunter, a despicable fellow, 134. how to act in company with a, 135.

Potterer, or poking-shot, 99.

Powder, different brands of, 471 . efforts to remedy its present objectionable qualities, 471 .

Powder-prover, 438.

Powers, N., of Iowa, load of game connected by, 111.

Prairie-chicken, 202. (See Grouse.)

Preseott refers to the wild turkey in his "Conquest of Mexico," 184.

Primaries, large quill-feathers, 26. their position and use, 26. peculiarly constructed in the hawk, 26.

Pugh, English artist, anecdote of, 133.
Q.

Quadrupeds, change of pelage in, 30 . Quail not a partridge, 128.

different in habits, 128. in flesh, 128 .

is polygamous, $12 \mathrm{~S}$. a migratory bird, 128 .

trail at night, 129.

employed in combat, 129.

not esteemed as food, 129

assemble in innumerable bodies, 137 killed in immense numbers, 137 . people surfeited with, 137.

Quail snipe, 302 .

\section{IR.}

Rabbit, gray, 385. (See HARE.)

liail or sora, Rallus Carolinus, 263. descrintion, nomenclature, 263 . history, etc., 264.

singular characteristics, 267.

their food and resorts, 268.

shooting, 270.

paraphernalia for shooting, 273 .

pushers for shooting, 273.

tides, 274.

numbers killed, 276.

shooting in Virginia, $27 \%$.

fire-shooting, 277 .

netting, 278 .

fish prey upon, $27 \mathrm{~S}$.

where to shoot, 278.

expense of shooting, 279 .

terms applicable to, 34.

cooking, 504.

vent-feathers large in the, 27.

Rallus crepitans, clapper-rail or mud-hen, 253.

nomenclature and locality, 283.

period of incubation, 284.

where killed, 285.

Rallus elegans, great red-breasted rail, $2 S 1$. king-rail, fresh-water marsh-hen, 251. description, 281.

history, habits, and haunts, 292.

Raspail, Monsieur, theory of serpent-charaning. 122.

Rattlesnake, curious experiments with, 121. Red-headed duck, 35 .

red-head, 35.

Anas ferina, $35 t$.

habits and haunts, 354 .

red-headed widgeon of England, 35\%.

Reed-bird, rice-bunting, 256 .

Emberiza oryzivora, 256.

history and nomenclature, 256.

description, 257.

migrations, their feeding-grounds, 257.

shooting, 258.

netting, 259 .

compared with ortolan of Europe, $25 \%$. anecdote, 259.

progress south, 260. 
Reed-bird, curious facts, 261. as a cage-bird, 261. change of plumage, 262. terms applicable to, 34 . cooking, 504.

liegister, extract from a friend's shooting, 160.

Retriever, description of, 55. (See Dog.) Kive-bunting, 256. (See liEED-BIRD.) lille, shooting with a, 98. exploits of the Toomers with, 98 . killing pigeons with, 98. striking cricket-balls with, 98. exploits of our backwoolsmen with, 98 . German jägers use, 99 .

killing squirrels with, 99 . wild turkeys with, 99. exploits of keel-boatmen with, 99 . driving the nail with, yy. snufting the candle with, 99. shooting apples from the head with, 99. Ring-plover, 297.

Rock Island, numbers of partridges on, 155.

Rocky Mountains, canvas-back on the streams of the, 316.

Romans, festive boards of the, 494.

Ruffed grouse, 189. (See Grouse.)

liumford, Count, comments on cooking, 488.

Rump, Bill, celebrated rail-pusher, 273.

IRussia, snipe in, 241.

liusting, to prevent, of barrels, 427 . how to remove, 427 .

\section{S.}

Sargent, Dr. R. Percy, observation on labits of wild turkey, 176.

furtber observation, 176.

Sauces or gravies, 508.

Savages, their gluttony, 493.

Scapulars, shoulder-feathers, 26.

Schwarz, Berthold, discoverer of gunpowder, 433.

invention of gunpowder attributed to, 457.

monument erected at Freiburg to, $45 \mathrm{~S}$.

Scientia popinæ, 492.

Seiurus migratorius, 404. (See SovinneL*) Season of 1855 and '5f, particularly destructive to game, 139.

numbers of birds as well as animals destroyed in consequence of the snow during, 139.

Secondaries, second quill-feathers, 26.

Serpents, conflicts with partridges, 120 .

eharming birds, 121.

popular fallacy, 121.

Dr. Gilmun's experiments with, 121.

venomous, 121.

king, 121.

Kaspail's theory, 122 .

Setter, description of, 4t. (See Dog.)

Setters, early in the season, 161.
Selters, suffer for want of water, 161.

Shells, Americun, equal to the imported, 472.

paper $v 8$. metal, 472 .

Shoemaker, Dr., cases of poisoning by eating grouse, 126.

remedies used by, 126.

Shooting, art of, on the wing, 95 .

soon aequired, 95.

first grand desideratum, 95 .

nicety in, 95 .

carried to great perfection, 98 .

exploits of Richard and Edward 'Toomer, 98.

particular instructions for, 100 .

when the bird should be killed, 101.

in thickets, 102 .

be eool, when, 102 .

requires patience and practice, 102.

when the bird is crossing, 106 .

too low, too high, 107.

both eyes open, $10 \mathrm{~s}$.

in America different from that of Lingland, 110.

Shore-birds, terms applicable to, 34 .

Short, Dr., expluits among the suipe, 111.

Shot, soft and chilled, 472 .

sizes of, 472 .

Siberia, snipe in, 240.

Sickle-bill, 291. (See Curr.w.)

Sink, 329. (See BatTERY.)

Skiuner, J. S., comments on food of partridges, 125.

account of good shooting, 159 .

fanciful notion of the feeling of wondcocks, 218.

comments on ambition of killing for quantity, 229.

reprobates this eruel ambition, 230 .

Skipwith, Mr., captures sora rails at sea, 266.

Sleep, how necessary, 529 .

should be moderate, 529 .

less sleep in warm weatlier, 529.

some require more than others, 529 .

Napoleon required little, 529.

Frederick the Great required little, 529.

Smith, Dr., interesting letter of, 146 .

his views of partridges retaining scent, 146.

subject fully discussed, 146.

Smyrna, British eruiser's visited, 153.

Snap-shot, when most successful, 108. a disagreeable companion, $\mathbf{1 0 9}$.

shooting with both eyes open, 109.

Snipe, terms applicable, 31.

sudden and irregular flight of, 97 .

zigzag tlight of the, 100.

abundant on borders of Mud Creek, 101.

white, 132.

Snipe, 240.

Scolopax WVilsonii, 240. 
Snipe, Scolopax gallinago, 210.

Wilson's snipe, 240 .

English snipe, 240.

widely disseminated, 240.

varieties, 241.

why called Wilson's snipe, 241.

resembles the English variety, 241.

description, 242 .

location and food, 243.

incubation, young brood, 245 .

return to the South, 245 .

restless spirit, 246 .

perception of cold, 246.

voracious feeders, 246.

seldom found in the woods, $2 \pm 7$.

difỉcult to shoot, 247.

shooting aneedote, 250 .

during rainy weather, 252.

dogs for hunting, 252 .

fly against the wind, 253.

advantages of shooting, 254 .

white or pied, $25 \pm$.

cooking, 502.

Snipe, red-breasted, 302.

Scolopax noveboracensis, 302 .

quail snipe, 302.

habits and haunts, 302 .

flesh and food, 302 .

how and when killed, 302.

description, 303 .

Snow, beavy fall of, 139 .

its fearful consequences, 140 .

Sora, 263. (See RAIL.)

Sore throat, how to treat a, 538 .

Spain, introduction of wild turkey from, 183.

gun-barrels imported from, 477.

Spaniel, description of, 52. (Seo Dog.) terms applicable to, 32. verses in memory of a, 238 .

Sporting, terms used in, 32 . general ignorance of these terms, 32 . easily acquired, 32 .

writers on, 32.

Sportsman's beef, how made, 511

Sportsmen should be careful of birds in vinter, 117.

hints to, 135 .

practical observations for, 136 .

should keep cool, 153 .

during rainy weather, 153.

should not be too eager, 155 .

should refresh themselves, 156 .

directions for, to hunt dogs, 156.

should tlush the game, 156.

Sprain, how to be treated, 534 .

Sprigtail, 370.

pintail, 370 .

Anas acuta, 370

handsome duck, 370 .

habits and haunts, 370 .

abundant in England, 370 .

description, 370 .

Squirrels, 396.
Squirrels, varieties, habits, locality, 397. general characteristics, 397. activity and strength, 399. captivity of, 400 . other characteristics, 401. enemies of shooting, 402 . barking, flesh of, 403 .

Squirrel, gray, 404 .

migritory, 404

dimensions, locality, 404 .

habits and migrations, 404 . cooking, 514 .

Staley, Andrew, shooting in company with, 176.

Stirley, John, white snipe in possession of, 254.

Stock, gun, shape of, 429 . various styles of, 430 .

Stockings, shooting, 425.

Stockton, H. H., remarkable partridge shot by, 132 .

Stockton, Commodore, experiments on bursting of guns, 444 . recoil of guns, 444,450 .

St. Ildephonso, woodcocks feeding in aviary of, 219.

St. Lawrence River, reed-birds on, 257.

St. Louis, game shipped from, $15 \mathrm{~S}$.

St. Pctersburg, frozen markets, 497.

Stone-curlew, 299. (See IVILlet.)

Summer duck, 372 .

Anas sponsa, 372 .

wood-duck, 372 .

beautiful fowl, 372 .

delights in the small streams, 372

description, 373.

Surfice-boat, 329. (See BAtTERY.)

Swallows, the primary feathers in, 26. shooting, a mere knack, 9S.

Swan, American, 383.

Cygnus Americana, 383.

Swan, trumpeter, 383.

Cygnus bucinator, 383 .

habits, haunts, 383 .

easily domesticated, 384.

Swans, a whiteness of, 34 .

Sweden, snipres in, 241.

\section{'.}

Tapahannock marshes, partridges sbot on, 126.

Tarsi, shanks of the legs, 27.

Taxidermy, art of preserving and mounting birds, 514 .

directions for skinning birds, 515 .

Lee, Mrs., work on, 518.

Brown, Captain, work on, 518. preserving egg-shells, 519 .

Teal, blue-winged, 363 .

Anas discors, 363.

habits and haunts, 363 .

their food, $36 t$.

how best cooked, 361 . 
Teal, description, 364 .

Teal, green-winged, 365 .

Anas crecca, 365.

habits and characteristics, 365 .

Telltale snipe, 304.

godwit, 304 .

greater yellow-shanks, 304.

Scolopax vociferus, 304 .

Tennessee, ruffed grouse in barrens of, 159 . pinnated grouse in barrens of, 189.

Tertiary, third quill-feathers, 26. their position and character, 26.

Tetrao umbellus, 189. cupido, 202.

Canadensis, 210. saliceti, 210.

Tezcucan monarchs, consumed large numbers of turkeys, 184.

Thorpe, T. B., woodeock fire-hunting by, 234.

Tibia, thigh-bone, 27 .

Toomer, Richard and Edward, their wonderful exploits with gun and ritle, 98.

Turkey, wild, 172.

Meleagris gallipavo, 172.

deseription, 173.

natural history of, 175.

in former times, 175 .

their near extinetion, 175 .

found in Virginia, 176.

found in other States, 176.

Dr. Sargent's remarks on, 176.

neighborhood of Natchez, $17 \pi$.

incubation, 177.

very salacious, their conflicts, 177.

Audubon's comments, 177.

preparing the nest, 178 .

Dr. Sargrent's remarks, 17 S.

the action of the hen, $17 \mathrm{~S}$.

conceal their eggs, 178.

number of emgs, 179

young brood, 179 .

their future life, 180 .

but one brood, 180 .

condition of the males, 180 .

food of the, 180 .

their introduction into Spain, 183.

their introduction into England, 183.

why called turkey, 183.

a valuable fowl, is?.

Buffon on the origin, 184.

referred to by Prescott, 184.

domesticated by the Aztecs, 184.

consumed by the 'Tezcucan monarchs, 184.

trapping, 184.

shooting, 185.

good dog for bunting, 186.

run with amazing celerity, 186.

easily killed, 186.

when roosting, 186 .

Dr. Sargent's remarks, 186.

decoying, 186 .

enemies of, 187 .
Turks, a band of pirates, 1 2.

tufts of hair worn by the, 183 .

\section{U.}

Ude, Louis Eustache, on the pleasures of the table, 495 .

Uffano, remarks on the use of gunpowder, $45 \overline{5}$.

\section{V.}

Valisineria Americana, 317.

Venison soup, how made, 511.

Viellot, statement of, respecting the habit of woodcocks carrying their young ou their back, 221 .

Virginia, partridge-shooting in, 158. wild turkey in, 176.

Vitellius, feast given by, 496 .

Vitney, king of China, uses cannon, $\mathbf{4 5 6}$.

\section{W.}

Wadding or wads, various kinds, 411.

Walton, Sir Isaac, followers of, 372.

West Indies, reed-bird in, 260. suipe in, 240.

Western Hemisphere, wild turkey indigenous to, 182.

Wetherill, George D., partridges presented by, 122 .

large bird shot by, 126.

large woodeock in possession of, 215 .

Wheel-lock goune invented, 458 .

Whewer, whim, or widgeon of England, 358.

Whimbrel, Scolopax phæpus of England, 290.

Whistling plover, Charadrius apricarius, 294.

White thickening, 509 .

Widgeon, Anas Americana, 357. bald-pates, 357 .

companion of the canvas-back, 357 . not inferior in flavor, 357 .

locality, 357 .

description, 358.

resembles the English widgeon, 358 .

how pursued in England, 359.

easily domesticated, 359 .

at the North and South, 359

Wild celery, food of the canvas-back, 316 .

Wild drake, 360. (See MallarD.)

Wild-fowl, peculiar construction of the rump feathers of, 27.

terms applicable to, 34.

a tlock of, a couple of, 34 .

a team of, a badelynge of, 34 .

present and future numbers of, on Chesapeake Bay, 351. cooking, 506 .

Wild-fowl shooting, bow pursued in America, 305.

no child's sport, 305. 
Wild-fowl shooting, paraphernalia necessary for, 306 . use of liquor in, 306 .

IVillet, Scolopax semipalmata, 299. semipalmated snipe, or stone-curlew, 299.

habits and haunts, 299.

not known in England, 300.

period and place of incubation, 300 .

their food, 300 .

character of their flesh, 300 .

description, 301.

affection for each other, 301.

Willow grouse, 210.

Wilson's anecdote of ruffed grouse, 192. snipe, Scolopax Wilsonii, 240. plover, 297.

Wing, bastard, description of, 26. lesser coverts of the, 26 .

greater coverts of the, 26.

to stop the hemorrhage of, 520 .

to pinion or amputate a wounded, 521 .

Wisconsin, abundance of game in, 112. venison in, 112.

prairie-chickens in, 112.

pheasants, partridges, and wild turkeys in, 112.

immense shipment of game from, 112.

Wolves abundant in Iowa, 111. great numbers destroyed, 139.

Woodcock, terms applicable to, 33 . startling flight of the, 100 . cooking, 502 .

Woodcock, Scolopax minor, 212. attractive to the sportsman, 213. nomenclature, 214.
Woodcock, description, 214. compared with the English variety, 214.

height, one species, 214.

habits, migrations, 216.

formation of the head, 216 .

imperfect vision, 216.

feeding and food, 217.

vulgar notion, 218.

as seen in the aviary of St. Ildephonso, 219.

incubation, 220 .

singular mancurres, 221.

carrying their young-two broods, 221 .

proper time for shooting, 222.

game-lars on the subject, 223.

ingenuity to conceal their young, 226.

resorts of, 228 .

foolish ambition of killing, 229 .

disappearance of, 251 .

flight of, 233.

fire-hunting, description of, 233.

nets and snares to take, 235 .

dogs for shooting, 236 .

shooting in England, 237.

bells used for hunting, 237 .

Woodpecker, peculiar formation of the rump feathers of, 26.

\section{Y.}

Yellow-shank snipe, Scolopax flavipes, 304.

\section{Z.}

Zizania aquatica, 268. 
(5) 






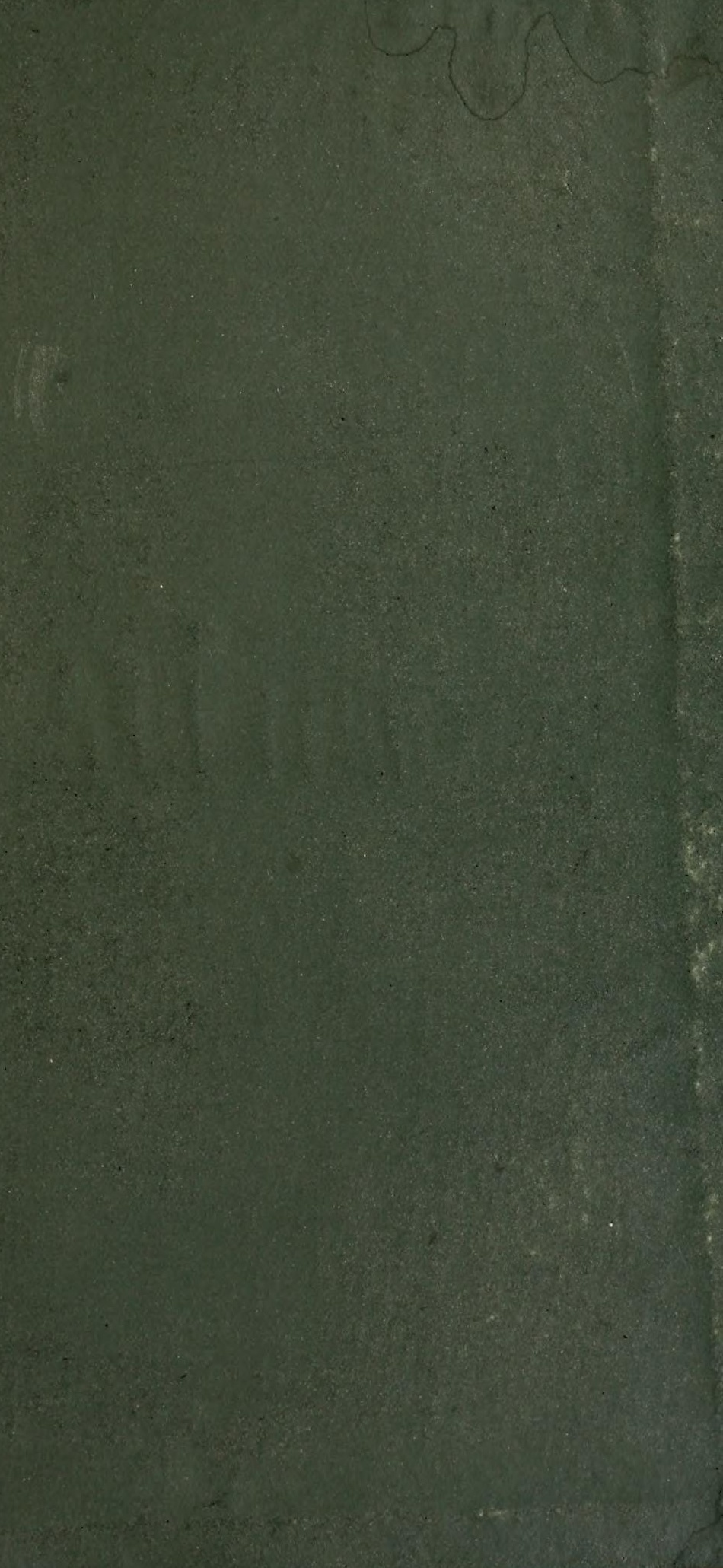




\section{LIBRARY OF CONGRESS}

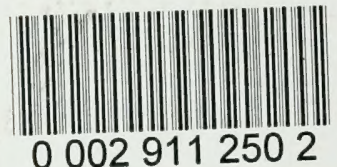

00029112502

$\frac{4}{4 x^{4}}+\frac{2}{4}$

(4)

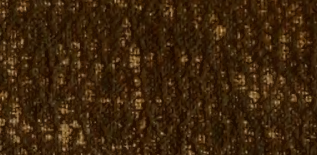

$\frac{4}{4}+4$

1.

(a)

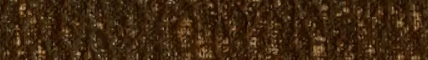

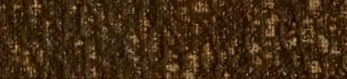

4.

I.

197 of

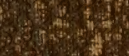

